BRUNO NOGUEIRA FUKASAWA

\title{
PROPOSTA DE MODELOS DE SUPORTE À DECISÃO NO PLANEJAMENTO DE REÚSO DE ÁGUA
}

\author{
Versão corrigida
}

Dissertação apresentada à Escola Politécnica da Universidade de São Paulo para a obtenção de título de Mestre em Engenharia.

SÃO PAULO 
BRUNO NOGUEIRA FUKASAWA

\title{
PROPOSTA DE MODELOS DE SUPORTE À DECISÃO NO PLANEJAMENTO DE REÚSO DE ÁGUA
}

\author{
Versão corrigida
}

Dissertação apresentada à Escola Politécnica da Universidade de São Paulo para a obtenção de título de Mestre em Engenharia.

Orientação: Prof. Dr. José Carlos Mierzwa

Área de concentração: Engenharia Hidráulica e Ambiental

\section{SÃO PAULO}


Autorizo a reprodução e divulgação total ou parcial deste trabalho, por qualquer meio convencional ou eletrônico, para fins de estudo e pesquisa, desde que citada a fonte.

Este exemplar foi revisado e corrigido em relação à versão original, sob responsabilidade única do autor e com a anuencia de seu orientador.

São Paulo, 22 de MarGO

\section{Catalogação-na-publicação}

Fukasawa, Bruno Nogueira

Proposta de elementos de suporte à decisão no planejamento de reúso de água / B. N. Fukasawa - versão corr. - São Paulo, 2021.

$227 \mathrm{p}$.

Dissertação (Mestrado) - Escola Politécnica da Universidade de São Paulo. Departamento de Engenharia de Hidráulica e Ambiental.

1.Reúso de água 2.Planejamento 3.Suporte à decisão 4.Reúso não potável I.Universidade de São Paulo. Escola Politécnica. Departamento de Engenharia de Hidráulica e Ambiental II.t. 
"[...] had not the river in anger taken human form, and spoken to him from out the deep waters saying, 'Achilles, if you excel all in strength, so do you also in wickedness, for the gods are ever with you to protect you: if, then, the son of Saturn has vouchsafed it to you to destroy all the Trojans, at any rate drive them out of my stream, and do your grim work on land. My fair waters are now filled with corpses, nor can I find any channel by which I may pour myself into the sea for I am choked with dead, and yet you go on mercilessly slaying. I am in despair, therefore, O captain of your host, trouble me no further."'

"Meanwhile Achilles sprang from the bank into mid-stream, whereon the river raised a high wave and attacked him. He swelled his stream into a torrent, and swept away the many dead whom Achilles had slain and left within his waters."

"Then the son of Peleus lifted up his voice to heaven saying, 'Father Jove, is there none of the gods who will take pity upon me, and save me from the river?' [...] 'She told me I was to fall under the walls of Troy by the flying arrows of Apollo; would that Hector, the best man among the Trojans, might there slay me; then should I fall a hero by the hand of a hero; whereas now it seems that I shall come to a most pitiable end, trapped in this river as though I were some swineherd's boy, who gets carried down a torrent while trying to cross it during a storm."

The lliad - Book XXI, vv. 200-283

Homero

(Tradução em prosa de Samuel Butler)

\author{
"Sempre pensara em ir \\ caminho do mar. \\ Para os bichos e rios \\ nascer já é caminhar. \\ Eu não sei o que os rios \\ têm de homem do mar; \\ sei que se sente o mesmo \\ e exigente chamar." \\ O rio
}

João Cabral de Melo Neto 


\section{AGRADECIMENTOS}

Ao Prof. José Carlos Mierzwa pela indispensável e enriquecedora orientação ao longo do desenvolvimento da pesquisa, e ao saudoso Prof. Ivanildo pela inspiração.

Às colegas do Centro Internacional de Referência em Reúso de Água da USP (CirraUSP) pelas ideias, discussões temáticas e cafezinhos compartilhados.

A membros do Laboratório de Geoprocessamento (LABGEO) da EPUSP pelo suporte técnico em geoprocessamento, e a servidores do Departamento de Águas e Energia Elétrica (DAEE), Companhia de Saneamento Básico do Estado de São Paulo (Sabesp), Agência Nacional de Águas (ANA) e Fundação Sistema Estadual de Análise de Dados (Seade) pela solicitude em disponibilizar bases dados e sanar dúvidas.

À Escola Politécnica da USP (USP), Fundação para o Desenvolvimento Tecnológico da Engenharia (FDTE) e Núcleo de Apoio à Pesquisa Cidades (USP Cidades) pelo apoio e possibilidade de realização da pesquisa.

Às muitas pessoas queridas que, a seus tempos e maneiras, providenciaram condições e incentivo para que este trabalho fosse iniciado, conduzido e finalizado.

E à arte do encontro, embora haja tanto desencontro pela vida. 


\section{RESUMO}

O cenário atual de recursos hídricos e saneamento básico no Brasil, no qual são evidentes as crescentes demandas por água e os baixos indicadores de tratamento de esgotos, conduz a sérios problemas de abastecimento, degradação de mananciais e a altos custos de produção de água. São necessárias, assim, ações sistemáticas que busquem diversificar as fontes de água para atender os diferentes usos, entre as quais o reúso figura como importante recurso.

Este trabalho propôs dois modelos de suporte à decisão que objetivam orientar o planejamento estratégico da prática de reúso não potável. Ambos foram aplicados a uma área de estudo escolhida, a Região Metropolitana de São Paulo (RMSP), para verificação de seu desempenho e discussão dos resultados.

O primeiro deles é o Índice de Potencial de Reúso (IPR), um índice multicritério adimensional que classifica áreas com relação à sua "atratividade de reúso". O IAR foi desenvolvido tendo como base um Método Multicritério de Apoio à Decisão (MMAD), mais especificamente o Analytic Hierarchy Process (AHP). Sua estrutura inclui critérios técnicos, ambientais e socioeconômicos, bem como operações de normalização, análise de sensibilidade e classificação de dados.

O segundo é o Modelo ETE-usuário, um modelo de sistematização de procedimentos que tem como objetivo estimar vazões potenciais de reúso a partir de critério de viabilidade econômica. $\mathrm{O}$ modelo identifica os usuários que permitem produção e distribuição de água de reúso em condições que garantam viabilidade econômica, os denominados "usuários-âncora". O modelo inclui caracterização das ofertas (ETEs) e demandas (usuários); estabelecimento de padrões de qualidade de água de reúso e de arranjos de tratamento; estimativas de custos de capital (Capex) e de operação \& manutenção (Opex); composição de tarifa; cenários de custos e de abastecimento; e comparação a custos locais de água.

Como resultados da aplicação do IPR à RMSP, os municípios com maior IPR foram São Paulo (IPR = 0,786), Suzano $(0,375)$, Barueri $(0,309)$, Mogi das Cruzes $(0,296)$ e Taboão da Serra $(0,291)$. O Modelo ETE-usuário resultou em vazões potenciais entre 1,49 e $3,29 \mathrm{~m}^{3} / \mathrm{s}$ (20 e 120 usuários-âncora, respectivamente), com variações entre 0,54 a $3,45 \mathrm{~m}^{3} / \mathrm{s}$ para cenários pessimistas e otimistas, representando entre 0,6 e $3,9 \%$ da demanda consuntiva total da RMSP.

Os modelos prezaram pelo uso de bases de dados acessíveis e de procedimentos replicáveis, estimulando sua reprodução, aprimoramento e integração a sistemas de suporte à decisão. Adicionalmente foram criados mapas e recursos online para compreensão mais ampla dos resultados, uma vez que o trabalho contou extensivo uso de Sistema de Informações Geográficas (SIG).

Além das discussões sobre os modelos em si, também foram levantados temas correlatos como inclusão do reúso como elemento de planejamento urbano, econômico e ambiental; necessidade de articulação multissetorial para diversificação de matriz hídrica; centralização versus. descentralização para produção e distribuição de água de reúso; e acesso público à informação sobre água.

Palavras-chave: reúso não potável; potencial de reúso; modelo de suporte à decisão; planejamento; Região Metropolitana de São Paulo (RMSP). 


\begin{abstract}
The current Brazilian situation on water resources and basic sanitation, in which everincreasing water intakes and low wastewater treatment coverage are evident, leads to severe supply problems, deterioration of water bodies quality, and high costs with water production. Systematic actions to diversify water sources urge to be taken, and water reuse, along with other solutions, features as an important component on water planning and management.
\end{abstract}

This work purposed two different support decision models that aim to guide direct nonpotable water reuse strategic planning actions. Both of them were applied to a chosen study area, the Metropolitan Region of São Paulo (MRSP), in order to verify their performances and discuss the results obtained.

The first one is the Water Reuse Potential Index (WRPI), a multi-criteria dimensionless index that assess and ranks areas regarding their 'reuse attractiveness/suitability'. The WRPI was developed with the use of a Multi-Criteria Decision Analysis (MCDA) method, namely the Analytic Hierarchy Process (AHP). The model comprises technical, environmental, and socioeconomic criteria, as well as additional operations such as parameter normalization, sensitivity analysis, and results classification.

The second one is the WWTP-user Model (WWTP, Wastewater Treatment Plant), a systemization of procedures with the objective of estimating potential water reuse flows through an economic feasibility approach. The model identifies users - 'anchor users' - whose characteristics allow economically viable water reuse production and distribution. The model encompasses procedures such as: characterization of reclaimed water offers (WWTPs) and demands (users); water reuse quality standards and generic treatment trains; estimates of capital (Capex) and operational (Opex) expenditures; tariff composition; supply and costs scenarios; and comparison with local potable water costs.

As outcomes from the application of the WRPI to the MRSP, the cities with higher WRPI were São Paulo (WRPI = 0.786), Suzano (0.375), Barueri (0.309), Mogi das Cruzes (0.296) and Taboão da Serra (0.291). On the other hand, the WWTP-user Model resulted in potential reclaimed water flows ranging from 1.49 to $3.29 \mathrm{~m} / \mathrm{s}$ (20 and 120 anchor users, respectively), stretching to 0.54 to $3.45 \mathrm{~m}^{3} / \mathrm{s}$ for more optimistic and pessimist alternative scenarios. These values represent between 0.6 to $3.9 \%$ of total consumptive water intake in the MRSP.

Both models prioritized the use of easy-to-get datasets and appealed to replicable procedures, encouraging their extension to other regions, methodological improvements, and integration to support-decision systems. Online interactive maps and data repositories were created to allow broader comprehension of the results, since there was extensive use of Geographic Information System (GIS).

Besides the discussions about the models themselves, some adjacent themes unearthed from this research, like water reuse as an element of urban, environmental and economic planning; the need for multi-sectorial articulation to properly address water supply diversification; centralization versus decentralization in reclaimed water production and distribution; and the importance of public access to water-related data.

Keywords: non-potable reuse; reuse potential; decision support model; planning; Metropolitan Region of São Paulo (MRSP). 


\section{LISTA DE SÍMBOLOS E ACRÔNIMOS}

\begin{tabular}{|c|c|}
\hline Símbolo & Significado \\
\hline$\overline{\mathrm{AHP}}$ & Analytic Hierarchy Process \\
\hline AMT & Altura manométrica total \\
\hline ANA & Agência Nacional de Águas \\
\hline BH-AT & Bacia hidrográfica do Alto Tietê \\
\hline BH-PS & Bacia hidrográfica Paraíba do Sul \\
\hline BRL & Reais \\
\hline C & Coeficiente de retorno \\
\hline C10 & Cenário 1 - otimista \\
\hline C1P & Cenário 1 - pessimista \\
\hline C1R & Cenário 1 - realista \\
\hline $\mathrm{C} 2 \mathrm{O}$ & Cenário 2 - otimista \\
\hline $\mathrm{C} 2 \mathrm{P}$ & Cenário 2 - pessimista \\
\hline $\mathrm{C} 2 \mathrm{R}$ & Cenário 2 - realista \\
\hline Capex & Capital expenditures (custos de capital) \\
\hline Capex $x_{\text {adutoras }}$ & Capex de adutoras \\
\hline Capex & Capex de estações elevatórias \\
\hline Capex $x_{\text {trat }}$ & Capex de sistemas de tratamento \\
\hline CBH-PS & Comitê de bacia hidrográfica do Paraíba do Sul \\
\hline $\mathrm{CCl}$ & Construction Cost Index \\
\hline Cetesb & Companhia Ambiental do Estado de São Paulo \\
\hline $\mathrm{CL}$ & Cloro \\
\hline CNAE & Classificação Nacional de Atividades Econômicas \\
\hline $\mathrm{C}_{\mathrm{NP}}$ & Coeficiente não potável \\
\hline DAEE & Departamento de Águas e Energia Elétrica (Estado de São Paulo) \\
\hline $\mathrm{DBO}_{5,20}$ & Demanda bioquímica de oxigênio \\
\hline DN & Diâmetro nominal (tubulação) \\
\hline DQO & Demanda química de oxigênio \\
\hline $\mathrm{EE}$ & Estação elevatória \\
\hline ENR & Engineering News-Record \\
\hline ETE & Estação de tratamento de esgotos \\
\hline ETo & Evapotranspiração \\
\hline FABHAT & Fundação de Apoio à Bacia Hidrográfica do Alto Tietê \\
\hline FAIR & Findable, accessible, interoperable, reusable \\
\hline $\mathrm{FC}$ & Fluxo de caixa \\
\hline $\mathrm{FQ}$ & Físico-químico \\
\hline FT & Filtração terciária \\
\hline GC & Grandes consumidores \\
\hline IC & Índice de Consistência \\
\hline ICTEM & Indicador de Coleta e Tratabilidade de Esgotos da População Urbana de Município \\
\hline IPR & Índice de Potencial de Reúso \\
\hline IR & Índice randômico \\
\hline $\mathrm{L}$ & Comprimento (adutora) \\
\hline LAC & Lodos ativados convencional \\
\hline MBR & Biorreator com membranas (membrane bioreactor) \\
\hline $\operatorname{MBR}(\mathrm{RN})$ & Biorreator com membranas com remoção de nitrogênio (desnitrificação) \\
\hline MCidades & Ministério das Cidades \\
\hline MF & Microfiltração \\
\hline
\end{tabular}


Símbolo Significado

\begin{tabular}{|c|c|}
\hline MMAD & Método multicritério de apoio à decisão \\
\hline $\mathrm{O}_{3}$ & Ozônio \\
\hline Opex & Operational expenditures (custos operacionais) \\
\hline Opexad $_{a}$ & Opex de adução (distribuição) \\
\hline Opex trat & Opex de tratamento \\
\hline OR & Osmose reversa \\
\hline$P$ & Potência \\
\hline$P$ & Precipitação \\
\hline$P$ & Fósforo (nutriente) \\
\hline $\mathrm{P} 1$ & Padrão de qualidade de água de reúso 1 (irrigação - uso irrestrito) \\
\hline P2 & Padrão de qualidade de água de reúso 2 (industrial - usos gerais e TR) \\
\hline P3 & Padrão de qualidade de água de reúso 3 (industrial - caldeira) \\
\hline PBH-AT & Plano de bacia hidrográfica da $\mathrm{BH}$ do Alto Tietê \\
\hline PBH-PS & Plano de bacia hidrográfica da BH do Paraíba do Sul \\
\hline PDE & Plano Diretor de Esgotos \\
\hline POA & Processo oxidativo avançado \\
\hline Q & Vazão (genérico) \\
\hline$Q_{95 \%}$ & Vazão 95\% \\
\hline QGIS & Quantum GIS \\
\hline$Q_{N P}$ & Vazão não potável \\
\hline Qout & Vazão outorgada \\
\hline $\mathrm{RC}$ & Razão de Consistência \\
\hline Regla & Sistema Federal de Regulação de Uso \\
\hline RMSP & Região Metropolitana de São Paulo \\
\hline RNPD & Reúso não potável direto \\
\hline RNPI & Reúso não potável indireto \\
\hline RPD & Reúso potável direto \\
\hline RPI & Reúso potável indireto \\
\hline Sabesp & Companhia de Saneamento Básico do Estado de São Paulo \\
\hline SDT & Sólidos dissolvidos totais \\
\hline SIG & Sistema de Informações Geográficas \\
\hline SNIS & Sistema Nacional de Informações sobre Saneamento \\
\hline SRC & Sistema de referência de coordenadas \\
\hline SST & Sólidos suspensos totais \\
\hline TGCD & Taxa Geométrica de Crescimento Demográfico \\
\hline TL & Transformação linear \\
\hline TR & Torre de resfriamento \\
\hline UA & Usuário-âncora \\
\hline UASB & Upflow Anaerobic Sludge Blanket \\
\hline UF & Ultrafiltração \\
\hline UGRHI & Unidade de Gerenciamento de Recursos Hídricos \\
\hline USD & Dólares (EUA) \\
\hline UV & Radiação ultravioleta \\
\hline VA & Valor adicionado \\
\hline VPL & Valor presente líquido \\
\hline w & Peso (prioridade) de critérios e subcritérios \\
\hline$\lambda_{\text {máx }}$ & Autovalor máximo de uma matriz \\
\hline
\end{tabular}




\section{LISTA DE FIGURAS}

Figura 1: Vazões retiradas de água no Brasil por tipo de uso entre 2000 e 2018 .......6

Figura 2: População urbana atendida por tratamento de esgotos por faixa eficiência

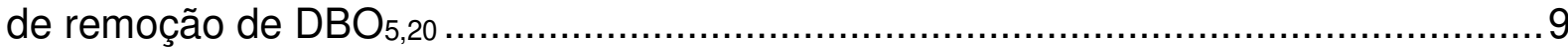

Figura 3: Tipos de reúso conforme arranjo e finalidade ............................................ 12

Figura 4: Gráfico do consumo de água de reúso entre 1963 e 2017 no mundo ........14

Figura 5: Distribuição do consumo de água de reúso (após tratamento terciário) no mundo de acordo com tipo de uso ................................................................. 14

Figura 6: Curvas, médias e valores isolados de Capex de tratamento (USD/m³/ano)

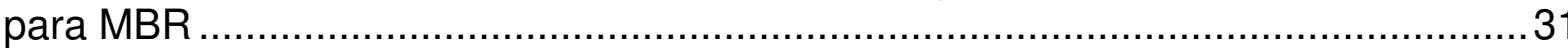

Figura 7: Curvas e médias de Capex de tratamento (USD/m³/ano) para desinfecção

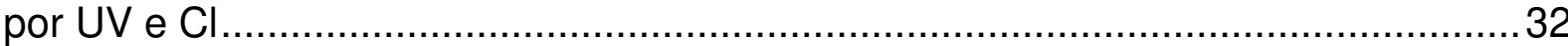

Figura 8: Curvas de Capex de tratamento (USD/m³/ano) para OR ...........................32

Figura 9: Curvas, médias e valores isolados de Opex de tratamento $\left(\mathrm{USD} / \mathrm{m}^{3}\right)$ para

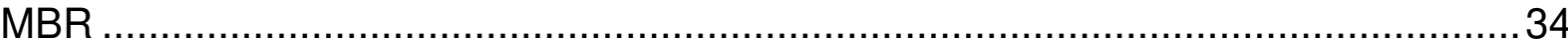

Figura 10: Curvas, médias e valores isolados de Opex de tratamento (USD/m³) para CL e UV

Figura 11: Curvas, médias e valores isolados de Opex de tratamento (USD $\left./ \mathrm{m}^{3}\right)$ para OR

Figura 12: Curvas de Capex para estações elevatórias em USD/m³/ano …...............37

Figura 13: Curvas de Capex para estações elevatórias em USD/CV ..........................37

Figura 14: Curvas de Capex para adutoras em USD/m ..............................................39

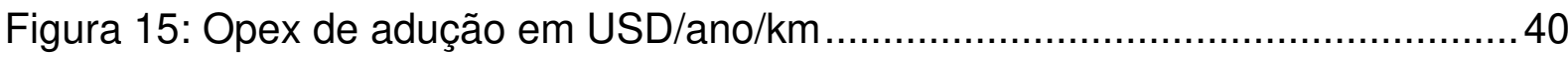

Figura 16: Exemplos de utilização de SIG: modelagem hidráulica e otimização no planejamento de sistemas urbanos de reúso nos $\operatorname{EUA}^{(1)}$ (à esq.) e detecção de áreas favoráveis ao aproveitamento de água de chuva na Índia ${ }^{(2)}$ (à dir.)

Figura 17: Hierarquização de elementos em um modelo AHP de dois níveis 58

Figura 18: Diagrama de desenvolvimento do modelo do Índice de Potencial de Reúso (IPR). 69

Figura 19: Diagrama de desenvolvimento do modelo ETE-usuário 76

Figura 20: Estrutura do Modelo do Índice de Potencial de Reúso (IPR) 
Figura 21: Diagrama da estrutura hierárquico do modelo do Índice de Potencial de Reúso (IPR) utilizando metodologia do Analytic Hierarchy Process (AHP).

Figura 22: Gráficos das prioridades globais dos subcritérios 88

Figura 23: Estrutura do modelo ETE-usuário 93

Figura 24: Exemplo de determinação do comprimento de adutoras (L) utilizando-se QNEAT3 no QGIS3 com base em arquivo vetorial de sistema viário. 103

Figura 25: Exemplo (ETE São João, Guarulhos) de determinação de distâncias entre ETEs e usuários e de extração de elevação de ETEs e usuários. 104

Figura 26: Diagrama com estrutura de componentes de custos de tratamento e distribuição de água de reúso 106

Figura 27: Funções de Capex de tratamento (Capextrat) adotadas ..........................108

Figura 28: Funções de Opex de tratamento (Opextrat) adotadas ............................ 108

Figura 29: Funções de Capex (USD/m³/ano) e Opex (USD/m³) por arranjo de tratamento

Figura 30: Função de Capexadutoras adotada - em função de DN (à esq.) e de Q (à

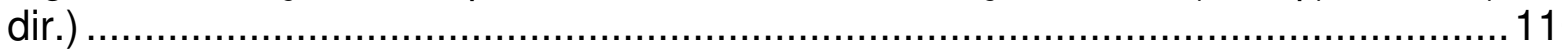

Figura 31: Função de Capex de elevatórias adotada ...........................................111

Figura 32: Gráfico de superfície da função de Opexad (USD/m³) em função de $Q$

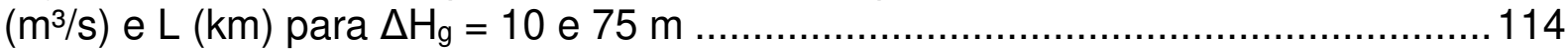

Figura 33: Gráfico de superfície de tarifa $\left(\mathrm{USD} / \mathrm{m}^{3}\right)$ para arranjo $\mathrm{MBR}(\mathrm{RN})+\mathrm{UV}+\mathrm{CL}$

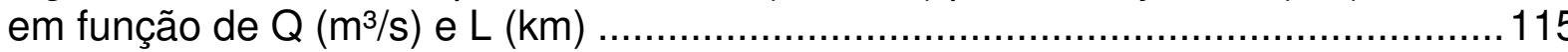

Figura 34: Limites da Região Metropolitana de São Paulo (RMSP) e das Unidades de Gerenciamento de Recursos Hídricos (UGHRIs) 2, 5, 6, 7, 10 e $11 .$.

Figura 35: De cima para baixo - disponibilidade hídrica per capita, balanço hídrico (demandas/Q95\%) e capacidade de diluição dos corpos hídricos por município......122

Figura 36: Gráfico da distribuição das demandas de água por tipo de uso na RMSP

Figura 37: Gráfico da distribuição das demandas de água por tipo de uso e município da RMSP

Figura 38: Outorgas de captação ativas para finalidades industriais e de irrigação na RMSP 
Figura 39: ETEs ativas na RMSP por faixa de vazão e índice de tratamento de esgotos por município (IN046 do SNIS)....

Figura 40: Localização das ETEs e de outorgas de captação para finalidades industriais e de irrigação na RMSP

Figura 41: Subcritérios normalizados por município.............................................142

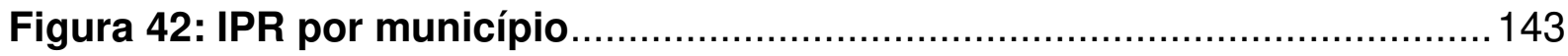

Figura 43: Mapa dos valores de IPR por município............................................. 146

Figura 44: Composição de IPR por critério (à esq.) e participação \% de cada critério

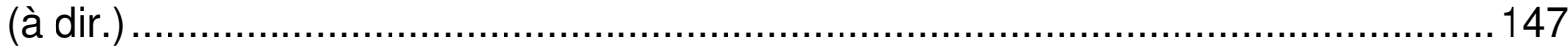

Figura 45: Gráfico de IPR na análise de sensibilidade .......................................150

Figura 46: Mapas com resultados da análise de sensibilidade para $\mathrm{w}_{\text {tec }}=0,1 ; 0,3$;

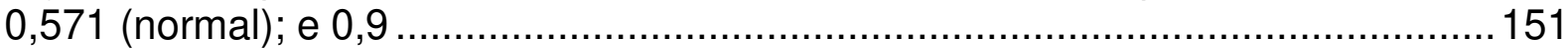

Figura 47: Vazões potenciais de reúso por ETE para todos os cenários ................157

Figura 48: Vazões potenciais de reúso por ETE e finalidade de uso - C1R e C2R 158

Figura 49: Exemplos de variação de tarifa por usuário para os seis cenários para três usuários (ID 62786, 11903 e 82327) 162

Figura 50: Vazão (à esq.) e quantidade (à dir.) de usuários classe A e B por cenário 163

Figura 51: Distribuição da variação (\%) dos cenários otimista e pessimista em relação ao realista para C1 e C2 em função de QNP.

Figura 52: Tarifa e decomposição de custos para usuários-âncora (classe A) - C1R (120 usuários) 165

Figura 53: Comparação de participação no Capex e Opex de custos de adução para usuários classes A e B - C1R. 166

Figura 54: Vazões potenciais de reúso totais por finalidade para todos os cenários

Figura 55: Dispersão 3D de tarifas (USD/m³) em função de $Q\left(\mathrm{~m}^{3} / \mathrm{s}\right)$ e $\mathrm{L}(\mathrm{km})$ para a ETE Suzano - C1R e C2R 171

Figura 56: Distribuição dos usuários-âncora em relação à ETE Suzano para C1R: traçados de adutoras (em amarelo) e OD (origem-destino) com tarifas (em azul).. 172

Figura 57: Participação por atividade econômica (grupo CNAE 2.0) na vazão potencial de reúso da ETE Suzano 
Figura 58: Distribuição dos usuários-âncora em relação à ETE Biritiba-Mirim para C1R: traçados de adutoras (em amarelo) e OD (origem destino) com tarifas (em azul)

Figura 59: Distribuição dos usuários-âncora em relação à ETEs Parque dos Pinheiros, Aldeia da Serra, Bandeirantes e Pinheirinho para C1R: traçados de adutoras (em amarelo) e OD (origem destino) com tarifas (em azul).....

Figura 60: Distribuição dos usuários-âncora em relação à ETEs Parque Andreense, Cotia/Jardim Japão e Mairiporã - Sede para C1R: traçados de adutoras (em amarelo) e OD (origem destino) com tarifas (em azul)

Figura 61: Distribuição dos usuários-âncora em relação às ETEs da RMSP - cenário C1R 183

Figura 62: Distribuição dos usuários-âncora em relação às ETEs da RMSP - cenário $\mathrm{C} 2 \mathrm{R}$ 184

Figura 63: Interface do webGIS: mapas interativos com resultados do IPR (à esq.) e ETE-usuário (à dir.) 188

\section{ANEXOS}

Figura A 1: Curvas de Capex MBR(RN) e Capex MBR 240

Figura A 2: Curvas de Opex de $M B R(R N)$ e MBR

Figura C 1: Distribuição dos usuários-âncora em relação à ETE Mauá para C1R: traçados de adutoras (em amarelo) e OD (origem destino) com tarifas (em azul) ..247

Figura C 2: Distribuição dos usuários-âncora em relação à ETE Leste para C1R: traçados de adutoras (em amarelo) e OD (origem destino) com tarifas (em azul) ..248

Figura C 3: Distribuição dos usuários-âncora em relação às ETEs Várzea do Palácio e São Miguel para C1R: traçados de adutoras (em amarelo) e OD (origem destino) com tarifas (em azul) 250

Figura C 4: Distribuição dos usuários-âncora em relação à ETE Parque Novo Mundo para C1R: traçados de adutoras (em amarelo) e OD (origem destino) com tarifas (em azul) 251 


\section{LISTA DE TABELAS}

Tabela 1: Vazões retiradas, consumidas e retornadas no Brasil por tipo de uso em 2018

Tabela 2: Experiências de reúso no mundo - processos de tratamento adotados, tipo de reúso, finalidade e vazões de projeto.

Tabela 3: Referências de padrões qualidade de água de reúso para irrigação 20

Tabela 4: Estimativas de porcentagem uso de água para resfriamento em atividades industriais

Tabela 5: Referências de padrões de qualidade para uso em sistemas de resfriamento industriais (TR, torres de resfiamento)

Tabela 6: Parâmetros de qualidade para uso em caldeiras de acordo com a pressão de operação

Tabela 7: Relação simplificada de processos e tecnologias de tratamento e aptidão para produção de água de reúso

Tabela 8: Funções e valores de Capex (USD/m³/ano) para diferentes sistemas de tratamento

Tabela 9: Funções de Opex para diferentes sistemas de tratamento em USD/m³/ano

Tabela 10: Funções de Capex para estações elevatórias em USD/m³/ano 36

Tabela 11: Funções de Capex para estações elevatórias em USD/CV 37

Tabela 12: Funções de Capex para adutoras em USD/m 38

Tabela 13: Potencial de reúso por município da RMSP segundo o programa Interáguas

Tabela 14: Resumo de pontos principais de estudos sobre reúso que contemplam a RMSP

Tabela 15: Compilação de normas, manuais e leis que contemplam reúso 49

Tabela 16: Compilação de padrões de qualidade de água de reúso previstos em referências nacionais

Tabela 17: Alguns dos principais MMAD e suas vantagens, desvantagens e áreas de áreas de aplicação 55

Tabela 18: Compilação de trabalhos com abordagem MMAD 
Tabela 19: Intensidade de importância na comparação paritária 58

Tabela 20: Índice Randômico (IR) para matrizes de ordem $\mathrm{n} \leq 10$ 60

Tabela 21: Principais métodos de classificação de dados 63

Tabela 22: Desenvolvimento do modelo de IPR e referências utilizadas. 68

Tabela 23: Detalhes sobre o desenvolvimento do modelo ETE-usuário 75

Tabela 24: Critérios e subcritérios que compõem o Indicador de Potencial de Reúso (IPR)

Tabela 25: Importâncias paritárias e análise de consistência: níveis 1 e 2 86

Tabela 26: Prioridades locais e globais para os critérios e subcritérios do IPR 87

Tabela 27: Métodos de normalização utilizados para cada subcritério 88

Tabela 30: Classes previstas para classificação do IPR 90

Tabela 28: Prioridades dos critérios para a variação do critério prevalente (técnico) 90 Tabela 29: Prioridades globais dos subcritérios para a variação do critério prevalente (técnico). 91

Tabela 31: Relação de bases de dados de entrada 95

Tabela 32: Seções e divisões da CNAE 2.0 utilizadas na classificação de usuários segundo atividade econômica 96

Tabela 33: Coeficiente de demanda não potável ( $\mathrm{C}_{\mathrm{NP}}$ ) por divisões (1 a 43) da CNAE 2.0 .98

Tabela 34: Padrões de qualidade P1, P2 e P3 definidos e relação 99

Tabela 35: Padrões de referência de água de reúso não potáveis adotados 100

Tabela 36: Processos considerados para composição de arranjos de tratamento .100 Tabela 37: Atuação de processos de tratamento sobre os parâmetros de qualidade

Tabela 38: Arranjos de tratamento para produção de água de reúso 101

Tabela 39: Funções de Capextr e Opextr por processo de tratamento 107

Tabela 40: Funções de Capextr e Opextr por arranjo de tratamento 109

Tabela 41: Resumo das funções de custo e outras equações 112 
Tabela 42: Relação de variáveis utilizadas nas funções de custos

Tabela 43: Relação de variáveis para cálculo de tarifa

Tabela 44: Cenários de abastecimento

Tabela 45: Parâmetros de composição dos cenários de custos

Tabela 46: Siglas para identificação dos cenários de abastecimento e de custos .. 117

Tabela 47: Regra de classificação da tarifa de água de reúso em relação a custos locais

Tabela 48: Estimativas de demandas consuntivas de água na BH-AT 123

Tabela 49: Demandas de água por tipo de uso e município da RMSP 124

Tabela 50: Comparação entre estimativas de demandas industriais na RMSP ......128

Tabela 51: Comparação entre estimativas de demandas de irrigação na RMSP ...129

Tabela 52: Outorgas de captação ativas para finalidades industrial e de irrigação na

RMSP de acordo com tipo de uso

Tabela 53: Estimativa de demanda de irrigação mensal a partir de P e ETo. 133

Tabela 54: Geração, coleta e tratamento de esgotos nos municípios da RMSP ....134

Tabela 55: Relação das ETEs ativas da RMSP 135

Tabela 56: Tabela de tarifas para grandes consumidores (GC) da Sabesp na RMSP

Tabela 57: Fontes de dados para inserção no modelo do IPR na RMSP 139

Tabela 58: IPR por município 143

Tabela 59: Classificação de resultados de IPR por quebras naturais de Jenks 144

Tabela 60: Resultados classificados de IPR por município 144

Tabela 61: Valores de IPR por município na análise de sensibilidade 148

Tabela 62: Fontes de dados de entrada para aplicação do modelo ETE-usuário à RMSP

Tabela 63: Regra de classificação da tarifa de água de reúso para a RMSP 154

Tabela 64: Vazões potenciais de reúso e quantidade de usuários-âncora por ETE para todos os cenários. 
Tabela 65: Comparação entre as vazões potenciais de reúso por ETEs e déficit de saneamento por município

Tabela 66: Resumo das vazões potenciais de reúso e quantidade de usuáriosâncora para os seis cenários estudados

Tabela 67: Relação dos vinte principais usuários-âncora (menores tarifas para C1R)

Tabela 68: Vazão e quantidade de usuários classe A e B por cenário 162

Tabela 69: Vazões potenciais de reúso (I/s) segundo divisões e classes da CNAE $2.0-\mathrm{C} 1 \mathrm{R}$ e $\mathrm{C} 2 \mathrm{R}$.

Tabela 70: Vazões potenciais de reúso (\%) segundo divisões e classes da CNAE 2.0

$-\mathrm{C} 1 \mathrm{R}$ e C2R

Tabela 71: Usuários-âncora para a ETE Suzano para C1R

Tabela 72: Usuários-âncora para a ETE Biritiba-Mirim - C1R

Tabela 73: Usuários-âncora para a ETEs Pinheirinho, Aldeia da Serra, Bandeirantes, Cotia/Jardim Japão, Mairiporã - Sede, Parque Andreense e Parque dos Pinheiros -

C1R

Tabela 74: Comparação porcentual do potencial de reúso por cenários com demandas totais para indústria e irrigação e consuntiva total da RMSP.

Tabela 75: Comparação das vazões potenciais de reúso por ETE para a RMSP deste trabalho e as apresentadas por estudos similares

Tabela 76: Comparação dos resultados da aplicação dos modelo ETE-usuário com outros estudos contemplam a área de estudo (RMSP).

\section{ANEXOS}

Tabela A 1: Relação completa de seções e divisões segundo a CNAE 2.0 do IBGE utilizadas para classificação de usuários

Tabela A 2: Métodos de determinação das funções de custo

Tabela A 3: Funções originais de Capex e Opex de tratamento utilizadas como referência

Tabela A 4: Funções originais de Capex de adução utilizadas como referência.....231

Tabela A 5: Quantitativo de peças hidráulicas para determinação de $\Sigma$ Ks padrão nas adutoras 
Tabela A 6: Parâmetros de dimensionamento, quantitativo e custos unitários para implantação de tanque anóxico para $\operatorname{MBR}(\mathrm{RN})$.

Tabela A 7: Custos em função de vazão para implantação de tanque anóxico para $\operatorname{MBR}(\mathrm{RN})$

Tabela A 8: Parâmetros de dimensionamento para implantação de sistema de recirculação de efluente nitrificado para $M B R(R N)$ 239

Tabela A 9: Custos para implantação de sistema de recirculação de efluente nitrificado para $\mathrm{MBR}(\mathrm{RN})$ 239

Tabela A 10: Valores de Capex de $\operatorname{MBR}(\mathrm{RN})$ em função da vazão 239

Tabela A 11: Variáveis para cálculo do \% de demanda de $\mathrm{O}_{2}$ satisfeita pela desnitrificação

Tabela A 12: Variáveis para cálculo da \% de Opex reduzida pela desnitrificação ..241

Tabela A 13: Variáveis para cálculo de aumento de Opex por conta da desnitrificação (custos energéticos com recirculação)

Tabela A 14: Valores de Opex MBR(RN) em função de vazão

Tabela B 1: Parâmetros absolutos e normalizados e resultados completos de IPR para a RMSP por subcritério

Tabela C 1: Usuários-âncora para a ETE Mauá - C1R …………………….....246

Tabela C 2: Usuários-âncora para a ETE Leste - C1R..........................................248

Tabela C 3: Usuários-âncora para as ETEs São Miguel e Várzea do Palácio - C1R

Tabela C 4: Usuários-âncora para as ETE Parque Novo Mundo - C1R 250

Tabela C 5: Resultados detalhados da aplicação do Modelo ETE-usuário à RMSP por ETE - cenários C1R e C2R

Tabela C 6: Resultados completos da aplicação do Modelo ETE-usuário à RMSP para todos os usuários-âncora e cenários 


\section{SUMÁRIO}

1 INTRODUÇÃO E JUSTIFICATIVA .................................................................

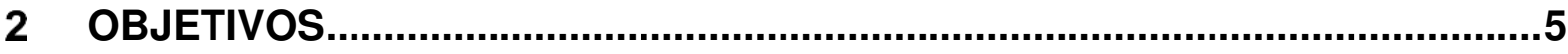

3 REVISÃO BIBLIOGRÁFICA E LEVANTAMENTO DE DADOS.........................6

\subsection{ABASTECIMENTO DE ÁGUA E COLETA E TRATAMENTO DE ESGOTOS NO}

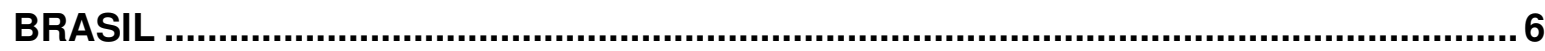

3.1.1 Panorama nacional de água e esgotos.................................................... 6

3.1.2 Disponibilidade, acessibilidade e qualidade de dados sobre recursos hídricos e saneamento básico ................................................................................ 10

3.2 REÚSO DE ÁGUA .................................................................................... 12

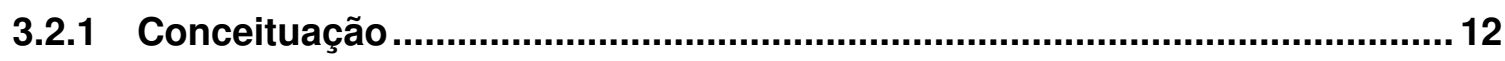

3.2.2 Histórico, panorama atual e experiências .................................................... 13

3.2.3 Reúso para abastecimento de demandas não potáveis ..............................17

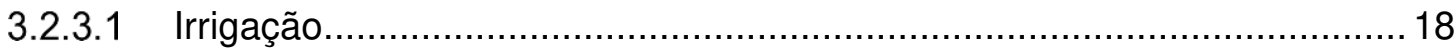

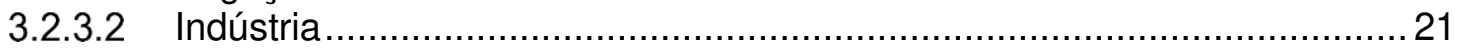

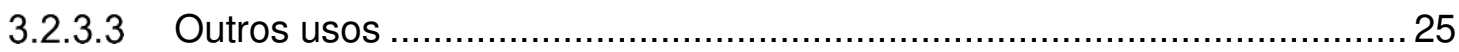

3.2.4 Tecnologias e processos para produção de água de reúso não potável ... 26 3.2.5 Custos atribuídos a processos e sistemas de produção e distribuição de

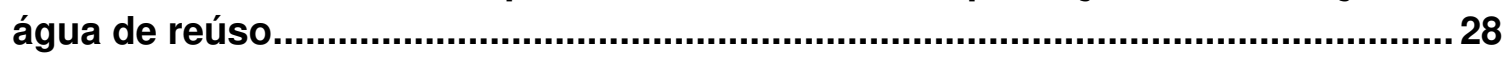

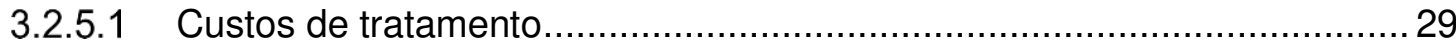

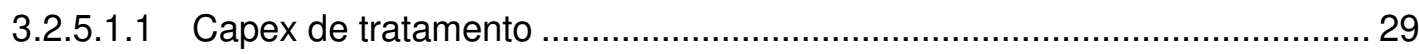

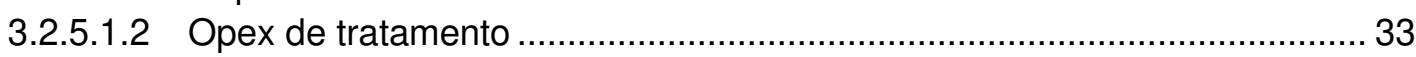

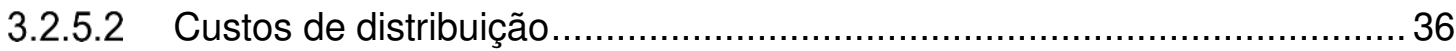

3.2.5.2.1 Capex de estações elevatórias ............................................................. 36

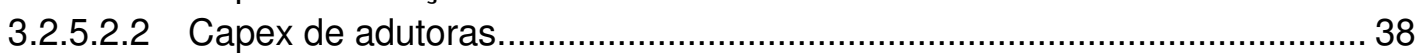

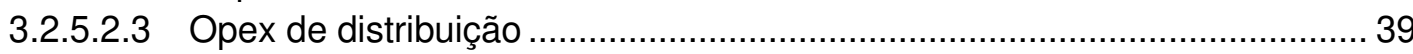

3.2.6 Diretrizes de planejamento em reúso ....................................................... 40

3.2.7 Estudos nacionais de viabilidade de reúso no Brasil e na Região

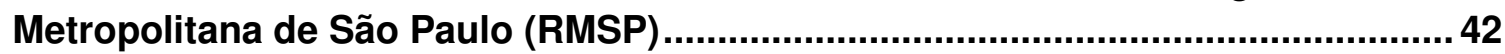

3.2.8 Aspectos legais e normativos sobre reúso no Brasil ..................................47

3.3 SISTEMAS DE INFORMAÇÕES GEOGRÁFICAS E MÉTODOS MULTICRITÉRIO DE APOIO À DECISÃO................................................................................. 51

3.3.1 Sistemas de Informações Geográficas (SIG)........................................... 51

3.3.2 Métodos Multicritério de Apoio à Decisão (MMAD) ....................................54

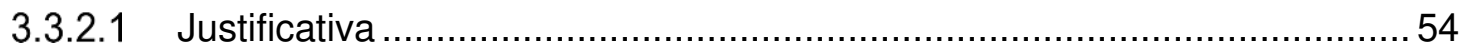

3.3.2.2 O método Analytic Hierarchy Process (AHP) ….................................. 56

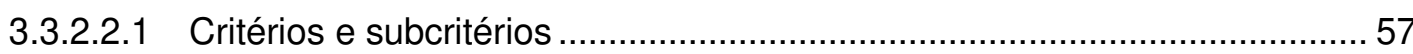

3.3.2.2.2 Comparação paritária e matriz de importâncias........................................ 58

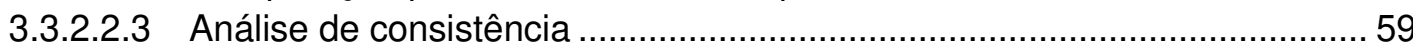

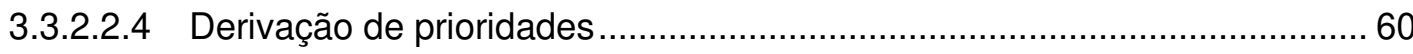




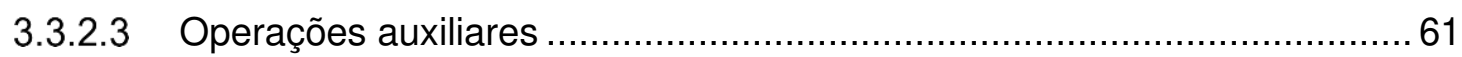

3.3.2.3.1 Métodos de normalização de parâmetros ...................................................... 61

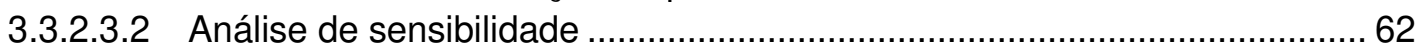

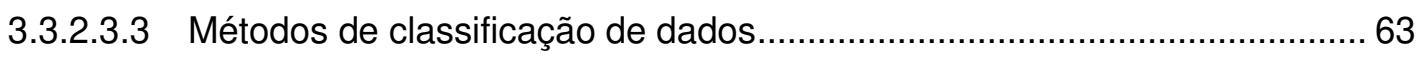

4 METODOLOGIA

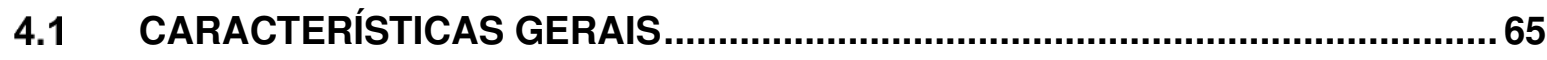

4.2 DESENVOLVIMENTO DO ÍNDICE DE POTENCIAL DE REÚSO (IPR) ...............66

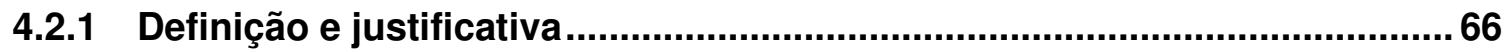

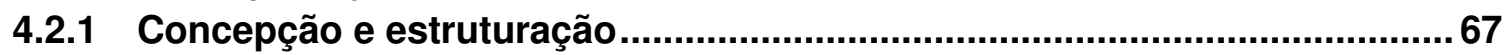

4.3 DESENVOLVIMENTO DO MODELO ETE-USUÁRIO ……...............................72

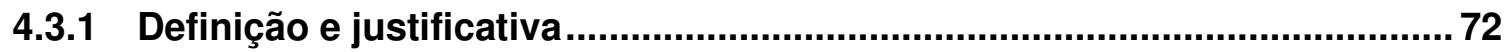

4.3.1 Concepção e estruturação........................................................................73

4.4 SISTEMA DE INFORMAÇÕES GEOGRÁFICAS (SIG) E RECUSOS ONLINE ...76

4.4.1.1 Softwares, complementos e Sistemas de Referências de Coordenadas (SRCs) 77

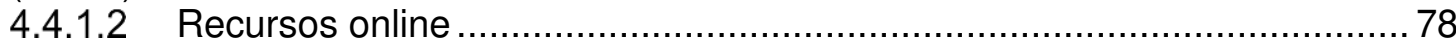

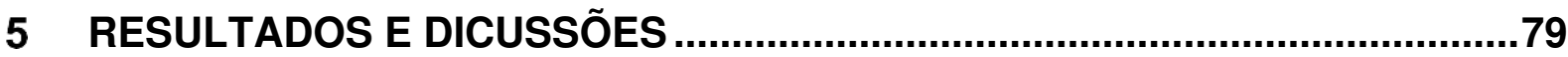

$5.1 \quad$ IPR (ÍNDICE DE POTENCIAL DE REÚSO) ……............................................... 79

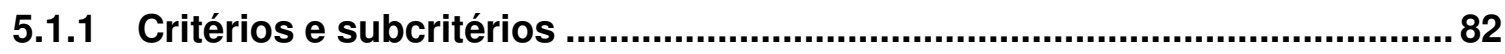

5.1.2 Matriz de importâncias paritárias e análise de consistência.........................86

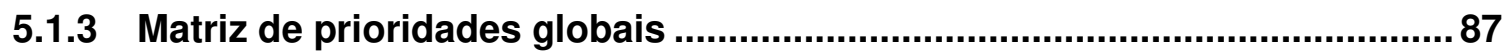

5.1.4 Métodos de normalização dos parâmetros .................................................. 88

5.1.5 Fórmula de cálculo do Índice de Potencial de Reúso (IPR)........................89

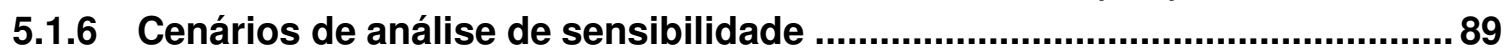

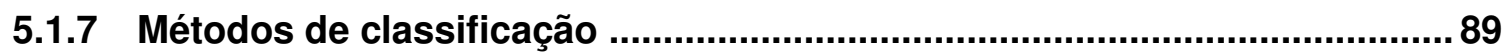

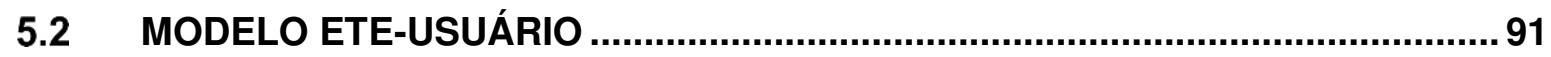

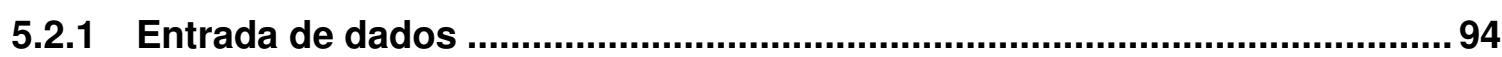

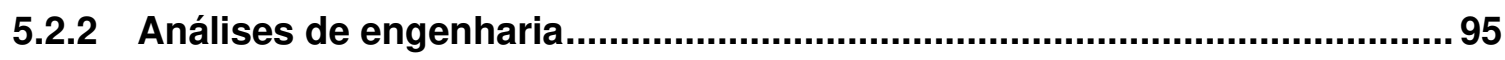

5.2.2.1 Classificação dos usuários por atividade econômica .................................95

5.2.2.2 Demanda não potável ( $\left.Q_{\mathrm{NP}}\right)$ e Coeficiente não potável $\left(\mathrm{C}_{\mathrm{NP}}\right)$....................96

5.2.2.3 Padrões de qualidade de água de reúso e arranjos de tratamento .............99

5.2.2.4 Traçado de adutoras e determinação de desnível geométrico ................. 102

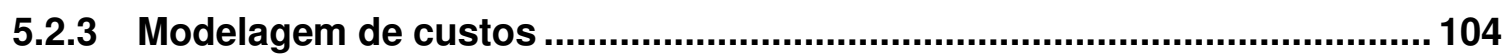

5.2.3.1 Funções de custo de capital e de operação .......................................... 104

5.2.3.2 Custos de tratamento - Capex trat e Opex trat ………………………..... 107

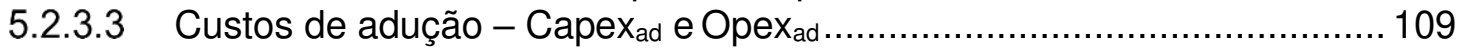

5.2.3.3.1 Capex de adutoras - Capexadutoras ……………………………………........ 109

5.2.3.3.2 Capex de estações elevatórias - Capex $x_{\mathrm{ee}}$ ……………………………...... 110

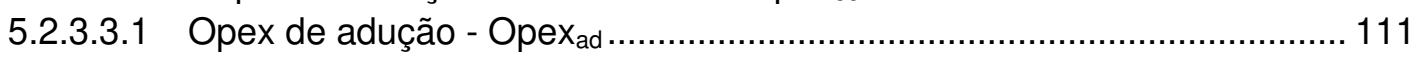

5.2.3.4 Resumo das funções de custos e relação das variáveis ......................... 112

5.2.3.5 Tarifas mínimas praticáveis ............................................................ 114

5.2.4 Cenários de abastecimento e de custos...................................................116 
5.2.4.1 Cenários de abastecimento …......................................................... 116

5.2.4.2 Cenários de custos ....................................................................... 116

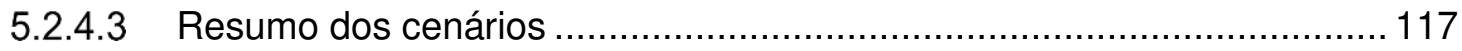

5.2.5 Determinação de usuário-âncora e agregação de resultados.................... 118

5.2.5.1 Regra de determinação de usuário-âncora .......................................... 118

5.2.5.2 Agregação de dados e potencial de reúso total .................................... 119

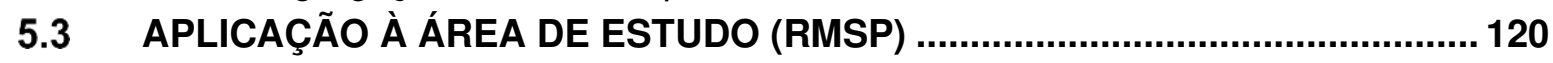

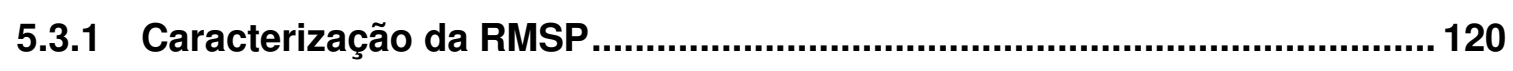

5.3.1.1 Demandas consuntivas de água ................................................... 123

5.3.1.2 Demandas de interesse específico para reúso não potável: indústria e irrigação 127

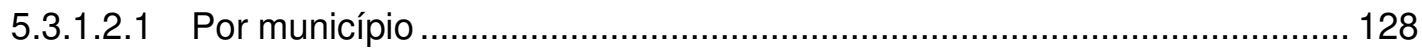

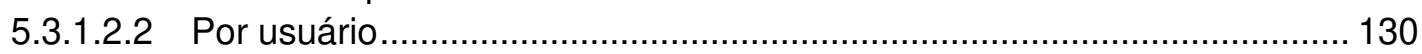

5.3.1.2.3 Evapotranspiração local para ajuste das demandas de irrigação ............ 132

5.3.1.3 Coleta e tratamento de esgotos .................................................... 133

5.3.1.4 Sobreposição espacial de outorgas e ETEs...................................... 137

5.3.1.5 Custos de aquisição de água .......................................................... 139

5.3.2 Índice de Potencial de Reúso (IPR) por município.................................... 139

5.3.2.1 Bases de dados de entrada e pré-processamento ................................. 139

5.3.2.2 Parâmetros normalizados por município ............................................. 141

5.3.2.3 Resultados de IPR por município....................................................... 142

5.3.2.4 Análise de sensibilidade ............................................................ 148

5.3.3 Potencial de reúso por ETE-usuário ......................................................... 152

5.3.3.1 Bases de dados de entrada e pré-processamento ............................... 152

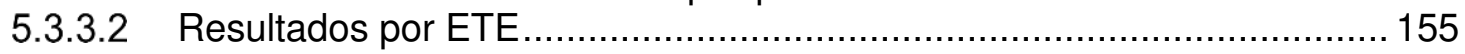

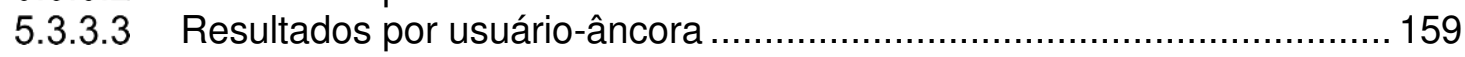

5.3.3.3.1 Por custo decomposto .................................................................... 164

5.3.3.4 Resultados por atividade econômica ................................................... 167

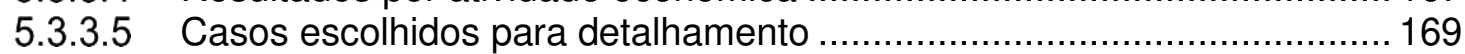

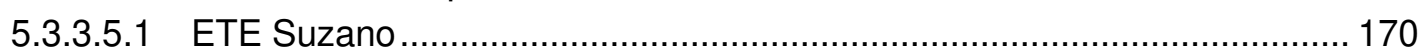

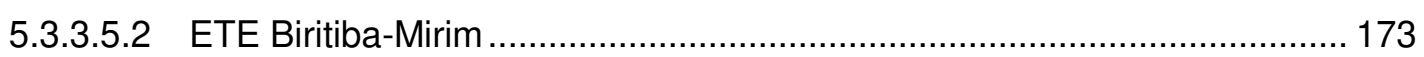

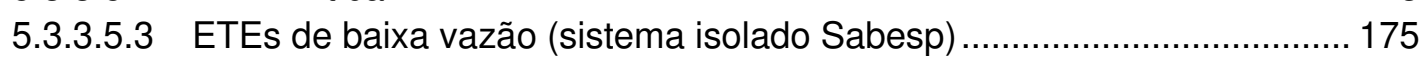

5.3.3.6 Resumo e comparação com estudos similares .................................... 181

5.4 RECURSOS ONLINE............................................................................ 188

5.5 DISCUSSÃO SOBRE OS MODELOS E POSSIBILIDADES DE

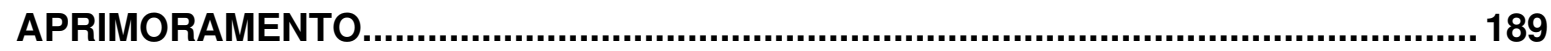

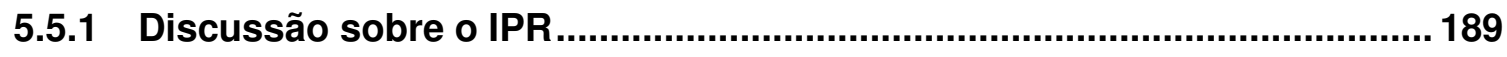

5.5.2 Discussão sobre o modelo ETE-usuário ................................................ 191

6 CONSIDERAÇÕES FINAIS ....................................................................197

7 CONCLUSÕES....................................................................................205

8 REFERÊNCIAS BIBLIOGRÁFICAS E FONTES DE DADOS ........................209 
ANEXO A. INFORMAÇÕES COMPLEMENTARES SOBRE A ESTRUTURA DO

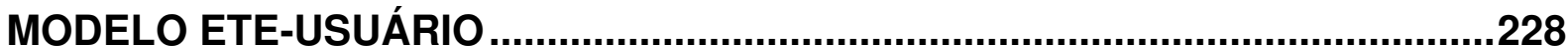

A1. Relação das divisões CNAE 2.0 utilizadas para tipificação das atividades econômicas dos usuários 228

A2. Resumo das referências utilizadas para determinação das funções de custos 229

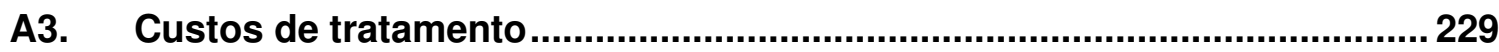

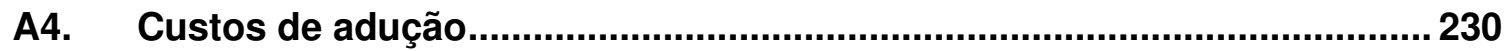

A5. Composição de tarifa mínima ..................................................................... 236

A6. Custos específicos de desnitrificação - MBR(RN).................................... 237

ANEXO B. RESULTADOS COMPLEMENTARES DA APLICAÇÃO DO IPR À RMSP

ANEXO C. RESULTADOS COMPLEMENTARES DA APLICAÇÃO DO MODELO ETE-USUÁRIO À RMSP............................................................................246

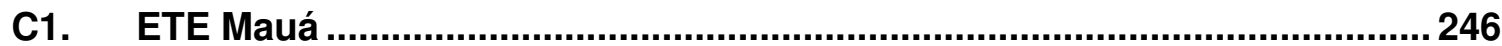

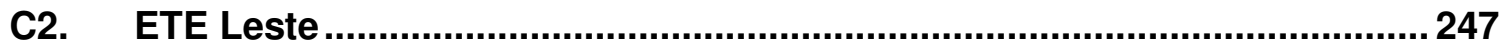

C3. ETEs Várzea do Palácio e São Miguel Paulista ........................................... 249

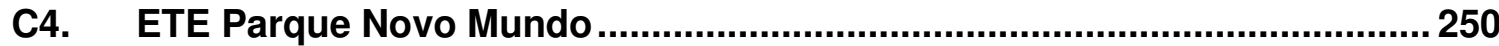

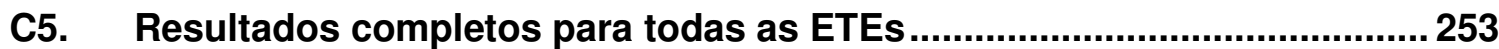

C6. Resultados completos por usuário-âncora ............................................. 259 


\section{INTRODUÇÃO E JUSTIFICATIVA}

Atualmente, o abastecimento de água no Brasil é realizado, essencialmente, a partir da captação de água bruta de mananciais superficiais ou subterrâneos (ANA, 2017a), seguindo para o tratamento em Estações de Tratamento de Água (ETAs) convencionais e distribuição. $\mathrm{O}$ crescente adensamento populacional observado nas últimas décadas resultou em maiores demandas por água em áreas reduzidas e na degradação de mananciais em decorrência de lançamentos de efluentes in natura e/ou inadequadamente tratados. Isto, por sua vez, conduz a um cenário de escassez hídrica qualiquantitativa intensa (ANA, 2018a) e a inevitáveis custos com a busca por fontes distantes de água de melhor qualidade.

A busca por novas fontes de água, ainda que atenue os problemas de escassez hídrica locais, tem como consequência custos elevados com recalque, possíveis conflitos pelo uso de água entre bacias hidrográficas, aumento do índice de perdas por conta das maiores extensões das linhas de adução e, caso não haja investimentos compatíveis em coleta e tratamento de efluentes, comprometimento da qualidade dos recursos hídricos locais. A diversificação da matriz de oferta de água é, neste contexto, uma das alternativas viáveis para a garantia de abastecimento seguro dos diversos setores consumidores. O reúso de água oriundo do tratamento de esgotos sanitários domésticos é um importante componente desse processo e vem sendo gradualmente aplicado com sucesso em diversos países, principalmente em regiões onde a escassez hídrica é mais severa. Entre as diversas definições de reúso, pode-se qualificá-lo como o uso de efluentes tratados para fins benéficos, tais como irrigação, usos industriais e fins urbanos não potáveis (MIERZWA, 2002).

Diferentemente de outras fontes alternativas de água, como aproveitamento de água de chuva, o uso de efluentes sanitários tratados apresenta constância ao longo do tempo, o que o caracteriza como fonte de alta confiabilidade. Onde quer que haja consumo de água para fins de abastecimento humano haverá geração praticamente imediata de efluentes em proporções volumétricas equivalentes, sendo essa conjunção simultaneidade/proporcionalidade no espaço-tempo importante atributo que torna a opção do reúso atraente do ponto de vista de confiabilidade de suprimento. 
Complementarmente a medidas de uso eficiente da água, a prática de reúso que assegure segurança sanitária e viabilidade econômica é um recurso valioso, porém subutilizado, que promove o aumento da disponibilidade de água e redução da exploração dos mananciais (EUROPEAN COMMISSION, 2016).

Segundo o SNIS - Sistema Nacional de Informações sobre Saneamento (SNS/MDR, 2019), o Brasil produziu em 2018, em média, $514 \mathrm{~m}^{3} / \mathrm{s}$ de água potável, sendo somente $316 \mathrm{~m}^{3} / \mathrm{s}$ de fato entregues aos usuários (em razão de perdas na distribuição). Desse valor, apenas $136 \mathrm{~m}^{3} / \mathrm{s}$ de esgoto foram tratados, o que equivale a 43\% da água entregue. Os dados do "Atlas Esgotos" (ANA, 2017b) apontam para a mesma realidade: somente $42,6 \%$ da população urbana brasileira têm seus esgotos submetidos a algum tipo de tratamento em Estações de Tratamento de Esgotos (ETEs) antes do lançamento em corpos hídricos.

Esses números indicam a fragilidade no cumprimento aos padrões de qualidade exigidos pelas resoluções oㅜ 357 e 430 do Conselho Nacional de Meio Ambiente (Conama) e previstos em legislações ambientais estaduais. Torna-se claro que ainda são necessários investimentos massivos na área de saneamento básico no que tange aos serviços de coleta e tratamento de esgotos. Assim, vislumbrar o planejamento de reúso dos efluentes tratados para atendimento às demandas não potáveis configura oportunidade de proteção dos recursos hídricos e concomitantemente ao aumento da segurança no abastecimento.

Segundo ANA (2019), as vazões retiradas de água para usos em irrigação e na indústria em 2018 foram, respectivamente, de $1.020 \mathrm{~m}^{3} / \mathrm{s}$ (49,8\% do total) e $196 \mathrm{~m}^{3} / \mathrm{s}$ $(9,6 \%)$. Por motivos que variam desde a localização dos usuários (posicionados em áreas muito distantes das fontes geradores de esgoto) a exigências de qualidade (padrões muito rigorosos para usos específicos), o reúso de água a partir de esgotos pode ser mais ou menos propício. A título de exemplo, no caso de indústrias farmacêuticas ou alimentícias, a água deve possuir elevado grau de pureza; por outro lado, sistemas industriais complementares (por exemplo refrigeração) requerem padrões de qualidade menos restritivos, e, consequentemente, menores exigências de tratamento (MIERZWA; HESPANHOL, 2005). 
Hoje no Brasil ainda não há legislações federais ${ }^{1}$ que estipulem padrões de qualidade de água de reúso, mas os municípios e estados vêm se mobilizando e criando suas próprias regulações. É o caso do município de Campinas/SP, por meio da Resolução conjunta SDVS/SMS n 09/2014 (CAMPINAS, 2014); do estado de São Paulo, com a Resolução conjunta SES/SIMA № 01 de 13 de fevereiro de 2020 (ESTADO DE SÃO PAULO, 2020); e do estado do Ceará, por meio da Resolução COEMA ํo 02 de 02/02/2017 (CEARÁ, 2017). Essas publicações disciplinam os usos finais passíveis de atendimento com água de reúso e determinam seus respectivos padrões de qualidade.

As demandas crescentes por água em regiões urbanas adensadas e a crescente necessidade de expansão dos serviços de coleta e tratamento de esgotos resultam na oportunidade de avaliação da viabilidade de utilização dos efluentes gerados para o abastecimento de demandas não potáveis, respeitando-se critérios de qualidade que tragam segurança sanitária aos usuários e garantam bom desempenho dos processos a serem abastecidos.

De acordo com o PLANSAB - Plano Nacional de Saneamento Básico (SNSA/MCIDADES, 2013), pretende-se, até 2033, que os índices de coleta e tratamento de esgotos superem $90 \%$ no Brasil. Ou seja, o planejamento da expansão da infraestrutura de esgotamento sanitário é uma grande oportunidade para a implantação de sistemas de reúso para abastecimento não potável. Isto resultaria na melhoria das condições sanitárias da população, diminuição da pressão sobre recursos hídricos, redução de necessidade de busca por água de mananciais distantes e garantia de maior segurança no abastecimento.

O panorama atual indica que há diversas regiões no Brasil em que a escassez hídrica é crônica e os serviços de coleta e tratamento de esgotos são deficitários e atendem uma parcela reduzida da população. Paralelamente a isso, existem relevantes

\footnotetext{
${ }^{1}$ Vale lembrar a publicação da norma ABNT NBR 13.863/19 em 2019, a qual trata sobre fontes alternativas não potáveis, incluindo reúso não potável, em edificações. Entretanto, a norma não possui caráter legal e se restringe especificamente a edificações. O item 3.2.8 aborda o assunto mais detalhadamente.
} 
demandas, como a industrial e de irrigação, que podem ser supridas por água de reúso com qualidade não potável, além da necessidade, ainda que para lançamento em corpos d'água, de adoção de processos de tratamento mais eficientes.

Portanto, é necessário que sejam compreendidos de maneira criteriosa os principais aspectos relacionados à adoção de reúso não potável no Brasil, aliando-se avaliações qualiquantitativas das potenciais demandas, realidade atual de saneamento básico e recursos hídricos, custos de capital e operacionais, e aspectos regulatórios pertinentes, de modo que a tomada de decisão tenha subsídios suficientes e seja possível o planejamento coordenado do reúso juntamente a outras soluções de gestão de água. 


\section{OBJETIVOS}

Este trabalho objetiva desenvolver e aplicar elementos de suporte à decisão no planejamento de reúso de água para fins não potáveis.

Como objetivos específicos, o trabalho também pretende:

- contribuir com a compreensão de fatores que influenciam positivamente a aplicação de programas de reúso não potável;

- fornecer elementos práticos que balizem a tomada de decisão quanto ao planejamento de reúso

- desenvolver elementos que possam ser incorporados por ferramentas/sistemas digitais de suporte à decisão no planejamento em reúso. 


\section{REVISÃO BIBLIOGRÁFICA E LEVANTAMENTO DE DADOS}

\subsection{ABASTECIMENTO DE ÁGUA E COLETA E TRATAMENTO DE ESGOTOS NO BRASIL}

\subsubsection{Panorama nacional de água e esgotos}

No Brasil, as principais fontes de informações sobre águas e esgotos em nível nacional são produzidas pela Agência Nacional de Águas (ANA) e pelo Sistema Nacional de Informações sobre Saneamento (SNIS). Desde 2009 a ANA publica anualmente o relatório "Conjuntura dos Recursos Hídricos no Brasil", documento que aborda aspectos de disponibilidade hídrica, usos consuntivos de água, qualidade dos corpos hídricos, monitoramento de informações de hidrometeorológicas e de recursos hídricos, regulação e fiscalização, e alocação de recursos. A Figura 1 apresenta o histórico das vazões retiradas para usos consuntivos no Brasil.

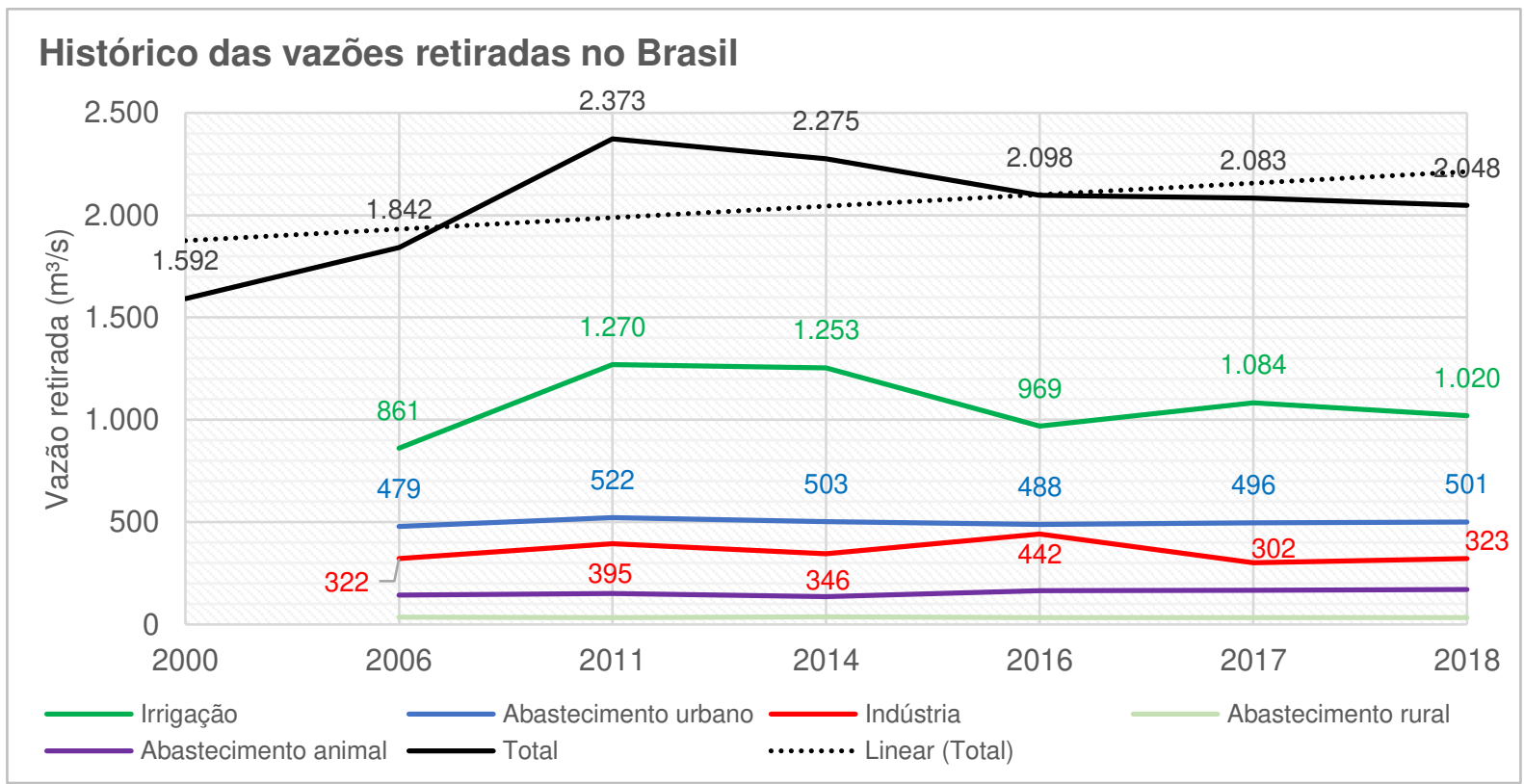

NOTA: a partir de 2017 a ANA desagregou os usos para indústria em "indústria", "mineração" e "termelétricas". No gráfico acima, esses usos foram agregados para comparação com os anos anteriores.

Figura 1: Vazões retiradas de água no Brasil por tipo de uso entre 2000 e 2018 Fonte: adaptado de ANA (2009, 2012, 2015, 2017a, 2018a, 2019)

A tendência observada nas últimas décadas é de crescimento das vazões retiradas, com projeção de aumento de $26 \%$ até 2030 em relação a 2017 (ANA, 2019). De forma 
mais detalhada para o ano de 2018, a Tabela 1 apresenta as vazões retiradas, consumidas e de retorno, assim como o coeficiente de retorno (C).

Tabela 1: Vazões retiradas, consumidas e retornadas no Brasil por tipo de uso em 2018

\begin{tabular}{|c|c|c|c|c|c|c|c|}
\hline \multirow{2}{*}{ Uso } & \multicolumn{2}{|c|}{ Vazão retirada } & \multicolumn{2}{|c|}{ Vazão consumida ${ }^{(1)}$} & \multicolumn{2}{|c|}{ Vazão de retorno } & \multirow{2}{*}{$\begin{array}{c}\mathbf{C}^{(2)} \\
\%\end{array}$} \\
\hline & $\mathrm{m}^{3} / \mathrm{s}$ & $\%$ & $\mathrm{~m}^{3} / \mathrm{s}$ & $\%$ & $\mathrm{~m}^{3} / \mathrm{s}$ & $\%$ & \\
\hline Irrigação & $1.019,9$ & $49,8 \%$ & 728,1 & $66,1 \%$ & 291,8 & $30,8 \%$ & $28,6 \%$ \\
\hline Abastecimento urbano & 500,6 & $24,4 \%$ & 100,1 & $9,1 \%$ & 400,5 & $42,3 \%$ & $80,0 \%$ \\
\hline Indústria & 195,6 & $9,6 \%$ & 105,1 & $9,5 \%$ & 90,5 & $9,6 \%$ & $46,3 \%$ \\
\hline Mineração & 34,5 & $1,7 \%$ & 10,1 & $0,9 \%$ & 24,4 & $2,6 \%$ & $70,7 \%$ \\
\hline Termelétricas $^{(3)}$ & 92,7 & $4,5 \%$ & 2,9 & $0,3 \%$ & 89,8 & $9,5 \%$ & $96,9 \%$ \\
\hline Abastecimento rural & 33,8 & $1,7 \%$ & 27,1 & $2,5 \%$ & 6,7 & $0,7 \%$ & $19,8 \%$ \\
\hline Abastecimento animal & 170,8 & $8,3 \%$ & 128,0 & $11,6 \%$ & 42,8 & $4,5 \%$ & $25,1 \%$ \\
\hline TOTAL & 2.048 & $100,0 \%$ & 1.101 & $100,0 \%$ & 947 & $100 \%$ & $46,2 \%$ \\
\hline
\end{tabular}

(1) Vazão consumida é igual à subtração da vazão retirada pela de retorno.

(2) $C$ (coeficiente de retorno) = vazão de retorno / vazão retirada.

(3) ANA (2018a) aponta modificações na metodologia de cálculo de vazão retirada para uso em termelétricas, resultando em redução a partir de 2017.

Em termos de vazão retirada, a irrigação é, sem dúvidas, o uso mais representativo, com demanda de $1.019,9 \mathrm{~m}^{3} / \mathrm{s}(49,8 \%$ do total). Uma característica do uso em irrigação é que uma pequena parcela da água retirada é retornada à bacia na forma de efluente (baixo coeficiente de retorno, C), em decorrência de incorporação da água às culturas plantadas e do fenômeno de evapotranspiração. Isto implica em altos consumos, representando 66,1\% de toda água consumida no Brasil (vazão consumida de $728,1 \mathrm{~m}^{3} / \mathrm{s}$ e $\mathrm{C}=28,6 \%$ ). Diametralmente oposta é a dinâmica atribuída ao uso para usinas termelétricas, em que quase a totalidade da água consumida retorna à bacia ( $C=96,9 \%)$. Ou seja, as termelétricas demandam $4,5 \%$ da água, mas correspondem a apenas $0,3 \%$ de todo o consumo ${ }^{2}$.

consumo urbano, que se refere, essencialmente, ao abastecimento humano nas cidades, é o segundo mais importante em termos de vazão retirada $(500,6 \mathrm{~m} 3 / \mathrm{s})$ e possui coeficiente de retorno alto (80\%). Ou seja, dos 500,6 m³ demandados para

\footnotetext{
${ }^{2} \mathrm{O}$ uso de água em termelétricas é essencialmente em sistemas de resfriamento úmidos ou híbridos, e a intensidade da utilização depende do tipo de sistema (aberto, semifechado etc.), das tecnologias implantadas e de variáveis de processo e ambientais. Segundo o IEMA (2016), a maior parte do parque termelétrico brasileiro utiliza sistemas de resfriamento úmidos de circuito semifechado, nos quais as perdas por evaporação são da ordem de $80 \%$. No entanto, as usinas brasileiras com maiores demandas de água para resfriamento adotam sistemas de resfriamento com perdas inferiores $1 \%$, o que resulta em alto coeficiente de retorno e baixa vazão consumida.
} 
uso urbano em 2018, 400,5 m³/s retornaram ao meio ambiente na forma de esgotos. Isso possui especial importância na abordagem das possibilidades de reúso em meio urbano, dado que a disponibilidade de efluente, seja ele bruto ou tratado, sempre existirá, no tempo e espaço, enquanto houver demanda.

Os usos industriais, os quais a partir de ANA (2018a) foram desagregados (indústria, mineração e termelétricas), representam a terceira maior vazão retirada $\left(195,6 \mathrm{~m}^{3} / \mathrm{s}\right.$, $9,6 \%$ ) e quarta consumida $\left(105,1 \mathrm{~m}^{3} / \mathrm{s}, 9,5 \%\right)$.

Em 2018, a ANA publicou o "Atlas esgotos: despoluição de bacias hidrográficas" (ANA, 2017b), estudo inédito que aborda o cenário atual de coleta e tratamento de esgotos da população urbana no país e propõe ações de planejamento para auxílio à tomada de decisão. O relatório caracteriza a situação de esgotamento sanitário de 5.570 sedes municipais brasileiras e analisa os impactos oriundos do lançamento de cargas poluidoras, além de propor ações, com enfoque no tratamento de esgotos, para proteção dos recursos hídricos (ANA, 2017b).

O Atlas Esgotos apresenta detalhamento dos processos de tratamento utilizados nas ETEs brasileiras. Importante porcentagem do esgoto tratado no Brasil ainda é submetida a processos pouco eficazes (utilizando-se como métrica a eficiência de remoção de Demanda Bioquímica de Oxigênio, $\mathrm{DBO}_{5,20}$ ), a exemplo de sistemas que contam somente com tratamentos preliminar ou primário, como decantadores primários ou apenas etapas anaeróbias. A Figura 2 apresenta as parcelas da população brasileira atendidas por cada tipo de solução de tratamento de esgotos. 


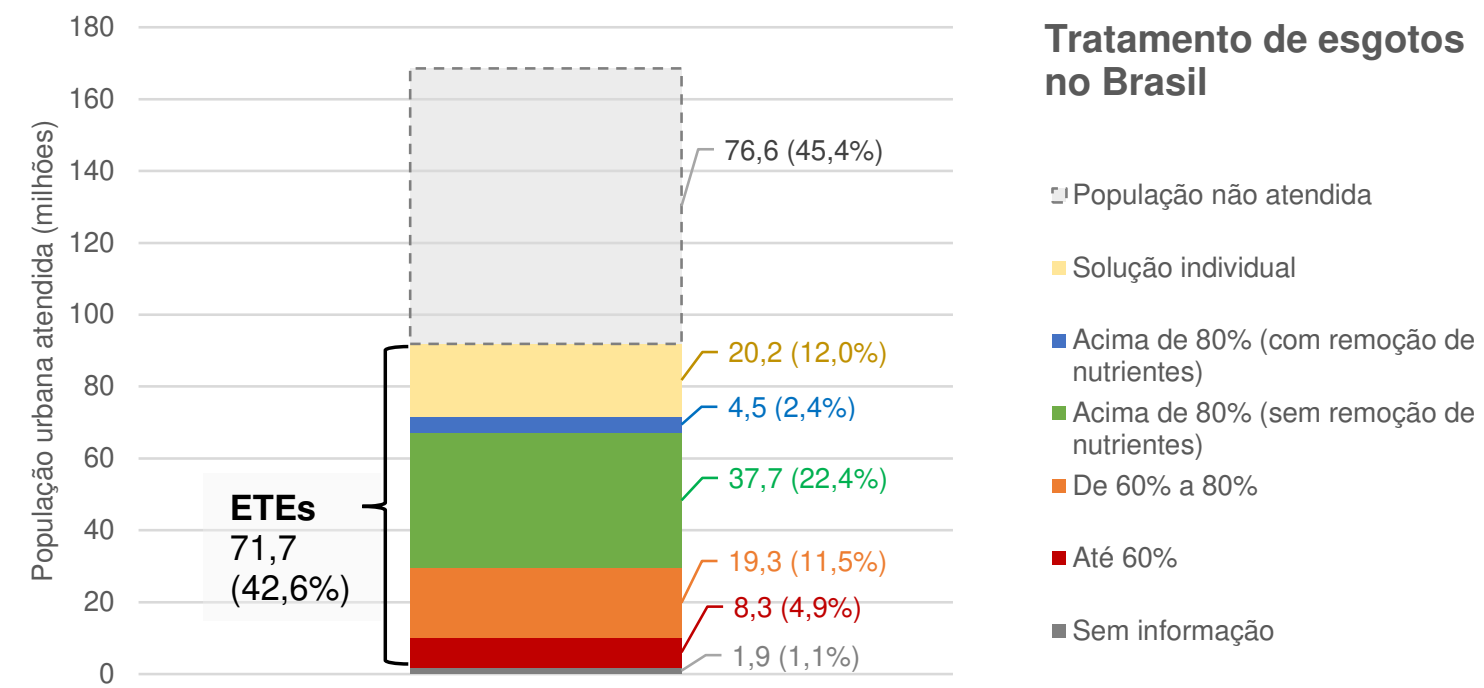

Nota: valores referentes somente à população urbana à época (168,5 milhões). População rural (aprox. 33 milhões) não contemplada.

Figura 2: População urbana atendida por tratamento de esgotos por faixa eficiência de remoção de $\mathrm{DBO}_{5,20}$

Fonte: adaptado de ANA (2017b). Elaborado pelo autor.

Dos 168,5 milhões habitantes urbanos do Brasil (ano base de 2013), 71,7 milhões $(42,6 \%)$ têm seus esgotos submetidos a algum tratamento em ETEs. Outros 20,2 milhões (12,0\%) possuem tratamento do tipo "solução individual" e 76,6 milhões $(45,4 \%)$ não são contemplados por nenhum tratamento. Além disso, dos 71,7 milhões contemplados com coleta e tratamento de esgotos, importante parcela (10,2 milhões) é atendida por processos com eficiências de remoção de $\mathrm{DBO}_{5,20}$ inferiores a $60 \%$ ou por ETEs cuja eficiência não foi informada. Assumindo-se que essa porção da população tem seus esgotos tratados de maneira inadequada ${ }^{3}$, chega-se à conclusão de que somente 61,5 milhões (36,5\% da população urbana) são atendidos por ETEs que contam com processos que garantam eficiência mínima.

Além da própria eficiência das ETEs, também deve ser considerada a capacidade de diluição dos corpos d'água receptores, atentando-se aos padrões de lançamento (resolução Conama $n^{\circ} 430 / 2011$ ) e de enquadramento e qualidade de corpos hídricos (resolução Conama $n^{\circ}$ 357/2005). Nesse escopo, o Atlas afirma que 57\% da população urbana reside em municípios que não dispõem de vazão suficiente (em

\footnotetext{
${ }^{3}$ A eficiência mínima de remoção de $\mathrm{DBO}_{5,20}$ estipulada pela resolução CONAMA 430/2011 é de $60 \%$.
} 
termos de Q95\% $^{4}$ ) para diluição dos efluentes tratados, havendo necessidade de adoção de processos com maiores eficiências de remoção de matéria orgânica e nutrientes.

\subsubsection{Disponibilidade, acessibilidade e qualidade de dados sobre recursos hídricos e saneamento básico}

Um assunto que globalmente vem ganhando espaço nas discussões acerca de planejamento e gestão de água é a necessidade da geração, organização e disponibilização de informações. $O$ tema tem sido abordado por recentes publicações de organizações transnacionais (HLPW, 2016, 2017; UNESCO, 2018; WWAP, 2017) e foi um dos destaques do $8^{\circ}$ Fórum Mundial da Água ocorrido em Brasília em março de 2018.

Segundo a Unesco (2018), não se pode gerenciar o que não é medido e compreendido, o que reforça a importância da gestão de dados, principalmente em áreas como a de planejamento. A dificuldade e a complexidade dessa gestão podem ser atribuídas a (UNESCO, 2018):

1. Alto número de agentes produtores de informação abordando grande número de tópicos distintos;

2. A informação é geralmente incompleta e dispersa;

3. Falta de homogeneidade e comparabilidade;

4. Falta de rastreabilidade da informação dos bancos de dados existentes e dificuldade em identificar o que já existe;

5. Falta de estruturas institucionais e legislativas que regulem a organização e disseminação das informações;

6. Informações geradas com financiamento público são comumente consideradas confidenciais e nem sempre são disponibilizadas ao público.

\footnotetext{
${ }^{4}$ Q95\%: vazão do corpo hídrico que estatisticamente é superada durante 95\% do ano.
} 
No Brasil, ainda que existam diversas bases de dados no setor de saneamento, há problemas de compatibilização que dificultam a reflexão realista e objetiva sobre o cenário atual, seja no âmbito local ou regional. Diferentes órgãos disponibilizam dados e informações com diferentes métodos de coleta, abrangências, frequências e tipologias. Tomando como exemplo o Brasil, em nível nacional o Ministério do Desenvolvimento Regional (MDR) é responsável pelo Sistema Nacional de Informações Sobre o Saneamento (SNIS); o Instituto Brasileiro de Geografia e Estatística (IBGE) pela Pesquisa Nacional de Saneamento Básico (PNSB) e pela Pesquisa Nacional por Amostra de Domicílio (PNAD); e a Agência Nacional de Águas (ANA) publica o "Atlas Brasil: Abastecimento Urbano de Água" e o recente "Atlas Esgotos" (FGV, 2018). Soma-se a isso a existência de órgãos estaduais e municipais que também possuem bases de dados dentro da mesma temática, como é o caso, para o estado de São Paulo, da Companhia Ambiental do Estado de São Paulo (Cetesb), a Secretaria Estadual de Recursos Hídricos e Saneamento Básico (SSRHSP), Departamento Estadual de Águas e Energia Elétrica (DAEE), fundações e comitês de bacias hidrográficas e as concessionárias de saneamento.

Frente a essas preocupações, em 2016 foi criado o High Level Panel on Water (HLPW) com a finalidade de promover a implantação do Objetivo de Desenvolvimento Sustentável 6 (Sustainable Development Goal, SDG6), ou ODS6, um entre os 17 propostos pela ONU e que objetiva "garantir disponibilidade e gestão sustentável de água e saneamento básico a todos" (ONU, 2015). O Plano de Ação do HLPW posiciona a questão das informações referentes à água (water-related information) no cerne de toda a discussão sobre planejamento e gestão. Um dos pontos centrais versa que informação é necessária à construção de entendimento compartilhado dos desafios hídricos nas escalas local, nacional e regional, particularmente das vulnerabilidades, interdependências e oportunidades-chave associadas à água (HLPW, 2016).

Ainda que aparentemente seja este um assunto alheio a este trabalho, o tema adquiriu especial importância ao longo do desenvolvimento da pesquisa por conta da necessidade de uso extensivo de dados de fontes diversas e muitas vezes conflitantes entre si, conforme será demonstrado em tópicos específicos mais à frente. 


\subsection{REÚSO DE ÁGUA}

\subsubsection{Conceituação}

Uma das definições de reúso é "o uso de efluentes tratados para fins benéficos, tais como irrigação, uso industrial e fins urbanos não potáveis" (MIERZWA, 2002). De acordo com os arranjos de tratamento e distribuição adotados e o tipo de uso final, pode-se classificar o reúso conforme ilustra a Figura 3.

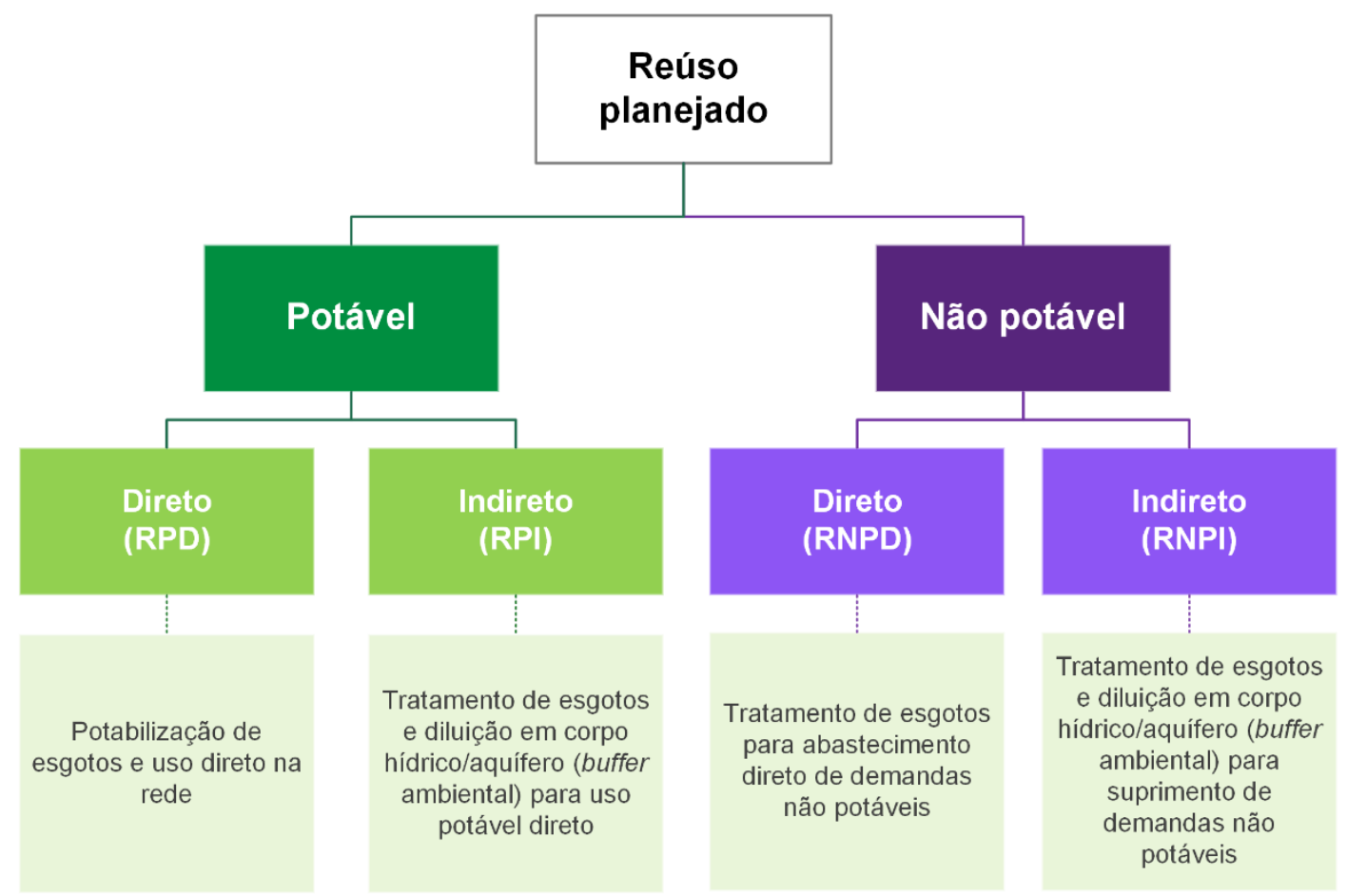

Figura 3: Tipos de reúso conforme arranjo e finalidade

Fonte: adaptado de Hespanhol (2015). Elaborado pelo autor.

Cada um dos tipos de reúso implica em procedimentos, tecnologias, legislações, cuidados e, evidentemente, custos distintos. Contextos diferentes irão resultar em maior viabilidade de determinado tipo de reúso, o que depende de fatores como a disponibilidade hídrica natural local, tipo de efluentes gerados, tipos de usuários e suas características, questões legais, aceitação pública, entre outros.

Há também o que é comumente denominado "reúso não planejado", ou seja, aquele que não ocorre dentro de programas de reúso conscientemente concebidos, monitorados e gerenciados. É o caso de mananciais superficiais utilizados para 
abastecimento urbano contaminados por esgotos lançados in natura ou não suficientemente tratados.

Neste trabalho, o termo "reúso", quando não especificado, será referente ao reúso não potável direto, ou RNPD.

\subsubsection{Histórico, panorama atual e experiências}

Com raras exceções, quase todas as atividades humanas que demandam água incorrem na produção de efluentes, costumeiramente denominados "esgotos". Ainda que os efluentes sejam um componente crítico no ciclo de gestão das águas, são geralmente considerados um fardo ou um incômodo secundário a ser ignorado. Face às sempre crescentes demandas por água, os esgotos vêm despontando como fonte confiável de água, deslocando o antigo paradigma de "tratamento e disposição final" para "reúso, reciclo e recuperação de recursos". Nesse sentido, os esgotos deixam de ser encarados somente como um contratempo a ser resolvido e passam a constituir parte da própria solução à problemática de abastecimento (WWAP, 2017).

De acordoo AQUASTAT da Food and Agriculture Organization of the United Nations (FAO), a vazão de água de reúso proveniente de tratamento de esgoto urbano utilizada no mundo é de 43,4 milhões de $\mathrm{m}^{3} / \mathrm{dia}$, ou $503 \mathrm{~m} 3 / \mathrm{s}$. A China, EUA e África do Sul concentram sozinhos mais de $50 \%$ de toda a água de reúso produzida e utilizada no mundo (FAO, 2016). Globalmente, o aumento do uso de água de reúso é notável a partir de meados da década de 1990, superando os $500 \mathrm{~m} 3 / \mathrm{s}$ nos anos 2013 , conforme se observa na Figura 4. 


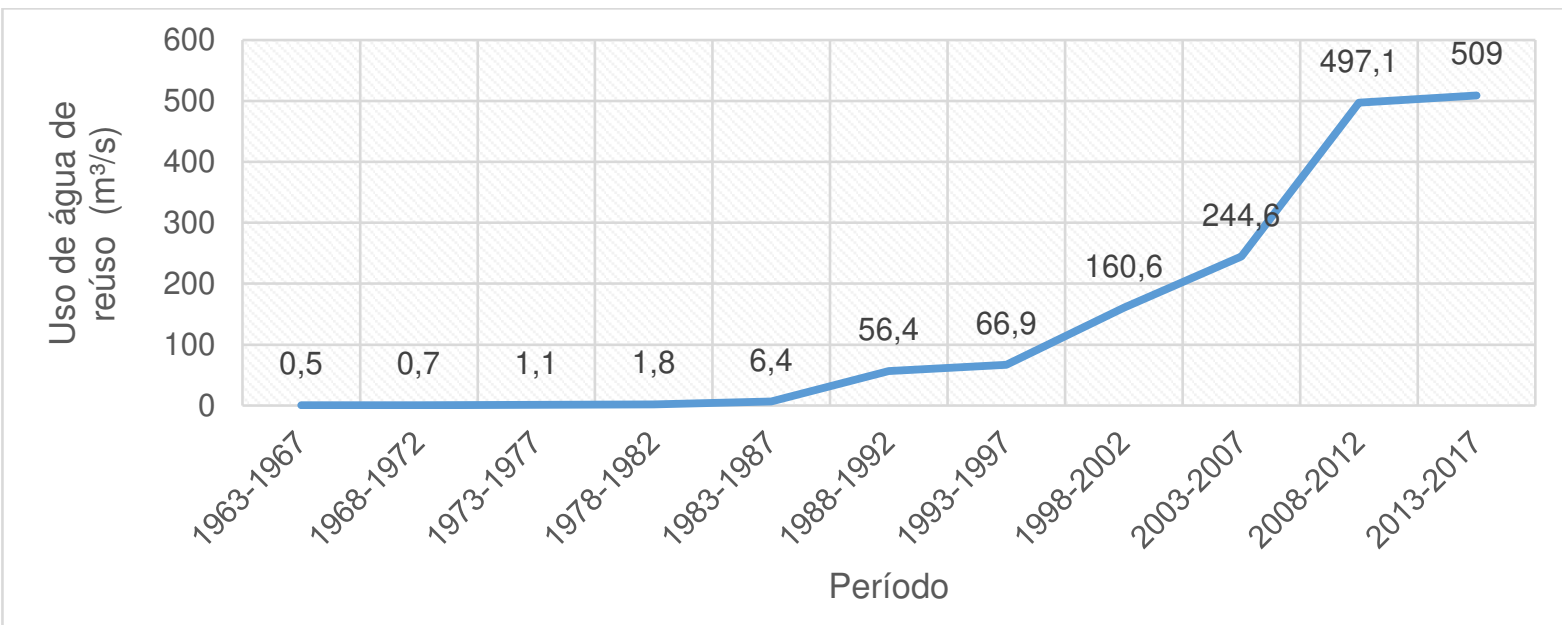

Figura 4: Gráfico do consumo de água de reúso entre 1963 e 2017 no mundo

Fonte: adaptado de FAO (2016)

Em relação aos usos da água de reúso tratada em nível terciário (Figura 5), as demandas de irrigação (agrícola e paisagística) e uso industrial são as mais relevantes e juntas correspondem a mais de $70 \%$ do total mundial (LAUTZE et al., 2014). Em geral, usos para irrigação e determinados processos industriais requerem padrões de qualidade menos exigentes e comumente estão concentrados em usuários individuais com demandas expressivas, o que torna justificável e viável a sua prevalência entre os demais.

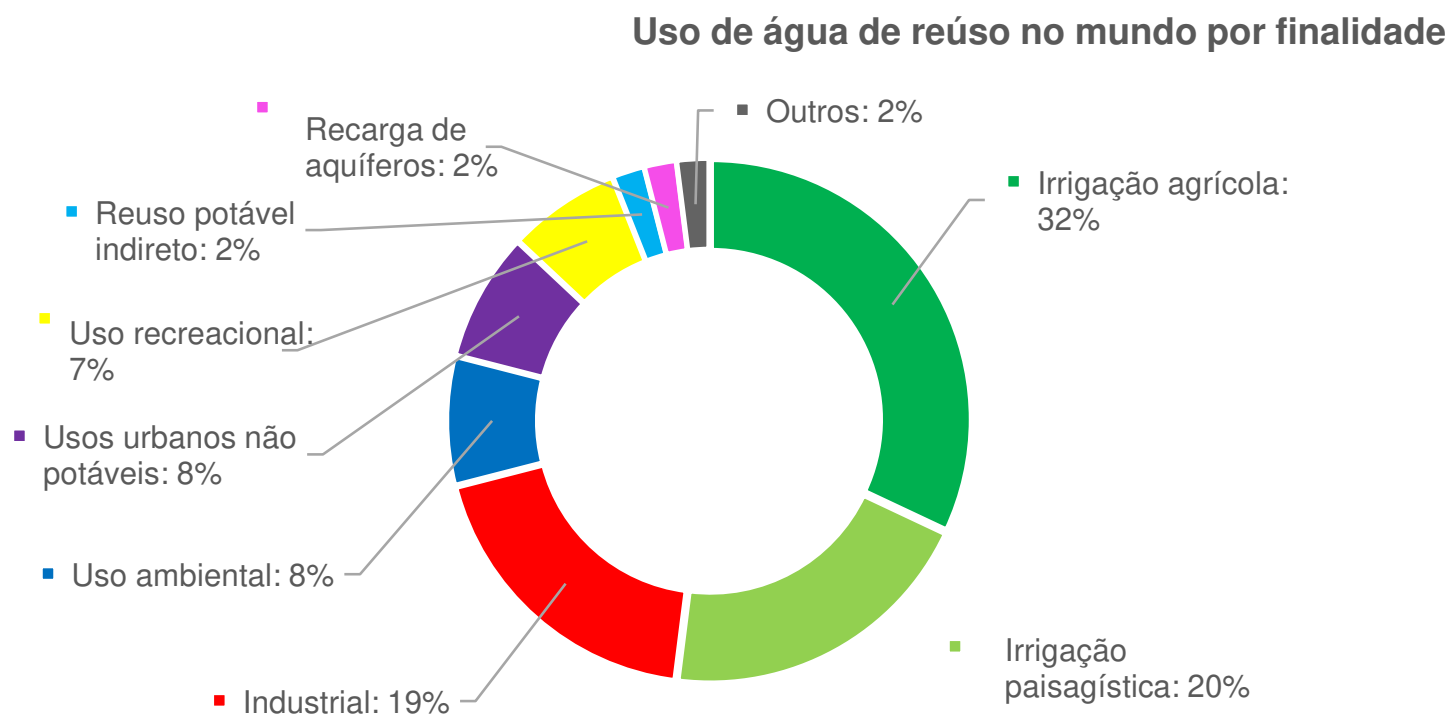

Figura 5: Distribuição do consumo de água de reúso (após tratamento terciário) no mundo de acordo com tipo de uso

Fonte: adaptado de Lautze et al. (2014). Elaborado pelo autor. 
É importante que o reúso seja visto não como uma prática isolada, mas sim como um dos pilares constituintes da emergente economia circular. Pode-se definir economia circular como um sistema econômico baseado em modelos de negócio que substituem o conceito de economia linear (take-make-dispose) a partir da redução e, alternativamente, reúso e/ou reciclagem de recursos nos processos de produção, distribuição e consumo, buscando a minimização da extração de recursos naturais aliada ao desenvolvimento econômico (KIRCHHERR et al., 2018; PETIT-BOIX; LEIPOLD, 2018; VOULVOULIS, 2018).

No que se refere à viabilidade técnica da prática de reúso, hoje são disponíveis tecnologias que permitem o tratamento de efluentes sanitários domésticos com qualidade suficiente para atender padrões de qualidade para usos não potáveis. A utilização de processos biológicos associados à separação de fases por membranas, osmose reversa para separação de sólidos dissolvidos e íons, filtração terciária, entre outros, pode viabilizar a produção de água de reúso com diferentes padrões de qualidade (HESPANHOL, 2015).

Além do reúso não potável, experiências de reúso potável indireto e direto já existem, como é o exemplo de Goreangab (Namíbia), NEWater (Singapura), Big Spring (EUA) e Cloudcroft (EUA) (GUO et al., 2014; MCIDADES, 2016; PAOLI, 2016), evidenciando a viabilidade técnica de produção de água de alta qualidade a partir de efluentes municipais.

A Tabela 2 compila distintas experiências de reúso no mundo, incluindo duas na RMSP (Aquapolo e ETE Jesus Netto). A maioria, como esperado, são programas de RNPD para abastecimento a demandas industriais e de irrigação, como é o caso do Aquapolo e Jesus Netto, bem como Beichen Hi Tech Park, Vale do Mezquital e Western Corridor. Há também casos singulares e simbólicos como o da planta de Goreangab (Windhoek, Namíbia, reúso potável direto), NEWater (Singapura, reúso não potável direto e potável direto) e Orange County (EUA, recarga de aquífero). Para cada uma das experiências são apresentados os processos/unidades principais de tratamento, finalidades de uso e a capacidade de produção de água de reúso (“Q”). 
REVISÃO BIBLIOGRÁFICA E LEVANTAMENTO DE DADOS

Tabela 2: Experiências de reúso no mundo - processos de tratamento adotados, tipo de reúso, finalidade e vazões de projeto

\begin{tabular}{|c|c|c|c|c|c|c|}
\hline Nome & Localização & $\begin{array}{l}\text { Etapas de tratamento } \\
\text { principais }\end{array}$ & Tipo de reúso & Usos finais & $Q(\mathrm{I} / \mathrm{s})$ & Referência \\
\hline Aquapolo & São Paulo (Brasil) & $\mathrm{MBR}+\mathrm{OR}+\mathrm{UV}$ & RNPD & Industrial & 1.000 & Paoli (2016) \\
\hline Beichen Hi Tech Park & Tianjin (China) & $\mathrm{MBR}+\mathrm{OR}+\mathrm{O}_{3}$ & RNPD & Industrial & 2.197 & Paoli (2016) \\
\hline Big Spring & Texas (EUA) & $\mathrm{MBR}+\mathrm{OR}+\mathrm{UV} / \mathrm{POA}+\mathrm{FT}$ & RPD & Potável & 92 & Guo et al. (2014) \\
\hline Chipre & Chipre & $L A C+R N+C L$ & RNPD/RPI & $\begin{array}{l}\text { Irrigação paisagística e recarga de } \\
\text { aquífero }\end{array}$ & 111 & Paoli (2016) \\
\hline Cloudcroft & Novo México (EUA) & $\mathrm{MBR}+\mathrm{OR}+\mathrm{UV} / \mathrm{POA}$ & RPI & Potável & 4 & Guo et al. (2014) \\
\hline Costa Brava & Costa Brava (Espanha) & $\mathrm{FT}+\mathrm{UV}+\mathrm{CL}$ & RNPD/RPI & $\begin{array}{l}\text { Recarga de aquífero, urbano, vazão } \\
\text { ambiental }\end{array}$ & 203 & Paoli (2016) \\
\hline Edward C. Little & El Segundo (EUA) & Múltiplos, de acordo com o uso & RNPD/RPI & $\begin{array}{l}\text { Múltiplos (irrigação paisagística, urbanos, } \\
\text { industrial e recarga de aquífero) }\end{array}$ & 1.968 & Paoli (2016) \\
\hline ETE Jesus Netto & São Paulo (Brasil) & $\mathrm{UASB} / \mathrm{LAC}+\mathrm{FT}+\mathrm{CL}$ & RNPD & Urbano e industrial & 52 & Sabesp (2015) \\
\hline Goreangab & Windhoek (Namíbia) & LAC + múltiplas barreiras + UV & RPD & Potável & 184 & Paoli (2016) \\
\hline Hampton Roads & York County (EUA) & $\mathrm{LAC}+\mathrm{SBR}+\mathrm{CL}$ & RPD & Industrial & 16 & Paoli (2016) \\
\hline Honololu & Honololu (EUA) & $\mathrm{LAC}+\mathrm{FT}+\mathrm{OR}+\mathrm{UV}$ & RNPD & Urbano, industrial, vazão ambiental & 570 & Paoli (2016) \\
\hline Madri & Madri (Espanha) & $\mathrm{LAC}+\mathrm{UV}$ & RNPI & Urbano & 108 & Paoli (2016) \\
\hline Michelson / Los Alisos & Orange County (EUA) & $\mathrm{MBR}+\mathrm{OR}+\mathrm{UV}+\mathrm{CL}$ & RNPD & Irrigação paisagística e urbano & 1.750 & Paoli (2016) \\
\hline Milão & Milão (Itália) & $\mathrm{LA}+\mathrm{FT}+\mathrm{UV}$ & RNPD & Irrigação (indireta) & 3.999 & Paoli (2016) \\
\hline NEWater & Singapura & $\mathrm{MBR}+\mathrm{OR}+\mathrm{UV}$ & RNDP/RPI & Urbano e potável & 2.600 & Paoli (2016) \\
\hline Orange County & Orange County (EUA) & $\mathrm{MBR}+\mathrm{OR}+\mathrm{UV} / \mathrm{POA}$ & $\mathrm{RPI}$ & Recarga de aquífero & 5.242 & Paoli (2016) \\
\hline Perth & Perth (Austrália) & $\mathrm{LAC}+\mathrm{UF}+\mathrm{OR}+\mathrm{UV}$ & RPI & Recarga de aquífero & 600 & MCidades (2016) \\
\hline Salinas Valley & Monterey County (EUA) & $\mathrm{LAC}+\mathrm{FT}+\mathrm{CL}$ & RNPD & Irrigação agrícola & 869 & Paoli (2016) \\
\hline Torreele & St-André (Bélgica) & $\mathrm{MBR}+\mathrm{OR}$ & $\mathrm{RPI}$ & Recarga de aquífero & 57 & Paoli (2016) \\
\hline Upper Occoquan & Virgínia (EUA) & $\mathrm{FT}+\mathrm{CL}+\mathrm{CAG}$ & $\mathrm{RPI}$ & Recarga de manancial superficial & 2.400 & $\begin{array}{l}\text { Paoli (2016), } \\
\text { MCidades (2016) } \\
\end{array}$ \\
\hline Vale do Mezquital & $\begin{array}{l}\text { Cidade do México } \\
\text { (México) }\end{array}$ & $\mathrm{LAC}+\mathrm{FT}+\mathrm{FQ}$ & RNPD & Irrigação & 35.000 & MCidades (2016) \\
\hline Western Corridor & $\begin{array}{l}\text { South East Queensland } \\
\text { (Austrália) }\end{array}$ & $\mathrm{MBR}+\mathrm{OR}+\mathrm{POA}+\mathrm{UV}$ & RNPD & Industrial e agricultura & 793 & Paoli (2016) \\
\hline $\begin{array}{ll}\text { CAG } & \text { Carvão ativado granular } \\
\text { CL } & \text { Cloração } \\
\text { FT } & \text { Filtração terciária } \\
\text { LA } & \text { Lodos ativados } \\
\text { MBR } & \text { Membrane bioreactor } \\
\mathrm{O}_{3} & \text { Ozônio } \\
\text { OR } & \text { Osmose reversa } \\
\text { POA } & \text { Processos oxidativos ava }\end{array}$ & $\begin{array}{l}\text { RNPD } \\
\text { RNPI } \\
\text { RPD } \\
\text { RPI } \\
\text { UASB } \\
\text { UF } \\
\text { UV }\end{array}$ & $\begin{array}{l}\text { Reúso não potável direto } \\
\text { Reúso não potável indireto } \\
\text { Reúso potável direto } \\
\text { Reúso potável indireto } \\
\text { Upflow anaerobic sludge blanket } \\
\text { Ulltrafiltracãão } \\
\text { Radiação ultravioleta }\end{array}$ & & & & \\
\hline
\end{tabular}


Mesmo com comprovada disponibilidade de meios técnicos e de viabilidade econômica para a prática de reúso, há pontos fundamentais para o êxito da sua aplicação que nem sempre são evidentes. Smith et al. (2018) apontam que há autores que defendem que o maior e principal obstáculo à aplicação do reúso não se refere a critérios técnicos, mas sim de aceitação pública. Essa hipótese é reforçada pela existência de casos emblemáticos em que a percepção negativa da população resultou no insucesso de iniciativas de reúso, como nos casos de Toowoomba na Austrália (HURLIMANN; DOLNICAR, 2010; SMITH et al., 2018) e Tianjin na China (GU et al., 2015).

Estudos de opinião pública sobre fontes alternativas de água indicam que a aceitação tende a ser maior quando não há contato humano direto com a água, como no caso de irrigação (HURLIMANN; DOLNICAR, 2016). Ou seja, usos como o reúso não potável, no qual não há contato direto e os riscos são considerados menores, tendem a ser vistos como menos controversos pela população (GOODWIN et al., 2018). Diante disso, Hurlimann (2008) defende que a adoção e consolidação prévia de programas de reúso não potável cria cenários mais favoráveis à futura aceitação de usos potáveis, estratégia que pode ampliar o sucesso de ações de diversificação de fontes de água. EPA (2012), Fielding \& Roiko (2014) e Goodwin et al. (2018) também sublinham como a ampliação de medidas de acesso à informação impacta positivamente na percepção pública em relação ao reúso, corroborando com a discussão sobre a importância da gestão de dados nas áreas de recursos hídricos e saneamento.

\subsubsection{Reúso para abastecimento de demandas não potáveis}

Conforme recém levantado, os usos mais expressivos de água de reúso não potável direto no mundo são os de irrigação e industrial. Dessa maneira, neste tópico serão explorados em maior detalhe aspectos específicos referentes a esses dois usos. 


\subsubsection{Irrigação}

O uso de esgotos tratados para fins de irrigação de culturas agrícolas é talvez a prática de reúso mais antiga conhecida, sendo realizada já por sociedades mesopotâmicas pré-históricas desde a Idade do Bronze (JARAMILLO; RESTREPO, 2017).

As vantagens da prática são múltiplas: despressurização de mananciais, redução de necessidade de uso de fertilizantes químicos; aumento de produtividade e melhoria da qualidade de corpos hídricos receptores pela redução das cargas lançadas, com destaque ao fósforo. Esse macronutriente é extensivamente aplicado na agricultura e também está presente em importantes concentrações nas excretas humanas (OMS, 2006; WWAP, 2017), sendo o principal responsável pela eutrofização de corpos hídricos, principalmente em ambientes lênticos.

Como a irrigação visa, essencialmente, repor as perdas que ocorrem por evapotranspiração, a demanda tem caráter sazonal e está sujeita a variações climáticas e a características hidrogeológicas locais e das próprias espécies irrigadas. Os volumes requeridos naturalmente variam ao longo do ano, aspecto este fundamental no planejamento de fornecimento de água de reúso. A experiência mundial tem demonstrado que tentativas de fornecimento de vazão fixa de água de reúso para usuários irrigantes tendem a falhar caso não haja devida definição dos arranjos de distribuição junto aos potenciais usuários (U.S. EPA, 2012).

Os principais riscos do uso de água de reúso para irrigação são de saúde pública (risco microbiológico) e ambiental, a saber (ALCALDE-SANZ; GAWLIK, 2017; OMS, 2006; WWAP, 2017):

- riscos de saúde pública: contaminação química ou biológica dos consumidores finais (principalmente no caso de culturas consumidas cruas ou pouco processadas) e de trabalhadores que tenham contato direto ou indireto com a água ou as culturas produzidas;

- riscos ambientais: relacionados a efeitos adversos no solo, lenço freático, água superficial e comprometimento de ecossistemas dependentes. 
Há também outros fatores de risco ainda pouco discutidos, como aqueles referentes às esferas institucional e econômica. Alcalde-Sanz \& Gallik (2017) trazem à tona o tema de que a falta de homogeneização de padrões de qualidade da água no reúso agrícola na União Europeia pode implicar em barreiras à comercialização de produtos entre os estados-membro, já que as legislações e normativas nacionais apresentam divergências entre si.

A depender da matriz econômica do país, as demandas para uso agrícola correspondem a parcelas muito significativas da vazão total retirada, como é o caso do Brasil (49,8\% em 2018) (ANA, 2019). No entanto, nem sempre as demandas de irrigação mais expressivas se encontram próximas a grandes centros urbanos onde há geração intensiva de esgoto (WWAP, 2017), o que pode limitar o potencial de suprimento dessas demandas por água de reúso.

Não há um padrão único de qualidade de água de reúso para irrigação. Em geral, as legislações e normativas estabelecem mais de um padrão, sendo um mais e outro menos restritivo, dependendo das culturas irrigadas (consumidas cruas, processadas, não alimentícias etc.), tipo de acesso à área (restrição severa, restrição moderada) e método de irrigação (inundação, sulcos, aspersão, gotejamento) (ALCALDE-SANZ; GAWLIK, 2017; HESPANHOL, 2002). Ressalta-se que esgotos tratados em nível secundário, ainda que atendam a parâmetros microbiológicos e de matéria orgânica, podem comprometer o bom funcionamento de sistemas de irrigação mais sensíveis (como gotejamento) por conta de presença de sólidos suspensos (EPA, 2012).

Os principais parâmetros de qualidade da água para irrigação são os microbiológicos (coliformes termotolerantes e ovos de helmintos), sólidos em suspensão (SST / turbidez) e cloro (FAO, 2003). A Tabela 3 compila padrões de qualidade de água de reúso para fins de irrigação disponíveis na literatura. 
Tabela 3: Referências de padrões qualidade de água de reúso para irrigação

\begin{tabular}{|c|c|c|c|c|c|c|c|c|c|}
\hline \multirow[b]{2}{*}{ Parâmetro } & \multirow[b]{2}{*}{ Unid. } & \multicolumn{3}{|c|}{ FAO (2003) } & \multicolumn{2}{|c|}{$\begin{array}{c}\text { EPA } \\
(2012) \\
\end{array}$} & \multicolumn{2}{|c|}{$\begin{array}{c}\text { MCidades } \\
(2017 a) \\
\end{array}$} & \multirow{2}{*}{$\begin{array}{c}\begin{array}{c}\text { ABNT } \\
(2019)\end{array} \\
\begin{array}{c}\text { Irrigação } \\
\text { paisagística } \\
\text { (a) }\end{array}\end{array}$} \\
\hline & & $\begin{array}{c}\text { Culturas } \\
\text { não } \\
\text { alimentícias }\end{array}$ & $\begin{array}{l}\text { Culturas } \\
\text { alimentícias } \\
\text { - acesso } \\
\text { restrito }\end{array}$ & $\begin{array}{c}\text { Culturas } \\
\text { alimentícias - } \\
\text { acesso } \\
\text { irrestrito }\end{array}$ & $\begin{array}{l}\text { Culturas não } \\
\text { alimentícias / } \\
\text { processadas }\end{array}$ & $\begin{array}{l}\text { Culturas } \\
\text { alimentícias }\end{array}$ & $\begin{array}{l}\text { Uso } \\
\text { restrito }\end{array}$ & $\begin{array}{l}\text { Uso } \\
\text { irrestrito }\end{array}$ & \\
\hline $\begin{array}{l}\text { Coliformes } \\
\text { termotolerantes }\end{array}$ & $\begin{array}{l}\text { UFC/ } \\
100 \mathrm{ml}\end{array}$ & $<1.000$ & $<200$ & $<5$ & $\leq 200$ & Ausentes & $<1.000$ & $<10$ & $\leq 200$ \\
\hline Turbidez & NTU & - & - & - & - & $<2$ & - & $<5$ & $<5$ \\
\hline $\mathrm{pH}$ & - & - & - & - & $6,0-9,0$ & $6,0-9,0$ & $\begin{array}{c}6,0- \\
9,0\end{array}$ & $6,0-9,0$ & $6,0-9,0$ \\
\hline $\mathrm{DBO}_{5,20}$ & $\mathrm{mgO}_{2} / \mathrm{l}$ & $<20$ & $<20$ & $<10$ & $<30$ & $<10$ & $<30$ & $<15$ & $\leq 20$ \\
\hline $\begin{array}{l}\text { Ovos de } \\
\text { helmintos }\end{array}$ & ovo/l & Ausentes & Ausentes & Ausentes & - & - & $<1$ & $<1$ & - \\
\hline $\begin{array}{l}\text { Cloro residual } \\
\text { livre }\end{array}$ & $\mathrm{mg} / \mathrm{l}$ & - & - & - & - & - & - & - & $\begin{array}{c}0,5-5,0 \\
(0,2-2,0) \\
\text { (b) }\end{array}$ \\
\hline $\begin{array}{l}\text { Cloro residual } \\
\text { total }\end{array}$ & $\mathrm{mg} / \mathrm{l}$ & - & - & - & $>1,0$ & $>1,0$ & $>1,0$ & $>1,0$ & - \\
\hline $\begin{array}{l}\text { Sólidos } \\
\text { suspensos } \\
\text { totais }\end{array}$ & $\mathrm{mg} / \mathrm{l}$ & $<1.000$ & $<200$ & $<20$ & $<20$ & - & - & - & - \\
\hline $\begin{array}{l}\text { Condutividade } \\
\text { elétrica }\end{array}$ & $\mu \mathrm{S} / \mathrm{cm}$ & - & - & - & - & - & - & - & $\leq 3.200$ \\
\hline
\end{tabular}

(a) Padrão de qualidade da ABNT NBR 16.783:2019 não se refere exclusivamente à irrigação paisagística, mas também a usos como descargas de sanitários e mictórios e lavagens. (b) Faixa de valores entre parênteses é a recomendada.

Na sequência seguem algumas considerações sobre os parâmetros destacados.

- Em razão dos evidentes riscos sanitários, coliformes termotolerantes são o indicador mais comum em padrões de reúso para irrigação. Os limites diferem de acordo com a restrição do uso, variando de 1.000 UFC/100 ml para culturas não alimentícias em FAO (2003) a ausência em 100 ml para alimentícias em EPA (2012).

- Turbidez não é um parâmetro presente em todos os padrões. Para as referências que o incluem, seu limite varia de 2 a 5 NTU (EPA, 2012; MCidades, 2017a; ABNT, 2019). Altas concentrações de sólidos em suspensão favorecem que micro-organismos patogênicos se "abriguem" em partículas, o que prejudica a eficiência de processos de desinfecção (efeito conhecido como shielding), bem como também levam à aceleração da colmatação do solo irrigado e à consequente perda de capacidade de percolação.

- O controle da $\mathrm{DBO}_{5,20}$, que geralmente é limitada a até $20-30 \mathrm{mgO} / \mathrm{l}$, também é necessário para que não haja decomposição, principalmente anaeróbica, de matéria orgânica na distribuição e reservação da água de reúso, fenômeno que leva ao desprendimento indesejado de gases como sulfeto de hidrogênio $\left(\mathrm{H}_{2} \mathrm{~S}\right)$. 
- Ovos de helmintos não são inativados por processos de desinfecção comuns, como cloro e UV. Em razão de seu alto diâmetro efetivo, é possível realizar sua separação por processos como filtração terciária granular ou ultrafiltração (UF).

- Ainda que a presença de cloro residual seja importante para garantia de ausência de coliformes na distribuição e reservação, espécies vegetais geralmente possuem baixa tolerância ao $\mathrm{Cl}$ e a suas espécies dissociadas. Por isso, a exemplo da ABNT (2019), são recomendadas concentrações mínimas e máximas de cloro.

\subsubsection{Indústria}

Depois dos usos para irrigação, o reúso para fins industriais é o mais relevante em termos quantitativos no mundo (LAUTZE et al., 2014). Os usos de água na indústria são múltiplos, dentre os quais podem-se destacar (MIERZWA; HESPANHOL, 2005): uso como matéria-prima (incorporação ao produto final); como fluido auxiliar (preparação de suspensões e soluções químicas, reagentes químicos, lavagens etc.); geração de energia; fluido de aquecimento e/ou resfriamento; e transporte e assimilação de contaminantes.

Entre eles, há um que apresenta uma característica especial: o uso em sistemas de resfriamento (ou Torres de Resfriamento, TRs), os quais "são partes integrais das operações de uma unidade industrial e têm como objetivo resfriar os equipamentos e os processos de uma planta, possibilitando-lhes operar econômica e eficientemente" (CNI, 2017a). A proporcionalidade de uso de água para resfriamento em plantas industriais pode superar, para alguns setores, $90 \%$ do total, o que, somado ao fato de que o processo tolera utilização de água com padrões de qualidade pouco restritivos (MIERZWA, 2002) e independe da qualidade requerida no processo produtivo em si (CNI, 2017a), cria oportunidades para a prática de reúso não potável.

Entretanto, dados sobre uso de água para resfriamento na indústria são escassos. A própria Confederação Nacional da Indústria (CNI) aponta que a falta de padrões e referências de consumo de água em processos industriais é hoje uma limitação na gestão de águas, principalmente no que se refere ao estabelecimento de métricas para mensuração de desempenho ambiental e criação de benchmarking (CNI, 2017a). 
Posta a limitação de dados referentes à indústria brasileira, foram buscadas referências internacionais de distribuição de consumo de água por atividade industrial, sendo utilizados levantamentos realizados por Van der Leeden et al. (1990), Moström (2015) e Statistics Canada (2018). Conforme apresenta a Tabela 4, as atividades foram divididas segundo a tipologia da Classificação Nacional de Atividade Econômicas (CNAE 2.0) para as divisões 5 a 43.

Tabela 4: Estimativas de porcentagem uso de água para resfriamento em atividades industriais

\begin{tabular}{|c|c|c|c|c|c|}
\hline \multirow{2}{*}{\multicolumn{2}{|c|}{ Divisão CNAE 2.0}} & \multicolumn{4}{|c|}{ \% de uso de água para resfriamento (TR) } \\
\hline & & \multirow{2}{*}{$\begin{array}{l}\text { Van der } \\
\text { Leeden et al. } \\
(1990) \\
-\end{array}$} & \multirow{2}{*}{$\begin{array}{l}\text { Van der } \\
\text { Leeden et al. } \\
(1990) \\
\end{array}$} & \multirow{2}{*}{$\begin{array}{l}\text { Statistics } \\
\text { Canada } \\
(2018)\end{array}$} & \multirow{2}{*}{$\begin{array}{l}\text { Moström } \\
(2015)\end{array}$} \\
\hline 5 & Extração de carvão mineral & & & & \\
\hline 6 & Extração de petróleo e gás natural & - & - & - & - \\
\hline 7 & Extração de minerais metálicos & - & - & - & - \\
\hline 8 & Extração de minerais não-metálicos & - & - & - & - \\
\hline 9 & Atividades de apoio à extração de minerais & - & - & - & $3 \%$ \\
\hline 10 & Fabricação de produtos alimentícios & $35 \%$ & $60 \%$ & $37 \%$ & $66 \%(3)$ \\
\hline 11 & Fabricação de bebidas & $72 \%(1)$ & $60 \%$ & $46 \%$ & $66 \%(3)$ \\
\hline 12 & Fabricação de produtos do fumo & - & - & - & $66 \%(3)$ \\
\hline 13 & Fabricação de produtos têxteis & $57 \%$ & $61 \%$ & $18 \%$ & $7 \%(4)$ \\
\hline 14 & $\begin{array}{l}\text { Confecção de artigos do vestuário e } \\
\text { acessórios }\end{array}$ & - & - & $27 \%$ & $7 \%(4)$ \\
\hline 15 & $\begin{array}{l}\text { Preparação de couros e fabricação de } \\
\text { artefatos de couro, artigos para viagem e } \\
\text { calçados }\end{array}$ & - & - & - & $7 \%(4)$ \\
\hline 16 & Fabricação de produtos de madeira & $58 \%$ & $66 \%$ & $27 \%$ & $2 \%$ \\
\hline & $\begin{array}{l}\text { Fabricação de celulose, papel e produtos de } \\
\text { papel }\end{array}$ & $18 \%$ & $23 \%$ & $24 \%$ & $38 \%$ \\
\hline 18 & Impressão e reprodução de gravações & - & - & - & $3 \%$ \\
\hline 19 & $\begin{array}{l}\text { Fabricação de coque, de produtos derivados } \\
\text { do petróleo e de biocombustíveis }\end{array}$ & $95 \%$ & $92 \%$ & $79 \%$ & $83 \%$ \\
\hline 20 & Fabricação de produtos químicos & $79 \%$ & $92 \%$ & $81 \%$ & $92 \%$ \\
\hline & $\begin{array}{l}\text { Fabricação de produtos farmoquímicos e } \\
\text { farmacêuticos }\end{array}$ & - & - & - & $92 \%$ \\
\hline 22 & $\begin{array}{l}\text { Fabricação de produtos de borracha e de } \\
\text { material plástico }\end{array}$ & $86 \%$ & $59 \%$ & $67 \%$ & $46 \%$ \\
\hline 23 & $\begin{array}{l}\text { Fabricação de produtos de minerais não- } \\
\text { metálicos }\end{array}$ & $82 \%(2)$ & $71 \%$ & $44 \%$ & - \\
\hline 24 & Metalurgia & $54 \%$ & $40 \%$ & $60 \%$ & $84 \%$ \\
\hline 25 & $\begin{array}{l}\text { Fabricação de produtos de metal, exceto } \\
\text { máquinas e equipamentos }\end{array}$ & - & - & $9 \%$ & - \\
\hline 26 & $\begin{array}{l}\text { Fabricação de equipamentos de informática, } \\
\text { produtos eletrônicos e ópticos }\end{array}$ & - & - & $16 \%$ & $5 \%$ \\
\hline 27 & $\begin{array}{l}\text { Fabricação de máquinas, aparelhos e } \\
\text { materiais elétricos }\end{array}$ & - & - & $43 \%$ & $82 \%$ \\
\hline 28 & Fabricação de máquinas e equipamentos & - & - & $0 \%$ & - \\
\hline 29 & $\begin{array}{l}\text { Fabricação de veículos automotores, } \\
\text { reboques e carrocerias }\end{array}$ & $28 \%(5)$ & $48 \%(5)$ & $47 \%(5)$ & $54 \%(5)$ \\
\hline 30 & $\begin{array}{l}\text { Fabricação de outros equipamentos de } \\
\text { transporte, exceto veículos automotores }\end{array}$ & $28 \%(5)$ & $48 \%(5)$ & $47 \%(5)$ & $54 \%(5)$ \\
\hline 31 & Fabricação de móveis & - & - & - & $0 \%$ \\
\hline & Fabricação de produtos diversos & - & - & $26 \%$ & - \\
\hline & $\begin{array}{l}\text { Manutenção, reparação e instalação de } \\
\text { máquinas e equipamentos }\end{array}$ & - & - & - & $0 \%$ \\
\hline & Outras indústrias de transformação & - & - & $0 \%(6)$ & $72 \%(6)$ \\
\hline & Eletricidade, gás e outras utilidades & - & - & - & $68 \%$ \\
\hline
\end{tabular}




\begin{tabular}{llllll}
\hline \multirow{2}{*}{ Divisão CNAE 2.0 } & \multicolumn{3}{l}{ \% de uso de água para resfriamento (TR) } \\
\cline { 3 - 5 } & $\begin{array}{l}\text { Van der } \\
\text { Leeden et al. } \\
(1990)\end{array}$ & $\begin{array}{l}\text { Van der } \\
\text { Leeden et al. } \\
(1990)\end{array}$ & $\begin{array}{l}\text { Statistics } \\
\text { Canada } \\
(2018)\end{array}$ & $\begin{array}{l}\text { Moström } \\
(2015)\end{array}$ \\
\hline 36 & Captação, tratamento e distribuição de água & - & - & - & - \\
\hline 37 & Esgoto e atividades relacionadas & - & - & - \\
\hline 38 & $\begin{array}{l}\text { Coleta, tratamento e disposição de resíduos; } \\
\text { recuperação de materiais }\end{array}$ & - & - & - \\
\hline 39 & $\begin{array}{l}\text { Descontaminação e outros serviços de gestão } \\
\text { de resíduos }\end{array}$ & - & - & - \\
\hline 41 & Construção de edifícios & - & - & - & - \\
\hline 42 & Obras de infraestrutura & - & - & - & - \\
\hline 43 & Serviços especializados para construção & - & - & - \\
\hline
\end{tabular}

NOTA: as divisões previstas na CNAE 2.0 não são exatamente coincidentes com as apresentadas em literatura internacional. As correlações foram realizadas de acordo com critério de proximidade.

(1) Apenas para bebidas maltadas.

(2) Apenas para fabricação de cimento.

(3) Setores agrupadas de acordo com a divisão de atividades econômicas da Suécia (produtos alimentícios, bebidas e tabaco).

(4) Setores agrupadas de acordo com a divisão de atividades econômicas da Suécia (produtos têxteis, de vestuário e couro).

(5) Atividades não discriminadas ("veículos de transporte").

(6) Outras atividades de transformação. Divisão inexistente na CNAE 2.0.

Fonte: adaptado de Van der Leeden et al. (1990), Moström (2015) e Statistics Canada (2018)

Vê-se que para atividades como produção de produtos químicos, gases industriais e materiais plásticos, a porcentagem de água destinada à reposição de sistemas de resfriamento é superior a $80-90 \%$.

Sendo a água o fluido de resfriamento, sua qualidade é fator determinante na operação. Altas concentrações de dureza, alcalinidade, Sólido Suspensos Totais (SST), ferro e manganês levam a depósitos e incrustações indesejados; de microorganismos e nutrientes favorecem a formação de depósitos orgânicos; e de SDT contribui para a ocorrência de corrosões (MIERZWA; HESPANHOL, 2005). Esses fatores causam redução da performance ou perda de eficiência da torre (resistência à troca de calor nos chillers) e redução da vida útil dos componentes.

Não é exatamente possível estabelecer um único padrão de qualidade de água para uso em TRs, já que há expressiva variabilidade de tecnologias, materiais e regimes de operação. Em outras palavras, é necessário que se avaliem o sistema de resfriamento e seus componentes, a água disponível, as opções de tratamento e as condições operacionais a serem aplicadas (SDCWA, 2009). É comum, inclusive, que normativas e legislações deixem a cargo do próprio operador dos sistemas a definição dos padrões de água para uso em resfriamento, como é o caso da Resolução Coema 02/17 (CEARÁ, 2017) e da norma ABNT NBR 16.783/19 (ABNT, 2019). Ainda assim, há referências que indicam parâmetros de qualidade críticos a serem controlados e 
seus respectivos valores. A Tabela 5 apresenta cinco padrões distintos para uso em TRs, indicando também os valores mais e menos restritivos para cada um deles.

Tabela 5: Referências de padrões de qualidade para uso em sistemas de resfriamento industriais (TR, torres de resfiamento)

\begin{tabular}{|c|c|c|c|c|c|c|c|c|}
\hline Parâmetro & Unidade & $\begin{array}{l}\text { SindusCon- } \\
\text { SP (2005) }\end{array}$ & $\begin{array}{c}\text { CNI } \\
(2017 a)\end{array}$ & $\begin{array}{l}\text { Mierzwa } \\
(2002)^{(a)}\end{array}$ & $\begin{array}{c}\text { EPA } \\
(2012)\end{array}$ & $\begin{array}{c}\text { Sabesp } \\
\text { (2010a); } \\
\text { MCidades } \\
(2017 a)^{(b)}\end{array}$ & $\begin{array}{l}\text { Mais } \\
\text { restritivo }\end{array}$ & $\begin{array}{l}\text { Menos } \\
\text { restritivo }\end{array}$ \\
\hline $\mathrm{pH}$ & - & $6,8-7,2$ & $6,9-9,0$ & $6,9-9,0$ & $\begin{array}{c}6,0- \\
9,0\end{array}$ & $6,5-7,5$ & 6,5 a 7,5 & 6,0 a 9,0 \\
\hline $\mathrm{DBO}_{5,20}$ & $\mathrm{mgO}_{2} / \mathrm{l}$ & - & $<25$ & $<25$ & $<30$ & $<10$ & $<10$ & $<30$ \\
\hline DQO & $\mathrm{mgO}_{2} / \mathrm{l}$ & $<75$ & $<75$ & $<75$ & - & $<20$ & $<20$ & $<75$ \\
\hline $\begin{array}{l}\text { Sólidos suspensos } \\
\text { totais }\end{array}$ & $\mathrm{mg} / \mathrm{l}$ & $<100$ & $<100$ & $<100$ & $<30$ & $<5$ & $<5$ & $<100$ \\
\hline Turbidez & UNT & - & $<50$ & $<50$ & - & $<1,0$ & $<1,0$ & $<50$ \\
\hline $\begin{array}{l}\text { Sólidos dissolvidos } \\
\text { totais }\end{array}$ & $\mathrm{mg} / \mathrm{l}$ & $<500$ & $<500$ & - & - & - & \multicolumn{2}{|c|}{$<500$} \\
\hline $\begin{array}{l}\text { Condutividade } \\
\text { elétrica }\end{array}$ & $\mu \mathrm{S} / \mathrm{cm}$ & - & - & - & - & $<600$ & \multicolumn{2}{|c|}{$<600$} \\
\hline Nitrogênio amoniacal & $\mathrm{mg} / \mathrm{l}$ & $<1$ & $<1$ & $<1$ & - & $<1$ & \multicolumn{2}{|c|}{$<1$} \\
\hline Nitrato & $\mathrm{mg} / \mathrm{l}$ & - & - & - & - & $<5$ & \multicolumn{2}{|c|}{$<5$} \\
\hline Fósforo total & $\mathrm{mg} / \mathrm{l}$ & $<1$ & - & - & - & $<0,5$ & \multicolumn{2}{|c|}{$<0,5$} \\
\hline Alcalinidade & $\mathrm{mg} / \mathrm{l}$ & $<350$ & $<350$ & - & - & - & \multicolumn{2}{|c|}{$<350$} \\
\hline Dureza & $\mathrm{mgCaCO}_{3} / \mathrm{l}$ & $<650$ & $<650$ & - & - & $<100$ & $<100$ & $<650$ \\
\hline Cloreto & $\mathrm{mg} / \mathrm{l}$ & $<500$ & $<500$ & - & - & - & \multicolumn{2}{|c|}{$<500$} \\
\hline Alumínio & $\mathrm{mg} / \mathrm{l}$ & $<0,1$ & $<0,1$ & $<0,1$ & - & $<0,2$ & $<0,1$ & $<0,2$ \\
\hline Bicarbonato & $\mathrm{mg} / \mathrm{l}$ & $<24$ & $<24$ & $<24$ & - & - & \multicolumn{2}{|c|}{$<24$} \\
\hline Cálcio & $\mathrm{mg} / \mathrm{l}$ & $<50$ & $<50$ & $<50$ & - & - & \multicolumn{2}{|c|}{$<50$} \\
\hline Cloro residual total & $\mathrm{mg} / \mathrm{l}$ & - & - & - & $>1,0$ & - & \multicolumn{2}{|c|}{$>1,0$} \\
\hline Cobre & $\mathrm{mg} / \mathrm{l}$ & - & - & - & - & $<0,1$ & \multicolumn{2}{|c|}{$<0,1$} \\
\hline $\begin{array}{l}\text { Coliformes } \\
\text { termotolerantes }\end{array}$ & UFC/100 ml & - & - & - & $<200$ & - & \multicolumn{2}{|c|}{$<200$} \\
\hline Coliformes totais & UFC/100 ml & $<2,2$ & - & - & - & - & \multicolumn{2}{|c|}{$<2,2$} \\
\hline $\begin{array}{l}\text { Compostos } \\
\text { orgânicos }\end{array}$ & $\mathrm{mg} / \mathrm{l}$ & - & - & $<1,0$ & - & - & \multicolumn{2}{|c|}{$<1,0$} \\
\hline Fenois & $\mathrm{mg} / \mathrm{l}$ & - & - & - & - & $<0,13$ & \multicolumn{2}{|c|}{$<0,13$} \\
\hline Ferro & $\mathrm{mg} / \mathrm{l}$ & $<0,5$ & - & $<0,5$ & - & $<0,3$ & \multirow{2}{*}{\multicolumn{2}{|c|}{\begin{tabular}{c|l}
$<0,3$ & $<0,5$ \\
\multicolumn{3}{c}{$<$}
\end{tabular}}} \\
\hline Fosfato & $\mathrm{mg} / \mathrm{l}$ & & $<4$ & $<4$ & - & - & & \\
\hline Magnésio & $\mathrm{mg} / \mathrm{l}$ & $<30$ & $<0,5$ & $<0,5$ & - & - & $<0,5$ & $<30$ \\
\hline Manganês & $\mathrm{mg} / \mathrm{l}$ & $<0,5$ & - & $<0,5$ & - & - & \multicolumn{2}{|c|}{$<0,5$} \\
\hline$O \& G$ & $\mathrm{mg} / \mathrm{l}$ & - & - & - & - & $<5$ & \multicolumn{2}{|c|}{$<5$} \\
\hline Sílica & $\mathrm{mg} / \mathrm{l}$ & $<50$ & - & $<50$ & - & $<20$ & $<20$ & $<50$ \\
\hline Sulfatos & $\mathrm{mg} / \mathrm{l}$ & $<200$ & $<200$ & $<200$ & - & - & $<200$ & $<200$ \\
\hline Sulfetos & $\mathrm{mg} / \mathrm{l}$ & - & - & - & - & $<0,1$ & \multicolumn{2}{|c|}{$<0,1$} \\
\hline Surfactantes & $\mathrm{mg} / \mathrm{l}$ & - & - & - & - & $<1,0$ & \multicolumn{2}{|c|}{$<1,0$} \\
\hline
\end{tabular}

NOTA 1: parâmetros destacados são os conhecidamente utilizados no monitoramento de qualidade de água de reposição de TRs. NOTA 2: a ABNT NBR 16.873:2019, que trata de uso não potável em edificações, contempla o uso em sistemas de resfriamento, mas não estabelece padrões de qualidade para essa finalidade.

(1) Crook (1996) apud Mierzwa (2002)

(2) Referente ao padrão de qualidade proposto pelo Aquapolo para uso em TRs no Polo Petroquímico de Capuava

A título de exemplo, o Aquapolo, maior experiência de reúso brasileira e quinta maior do mundo, utiliza Tertiary Membrane Biorreactor (TMBR) e Osmose Reversa (OR) para produção de água de reúso a partir do efluente da ETE ABC para abastecimento do polo petroquímico de Mauá com capacidade instalada de 1,0 m³/s e produção atual de $0,65 \mathrm{~m}^{3} / \mathrm{s}$ (MCIDADES, 2017b). 
Outro uso relevante na indústria é basicamente o oposto às TRs: sistemas de geração de vapor ou aquecimento de água a partir do uso de caldeiras. Dadas as condições extremas de temperatura e pressão, a qualidade de água necessária é inclusive próxima ou superior à de potabilidade, exigindo tratamentos mais avançados como troca iônica e osmose reversa (U.S. EPA, 2012).

A maior preocupação se deve à presença de componentes com potencial de formação de depósitos, incrustações ou de corrosão/oxidação, como sólidos dissolvidos, carbonatos, bicarbonatos, sílica e íons. Por isso, são parâmetros de controle os SST, Sólidos Dissolvidos Totais (SDT),condutividade elétrica, alcalinidade, dureza e sílica, entre outros. Quanto maior a pressão de operação, mais restritiva é a qualidade da água de reposição. A formação de depósitos inorgânicos nas paredes e em outros componentes das caldeiras impõe resistência à transferência de calor à água, levando à necessidade de maior queima de combustíveis para aquecimento, maiores riscos operacionais e comprometimento por vezes irreversível de partes do sistema (CNI, 2017a).

A Tabela 6 apresenta alguns dos principais parâmetros de controle de qualidade de água para uso em caldeiras de acordo com faixas de pressão de operação segundo EPA (2012).

Tabela 6: Parâmetros de qualidade para uso em caldeiras de acordo com a pressão de operação

\begin{tabular}{llllll}
\multirow{2}{*}{ Parâmetro } & \multirow{2}{*}{ Unid. } & \multicolumn{4}{l}{ Pressão de operação no tambor (psig) } \\
\cline { 3 - 6 } & $\mathrm{mg} / \mathrm{l}$ & $700-300$ & $601-750$ & $901-1000$ & $1501-2000$ \\
\hline SDT máx & $\mathrm{mg} / \mathrm{l}$ & 15 & $200-1.000$ & $125-625$ & 50 \\
\hline SST máx & $\mu \mathrm{S} / \mathrm{cm}$ & $1.100-5.400$ & $300-1500$ & $200-1000$ & 80 \\
\hline Condutividade elétrica máx & $\mathrm{mgCaCO}_{3} / \mathrm{l}$ & 350 & 200 & 100 & $\mathrm{ND}$ \\
\hline Alcalinidade máx & $\mathrm{mgSiO}_{2} / \mathrm{l}$ & 150 & 30 & 8 & 1 \\
\hline Sílica máx & &
\end{tabular}

Fonte: EPA (2012)

\subsubsection{Outros usos}

Outros usos de relevância que, no entanto, não serão diretamente abordados neste trabalho, são para fins urbanos e privados, incluindo lavagens de logradouros e áreas públicas, veículos (ônibus, trens), irrigação paisagística e usos não potáveis em empreendimentos comerciais e residenciais. 
A título de exemplo, Sabesp (2015) indica fornecimento de água de reúso na RMSP (excluindo-se o Aquapolo) com vazão média de 135.000 m³/mês (ou $52 \mathrm{~L} / \mathrm{s}$ ), já incluindo o fornecimento para usos industriais da Coat Correntes e da Santher, com vazão da ordem de 20-30 L/s. No caso de usos de fato urbanos (irrigação e lavagens), o polimento de efluente secundário adotado é de filtração multimídia areia/antracito e desinfecção com hipoclorito de sódio (SABESP, 2015).

$\mathrm{Na}$ última década tem-se visto, principalmente em grandes regiões metropolitanas, a difusão de empresas especializadas que atuam no fornecimento de água proveniente de fontes alternativas potáveis e não potáveis (água de poço, aproveitamento de água de chuva e principalmente água de reúso) em empreendimentos comerciais (shopping centers, condomínios), condomínios residenciais e indústrias. Modelos de negócio como o BOT (built, operate and transfer) em que o cliente não arca com custos de capital e "compra" mensalmente a água por $\mathrm{m}^{3}$ são altamente atrativos e têm levado grandes consumidores a "migrar" do modelo convencional de abastecimento (rede pública) para produção de água no próprio estabelecimento (onsite). Esse panorama, ainda não abordado na literatura técnica ${ }^{5}$, tem se tornado cada vez mais comum no mercado de engenharia e vem despertando a preocupação e mobilização de empresas de saneamento em razão da perda de clientes, em especial dos comumente denominados "grandes consumidores".

\subsubsection{Tecnologias e processos para produção de água de reúso não potável}

Há décadas já existem tecnologias para a produção de água de reúso a partir de esgotos municipais, antes mesmo do advento do uso de membranas de microfiltração (MF), ultrafiltração (UF) e/ou osmose reversa (OR). Um exemplo simbólico é a planta de Goreangab (Namíbia), que desde a década de 1960 entrega água de reúso com qualidade potável para abastecimento público. Ao longo dos anos, o uso de membranas para tratamento de efluentes e produção de água de reúso vem

\footnotetext{
${ }^{5}$ Pelo fato de não ainda não ser um tema explorado na literatura técnica, as informações sobre o assunto são oriundas da atuação deste autor no mercado privado de fontes alternativas de água em áreas urbanas.
} 
aumentando, também em razão da redução de seus custos de implantação e da demanda de energia elétrica entre as décadas de 1990 e 2000 (JUDD, 2017).

A depender das características do afluente e da qualidade final requerida, distintos arranjos de tratamento são requeridos. A Tabela 7 exemplifica seis usos não potáveis e as respectivas necessidades de tratamento (após tratamento secundário).

Tabela 7: Relação simplificada de processos e tecnologias de tratamento e aptidão para produção de água de reúso

\begin{tabular}{|c|c|c|c|c|}
\hline Exigência & $\begin{array}{l}\text { Uso final não } \\
\text { potável }\end{array}$ & Característica & $\begin{array}{l}\text { Polimento após } \\
\text { secundário }(a, b)\end{array}$ & $\begin{array}{l}\text { Tecnologias / processos } \\
\text { típicos (c) }\end{array}$ \\
\hline \multirow[t]{5}{*}{$\begin{array}{l}\text { Menos } \\
\text { exigente }\end{array}$} & $\begin{array}{l}\text { Irrigação } \\
\text { paisagística restrita }\end{array}$ & Sem contato & Desinfecção & $\mathrm{Cl}$ \\
\hline & $\begin{array}{l}\text { Irrigação } \\
\text { paisagística } \\
\text { irrestrita }\end{array}$ & Com contato & $\begin{array}{l}\text { Desinfecção, } \\
\text { eventual remoção } \\
\text { adicional de sólidos }\end{array}$ & Cl, filtração terciária, UF \\
\hline & $\begin{array}{l}\text { Irrigação agrícola } \\
\text { restrita }\end{array}$ & $\begin{array}{l}\text { Culturas não } \\
\text { alimentícias ou } \\
\text { alimentícias } \\
\text { processadas }\end{array}$ & $\begin{array}{l}\text { Desinfecção, } \\
\text { eventual remoção } \\
\text { adicional de sólidos }\end{array}$ & Cl, filtração terciária, UF \\
\hline & $\begin{array}{l}\text { Irrigação agrícola } \\
\text { irrestrita }\end{array}$ & $\begin{array}{l}\text { Culturas ingeridas } \\
\text { cruas }\end{array}$ & $\begin{array}{l}\text { Desinfecção, } \\
\text { eventual remoção } \\
\text { adicional de sólidos }\end{array}$ & $\begin{array}{l}\mathrm{Cl}, \mathrm{O}_{3} \text {, UV, filtração terciária, } \\
\text { UF }\end{array}$ \\
\hline & $\begin{array}{l}\text { Industrial } \\
\text { (resfriamento) }\end{array}$ & $\begin{array}{l}\text { Água de } \\
\text { reposição de } \\
\text { sistemas de } \\
\text { resfriamento }\end{array}$ & $\begin{array}{l}\text { Remoção de nitrato } \\
\text { + filtração terciária / } \\
\text { MF / UF + } \\
\text { desinfecção }\end{array}$ & $\begin{array}{l}\text { Remoção de nitrato / físico- } \\
\text { química de nutrientes, } \\
\text { filtração granular / MF / UF, } \\
\text { cloro, } \mathrm{O}_{3}, \mathrm{UV}\end{array}$ \\
\hline $\begin{array}{l}\text { Mais } \\
\text { exigente }\end{array}$ & $\begin{array}{l}\text { Industrial } \\
\text { (caldeiras) }\end{array}$ & $\begin{array}{l}\text { Água de } \\
\text { reposição de } \\
\text { caldeira }\end{array}$ & $\begin{array}{l}\text { Filtração terciária / } \\
\text { MF / UF + } \\
\text { desmineralização } \\
\text { +desinfecção }\end{array}$ & $\begin{array}{l}\text { Remoção de nutrientes / } \\
\text { físico-química de nutrientes, } \\
\text { filtração granular / MF / UF, } \\
\text { OR, cloro, } \mathrm{O}_{3} \text {, UV }\end{array}$ \\
\hline
\end{tabular}

MF: milcrofiltração; UF: ultrafiltração; Cl: desinfecção com cloro; OR: osmose reversa; UV: radiação ultravioleta; O3: ozônio.

(a) Todos exigem, minimamente, tratamento de esgoto em nível secundário, o que, evidentemente, já inclui também o preliminar e/ou primário.

(b) Considerando esgoto doméstico como afluente.

(c) Após o secundário mecanizado.

Fontes: baseado em Schimmoller \& Kealy (2013); MCidades (2017a); Pistocchi et al. (2018); WWAP (2017); Salgot et al. (2018). Elaborado pelo autor.

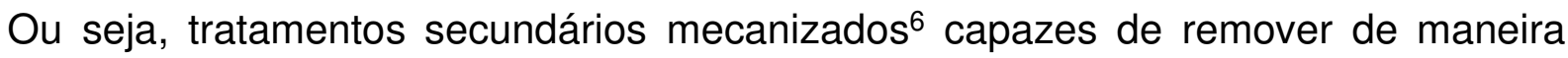
satisfatória $\mathrm{DBO}_{5,20}$ e sólidos em suspensão sucedidos por polimento e desinfecção podem produzir água compatível com diversos usos não potáveis. A complexidade do polimento depende das exigências dos usos finais, variando de simples desinfecção

${ }^{6}$ A literatura trata de forma diferente tratamentos secundários "não mecanizados" (lagoas, fossas etc.) dos "mecanizados" (lodos ativados, MBBR etc.). Neste caso, trata-se dos mecanizados, que tipicamente apresentam maiores eficiências. 
para usos de irrigação pouco exigentes até remoção de nutrientes (nitrificação/desnitrificação), UF, OR e desinfecção com UV/O3/ozônio para caldeiras industriais, por exemplo.

Há de se levar em consideração de que "tratar demais" (overtreat) o efluente também não é desejado, dado que isso implica em custos desnecessários e, consequentemente, tarifas mais altas para o usuário final, comprometendo a viabilidade econômica de programas de reúso. Por isso, o conceito de tratamento fitto-purpose, ou seja, tratamento compatível com a finalidade, deve ser prezado no momento da escolha por arranjos de tratamento, compatibilizando aspectos sanitários, de processo e de custos (CHHIPI-SHRESTHA et al., 2017a; SCHIMMOLLER; KEALY, 2013).

\subsubsection{Custos atribuídos a processos e sistemas de produção e distribuição de água de reúso}

Os principais custos associados ao reúso, assim como no tratamento convencional de esgoto, são os referentes à implantação (Capex, capital expenditures) e operação (Opex, operational expenditures) de sistemas de tratamento e de distribuição. Assim, este item apresenta uma compilação de Capex e Opex para sistemas tratamento e distribuição, incluindo as plantas de tratamento, sistemas elevatórios e adutoras.

Tanto o Capex como o Opex são altamente dependentes de variáveis locais, escolhas de projeto e dos objetivos e diretrizes de cada programa de reúso. Ainda assim, a literatura aponta valores e funções de custos de referência determinadas a partir de estimativas ou colhidas de experiências reais já consolidadas, o que fornece subsídio a pesquisadores e profissionais da área em estudos de concepção e projeções de custos durante as etapas de planejamento.

É fundamental ter em mente o conceito de "ganho de escala" na avaliação de custos de reúso. Sistemas de maior capacidade tendem a apresentar custos unitários (ou seja, por $\mathrm{m}^{3}$ ) menores, dado que os custos fixos se "diluem" nos maiores volumes produzidos. Isso é corroborado por estudos como os de Guo et al. (2014) e Jung 
(2018). Isso significa que a utilização estrita de custos unitários fixos em estimativas leva a prejuízos na compreensão das variações por conta da escala.

Assim, conforme será visto nos próximos itens, prezou-se pelo levantamento de referências que apresentassem custos em função de variáveis de interesse, como vazão ou potência (este no caso de sistemas elevatórios), tendo como objetivo contemplar as supracitadas variações de custos unitários em razão da escala.

Custos presentes em literatura geralmente são expressos com grande heterogeneidade de unidades de vazão ( $\mathrm{m}^{3} / \mathrm{s}, \mathrm{l} / \mathrm{s}, \mathrm{m}^{3} / \mathrm{dia}, \mathrm{m}^{3} / \mathrm{ano}, \mathrm{GPD}, \mathrm{MLD}$, eq. populacional etc.), moedas correntes (BRL, USD, EUR), ano-base e indicador de custo (USD/GDP, BRL\$/mil pe, EUR/pe, mi BRL/mil pe etc.). Por isso, para exposição mais clara, as funções e valores unitários de custos foram compatibilizados. As vazões foram convertidas para $\mathrm{m}^{3} / \mathrm{s}$, Capex em USD/m3/ano ou USD/m (no caso de adutoras) e Opex em USD $/ \mathrm{m}^{3}$. Todos os valores foram também corrigidos pela inflação para set/2019 pelo índice Construction Cost Index $(\mathrm{CCl})^{7}$ da Engineering News-Record (ENR) e convertidos em USD pela cotação monetária média do ano-base.

\subsubsection{Custos de tratamento}

\subsection{Capex de tratamento}

Conforme estudado no item 3.2.3.3, há determinados arranjos que são tipicamente empregados para produção de água de reúso a partir de esgotos sanitários, essencialmente sistemas biológicos com membranas (MBR, membrane bio reactor), polimento com OR e desinfecção (cloro, ozônio e UV). Portanto, os custos levantados se referem basicamente a esses arranjos e não consideram outras possibilidades comumente aplicadas no tratamento convencional, como reatores UASB (Upflow Anaerobic Sludge Blanket), lagoas, filtros biológicos percoladores (FBP) ou lodos ativados convencional (LAC) e suas variações.

\footnotetext{
${ }^{7}$ Disponíveis em: https://www.nrcs.usda.gov/wps/portal/nrcs/main/national/technical/econ/prices/
} 
A Tabela 8 apresenta funções, médias e valores isolados de Capex e Opex para diferentes processos e sistemas de tratamento capazes de produzir água de reúso com qualidade aceitável para usos não potáveis. As equações originais são apresentadas no ANEXO A.

Tabela 8: Funções e valores de Capex (USD/m3/ano) para diferentes sistemas de tratamento

\begin{tabular}{|c|c|c|c|c|c|}
\hline \multirow{2}{*}{ Referência } & \multirow{2}{*}{ Processo } & \multirow{2}{*}{$\begin{array}{l}\text { Ano- } \\
\text { base }^{(a)}\end{array}$} & Função ou custo médio (b) & \multirow{2}{*}{$\begin{array}{l}\text { Faixa de vazão } \\
\left(\mathrm{m}^{3} / \mathrm{s}\right)\end{array}$} & \multirow{2}{*}{ Observações } \\
\hline & & & C em USD/(m³/ano) e $Q$ em m³/s & & \\
\hline $\begin{array}{l}\text { Adham \& } \\
\text { DeCarolis (2004) }\end{array}$ & MBR & 2004 & $C=4,686 Q^{-0,253}$ & $0,0088-0,43$ & $\begin{array}{l}\text { Determinada por este } \\
\text { autor com } \mathrm{R}^{2}=0,929\end{array}$ \\
\hline $\begin{array}{l}\text { Adham \& } \\
\text { DeCarolis (2004) }\end{array}$ & MBR & 2004 & $(\$ 5,37-\$ 7,37)$ & $0,04-0,22$ & $\begin{array}{l}\text { Estudo apresenta função } \\
\text { acima e também valores } \\
\text { isolados }\end{array}$ \\
\hline Côte et al. (2004) & MBR & 2004 & $C=2,895 Q^{-0,252}$ & $0,044-0,880$ & $\begin{array}{l}\text { Determinada por este } \\
\text { autor com } \mathrm{R}^{2}=0,990\end{array}$ \\
\hline DeCarolis (2007) & MBR & 2007 & $(\$ 6,95-\$ 8,72)$ & $0,04-0,22$ & - \\
\hline EPA (2007) & MBR & 2007 & $(\$ 0,91-\$ 2,61)$ & - & - \\
\hline $\begin{array}{l}\text { Molinos-Senante } \\
\text { et al. (2012) }\end{array}$ & MBR & 2012 & $C=1,233 Q^{-0,352}$ & Até 0,005 & $\begin{array}{l}\text { Sistemas de pequeno } \\
\text { porte }(<2.00 \mathrm{pe}) .1 \mathrm{pe}= \\
200 \mathrm{l} / \mathrm{pessoa} / \mathrm{dia}\end{array}$ \\
\hline Guo et al. (2014) & MBR & 2014 & $C=0,361 Q^{-1} \times 10^{0,569 \times(\log (Q)+4,937)^{1,135}-2,395}$ & $0,003-2,2$ & - \\
\hline $\begin{array}{l}\text { Tran et al. (2016a, } \\
2016 b)\end{array}$ & MBR & 2013 & $(\$ 6,40-\$ 9,60)$ & - & - \\
\hline Judd (2017) & MBR & 2015 & $(\$ 1,07-\$ 2,63)$ & 0,231 & - \\
\hline CNI (2019a) & MBR & 2017 & $C=0,3632 Q^{-0,252}$ & $0,50-1,0$ & $\begin{array}{l}\text { Considera adaptação de } \\
\text { LA para MBR, o que } \\
\text { implica em menor Capex }\end{array}$ \\
\hline EPA (2005) & UV & 2005 & $C=0,0735 Q^{-0,274}$ & $0,01-22,8$ & $\begin{array}{l}\text { Determinada por este } \\
\text { autor com } \mathrm{R}^{2}=0,873\end{array}$ \\
\hline $\begin{array}{l}\text { Tran et al. (2016a, } \\
2016 b)\end{array}$ & UV & 2013 & $(\$ 0,005-\$ 0,22)$ & $1,1-3,1$ & - \\
\hline $\begin{array}{l}\text { Tran et al. (2016a, } \\
2016 b)\end{array}$ & $\mathrm{CL}$ & 2013 & $(\$ 0,006-\$ 0,26)$ & $0,9-1,1$ & - \\
\hline MCidades (2017a) & $\mathrm{CL}$ & 2017 & $C=0,00761 Q^{-0,66(d)}$ & Até 0,09 & $\begin{array}{l}\text { Determinada por este } \\
\text { autor com } \mathrm{R}^{2}=0,983\end{array}$ \\
\hline EPA (2005) & OR & 2005 & $C=0,5314 \mathrm{Q}^{-0,122}$ & $0,04-8,8$ & $\begin{array}{l}\text { Determinada por este } \\
\text { autor com } R^{2}=0,989\end{array}$ \\
\hline $\begin{array}{l}\text { Tran et al. (2016a, } \\
2016 b)\end{array}$ & OR & 2013 & $(\$ 0,90-\$ 2,40)$ & $0,44-4,38$ & - \\
\hline Guo et al. (2014) & OR & 2014 & $C=0,361 Q^{-1} \times 10^{0,966 \times(\log (Q)+4,937)^{0,929}-3,918}$ & $0,003-2,2$ & - \\
\hline Judd (2017) & OR & 2015 & $C=6,247 e^{-0,409 Q}$ & $0,44-7,22$ & $\begin{array}{l}\text { Determinada por este } \\
\text { autor com } R^{2}=0,676\end{array}$ \\
\hline $\begin{array}{l}\text { Herman et al. } \\
(2017)\end{array}$ & OR & 2017 & $C=3,66 \mathrm{Q}^{-0,305}$ & $0,26-5,26$ & $\begin{array}{l}\text { Determinada por este } \\
\text { autor com } \mathrm{R}^{2}=0,921\end{array}$ \\
\hline
\end{tabular}

(a) Ano-base da estimativa de custos, que eventualmente pode ser diferente do da publicação. O ano-base foi utilizado para correção monetária (conversão para USD e ajuste da inflação pelo CCI-ENR). Quando não explicitamente declarado, assumiu-se ano-base igual ao da publicação.

(b) Funções e valores padronizados para Q em m³/s e C em USD/(m³/ano). Correções a partir do CCI-ENR do ano-base do custo até set/2019 e da cotação monetária média (EUR, USD e BRL) para o ano-base de custos. Funções originais são apresentadas no ANEXO A.

(c) O PDE apresenta valores finais por $\mathrm{m}^{3}$, considerando plano de negócios. O Capex foi calculado retroativamente, sabendo-se que $\mathrm{i}=3,89 \%$ a.a., $\mathrm{N}=30$ anos e Opexanual $=10 \%$ do Capex.

(d) Publicação apresenta gráfico com 30 custos totais de sistemas de cloração implantados e sua respectiva função, mas não descreve a equação. Depreende-se do gráfico que é utilizada regressão por equação polinomial (grau 2), o que, ainda que apresente maior $\mathrm{R}^{2}$ para os valores estudados (até $90 \mathrm{l} / \mathrm{s}$ ), resulta em redução (ponto de deflexão) de capex total para vazões mais altas, o que é clara incoerência, Por isso, utilizou-se regressão por equação potencial com $R^{2}=0,9826$. 
Para o caso de biorreatores com membranas (MBR), o Capex varia de 15,0 $\mathrm{USD} / \mathrm{m}^{3} /$ ano (vazões mais baixas) a $1,0 \mathrm{USD} / \mathrm{m}^{3} /$ ano (vazões mais altas). A Figura 6 mostra funções de custo e custos unitários isolados para sistemas MBR.

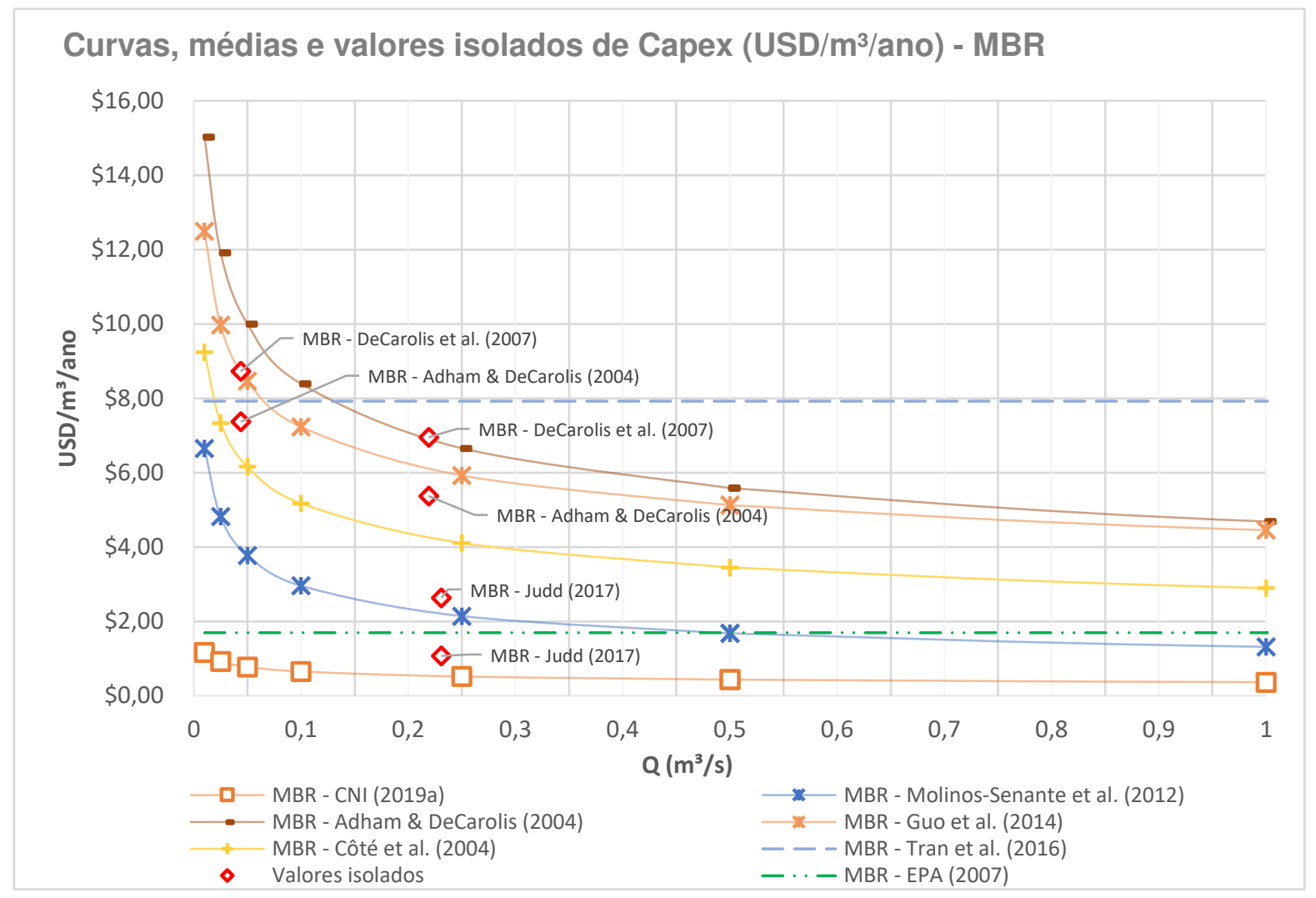

Nota 1: funções corrigidas para USD a partir da moeda original de acordo com a cotação média do ano-base e inflação corrigida do ano-base até set/2019 pelo CCI/ENR. Nota 2: linhas tracejadas representam custos unitários isolados, ou seja, não apresentados na literatura em função de vazão. Nota 3: CNI (2019a) e Sabesp (2010a) referem-se à instalação de membranas externas de MF/UF em sistemas de lodos ativados já existentes, sendo, portanto, adaptações com custos de obras civis reduzidos.

Figura 6: Curvas, médias e valores isolados de Capex de tratamento (USD/m³/ano) para MBR Fontes: adaptado de Côté et al. (2004); Adham \& DeCarolis (2004); EPA (2007); DeCarolis et al. (2007); Molinos-Senante (2012); Guo et al. (2014); Tran et al. (2016b, 2016a); Judd (2017); CNI (2019a)

Mesmo com visível variabilidade, a média se situa entre 3 e $9 \mathrm{USD} / \mathrm{m}^{3} / \mathrm{ano}$, valor próximo ao apresentado por Côté et al. (2004). O ganho de escala é claramente notado pelo comportamento das curvas, as quais começam a exibir tendência assintótica para vazões a partir de $0,10-0,25 \mathrm{~m}^{3} / \mathrm{s}$.

Para processos de desinfeção utilizando UV e solução de cloro os custos são substancialmente inferiores, estando sempre abaixo de 0,30 USD/m³/ano, conforme Figura 7. 
Curvas, médias e valores isolados de Capex (USD/m³/ano) - UV e CL

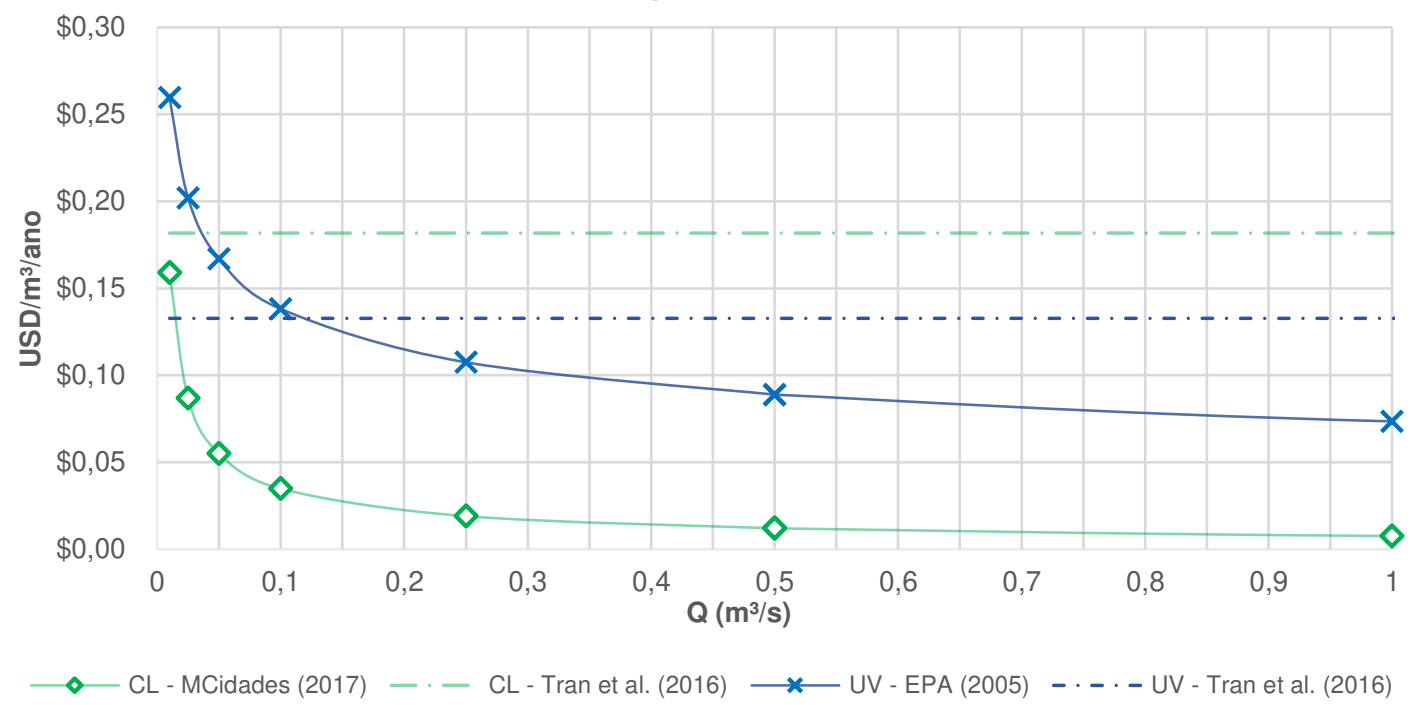

Nota 1: funções corrigidas para USD a partir da moeda original de acordo com a cotação média do ano-base e inflação corrigida do ano-base até set/2019 pelo CCI/ENR. Nota 2: linhas tracejadas representam custos unitários isolados, ou seja, não apresentados na literatura em função de vazão.

Figura 7: Curvas e médias de Capex de tratamento (USD/m³/ano) para desinfecção por UV e Cl Fontes: adaptado de EPA (2005); Tran et al. (2016b, 2016a); MCidades (2017a)

Para OR, os valores disponíveis na literatura apresentam variação mais acentuada, mas mantêm ainda o comportamento de ganho de escala, conforme Figura 8.

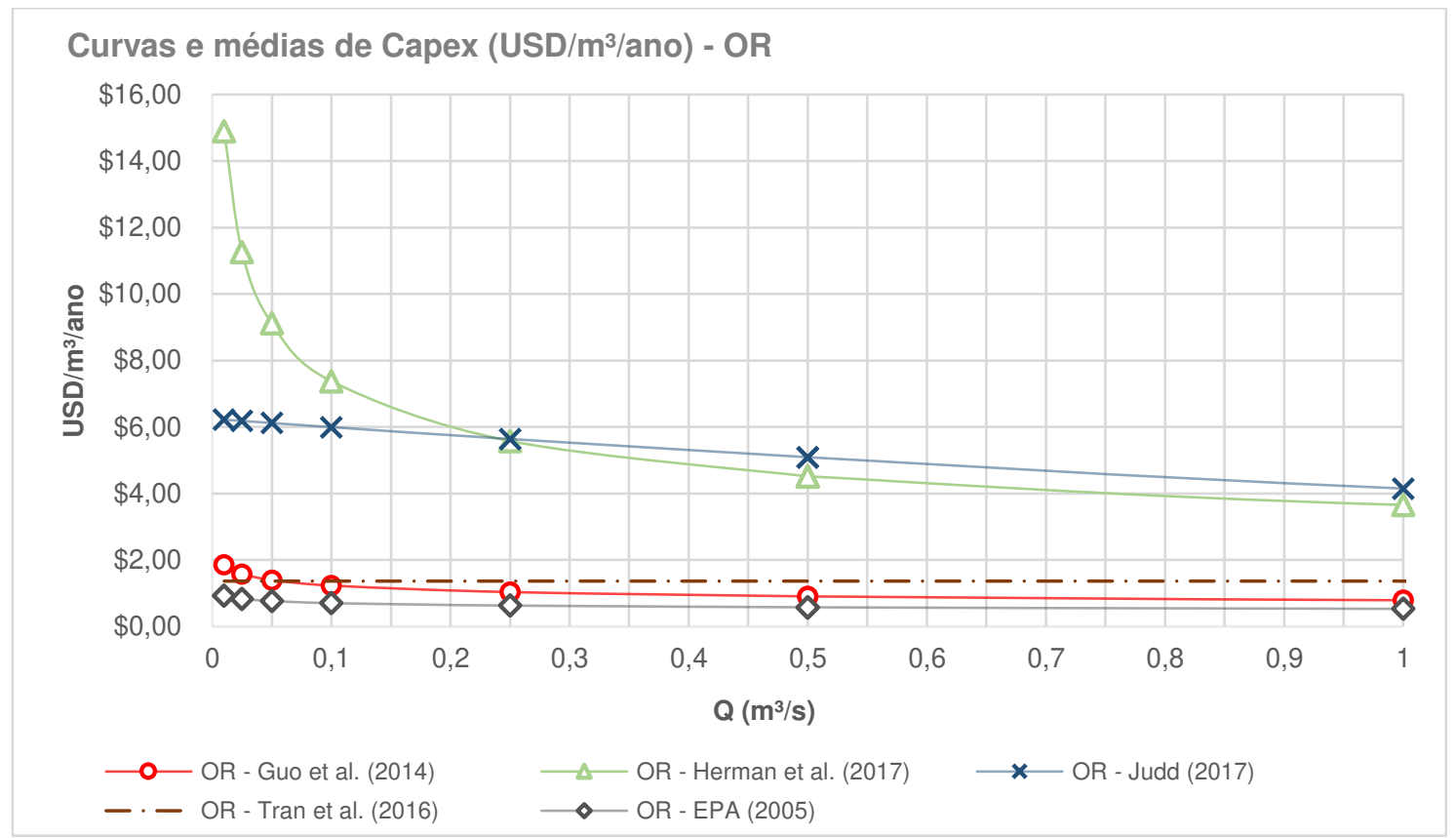

Nota 1: funções corrigidas para USD a partir da moeda original de acordo com a cotação média do ano-base e inflação corrigida do ano-base até set/2019 pelo CCI/ENR. Nota 2: linhas tracejadas representam custos unitários isolados, ou seja, não apresentados na literatura em função de vazão.

Figura 8: Curvas de Capex de tratamento (USD/m $3 / a n o)$ para OR

Fontes: adaptado de EPA (2005); Guo et al. (2014); Tran et al. (2016b, 2016a); Herman et al.

(2017); Judd (2017) 


\subsection{Opex de tratamento}

O Opex de tratamento se deve principalmente às demandas de energia elétrica (sopradores, bombas), troca de equipamentos, aquisição de produtos químicos e mão-de-obra. Para o caso de sistemas MBR, os maiores custos de operação são relacionados à demanda de energia elétrica (principalmente para aeração) e reposição de membranas, representando, respectivamente, cerca de $35 \%$ e $25 \%$ do total (ADHAM; DECAROLIS, 2004; DECAROLIS et al., 2007), situação similar também para OR.

A Tabela 9 apresenta funções e custos isolados de Opex para os processos de tratamento determinados. Equações originais são apresentadas no ANEXO A.

Tabela 9: Funções de Opex para diferentes sistemas de tratamento em USD/m³/ano

\begin{tabular}{|c|c|c|c|c|c|}
\hline \multirow{2}{*}{ Referência } & \multirow{2}{*}{ Processo } & \multirow{2}{*}{$\begin{array}{l}\text { Ano- } \\
\text { base (a) }\end{array}$} & \multirow{2}{*}{$\begin{array}{l}\text { Função ou custo médio (b) } \\
\text { C em USD/m³ e Q em m³/s }\end{array}$} & \multirow{2}{*}{$\begin{array}{l}\text { Faixa de } \\
\text { vazão }\left(\mathrm{m}^{3} / \mathrm{s}\right)\end{array}$} & \multirow{2}{*}{ Observações } \\
\hline & & & & & \\
\hline $\begin{array}{l}\text { Adham \& } \\
\text { DeCarolis (2004) }\end{array}$ & MBR & 2004 & $C=0,151 Q^{-0,119}$ & $0,0088-0,43$ & $\begin{array}{l}\text { Determinada por este } \\
\text { autor com } R^{2}=0,838\end{array}$ \\
\hline Côte et al. (2004) & MBR & 2004 & $C=0,156 Q^{-0,299}$ & $0,044-0,880$ & $\begin{array}{l}\text { Determinada por este } \\
\text { autor com } \mathrm{R}^{2}=0,963\end{array}$ \\
\hline $\begin{array}{l}\text { Molinos-Senante } \\
\text { et al. (2012) }\end{array}$ & MBR & 2012 & $C=0,0067 Q^{-1}+0,635$ & Até 0,005 & $\begin{array}{l}\text { Sistemas de pequeno } \\
\text { porte }(<2.00 \mathrm{pe}) .1 \mathrm{pe} \\
=200 \mathrm{l} / \mathrm{pessoa} / \mathrm{dia}\end{array}$ \\
\hline $\begin{array}{l}\text { Tran et al. } \\
(2016 a, 2016 b)\end{array}$ & MBR & 2013 & $C=0,22 \quad(\$ 0,02-\$ 0,37)$ & $0,02-0,2$ & - \\
\hline Guo et al. (2014) & MBR & 2014 & $C=3,61 Q^{-1} \times 10^{0,639 \times(\log (Q)+4,937)^{1,143}-5,367}$ & $0,003-2,2$ & - \\
\hline CNI (2019a) & MBR & 2017 & $C=0,334 Q^{-0,075}$ & $0,05-1,0$ & - \\
\hline $\begin{array}{l}\text { Iglesias et al. } \\
(2010)\end{array}$ & $\mathrm{CL}$ & 2010 & $C=\mathbf{0 , 0 1}$ & - & - \\
\hline $\begin{array}{l}\text { Tran et al. } \\
(2016 a, 2016 b)\end{array}$ & $\mathrm{CL}$ & 2013 & $(\$ 0,004-\$ 0,02)$ & $0,02-0,2$ & - \\
\hline MCidades (2017a) & $\mathrm{CL}$ & 2017 & $C=0,03$ & - & $\begin{array}{l}60 \mathrm{mg} / \mathrm{l}, \mathrm{NaClO} 10 \% \\
\mathrm{R} \$ 1,40 / \mathrm{kgCl}\end{array}$ \\
\hline EPA (2005) & UV & 2005 & $C=0,0735 Q^{-0,274}$ & $0,01-22,8$ & $\begin{array}{l}\text { Determinada por este } \\
\text { autor com } R^{2}=0,672 \\
\end{array}$ \\
\hline $\begin{array}{l}\text { Tran et al. } \\
(2016 a, 2016 b)\end{array}$ & UV & 2013 & $(\$ 0,01-\$ 0,03)$ & $1,1-3,1$ & - \\
\hline Guo et al. (2014) & OR & 2014 & $C=3,61 Q^{-1} \times 10^{0,534 \times(\log (Q)+4,937)^{1,253}-5,214}$ & $0,003-2,2$ & - \\
\hline $\begin{array}{l}\text { Tran et al. } \\
(2016 a, 2016 b)\end{array}$ & OR & 2013 & $(\$ 0,26-\$ 0,33)$ & $0,44-4,38$ & - \\
\hline Judd (2017) & OR & 2015 & $(\$ 0,50-\$ 0,91)$ & $0,44-7,22$ & - \\
\hline Herman et al. (2017) & OR & 2017 & $C=0,2906 Q^{-0,259}$ & $0,26-5,26$ & $\begin{array}{l}\text { Determinada por este } \\
\text { autor com } \mathrm{R}^{2}=0,913\end{array}$ \\
\hline $\begin{array}{l}\text { Schimmoler \& Kealy } \\
(2013)\end{array}$ & OR & 2013 & $C=0,297 Q^{-0,39}$ & $0,02-3,07$ & $\begin{array}{l}\text { Determinada por este } \\
\text { autor com } \mathrm{R}^{2}=0,91\end{array}$ \\
\hline
\end{tabular}

(a) Ano-base da estimativa de custos, que eventualmente pode ser diferente do da publicação. O ano-base foi utilizado para correção monetária (conversão para USD e ajuste da inflação pelo CCI-ENR). Quando não explicitamente declarado, assumiu-se ano-base igual ao da publicação.

(b) Funções e valores padronizados para $Q$ em m³/s e C em USD/(m³/ano). Correções a partir do CCI-ENR do ano-base do custo até set/2019 e da cotação monetária média (EUR, USD e BRL) para o ano-base de custos. Funções originais são apresentadas no ANEXO A. 
Para sistemas MBR, o Opex unitário (USD/m³) permanece abaixo dos $0,70 \mathrm{USD} / \mathrm{m}^{3}$, chegando a menos de $0,20 \mathrm{USD} / \mathrm{m}^{3} /$ ano para vazões próximas a $1,0 \mathrm{~m} 3 / \mathrm{s}$. Os ganhos de escala observados no Capex são também evidentes para o Opex, como ilustra a Figura 9.

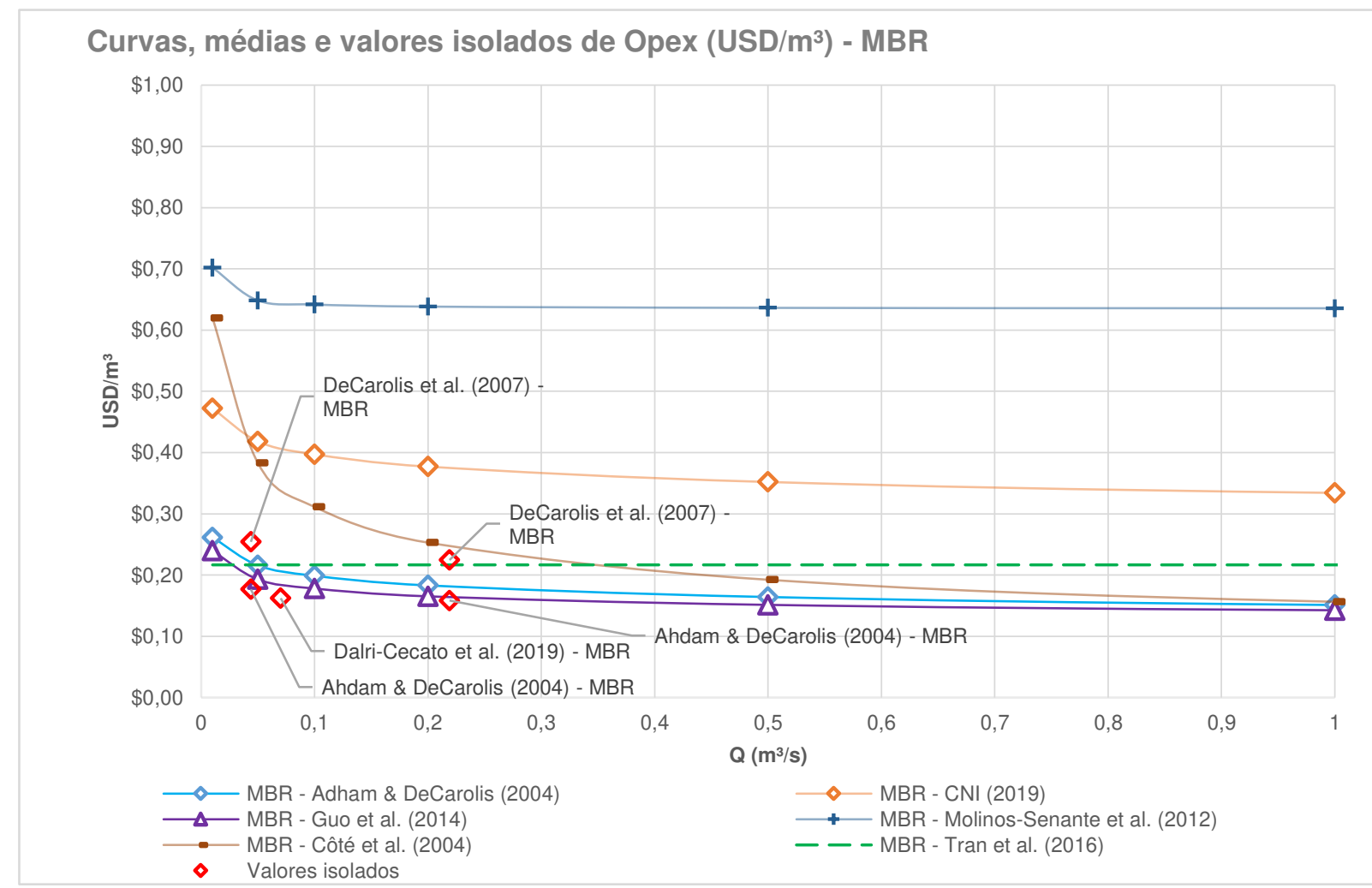

Nota 1: funções corrigidas para USD a partir da moeda original de acordo com a cotação média do ano-base e inflação corrigida do ano-base até set/2019 pelo CCI/ENR. Nota 2: linhas tracejadas representam custos unitários isolados, ou seja, não apresentados na literatura em função de vazão.

Figura 9: Curvas, médias e valores isolados de Opex de tratamento (USD/m³) para MBR Fontes: adaptado de Côté et al. (2004); Adham \& DeCarolis (2004); EPA (2007); DeCarolis et al. (2007); Molinos-Senante (2012); Guo et al. (2014); Tran et al. (2016b, 2016a); Judd (2017); CNI (2019a)

Custos de processos de desinfeção por cloro e UV são muito reduzidos em comparação aos de MBR e de OR. Afora manutenção e substituição de equipamentos, custos de cloração se devem basicamente à própria aquisição do produto. No caso da UV, os custos são basicamente os de gastos com energia elétrica. Ambos estão na ordem de alguns poucos centavos de dólar por $\mathrm{m}^{3}$, entre 0,01 e $0,03 \mathrm{USD} / \mathrm{m}^{3}$, conforme se vê na Figura 10. 


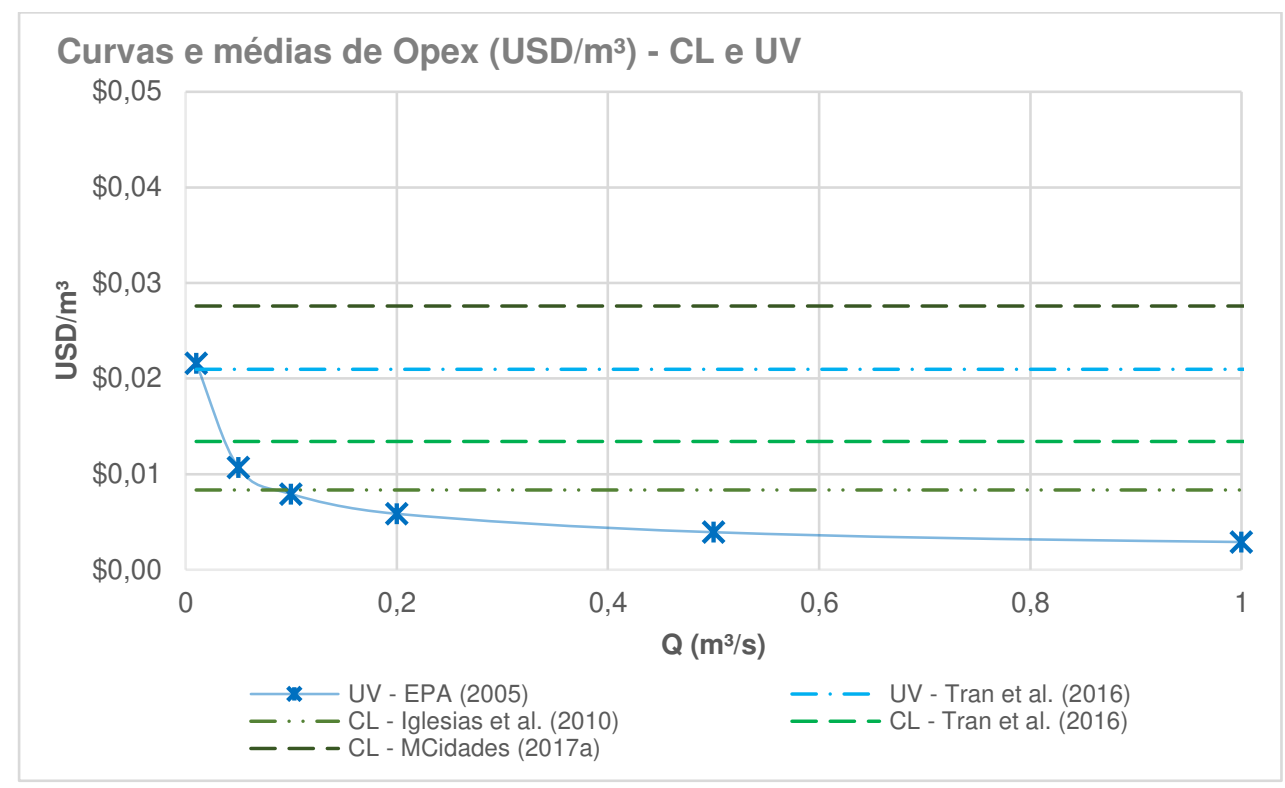

Nota 1: funções corrigidas para USD a partir da moeda original de acordo com a cotação média do ano-base e inflação corrigida do ano-base até set/2019 pelo CCI/ENR. Nota 2: linhas tracejadas representam custos unitários isolados, ou seja, não apresentados na literatura em função de vazão.

Figura 10: Curvas, médias e valores isolados de Opex de tratamento (USD/ $\left.\mathrm{m}^{3}\right)$ para $\mathrm{CL}$ e UV Fontes: adaptado de EPA (2005); Iglesias et al. (2010); Tran et al. (2016b, 2016a); MCidades (2017a)

Para OR, as demandas de energia elétrica são muito expressivas, levando a custos que podem chegar próximos a 2,0 USD/m³ para vazões baixas e entre $0,20-0,40$ USD $/ \mathrm{m}^{3}$ para mais altas, como se vê na Figura 11.

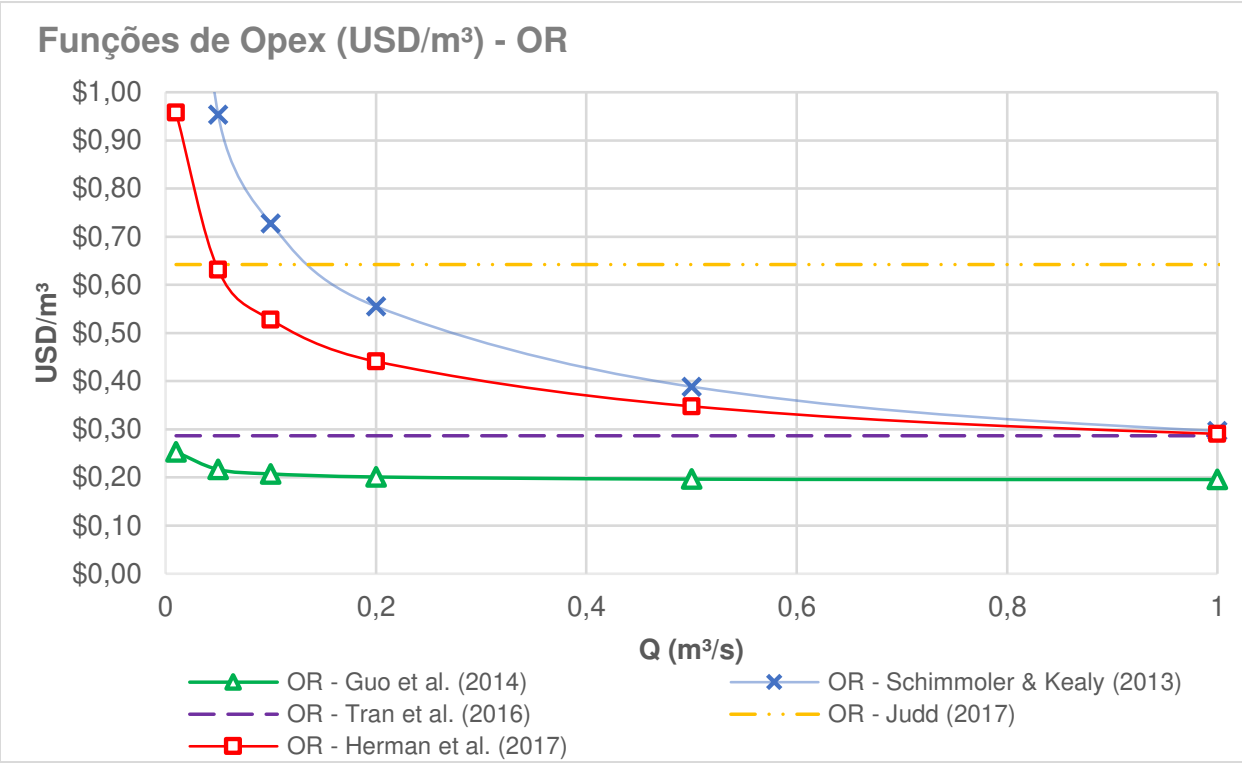

Nota 1: funções corrigidas para USD a partir da moeda original de acordo com a cotação média do ano-base e inflação corrigida do ano-base até set/2019 pelo CCI/ENR. Nota 2: linhas tracejadas representam custos unitários isolados, ou seja, não apresentados na literatura em função de vazão.

Figura 11: Curvas, médias e valores isolados de Opex de tratamento (USD/m³) para OR Fontes: adaptado de EPA (2005); Schimmoler e Kealy (2013); Guo et al. (2014); Tran et al. (2016b, 2016a); Herman et al. (2017); Judd (2017) 


\subsubsection{Custos de distribuição}

Os custos (Capex e Opex) de distribuição consideram tanto as estações elevatórias (EE) como adutoras.

\subsection{Capex de estações elevatórias}

Os custos de estações elevatórias (EE) se devem, fundamentalmente, a obras civis e equipamentos eletromecânicos. Em geral, a literatura apresenta custos totais em função da vazão de bombeamento, dado que autores como Hernández-Sancho (2015) afirmam que a maior parte dos gastos se deve a obras civis, implicando em menor influência da potência requerida. No entanto, curvas de custos da Sabesp (2010a) mostram o contrário, com valores médios de $24 \%$ de custos com obras civis e $76 \%$ de eletromecânica.

$\mathrm{Na}$ Tabela 10 e na Figura 12 são apresentadas funções de Capex de EE em função de vazão (m³/ano).

Tabela 10: Funções de Capex para estações elevatórias em USD/m³/ano

\begin{tabular}{|c|c|c|}
\hline \multirow{2}{*}{ Referência } & \multirow{2}{*}{ Ano-base ${ }^{\text {(a) }}$} & Função (b) \\
\hline & & $\mathrm{C}$ em USD/m³/ano e $Q$ em m³/s \\
\hline COWI (2005) & 2005 & $C=0,01276 Q^{-0,6}$ \\
\hline Brites (2010) & 2010 & $C=0,1557 Q^{-0,18}$ \\
\hline Hernández-Sancho et al. (2015) & 2015 & $C=0,0130 Q^{-0,456}$ \\
\hline CNI (2019a) & 2017 & $C=0,0307 Q^{-0,32}$ \\
\hline
\end{tabular}

(a) Ano-base da estimativa de custos, que eventualmente pode ser diferente do da publicação. $O$ ano-base fol utilizado para correção monetária (conversão para USD e ajuste da inflação pelo CCI-ENR). (b) Correções a partir do CCI-ENR do ano-base do custo até set/2019 e da cotação monetária média para o ano-base de custos. Funções originais são apresentadas no ANEXO A. 
Funções de Capex de EE (USD/m³/ano)

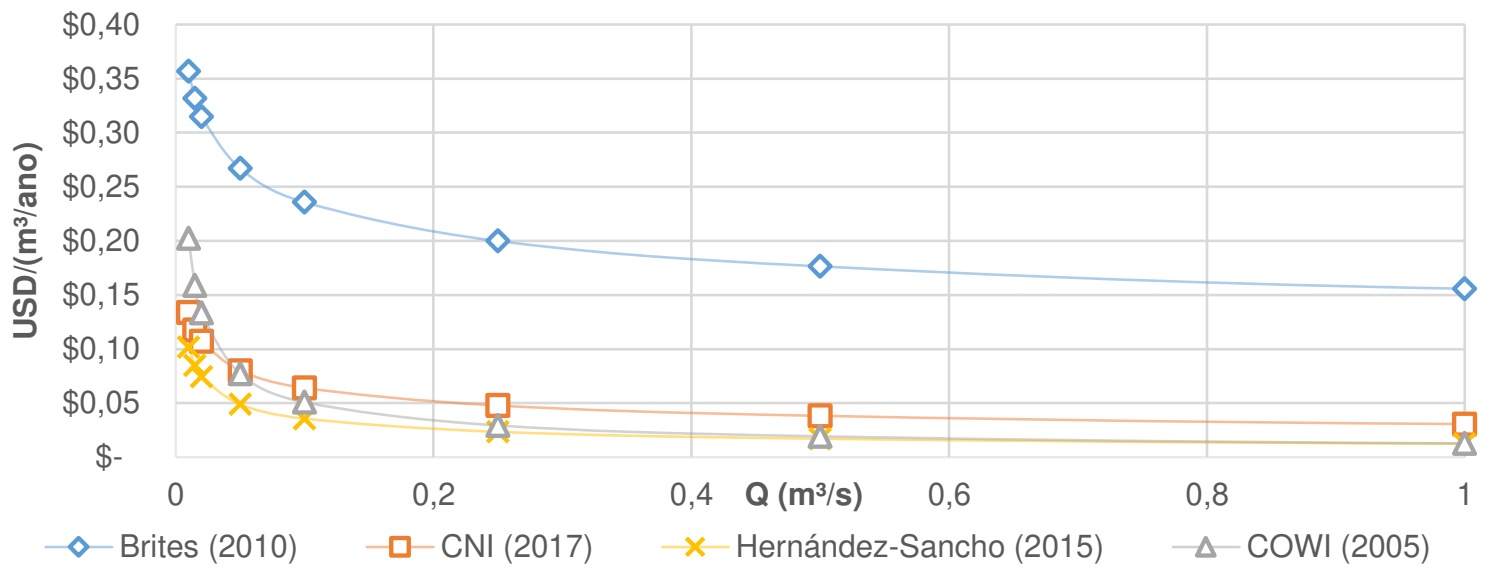

Nota: custos corrigidos para USD a partir da moeda original de acordo com a cotação média do ano-base e inflação corrigida do ano-base até set/2019 pelo CCI/ENR

Figura 12: Curvas de Capex para estações elevatórias em USD/m³/ano

Fontes: adaptado de COWI (2005); Brites (2010); Hernández-Sancho (2015); CNI (2019a)

Na Tabela 11 e na Figura 13 constam custos em função de potência requerida, bem como a divisão entre custos de obras civis e eletromecânica.

Tabela 11: Funções de Capex para estações elevatórias em USD/CV

\begin{tabular}{lll}
\hline \multirow{2}{*}{ Referência } & $\begin{array}{l}\text { Ano- } \\
\text { base }^{(a)}\end{array}$ & Função $^{(b)}$ \\
\cline { 3 - 3 } Sabesp (2010a) - eletromecânica & 2010 & $C=13.716 P^{-0,4778}$ \\
\hline Sabesp (2010a) - obras civis & 2010 & $C=12.984 P^{-0,3148}$ \\
\hline Sabesp (2010a) - total & 2010 & $C=24.622 P^{-0,3568(c)}$ \\
\hline
\end{tabular}

(a) Ano-base da estimativa de custos, que eventualmente pode ser diferente do da publicação. $O$ ano-base foi utilizado para correção monetária (conversão para USD e ajuste da inflação pelo CCI-ENR). (b) Correções a partir do CCI-ENR do ano-base do custo até set/2019 e da cotação monetária média para o ano-base de custos. Funções originais são apresentadas no ANEXO A. (c) Função de custos totais não é equivalente à soma das duas outras funções, dado que $R^{2}<1,0$.

\section{Funções de Capex de EE (USD/CV)}

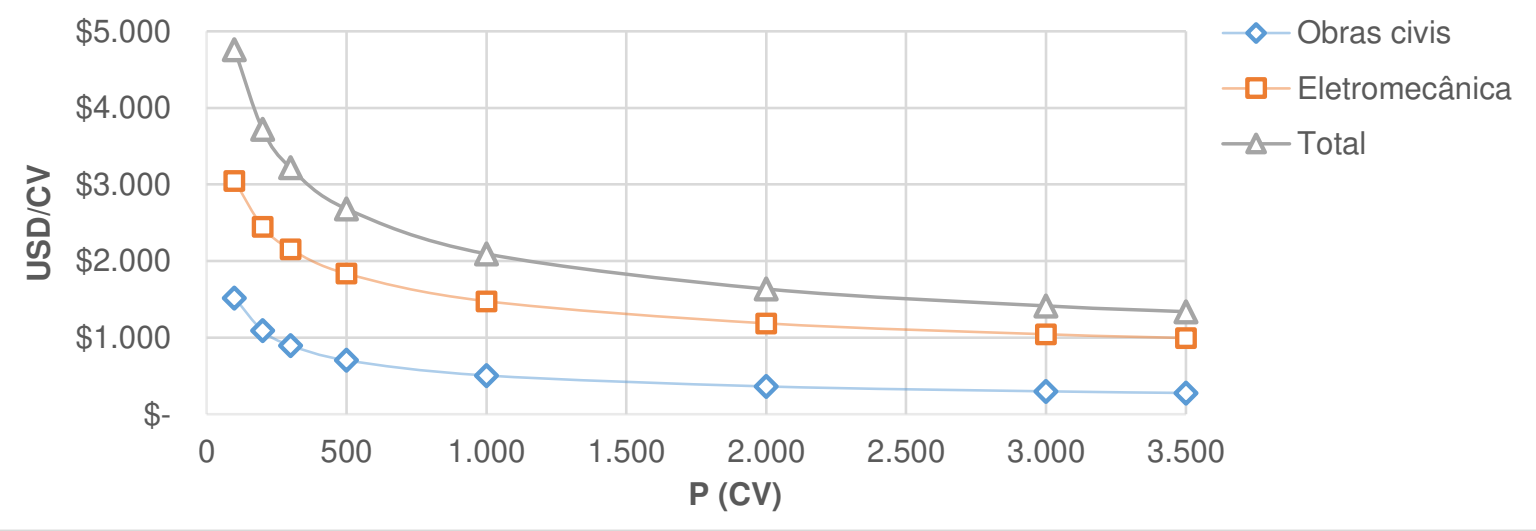

Figura 13: Curvas de Capex para estações elevatórias em USD/CV

Nota: custos corrigidos para USD a partir da moeda original de acordo com a cotação média do anobase e inflação corrigida do ano-base até set/2019 pelo CCI/ENR.

Fontes: adaptado de Sabesp (2010a) 
Seja em função da vazão ou da potência requerida, vê-se a mesma tendência de ganho de escala observada nos custos de tratamento.

\subsection{Capex de adutoras}

O Capex adutoras é depende das distâncias entre produtor de água de reúso, traçado da linha, características topográficas (desníveis geométricos) e de terreno/infraestrutura (malha viária, interferências, travessias etc.), bem como das próprias vazões a serem transportadas, materiais de tubulação, método de escavação e recobrimento, tarifa de energia elétrica, entre outros.

Os custos unitários de Capex são usualmente representados em função do diâmetro nominal (DN) das tubulações e consideram materiais, mão-de-obra, escavações e escoramentos. A Tabela 12 e a Figura 14 apresentam funções de Capex de adutoras.

Tabela 12: Funções de Capex para adutoras em USD/m

\begin{tabular}{|c|c|c|c|}
\hline Referência & $\begin{array}{l}\text { Ano- } \\
\text { base }^{(a)}\end{array}$ & Função $^{\text {(b) }}$ & Observação \\
\hline COWI (2005) & 2005 & $\begin{array}{l}\text { C em USD/m e DN }(\mathrm{mm}) \\
C=0,0016 D N^{2}+0,5127 D N\end{array}$ & Áreas rurais \\
\hline $\begin{array}{l}\text { Hernández-Sancho } \\
\text { et al. (2015) }\end{array}$ & 2015 & $C=0,00033 D N^{2}+0,421 D N-5,371$ & Espaços abertos \\
\hline $\begin{array}{l}\text { Hernández-Sancho } \\
\text { et al. (2015) }\end{array}$ & 2015 & $C=0,00032 D N^{2}+0,330 D N-21,793$ & Áreas reservadas \\
\hline $\begin{array}{l}\text { Hernández-Sancho } \\
\text { et al. (2015) }\end{array}$ & 2015 & $C=0,00027 D N^{2}+0,297 D N-20,450$ & Viário \\
\hline Da Luz (2014) & 2006 & $C=0,0002 D N^{2}+0,302 D N+22,103^{(\mathrm{c})}$ & - \\
\hline CNI (2019a) & 2017 & $C=0,0009 D N^{2}+0,593 D N+29,141(\mathrm{~d})$ & $\begin{array}{l}\text { Recomposição } \\
\text { de } 40 \% \text { de } \\
\text { asfalto }\end{array}$ \\
\hline
\end{tabular}

(a) Ano-base da estimativa de custos, que eventualmente pode ser diferente do da publicação. O ano-base fol utilizado para correção monetária (conversão para USD e ajuste da inflação pelo CCI-ENR).

(b) Correções a partir do CCI-ENR do ano-base do custo até set/2019 e da cotação monetária média para o anobase de custos. Funções originais são apresentadas no ANEXO A.

(c) Estudo apresenta Capex unitários de adutoras para DN entre 100 e 800 mm. Função foi determinada por este autor com $\mathrm{R}^{2}=0,9955$

(d) Estudo apresenta Capex unitários de adutoras para DN entre 50 e $1000 \mathrm{~mm}$. Função foi determinada por este autor com $R^{2}=0,9971$ 


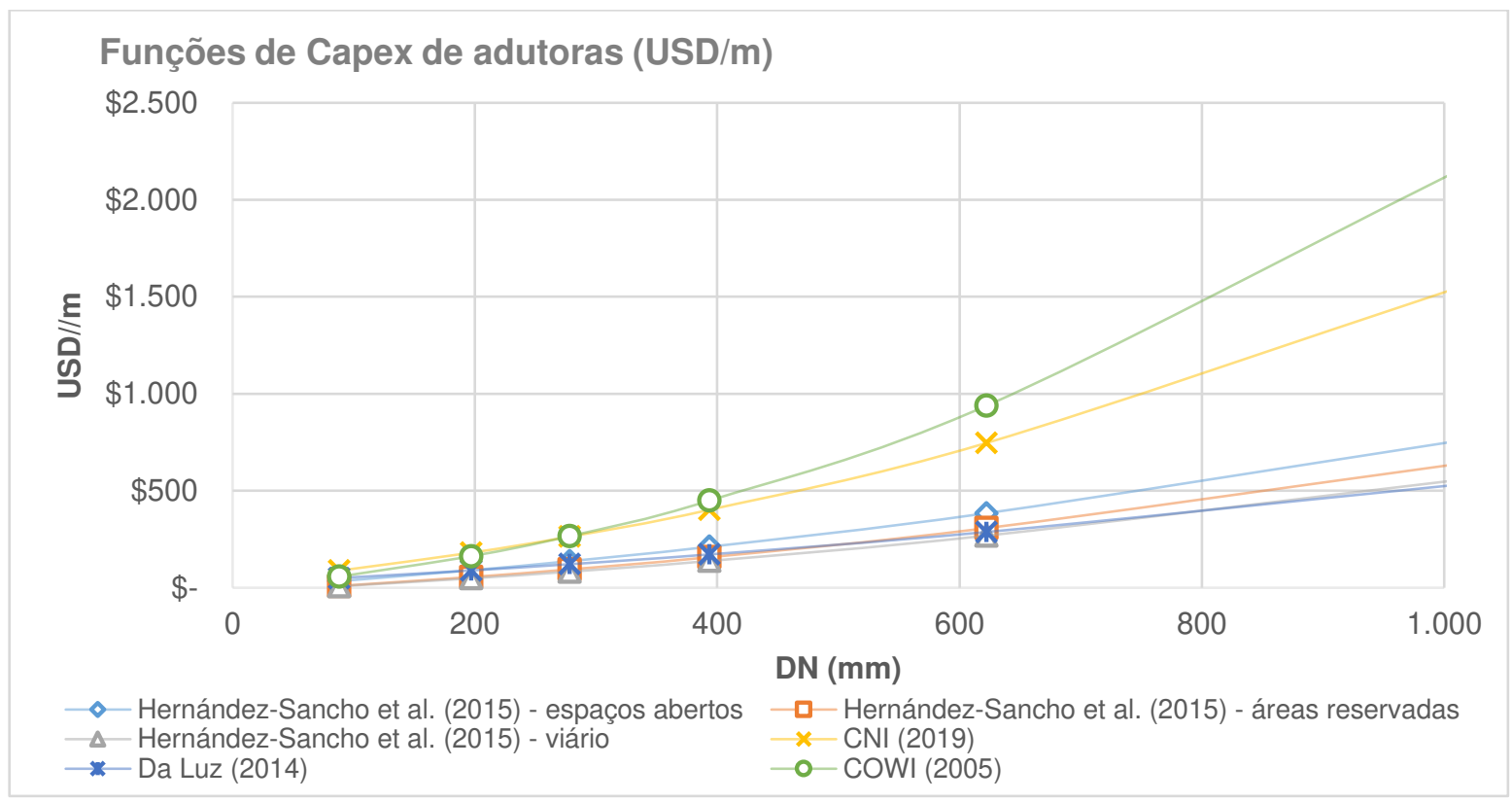

Figura 14: Curvas de Capex para adutoras em USD/m

Nota: custos corrigidos para USD a partir da moeda original de acordo com a cotação média do anobase e inflação corrigida do ano-base até set/2019 pelo CCl/ENR

Fontes: adaptado de COWI (2005); Brites (2010); Hernández-Sancho (2015); CNI (2019a)

\subsection{Opex de distribuição}

O Opex de distribuição se deve, majoritariamente, ao consumo de energia elétrica para pressurização de água, o que, por sua vez, é função da altura manométrica total (AMT) do sistema elevatório. Custos com manutenção das linhas, troca de equipamentos e dispositivos se encontram na faixa de $3 \%$ a $6 \%$ do Capex total do sistema de bombeamento (MCIDADES, 2017a; NOGUEIRA, 2010; OECD EAP, 2005), ou são estimados em valor fixo, como 0,003 USD por $\mathrm{m}^{3}$ bombeado ( $\mathrm{CNI}$, 2019a).

Os custos com energia elétrica são determinados por arranjos muito específicos das linhas de recalque, de terreno (traçado e desníveis geométricos) e da tarifa de energia elétrica local, o que os tornam muito característicos para cada caso. Ao mesmo tempo, equações elementares da física e da engenharia hidráulica, como a equação da continuidade, fórmula de Bresse, fórmula de Hazen-Williams para condutos forçados e equações práticas de potência requerida podem ser aplicadas para a estimativa da potência mínima de conjuntos motor-bomba de sistemas elevatórios. Dado isso, a literatura comumente não relata valores e/ou funções de custo para o recalque de 
água, o que se justifica pela peculiaridade de cada caso e pela possibilidade de estimativas relativamente simples.

Ainda assim, alguns estudos, como Hunter Water Corporation (2013) e Pistocchi et al. (2018), apresentam equações de referência de Opex para adução em função do DN e do comprimento da linha de recalque, conforme ilustra a Figura 15.

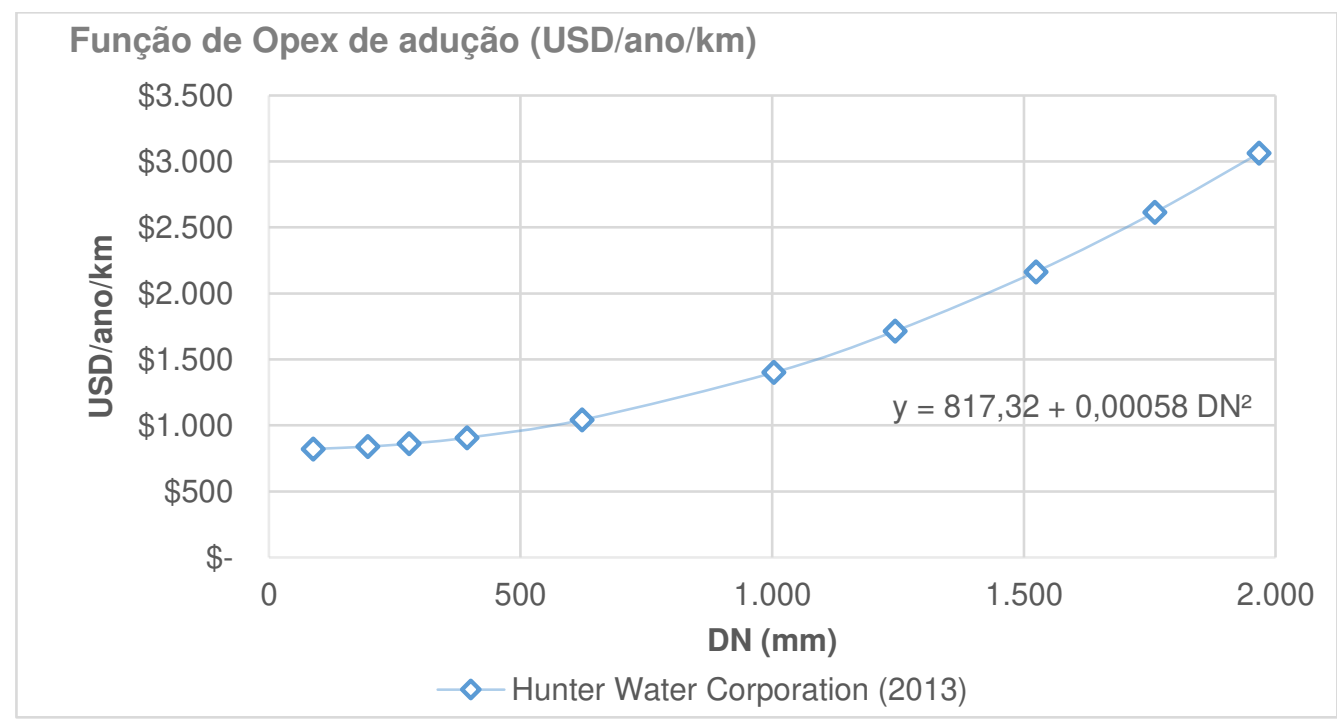

Figura 15: Opex de adução em USD/ano/km

Fonte: Hunter Water Corporation (2013)

\subsubsection{Diretrizes de planejamento em reúso}

Independentemente da capacidade ou tipo dos sistemas e programas de reúso a serem implantados, há etapas que devem ser observadas em um processo de inclusão do reúso como parte de um plano de gestão integrada das águas. A United States Environmental Protection Agency (U.S. EPA) sugere, com base em recomendações da WateReuse Association (WRA), os seguintes passos (U.S. EPA, 2012):

1. identificação da quantidade de água de reúso disponível;

2. levantamento de todos os usuários existentes e futuros;

3. identificação dos potenciais usuários;

4. verificação da aceitação dos usuários em relação à água de reúso;

5. comparação entre oferta e demanda por água de reúso;

6. elaboração do layout de distribuição de água de reúso; 
7. definição da lista de usuários;

8. determinação da viabilidade econômica;

9. compilação da lista final de usuários e do sistema de distribuição;

10. preparação dos arranjos e pontos de venda;

11. regularização junto aos órgãos pertinentes;

12. execução das obras de retrofit;

13. execução de testes de conexão cruzada;

14. início da operação.

A Comissão Europeia (2016), por sua vez, apresenta nove "passos-chave" no planejamento de reúso, os quais são atrelados às determinações da WFD (EU Water Framework Directive). São eles:

1. Determinar a pressão e o impacto nos corpos hídricos em razão da escassez de água e superexploração de mananciais, bem como as necessidades de água dos usuários locais para os cenários atual e futuro, determinando se a escassez é suficientemente severa a ponto de tornar viável a prática de reúso de esgotos.

2. Identificar as ações ou fontes de água apropriadas para suprimento das necessidades atuais e futuras de água, indicando, quantitativamente, como cada fonte pode contribuir para atendimento das demandas específicas.

3. Identificar as vazões de esgoto que podem ser tratadas para geração de água de reúso e alocá-las referentemente às demandas individuais.

4. Determinar a necessidade de tratamento e outros requerimentos para garantia de uso seguro e proteção ao meio ambiente, levando-se em consideração as legislações aplicáveis.

5. Identificar os distintos custos (incluídos os de energia elétrica, externalidades etc.) associados ao tratamento de efluentes de diferentes qualidades para atendimento às demandas dos usuários identificados.

6. Comparar os custos (incluídas as externalidades) com os de outras alternativas (inclusive o da "não ação") e sua relação com os possíveis benefícios (incluídas as externalidades). Quando apropriado, realizar análises mais detalhadas das demais alternativas. 
7. Determinar os arranjos de financiamento possíveis para desenvolvimento, implantação e operação de reúso, bem como tarifas adequadas. O projeto é viável? Quem pagará e quem será beneficiado?

8. Garantir que os detalhes contratuais estejam formalmente acordados entre o produtor de água de reúso e os usuários, promovendo regulação das relações entre as partes e definindo os respectivos deveres e obrigações.

9. Estabelecer sistemas de monitoramento e controle para garantia do uso seguro, tanto em relação aos usuários e como ao meio ambiente, da água de reúso, buscando-se o cumprimento das obrigações legais por parte do operador.

Ambas as diretrizes destacam alguns pontos-chave, como a avaliação do balanço entre oferta e demanda, identificação e caracterização individual dos potenciais usuários e análises de viabilidade econômica dos programas de reúso.

\subsubsection{Estudos nacionais de viabilidade de reúso no Brasil e na Região Metropolitana de São Paulo (RMSP)}

Ainda que seja uma prática ainda incipiente no Brasil, o reúso não é um assunto exatamente novo, sendo objeto de estudo desde os anos 1990. Neste item são apresentados alguns estudos realizados no Brasil e na Região Metropolitana de São Paulo (RMSP), a área de estudo escolhida para aplicação dos modelos de planejamento de reúso desenvolvidos nesta pesquisa.

Em nível nacional, o estudo mais relevante no tema até o momento é o conduzido pelo antigo Ministério das Cidades em parceria com o Instituto Interamericano de Cooperação para a Agricultura (IICA) em 2017 (MCIDADES, 2017b). A metodologia se divide em análise "macro", em nível municipal, e "micro", aplicada a algumas ETEs específicas. O estudo chega à conclusão de que o potencial de reúso em curto-médio prazo no Brasil é de $13 \mathrm{~m} / \mathrm{s}$, incluindo possibilidades de reúso potável indireto (RPI). Desse total, $7 \mathrm{~m} 3 / \mathrm{s}$ estão na região Sudeste, e aponta-se que há potencialidade de aplicação de reúso para atendimento de demandas industriais na RMSP, bem como nas regiões metropolitanas de Campinas, Rio de Janeiro, Vitória e no Vale do Paraíba. 
Em outras Unidades da Federação (UFs) estudos como Malinowski (2006) (Paraná), Generino (2006) (Distrito Federal), Caixeta (2010) (Ceará), Fukasawa et al. (2017) (Ceará) e CNI (2019b, 2019c, 2019d, 2019a, 2019e) (Rio de Janeiro, Ceará, Rio Grande do Norte, Espírito Santo e Ceará) trouxeram contribuições importantes para a compreensão dos potenciais de reúso para atendimento a demandas não potáveis.

Especificamente na RMSP, a pesquisa de Filho (1987) abordou as possibilidades de reúso na área, porém dentro de um quadro mais amplo dentro do cenário nacional. $O$ autor chega à conclusão de que as demandas industriais estariam demasiadamente dispersas no território da RMSP, tornando o reúso inviável em razão da necessidade de "complexos sistemas duplos, provavelmente antieconômicos" (FILHO, 1987). A sugestão realizada é, portanto, que o reúso seja aplicado prioritariamente internamente nas indústrias. Ainda assim, é apontada a existência de uma única planta industrial que poderia ser abastecida por água de reúso proveniente de ETEs municipais: a Cia. Suzano de Papel e Celulose, localizada no município de Suzano.

A tese de doutoramento de Mancuso (1992) discorre especificamente sobre as possibilidades de reúso na RMSP, incluindo atendimento a demandas industriais e de irrigação. O autor não considera o reúso potável direto viável, principalmente sob os argumento da necessidade de extensos estudos na área aliada às "dificuldades para a condução e viabilização de qualquer tipo de pesquisa [no Brasil]" (MANCUSO, 1992) e dos custos excessivos quando em comparação ao reúso indireto. Mancuso aponta que a dispersão das indústrias na RMSP não favorece a aplicação de reúso não potável direto, dado que a necessidade de implantação de redes duplas de distribuição resultaria em custos impeditivos. Ainda assim, destaca que nas proximidades da ETE Suzano há uma indústria de papel e celulose com demanda representativa, sendo possível "liberar até $0,9 \mathrm{~m}^{3} / \mathrm{s}$ (suficientes para abastecer cerca de 310.000 pessoas) de águas primárias para serem incorporadas ao Sistema Produtor Alto Tietê" (MANCUSO, 1992), conclusão similar à indicada no trabalho de Filho (1987).

Em 2010 o Plano Diretor de Esgotos da Região Metropolitana de São Paulo - PDE 2010 (SABESP, 2010a) abordou o reúso na RMSP em um de seus capítulos, 
elencando que os possíveis usos são o urbano (irrigação paisagística, lavagem de logradouros, lavagem de veículos etc.), agrícola e florestal, e industrial.

Quanto ao reúso agrícola, apesar de o PDE levantar sua possibilidade, de início já descarta a alternativa, "principalmente por problemas logísticos, distância das estações de tratamento de esgotos em relação às áreas com maior potencial de utilização da água de reúso, implicando na construção de uma adutora com grande extensão e, consequentemente, custo elevado da água de reúso, em relação às opções disponíveis para os agricultores" (SABESP, 2010a).

Para avaliação dos potenciais usuários industriais, o PDE selecionou municípios com demanda industrial acima de $0,1 \mathrm{~m}^{3} / \mathrm{s}$ e considerou usuários com demandas superiores a $0,01 \mathrm{~m}^{3} / \mathrm{s}$, o que foi determinado a partir das outorgas de captação. $O$ plano afirma, conforme também se pôde constatar neste levantamento bibliográfico, que não existem estudos atualizados e específicos para o Brasil quanto à distribuição do consumo de água por segmento industrial, e assume que aprox. 60\% das demandas de uma planta são referentes a sistemas de resfriamento e passíveis de atendimento por água de reúso não potável. O PDE estima vazão potencial de reúso de $4,27 \mathrm{~m}^{3} / \mathrm{s}$ para a indústria, destacando as estações Suzano, São Miguel e Parque Novo Mundo como as principais.

O PDE também faz considerações sobre custos de produção de água de reúso e, a partir de referências internacionais de exigência de qualidade por tipo uso, admite duas classes: clarificada sem desnitrificação e clarificada com desnitrificação (para usos industriais). Os custos unitários variam de 0,28 a 0,49 USD $/ \mathrm{m}^{3}$ para água sem desnitrificação e de 0,72 a 0,93 USD $/ \mathrm{m}^{3}$ com desnitrificação.

Em 2012, o Consórcio Coroado, iniciativa internacional coordenada pela União Europeia e que contou com colaboração da Universidade de São Paulo (USP), avaliou o potencial de reúso em três distintas regiões: bacia do Alto Tietê/RMSP, bacia do rio Copiapó (Chile) e bacia dos rios Bravo e Baixo Grande (México). Em essência, os dados e conclusões apresentados pelo Projeto Coroado para a RMSP são os mesmos presentes no PDE 2010: indica-se que o maior potencial está no abastecimento industrial a partir das ETEs do Sistema Principal; que os usos urbanos não potáveis, 
apesar de possuírem alguma significância, estão demasiadamente dispersos pela RMSP e são individualmente muito baixos; e que os agrícolas se localizam muito distantes das ETEs para que haja viabilidade econômica (COROADO CONSORTIUM, 2012).

Em 2017, para o caso específico de demandas industriais na RMSP, CNI (2017b) estimou vazão potencial de reúso de $4,45 \mathrm{~m}^{3} / \mathrm{s}$ distribuída em 730 usuários. A metodologia utilizou delimitação de área de influência determinada por raio de $10 \mathrm{~km}$ em torno das cinco ETEs do Projeto Tietê (ETEs Barueri, ABC, Parque Novo Mundo, Suzano e São Miguel) e de utilização de outorgas de captação do DAEE e da ANA para finalidades industriais. O estudo também chegou a custos de produção, distribuição e reservação de água de reúso por $m^{3}$ entre $R \$ 1,357$ e $R \$ 2,682$. As premissas adotadas foram: adaptação das ETEs de LAC a MBR com implantação membranas de UF do tipo placa plana submersa nos decantadores secundários; capacidades entre 50 e $500 \mathrm{l} / \mathrm{s}$; linhas de distribuição entre 8,0 e 13,0 km (sendo um trecho por recalque e outro por gravidade); e reservatórios entre 500 e $2.000 \mathrm{~m}^{3}$.

O supracitado estudo de MCidades (2017b) apresenta apenas resultados agregados por região, o que impossibilita a avaliação dos valores para a RMSP. No entanto, foram solicitados diretamente ao MDR (Ministério de Desenvolvimento Regional) informações mais detalhadas por município, conforme apresenta a Tabela 13.

Tabela 13: Potencial de reúso por município da RMSP segundo o programa Interáguas

\begin{tabular}{|c|c|c|c|c|}
\hline \multirow[b]{2}{*}{ Município } & \multicolumn{4}{|c|}{ Potencial de reúso (l/s) } \\
\hline & Industrial & Irrigação & $\begin{array}{l}\text { Reúso potável } \\
\text { indireto (RPI) }\end{array}$ & Total \\
\hline Arujá & 11,2 & - & - & 11,2 \\
\hline Barueri & $1.506,3$ & - & - & $1.506,3$ \\
\hline Biritiba-Mirim & - & - & 6,0 & 6,0 \\
\hline Cotia & 3,0 & - & - & 3,0 \\
\hline Embu-Guaçu & 3,5 & - & - & 3,5 \\
\hline Guarulhos & 62,0 & - & - & 62,0 \\
\hline Mauá & 56,3 & - & - & 56,3 \\
\hline Mogi das Cruzes & 9,4 & - & - & 9,4 \\
\hline Pirapora do Bom Jesus & - & 0,0 & - & 0,0 \\
\hline Salesópolis & 3,1 & - & - & 3,1 \\
\hline Santo André & 0,2 & - & - & 0,2 \\
\hline São Bernardo do Campo & 2,1 & - & - & 2,1 \\
\hline São Paulo & 773,8 & - & - & 773,8 \\
\hline Suzano & - & 278,4 & - & 278,4 \\
\hline Total & $2,430,8$ & 278,4 & 6,0 & $2.715,2$ \\
\hline
\end{tabular}

Fonte: MCidades (2017c) 
A Tabela 13 mostra então que na RMSP o potencial total de reúso é de $2.715 \mathrm{l} / \mathrm{s}$ (MCIDADES, 2017c), sendo 2.431 I/s referentes a usos industriais. O maior potencial está concentrado nos municípios de Barueri, São Paulo e Suzano.

\section{A Tabela 14 compila pontos de destaque dos estudos de potencial de reúso na RMSP acima levantados.}

Tabela 14: Resumo de pontos principais de estudos sobre reúso que contemplam a RMSP

\begin{tabular}{|c|c|c|c|}
\hline Autor & Principais conclusões & Abordagem / metodologia & Potencial de reúso \\
\hline Filho (1987) & $\begin{array}{l}\text { Reúso não potável direto não é } \\
\text { economicamente viável, } \\
\text { principalmente porque demandas } \\
\text { industriais e de irrigação são muito } \\
\text { dispersas no território. Reúso } \\
\text { interno em indústrias é uma opção } \\
\text { a ser considerada. Uma planta em } \\
\text { singular é apontada como possível } \\
\text { usuária de água de reúso. }\end{array}$ & $\begin{array}{l}\text { Comparação entre demanda } \\
\text { industrial todas e soma da vazão de } \\
\text { esgoto tratado para a RMSP como } \\
\text { um todo. ETEs e usuários não são } \\
\text { comparados individualmente }\end{array}$ & $\begin{array}{l}\text { Não é exatamente } \\
\text { calculado, mas indica- } \\
\text { se possibilidade de } \\
\text { suprimento de } 1,38 \\
\mathbf{m}^{3} / \mathbf{s} \text { de uma única } \\
\text { planta industrial }\end{array}$ \\
\hline $\begin{array}{l}\text { Mancuso } \\
\text { (1992) }\end{array}$ & $\begin{array}{l}\text { Reúso não potável direto não é } \\
\text { economicamente viável por conta } \\
\text { da dispersão de usuários no } \\
\text { território. Reúso não potável indireto } \\
\text { a partir da ETA Baixo Cotia } \\
\text { apresenta maior potencialidade }\end{array}$ & $\begin{array}{l}\text { Similar a Filho (1987), com } \\
\text { avaliações a RMSP como um todo }\end{array}$ & $\begin{array}{l}\text { Não é exatamente } \\
\text { calculado, mas a } \\
\text { mesma planta citada } \\
\text { por Filho (1987), porém } \\
\text { com vazão de } \mathbf{0 , 9} \mathbf{~ m} \mathbf{3}^{\mathbf{3}} \mathbf{s}\end{array}$ \\
\hline
\end{tabular}

Reúso não potável direto para a indústria possui potencial relevante, principalmente na cidade de São Sabesp Paulo. No entanto, distâncias entre (2010a) ETEs e usuários pode ser economicamente limitante. Demandas urbanas e de irrigação são muito dispersas (urbanas) ou muito distantes das ETEs (irrigação)
Análise para municípios com demanda industrial total acima de $0,1 \mathrm{~m}^{3} / \mathrm{s}$ (cálculo a partir de demandas industriais de captação). Foram consideradas somente as outorgas superiores a $0,01 \mathrm{~m}^{3} / \mathrm{s}(10$ $\mathrm{l} / \mathrm{s})$. Para cada usuário industrial, assumiu-se que $60 \%$ de suas demandas (vazão outorgada) podem ser atendidas por água não potável. Indústrias com vazões relevantes e razoavelmente próximas a ETEs de grande porte foram listadas individualmente

Mesma de Sabesp (2010a)

Consideração de outorgas

industriais de captação localizadas

a até $10 \mathrm{~km}$ de distância das cinco principais ETEs da RMSP.
$4,27 \mathrm{~m}^{3} / \mathrm{s}$ (industrial)

4,27 $\mathrm{m}^{3} / \mathrm{s}$ (industrial)

4,45 m³ (industrial)

Modelagem considerando vazão afluente à ETEs, necessidade de novas fontes de abastecimento, manutenção de vazões mínimas ambientais dos corpos receptores (lançamento de esgoto tratado) e existência de fontes alternativas
$2,72 \mathrm{~m}^{3} / \mathrm{s}$ (total) 2.42 (industrial) $0,28 \mathrm{~m}^{3} / \mathrm{s}$ (irrigação) $0,06 \mathrm{~m}^{3} / \mathrm{s}$ (reúso potável indireto) (2017b, usos industriais e de irrigação tem 2017c) importante potencial 


\subsubsection{Aspectos legais e normativos sobre reúso no Brasil}

Atualmente, as únicas referências em nível nacional sobre reúso não potável são a resolução $n^{\circ}$ 54/2005 do Conselho Nacional de Recursos Hídricos (CNRH) e a norma ABNT:NBR 16.783 - Uso de fontes alternativas não potáveis em edificações.

A resolução $n^{\circ}$ 54/2005 do CNRH estabelece modalidades, diretrizes e critérios gerais para a prática de reúso direto não potável em território nacional (BRASIL, 2005). A resolução determina que as modalidades devem ser seguidas pelas legislações estaduais e municipais, cada qual determinando classes de uso e respectivos padrões de qualidade de acordo com o uso ou tipo de restrição ao acesso (restrito ou moderado) à área em que será realizada a prática de reúso. Conforme consta no Art. 3ํ da resolução, as modalidades de reúso não potável são (BRASIL, 2005):

I. reúso para fins urbanos: utilização de água de reúso para fins de irrigação paisagística, lavagem de logradouros públicos e veículos, desobstrução de tubulações, construção civil, edificações, combate a incêndio, dentro da área urbana;

II. reúso para fins agrícolas e florestais: aplicação de água de reúso para produção agrícola e cultivo de florestas plantadas;

III. reúso para fins ambientais: utilização de água de reúso para implantação de projetos de recuperação do meio ambiente;

IV. reúso para fins industriais: utilização de água de reúso em processos, atividades e operações industriais; e,

V. reúso na aquicultura: utilização de água de reúso para a criação de animais ou cultivo de vegetais aquáticos.

A norma ABNT:NBR 16.783:2019 trata exclusivamente do uso de água não potável em edificações, incluindo finalidades como descargas de bacias sanitárias e mictórios, lavagens de pisos e veículos, irrigação paisagística e em sistemas de resfriamento. Consideram-se fontes de água não potável tanto o reúso como água de chuva, água de condensado de sistemas de ar-condicionado e água de rebaixamento de lençol freático. Os usos para reposição de sistemas de resfriamento, como torres de 
resfriamento (TR), são previstos na norma, mas o padrão de qualidade determinado não se aplica a essa finalidade (ABNT, 2019; CBIC, 2019).

O surgimento das primeiras legislações estaduais e municipais sobre reúso iniciou-se em meados da década de 2010, quase 10 anos depois da publicação da resolução $n^{\circ}$ 54/2005 do CNRH. A primeira publicação que define classes de uso, padrões de qualidade e outras considerações é a Resolução Conjunta SVDS/SMS nº 09/2014 do município de Campinas - SP (CAMPINAS, 2014). Em seguida, o município de Belo Horizonte (2015), estado do Ceará (2017) e o estado de São Paulo (2017), entre outros, também publicaram suas próprias legislações referentes ao assunto.

O estado de São Paulo publicou em 2020 a resolução conjunta SES/SIMA n ${ }^{\circ}$ $01 / 2020^{8}$, a qual disciplina o reúso não potável direto para atendimento a fins urbanos a partir de efluentes de ETEs públicas ou privadas, excluindo-se aquelas implantadas por estabelecimentos comerciais ou industriais (ESTADO DE SÃO PAULO, 2020). A resolução considera que "que o reúso direto não potável de água configura-se como iniciativa importante para o aprimoramento da gestão dos recursos hídricos, incluindo o estabelecimento de padrões menos exigentes para usos não nobres da água" (ESTADO DE SÃO PAULO, 2020), o que indica a movimentação do Poder Público no sentido de incluir o reúso não potável como um elemento de gestão integrada de recursos hídricos.

A Tabela 15 apresenta uma compilação de leis e normas brasileiras, bem também como outras publicações frequentemente utilizadas como referência, como a norma ABNT NBR 13.969/1997 e o manual "Conservação e reúso de água em edificações" produzido pelo SindusCon-SP (Sindicato da Construção Civil do Estado de São Paulo) em colaboração da ANA.

\footnotetext{
${ }^{8}$ Esta resolução atualiza a Resolução conjunta SES/SMA/SSRH Nº1 de 2017.
} 
Tabela 15: Compilação de normas, manuais e leis que contemplam reúso

\begin{tabular}{|c|c|c|c|c|c|}
\hline Ano & Nome & Tipo & Abrangência & Usos contemplados & $\begin{array}{l}\text { Apresenta } \\
\text { padrões de } \\
\text { qualidade? }\end{array}$ \\
\hline 1997 & ABNT NBR 13969:1997 & $\begin{array}{l}\text { Norma } \\
\text { técnica }\end{array}$ & Nacional & Urbanos e agrícolas & Sim \\
\hline 2005 & $\begin{array}{l}\text { Resolução } N^{\circ} 54 \text { de } 28 \text { de } \\
\text { novembro de } 2005\end{array}$ & Resolução & Nacional & $\begin{array}{l}\text { Urbanos, agrícolas, } \\
\text { ambientais, } \\
\text { industriais e em } \\
\text { aquicultura }\end{array}$ & Não \\
\hline 2005 & $\begin{array}{l}\text { Conservação e reúso de } \\
\text { água em edificações }\end{array}$ & Manual & Nacional & $\begin{array}{l}\text { Urbanos, agrícolas e } \\
\text { industriais }\end{array}$ & Sim \\
\hline 2014 & $\begin{array}{l}\text { Resolução conjunta } \\
\text { SVDS/SMS Nº 09/2014 }\end{array}$ & $\begin{array}{l}\text { Resolução } \\
\text { municipal }\end{array}$ & $\begin{array}{l}\text { Campinas } \\
(\mathrm{SP})\end{array}$ & Urbanos e industriais & Sim \\
\hline 2015 & $\begin{array}{l}\text { Lei } N^{\circ} 10.840 \text { de } 28 \text { de } \\
\text { agosto de } 2015\end{array}$ & Lei municipal & $\begin{array}{l}\text { Belo Horizonte } \\
\text { (MG) }\end{array}$ & $\begin{array}{l}\text { Urbanos (somente } \\
\text { edificações) }\end{array}$ & Sim \\
\hline 2015 & $\begin{array}{l}\text { Lei № } 16.174 \text { de } 22 \text { de abril } \\
\text { de } 2015\end{array}$ & Lei municipal & $\begin{array}{l}\text { Município de } \\
\text { São Paulo }\end{array}$ & Urbanos & Não \\
\hline 2017 & $\begin{array}{l}\text { Resolução COEMA nº } 02 \\
\text { de 02/02/2017 }\end{array}$ & $\begin{array}{l}\text { Resolução } \\
\text { estadual }\end{array}$ & $\begin{array}{l}\text { Estado do } \\
\text { Ceará }\end{array}$ & $\begin{array}{l}\text { Urbanos, agrícolas, } \\
\text { ambientais, } \\
\text { industriais e em } \\
\text { aquicultura }\end{array}$ & Sim \\
\hline 2019 & ABNT NBR 16.873:2019 (2) & $\begin{array}{l}\text { Norma } \\
\text { técnica }\end{array}$ & Nacional & $\begin{array}{l}\text { Urbanos e irrigação } \\
\text { (somente em } \\
\text { edificações) }\end{array}$ & Sim \\
\hline 2020 & $\begin{array}{l}\text { Resolução conjunta } \\
\text { SES/SIMA N N 01, de } 13 \text { de } \\
\text { fevereiro de } 2020 \text { (3) }\end{array}$ & $\begin{array}{l}\text { Resolução } \\
\text { estadual }\end{array}$ & $\begin{array}{l}\text { Estado de São } \\
\text { Paulo }\end{array}$ & Urbanos & Sim \\
\hline
\end{tabular}

(1) Ainda que não possua caráter normativo ou legal, o manual é amplamente utilizado como referência em projetos de reúso. (2) A norma trata de água não potável em edificações, o que inclui também outras fontes como água de chuva e de sistemas de resfriamento. (3) Essa resolução atualiza a Resolução conjunta SES/SMA/SSRH N01 de 2017.

Fonte: ABNT (1997, 2019), Brasil (2005), SindusCon-SP (2005), Campinas (2014), Belo Horizonte (2015), São Paulo (2015), Ceará (2017), Estado de São Paulo (2020)

A Tabela 16 compila padrões de qualidade presentes em diferentes leis, resoluções, normas e demais publicações relevantes sobre o tema, contemplando diferentes usos de água não potável. 
REVISÃO BIBLIOGRÁFICA E LEVANTAMENTO DE DADOS

Tabela 16: Compilação de padrões de qualidade de água de reúso previstos em referências nacionais

\begin{tabular}{|c|c|c|c|c|c|c|c|c|c|c|c|c|c|c|c|c|c|c|c|c|}
\hline \multirow[t]{2}{*}{ Parâmetro } & \multirow[t]{2}{*}{ Unidade } & \multicolumn{2}{|c|}{$\begin{array}{l}\text { Resolução N'01/20 } \\
\text { SES/SIMA } \\
\text { (São Paulo) }\end{array}$} & \multicolumn{2}{|c|}{$\begin{array}{c}\text { Resolução } \\
\text { No09/14 } \\
\text { SVDS/SMS } \\
\text { (Campinas - } \\
\text { SP) }\end{array}$} & \multicolumn{4}{|c|}{ ANBT NBR 13.969:1997 } & \multicolumn{5}{|c|}{$\begin{array}{l}\text { Conservação e reúso de água em } \\
\text { edificações } \\
\text { SindusCon-SP }(2005)\end{array}$} & \multicolumn{4}{|c|}{$\begin{array}{l}\text { Resolução COEMA Nº2/2017 } \\
\text { (Ceará) }\end{array}$} & \multirow{2}{*}{$\begin{array}{l}\text { Lei No } \\
10.040 / 15 \\
\text { (Belo } \\
\text { Horizonte - } \\
\text { MG) }\end{array}$} & \multirow[t]{2}{*}{$\begin{array}{l}\text { ABNT NBR } \\
\text { 16783: } 2019\end{array}$} \\
\hline & & $\begin{array}{l}\text { Restrição } \\
\text { moderada }\end{array}$ & $\begin{array}{l}\text { Restriçã } \\
\text { o severa }\end{array}$ & $\begin{array}{c}\text { Classe } \\
\text { A }\end{array}$ & $\begin{array}{c}\text { Classe } \\
B\end{array}$ & $\begin{array}{c}\text { Classe } \\
1\end{array}$ & $\begin{array}{c}\text { Classe } \\
2\end{array}$ & $\begin{array}{c}\text { Classe } \\
3\end{array}$ & $\begin{array}{c}\text { Classe } \\
4\end{array}$ & $\begin{array}{c}\text { Classe } \\
1\end{array}$ & Classe 2 & Classe 3 & $\begin{array}{l}\text { Classe } 4 \\
\text { - sem } \\
\text { recirc. }\end{array}$ & $\begin{array}{l}\text { Classe } 4 \\
\text { - com } \\
\text { recirc. }\end{array}$ & Urbanos & $\begin{array}{l}\text { Agrícolas e } \\
\text { florestais }\end{array}$ & $\begin{array}{l}\text { Ambient } \\
\text { ais }\end{array}$ & $\begin{array}{c}\text { Aquicult } \\
\text { ura }\end{array}$ & & \\
\hline $\mathrm{pH}$ & - & $6-9$ & $6-9$ & - & - & $6-8$ & - & - & - & $6-9$ & $6-9$ & $6-9$ & $5-8,3$ & $\begin{array}{l}6,8- \\
7,2\end{array}$ & $6-8,5$ & $6-8,5$ & $6-8,5$ & $6-8,5$ & $6-9$ & $6-9$ \\
\hline $\mathrm{DBO}_{5,20}$ & $\mathrm{mgO}_{2} / \mathrm{l}$ & $\leq 10$ & $\leq 30$ & $\leq 5$ & $\leq 30$ & - & - & - & - & $\leq 10$ & $\leq 30$ & $<20$ & - & - & - & - & - & - & - & $\leq 20$ \\
\hline OD & $\mathrm{mgO}_{2} / \mathrm{l}$ & - & - & - & - & - & - & - & $>2$ & - & - & - & $>0$ & - & - & - & - & - & $\geq 2$ & - \\
\hline Turbidez & UNT & $\begin{array}{l}\leq 0,2^{\text {(a) }} \\
\leq 2,0\end{array}$ & - & $\leq 1,0$ & $\leq 5,0$ & $<5$ & $<5$ & $<10$ & - & $\leq 2$ & - & $<5$ & - & - & - & - & - & - & - & $\leq 5$ \\
\hline SST & $\mathrm{mg} / \mathrm{l}$ & $\leq 0,5^{\text {(a) }}$ & $<30$ & $\leq 5,0$ & $\leq 30$ & - & - & - & - & $\leq 5$ & 30 & $<20$ & $\leq 5.000$ & $\leq 100$ & - & - & - & - & - & - \\
\hline SDT & $\mathrm{mg} / \mathrm{l}$ & $<450$ & $<2.000$ & - & - & $<200$ & - & - & - & $\leq 500$ & - & $<1.500$ & $\leq 1.000$ & $\leq 500$ & - & - & - & - & $\leq 200$ & $<3.200$ \\
\hline $\begin{array}{l}\text { Condutividad } \\
\text { e elétrica }\end{array}$ & $\mu \mathrm{S} / \mathrm{cm}$ & $<700^{\text {(b) }}$ & $<3.000$ & - & - & - & - & - & - & - & - & $<3.000$ & - & - & $\leq 3.000$ & $\leq 3.000$ & $\leq 3.000$ & $\leq 3.000$ & - & $\leq 2.000$ \\
\hline $\begin{array}{l}\text { Coliformes } \\
\text { totais }\end{array}$ & $\begin{array}{l}\text { UFC/100 } \\
\mathrm{ml}\end{array}$ & - & - & - & - & - & - & - & - & - & - & - & - & $\leq 2,2$ & - & - & - & - & ND & - \\
\hline $\begin{array}{l}\text { Coliformes } \\
\text { termotolerant } \\
\text { es }\end{array}$ & $\begin{array}{l}\text { UFC/100 } \\
\mathrm{ml}\end{array}$ & ND & $<200$ & $\leq 100$ & $\leq 200$ & $<200$ & $<500$ & $<500$ & $<5.000$ & ND & $\leq 1.000$ & $\leq 200$ & - & - & $\leq 1.000$ & $\begin{array}{l}\text { ND ou } \leq \\
1.000^{(c)}\end{array}$ & $\leq 10^{4}$ & $\leq 1.000$ & ND & - \\
\hline E. Coli & & ND & $<120$ & $\leq 100$ & $\leq 200$ & - & - & - & - & - & - & - & - & - & - & - & - & - & - & $\leq 200$ \\
\hline $\begin{array}{l}\text { Ovos de } \\
\text { helmintos }\end{array}$ & ovos/l & $<1$ & 1 & - & $<1$ & - & - & - & - & - & - & - & - & - & $\leq 1$ & $\begin{array}{c}\text { ND ou } \leq \\
1\end{array}$ & $\leq 1$ & ND & - & - \\
\hline $\begin{array}{l}\text { Giardia e } \\
\text { Cryptosporidi } \\
\text { um }\end{array}$ & $\begin{array}{l}\text { cistos ou } \\
\text { oocistos/l }\end{array}$ & ND & - & - & $\leq 0,05$ & - & - & - & - & - & - & - & - & - & - & - & - & - & - & - \\
\hline $\begin{array}{l}\text { Cloro } \\
\text { residual total }\end{array}$ & $\mathrm{mg} / \mathrm{l}$ & $\begin{array}{l}\geq 0,5^{\text {(a) }} \\
\geq 1,0\end{array}$ & $\geq 1,0$ & $\leq 1,5$ & $\leq 3,0$ & $\begin{array}{l}0,5 \\
1,5\end{array}$ & $>0,5$ & - & - & - & - & $<1$ & - & - & - & - & - & - & $0,5-2,0$ & - \\
\hline $\begin{array}{l}\text { Cloro } \\
\text { residual livre }\end{array}$ & $\mathrm{mg} / \mathrm{l}$ & - & - & $\leq 1,0$ & $\leq 2,0$ & - & - & - & - & - & - & - & - & - & - & - & - & - & - & $\begin{array}{c}0,5-5,0 \\
(0,5-2,0)^{(d)}\end{array}$ \\
\hline
\end{tabular}

OD: oxigênio dissolvido. SST: sólidos suspensos totais. SDT: sólidos dissolvidos totais. ND: não detectável.

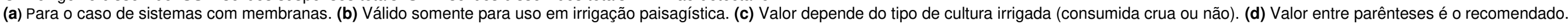

Fonte: ABNT (1997, 2019), Brasil (2005), SindusCon-SP (2005), Campinas (2014), Belo Horizonte (2015), São Paulo (2015), Ceará (2017), Estado de 


\subsection{SISTEMAS DE INFORMAÇÕES GEOGRÁFICAS E MÉTODOS MULTICRITÉRIO DE APOIO À DECISÃO}

O desenvolvimento e aplicação dos modelos propostos neste trabalho fez uso de dois recursos específicos: Sistemas de Informações Geográficas (SIG) e Métodos Multicritério de Apoio à Decisão (MMAD). Este tópico compila brevemente levantamento bibliográfico sobre ambos, buscando trazer adequado subsídio à sua utilização em etapas posteriores.

Ainda que sejam assuntos em si diferentes e independentes, a abordagem casada de MMAD-SIG é comum em literatura, principalmente em aplicações com forte natureza espacial, como é o caso de ações de planejamento territorial, de recursos hídricos e saneamento.

\subsubsection{Sistemas de Informações Geográficas (SIG)}

A utilização de recursos espaciais para a localização, interpretação de dados e tomada de ação remonta ao que provavelmente tenha sido a primeira aplicação científica do que se denomina hoje Sistema de Informações Geográficas (SIG). Em 1854, durante a ocorrência de uma severa epidemia de cólera na Inglaterra, o médico John Snow (1813-1858) formulou a hipótese de que a cólera seria uma doença de veiculação hídrica, e não aérea como se acreditava à época. Como argumentação, Snow utilizou mapas elaborados por ele próprio que evidenciavam que nas proximidades de um dos principais poços de Londres (Broad Street pump) a incidência de mortes por cólera era muito superior à das redondezas (KOCH; DENIKE, 2009). fechamento do poço pela autoridade municipal e a redução da mortalidade por cólera provaram, apesar da resistência de críticos, que sua hipótese estava correta. Por seus feitos, John Snow é considerado o criador da epidemiologia (GOLDSTEIN, 2012), e, ao mesmo tempo, importante colaborador para o estabelecimento do uso de análises espaciais para a resolução de problemas reais.

SIG é um sistema de coleta, armazenamento, manipulação, análise e apresentação de dados geográficos para suporte à tomada de decisão. O que o diferencia de demais 
sistemas de informações é justamente sua capacidade de referenciar geograficamente informações, culminando na possibilidade de produção de mapas. A capacidade de SIG de integrar informações das mais diversas fontes auxilia a coordenação de análises situacionais, uma vez que permite a sobreposição de registros de, por exemplo, de infraestrutura de saneamento básico e rede de saúde pública, fornecendo aos tomadores de decisão possibilidade de observação mais clara do panorama geral que envolve as problemáticas e questões de planejamento (MALCZEWSKI; RINNER, 2015).

Entre as principais vantagens na utilização de SIG, Shamsi (2005) destaca que:

- podem reduzir significantemente o tempo e os custos em comparação a metodologias de análise convencionais;

- permitem a integração de informações das mais diversas naturezas, ilustrando padrões, relações e conexões que não são óbvias a partir de observações não espaciais;

- oferecem, a partir da criação de panoramas gerais e de fácil compreensão, suporte à tomada de decisão por técnicos e não técnicos;

- são altamente versáteis e aplicáveis em diversas áreas, permitindo plataforma de comunicação comum entre diversos stakeholders e públicos.

A literatura aponta diversos trabalhos com uso de SIG nas áreas de recursos hídricos e saneamento. São exemplos: sistemas de planejamento de fornecimento de água de reúso a partir de efluentes de ETEs nos EUA (LEE et al., 2018); identificação de áreas favoráveis ao aproveitamento de água de chuva na Austrália (INAMDAR et al., 2018); previsão de demanda de água e avaliação de uso de fontes alternativas em meios urbanos nos EUA (SHARVELLE et al., 2017); detecção de áreas favoráveis à captação e aproveitamento de água de chuva na Índia (SINGH et al., 2017); estimativa de demandas de água na Austrália (JAYARATHNA et al., 2017); gerenciamento de águas superficiais em áreas de irrigação no Brasil (ALVES et al., 2017); gestão de concessão de outorgas de uso de água por meio de sistema web na Europa (LATRE et al., 2013); detecção e classificação de áreas favoráveis à recarga de aquíferos com efluentes domésticos tratados na Tunísia (GDOURA et al., 2015); modelagem hidráulica de sistemas urbanos de distribuição de água (EDWARDS et al., 2009); e gestão de bacias hidrográficas (GOULTER; FORREST, 1987). 
A Figura 16 exemplifica o uso de SIG em dois estudos nas áreas de saneamento e recursos hídricos.

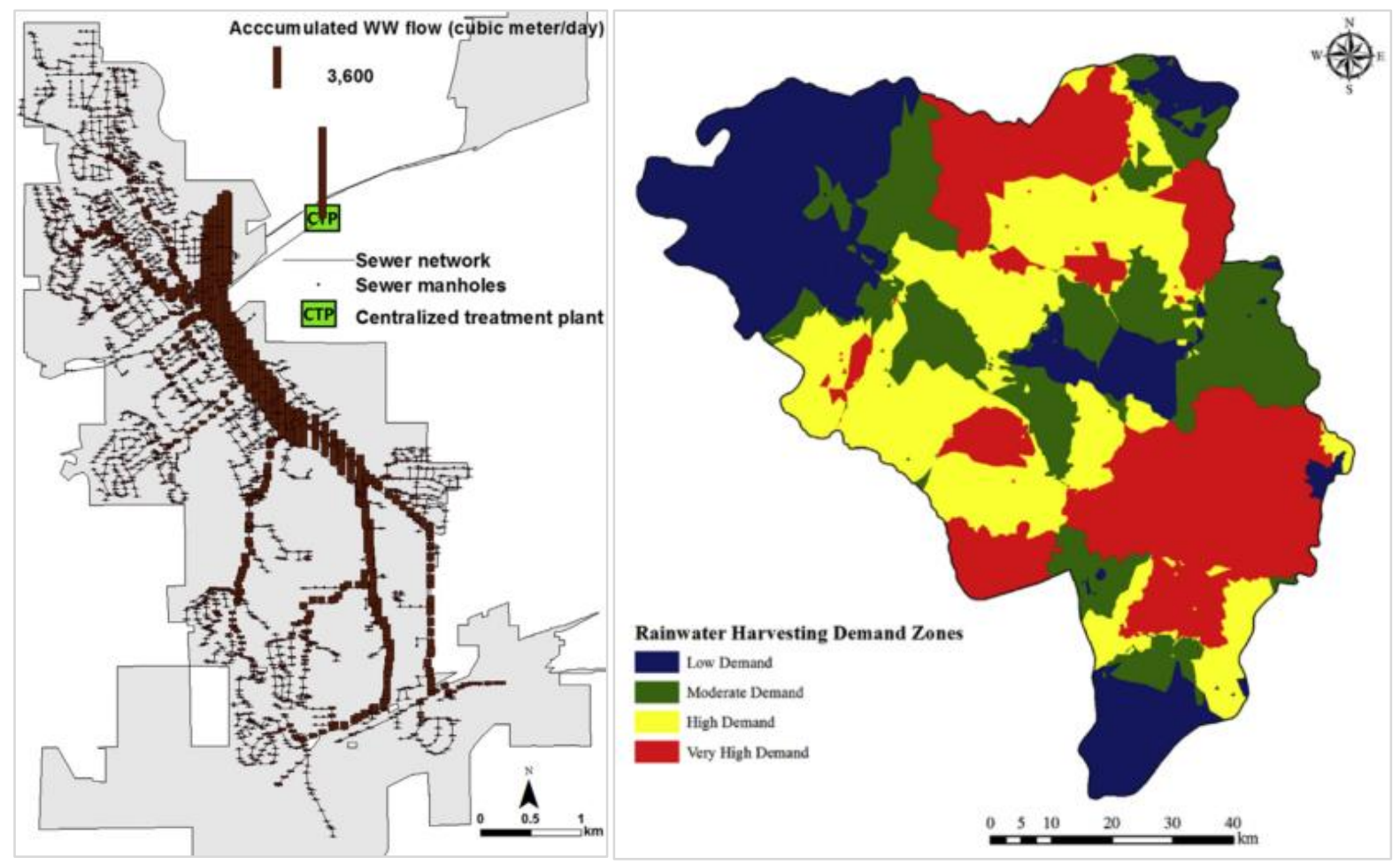

Figura 16: Exemplos de utilização de SIG: modelagem hidráulica e otimização no planejamento de sistemas urbanos de reúso nos $\operatorname{EUA}^{(1)}$ (à esq.) e detecção de áreas favoráveis ao aproveitamento de água de chuva na Índia ${ }^{(2)}$ (à dir.).

Fontes: (1) Lee et al. (2018); (2) Singh et al. (2017)

Uma característica inerente ao SIG moderno é o uso de softwares específicos de geoprocessamento, tais como ArcGIS, SPRING, GRASS e QGIS. Entre os softwares de código aberto (open source) e de licença gratuita, o QGIS é o que mais vem se popularizando no mundo, principalmente em razão de sua fácil interface de uso, relativa baixa exigência de capacidade de processamento computacional, existência de comunidade ativa e de manuais online para suporte ao usuário, grande quantidade de plugins que incrementam as funcionalidades do programa, compatibilidade com os principais sistemas operacionais e compatibilidade com diversas extensões de arquivos de geoprocessamento (GICC, 2017; ORENGO, 2015). Por isso, conforme consta no item 4.4, O QGIS foi utilizado para todas as operações de geoprocessamento deste trabalho, incluindo a geração de mapas interativos online. 


\subsubsection{Métodos Multicritério de Apoio à Decisão (MMAD)}

\subsubsection{Justificativa}

Nos dias atuais, a tomada de decisão vem sendo caracterizada pela necessidade de consideração de número cada vez maior de opções e critérios, estes muitas vezes contraditórios entre si, o que confere alta complexidade à escolha das ações mais adequadas a cada contexto. A necessidade de inclusão de múltiplos aspectos políticos, econômicos, tecnológicos, ambientais e sociais demandam grande esforço para resolução de dilemas e escolha de alternativas. Frente a isso, há necessidade de adoção de tratamento qualificado e utilização de métodos de apoio à decisão em diversas circunstâncias. Nesse contexto, surge a importância da utilização de ferramentas como os Métodos Multicritério de Apoio à Decisão (MMAD) (LIMA et al., 2014).

Os MMAD (em inglês Multi-Criteria Decision Analisys, MCDA, ou Multi-Criteria Decision-Making, MCDM) são métodos sistemáticos de sintetização de conhecimento que permitem a comparação de opções face a critérios, quantitativos ou qualitativos, pré-determinados que abarcam os principais aspectos necessários ao processo de tomada de decisão (ESMAIL; GENELETTI, 2018). Esses métodos são comumente empregados em diversas áreas da engenharia, recursos hídricos, gestão de bacias hidrográficas e recursos hídricos como ferramentas de observação e análise ampla dos múltiplos elementos fundamentais necessários ao tratamento estruturado de dados e à tomada de decisão (JELOKHANI-NIARAKI et al., 2018).

Desde a criação dos MMAD em meados dos anos 1970, muitos novos métodos foram concebidos, além de modificações e extensões dos já existentes. Estima-se que nos dias atuais haja mais de 100 MMAD, o que pode trazer dificuldades a pesquisadores e demais usuários na escolha do método apropriado às suas finalidades (SAATY; ERGU, 2015).

Assim, é inevitável que haja esforços em se comparar os distintos MMAD com vistas à identificação das vantagens, desvantagens e adequação a diferentes contextos (SAATY; ERGU, 2015; VELASQUEZ; HESTER, 2013). Para alguns dos principais 
MMAD apontados na literatura, Campolina et al. (2017) fizeram as considerações apresentadas na Tabela 17.

Tabela 17: Alguns dos principais MMAD e suas vantagens, desvantagens e áreas de áreas de aplicação

\begin{tabular}{|c|c|c|c|}
\hline Método & Vantagens & Desvantagens & $\begin{array}{l}\text { Principais áreas de } \\
\text { aplicação }\end{array}$ \\
\hline $\begin{array}{l}\text { AHP (Analytic } \\
\text { Hierarchy Process) }\end{array}$ & $\begin{array}{l}\text { Facilidade de uso, } \\
\text { estrutura hierárquica } \\
\text { que confere } \\
\text { versatilidade para } \\
\text { diversos contextos }\end{array}$ & $\begin{array}{l}\text { Interdependência entre } \\
\text { critérios e alternativas }\end{array}$ & $\begin{array}{l}\text { Gerenciamento de recursos, } \\
\text { gestão corporativa, gestão } \\
\text { pública, planejamento } \\
\text { estratégico }\end{array}$ \\
\hline ELECTRE & $\begin{array}{l}\text { Considera incerteza e } \\
\text { situações "nebulosas" }\end{array}$ & $\begin{array}{l}\text { Comparação par a par } \\
\text { implica que as } \\
\text { desvantagens das } \\
\text { alternativas não sejam } \\
\text { identificadas diretamente }\end{array}$ & $\begin{array}{l}\text { Economia, meio ambiente, } \\
\text { gerenciamento hídrico e } \\
\text { energético, transportes }\end{array}$ \\
\hline PROMETHEE & $\begin{array}{l}\text { Facilidade de uso, não } \\
\text { requer pressuposto de } \\
\text { proporcionalidade dos } \\
\text { critérios }\end{array}$ & $\begin{array}{l}\text { Não proporciona método } \\
\text { claro de atribuição de pesos }\end{array}$ & $\begin{array}{l}\text { Meio ambiente, gerenciamento } \\
\text { hídrico e energético, negócios } \\
\text { e finanças, logística e } \\
\text { transportes }\end{array}$ \\
\hline TOPSIS & Simplicidade de uso & $\begin{array}{l}\text { Dificuldade na interrelação } \\
\text { de critérios e no processo } \\
\text { de ponderação }\end{array}$ & $\begin{array}{l}\text { Logística, engenharia, } \\
\text { negócios, meio ambiente, } \\
\text { gerenciamento de recursos } \\
\text { hídricos }\end{array}$ \\
\hline
\end{tabular}

Fonte: adaptado de Campolina et al. (2017)

Um problema comum a diversas aplicações ambientais é o de seleção, avaliação e classificação de áreas. No caso de planejamento de reúso, uma exemplificação seria a identificação de áreas mais favoráveis à implantação de programas de reúso, levando-se em conta atributos de diferentes naturezas, como ambientais, técnicos e econômicos. A natureza tanto multicriterial como espacial desse tipo de problema favorece o uso combinado de MMAD e SIG, abordagem bastante comum em literatura. A Tabela 50 apresenta diversos estudos que utilizam MMAD em diferentes áreas do conhecimento, principalmente nos temas de recursos hídricos e meio ambiente.

Tabela 18: Compilação de trabalhos com abordagem MMAD

\begin{tabular}{lll}
\hline Fonte & Tema & $\begin{array}{l}\text { MMAD } \\
\text { utilizado }\end{array}$ \\
\hline Paul et al. (2020) & $\begin{array}{l}\text { Identificação e classificação de áreas agrícolas } \\
\text { para irrigação com água de reúso }\end{array}$ & AHP \\
\hline $\begin{array}{l}\text { Chhipi-Seresta et al. } \\
(2018)\end{array}$ & $\begin{array}{l}\text { Método de seleção de usos de água de reúso em } \\
\text { áreas urbanas }\end{array}$ & $\begin{array}{l}\text { AHP + teoria } \\
\text { dos jogos }\end{array}$ \\
\hline Inamdar et al. (2018) & $\begin{array}{l}\text { Avaliação de áreas favoráveis ao aproveitamento } \\
\text { de água de chuva }\end{array}$ & PROMETHEE II \\
\hline Aydi (2018) & $\begin{array}{l}\text { Avaliação da vulnerabilidade de aquíferos à } \\
\text { poluição }\end{array}$ & AHP \\
\hline $\begin{array}{l}\text { Alami Merrouni et al. } \\
(2018)\end{array}$ & $\begin{array}{l}\text { Identificação de áreas para implantação de plantas } \\
\text { de energia solar de concentração com sistemas de } \\
\text { resfriamento úmido ou seco }\end{array}$ & AHP \\
\hline
\end{tabular}




\begin{tabular}{|c|c|c|}
\hline Fonte & Tema & $\begin{array}{l}\text { MMAD } \\
\text { utilizado }\end{array}$ \\
\hline Dell'Ovo et al. (2018) & $\begin{array}{l}\text { Planejamento no setor de aparelhos públicos de } \\
\text { saúde }\end{array}$ & AHP \\
\hline $\begin{array}{l}\text { Ebrahimian Ghajari et al. } \\
(2018)\end{array}$ & $\begin{array}{l}\text { Avaliação de vulnerabilidade urbana a distintos } \\
\text { cenários de explosões intencionais }\end{array}$ & AHP-fuzzy \\
\hline Teixeira et al. (2018) & Identificação de áreas favoráveis à aquicultura & $\mathrm{AHP}$ \\
\hline Villacreses et al. (2017) & $\begin{array}{l}\text { Identificação de áreas favoráveis à implantação de } \\
\text { plantas de geração eólica }\end{array}$ & $\begin{array}{l}\text { AHP, TOPSIS, } \\
\text { VIKOR e OCRA }\end{array}$ \\
\hline Vasileiou et al. (2017) & $\begin{array}{l}\text { Identificação de áreas off-shore para implantação } \\
\text { de plantas híbridas eólica e de maré }\end{array}$ & AHP \\
\hline Alves et al. (2017) & $\begin{array}{l}\text { Gerenciamento da água superficial no perímetro } \\
\text { irrigado }\end{array}$ & AHP \\
\hline Yalcin \& Kilic Gul (2017) & $\begin{array}{l}\text { Avaliação de locais para exploração de recursos } \\
\text { geotérmicos }\end{array}$ & AHP \\
\hline Watson \& Hudson (2015) & $\begin{array}{l}\text { Identificação de áreas adequadas à produção de } \\
\text { energia solar e eólica }\end{array}$ & AHP \\
\hline Neji \& Turki (2015) & $\begin{array}{l}\text { Delimitação de perímetro agrícola passível de } \\
\text { irrigação com esgoto tratado }\end{array}$ & $\mathrm{CP}$ \\
\hline Gdoura et al. (2015) & $\begin{array}{l}\text { Classificação e avaliação de áreas viáveis para } \\
\text { recarga de aquífero com água de reúso }\end{array}$ & AHP \\
\hline
\end{tabular}

AHP: Analytic Hierarchy Process; CP: Compromised Programming; MMAD: Método Multicritério de Apoio à Decisão; SIG: Sistema de Informações Geográficas.

Fonte: elaborado pelo autor.

Dentre os métodos, a literatura recente aponta que o AHP é um dos MMAD mais empregados, somando-se a isso o fato de possuir fácil interface com ambiente SIG (ALAMI MERROUNI et al., 2018; ALVES et al., 2017; ANANE et al., 2012; GDOURA et al., 2015; HUANG, 2017). Portanto, face às características de possuir simples aplicação (CAMPOLINA et al., 2017; MALINOWSKI, 2006) e de apresentar flexibilidade de aplicação em diversas áreas de conhecimento (CAMPOLINA et al., 2017; HUANG, 2017), o AHP será mais profundamente estudado e, por conseguinte, aplicado no desenvolvimento de parte desta pesquisa.

\subsubsection{O método Analytic Hierarchy Process (AHP)}

O método AHP foi proposto pelo psicólogo e professor norte americano Thomas Saaty em 1980 e fundamenta-se na ideia de que a intuição humana é baseada na identificação de objetos/ideias e no seu relacionamento (MALINOWSKI, 2006). Saaty $(1988,2008)$ parte do princípio de que somos todos, fundamentalmente, tomadores de decisão e que as escolhas com as quais nos deparamos são complexas e requerem decisões lógicas. 
O AHP trabalha com a ideia central da teoria da análise hierárquica, que consiste na redução do sistema analisado a uma sequência de comparação aos pares, processo que seria correspondente à lógica natural do ser humano ao se deparar com problemas de tomada de decisão. Saaty (2008) propõe que o processo decisório seja decomposto nos seguintes passos:

1. Definir o problema e determinar que tipo de conhecimento é buscado.

2. Estruturar a hierarquia de decisão iniciando-se a partir do nível mais alto (objetivo principal) e depois partindo para os níveis intermediários (critérios, subcritérios).

3. Construir o conjunto de comparação paritária entre os subcritérios e critérios.

4. As prioridades derivadas das comparações paritárias irão representar os pesos que cada subcritério e critério terão no modelo.

Em outras palavras, o método prevê que o problema seja decomposto em níveis e que, para cada um deles, os elementos sejam comparados par a par para a definição de suas prioridades dentro do modelo.

\subsection{Critérios e subcritérios}

Os critérios devem, em essência, descrever o problema avaliado de forma completa e, ao mesmo tempo, serem reduzidos ao menor número possível (HUANG, 2017). Para Saaty (1990), a principal tarefa na construção de um MMAD é justamente decidir quais são os fatores importantes para a tomada de decisão. A definição de quais e quantos serão os critérios e subcritérios cabe ao(s) autor(es) do modelo, estando sujeita à sua experiência na área e à inevitável subjetividade pessoal. A Figura 17 ilustra uma estrutura hierárquica genérica de acordo com o AHP. 


\section{Objetivo geral}

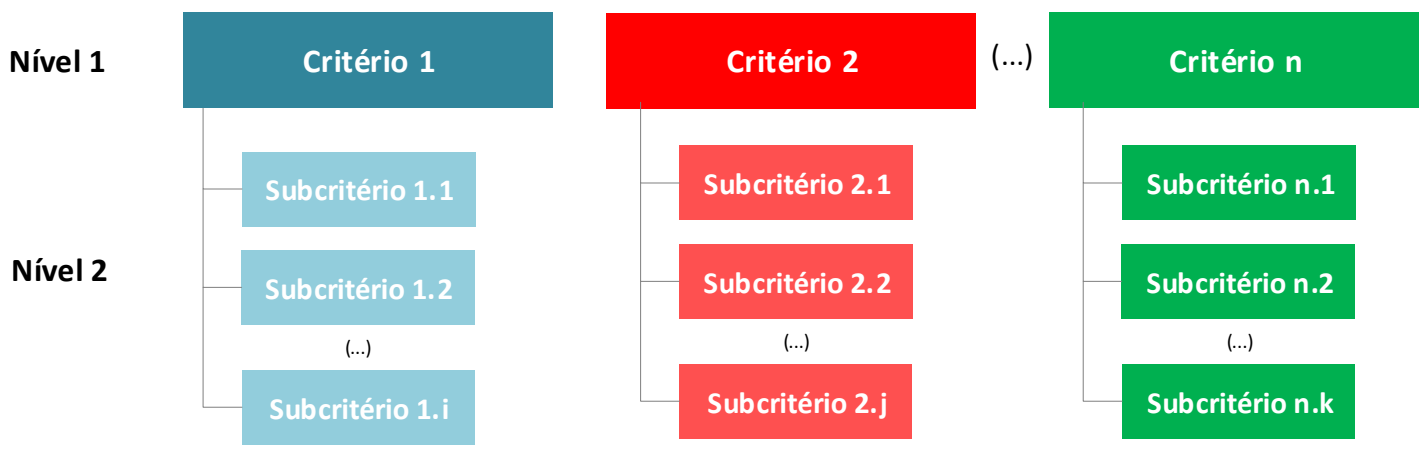

Figura 17: Hierarquização de elementos em um modelo AHP de dois níveis Fonte: adaptado de Lima et al. (2014) e Malinowski (2006). Elaborado pelo autor.

\subsection{Comparação paritária e matriz de importâncias}

A comparação paritária (pairwise comparison) é um dos fundamentos do método AHP. Esse procedimento consiste em comparar par a par os subcritérios (nível 2) e em seguida repetir a ação para os critérios (nível 1). A comparação é realizada por meio de escala numérica que indica quão mais importante um elemento é em relação a outro. Saaty (2008) determina que a escala seja constituída de números inteiros de 1 a 9, sendo os valores ímpares (1, 3, 5, 7 e 9) equivalentes a importâncias relativas "igual", "moderada", "forte", "muito forte" e "absoluta", respectivamente, e os números pares (2, 4, 6 e 8) a intensidades intermediárias, conforme elucida a Tabela 19.

Tabela 19: Intensidade de importância na comparação paritária

\begin{tabular}{|c|c|c|}
\hline Intensidade & Importância & Descrição \\
\hline 1 & Igual & $\begin{array}{l}\text { Ambas as atividades contribuem igualmente } \\
\text { para o objetivo }\end{array}$ \\
\hline 2 & Fraca & - \\
\hline 3 & Moderada & $\begin{array}{l}\text { Experiência e julgamento favorecem } \\
\text { levemente uma atividade em relação à outra }\end{array}$ \\
\hline 4 & Moderada + & - \\
\hline 5 & Forte & $\begin{array}{l}\text { Experiência e o julgamento favorecem } \\
\text { fortemente uma atividade em relação à outra }\end{array}$ \\
\hline 6 & Forte + & - \\
\hline 7 & $\begin{array}{l}\text { Muito forte; } \\
\text { importância } \\
\text { demonstrada }\end{array}$ & $\begin{array}{l}\text { Uma atividade é muito fortemente favorecida } \\
\text { em relação à outra; sua dominância é } \\
\text { demonstrada pela experiência prática }\end{array}$ \\
\hline 8 & Muito forte + & - \\
\hline 9 & Importância absoluta & $\begin{array}{l}\text { A evidência de favorecimento de uma } \\
\text { atividade sobre a outra possui o grau mais } \\
\text { alto de afirmação possível }\end{array}$ \\
\hline
\end{tabular}

Fonte: adaptado de Saaty (2008) 


\subsection{Análise de consistência}

Uma importante etapa de aplicação do método AHP é a análise de consistência. O princípio da análise é: se atribui-se ao critério "A" importância 3 vezes maior referente a "B", e a "B" 2 vezes maior em relação a "C", matematicamente "A" deve ser 6 vezes mais importante em relação a "C". No entanto, como a atribuição de importâncias é subjetiva e a comparação é realizada para cada par individualmente, é esperado que a relação de "A" e "C" não seja necessariamente igual a 6 (MU; PEREYRA-ROJAS, 2017).

O AHP prevê e aceita algum grau de inconsistência. A mensuração de consistência da matriz é realizada pela utilização da variável Razão de Consistência $(R C)$, a qual deve ser inferior a 0,10. O cálculo da RC segue os seguintes passos (MU; PEREYRAROJAS, 2017):

1. Determinação do autovalor máximo da matriz ( $\left.\lambda_{\text {máx }}\right)$.

2. Determinação do Índice de Consistência (IC) a partir do $\lambda_{\text {máx }}$ e da ordem da matriz (n).

3. Cálculo da Razão de Consistência (RC) a partir do Índice de Consistência (IC) e do Índice Randômico (IR), o qual foi calculado por Saaty \& Vargas (2012) para matrizes com diferentes ordens "n".

O IC é determinado em função do autovalor máximo e da ordem da matriz, conforme a Equação 1.

$$
I C=\frac{\lambda_{m a ́ x}-n}{n-1}
$$

Equação 1

$\begin{array}{ll}\text { IC } & \text { Índice de Consistência } \\ \lambda_{\text {máx }} & \text { autovalor máximo da matriz } \\ \mathrm{n} & \text { ordem da matriz }\end{array}$

A Razão de Consistência $(R C)$ é dependente do Índice de Consistência (IC) e do Índice Randômico (IR). O IR representa o máximo IC possível para uma matriz, o que foi determinado como o valor médio de IC para simulações de 500 matrizes de ordens " $\mathrm{n}$ " diferentes com valores randômicos (MU; PEREYRA-ROJAS, 2017; SAATY; 
VARGAS, 2012). Os valores de IR são dependentes da ordem da matriz e são apresentados na Tabela 20 para $\mathrm{n} \leq 10$.

Tabela 20: Índice Randômico (IR) para matrizes de ordem $\mathrm{n} \leq 10$

\begin{tabular}{ccccccccccc}
$\mathbf{n}$ & $\mathbf{1}$ & $\mathbf{2}$ & $\mathbf{3}$ & $\mathbf{4}$ & $\mathbf{5}$ & $\mathbf{6}$ & $\mathbf{7}$ & $\mathbf{8}$ & $\mathbf{9}$ & $\mathbf{1 0}$ \\
\hline $\mathrm{IR}$ & 0 & 0 & 0,52 & 0,89 & 1,11 & 1,25 & 1,35 & 1,40 & 1,45 & 1,49 \\
\hline
\end{tabular}

Fonte: Saaty \& Vargas (2012)

Por fim, a RC é calculada por:

$$
R C=\frac{I C}{I R} \leq 0,10
$$

Equação 2

RC Razão de Consistência

IC Índice de Consistência

IR Índice Randômico

Portanto, o AHP tolera que a o valor de inconsistência de uma matriz seja inferior ou igual a $10 \%$ da inconsistência de uma matriz aleatória de mesma ordem, o que é representado pela restrição $R C \leq 0,10$. Caso a $R C$ supere esse valor, recomenda-se que a atribuição de pesos na comparação paritária seja revisada, conferindo-Ihe consistência aceitável (MALINOWSKI, 2006).

\subsection{Derivação de prioridades}

Após a atribuição paritária de importância, o AHP prevê a derivação das prioridades. A derivação consiste no processo de, a partir das importâncias paritárias entre os elementos, definir a importância global de cada um. Ou seja, a comparação paritária estabelece a importância relativa de um elemento em relação ao outro, mas não seu peso total no modelo, o que é calculado pela derivação de prioridades.

Há mais de uma maneira de se realizar esse processo, o que, inclusive, é em si um tema de discussão dentro do desenvolvimento e aplicação do método (ISHIZAKA; LUSTI, 2006). Ishizaka \& Lusti (2006) compararam quatro métodos distintos de derivação de prioridade e concluíram que não há, necessariamente, o "melhor", já que cada um apresenta vantagens frente a diferentes aspectos. Os autores discorrem sobre o método mais antigo, simples e mais amplamente utilizado, o Método da Média 
dos Valores Normalizados, e afirmam que os resultados obtidos por ele são adequados e apresentam poucas contradições.

O vetor que representa as prioridades dos critérios e subcritérios é denominado " $w$ " (weight) e é um vetor coluna n-dimensional, sendo " $\mathrm{n}$ " a ordem da matriz de importâncias paritárias de cada nível. Para uma matriz $X=\left(a_{i, j}\right)_{n}$ em que "i" e "j" são, respectivamente, as linhas e colunas de prioridades paritárias e " $\mathrm{n}$ " a ordem da matriz, o Método das Médias dos Valores Normalizados prevê a obtenção do vetor "w" por meio dos seguintes procedimentos (MU; PEREYRA-ROJAS, 2017; SAATY, 2008):

1. somar os valores de cada coluna "j" da matriz " $X$ ";

2. normalizar cada valor "ai,j" em relação ao total (passo 1) de sua coluna "j";

3. o vetor "w" é composto pela média dos valores normalizados (passo 2) de cada linha "i".

\subsubsection{Operações auxiliares}

Há algumas operações necessárias para a adequada aplicação do AHP que não são exclusividades do método, e que por isso serão tratadas em tópico à parte a seguir. São o caso da normalização de parâmetros, análise de sensibilidade e classificação de dados.

\subsection{Métodos de normalização de parâmetros}

Uma vez que cada os parâmetros (subcritérios) a serem introduzidos no modelo possuem unidades e amplitudes distintas, é necessária uma etapa de normalização dos dados para criação de escala comum (SAATY, 2000). Em essência, a normalização consiste na conversão dos valores a escalas que variam, geralmente, de 0 a 1 (ou 0 a 10 em alguns casos), sendo que 0 representa a condição menos desejável em relação ao objetivo do modelo, e, analogamente, 1 equivale à condição mais desejável (GDOURA et al., 2015; WATSON; HUDSON, 2015).

Há variadas regras de normalização de parâmetros, e a literatura aponta que método de Transformação Linear é o mais utilizado (YALCIN; KILIC GUL, 2017). Dependendo da natureza dos parâmetros que compõem o modelo, há duas principais 
possibilidades de transformação linear, as quais podem ser expressas pelas seguintes relações: (i) quanto maior o valor do parâmetro mais favorável é a condição (convergência ao máximo); (ii) quanto menor o valor do parâmetro mais favorável é a condição (convergência ao mínimo) (TORRIERI, 2017). Matematicamente, essas relações são escritas conforme a Equação 3 e a Equação 4 (WATSON; HUDSON, 2015; YALCIN; KILIC GUL, 2017):

(i) Convergência ao máximo

$$
\begin{aligned}
& \boldsymbol{x}_{\text {norm }}=\frac{\boldsymbol{x}-\boldsymbol{x}_{\text {mín }}}{\boldsymbol{x}_{\text {máx }}-\boldsymbol{x}_{\text {mín }}} \\
& x_{\text {norm }}=1-\frac{x-x_{\min }}{x_{\text {máx }}-x_{\text {mín }}}
\end{aligned}
$$

(ii) Convergência ao mínimo

$\begin{array}{ll}X_{\text {norm }} & \text { valor normalizado } \\ X & \text { valor a ser normalizado } \\ X_{\text {máx }} & \text { valor máximo da série } \\ X_{\text {mín }} & \text { valor mínimo da série }\end{array}$

\subsection{Análise de sensibilidade}

Assim como outros MMAD, o AHP também prevê a etapa de análise de sensibilidade, a qual promove a verificação da variação dos resultados do modelo em decorrência de modificações das prioridades atribuídas (SAATY; SAGIR, 2015) e permite a determinação da robustez do modelo frente às incertezas das etapas precedentes de sua construção (ESMAIL; GENELETTI, 2018).

A determinação de cenários para análise de sensibilidade varia significativamente de acordo com os objetivos do modelo. Uma abordagem utilizada por Saaty \& Sagir (2015), Luthra et al. (2015) e Sindhu et al. (2017) é a variação gradual do critério com maior prioridade. Esse processo permite a observação das variações no resultados oriundas de pequenas modificações graduais, auxiliando ao tomador de decisão compreender a sensibilidade do modelo às variações de prioridades dos critérios e subcritérios (LUTHRA et al., 2015). Nesse caso, as prioridades do critério escolhido variam de 0,1 a 0,9 em intervalos de 0,1 , enquanto os demais mantêm a proporcionalidade em relação ao valor complementar (a soma de todas as prioridades deve ser sempre igual a 1,0$)$. 


\subsection{Métodos de classificação de dados}

Posto que os MMAD objetivam subsidiar a tomada de decisão, os resultados encontrados podem ter sua interpretação facilitada por meio da categorização dos valores em grupos qualitativos, como "muito bom", "bom", "regular", "ruim" ou "muito ruim", por exemplo. Isso possui especial importância na criação de linguagem mais acessível, principalmente a públicos não técnicos.

A categorização de séries numéricas pode ser realizada de diversas maneiras, as quais dependem tanto da natureza dos valores como do objetivo da exposição, e conduzem a classificações, e consequentemente interpretações, distintas (CAO et al., 2014). Os principais métodos constantes em literatura são: intervalos iguais, quebras naturais de Jenks, desvio padrão e quantil (CAO et al., 2014; OSARAGI, 2002; WEI et al., 2017), conforme é mostrado na Tabela 21.

Tabela 21: Principais métodos de classificação de dados

\begin{tabular}{|c|c|c|c|}
\hline Método & Principal característica & Vantagem & Desvantagem \\
\hline $\begin{array}{l}\text { Intervalos } \\
\text { iguais }\end{array}$ & $\begin{array}{l}\text { Divide a série em intervalos de } \\
\text { distâncias idênticas a partir } \\
\text { dos valores mínimo e máximo }\end{array}$ & $\begin{array}{l}\text { Fácil aplicação e } \\
\text { compreensão }\end{array}$ & $\begin{array}{l}\text { Agrupamentos pouco } \\
\text { representativos caso a } \\
\text { série seja heterogênea }\end{array}$ \\
\hline $\begin{array}{l}\text { Quebras } \\
\text { naturais de } \\
\text { Jenks }\end{array}$ & $\begin{array}{l}\text { Reduz desvio padrão dentro } \\
\text { da mesma classe a partir de } \\
\text { identificação de pontos de } \\
\text { quebra relativamente grandes } \\
\text { na série }\end{array}$ & $\begin{array}{l}\text { Cria grupos com } \\
\text { maior } \\
\text { homogeneidade } \\
\text { interna (menor } \\
\text { desvio padrão) }\end{array}$ & $\begin{array}{l}\text { É muito dependente da } \\
\text { série de dados e pode } \\
\text { resultar em pouca } \\
\text { comparabilidade entre } \\
\text { séries distintas }\end{array}$ \\
\hline $\begin{array}{l}\text { Desvio } \\
\text { padrão }\end{array}$ & $\begin{array}{l}\text { Classifica a série em relação } \\
\text { ao valor de desvio de cada } \\
\text { elemento em relação à média } \\
\text { aritmética da série }\end{array}$ & $\begin{array}{l}\text { Permite identificação } \\
\text { de elementos de } \\
\text { acordo com sua } \\
\text { proximidade/distânci } \\
\text { a em relação à } \\
\text { média }\end{array}$ & $\begin{array}{l}\text { Oculta os valores absolutos } \\
\text { dos dados, e a existência } \\
\text { de valores extremos } \\
\text { (outliers) pode influenciar } \\
\text { muito os resultados }\end{array}$ \\
\hline Quantil & $\begin{array}{l}\text { Divide a série em números } \\
\text { iguais de elementos }\end{array}$ & $\begin{array}{l}\text { Permite avaliações } \\
\text { simples de grupos de } \\
\text { elementos ( } 10 \% \\
\text { mais ricos de um } \\
\text { país, por exemplo) }\end{array}$ & $\begin{array}{l}\text { Pode levar ao agrupamento } \\
\text { de elementos em classes } \\
\text { internamente muito } \\
\text { distintas ou separar valores } \\
\text { numericamente muito } \\
\text { próximos em classes } \\
\text { diferentes }\end{array}$ \\
\hline
\end{tabular}

Fonte: adaptado de Osaragi (2002), Cao et al. (2014), Wei et al. (2017) e Teixeira et al. (2018)

Não se pode afirmar que um método é, em absoluto, superior aos demais. Conforme consta acima, deve-se ter atenção tanto à natureza da série de dados avaliada como ao objetivo buscado na classificação, de modo que os agrupamentos não amplifiquem 
a inevitável perda de informação inerente ao processo de categorização de dados (OSARAGI, 2002).

Como exemplos, Teixeira et al. (2018) utilizaram, para classificação de potencial de utilização de áreas para atividades de aquicultura em Portugal cinco classes definidas a priori (altamente recomendado, muito recomendado, recomendado, pouco recomendado e muito pouco recomendado) divididas pelo Método de Intervalos Iguais. Por sua vez, Yalcin \& Kilic Gul (2017) classificam o potencial geotérmico de áreas na bacia de Akarcay (Turquia) em seis classes (muito baixo, baixo, médio, alto, muito alto e extremamente alto) por quebras naturais de Jenks. 


\section{METODOLOGIA}

\subsection{CARACTERÍSTICAS GERAIS}

A proposta deste trabalho contempla o desenvolvimento de dois modelos distintos de para suporte à decisão em planejamento de reúso de água. Ambos foram desenvolvidos e aplicados a uma área de estudo escolhida, a Região Metropolitana de São Paulo (RMSP).

O primeiro deles foi denominado Índice de Potencial de Reúso (IPR), uma variável quantitativa que avalia e classifica áreas em relação a seu potencial de reúso. O IPR é focado na avaliação de reúso de áreas geográficas mais abrangentes, como municípios, Unidades da Federação ou bacias hidrográficas.

A segundo foi denominado Modelo ETE-usuário, e tem como foco a análise de viabilidade técnico-econômica a partir de possíveis fontes de água de reúso e potenciais usuários de água não potável. Nessa abordagem, as análises são realizadas no nível dos usuários, alocando-os individualmente em referência a possíveis ofertas de água de reúso e determinando os usuários prioritários (usuáriosâncora) a partir de critério de viabilidade técnico-econômica.

O desenvolvimento e forma de apresentação dos modelos foram orientados pela possibilidade de automatização de seus processos para incorporação em futuros sistemas/plataformas digitais, ensejando a elaboração de ferramentas dinâmicas de suporte à decisão. Os recursos online desenvolvidos (item 4.4) tiveram como objetivo, além da geração de conteúdo adicional para a compreensão dos resultados deste trabalho, demonstrar a potencialidade de sistemas automatizados com base em SIG. 


\subsection{DESENVOLVIMENTO DO ÍNDICE DE POTENCIAL DE REÚSO (IPR)}

\subsubsection{Definição e justificativa}

O Índice de Potencial de Reúso (IPR) é um índice que expressa a atratividade do reúso de determinada área em relação às demais analisadas.

O uso de índices e indicadores é muito recorrente na área ambiental. Uma de suas vantagens é a sintetização de múltiplos atributos em uma variável única, facilitando a compreensão por parte de públicos não técnicos e tomadores de decisão. Em recursos hídricos e saneamento, são exemplos, entre muitos outros, o Índice de Falkenmark (IF) de escassez hídrica; indicadores de cobertura de tratamento de esgotos, como o IN046 do SNIS; o Índice de Qualidade das Águas (IQA) da Cetesb; e o WTA (withdrawal-to-availability ratio), o qual é previsto como métrica do ODS6 (Objetivo de Desenvolvimento Sustentável 6) das Nações Unidas.

A definição conceitual sobre o que é um índice é uma tema ainda debatido na academia (GOMES, 2011). No entanto, em termos gerais autores consideram um índice um valor agregado resultante de procedimentos de cálculos estruturados que traduz o estado geral de um sistema ou fenômeno (GOMES, 2011; SICHE et al., 2007), o que se adequa à proposta do IPR.

O IPR é um índice multicritério adimensional normalizado que expressa a atratividade do reúso que permite a classificação de áreas em relação a seu potencial de reúso. Quanto às suas características, o IPR:

- é um índice porque agrega diversas variáveis individuais a partir de procedimentos estruturados de cálculo que resultam na obtenção de uma variável objetiva e sintética;

- é multicritério porque inclui variáveis de diferentes temas (técnicos, ambientais e socioeconômicos) e tipos (quantitativas e qualitativas) em seu cálculo; 
- é normalizado porque os valores que descrevem os parâmetros são submetidos a algum processo de normalização antes de sua inserção no modelo;

- é adimensional porque, em razão da normalização dos parâmetros de entrada, todos os valores são convertidos a uma escala pré-definida adimensional.

O modelo buscou equilibrar características presentes e futuras no que se refere à atratividade de reúso, objetivando apontar as áreas em que a condução de estudos mais aprofundados tem maiores chances de resultar em programas exitosos de reúso.

Ainda que o IPR possa ser aplicado a qualquer recorte geográfico, seu desenvolvimento foi realizado tendo como foco o município como unidade territorial de análise, o que se justifica por dois principais fatores:

i. em geral as informações existentes, como vazão de geração de esgotos e demandas de água , são disponibilizadas somente agregadas por município;

ii. os municípios são unidades administrativas coesas, o que permite que os elementos de planejamento interajam eficazmente junto aos tomadores de decisão.

A exemplos de trabalhos como os de Singh et al. (2017), Teixeira et al. (2018) e Paul et al. (2020), o IPR utiliza um Método Multicritério de Apoio à Decisão (MMAD) como base. Conforme levantado no item 3.3.2, o uso de métodos multicritério de apoio à decisão (MMAD) permite a consideração de múltiplos parâmetros quantitativos e/ou qualitativos no apoio à tomada de decisão.

Entre eles, o Analytic Hierarchy Process (AHP) se destaca como um método de fácil compreensão pelos tomadores de decisão, de aplicação relativamente simples (CAMPOLINA et al., 2017; MALINOWSKI, 2006), que vem sendo vastamente utilizado em diversas áreas do conhecimento (CAMPOLINA et al., 2017; HUANG, 2017). Por isso, o AHP foi adotado como o MMAD para estruturação do IPR.

\subsubsection{Concepção e estruturação}

O IPR é uma aplicação do AHP adaptada às peculiaridades desta pesquisa. Seu desenvolvimento foi realizado tendo como base a revisão bibliográfica sobre o AHP 
(item 3.3.2.2) e estudos que utilizam MMAD em aplicações semelhantes (vide item 3.3.2).

Em linhas gerais, o desenvolvimento do IPR pode ser dividido em três fases:

\section{Definição do problema e escolha do método a ser utilizado para sua estruturação.}

2. Desenvolvimento dos procedimentos de AHP: detalhamento de operações previstas no modelo AHP, como definição de estrutura hierárquica, escolha do critérios e subcritérios, comparação paritária e derivação de prioridades.

3. Determinação dos métodos das operações auxiliares: definição de métodos de normalização de dados, de análise de sensibilidade e de classificação de resultados.

A Tabela 22 apresenta as fases de desenvolvimento do IPR subdivididas em atividades específicas, bem como as referências utilizadas em cada uma delas.

Tabela 22: Desenvolvimento do modelo de IPR e referências utilizadas

\begin{tabular}{|c|c|c|c|}
\hline & Item & Descrição & Referências utilizadas \\
\hline \multirow{3}{*}{ 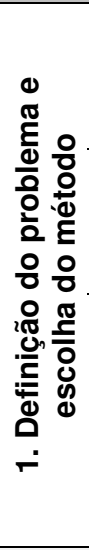 } & Definição do problema & $\begin{array}{l}\text { Desenvolvimento de um índice } \\
\text { sobre potencial de reúso }\end{array}$ & $\begin{array}{l}\text { Índices e indicadores já existentes e } \\
\text { amplamente empregados, como Îndice de } \\
\text { Falkenmark, IQA (Índice de Qualidade das } \\
\text { Águas) e WTA (withdrawal-to-availability ratio) }\end{array}$ \\
\hline & $\begin{array}{l}\text { Adoção de MMAD para } \\
\text { estruturação do IPR }\end{array}$ & $\begin{array}{l}\text { Baseada na utilização frequente } \\
\text { de MMAD para estruturação de } \\
\text { problemas complexos e } \\
\text { multitemáticos }\end{array}$ & $\begin{array}{l}\text { Lima et al. (2014); Campolina et al. (2017); } \\
\text { Jelokhani-Niaraki (2018) }\end{array}$ \\
\hline & $\begin{array}{l}\text { Adoção do AHP como } \\
\text { MMAD }\end{array}$ & $\begin{array}{l}\text { Baseada na ampla utilização do } \\
\text { método em literatura, } \\
\text { versatilidade, simplicidade de } \\
\text { aplicação e de compreensão por } \\
\text { parte dos usuários e alta } \\
\text { interoperabilidade com SIG }\end{array}$ & $\begin{array}{l}\text { Estudos que apontam a eficiência do AHP } \\
\text { como MMAD: Campolina et al. (2017); Huang } \\
\text { (2017). Estudos que utilizam o AHP em } \\
\text { modelos e avaliações: Vasileiou et al. (2017); } \\
\text { Alves et al. (2017); Yalcin \& Kilic Gul (2017); } \\
\text { Singh et al. (2017); Dell'Ovo et al. (2018); } \\
\text { Inamdar et al. (2018); Paul et al. (2020) }\end{array}$ \\
\hline \multirow{3}{*}{ 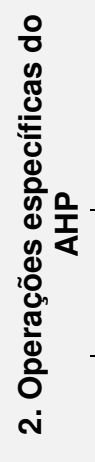 } & $\begin{array}{l}\text { Seleção de critérios e } \\
\text { subcritérios }\end{array}$ & $\begin{array}{l}\text { Critérios e subcritérios foram } \\
\text { determinados por este autor com } \\
\text { base no julgamento de variáveis } \\
\text { relevantes e passíveis de } \\
\text { obtenção no Brasil. }\end{array}$ & $\begin{array}{l}\text { Estudos com estruturas hierárquicas } \\
\text { semelhantes: Gdoura et al. (2015); Teixeira et } \\
\text { al. (2018); Paul et al. (2020) }\end{array}$ \\
\hline & $\begin{array}{l}\text { Comparação paritária e } \\
\text { análise de consistência }\end{array}$ & $\begin{array}{l}\text { Atribuição de importâncias e } \\
\text { análise de consistência da matriz. } \\
\text { Procedimento conforme previsto } \\
\text { pelo AHP }\end{array}$ & $\begin{array}{l}\text { Malinowski (2006); Saaty \& Vargas (2012); Mu } \\
\text { \& Pereyra-Rojas (2017) }\end{array}$ \\
\hline & $\begin{array}{l}\text { Derivação de prioridades e } \\
\text { obtenção da matriz de } \\
\text { prioridades }\end{array}$ & $\begin{array}{l}\text { Adoção do método da média dos } \\
\text { valores normalizados }\end{array}$ & Ishizaka \& Lusti (2006) \\
\hline m & Análise de sensibilidade & $\begin{array}{l}\text { Avaliação do comportamento do } \\
\text { modelo em razão de variações } \\
\text { das prioridades. Variação do }\end{array}$ & $\begin{array}{l}\text { Saaty \& Sagir (2015), Luthra et al. (2015) e } \\
\text { Sindhu et al. (2017) }\end{array}$ \\
\hline
\end{tabular}




\begin{tabular}{lll}
\hline Item & Descrição & Referências utilizadas \\
\hline $\begin{array}{l}\text { Normalização de } \\
\text { parâmetros }\end{array}$ & $\begin{array}{l}\text { Adoção do método de } \\
\text { Transformação Linear (TL) }\end{array}$ & $\begin{array}{l}\text { Gdoura et al. (2015), Villacreses et al. (2017), } \\
\text { Watson \& Hudson (2015) e Yalcin \& Kilic Gul } \\
\text { (2017). }\end{array}$ \\
\hline Classificação de resultados & $\begin{array}{l}\text { Adoção do método de quebras } \\
\text { naturais de Jenks }\end{array}$ & $\begin{array}{l}\text { Osaragi (2002), Cao et al. (2014), Wei et al. } \\
\text { (2017) }\end{array}$ \\
\hline
\end{tabular}

A Figura 18 mostra um fluxograma com procedimentos de desenvolvimento do IPR.

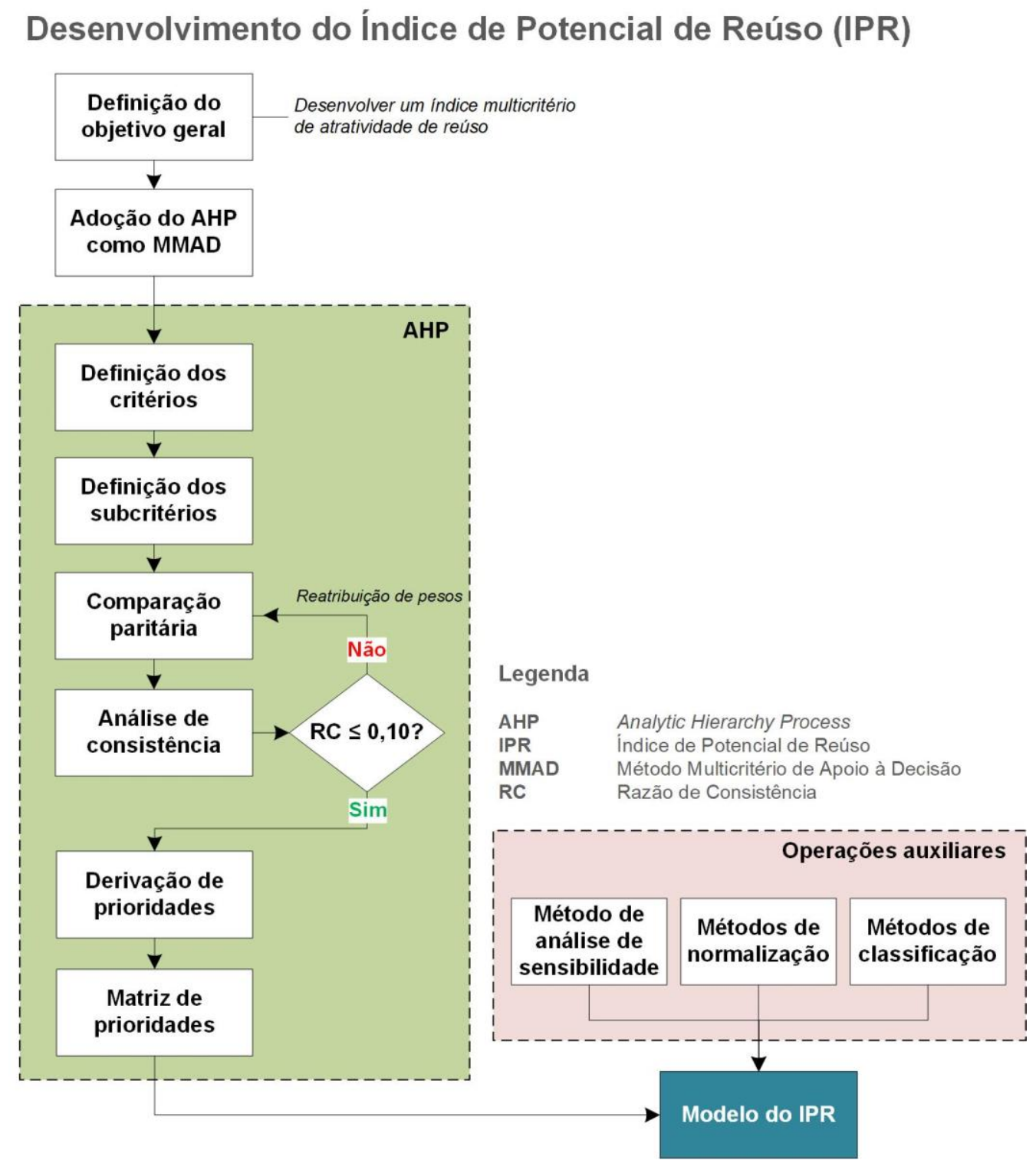

Figura 18: Diagrama de desenvolvimento do modelo do Índice de Potencial de Reúso (IPR) Fonte: elaborado pelo autor

Os tópicos a seguir descrevem com mais detalhes os itens referentes ao AHP e às operações auxiliares da Tabela 22 e Figura 18.

Definição dos critérios e subcritérios 
Foram selecionados critérios e subcritérios que, conforme o entendimento desta pesquisa, contemplam as variáveis importantes na modelagem do IPR. Uma das premissas adotadas foi a consideração não somente de aspectos usualmente utilizados em estudos sobre reúso (como vazões de esgoto e demandas de água), mas também características de escassez hídrica, capacidade de diluição dos corpos hídricos, projeções de crescimento populacional e valor adicionado (VA) pelas atividades de indústria e agropecuária.

Os subcritérios foram definidos levando-se em consideração três principais atributos:

- referem-se a aspectos objetivos que influenciam positiva ou negativamente o potencial de reúso;

- são variáveis de uso frequente em saneamento e gestão de recursos hídricos, sendo padrões aplicados no Brasil e em outros países;

- são regularmente atualizados e podem ser obtidos diretamente por consultas pela internet ou via contato direto com os órgãos responsáveis pela sua produção.

Autores que utilizam o AHP em aplicações ambientais usualmente adotam critérios ambientais, econômicos e técnicos na estrutura hierárquica, como pode ser visto nos trabalhos de Gdoura et al. (2015) e Paul et al. (2020). Esse tipo de divisão temática permite entendimento claro e simples dos diferentes fatores considerados, facilitando, por conseguinte, a estruturação do modelo e compreensão dos usuários.

Dessa forma, definiram-se três critérios (nível 1), técnico, ambiental e socioeconômico, cada um deles possuindo de dois a quatro subcritérios (nível 2). Os critérios e subcritérios, bem como os demais resultados do desenvolvimento do IPR, são apresentados no item 5.1 , visto que já se tratam de um resultado da elaboração do modelo.

\section{Comparação paritária e análise de consistência}

Definidos os critérios e subcritérios que compõem o modelo, procedeu-se à atribuição paritária de importâncias. Paralelamente à definição das importâncias, realizaram-se 
as devidas análises de consistência das matrizes de cada nível hierárquico. Os autovalores máximos de cada matriz $\left(\lambda_{\text {máx}}\right)$ foram calculados pelo software matemático Scilab. A partir dos autovalores e da ordem da matriz, calculou-se o Índice de Consistência (IC) pela Equação 1. Por fim, a Razão de Consistência (RC) foi calculada a partir dos Índices Randômicos (IC) propostos por Saaty \& Vargas (2012) (Tabela 20) e pela Equação 2 (item 3.3.2.2.2), e em seguida confrontada com o valor máximo de $R C$ permitido pelo método AHP $(R C \leq 0,10)$ para cada um dos níveis da estrutura hierárquica (nível 1 - critérios; nível 2 - subcritérios).

\section{Derivação de prioridades, obtenção de matriz de prioridades e cálculo de IPR}

A partir das comparações paritárias, o AHP prevê a derivação das prioridades de cada um dos subcritérios para obtenção da matriz final de prioridades. O procedimento foi realizado pelo Método das Médias dos Valores Normalizados. Conforme apresentado no item 3.3.2.2.3, Ishizaka \& Lusti (2006) atestam a eficácia do método, o que também é corroborado pela sua utilização pelo próprio criador do AHP (SAATY, 2008) e por demais pesquisadores da área de MMAD (MU; PEREYRA-ROJAS, 2017).

A partir das prioridades finais, o IPR é numericamente igual ao somatório dos produtos entre os valores normalizados de cada subcritério e sua respectiva prioridade global. Matematicamente, isso se expressa conforme a Equação 5.

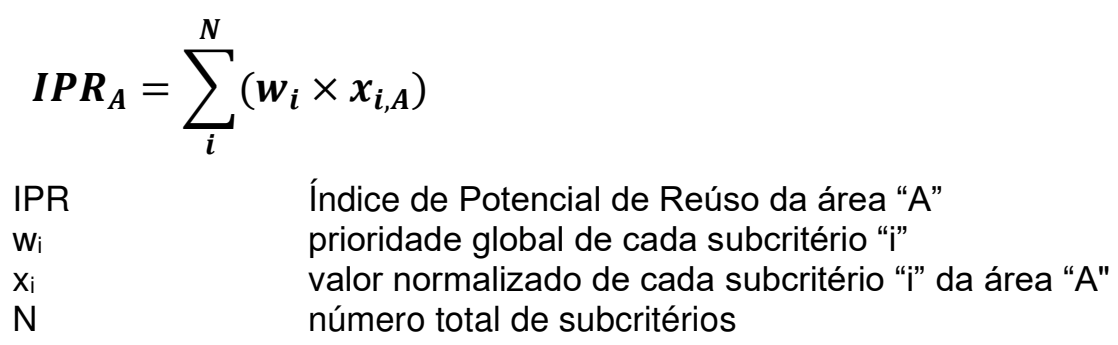

Equação 5

\section{Normalização de parâmetros}

Para inserção na Equação 5 é necessário que os valores dos subcritérios sejam normalizados. O método de normalização adotado foi o de Transformação Linear (TL), conforme a Equação 3 e Equação 4 (item 3.3.2.3).

Entre os autores que optaram pela utilização de transformação linear como método de normalização, destacam-se os trabalhos de Gdoura et al. (2015), Villacreses et al. (2017), Watson \& Hudson (2015) e Yalcin \& Kilic Gul (2017). 


\section{Análise de sensibilidade}

A análise de sensibilidade foi realizada pela variação gradual da prioridade do critério prevalente. Adotou-se procedimento conforme Saaty \& Sagir (2015), Luthra et al. (2015) e Sindhu et al. (2017), com alteração gradual da prioridade do critério com maior prioridade, cariando de 0,1 a 0,9 com passos fixos de 0,1 . Convencionou-se que o resultado original da derivação de prioridades denomina-se "normal".

\section{Método de classificação dos resultados}

Para classificação de resultados de IPR foram considerados os quatro métodos levantados no item 3.3.2.3.3: intervalos iguais, Quebras Naturais de Jenks, desvio padrão e quantil. Dado que um dos objetivos da classificação é facilitar a compreensão e agregar as áreas analisadas em grupos internamente homogêneos no que se refere a seu potencial de reúso, optou-se pelo método de Quebras Naturais de Jenks. O método agrupa os resultados em categorias que reduzem a variância intraclasse (e por conseguinte maximizam a variância interclasse), resultando em classes com maior homogeneidade interna (CAO et al., 2014; OSARAGI, 2002; WEl et al., 2017).

\subsection{DESENVOLVIMENTO DO MODELO ETE-USUÁRIO}

\subsubsection{Definição e justificativa}

O modelo ETE-usuário é uma sistematização de procedimentos que tem como objetivo identificar usuários prioritários de água de reúso por meio de critério de viabilidade econômica e, assim, estimar as vazões potenciais de reúso de determinada área.

Seu foco na viabilidade econômica se deve à centralidade desse aspecto no planejamento de reúso (SGROI et al., 2018; VOULVOULIS, 2018), sendo sua análise uma das etapas fundamentais previstas nas principais diretrizes sobre o assunto (THE EUROPEAN COMMISSION, 2016; U.S. EPA, 2012).

O modelo considera individualmente potenciais usuários e possíveis fontes de água de reúso. Foram denominados "usuários-âncora" aqueles com características que 
permitam a produção e distribuição de água de reúso com tarifas viáveis, levando-se em consideração os custos locais de água potável. As análises são realizadas no nível de detalhe do que se denominou "binômio ETE-usuário", ou seja, os potenciais usuários são avaliados individualmente em relação a cada uma das possíveis ofertas de água de reúso.

\subsubsection{Concepção e estruturação}

O desenvolvimento do modelo ETE-usuário se deu em três principais etapas:

1. Concepção do modelo.

2. Estruturação dos grupos de procedimentos.

3. Detalhamento de procedimentos específicos.

O desenvolvimento foi baseado na consulta a estudos, planos diretores, diretrizes e manuais relacionados ao tema de planejamento de reúso. Vale destacar que o modelo ETE-usuário proposto não necessariamente reproduz as estruturas e métodos constantes nas referências, sendo mais adequado afirmar que estas serviram de subsídio para a construção do modelo e de seus procedimentos específicos.

A concepção do modelo foi realizada tomando-se como base as diretrizes de programas de reúso presentes em U.S. EPA (2012) e Comissão Europeia (2016) (ver item 3.2.6). A partir disso, foram estabelecidas três premissas:

- identificação individual usuários prioritários, denominados "usuários-âncora", a partir de critério de viabilidade técnico-econômica, considerando custos de capital e de operação de tratamento e distribuição de água de reúso.

- atendimento a usos não potáveis industriais e de irrigação;

- oferta de água de reúso a partir de Estações de Tratamento de Esgotos (ETEs) municipais ativas.

A estruturação foi baseada em uma série de estudos e planos diretores sobre potencial de reúso. Os principais foram o Plano Diretor de Esgotos da Região Metropolitana de São Paulo (PDE 2010) (SABESP, 2010a); Projeto Coroado (COROADO CONSORTIUM, 2012); o Plano de Ação para Instituir uma Política de Reúso no Brasil (MCIDADES, 2017b); a metodologia de análise de potencial de reúso 
industrial (CNI, 2017b, 2019b); Innovation Demonstration for a Competitive and Innovative European Water Reuse Sector (DEMOWARE) (CAÑEQUE et al., 2015; PAOLI, 2016; ZAYAS et al., 2016); Lee et al. (2018); e Pistocchi et al. (2018).

A partir destes trabalhos, determinou-se que o modelo se divide em cinco grupos de procedimentos:

1. Entrada de dados: definição dos dados de entrada e de como estes se comportam no modelo.

2. Análises de engenharia: cruzamento e transformação dos dados de entrada, como caracterização dos usuários, determinação de vazões passíveis de atendimento por água não potável; definição de padrões de qualidade de água de reúso de acordo com a finalidade: estabelecimento de arranjos de tratamento para atingimento dos padrões definidos; e análises espaciais para estimativa de custos de distribuição de água, como estimativa de comprimento e traçado de adutoras.

3. Modelagem de custos e composição de tarifa: estimativa dos custos de produção e distribuição (adução) de água de reúso, levando em consideração os dados transformados na análise de engenharia; e estimativa de tarifa mínima de produção com base nos custos.

4. Estabelecimento de cenários: determinação de cenários que contemplem distintas realidades e resultem em variações de custos e, portanto, de potencial de reúso.

5. Determinação dos usuários-âncora e agregação dos resultados: identificação dos usuários prioritários (usuários-âncora) a partir das tarifas mínimas em comparação aos custos locais de água potável; e agregação dos valores e cálculo do potencial de reúso na área de estudo.

Cada um desses grupos é composto por procedimentos específicos cujos métodos foram desenvolvidos individualmente. Como referência foram utilizados estudos como Sabesp (2010a), Molinos-Senante et al. (2012), Guo et al. (2014), Cañeque et al. (2015), MCidades (2017a), Herman et al. (2017), Lee et al. (2018), CNI (2017b, 2019a), Pistocchi et al. (2018) e Chhipi-Sherestha et al. (2017a).

A Tabela 23 apresenta as três etapas de desenvolvimento, seu detalhamento e as respectivas referências utilizadas. 
Tabela 23: Detalhes sobre o desenvolvimento do modelo ETE-usuário

\begin{tabular}{|c|c|c|}
\hline $\begin{array}{l}\text { Etapa de } \\
\text { desenvolvimento }\end{array}$ & Referente a & Referências utilizadas \\
\hline 1. Concepção & Concepção geral do modelo & $\begin{array}{l}\text { U.S. EPA (2012) e Comissão Europeia } \\
\text { (2016) }\end{array}$ \\
\hline \multirow{5}{*}{$\begin{array}{l}\text { 2. Estruturação } \\
\text { geral }\end{array}$} & 1. Entrada de dados & \multirow{5}{*}{$\begin{array}{l}\text { Sabesp (2010a), Coroado (2012), Zayas } \\
\text { et al. (2016), CNI (2017b, 2019a), } \\
\text { MCidades (2017a), Pistocchi et al. } \\
\text { (2018); Lee et al. (2018) }\end{array}$} \\
\hline & 2. Análises de engenharia & \\
\hline & $\begin{array}{l}\text { 3. Modelagem de custos e } \\
\text { composição de tarifa }\end{array}$ & \\
\hline & 4. Determinacão de cenários & \\
\hline & $\begin{array}{l}\text { 5. Identificação de usuários-âncora } \\
\text { e determinação do potencial de } \\
\text { reúso }\end{array}$ & \\
\hline \multirow{11}{*}{$\begin{array}{l}\text { 3. Detalhamento } \\
\text { de procedimentos } \\
\text { específicos }\end{array}$} & $\begin{array}{l}\text { Definição de quais são os tipos de } \\
\text { dados e variáveis que alimentam o } \\
\text { modelo }\end{array}$ & Sabesp (2010a), CNI (2017b, 2019a) \\
\hline & $\begin{array}{l}\text { Classificação de usuários quanto à } \\
\text { sua atividade econômica }\end{array}$ & CNI (2017b, 2019a) \\
\hline & $\begin{array}{l}\text { Estimativa de demandas não } \\
\text { potáveis dos usuários }\end{array}$ & Sabesp (2010a); CNI (2017b, 2019a) \\
\hline & $\begin{array}{l}\text { Definição de padrões de qualidade } \\
\text { de água de reúso }\end{array}$ & Sabesp (2010a); Pistocchi et al. (2018) \\
\hline & $\begin{array}{l}\text { Definição de arranjos de } \\
\text { tratamento }\end{array}$ & $\begin{array}{l}\text { MCidades (2017a); Chhipi-Sherestha et } \\
\text { al. (2017a) }\end{array}$ \\
\hline & $\begin{array}{l}\text { Estrutura de decomposição de } \\
\text { custos }\end{array}$ & $\begin{array}{l}\text { CNI (2017b, 2019a); Chhipi-Sherestha } \\
\text { et al. (2017a); Herman et al. (2017) }\end{array}$ \\
\hline & $\begin{array}{l}\text { Uso de funções de custos de } \\
\text { tratamento e distribuição }\end{array}$ & $\begin{array}{l}\text { Molinos-Senante et al. (2012); Guo et al. } \\
\text { (2014); Chhipi-Sherestha et al. (2017a); } \\
\text { CNI (2019a) }\end{array}$ \\
\hline & Composição de tarifa mínima & ANA et al. (2005), CNI (2017b, 2019a) \\
\hline & Elaboração de cenários & $\begin{array}{l}\text { MCidades (2017a), Pistocchi et al. } \\
(2018)\end{array}$ \\
\hline & $\begin{array}{l}\text { Regra de identificação de usuários- } \\
\text { âncora }\end{array}$ & $\begin{array}{l}\text { Cañeque et al. (2015); MCidades } \\
\text { (2017a); Pistocchi et al. (2018) }\end{array}$ \\
\hline & Agregação de resultados & $\begin{array}{l}\text { Cañeque et al. (2015); MCidades } \\
\text { (2017a); Pistocchi et al. (2018) }\end{array}$ \\
\hline
\end{tabular}

(a) Por motivos práticos, são apresentados somente alguns dos principais procedimentos específicos na tabela.

A Figura 19 ilustra as etapas de desenvolvimento do modelo e as referências relacionadas na Tabela 23. 


\section{Desenvolvimento do modelo ETE-usuário}

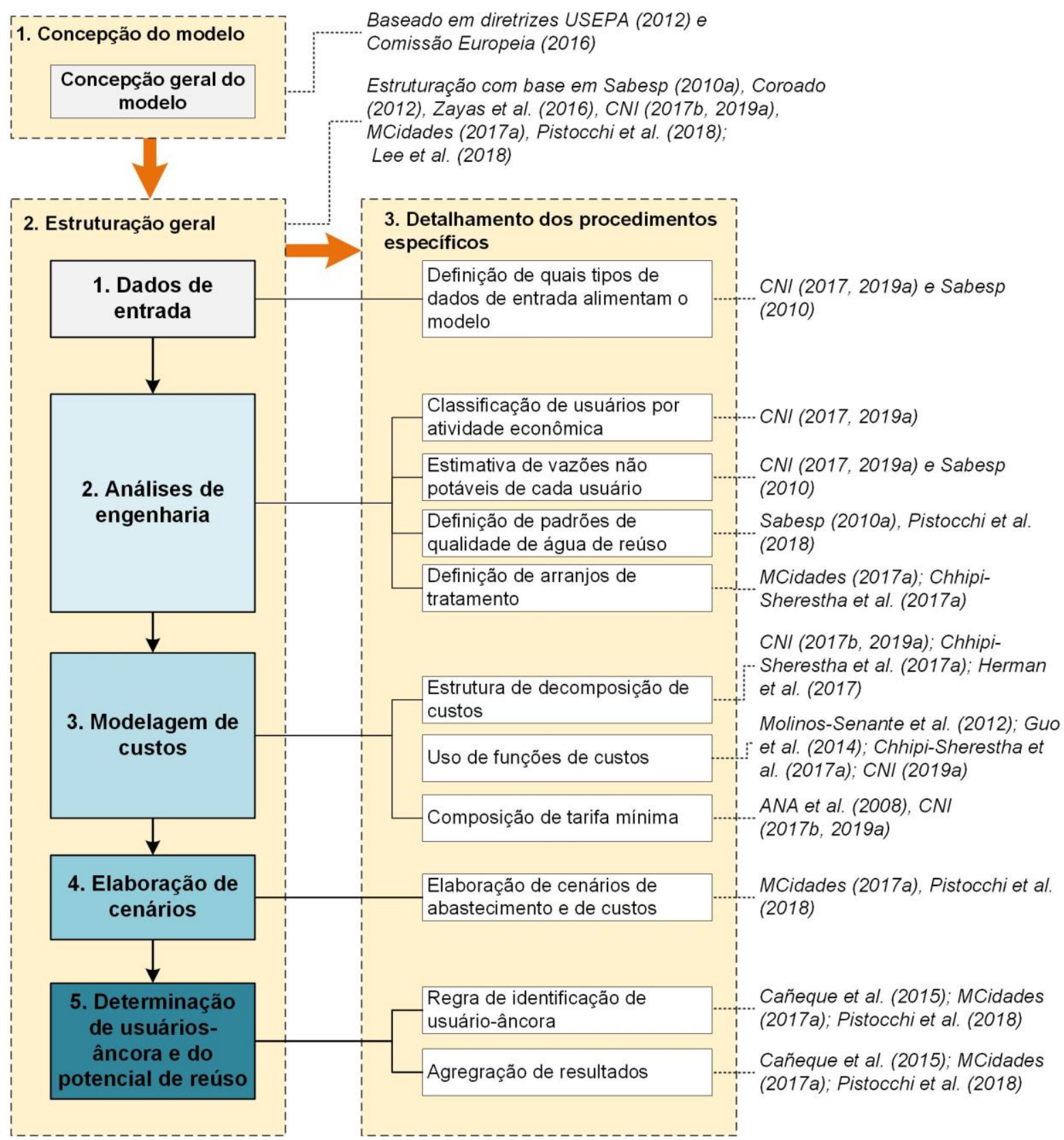

Figura 19: Diagrama de desenvolvimento do modelo ETE-usuário

Fonte: elaborado pelo autor

\subsection{SISTEMA DE INFORMAÇÕES GEOGRÁFICAS (SIG) E RECUSOS ONLINE}

Este trabalho contou com uso extensivo de Sistema de Informações Geográficas (SIG) em diversas etapas, como extração, verificação e pré-processamento de dados, 
análises espaciais e exposição de resultados. Neste tópico, serão brevemente expostos aspectos referentes ao uso de SIG.

\subsubsection{Softwares, complementos e Sistemas de Referências de Coordenadas (SRCs)}

Todas as análises e produtos espaciais foram elaborados por meio da utilização do software livre Quantum GIS (QGIS) versão 3.8.3 Zanzibar. Adicionalmente, os seguintes principais plugins foram utilizados em operações específicas:

- QuickMapService (v 0.19.10.1): conectividade a mapas temáticos e imagens de satélite online.

- Point Sampling Tool (v 0.5.2): extração de valores de elevação de arquivo raster de acordo com camada vetorial de pontos.

- QNEAT3 (v 1.0.3): traçado de caminhos mínimos entre pontos e geração de matriz OD (origem-destino).

- qgis2web (v 3.12.1): exportação de mapas para formato web (ver item 4.4.1.2).

Foram utilizados dois diferentes Sistemas de Referências de Coordenadas (SRCs). Para mapas em nível nacional ou estadual, os quais constam somente em caracterizações mais gerais, utilizou-se o SIRGAS2000 (Sistema de Referência Geocêntrico para as Américas), o qual é, desde 2005, o sistema de referência do Sistema Geodésico Brasileiro (SGB) e do Sistema Cartográfico Brasileiro (SCB) (IBGE, 2015a). Para análises espaciais e resultados específicos da área de estudos (RMSP) utilizou-se o sistema de projeção plana UTM SIRGAS 2000 / UTM zone 23S. A modificação do SRC para a análise mais detalhadas dá-se pelo fato de que em sistemas de coordenadas geodésicas (como o SIRGAS2000) as distâncias são expressas em graus, havendo distorções conforme se afasta da linha do Equador em direção aos polos, o que é especialmente importante para análises espaciais mais detalhadas (como no caso do modelo ETE-usuário). Como todo o território da área de estudo encontra-se na zona 23S, não foi necessário uso de mais de um SRC de projeção plana. 


\subsubsection{Recursos online}

Em complementação ao conteúdo desta dissertação, este trabalho inclui recursos online de apoio de dois tipos: (i) um repositório para download de bases de dados; (ii) mapas interativos com os resultados obtidos da aplicação dos modelos à RMSP. A criação desses recursos teve três principais motivações.

A primeira é a grande quantidade de resultados obtidos na aplicação dos modelos e sua inerente natureza espacial, o que dificulta sua compreensão por meio de relatórios e demais materiais impressos. Por isso, foram criados mapas interativos online que permitem a navegação e exploração do conteúdo por quaisquer interessados.

A segunda foi a dificuldade de obtenção, organização e pré-processamento de bases de dados. Assim, prezou-se pela criação de ferramentas de difusão que facilitassem o acesso às principais bases de dados e resultados, tendo como orientação os princípios de gestão de dados de pesquisa FAIR $^{9}$ (Findable, Accessible, Interoperable and Reusable).

A terceira foi a demonstração da possibilidade de integração dos modelos a sistemas automatizados baseados em SIG. Ainda que os mapas interativos criados se limitem a apresentar os resultados, entende-se que esse recurso auxilie na compreensão das potencialidades de utilização sistemas digitais para suporte ao planejamento de reúso de água.

Para criação de página web para acesso ao repositório utilizou-se a plataforma de criação e edição de sites Wix. Os mapas interativos foram criados pelo uso do plugin qgis2web do QGIS3 e recursos da biblioteca Java Leaflet.

\footnotetext{
${ }^{9}$ Mais informações em: https://www.go-fair.org/fair-principles/
} 


\section{RESULTADOS E DICUSSÕES}

Esta seção de resultados e discussões é estruturada da seguinte forma:

- 5.1. IPR (ÍNDICE DE POTENCIAL DE REÚSO). Apresentação da estrutura do modelo de IPR e de seus elementos constituintes.

- 5.2. MODELO ETE-USUÁRIO. Apresentação da estrutura do modelo ETEusuário e de seus elementos constituintes.

- 5.3. APLICAÇÃo À ÁREA DE ESTUDO (RMSP). Aplicação de ambos os modelos à área de estudo escolhida (RMSP) e discussão dos resultados.

- 5.4. RECURSOS ONLINE. Apresentação dos recursos online adicionais criados que complementam o conteúdo desta dissertação.

- $\quad$ 5.5 DISCUSSÃO SOBRE OS MODELOS. Discussão sobre o IPR e o modelo ETE-usuário, já considerando os aprendizados obtidos pela aplicação à RMSP.

\subsection{IPR (ÍNDICE DE POTENCIAL DE REÚSO)}

A partir do desenvolvimento exposto no item 4.2 chegou-se à estrutura final do IPR. A estrutura e a operação do modelo podem ser resumidas pelos seguintes pontos.

- O IPR busca classificar áreas de determinada região de estudo quanto a seu potencial de reúso não potável.

- O modelo tem como principal componente a estrutura hierárquica composta por critérios e subcritérios, a qual foi construída pelo uso do Analytic Hierarchy Process (AHP). Os critérios que compõem o modelo são: técnico, ambiental e socioeconômico, cada qual contanto com dois a quatro subcritérios.

- Cada subcritério corresponde a uma variável a ser inserida no modelo, e a matriz de prioridades define qual o peso desse subcritério dentro do modelo.

- Como as variáveis possuem naturezas e séries de dados com amplitudes distintas, faz-se necessária normalização dos parâmetros antes de sua utilização.

- O valor do IPR é calculado a partir dos valores normalizados das variáveis dos subcritérios e das prioridades destes no modelo.

- A análise de sensibilidade prevista analisa o comportamento do modelo frente a variações pré-definidas de prioridades dos critérios e subcritérios.

- A classificação de resultados agrupa os resultados em classes de IPR de acordo com critérios estatísticos pré-definidos. 
A Figura 20 apresenta o IPR, seus principais procedimentos e a indicação dos itens subsequentes deste capítulo que os detalham. O diagrama ilustra a aplicação do cálculo do IPR a uma área de estudo genérica composta por sub-áreas Área 1 , Área ... Árean. 
Estrutura do Índice de Potencial de Reúso (IPR)

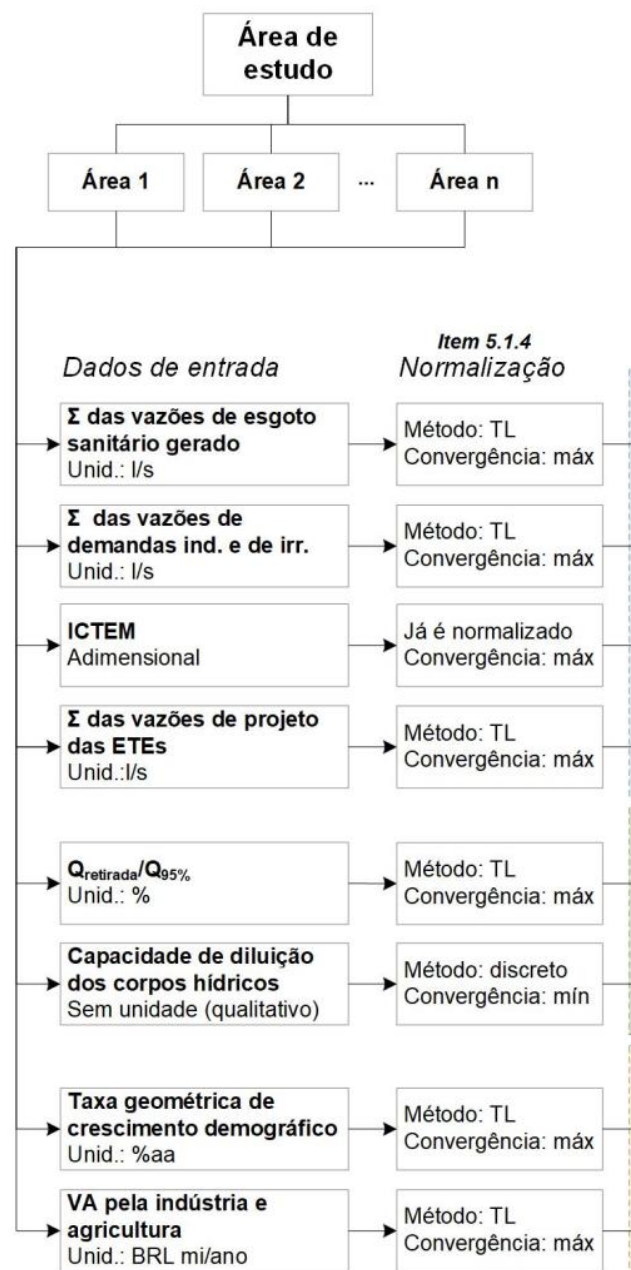

Unid.: BRL mi/ano

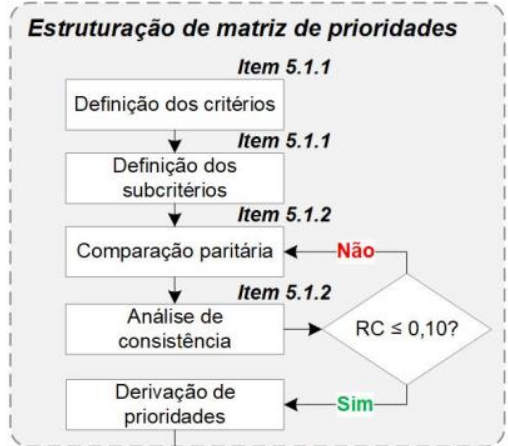

Item 5.1.6

Análise de sensibilidade

Matriz de Alteração das

prioridades 4 prioridades

Variação do critério técnico de

Técnico

0,1 a 0,9 em passos de 0,1

T1 - Geração de esgoto

T2 - Demandas industriais e

de irrigação

$\mathrm{W}_{\mathrm{T} 2}=0,162$

T3 - ICTEM

$W_{T 3}=0,088$

T4 - Capacidade de

tratamento das ETEs

$\mathrm{W}_{\mathrm{T} 4}=0,203$

Ambiental

A1 - Balanço hídrico

$\mathrm{W}_{\mathrm{A} 1}=0,143$

A2 - Capacidade de diluição

dos corpos hídricos

$\mathrm{W}_{\mathrm{A} 2}=0,143$

Socioeconômico

SE1 - Taxa geométrica de

$\rightarrow$ crescimento demográfico

$\mathrm{W}_{\mathrm{SE} 1}=0,048$

SE2 - VA pela indústria $e$

$\rightarrow$ agricultura

$\mathrm{W}_{\mathrm{SE} 1}=0,095$

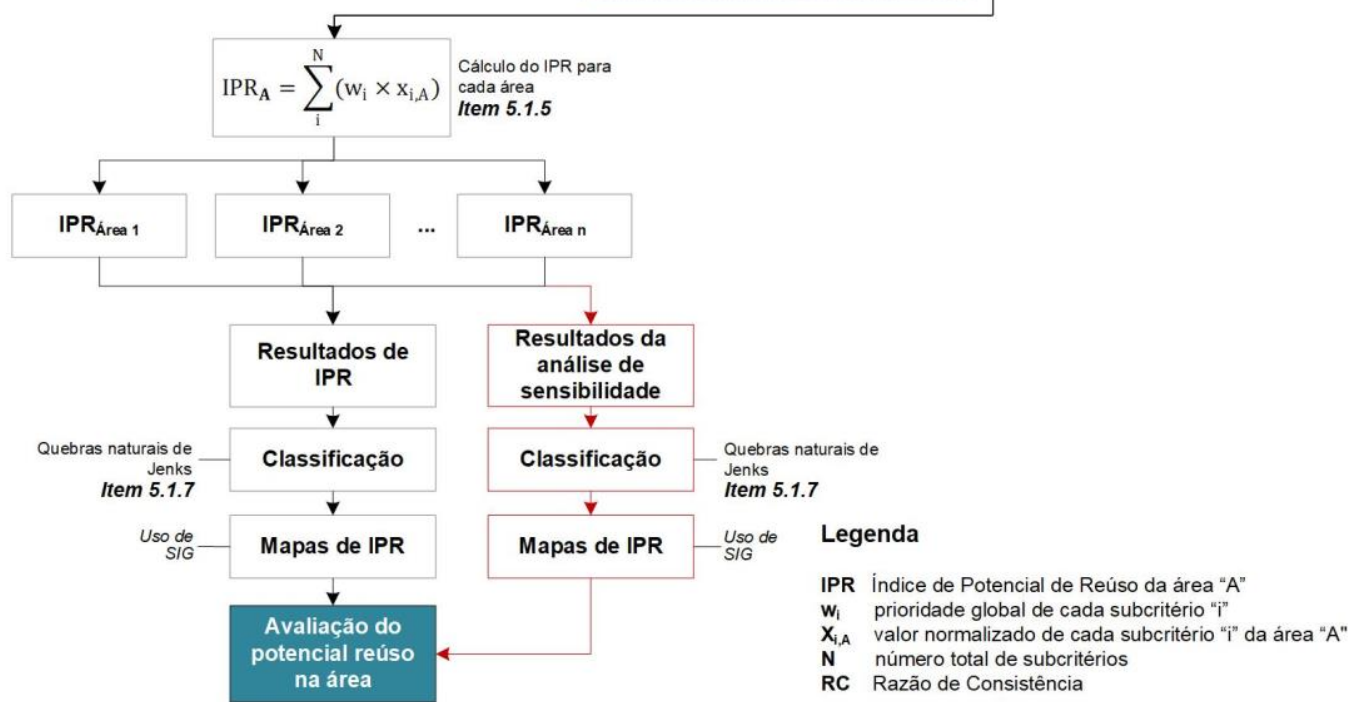

Figura 20: Estrutura do Modelo do Índice de Potencial de Reúso (IPR)

Fonte: elaborado pelo autor 


\subsubsection{Critérios e subcritérios}

A estrutura hierárquica do IPR é dividida em três critérios (técnico, ambiental e socioeconômico), cada qual composto por seus respectivos subcritérios. Ao total, são oito subcritérios, como mostra a Figura 21.

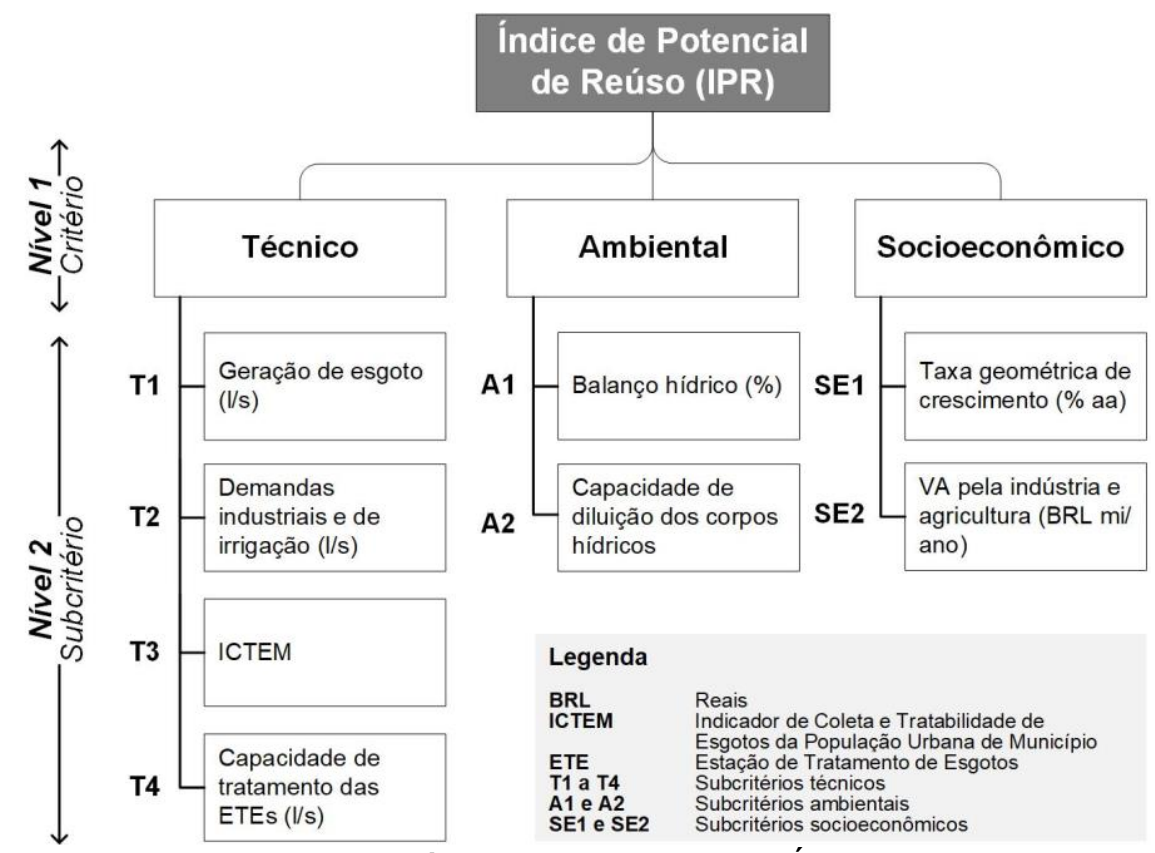

Figura 21: Diagrama da estrutura hierárquico do modelo do Índice de Potencial de Reúso (IPR) utilizando metodologia do Analytic Hierarchy Process (AHP)

Fonte: elaborado pelo autor.

As siglas de cada subcritério foram atribuídas de acordo com as iniciais dos nomes dos critérios aos quais estão submetidos. Ou seja, os que compõem o critério Técnico foram divididos em T1, T2, T3 e T4; Ambiental em A1 e A2; e SocioEconômico em SE1 e SE2. Os subcritérios, siglas, unidades e tipo de convergência são apresentados na Tabela 24.

Tabela 24: Critérios e subcritérios que compõem o Indicador de Potencial de Reúso (IPR)

\begin{tabular}{llll}
\hline Critério/subcritério & Sigla & Unid. & Conv. \\
\hline Técnico & & & \\
\hline Esgoto doméstico gerado & $\mathrm{T} 1$ & $\mathrm{l} / \mathrm{s}$ & máx \\
\hline Demandas industriais e agrícolas & $\mathrm{T} 2$ & $\mathrm{l} / \mathrm{s}$ & $\mathrm{máx}$ \\
\hline ICTEM & $\mathrm{T} 3$ & - & $\mathrm{máx}$ \\
\hline Capacidade instalada de tratamento de esgotos & $\mathrm{T} 4$ & $\mathrm{l} / \mathrm{s}$ & $\mathrm{máx}$ \\
\hline Ambiental & & & $\mathrm{máx}$ \\
\hline Balanço hídrico & $\mathrm{A} 1$ & $\%$ & mín \\
\hline Condição de capacidade de diluição dos corpos hídricos & $\mathrm{A} 2$ & - & \\
\hline Socioeconômico & & & máx \\
\hline Taxa geométrica de crescimento demográfico & $\mathrm{SE} 1$ & \%/aa & máx \\
\hline VA industrial e agrícola & $\mathrm{SE} 2$ & $\mathrm{BRL}$ mi/ano & \\
\hline
\end{tabular}


Nos itens a seguir é justificada a adoção de cada um dos subcritérios escolhidos. As fontes de dados variam de acordo com a área de estudo em que o IPR é aplicado, e por isso serão apresentadas somente na etapa de aplicação do IPR à área de estudo escolhida, a RMSP (item 5.3).

\section{T1 - Esgoto doméstico gerado}

Assumiu-se que um dos principais fatores positivos à possibilidade de reúso a partir de efluentes sanitários domésticos é a existência e intensidade da geração de esgotos domésticos, o que é diretamente dependente da população residente e de hábitos de consumo. Caso não haja disponibilidade de esgoto bruto, as possibilidades de reúso se reduzem por falta de oferta. Portanto, quanto maior o valor de T1, mais favorável é a condição ao reúso (convergência ao máximo). Todos os valores absolutos de T1 foram expressos em l/s.

\section{T2 - Demandas industriais e agrícolas}

A existência de demandas industriais e agrícolas foi considerada parâmetro de convergência ao máximo na determinação do potencial de reúso. Ou seja, quanto maiores as demandas, maiores as possibilidades de reúso. Conforme levantado no item 3.2.2, hoje as finalidades de reúso não potável de efluentes sanitários após tratamento terciário mais prevalentes são de irrigação e para fins industriais. Demandas não potáveis urbanas, tais como irrigação paisagística ou lavagens de áreas públicas, não são passíveis de detecção a partir de informações por município ou dados de outorgas e são, além disso, extremamente difusas no território. Todos os valores absolutos de T2 foram expressos em I/s.

\section{T3 - ICTEM}

O Indicador de Coleta e Tratabilidade de Esgoto da População Urbana de Município (ICTEM) é utilizado pela Companhia Estadual do Estado de São Paulo (Cetesb) para classificação dos municípios quanto à coleta e tratamento de esgotos sanitários e contempla aspectos de abrangência da rede de coleta, proporção entre esgoto gerado e tratado, eficiência do tratamento (em termos de remoção de $\mathrm{DBO}_{5,20}$ ), gestão dos resíduos sólidos gerados nas estações de tratamento e ocorrência ou não de 
desenquadramento do corpo hídrico objeto do lançamento de efluentes tratados (CETESB, 2018a).

Ainda que o indicador seja de uso exclusivo do Estado de São Paulo, seu cálculo pode ser replicado a qualquer município ou recorte geográfico, desde que haja dados mínimos sobre a infraestrutura de saneamento. Segundo Cetesb (2018b), o ICTEM é calculado por:

$$
I C T E M=0,015 C+0,015 T+0,065 E+D+Q
$$

ICTEM: Índice de Coleta e Tratabilidade de Esgoto da População Urbana de Município

C (\%) Porcentagem da população urbana atendida por rede de coleta de esgotos

$\mathrm{T}(\%)$ Porcentagem da população urbana com esgoto tratado

E (\%) Eficiência global de remoção de carga orgânica

$\mathrm{N}(\%)$ Eficiência de remoção da carga orgânica pelas ETEs

$\mathrm{D}$ (adim.): zero se destinação de lodos e resíduos de tratamento for inadequada e 0,2 se for adequada

$Q$ (adim.): zero se efluente desenquadrar a classe do corpo receptor ou existir lançamento direto ou indireto de esgotos não tratados. Será atribuído o valor de 0,3 se o efluente não desenquadrar a classe do corpo receptor

Assumindo-se que níveis mais altos de infraestrutura de coleta e tratamento de esgotos implicam em maiores facilidades na aplicação de programas de reúso, o ICTEM foi considerado um fator positivo ao reúso. Quanto maior seu valor, mais favorável é a condição (convergência ao máximo). O ICTEM é um indicador adimensional que varia entre de 0 e 10 e, portanto, não possui unidade.

\section{T4 - Capacidade instalada de tratamento de esgotos}

A capacidade instalada de tratamento de esgotos, expressa pelo somatório das vazões de projeto das ETEs ativas localizadas no município, foi considerada condição favorável ao potencial de reúso. Municípios que possuem maiores capacidades de tratamento de esgoto podem mais facilmente fornecer água de reúso (convergência ao máximo). Todos os valores absolutos de T4 foram expressos em l/s.

\section{A1 - Balanço hídrico}

O subcritério balanço hídrico foi mensurado pela razão entre as demandas totais e a disponibilidade hídrica natural. A disponibilidade hídrica natural, neste caso, é mensurada pela Q95\%. Esse indicador também é conhecido como DTA (demand-toavailability ratio). Quanto maior o valor de balanço hídrico, maior a pressão sobre os 
recursos hídricos locais. Dado que em áreas sob forte estresse hídrico a busca por fontes alternativas adquire maior importância, assumiu-se que quanto maior seu valor, mais favorável é a condição à implantação de reúso (convergência ao máximo). Todos os valores de balanço hídrico foram expressos em porcentagem (\%).

\section{A2 - Condição de capacidade de diluição dos corpos hídricos}

Assumiu-se que quanto pior a condição de capacidade de diluição dos corpos hídricos, mais favorável é a condição ao reúso. Em locais onde os corpos hídricos já tiveram sua capacidade de diluição de efluentes esgotadas, soluções de tratamento que resultem em efluentes municipais de melhor qualidade necessariamente deverão ser aplicadas, o que cria condições favoráveis ao aproveitamento desses mesmos efluentes em usos benéficos. Por isso, a capacidade de diluição foi considerada um fator positivo ao reúso, sendo o único subcritério com convergência ao mínimo. Esse parâmetro é estritamente qualitativo e, portanto, não possui unidade.

\section{SE1 - Taxa geométrica de crescimento demográfico (TGCD)}

De modo a se compreender a tendência de crescimento ou redução da população, o que está diretamente relacionado a alterações futuras das demandas de água e geração de esgotos, utilizou-se a taxa geométrica de crescimento demográfico (TGCD) para cada um dos municípios. Assumiu-se que quanto maior a tendência de crescimento, mais favorável é a condição ao reúso (convergência ao máximo), dado que tanto a geração de esgotos como a pressão sobre os recursos hídricos tendem a aumentar com acréscimos de população, principalmente em áreas urbanas altamente adensadas. Os valores absolutos de taxa de crescimento foram expressos em \% a.a (ao ano).

\section{SE2 - Valor adicionado (VA) pela indústria e agricultura}

Assumiu-se que quanto maior a riqueza gerada pelos setores industrial e agropecuário, mais favorável é a condição ao reúso (convergência ao máximo). Essas são as atividades econômicas mais comumente contempladas por programas de reúso não potável, a determinou-se que maior intensidade da atividade econômica 
desses setores é um fator positivo ao reúso. Os valores absolutos de Valor Adicionado (VA) foram expressos em milhões de Reais por ano ( $\mathrm{R} \$ \mathrm{mi} / \mathrm{ano})$.

\subsubsection{Matriz de importâncias paritárias e análise de consistência}

A Tabela 25 apresenta os valores da comparação paritária para os critérios (nível 1) e subcritérios (nível 2). Os autovalores máximos ( $\lambda_{\text {máx }}$ ), as Razões de Consistência $(R C)$ e sua verificação em relação ao limite tolerado pelo $A H P(R C \leq 0,10)$ são apresentadas abaixo de cada uma das matrizes.

Tabela 25: Importâncias paritárias e análise de consistência: níveis 1 e 2

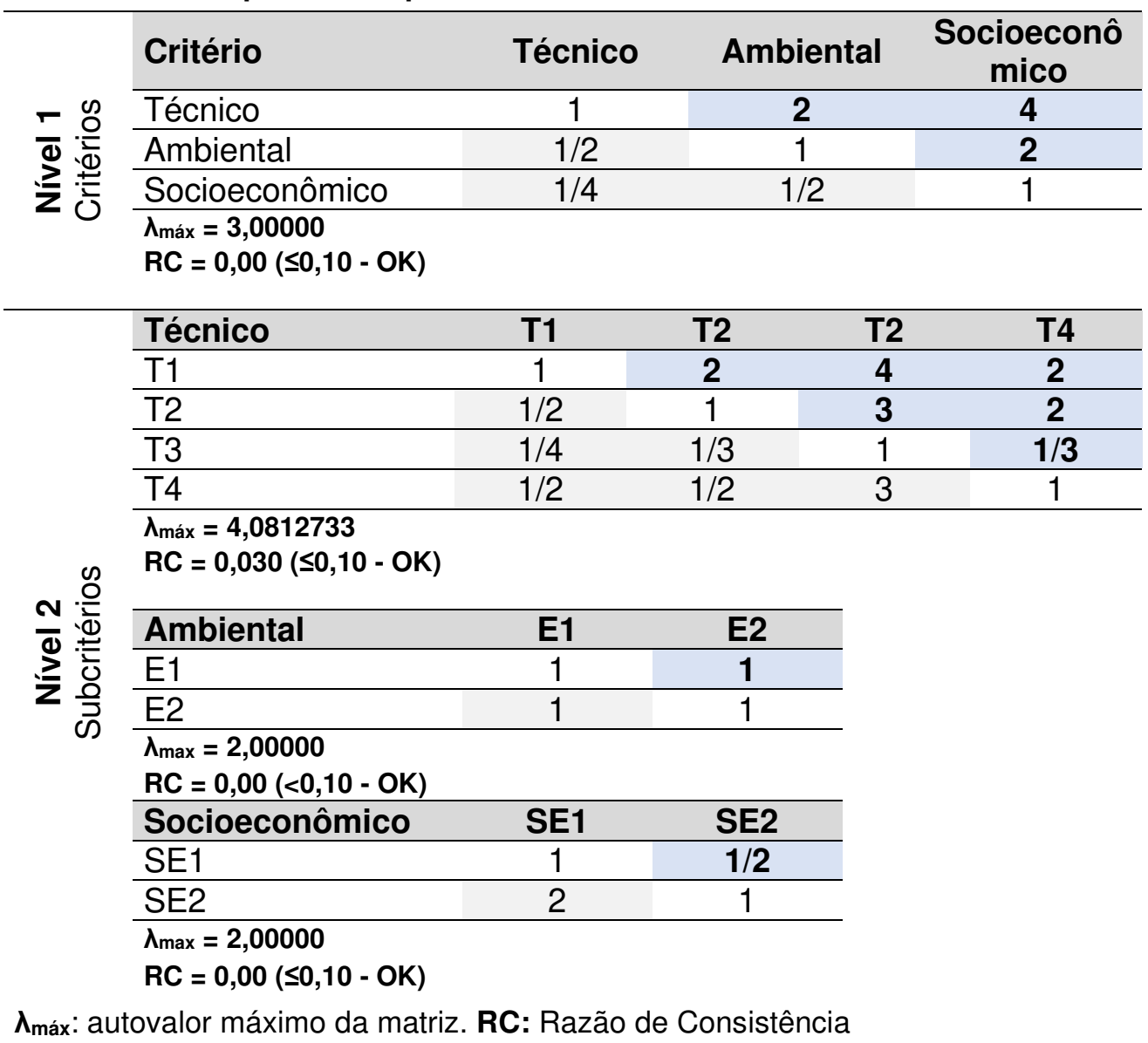

Para o nível 1 (critérios), o critério técnico foi aquele ao qual foi atribuído maior peso, com importância relativa "fraca" (2) em relação ao ambiental e "moderada +" (4) em relação aos socioeconômicos. A importância relativa do critério ambiental em relação aos socioeconômicos é "fraca" (2). 
No nível 2 (subcritérios), para os subcritérios técnicos (T1 a T4), T1 foi priorizado em relação aos demais, sendo o T3 o menos importante e T2 e T4 intermediários. Para os subcritérios ambientais (A1 a A2), ambos os subcritérios foram considerados de igual importância. Para os subcritérios socioeconômicos (SE1 a SE2), o subcritério SE2 tem importância "fraca" sobre o SE1.

Nenhum dos valores calculados de RC extrapolou o limite de 0,10, o que, de acordo com o método AHP, garante que as matrizes possuem inconsistências aceitáveis.

\subsubsection{Matriz de prioridades globais}

Para os critérios (nível 1) e subcritérios (nível 2), as prioridades locais e globais resultantes da derivação de prioridades pelo Método das Médias dos Valores Normalizados são as mostradas na Tabela 26. A letra "w" (weight) será utilizada para se referir às prioridades dos critérios e subcritérios.

Tabela 26: Prioridades locais e globais para os critérios e subcritérios do IPR

\begin{tabular}{|c|c|c|c|c|c|c|}
\hline Critério / Subcritério & Sigla & Unid. & Convergência & $\mathbf{W}_{\text {local }}$ & $\mathbf{W}_{\text {global }}$ & Posição \\
\hline Técnico & & & & & 0,571 & \\
\hline Esgoto doméstico gerado & $T 1$ & l/s & máx & 0,426 & 0,244 & $1^{\circ}$ \\
\hline $\begin{array}{l}\text { Demandas industriais e } \\
\text { agrícolas }\end{array}$ & T2 & $l / s$ & máx & 0,283 & 0,162 & $2^{\circ}$ \\
\hline ICTEM & T3 & - & máx & 0,088 & 0,050 & $7^{\circ}$ \\
\hline $\begin{array}{l}\text { Capacidade instalada de } \\
\text { tratamento }\end{array}$ & T4 & $l / s$ & máx & 0,203 & 0,116 & $5^{\circ}$ \\
\hline Ambiental & & & & & 0,286 & \\
\hline Balanço hídrico & A1 & $\%$ & máx & 0,500 & 0,143 & $3 / 4^{\circ}$ \\
\hline $\begin{array}{l}\text { Condição de capacidade de } \\
\text { diluição dos corpos hídricos }\end{array}$ & $A 2$ & $\%$ & mín & 0,500 & 0,143 & $3 / 4^{\circ}$ \\
\hline Socioeconômico & & & & & 0,143 & \\
\hline $\begin{array}{l}\text { Taxa geométrica de } \\
\text { crescimento demográfico }\end{array}$ & SE1 & $\% a a$ & máx & 0,333 & 0,048 & $8^{\circ}$ \\
\hline VA industrial e agrícola & SE2 & $\begin{array}{l}B R L \\
\text { mi/ano }\end{array}$ & máx & 0,667 & 0,095 & $6^{\circ}$ \\
\hline
\end{tabular}

O critério técnico resultou como o mais importante $\left(\mathrm{w}_{\mathrm{tec}}=0,571\right)$, seguido pelo ambiental $\left(W_{a m b}=0,286\right)$ e por último pelo socioeconômico ( $\left.W_{s e}=0,143\right)$. Quanto aos subcritérios, o com maior prioridade foi o de esgoto doméstico gerado ( $\mathrm{W} T 1=0,244$ ), e o com menor foi de taxa geométrica de crescimento demográfico (WSE2 $=0,048$ ). Como a soma total das prioridades globais deve ser igual a 1,0, cada valor de $\mathbf{w}_{\text {global }}$ dos critérios e subcritérios corresponde à porcentagem de cada elemento na 


\begin{tabular}{lllll}
\hline Sigla & Subcritério & Convergência & $\begin{array}{l}\text { Método de } \\
\text { normalização }\end{array}$ & Função de normalização \\
A2 & $\begin{array}{l}\text { Condição de } \\
\text { capacidade de diluição } \\
\text { dos corpos hídricos }\end{array}$ & mín & Regra discreta & $\begin{array}{l}\text { Nula }=1,0 \\
\text { Péssima/ruim }=0,667 \\
\text { Boa/ótima }=0,333 \\
\text { Infinita }=0\end{array}$ \\
\hline SE1 & $\begin{array}{l}\text { Taxa geométrica de } \\
\text { crescimento } \\
\text { demográfico }\end{array}$ & máx & TL & $x_{\text {norm }}=\frac{x-x_{\text {mín }}}{x_{\text {máx }}-x_{\text {mín }}}$ \\
\hline SE2 & PIB industrial e agrícola & máx & TL & $x_{\text {norm }}=\frac{x-x_{\text {mín }}}{x_{\text {máx }}-x_{\text {mín }}}$ \\
\hline
\end{tabular}

TL: transformação linear; $\mathbf{x}_{\text {norm: }}$ valor normalizado; $\mathbf{x}$ : valor de entrada a ser normalizado; $\mathbf{x}_{\min }$ : valor mínimo da série de dados de entrada; $\mathbf{X}_{\text {máx: }}$ valor máximo da série de dados de entrada.

Os subcritérios T1, T2, T4, A1, SE1 e SE2 são normalizados de acordo com a Equação 3 (item 3.3.2.3.1), possuindo todos convergência ao máximo. O ICTEM (T3) já é um valor normalizado de 0 a 10, e, para compatibilização com os demais (escala de 0 a 1), foi dividido por 10 . O subcritério A2 possui natureza qualitativa, e os quatro valores possíveis foram distribuídos discretamente em valores distribuídos entre 0 e 1 , sendo capacidade de diluição "ilimitada" a condição menos favorável (0) e a nula a mais favorável (1).

\subsubsection{Fórmula de cálculo do Índice de Potencial de Reúso (IPR)}

Substituindo-se as prioridades de cada subcritério (Tabela 26) na Equação 5, chegase à Equação 7 para cálculo do IPR para cada área genérica "A".

$$
\begin{aligned}
I P R_{A}=\sum_{i}^{N}\left(w_{i} \times x_{i, A}\right)= & 0,244 x_{T 1, A}+0,162 x_{T 2, A}+0,050 x_{T 3, A}+0,116 x_{T 4, A}+ \\
& 0,143 x_{A 1, A}+0,143 x_{A 2, A}+0,048 x_{S E 1, A}+0,095 x_{S E 2, A}
\end{aligned}
$$

$\mathrm{IPR}_{\mathrm{A}}$ Índice de Potencial de Reúso da área $\mathrm{A}$

$\mathbf{x}_{\mathbf{i}} \quad$ valor normalizado de cada subcritério "i" da área $A$

$\mathbf{w}_{\mathbf{i}} \quad$ prioridade global de cada subcritério "i" da área $\mathrm{A}$

$\mathbf{N}$ número total de subcritérios

\subsubsection{Métodos de classificação}

Como apresentado no item 4.2.1, o método de classificação adotado foi o de quebras naturais de Jenks. $O$ método busca reduzir a variância interna de cada classe, o que invariavelmente depende da série de dados a ser classificada. Ainda que não seja possível definir os intervalos em si antes da obtenção de resultados, é necessário 
estabelecer quais e quantas são as classes. Foram definidas cinco classes, variando de IPR "muito baixo" a "muito alto". A Tabela 28 apresenta as classes propostas.

Tabela 28: Classes previstas para classificação do IPR

\begin{tabular}{ll}
\hline Classificação de IPR & Intervalo de IPR \\
\hline Muito baixo & Definido na aplicação \\
\hline Baixo & (vide item 5.3.2.3) \\
\hline Considerável & \\
\hline Alto & \\
\hline Muito alto & \\
\hline
\end{tabular}

No item 5.3.2, em que o IPR é aplicado à área de estudo (RMSP), a definição dos intervalos será exemplificada a partir de resultados de IPR para os 39 municípios estudados.

Softwares de geoprocessamento, como o QGIS, possuem recursos nativos de classificação de dados que contemplam, entre outros, o método de quebra naturais de Jenks. Por isso, os procedimentos estatísticos para obtenção dos intervalos de cada classe (algoritmo de Jenks) não serão detalhados, dado que sua realização pode ser realizada diretamente em ambiente SIG.

\subsubsection{Cenários de análise de sensibilidade}

A partir da matriz de prioridades (Tabela 26) e do método de análise de sensibilidade (item 4.2.1), foram obtidas diferentes matrizes de prioridades de critérios (Tabela 29) e subcritérios (Tabela 30). Como o critério técnico é o que possui maior prioridade no modelo, seu peso foi variado de 0,1 a 0,9 em passos fixos de 0,1 . Ao total são nove cenários adicionais de análise se sensibilidade, cada um deles identificado pelo peso do critério técnico correspondente. Por exemplo, o cenário em que o peso do critério técnico é igual a 0,3 é identificado como "0,3". Convencionou-se que o resultado original da derivação de prioridades denomina-se "normal".

Tabela 29: Prioridades dos critérios para a variação do critério prevalente (técnico)

\begin{tabular}{|c|c|c|c|c|c|c|c|c|c|c|}
\hline \multirow{2}{*}{ Critério } & \multicolumn{10}{|c|}{ Prioridades globais dos critérios para variação de $w_{\text {tec }}$} \\
\hline & Normal & 0,1 & 0,2 & 0,3 & 0,4 & 0,5 & 0,6 & 0,7 & 0,8 & 0,9 \\
\hline Técnico & 0,571 & 0,100 & 0,200 & 0,300 & 0,400 & 0,500 & 0,600 & 0,700 & 0,800 & 0,900 \\
\hline Ambiental & 0,286 & 0,600 & 0,533 & 0,467 & 0,400 & 0,333 & 0,267 & 0,200 & 0,133 & 0,067 \\
\hline Socioeconômico & 0,143 & 0,300 & 0,267 & 0,233 & 0,200 & 0,167 & 0,133 & 0,100 & 0,067 & 0,033 \\
\hline
\end{tabular}


Tabela 30: Prioridades globais dos subcritérios para a variação do critério prevalente (técnico)

\begin{tabular}{|c|c|c|c|c|c|c|c|c|c|c|}
\hline \multirow{2}{*}{ Subcritério } & \multicolumn{10}{|c|}{ Prioridades globais dos subcritérios para variação de $w_{\text {tec }}$} \\
\hline & Normal & 0,1 & 0,2 & 0,3 & 0,4 & 0,5 & 0,6 & 0,7 & 0,8 & 0,9 \\
\hline T1 & 0,244 & 0,043 & 0,085 & 0,128 & 0,170 & 0,213 & 0,256 & 0,298 & 0,341 & 0,384 \\
\hline T2 & 0,162 & 0,028 & 0,057 & 0,085 & 0,113 & 0,141 & 0,170 & 0,198 & 0,226 & 0,254 \\
\hline T3 & 0,050 & 0,009 & 0,018 & 0,026 & 0,035 & 0,044 & 0,053 & 0,062 & 0,070 & 0,079 \\
\hline T4 & 0,116 & 0,020 & 0,041 & 0,061 & 0,081 & 0,102 & 0,122 & 0,142 & 0,163 & 0,183 \\
\hline A1 & 0,143 & 0,300 & 0,267 & 0,233 & 0,200 & 0,167 & 0,133 & 0,100 & 0,067 & 0,033 \\
\hline A2 & 0,143 & 0,300 & 0,267 & 0,233 & 0,200 & 0,167 & 0,133 & 0,100 & 0,067 & 0,033 \\
\hline SE1 & 0,048 & 0,100 & 0,089 & 0,078 & 0,067 & 0,056 & 0,044 & 0,033 & 0,022 & 0,011 \\
\hline SE2 & 0,095 & 0,200 & 0,178 & 0,156 & 0,133 & 0,111 & 0,089 & 0,067 & 0,044 & 0,022 \\
\hline
\end{tabular}

NOTA: escala de vermelho a azul indica a intensidade da prioridade. Valores mais altos tendem ao azul escuro.

Como previsto, o critério técnico passa gradualmente de menos importante ao mais importante, enquanto os demais têm suas prioridades aumentadas com a redução de Wtec. O mesmo ocorre para os subcritérios.

\subsection{MODELO ETE-USUÁRIO}

Com base no desenvolvimento apresentado no item 4.3, chegou-se à estrutura final do modelo ETE-usuário. A estrutura e operação do modelo podem ser resumidas pelos seguintes pontos.

- O modelo busca identificar usuários-âncora de água de reúso por meio de critério de viabilidade econômica.

- O nível de análise é realizado no que se denominou "ETE-usuário", ou seja, cada potencial usuário é analisado individualmente em relação às possíveis fontes de água de reúso. Portanto, "ETE-usuário" é a unidade mínima de análise do modelo.

- A partir de dados de usuário, oferta e regionais, são realizadas análises que subsidiam a estimativa de custos de produção e distribuição de água de reúso. Essas análises consideram caracterização dos usuários; estimativa das demandas não potáveis; definição de padrões de qualidade de água de reúso; definição de arranjos de tratamento para produção de água de reúso; traçado de adutoras; e determinação de potências requeridas para adução.

- A estimativa de custos contempla custos de capital (Capex) e operação \& manutenção (Opex) das etapas de produção e distribuição de água de reúso. Priorizou-se o uso de funções de custos que incorporem as variações de custos 
unitários em razão de ganhos de escala, evitando-se sempre que possível o uso de custos unitários fixos.

- Com base nos custos e em variáveis financeiras, são estimadas tarifas mínimas a partir do uso de Valor Presente Líquido (VPL) e variáveis financeiras.

- Os usuários-âncora são identificados por regra de comparação das tarifas calculadas com os custos locais de água.

- A análise conjunta dos usuários-âncora leva à determinação das vazões potenciais de reúso na área.

- São propostos cenários de abastecimento e de custos que promovem alterações nas variáveis de projeto e econômico-financeiras do modelo e que, consequentemente, resultam em vazões potenciais de reúso diferentes.

A Figura 23 apresenta a estrutura do modelo, bem como indicação dos itens deste tópico em que cada elemento é detalhado. 


\section{Estrutura do modelo ETE-usuário}

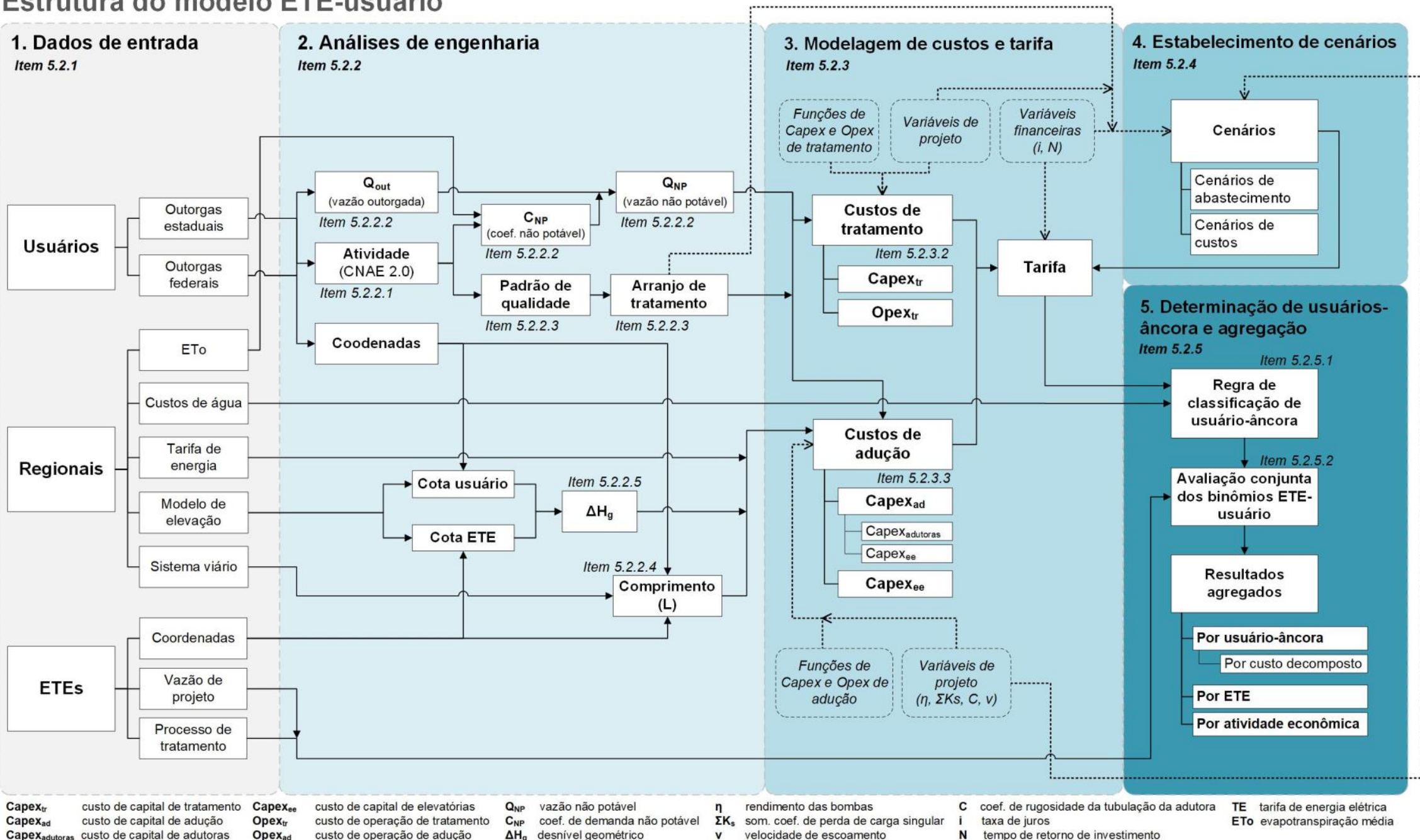

Figura 23: Estrutura do modelo ETE-usuário

Fonte: elaborado pelo autor 


\subsubsection{Entrada de dados}

Definiu-se que os dados de entrada se dividem em três grupos: usuários, ofertas e regionais. Para cada um desses grupos é necessário o uso de diferentes tipos de bases de dados.

Usuários: dados que se referem a características dos potenciais usuários de água de reúso. Optou-se pelo uso de registros outorgas de captação para identificação e caracterização dos usuários. As outorgas são os únicos dados indicativos de consumo atualmente disponíveis no Brasil que possuem atributos suficientes para espacialização individual. Demais informações são apresentadas em escalas mais amplas e pouco detalhadas, sempre agregadas por município ou ottobacia, impedindo a adequada identificação de usuários e realização de análises precisas. As outorgas também permitem identificação da atividade econômica. Usuários ligados à rede, ainda que possam ter expressiva relevância, não são passíveis de detecção individual, uma vez que as concessionárias não publicam tampouco disponibilizam sob consulta essa informação.

No Brasil, outorgas de águas subterrâneas e de rios estaduais são de responsabilidade de autoridades estaduais, enquanto para rios federais as outorgas são concedidas pela Agência Nacional de Águas. Portanto, será sempre necessária consulta e compatibilização de bases de dados federais e estaduais, a não ser em regiões onde comprovadamente não haja nenhum corpo hídrico de domínio da União.

Para todos os casos, as vazões utilizadas são as médias em $\mathrm{m}^{3} / \mathrm{s}$, ou seja, o volume de água demandado em um ano em $\mathrm{m}^{3}$ dividido por 365 dias x $86.400 \mathrm{~s} /$ dia.

Oferta: dados de estações de tratamento de esgotos (ETEs) ativas para identificação e caracterização das potenciais ofertas de água de reúso. Foram considerados dados de vazão de projeto, localização (coordenadas) e processo de tratamento.

Regionais: informações específicas sobre a área de estudo necessárias à aplicação do modelo, como sistema viário, Modelo Digital de Elevação (MDE), tarifas locais de água e de energia elétrica e evapotranspiração média (ETo). 
A Tabela 31 resume os grupos de dados de entrada apresentados acima, indicando também o uso das variáveis de interesse no modelo.

Tabela 31: Relação de bases de dados de entrada

\begin{tabular}{|c|c|c|c|}
\hline $\begin{array}{l}\text { Grupo de } \\
\text { dados }\end{array}$ & $\begin{array}{l}\text { Tipo de base de } \\
\text { dado }\end{array}$ & $\begin{array}{l}\text { Variáveis de } \\
\text { interesse }\end{array}$ & Utilizado no modelo para \\
\hline \multirow{3}{*}{ Usuário } & \multirow{3}{*}{$\begin{array}{l}\text { Registros de outorgas } \\
\text { de captação } \\
\text { estaduais e federais } \\
\text { ativas }\end{array}$} & Vazões outorgadas & $\begin{array}{l}\text { Determinação das vazões de água não } \\
\text { potável }\end{array}$ \\
\hline & & $\begin{array}{l}\text { Identificação do } \\
\text { usuário (nome / } \\
\text { CNPJ) }\end{array}$ & $\begin{array}{l}\text { Identificação da atividade econômica para } \\
\text { caracterização do usuário }\end{array}$ \\
\hline & & Coordenadas & $\begin{array}{l}\text { Localização do usuário para traçado de } \\
\text { adutora }\end{array}$ \\
\hline \multirow{3}{*}{ Oferta } & \multirow{3}{*}{$\begin{array}{l}\text { Bases de dados de } \\
\text { ETEs em operação } \\
\text { das concessionárias } \\
\text { atuantes }\end{array}$} & Vazões de projeto & $\begin{array}{l}\text { Comparação com as vazões potenciais de } \\
\text { reúso }\end{array}$ \\
\hline & & $\begin{array}{l}\text { Processo de } \\
\text { tratamento }\end{array}$ & $\begin{array}{l}\text { Avaliação geral do potencial de reúso na } \\
\text { área }\end{array}$ \\
\hline & & Coordenadas & $\begin{array}{l}\text { Localização da ETE para traçado da } \\
\text { adutora }\end{array}$ \\
\hline \multirow{5}{*}{ Regionais } & Sistema viário & $\begin{array}{l}\text { Malha viária (em } \\
\text { arquivo vetorial) }\end{array}$ & $\begin{array}{l}\text { Traçado conceitual de adutoras para } \\
\text { distribuição de água de reúso }\end{array}$ \\
\hline & $\begin{array}{l}\text { Modelo Digital de } \\
\text { Elevação (MDE) }\end{array}$ & $\begin{array}{l}\text { Cotas (em arquivo } \\
\text { tipo raster) }\end{array}$ & $\begin{array}{l}\text { Determinação de desnível geométrico para } \\
\text { cálculo de potência requerida na adução }\end{array}$ \\
\hline & $\begin{array}{l}\text { Custos locais de } \\
\text { água }\end{array}$ & Tarifas praticadas & $\begin{array}{l}\text { Identificação de usuários-âncora pela } \\
\text { comparação das tarifas mínimas } \\
\text { praticáveis }\end{array}$ \\
\hline & $\begin{array}{l}\text { Custos energia } \\
\text { elétrica }\end{array}$ & $\begin{array}{l}\text { Tarifa de energia } \\
\text { elétrica }\end{array}$ & Estimativa de custos \\
\hline & $\begin{array}{l}\text { Evapotranspiração } \\
\text { média (ETo) }\end{array}$ & $\begin{array}{l}\text { Evapotranspiração } \\
\text { média na região }\end{array}$ & $\begin{array}{l}\text { Cálculo de } \mathrm{C}_{\mathrm{NP}} \text { para demandas de } \\
\text { irrigação }\end{array}$ \\
\hline
\end{tabular}

\subsubsection{Análises de engenharia}

A partir dos dados de entrada são previstas análises que fornecem subsídio à etapa de modelagem de custos.

\subsubsection{Classificação dos usuários por atividade econômica}

Uma vez que o uso de água não potável varia de acordo com a atividade econômica (especialmente para a indústria), os usuários foram classificados de acordo com seus ramos de atividade. Foram utilizadas as tipologias determinadas pela Classificação Nacional de Atividades Econômicas 2.0 (CNAE 2.0) (IBGE, 2018), as quais se dividem em seção, divisão, grupo, classe e subclasse. Foram selecionadas as divisões das seções $\mathrm{A}$ e $\mathrm{F}$ e suas respectivas divisões, conforme a Tabela 32. A relação completa com as divisões CNAE 2.0 contempladas consta no ANEXO A. 
Tabela 32: Seções e divisões da CNAE 2.0 utilizadas na classificação de usuários segundo atividade econômica

\begin{tabular}{ll}
\hline Seção CNAE 2.0 & Divisão CNAE 2.0 \\
\hline $\begin{array}{l}\text { A - Agricultura, pecuária, produção florestal, } \\
\text { pesca e aquicultura }\end{array}$ & 1 a 3 \\
\hline B - Indústrias extrativas & 4 a 9 \\
\hline C - Indústrias de transformação & 10 a 33 \\
\hline D - Eletricidade e gás & 35 \\
\hline $\begin{array}{l}\text { E - Água, esgoto, atividades de gestão de } \\
\text { resíduos e descontaminação }\end{array}$ & 36 a 39 \\
\hline F - Construção & 41 a 43 \\
\hline
\end{tabular}

Fonte: IBGE (2018)

É padrão que bases de dados de outorga apresentem ao menos um dado que permita a caracterização da atividade econômica do usuário. Em geral constam o nome do requerente, nome fantasia (no caso de empresas) e, em alguns casos, o Cadastro Nacional de Pessoa Jurídica (CNPJ). Consultas simples na internet a partir de alguma dessas informações permitem a classificação dos usuários segundo a CNAE 2.0.

\subsubsection{Demanda não potável ( $\left.Q_{N P}\right)$ e Coeficiente não potável ( $\left.C_{N P}\right)$}

No caso da indústria, nem todas as demandas de um usuário podem ser abastecidas por água de qualidade não potável; para irrigação, as demandas sofrem intensas variações ao longo do ano em razão da sazonalidade. Assim sendo, é necessário ajustar os valores de demanda, conforme também aplicado por Coroado Consortium (2012) e Sabesp (2010a), a partir de estimativas de literatura sobre a decomposição do consumo de água de acordo com a atividade.

Como explicado no item 5.2.1, o modelo adota as vazões outorgadas para determinação das demandas de cada usuário, levando também em consideração as atividades econômicas exercidas. Para ajuste das vazões foram propostas duas variáveis: o Coeficiente de Demanda Não Potável ( $\left.C_{N P}\right)$ e a Vazão Não Potável (QNP).

O C $C_{N P}$ representa a porcentagem da demanda de determinado usuário que pode ser suprida por água de qualidade não potável em relação à vazão total demandada (no caso, a outorgada). A QNP é simplesmente o produto da vazão outorgada média (Qout) pelo $\mathrm{CNP}_{\mathrm{N}}$, conforme a Equação 8. 


$$
Q_{N P}=Q_{o u t} \times C_{N P}
$$

$\begin{array}{ll}\text { QNP } & \text { vazão não potável } \\ \text { Qout } & \text { vazão outorgada } \\ \text { CNP (\%) } & \text { coeficiente de demanda não potável }\end{array}$

O $\mathrm{C}_{\mathrm{NP}}$ foi determinado de formas diferentes a depender do tipo de uso:

- Usos de irrigação (divisões 1 a 4 da CNAE 2.0) assumiu-se que a vazão outorgada corresponde à demanda máxima ao longo do ano, e, por isso, são necessárias correções para obtenção de demanda média. $O$ ajuste foi feito a partir de estimativa de evapotranspiração média mensal local.

- Usos industriais (divisões 5 a 43 da CNAE 2.0): a porcentagem passível de atendimento por água não potável é igual à representatividade dos usos para resfriamento em TR (torres de resfriamento), conforme estudado no item 3.2.3.2.

No caso da irrigação, o uso de água visa a, essencialmente, repor as perdas que ocorrem por evapotranspiração (ETo), o que lhe confere caráter sazonal e sujeição a variações climáticas e características hidrogeológicas locais (U.S. EPA, 2012).

Assumindo-se que as vazões outorgadas correspondem às demandas de período de estiagem, é razoável deduzir que a vazão média real ao longo do ano é inferior à outorgada. Como a demanda mensal é a subtração entre a precipitação e a evapotranspiração (Demanda $a_{\text {irrigação }}=P-E T o$ ), definiu-se que $C_{N P}$ para irrigação é calculado pela Equação 9.

$$
\begin{aligned}
& C_{N P, i r r}=\frac{\sum_{i}^{N}\left(P_{i}-E T o_{i}\right)}{\operatorname{máx}\left\{P_{i}-E T o_{i}\right\} \times N} \\
& \mathrm{C}_{\mathrm{NP} \text {,irr }} \quad \text { coef. não potável de irrigação } \\
& \mathrm{Pi}_{\mathrm{i}} \quad \text { precipitação média no mês "i" } \\
& \text { EToi evapotranspiração média no mês "i" } \\
& \mathrm{N} \quad \text { meses/ano (12) }
\end{aligned}
$$

Equação 9

Ou seja, a partir da assunção de que a vazão outorgada corresponde à máxima

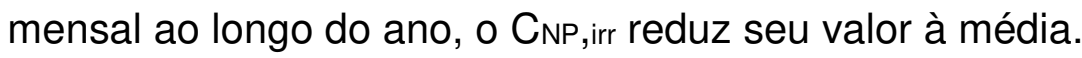

Para a indústria, foram utilizados valores presentes em literatura (ver item 3.2.3.2) de acordo com as divisões da CNAE 2.0 de cada usuário. Foram adotados valores 
médios presentes em literatura sempre que encontrada similaridade com as divisões

CNAE 2.0.

A Tabela 33 apresenta os valores de CNP obtidos para as divisões 1 a 43 da CNAE 2.0 .

Tabela 33: Coeficiente de demanda não potável $\left(C_{N P}\right)$ por divisões (1 a 43) da CNAE 2.0

\begin{tabular}{|c|c|c|}
\hline \multicolumn{2}{|c|}{ Divisão CNAE 2.0} & \multirow{2}{*}{$\begin{array}{l}\mathbf{C}_{\mathrm{NP}} \\
\text { De acordo com a } \\
\text { região (Equação 9) }\end{array}$} \\
\hline 1 & Agricultura, pecuária e serviços relacionados & \\
\hline 2 & Produção florestal & $\begin{array}{l}\text { De acordo com a } \\
\text { região (Equação 9) }\end{array}$ \\
\hline 3 & Pesca e aquicultura & (a) \\
\hline 5 & Extração de carvão mineral & (a) \\
\hline 6 & Extração de petróleo e gás natural & (a) \\
\hline 7 & Extração de minerais metálicos & (a) \\
\hline 8 & Extração de minerais não-metálicos & (a) \\
\hline 9 & Atividades de apoio à extração de minerais & $3 \%$ \\
\hline 10 & Fabricação de produtos alimentícios & $50 \%$ \\
\hline 11 & Fabricação de bebidas & $61 \%$ \\
\hline 12 & Fabricação de produtos do fumo & $66 \%$ \\
\hline 13 & Fabricação de produtos têxteis & $36 \%$ \\
\hline 14 & Confecção de artigos do vestuário e acessórios & $17 \%$ \\
\hline 15 & $\begin{array}{l}\text { Preparação de couros e fabricação de artefatos de couro, artigos para viagem e } \\
\text { calçados }\end{array}$ & $7 \%$ \\
\hline 16 & Fabricação de produtos de madeira & $38 \%$ \\
\hline 17 & Fabricação de celulose, papel e produtos de papel & $26 \%$ \\
\hline 18 & Impressão e reprodução de gravações & $3 \%$ \\
\hline 19 & Fabricação de coque, de produtos derivados do petróleo e de biocombustíveis & $87 \%$ \\
\hline 20 & Fabricação de produtos químicos & $86 \%$ \\
\hline 21 & Fabricação de produtos farmoquímicos e farmacêuticos & $92 \%$ \\
\hline 22 & Fabricação de produtos de borracha e de material plástico & $65 \%$ \\
\hline 23 & Fabricação de produtos de minerais não-metálicos & $66 \%$ \\
\hline 24 & Metalurgia & $60 \%$ \\
\hline 25 & Fabricação de produtos de metal, exceto máquinas e equipamentos & $9 \%$ \\
\hline 26 & Fabricação de equipamentos de informática, produtos eletrônicos e ópticos & $11 \%$ \\
\hline 27 & Fabricação de máquinas, aparelhos e materiais elétricos & $63 \%$ \\
\hline 28 & Fabricação de máquinas e equipamentos & $0 \%$ \\
\hline 29 & Fabricação de veículos automotores, reboques e carrocerias & $44 \%$ \\
\hline 30 & Fabricação de outros equipamentos de transporte, exceto veículos automotores & $44 \%$ \\
\hline 31 & Fabricação de móveis & $0 \%$ \\
\hline 32 & Fabricação de produtos diversos & $26 \%$ \\
\hline 33 & Manutenção, reparação e instalação de máquinas e equipamentos & $0 \%$ \\
\hline$--(2)$ & Outras indústrias de transformação(2) & $36 \%$ (b) \\
\hline 35 & Eletricidade, gás e outras utilidades & $68 \%$ \\
\hline 36 & Captação, tratamento e distribuição de água & (a) \\
\hline 37 & Esgoto e atividades relacionadas & (a) \\
\hline 38 & Coleta, tratamento e disposição de resíduos; recuperação de materiais & (a) \\
\hline 39 & Descontaminação e outros serviços de gestão de resíduos & (a) \\
\hline 41 & Construção de edifícios & (a) \\
\hline 42 & Obras de infraestrutura & (a) \\
\hline 43 & Serviços especializados para construção & (a) \\
\hline
\end{tabular}

(a) Correlação de atividade econômica não encontrada em literatura. $C_{N P}$ considerado igual a zero nesses casos.

(b) Outras atividades de transformação. Divisão inexistente na CNAE 2.0. $\mathrm{C}_{\mathrm{NP}}$ utilizado para as atividades de transformação para as quais não foi possível determinação de divisão de acordo com a CNAE 2.0.

Fonte: para a indústria, valores médios de Statistics Canada (2018), CNI (2017a), Moström (2015) e Van der Leeden et al. (1990) 


\subsubsection{Padrões de qualidade de água de reúso e arranjos de tratamento}

Com base nos usos previstos (irrigação e indústria), em padrões de qualidade tipicamente adotados em experiências de reúso (item 3.2.3) e em processos de tratamento disponíveis no mercado e economicamente viáveis (itens 3.2.4 e 3.2.5), foram definidos três padrões de qualidade de água distintos, identificados de acordo com suas características principais.

Os padrões foram denominados $\mathrm{P} 1, \mathrm{P} 2$ e P3 e se referem a diferentes qualidades de água de reúso. Suas características e correlação de atendimento a exigências legais de qualidade de corpos hídricos (corpos hídricos classe 2 do Conama 357/05) e a usos não potáveis industriais e de irrigação são apresentadas na Tabela 34.

Tabela 34: Padrões de qualidade P1, P2 e P3 definidos e relação

\begin{tabular}{|c|c|c|c|c|c|}
\hline \multirow{2}{*}{\multicolumn{2}{|c|}{ Padrão e características }} & \multirow{2}{*}{$\begin{array}{c}\begin{array}{c}\text { Atendimento } \\
\text { legal }\end{array} \\
\begin{array}{c}\text { Classe } 2^{(\text {a) }} \text { Conama } \\
357 / 05^{(\text {b) }}\end{array}\end{array}$} & \multicolumn{3}{|c|}{ Usos não potáveis } \\
\hline & & & $\begin{array}{c}\text { Irrigação } \\
\text { (uso irrestrito) }\end{array}$ & $\begin{array}{c}\text { Industrial } \\
\text { (usos gerais e } \\
\text { TR) }\end{array}$ & $\begin{array}{l}\text { Industrial } \\
\text { (caldeira) }\end{array}$ \\
\hline P1 & Clarificada e desinfetada & $\begin{array}{l}\text { Atende DBO, } \\
\text { turbidez e N-NH} 4\end{array}$ & OK & - & - \\
\hline P2 & $\begin{array}{l}\text { Clarificada, desnitrificada e } \\
\text { desinfetada }\end{array}$ & $\begin{array}{l}\text { Atende } \mathrm{DBO}, \\
\text { turbidez, } \mathrm{N}-\mathrm{NH}_{4} \mathrm{e} \\
\text { nitrato }\end{array}$ & OK & OK & - \\
\hline P3 & $\begin{array}{l}\text { Clarificada, desnitrificada, } \\
\text { desinfetada e } \\
\text { desmineralizada }\end{array}$ & $\begin{array}{l}\text { Atende } \mathrm{DBO}, \\
\text { turbidez, } \mathrm{N}-\mathrm{NH}_{4}, \\
\text { nitrato e } \mathrm{P}\end{array}$ & $\mathrm{OK}$ & OK & OK \\
\hline
\end{tabular}

(a) Classe 2: $\mathrm{DBO}_{5,20} \leq 5,0 \mathrm{mgO} / \mathrm{l}$; Turbidez $\leq 100 \mathrm{NTU} ; 1,0 \leq \mathrm{N}-\mathrm{NH}_{4} \leq 3,7 \mathrm{mg} / \mathrm{l}$ (para 7,5 $<\mathrm{pH}<8,5$ ); Nitrato $\leq 10$ $\mathrm{mg} / \mathrm{l} ; 0,030<\mathrm{P}_{\text {total }}<0,1 \mathrm{mg} / \mathrm{l}$.

(b) A resolução Conama 357/05 se refere à qualidade dos corpos hídricos, e não à do efluente lançado. No entanto, a resolução Conama 430/2011, que trata de padrões de lançamento, é demasiadamente leniente e prevê padrões de qualidade pouco exigentes e incompatíveis com a qualidade de água de reúso usualmente requerida para os usos propostos.

Algumas demandas não potáveis estão sujeitas a variações ao longo do ano, como o caso da irrigação (acordo com pluviosidade e ETo) e de usos em resfriamento (de acordo com temperatura e umidade do ar). Ou seja, em determinadas épocas esperase que haja excedente de água de reúso e consequente necessidade de lançamento em corpo hídrico. Por isso, os padrões levam em conta não somente as exigências dos usos finais, mas também requerimentos ambientais legais (Conama).

Os parâmetros de qualidade que compõem cada um dos padrões são conforme a Tabela 35. Os padrões foram definidos com base nas referências apresentadas no 
item 3.2.3, havendo também observância às exigências legais constantes no item 3.2.8.

Tabela 35: Padrões de referência de água de reúso não potáveis adotados

\begin{tabular}{llccc}
\hline \multirow{2}{*}{ Parâmetro } & \multirow{2}{*}{ Unidade } & \multicolumn{3}{c}{ Padrões de água de reúso } \\
\cline { 3 - 5 } & & P1 & P2 & P3 \\
\hline Coliformes termotolerantes & $\mathrm{UFC} / 100 \mathrm{ml}$ & Ausentes & Ausentes & Ausentes \\
\hline Ovos de helmintos & $\mathrm{ovo} / \mathrm{l}$ & $<1$ & - & - \\
\hline $\mathrm{DBO}_{5,20}$ & $\mathrm{mgO}_{2} / \mathrm{l}$ & $<20$ & $<10$ & $<10$ \\
\hline $\mathrm{DQO}$ & $\mathrm{mgO}_{2} / \mathrm{l}$ & - & $<20$ & $<20$ \\
\hline Turbidez & $\mathrm{NTU}$ & $<5,0$ & $<1,0$ & $<0,1$ \\
\hline SDT / condutividade elétrica & $\mathrm{mg} / \mathrm{l} / \mu \mathrm{S} / \mathrm{cm}$ & $<3.000 / 4.800$ & $<1.000 / 1.600$ & $<500 / 800$ \\
\hline Nitrogênio amoniacal & $\mathrm{mg} / \mathrm{l}$ & - & $<1,0$ & $<1,0$ \\
\hline Nitrato & $\mathrm{mg} / \mathrm{l}$ & - & $<1,0$ & $<1,0$ \\
\hline Fósforo total & $\mathrm{mg} / \mathrm{l}$ & - & - & $<0,1$ \\
\hline Cloro residual total & $\mathrm{mg} / \mathrm{l}$ & $1,0-3,0$ & $1,0-3,0$ & $1,0-3,0$ \\
\hline pH & - & $6,0-9,0$ & $6,0-9,0$ & $6,0-9,0$ \\
\hline
\end{tabular}

Com base em experiências exitosas de produção de água de reúso e em práticas de mercado (ver item 3.2.2) foram selecionados tecnologias e processos comumente empregados em estações, os quais são relacionados na Tabela 36. As siglas apresentadas na tabela serão adotadas para sua identificação a partir deste momento.

Tabela 36: Processos considerados para composição de arranjos de tratamento

\begin{tabular}{l|l}
\hline Sigla & Descrição \\
\hline MBR & Biorreator com membranas (UF) \\
\hline MBR(RN) & Biorreator com membranas (UF) e desnitrificação por reator anóxico \\
\hline OR & Osmose reversa \\
\hline UV & Radiação ultravioleta $\left(40 \mathrm{~mJ} / \mathrm{cm}^{2}\right)$ \\
\hline CL & Desinfecção com solução de hipoclorito de sódio \\
\hline
\end{tabular}

A Tabela 37 apresenta a eficiência esperada de cada um dos processos acima em relação aos parâmetros de qualidade que compõem os padrões, o que justifica os arranjos de tratamento que foram adotados. 
Tabela 37: Atuação de processos de tratamento sobre os parâmetros de qualidade

\begin{tabular}{|c|c|c|c|c|c|}
\hline \multirow{2}{*}{$\begin{array}{l}\text { Parâmetro de } \\
\text { qualidade }\end{array}$} & \multicolumn{5}{|c|}{ Processo/operação unitária } \\
\hline & MBR & MBR(RN) & OR & UV & $\mathbf{C L}$ \\
\hline $\begin{array}{l}\text { Coliformes } \\
\text { termotolerantes }\end{array}$ & +++ & +++ & +++ & +++ & +++ \\
\hline $\mathrm{DBO}_{5,20} / \mathrm{DQO}$ & +++ & +++ & -(a) & - & - (b) \\
\hline Turbidez & +++ & +++ & -(a) & - & - \\
\hline SDT & $+^{(\mathrm{c})}$ & $+^{(\mathrm{c})}$ & +++ & - & - \\
\hline Nitrogênio amoniacal & $+++(\mathrm{d})$ & $+++(\mathrm{d})$ & $+++(\mathrm{a})$ & - & -(b) \\
\hline Nitrato & - & +++ & +++ & - & - \\
\hline $\mathrm{P}$ total & - & - & +++ & - & - \\
\hline Cloro residual total & - & - & - & - & +++ \\
\hline Ovos de helmintos & +++ & +++ & +++ & - & - \\
\hline $\mathrm{pH}$ & $-(\mathrm{e})$ & $-(\mathrm{e})$ & $(\mathrm{f})$ & - & (g) \\
\hline
\end{tabular}

Classificação da atuação: - (nenhuma/não se aplica); + (baixa); ++ (média); +++ (alta)

(a) Retém compostos que implicam em DBO/turbidez e nitrogênio amoniacal, mas convém, para garantia de operação adequada e maior vida útil da membrana, que estes compostos sejam removidos à montante.

(b) Possui efeito na oxidação de compostos orgânicos e nitrogênio amoniacal, mas convém, por razões de economia com dosagem, realizar oxidação biológica à montante.

(c) Ação limitada a alguns íons bivalentes de acordo com o tipo de membrana.

(d) Idade do lodo de sistemas MBR garante possibilidade de nitrificação completa, desde que haja OD suficiente.

(e) Nitrificação "consome" alcalinidade, o que pode levar a reduções de pH por perda de "efeito tampão" caso o eventual déficit de alcalinidade não seja corrigido. Quando da existência de desnitrificação, parte da alcalinidade é "reposta", reduzindo a necessidade de correção.

(f) Remoção de íons pode levar à necessidade de correção de $\mathrm{pH}$.

(g) Adição de solução de cloro pode alterar o pH.

A partir dos processos/tecnologias (Tabela 36) e de sua correlação com os padrões de qualidade (Tabela 37), foram definidos três arranjos de tratamento. Os arranjos, suas características e o padrão ao qual atendem são apresentados na Tabela 38. Cada arranjo é nomeado pela concatenação das siglas que identificam os processos que os compõem.

Tabela 38: Arranjos de tratamento para produção de água de reúso

\begin{tabular}{|c|c|c|}
\hline $\begin{array}{l}\text { Arranjo de } \\
\text { tratamento }\end{array}$ & Características & Padrão \\
\hline \multirow{4}{*}{$\mathrm{MBR}+\mathrm{CL}$} & o Sistema biológico com membranas de UF. & \multirow{4}{*}{ P1 } \\
\hline & $\begin{array}{l}\text { - Nitrificação completa garantida pela alta idade do lodo de sistemas } \\
\text { MBR. }\end{array}$ & \\
\hline & $\begin{array}{l}\text { - Aplicação de solução de hipoclorito de sódio para } \\
\text { desinfecção/oxidação final e manutenção de cloro na distribuição e } \\
\text { reservação. }\end{array}$ & \\
\hline & $\begin{array}{l}\text { - Produção de água com baixas } \mathrm{DBO}_{5,20} \text { e turbidez, mas sem remoção } \\
\text { de nitrogênio (nitrato) e de sólidos dissolvidos }\end{array}$ & \\
\hline \multirow{3}{*}{$\begin{array}{l}\text { MBR(RN) + } \\
\text { UV + CL }\end{array}$} & ○ Sistema biológico com membranas de UF. & \multirow{3}{*}{ P2 } \\
\hline & $\begin{array}{l}\text { - Nitrificação completa garantida pela alta idade do lodo de sistemas } \\
\text { MBR. }\end{array}$ & \\
\hline & $\begin{array}{l}\text { - Pré-desnitrificação em tanque anóxico. Adição de etapa de } \\
\text { desnitrificação resulta em aumento do Capex por conta de câmara }\end{array}$ & \\
\hline
\end{tabular}




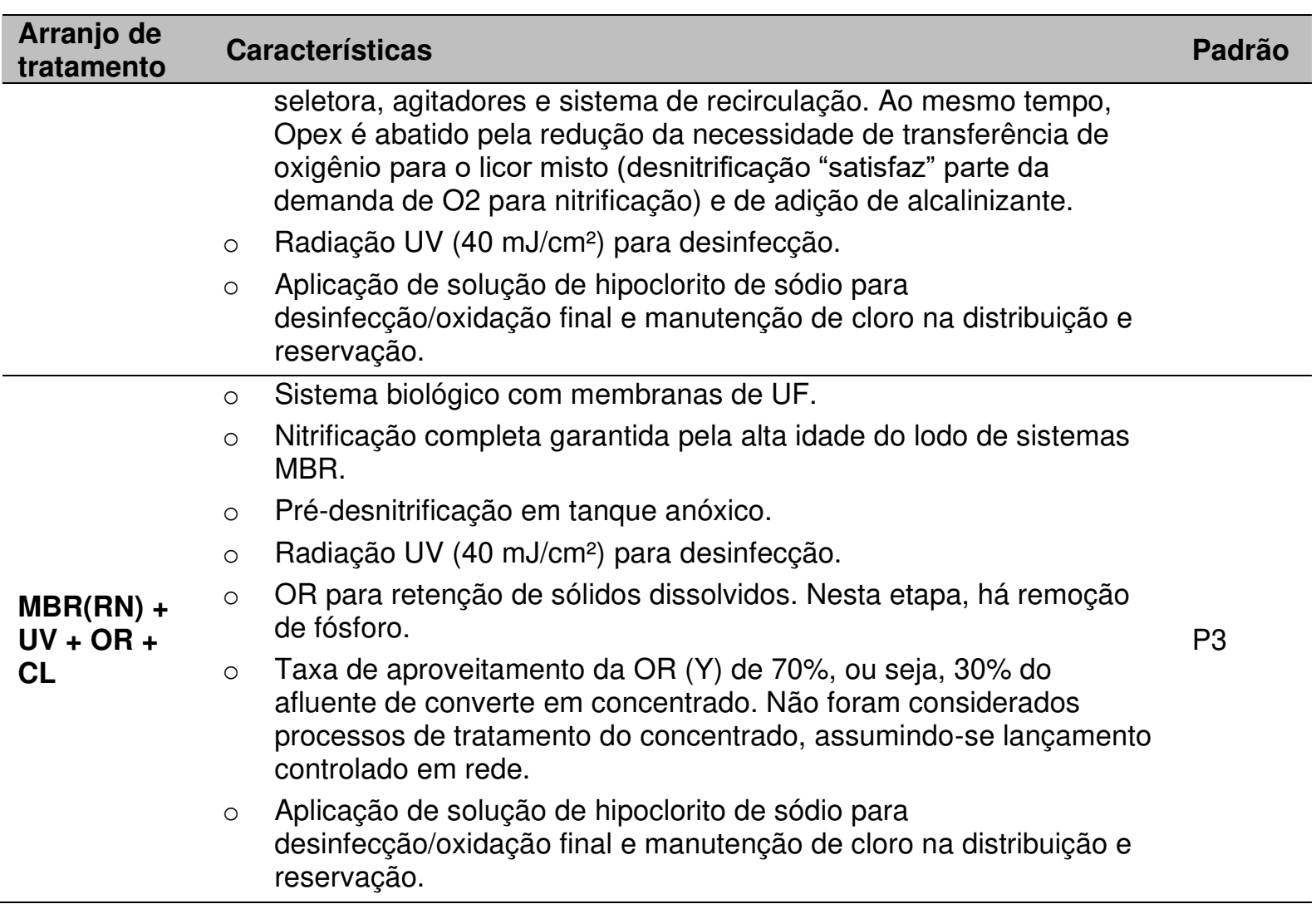

\subsubsection{Traçado de adutoras e determinação de desnível geométrico}

Para estimativa dos custos de distribuição é necessário compreender características da adutora que conecta o produtor de água de reúso (ETE) ao usuário. As principais variáveis a serem determinadas são o comprimento da adutora $(L)$ e o desnível geométrico $\left(\Delta \mathrm{H}_{\mathrm{g}}\right)$, as quais são aplicadas para estimativa da Altura Manométrica Total (AMT) do sistema elevatório. O modelo prevê obtenção de ambas em ambiente SIG.

O comprimento de adutoras $(\mathrm{L})$ foi determinado como sendo igual ao caminho mínimo entre a ETE e a outorga de captação a partir de traçado sobre o sistema viário. A distância euclidiana, isto é, a reta que conecta os dois pontos (ETE e usuário), não representa de forma apropriada o caminhamento de uma possível adutora, dado que o traçado hidráulico em áreas urbanas geralmente segue a malha viária.

Recursos nativos do QGIS e o plugin QNEAT3 permitem a determinação dos caminhos mínimos (shortest path) entre cada ETE e usuário. O algoritmo percorre os atributos vetoriais do arquivo do sistema viário partindo do ponto mais próximo à origem (ETE) até o mais próximo ao destino (outorga), considerando também as 
distâncias euclidianas para trechos não contemplados pela malha viária. Isso tem especial relevância no caso de ETEs ou outorgas localizadas em áreas afastadas de quaisquer logradouros. Considerando a terminologia adotada pelo QNEAT3, a distância total considerada é a soma de network cost, entry cost e exit cost, conforme ilustrado na Figura 24.

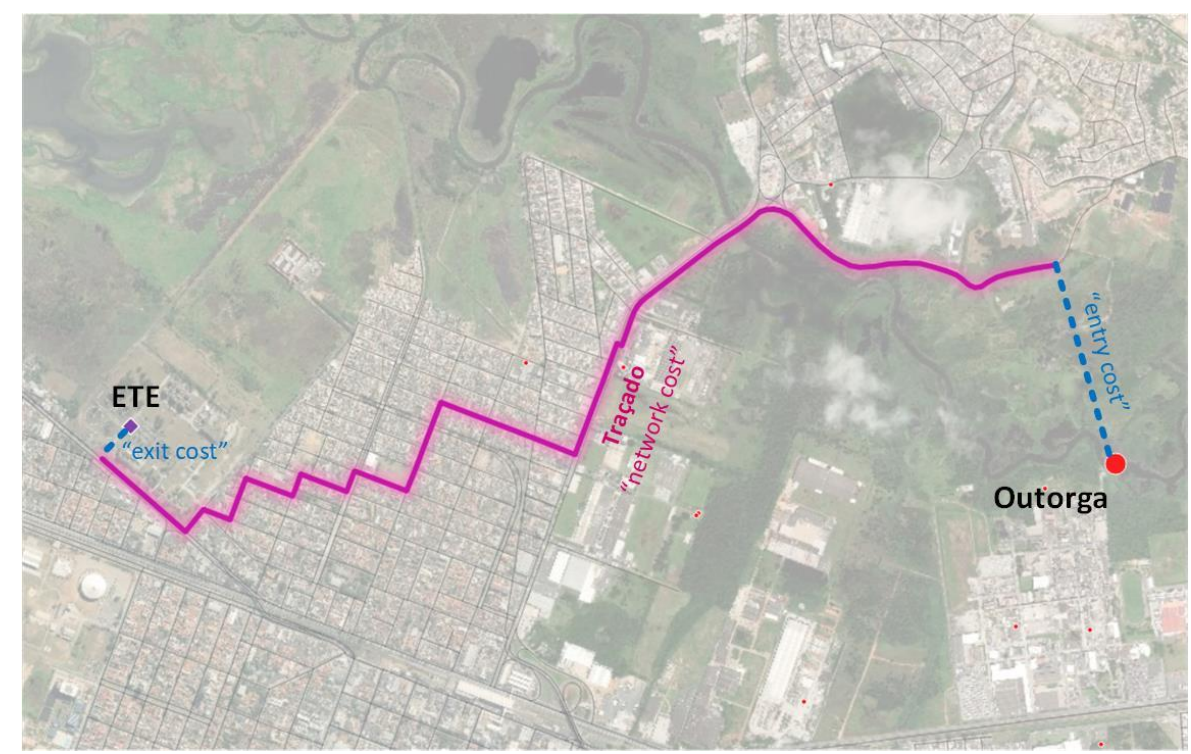

Figura 24: Exemplo de determinação do comprimento de adutoras (L) utilizando-se QNEAT3 no QGIS3 com base em arquivo vetorial de sistema viário

Fonte: elaborado pelo autor

O desnível geométrico $\left(\Delta \mathrm{H}_{\mathrm{g}}\right)$ foi considerado como igual à diferença de cotas entre a ETEs e o usuário. A obtenção das cotas pode ser realizada sobrepondo-se as camadas de outorgas e ETEs (shapefiles) na do Modelo Digital de Elevação (MDE) (raster) e realizando a extração pelo plugin Point Sampling Tool.

$\mathrm{O} \Delta \mathrm{H}_{\mathrm{g}}$ é igual, portanto, à subtração $\Delta H g=Z_{E T E}-Z_{\text {outorga }}$. Definiu-se que o valor mínimo de $\Delta \mathrm{H}_{\mathrm{g}}$ é de $10 \mathrm{~m}$, de maneira a se contemplar as necessidades mínimas de elevação de cota na própria estação e na linha de adução, conforme regra da Equação 10.

$\Delta H_{g}=\left\{\begin{array}{rr}Z_{E T E}-Z_{\text {out }}, & \Delta H_{g} \geq 10 \\ 10, & \Delta H_{g}<10\end{array}\right.$

$\Delta \mathrm{H}_{\mathrm{g}}(\mathrm{m}) \quad$ desnível geométrico

$\mathrm{Z}_{\mathrm{ETE}}(\mathrm{m}) \quad$ cota da ETE

$\mathrm{Z}_{\text {out }}(\mathrm{m}) \quad$ cota do ponto outorgado 
Uma observação importante é que se adotou que o desnível geométrico máximo é a diferença de cotas entre a ETE e a outorga, o que não é necessariamente verdadeiro em uma situação de projeto. A depender do perfil do terreno, há pontos mais altos a serem vencidos, a partir dos quais, inclusive, o escoamento pode ocorrer por gravidade. No entanto, uma vez que os custos estimados são em nível conceitual, e não de projeto, essa simplificação foi considerada aceitável.

A Figura 25 ilustra um exemplo de traçados de adutoras entre uma ETE e todos os usuários da área de estudo, bem como o Modelo Digital de Elevação (MDE).

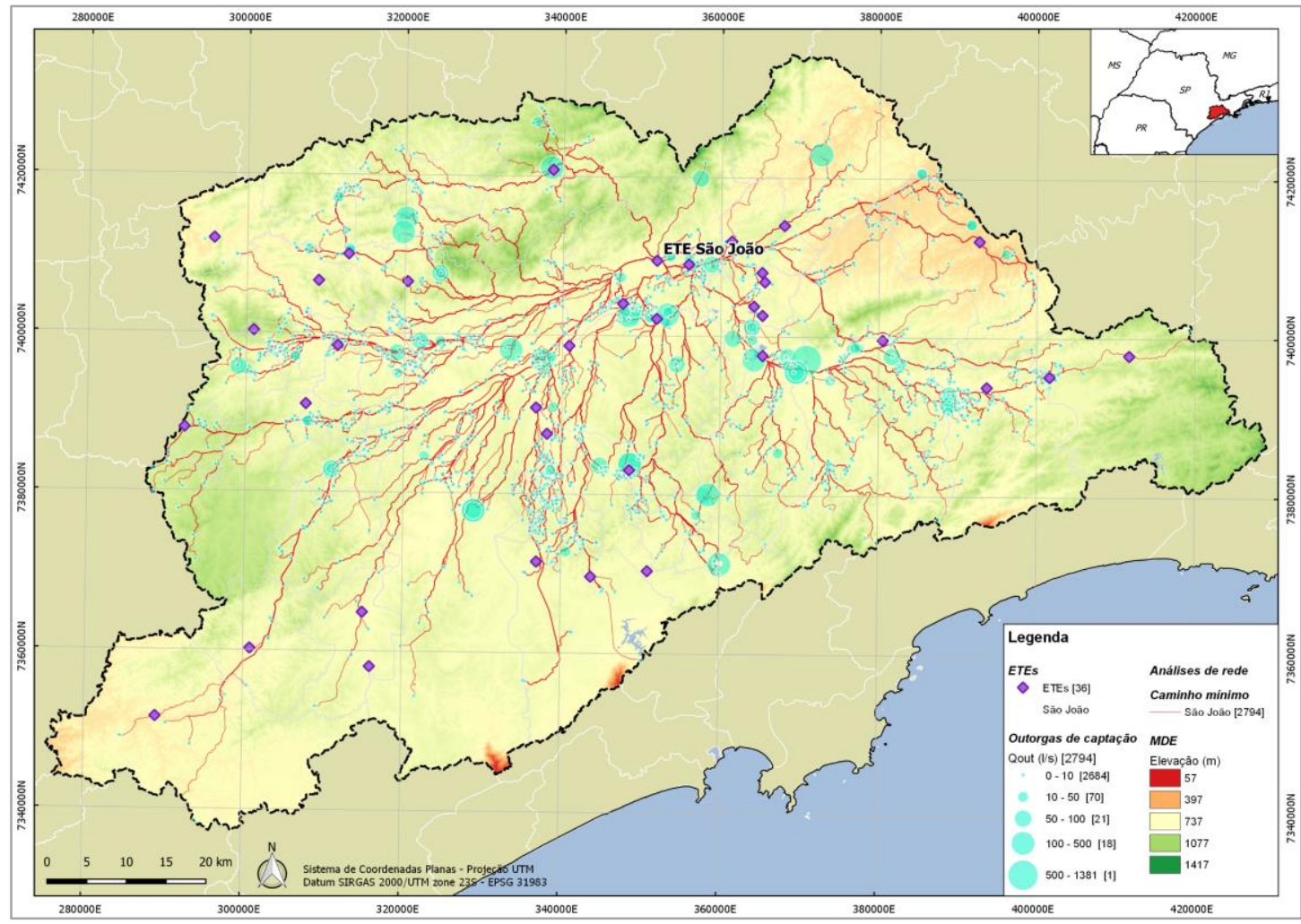

Figura 25: Exemplo (ETE São João, Guarulhos) de determinação de distâncias entre ETEs e usuários e de extração de elevação de ETEs e usuários.

Fonte: elevações segundo o MDE (SMA/CPLA/DIA, 2013). Elaborado pelo autor

\subsubsection{Modelagem de custos}

\subsubsection{Funções de custo de capital e de operação}

A modelagem de custos foi dividida em quatro principais componentes, sendo adotadas as siglas em língua inglesa Capex (capital expenditures, ou custos de 
capital) e Opex (operational expenditures, ou custos de operação e manutenção) para descrevê-las, a saber:

- Capextrat: custos de capital com tratamento. Compreende custos com a implantação de unidades de tratamento para adequação de efluente secundário para produção de água de reúso. Depende dos arranjos determinados no tópico 5.2.2.3.

- Opextrat: custos de operação e manutenção $(\mathrm{O} \& M)$ com tratamento. Custos de energia elétrica, insumos, mão-de-obra, depreciação etc. necessários para operação e manutenção dos sistemas produtores de água de reúso. Depende dos arranjos determinados no tópico 5.2.2.3.

- Capexad: custos de capital com adução. Divide-se em duas subcomponentes:

- Capexadutoras: custos de capital com a implantação de adutoras, considerando tubulações, escavação, assentamento e recomposição. Depende do diâmetro da tubulação e do comprimento da adutora.

- Capexee: custos de capital com a implantação de sistemas elevatórios. Depende da potência requerida pelo sistema, o que, por sua vez, é função de vazão aduzida e altura manométrica total (AMT) do sistema.

- Opexad: custos de operação e manutenção (O\&M) com adução. Custos de energia elétrica para pressurização de água de reúso para distribuição, bem como manutenção do sistema. Depende da AMT do sistema elevatório e tarifa de energia elétrica.

A Figura 26 ilustra a decomposição de custos adotada. 


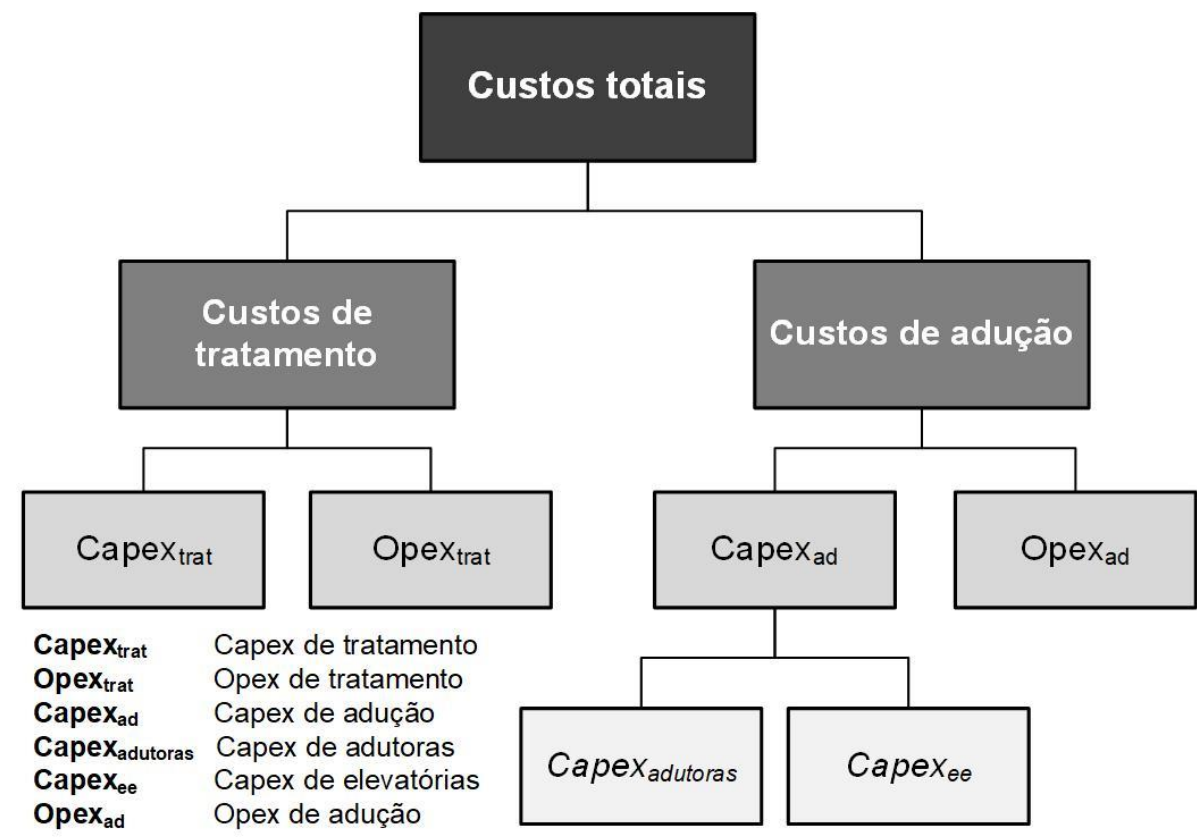

Figura 26: Diagrama com estrutura de componentes de custos de tratamento e distribuição de água de reúso

Conforme apresentado no item 3.2.5, sistemas centralizados de tratamento levam a ganhos de escala, mas também tendem a requerer maiores investimentos na distribuição da água produzida. De maneira a se contemplar variações de escala, a modelagem foi realizada com base em funções de custos, evitando-se sempre que possível o uso de valores unitários fixos. As equações são funções de diferentes variáveis a depender do componente de custo.

Todos os custos foram calculados em dólares americanos (USD) por duas principais razões: i) os arranjos de tratamento preveem o uso de membranas (UF e/ou OR), as quais ainda não são fabricadas no Brasil e estão sujeitas às variações de câmbio; ii) instabilidade do Real (BRL) nos últimos meses, o que pode levar a demasiada volatilidade das estimativas. Todos os valores foram corrigidos para set/2019 pelo índice Construction Cost Index $(\mathrm{CCI})^{10}$ da Engineering News-Record (ENR) e pela a cotação monetária média do ano-base da fonte de dados.

\footnotetext{
${ }^{10}$ Disponíveis em: https://www.nrcs.usda.gov/wps/portal/nrcs/main/national/technical/econ/prices/
} 
Neste tópico são apresentadas somente as funções finais obtidas, e informações complementares constam no ANEXO A.

\subsubsection{Custos de tratamento - Capextrat e Opextrat}

As funções de Capextrat e Opextrat resultantes são as apresentadas na Tabela 39.

Tabela 39: Funções de Capex tr $_{\text {e Opex }}$ por processo de tratamento

\begin{tabular}{ll|l}
\hline Item & $\begin{array}{l}\text { Função de Capex } \\
\mathrm{C}\left(\mathrm{USD} / \mathrm{m}^{3} / \mathrm{ano}\right) \mathrm{e} Q\left(\mathrm{~m}^{3} / \mathrm{s}\right)\end{array}$ & $\begin{array}{l}\text { Função de Opex } \\
\mathrm{C}\left(\mathrm{USD} / \mathrm{m}^{3}\right) \text { e } \mathrm{Q}\left(\mathrm{m}^{3} / \mathrm{s}\right)\end{array}$ \\
\hline $\mathrm{MBR}$ & $C=2,757 Q^{-0,251}$ & $C=0,2882 Q^{-0,09}$ \\
\hline $\mathrm{MBR}(\mathrm{RN})$ & $C=2,821 Q^{-0,25}$ & $C=0,2831 Q^{-0,089}$ \\
\hline OR ${ }^{(a)}$ & $C=-0,392 \ln (Q)+1,585$ & $C=0,270 Q^{-0,269}$ \\
\hline $\mathrm{UV}$ & $C=0,0735 Q^{-0,274}$ & $C=0,029 Q^{-0,436}$ \\
\hline $\mathrm{CL}$ & $C=0,0076 \mathrm{Q}^{-0,66}$ & $C=0,01$ \\
\hline
\end{tabular}

MBR: biorreator com membranas. MBR(RN): biorreator com membranas e desnitrificação por reator anóxico. OR: osmose reversa. UV: radiação ultravioleta. CL: desinfecção com solução de hipoclorito de sódio.

a) Para o caso de OR, a vazão de entrada deve considerar as perdas por geração de rejeito/concentrado. Ou seja, $Q_{e f l}=Q_{a f l} \times Y$, sendo Y o índice de aproveitamento do sistema. Valor padrão de $\mathrm{Y}$ adotado foi de $70 \%$, havendo variação de 60 a $80 \%$ nos cenários de custos.

Os custos acima se referem à vazão de saída das plantas/processos, isto é, à capacidade de produção de água. Isso é relevante no caso de OR, já que a geração de concentrado pode chegar a valores de até $50 \%$ da vazão afluente. Em outras palavras, as perdas por geração de lodo biológico e/ou rejeito de OR já estão contempladas. Os gráficos da Figura 27 (Capextrat) e Figura 28 (Opextrat) ilustram o comportamento gráfico das funções. 

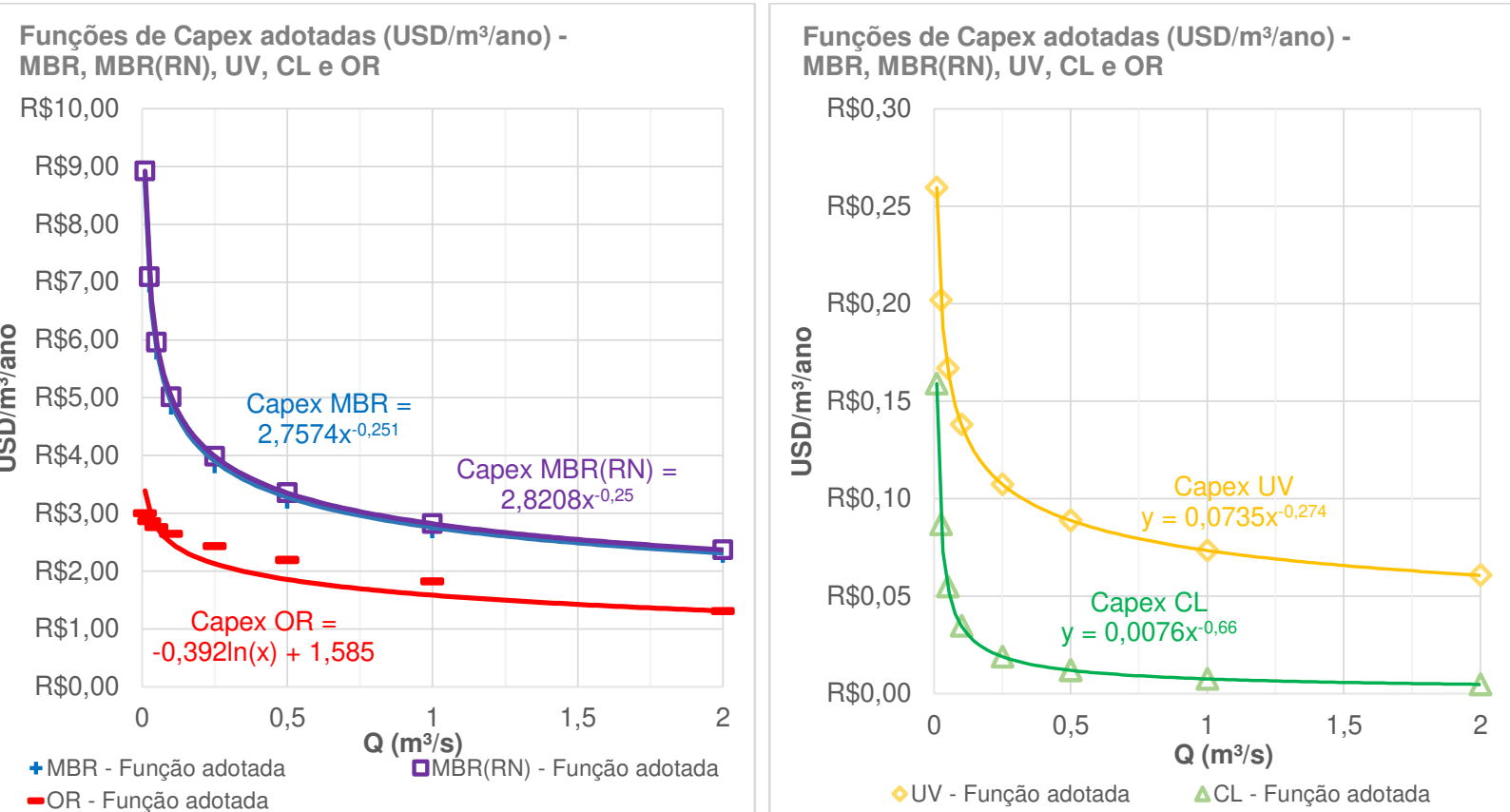

-OR - Função adotada

Figura 27: Funções de Capex de tratamento (Capex ${ }_{\text {trat }}$ ) adotadas

Funções de Opex adotadas (USD/m³/ano) MBR, MBR(RN) e OR

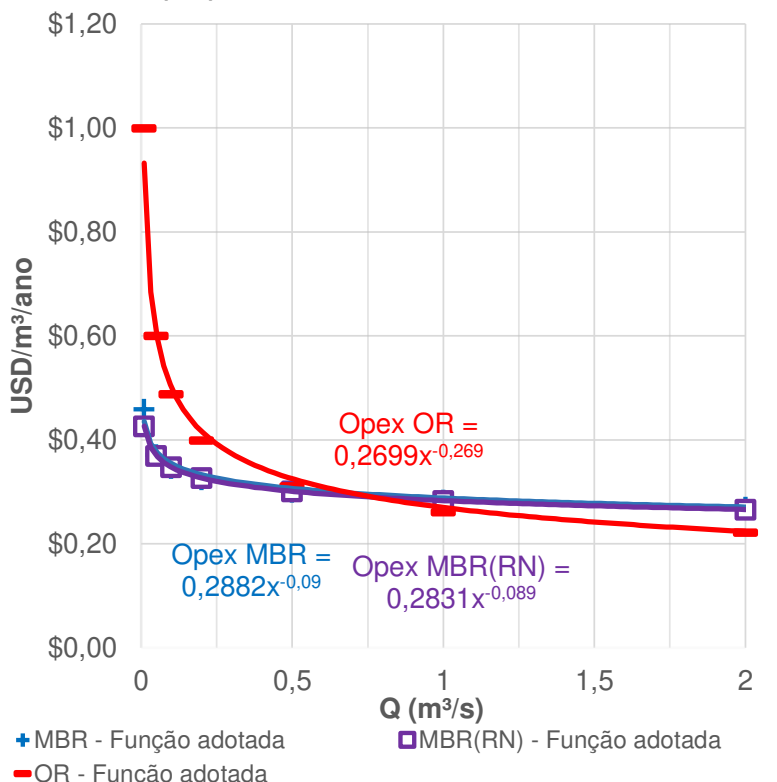

Funções de Opex adotadas (USD/m³/ano) UV e CL

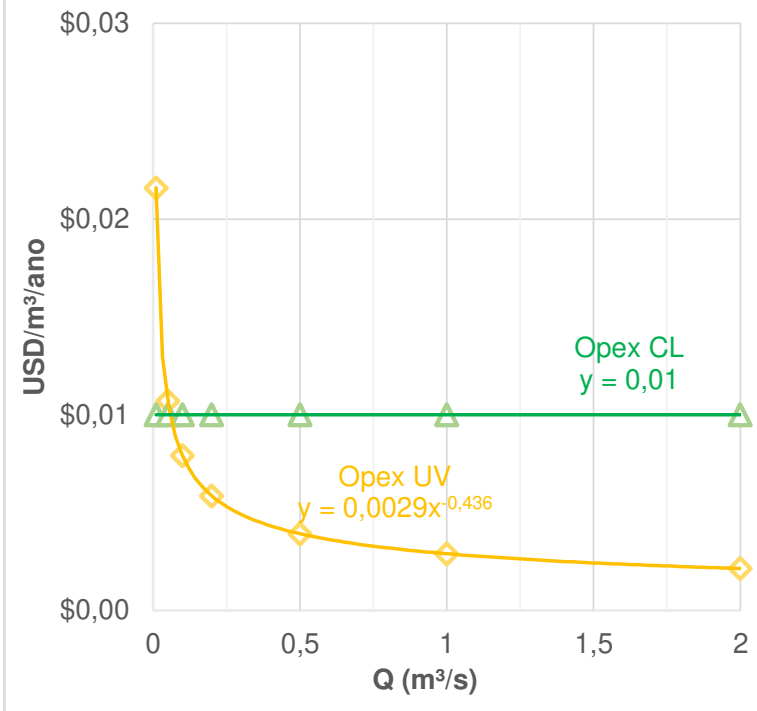

$\bullet$ UV - Função adotada $\quad \Delta \mathrm{CL}$ - Função adotada

Figura 28: Funções de Opex de tratamento (Opex trat$_{\text {) }}$ adotadas

As funções de custos dos arranjos de tratamento são a composição das funções de cada processo individual, e são conforme apresenta a Tabela 40. 


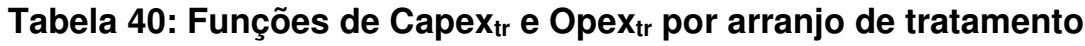

\begin{tabular}{ll|l}
\hline Item & $\begin{array}{l}\text { Função de Capex } \\
\mathrm{C}\left(\mathrm{USD} / \mathrm{m}^{3} / \mathrm{ano}\right) \text { e } \mathrm{Q}\left(\mathrm{m}^{3} / \mathrm{s}\right)\end{array}$ & $\begin{array}{l}\text { Função de Opex } \\
\mathrm{C}\left(\mathrm{USD} / \mathrm{m}^{3}\right) \text { e } \mathrm{Q}\left(\mathrm{m}^{3} / \mathrm{s}\right)\end{array}$ \\
\hline $\mathrm{MBR}+\mathrm{CL}$ & $C=2,357 Q^{-0,269}$ & $C=0,298 Q^{-0,087}$ \\
\hline $\mathrm{MBR}(\mathrm{RN})+\mathrm{UV}+\mathrm{CL}$ & $C=2,429 Q^{-0,267}$ & $C=0,320 Q^{-0,147}$ \\
\hline $\mathrm{MBR}(\mathrm{RN})+\mathrm{UV}+\mathrm{OR}+\mathrm{CL}^{\text {(a) }}$ & $C=4,01 Q^{-0,236}$ & $C=0,634 Q^{-0,212}$ \\
\hline
\end{tabular}

(a) Para o caso de OR, a vazão de entrada deve considerar as perdas por geração de rejeito/concentrado. Ou seja, $Q_{e f l}=Q_{a f l} \times Y$, sendo Y o índice de aproveitamento do sistema. Valor padrão de Y adotado foi de $70 \%$, havendo variação de 60 a $80 \%$ nos cenários de custos.

A Figura 29 apresenta as funções de Capextrat e Opextrat para os três arranjos.

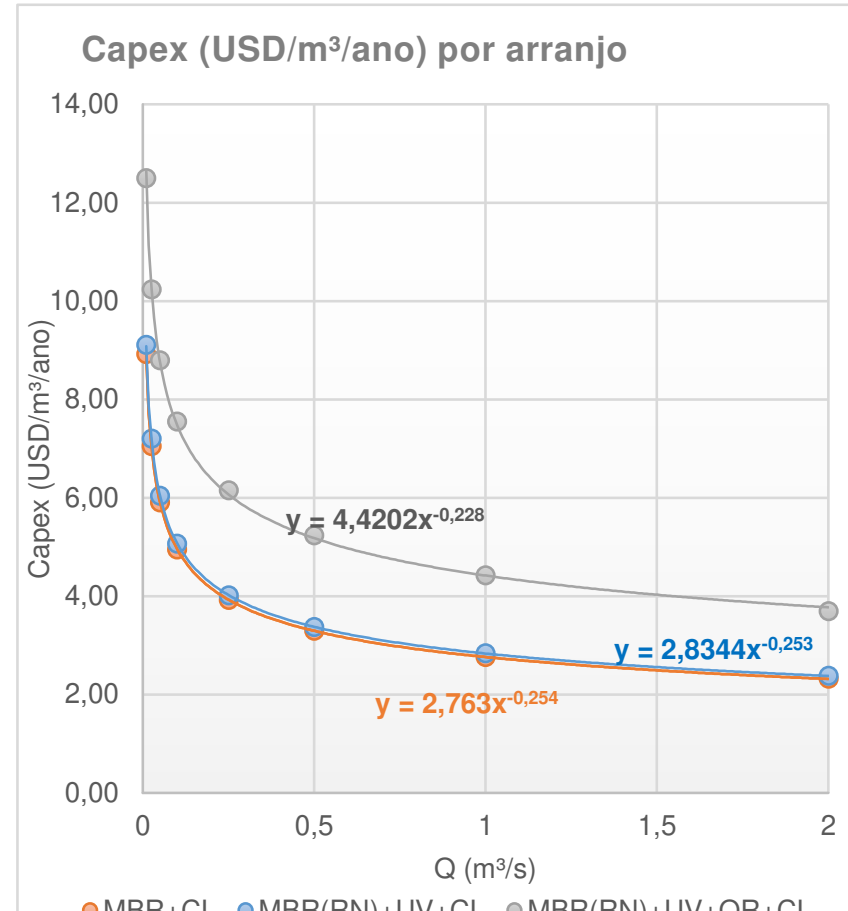

$\circ \mathrm{MBR}+\mathrm{CL} \quad \mathrm{OMBR}(\mathrm{RN})+\mathrm{UV}+\mathrm{CL} \circ \mathrm{MBR}(\mathrm{RN})+\mathrm{UV}+\mathrm{OR}+\mathrm{CL}$

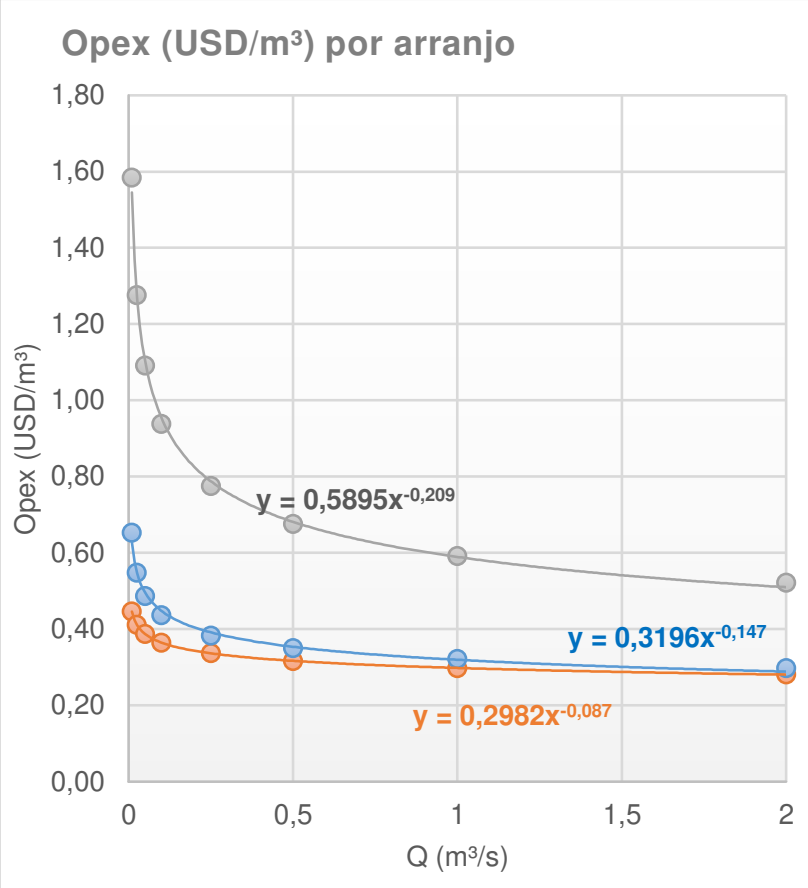

$\circ \mathrm{MBR}+\mathrm{CL} \circ \mathrm{MBR}(\mathrm{RN})+\mathrm{UV}+\mathrm{CL} \circ \mathrm{MBR}(\mathrm{RN})+\mathrm{UV}+\mathrm{OR}+\mathrm{CL}$

Figura 29: Funções de Capex (USD/m³/ano) e Opex (USD/m³) por arranjo de tratamento

\subsubsection{Custos de adução - Capexad e Opexad}

\subsection{Capex de adutoras - Capexadutoras}

A função de Capexadutoras é a apresentado na Equação 11.

$$
\text { Capex }_{\text {adutoras }}=0,0009 D N^{2}+0,593 D N+29,141
$$

Capexad (USD/m) custo por metro de adutora $\mathrm{DN}(\mathrm{mm})$ diâmetro nominal da adutora 
Como neste trabalho considerou-se que a velocidade de escoamento é fixa ${ }^{11}$, e que o DN é exatamente o resultante da equação da continuidade, a Equação 11 por ser reescrita em função de vazão $(\mathrm{Q})$, conforme Equação 12.

$$
\text { Capex }_{\text {adutoras }}=-37,8 Q^{2}+1.219,8 Q+163,3
$$

Capex $_{\text {ad }}(\mathrm{USD} / \mathrm{m})$ custo por metro de adutora $\mathrm{DN}(\mathrm{mm})$ diâmetro nominal da adutora

A Figura 30 mostra os gráficos de Capexadutoras em função de DN e de Q.

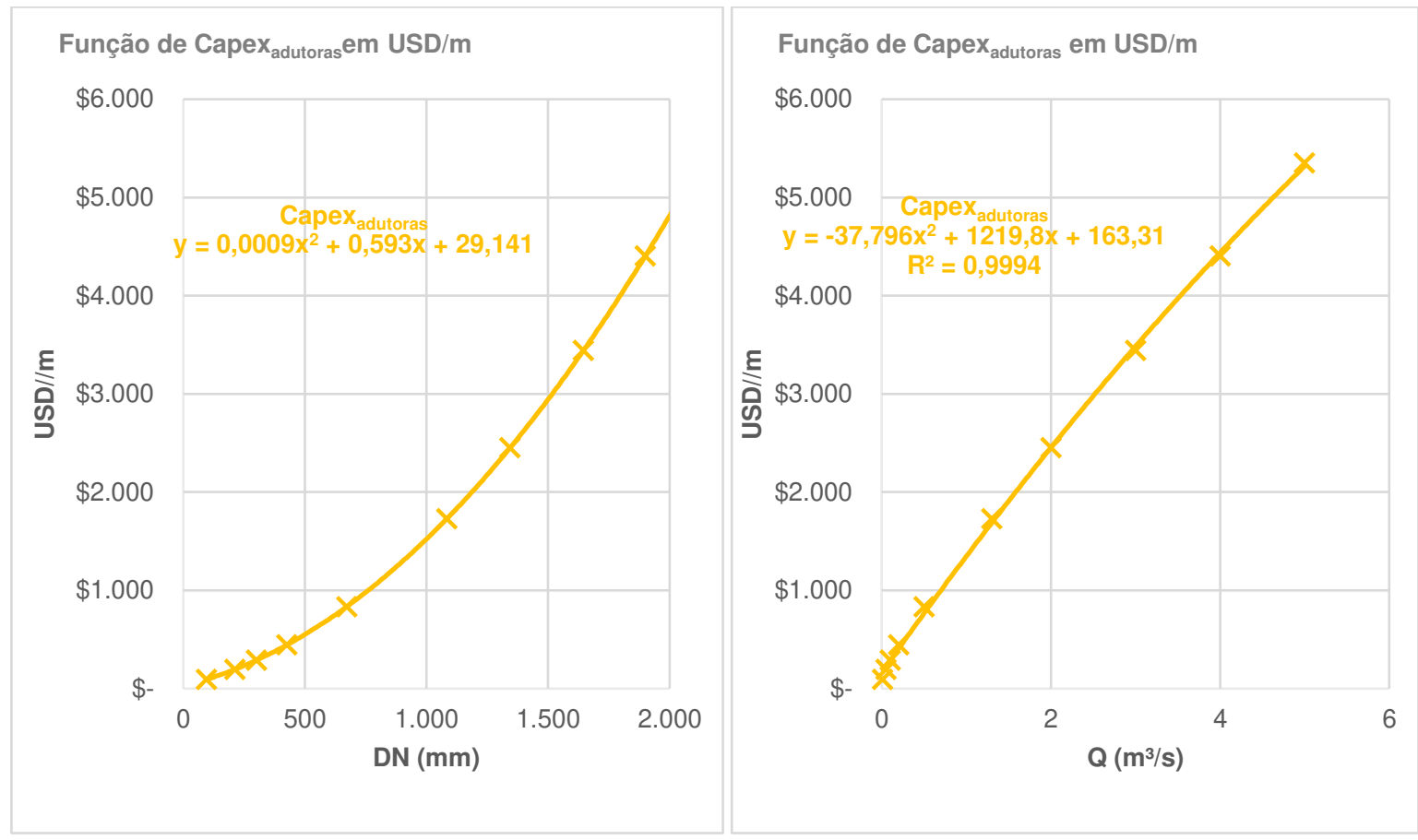

Figura 30: Função de Capexadutoras adotada - em função de DN (à esq.) e de Q (à dir.)

5.2.3.3.2 Capex de estações elevatórias - Capexee

O Capexee é calculado em função da potência requerida $(P)$ pelo sistema elevatório, e "P" é calculada pela Equação 13.

${ }^{11} \mathrm{~K}($ Bresse $)=0,95 \mathrm{e} \mathrm{v}=1,41 \mathrm{~m} / \mathrm{s}$. Ver ANEXO A para detalhamento. 


$$
P=\frac{9,85 \times Q}{\eta} \times\left(\frac{5,9461 \times Q^{-0,585} \times L}{C^{1,85} \times v^{-2,435}}+\frac{v^{2}}{2 g} \sum K_{s}+\Delta H_{g}\right)
$$

$P(k W)$

$\mathrm{Q}\left(\mathrm{m}^{3} / \mathrm{s}\right)$

AMT $(\mathrm{m})$

$\eta(\%)$

$\mathrm{C}\left(\mathrm{m}^{0,387 / \mathrm{s})}\right.$

$v(\mathrm{~m} / \mathrm{s})$

$L(m)$

$\Sigma \mathrm{Ks}$

$\mathrm{g}\left(\mathrm{m} / \mathrm{s}^{2}\right)$

$\Delta \mathrm{Hg}(\mathrm{m})$

potência requerida do conjunto motor-bomba

vazão

altura manométrica total

eficiência do conjunto motor-bomba

coeficiente de rugosidade

velocidade de escoamento

comprimento da tubulação

somatório dos coeficientes de perda de carga singular aceleração da gravidade desnível geométrico

A partir de "P", Capexee é calculado pela Equação 14.

$$
\text { Capex }_{e e}=22.066 P^{-0,3568}
$$

Capexee (USD/kW) custo unitário de estações elevatórias $\mathrm{P}(\mathrm{kW})$ potência

A Figura 31 mostra o gráfico de Capexee em função de $P$.

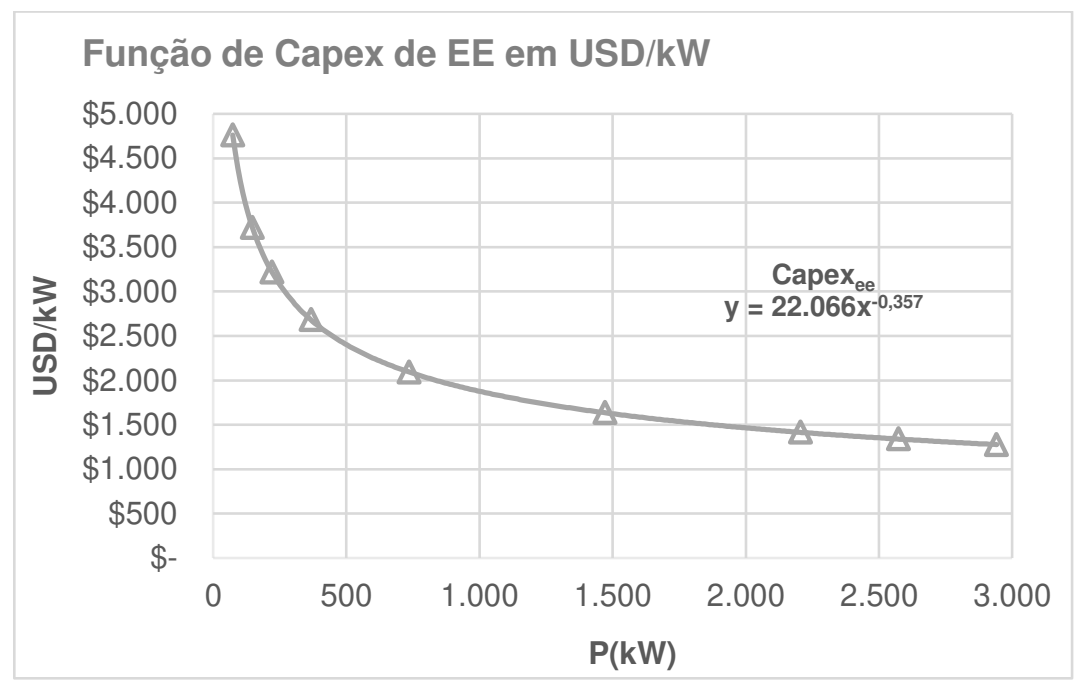

Figura 31: Função de Capex de elevatórias adotada

5.2.3.3.1 Opex de adução - Opexad

A função de Opexad é conforme Equação 15.

$$
\text { ope }_{\text {ad,anual }}=P \times t \times T E+4,5 \% \text { Capex }_{a d}
$$

Opexad (USD/ano) Opex anual de adução

Potência $(\mathrm{kW})$ potência requerida do conjunto motor-bomba

$\mathrm{t}$ (h/ano)

TE (USD/kWh)

tempo de operação anual

Capexee (USD)

tarifa de energia elétrica

Capex de adução 


\subsubsection{Resumo das funções de custos e relação das variáveis}

A Tabela 41 resume todas as funções de Capex e Opex apresentadas anteriormente, bem como a de potência do sistema elevatório. Vale lembrar que o desenvolvimento das equações apresentadas é detalhado no ANEXO A.

Tabela 41: Resumo das funções de custo e outras equações

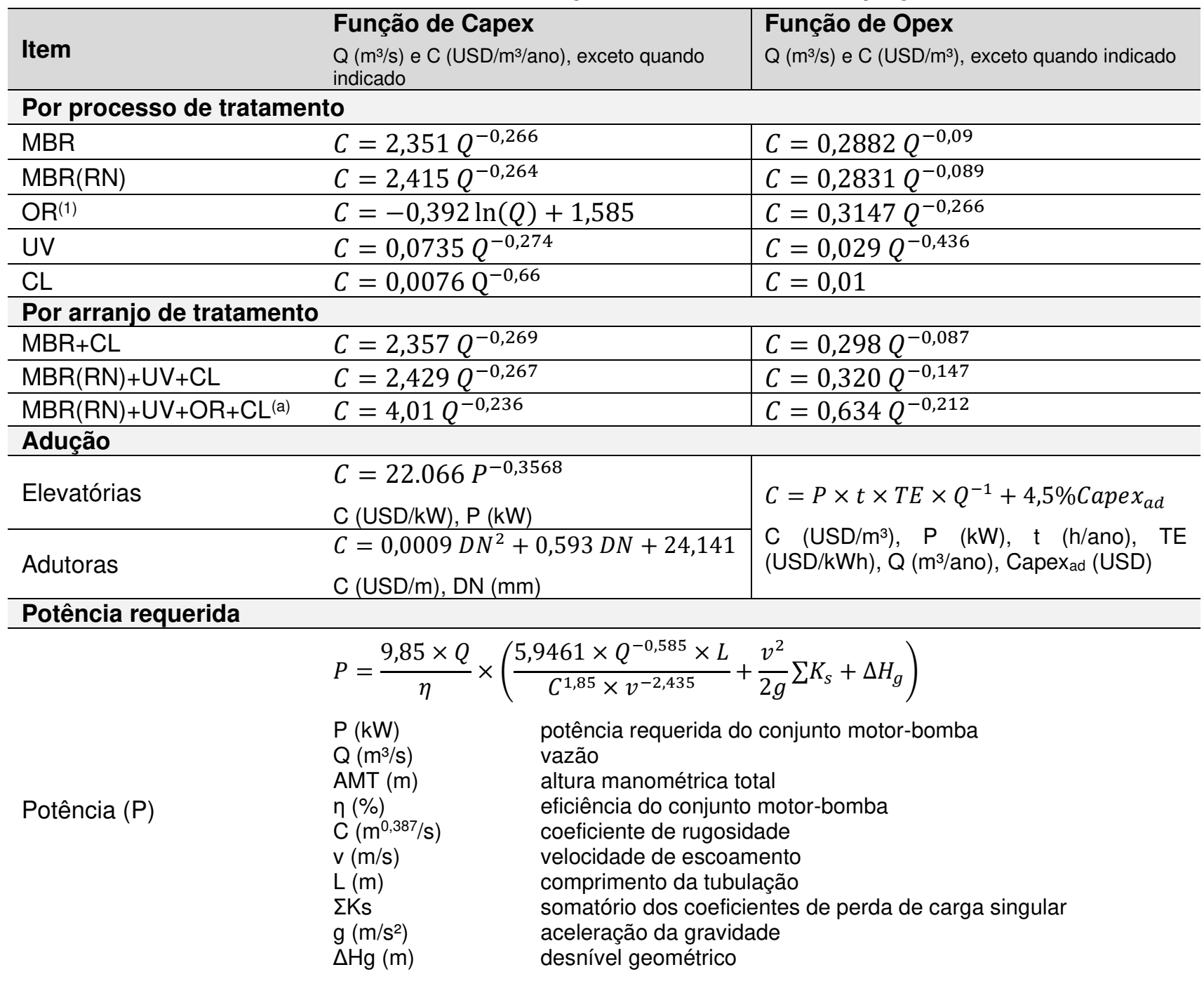

(a) Para o caso de OR, a vazão de entrada deve considerar as perdas por geração de rejeito/concentrado. Ou seja, $Q_{e f l}=$ $Q_{a f l} \times Y$, sendo $\mathrm{Y}$ o índice de aproveitamento do sistema. Valor padrão de Y adotado foi de $70 \%$, havendo variação de 60 a $80 \%$ nos cenários de custos.

A Tabela 42 relaciona as variáveis utilizadas nas funções de custos, indicando seus valores base. Como destacado na tabela, algumas delas tiveram seus valores modificados na composição dos cenários de custos, o que é abordado no item 5.2.4. 
Tabela 42: Relação de variáveis utilizadas nas funções de custos

\begin{tabular}{|c|c|c|c|c|}
\hline Sigla & Significado & Unid. & Valor base & Comentário \\
\hline Q & $\begin{array}{l}\text { Vazão produzida de } \\
\text { água de reúso }\end{array}$ & $\mathrm{m}^{3} / \mathrm{s}$ & $\begin{array}{l}\text { Varia conforme usuário } \\
\text { vazão outorgada do } \\
\text { usuário e atividade } \\
\text { econômica (CNP e QNP) }\end{array}$ & - \\
\hline DN & $\begin{array}{l}\text { Diâmetro nominal da } \\
\text { adutora }\end{array}$ & $\mathrm{mm}$ & Varia conforme vazão & - \\
\hline $\mathrm{L}$ & Comprimento da adutora & $\mathrm{m}$ & $\begin{array}{l}\text { Varia conforme distância } \\
\text { entre ETE e usuário e } \\
\text { configuração do sistema } \\
\text { viário }\end{array}$ & $\begin{array}{l}\text { Obtida conforme item } \\
\text { 5.2.2.4 }\end{array}$ \\
\hline AMT & $\begin{array}{l}\text { Altura manométrica total } \\
\text { do sistema elevatório }\end{array}$ & $\mathrm{m}$ & $\begin{array}{l}\text { Varia conforme L, DN, } \\
\sum \mathrm{Ks}, \mathrm{Q}, \Delta \mathrm{Hg}, \mathrm{C} \text { e v }\end{array}$ & - \\
\hline $\mathrm{P}$ & $\begin{array}{l}\text { Potência requerida pelo } \\
\text { sistema elevatório }\end{array}$ & $\mathrm{kW}$ & Varia conforme AMT & Conforme Equação 13 \\
\hline TE & Tarifa de energia elétrica & $\begin{array}{l}\text { USD/ } \\
\mathrm{kWh}\end{array}$ & $\begin{array}{l}\text { Varia de acordo com a } \\
\text { região(a) }\end{array}$ & - \\
\hline$g$ & Aceleração da gravidade & $\mathrm{m} / \mathrm{s}^{2}$ & 9,81 & - \\
\hline$\eta$ & $\begin{array}{l}\text { Rendimento médio das } \\
\text { bombas do sistema } \\
\text { elevatório }\end{array}$ & - & $80 \%(a)$ & Valor usual de projeto \\
\hline $\mathrm{Y}$ & $\begin{array}{l}\text { Taxa de aproveitamento } \\
\text { da OR }\end{array}$ & - & $70 \%$ (a) & Valor usual de projeto \\
\hline$\sum \mathrm{Ks}$ & $\begin{array}{l}\text { Somatório dos } \\
\text { coeficientes de perda de } \\
\text { carga singular }\end{array}$ & - & 20 & $\begin{array}{l}\text { Ver estimativa no } \\
\text { ANEXO A }\end{array}$ \\
\hline$\Delta \mathrm{Hg}$ & Desnivel geométrico & $\mathrm{m}$ & $\begin{array}{l}\text { Varia de acordo com cotas } \\
\text { entre ETE e usuário }\end{array}$ & $\begin{array}{l}\text { Obtida conforme item } \\
\text { 5.2.2.4 }\end{array}$ \\
\hline C & $\begin{array}{l}\text { Coeficiente de } \\
\text { rugosidade }\end{array}$ & $\begin{array}{l}\mathrm{m}^{0,385 /} \\
\mathrm{s}\end{array}$ & $120^{(a)}$ & Ferro dúctil (FD) / PEAD \\
\hline $\mathrm{v}$ & $\begin{array}{l}\text { Velocidade de } \\
\text { escoamento }\end{array}$ & $\mathrm{m} / \mathrm{s}$ & 1,41 & $\begin{array}{l}K=0,95 \text { (Bresse). Ver } \\
\text { ANEXO A }\end{array}$ \\
\hline Y & $\begin{array}{l}\text { Taxa de aproveitamento } \\
\text { da OR }\end{array}$ & $\%$ & $70 \%$ (a) & Valor usual de projeto \\
\hline
\end{tabular}

(a) Variáveis que tiveram seus valores modificados nos cenários previstos. Ver item 5.2.2.3.

Tanto o Capex como Opex unitários tendem a diminuir com o aumento de $Q$, o que se deve ao ganho de escala no tratamento. Já no caso da adução, Capexad é função somente de $D N$ (que é função de $Q$ ), mas Opexad é função de mais de uma variável $\left(\mathrm{Q}, \mathrm{L}, \Delta \mathrm{H}_{\mathrm{g}}\right)$. A Figura 32 ilustra as superfícies de custos de Opexad para variações de $L$ e $Q$ e $\Delta H_{g}$ (outras variáveis, como $T E$, v e $\sum K s$, foram fixadas). 

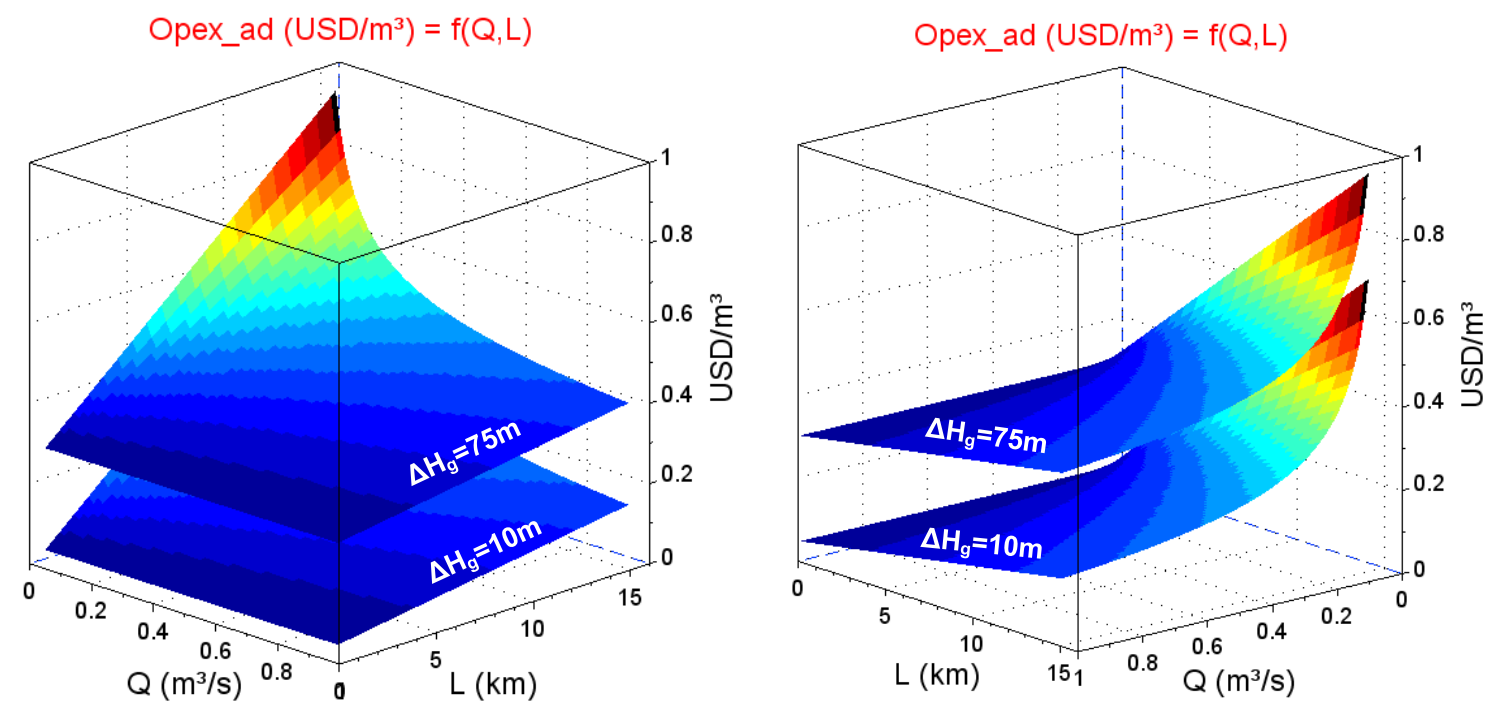

Nota: os gráficos mostram apenas ângulos diferentes da mesma superfície.

Figura 32: Gráfico de superfície da função de Opex ${ }_{a d}\left(U S D / m^{3}\right)$ em função de $Q\left(\mathrm{~m}^{3} / \mathrm{s}\right)$ e $L(\mathrm{~km})$ para $\Delta H_{g}=10$ e $75 \mathrm{~m}$

Fonte: elaborado pelo autor

\subsubsection{Tarifas mínimas praticáveis}

Com base nas equações de Capex e Opex, o modelo prevê o cálculo das tarifas mínimas praticáveis. Para tal, determinou-se que o valor mínimo da tarifa ocorre quando o Valor Presente Líquido (VPL) é igual a zero para o tempo de retorno considerado $(\mathrm{N})$, com taxa de juros anual fixa. A tarifa mínima é calculada pela Equação 16. Mais detalhes sobre o cálculo constam no ANEXO A.

$$
\text { Tarifa }=\left(\frac{\text { Capex } \times i}{1-(1+i)^{-N}}+\text { Opex }_{\text {anual }}\right) \frac{1}{Q_{\text {anual }}}
$$

Tarifa $\left(\mathrm{USD} / \mathrm{m}^{3}\right) \quad$ tarifa unitária a ser praticada Capex (USD)

Qanual ( $\left.\mathrm{m}^{3} / \mathrm{ano}\right)$ custo de implantação

Opexanual (USD/ano)

i (\% aa)

$\mathrm{N}$ (anos)

vazão anual

custo de operação anual

taxa anual de juros

tempo de retorno de investimento

A tarifa não considera impostos, taxas ou outros valores incidentes não explicitamente declarados.

A Tabela 43 relaciona as variáveis utilizadas no cálculo da tarifa. 
Tabela 43: Relação de variáveis para cálculo de tarifa

\begin{tabular}{|c|c|c|c|}
\hline Sigla & Significado & Unid. & Valor base \\
\hline Capex & Capex total & USD & \multirow{2}{*}{ Varia para cada binômio ETE-usuáric } \\
\hline Opex anual & Opex anual total & USD/ano & \\
\hline Qanual & Vazão anual produzida & $\mathrm{m}^{3} / \mathrm{ano}$ & $\begin{array}{l}\text { Varia conforme usuário vazão } \\
\text { outorgada do usuário e atividade } \\
\left.\text { econômica ( } C_{N P} \text { e } Q_{N P}\right)\end{array}$ \\
\hline $\mathrm{i}$ & Taxa anual de juros & $\%$ aa & $12 \%(\mathrm{a})$ \\
\hline $\mathrm{N}$ & $\begin{array}{l}\text { Tempo de retorno do } \\
\text { investimenro }\end{array}$ & anos & $20^{(a)}$ \\
\hline
\end{tabular}

(a) Variáveis que tiveram seus valores modificados nas variações previstas nos cenários. Ver item 5.2.2.3.

A tarifa depende, portanto, dos custos de produção e distribuição e de variáveis financeiras como "i" e "N".

A Figura 33 abaixo ilustra o comportamento genérico de tarifa (USD/m³) em função de $\mathrm{Q}\left(\mathrm{m}^{3} / \mathrm{s}\right)$ e $\mathrm{L}(\mathrm{km})$ para o arranjo de tratamento $\mathrm{MBR}(\mathrm{RN})+\mathrm{UV}+\mathrm{CL}$.
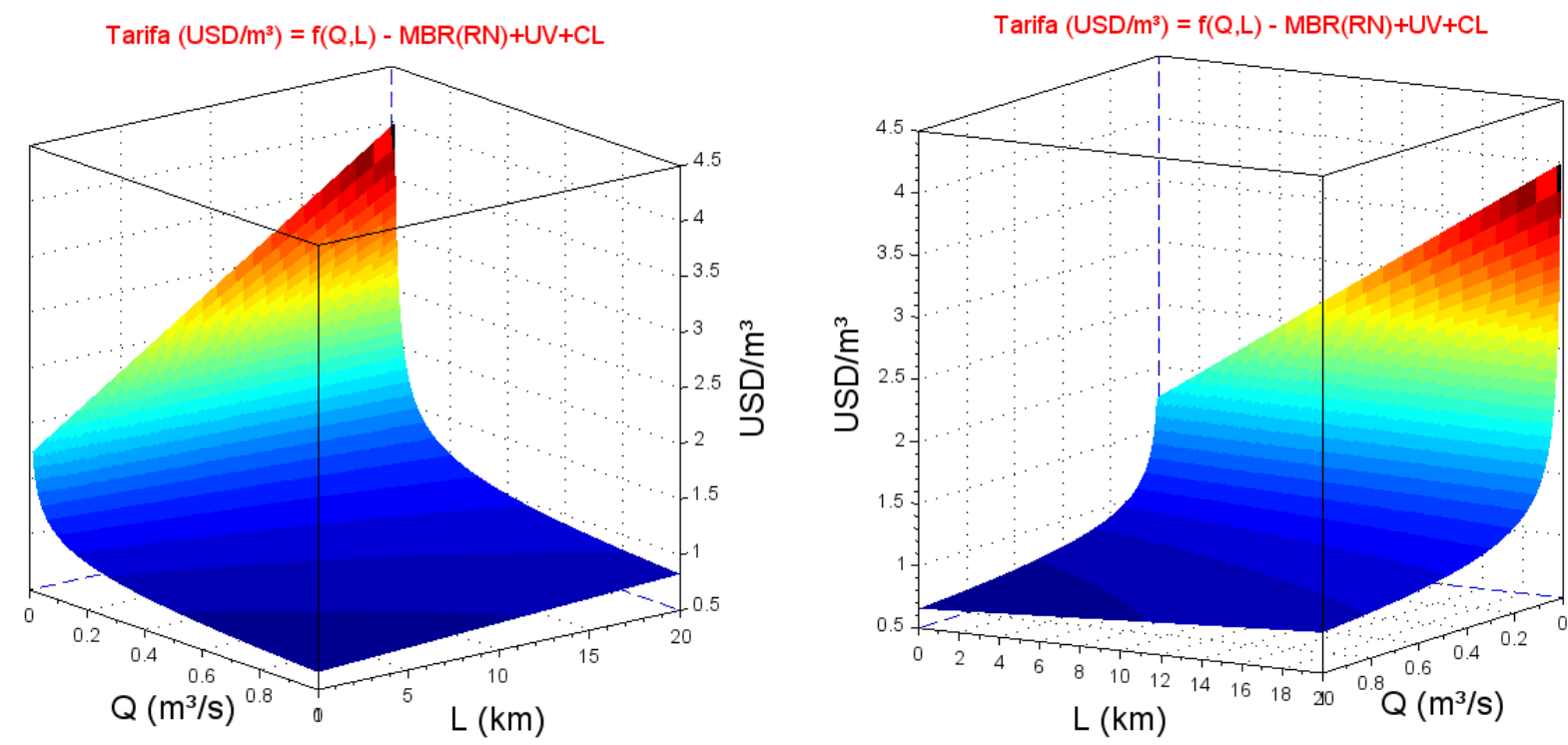

Nota: limite inferior de $\mathrm{Q}=0,010 \mathrm{~m} 3 / \mathrm{s}$. $\Delta \mathrm{Hg}$ fixado em $25 \mathrm{~m}$. Os gráficos mostram apenas ângulos diferentes da mesma superfície.

Figura 33: Gráfico de superfície de tarifa $\left(\mathrm{USD} / \mathrm{m}^{3}\right)$ para arranjo $\mathrm{MBR}(\mathrm{RN})+\mathrm{UV}+\mathrm{CL}$ em função de $Q\left(\mathrm{~m}^{3} / \mathrm{s}\right)$ e $L(\mathrm{~km})$

Fonte: elaborado pelo autor

Pela Figura 33 são evidentes tanto o ganho de escala por conta do aumento da vazão

(Q) como o aumento de custo em razão de maiores distâncias (L). 


\subsubsection{Cenários de abastecimento e de custos}

Em virtude na natureza conceitual de estudos de planejamento, é comum que sejam adotados múltiplos cenários que contemplem realidades diferentes. Foram estabelecidos dois tipos de cenário: de abastecimento e de custos.

\subsubsection{Cenários de abastecimento}

Considerando os usos contemplados (irrigação e indústria) e os respectivos requisitos de qualidade para uso, foram estabelecidos dois cenários distintos de abastecimento. No primeiro (Cenário 1, C1), os usos de irrigação são supridos por água clarificada e clorada (P1) e os industriais por clarificada, desnitrificada, desinfetada e clorada (P2), sendo este padrão compatível com usos em sistemas de resfriamento (TR). No segundo (Cenário 2, C2), os usuários industriais recebem água com padrão mais restritivo, havendo etapa adicional de remoção de sólidos dissolvidos e íons (OR) e aproximação à qualidade requerida para usos mais exigentes, como caldeiras. A Tabela 44 apresenta e explica os dois cenários de abastecimento previstos.

Tabela 44: Cenários de abastecimento

\begin{tabular}{|c|c|c|c|}
\hline Cenário & Uso / padrão & Arranjo & Diferença \\
\hline \multirow{2}{*}{ C1 } & Irrigação: P1 & $\mathrm{MBR}+\mathrm{CL}$ & \multirow{2}{*}{$\begin{array}{l}\text { Indústria recebe água com } \\
\text { qualidade intermediária } \\
\text { (próxima a padrão de TR) }\end{array}$} \\
\hline & Indústria: P2 & $\mathrm{MBR}(\mathrm{RN})+\mathrm{UV}+\mathrm{CL}$ & \\
\hline \multirow{2}{*}{$\mathrm{C} 2$} & Irrigação: P1 & $\mathrm{MBR}+\mathrm{CL}$ & \multirow{2}{*}{$\begin{array}{l}\text { Indústria recebe água com } \\
\text { qualidade superior (próxima a } \\
\text { padrão de caldeira) }\end{array}$} \\
\hline & Indústria: P3 & $\mathrm{MBR}(\mathrm{RN})+\mathrm{UV}+\mathrm{OR}+\mathrm{CL}$ & \\
\hline
\end{tabular}

Assim, C2 prevê que a indústria seja abastecida por água de maior qualidade, reduzindo a necessidade de polimentos adicionais por parte do usuário e tornando o produto (água de reúso) mais atraente do ponto de vista de segurança para os usuários. Isso, no entanto, invariavelmente leva a maiores custos de produção. Usos de irrigação não sofrem alterações entre os cenários C1 e C2.

\subsubsection{Cenários de custos}

De maneira a se contemplar variabilidade de parâmetros de projeto e econômicofinanceiros, foram elaborados três cenários de custos: realista (cenário base), otimista e pessimista. O otimista é aquele que leva a menores custos, e o pessimista, 
analogamente, aos maiores. Os parâmetros alterados para cada um são como apresenta a Tabela 45.

Tabela 45: Parâmetros de composição dos cenários de custos

\begin{tabular}{|c|c|c|c|c|c|}
\hline \multirow[b]{2}{*}{ Variável } & \multirow[b]{2}{*}{ Descrição } & \multirow[b]{2}{*}{ Unid. } & \multicolumn{3}{|c|}{ Cenários de custos } \\
\hline & & & $\begin{array}{l}\text { Pessim } \\
\text { ista }\end{array}$ & Realista & $\begin{array}{c}\text { Otimi } \\
\text { sta }\end{array}$ \\
\hline Y & $\begin{array}{l}\text { Taxa de aproveitamento } \\
\text { do sistema de OR }\end{array}$ & $\%$ & $60 \%$ & $70 \%$ & $80 \%$ \\
\hline$\eta$ & $\begin{array}{l}\text { Rendimento das bombas do } \\
\text { sistema } \\
\text { elevatório }\end{array}$ & $\%$ & $70 \%$ & $80 \%$ & $90 \%$ \\
\hline C & $\begin{array}{l}\text { Coeficiente de rugosidade da } \\
\text { tubulação de recalque }\end{array}$ & $\begin{array}{l}\mathrm{m}^{0,387 /} \\
\mathrm{s}\end{array}$ & 100 & 120 & 140 \\
\hline$\Sigma \mathrm{Ks}$ & $\begin{array}{l}\text { Somatório dos coeficientes de } \\
\text { perda de carga singular }\end{array}$ & - & 30 & 20 & 10 \\
\hline TE & Tarifa de energia elétrica (TE) & $\begin{array}{l}\text { USD/k } \\
\text { Wh }\end{array}$ & $\begin{array}{l}T E \times \\
0,80\end{array}$ & $\begin{array}{c}\text { TE } \\
\text { (varia de acordo com } \\
\text { a região) }\end{array}$ & $\begin{array}{r}T E \times \\
1,20\end{array}$ \\
\hline $\mathrm{N}$ & Tempo de retorno do investimento & anos & 25 & 20 & 15 \\
\hline $\mathrm{i}$ & Taxa de juros & $\%$ aa & $15 \%$ & $10 \%$ & $5 \%$ \\
\hline
\end{tabular}

Conforme se vê na Tabela 45, o cenário pessimista sempre prevê valores que resultam em maiores custos. Por exemplo, menores valores de "Y" levam a maiores perdas no tratamento, resultando em acréscimos no custo por $\mathrm{m}^{3}$; maiores perdas singulares $(\Sigma K s)$ na adução resultam em maior AMT, potência requerida e consequentemente gastos com energia elétrica; e menores tempos de retorno $(\mathrm{N})$ implicam em maiores tarifas para que VPL seja igual a zero.

\subsubsection{Resumo dos cenários}

A partir dos cenários de abastecimento e de custos, há seis possibilidades de tarifa para cada binômio ETE-usuário, sendo três para o cenário 1 e outras três para o 2 . Por conveniência, foram adotadas as siglas apresentadas na Tabela 46.

Tabela 46: Siglas para identificação dos cenários de abastecimento e de custos

\begin{tabular}{ccc}
\hline $\begin{array}{c}\text { Cenário de } \\
\text { abastecimento }\end{array}$ & Cenário de custos & Sigla \\
\hline \multirow{2}{*}{ C1 } & Pessimista & C1P \\
\cline { 2 - 3 } & Realista & C1R \\
\cline { 2 - 3 } & Otimista & C1O \\
\hline \multirow{2}{*}{ C2 } & Pessimista & C2P \\
\cline { 2 - 3 } & Realista & C2R \\
\cline { 2 - 3 } & Otimista & C2O \\
\hline
\end{tabular}




\subsubsection{Determinação de usuário-âncora e agregação de resultados}

\subsubsection{Regra de determinação de usuário-âncora}

Usuário-âncora é aquele cujo atendimento à demanda por si só garante viabilidade econômica de reúso não potável.

A avaliação de viabilidade da tarifa foi realizada comparando-se a tarifa mínima praticável com custos (tarifas) locais de água potável. É comum que empresas de saneamento estabeleçam tarifas mais baixas para Grandes Consumidores (GCs) em contratos de vazão firme. Conforme já abordado, usuários com maiores demandas tendem a favorecer economicamente a prática de reúso (ganho de escala), e por isso são os que têm maior probabilidade de serem considerados âncora.

Dessa forma, o modelo propõe que a análise de viabilidade econômica seja baseada em custos unitários de contratos de vazão firme para GCs na região analisada. A regra adotada é a mostrada na Tabela 47.

Tabela 47: Regra de classificação da tarifa de água de reúso em relação a custos locais

\begin{tabular}{cccl} 
Classe & Atratividade & $\begin{array}{c}\% \text { da tarifa de grandes } \\
\text { consumidores }\end{array}$ & Classificação \\
\hline A & Alta & $\leq 100 \%$ & Usuário-âncora \\
\hline B & Média & $>100 \%$ e $\leq 150 \%$ & Possível usuário-âncora \\
\hline C & Baixa/nenhuma & $>150 \%$ & Possível usuário secundário \\
\hline
\end{tabular}

São considerados âncora aqueles classificados como "A" (alta atratividade), ou seja, os que têm condição de viabilizar produção e distribuição de água de reúso com tarifa mínima inferior à praticada localmente pela empresa de saneamento. Os classe "B" possuem atratividade média e, em razão disso, têm probabilidade apresentar viabilidade em estudos mais detalhados. Os classificados como "C" já se encontram em condições em que os custos provavelmente serão impeditivos, mas podem ser abastecidos caso estejam próximos a usuários-âncora ou a adutoras, e por isso foram denominados "possíveis usuários secundários".

É evidente que a tarifa da concessionária a ser utilizada como referência é composta por muitos outros fatores não considerados neste trabalho, como o lucro da empresa, subsídio cruzado, taxas de contribuição para agência reguladora, entre outras, mas considerou-se aceitável seu uso como valor de referência. 


\subsubsection{Agregação de dados e potencial de reúso total}

Para um mesmo usuário, uma ou mais ETEs podem apresentar tarifas consideradas viáveis (classe $A$ ), e o cômputo de todos os binômios levaria à consideração da mesma outorga mais de uma vez e a erros na agregação de resultados. Sendo assim, para cada usuário foi considerada somente a ETE cuja tarifa de produção e distribuição de água de reúso é a mais baixa dentre todas para determinado usuário (ETE de referência). Em outras palavras, para o caso de usuários que apresentaram alta atratividade (classe A) em relação a mais de uma ETE, considerou-se somente o caso mais favorável (menor tarifa).

Há casos em que a ETE em questão possui vazão inferior à demanda não potável do usuário, o que, em tese, inviabilizaria o atendimento "imediato" às demandas. No entanto, dado que o modelo mira no planejamento a longo prazo, esses casos não foram desconsiderados, uma vez que futuras expansões das estações de tratamento poderão já contemplar a possibilidade de reúso não potável. Isso significa que a vazão atual da ETE não foi objetivamente considerada na determinação quantitativa do potencial de reúso, mas foi utilizada na discussão sobre o potencial de reúso na área e sobre as futuras oportunidades.

A partir dos resultados agregados e da remoção de duplicatas é possível estabelecer diferentes recortes para interpretação e compreensão dos resultados. São propostas três formas de agrupamento:

- Por ETE: avaliação dos resultados agregados por ETE, totalizando as vazões potenciais de reúso e comparando-as à capacidade da estação, considerandose também as variações previstas nos cenários.

- Por usuário-âncora: avaliação dos resultados sob a óptica dos usuáriosâncora identificados, sendo possível também a decomposição dos custos estimados (tratamento e operação) para cada um deles e consideração das variações previstas nos cenários.

- Por atividade econômica: agregação dos resultados agregados segundo as divisões de atividades econômicas da CNAE 2.0. 
Mesmo que tratem dos mesmos resultados, a divisão em grupos temáticos auxilia na compreensão de alguns aspectos de interesse específico. A divisão de resultados acima apresentada ficará mais clara na aplicação do modelo ETE-usuário à área de estudo (RMSP) (item 5.3.3).

\subsection{APLICAÇÃo À ÁREA DE ESTUDO (RMSP)}

Conforme proposta deste trabalho, os elementos desenvolvidos foram aplicados a uma área de estudo. A área escolhida foi a Região Metropolitana de São Paulo (RMSP). A escolha deu-se pela alta disponibilidade de dados para a região, bem como por sua representatividade frente a demais áreas metropolitanas não só brasileiras, mas também internacionais.

\subsubsection{Caracterização da RMSP}

A RMSP compreende 39 municípios e foi estabelecida pela Lei Complementar $n^{\circ} 14$, de 8 de junho de 1973 (BRASIL, 1973). Sua área coincide, em grande parte, com a UGRHI 06 (Bacia Hidrográfica do Alto Tietê - BH-AT), possuindo também parcelas nas UGRHIs 02 (Paraíba do Sul), 05 (Piracicaba/Capivari/Jundiaí - PCJ), 07 (Baixada Santista), 10 (Tietê/Sorocaba) e 11 (Ribeira de Iguape/Litoral Sul). A BH-AT sozinha representa $70 \%$ do território e 99,5\% da população da RMSP (FABHAT, 2018a). A Figura 34 mostra os limites da RMSP e das supracitadas UGRHIs. 


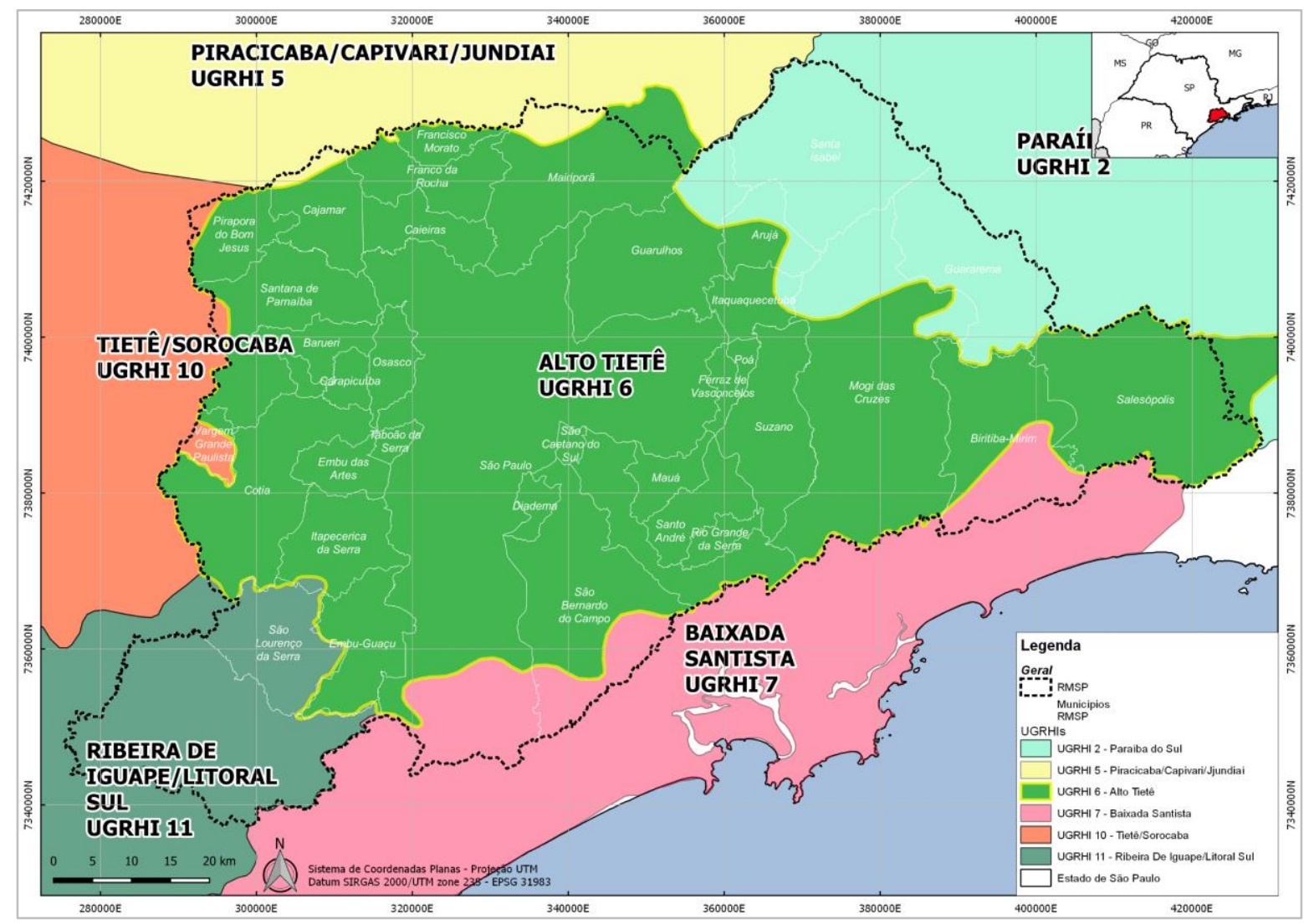

Figura 34: Limites da Região Metropolitana de São Paulo (RMSP) e das Unidades de Gerenciamento de Recursos Hídricos (UGHRIs) 2, 5, 6, 7, 10 e 11

Fonte: IGC-SP (2011) e IBGE (2015b). Elaborado pelo autor

Em virtude de sua alta concentração populacional, a BH-AT é a que possui a menor disponibilidade hídrica per capita do estado, com valor médio de 129,82 m³/hab/ano (FABHAT, 2017). Adicionalmente, as intensas atividades industriais e de serviços na região, além da existência de significativas extensões territoriais também dedicadas à agropecuária, conduzem a demandas cada vez maiores na UGRHI 06, o que resulta inclusive em impactos na bacias vizinhas e em dinâmicas hidrológicas e hidráulicas extremamente complexas na região (FABHAT, 2018a).

A Figura 35 apresenta mapas de disponibilidade hídrica per capita $\left(\mathrm{m}^{3} / \mathrm{hab} / \mathrm{ano}\right)$, situação de balanço hídrico (em função de Q95\%) e capacidade de diluição dos corpos hídricos por município da RMSP. 

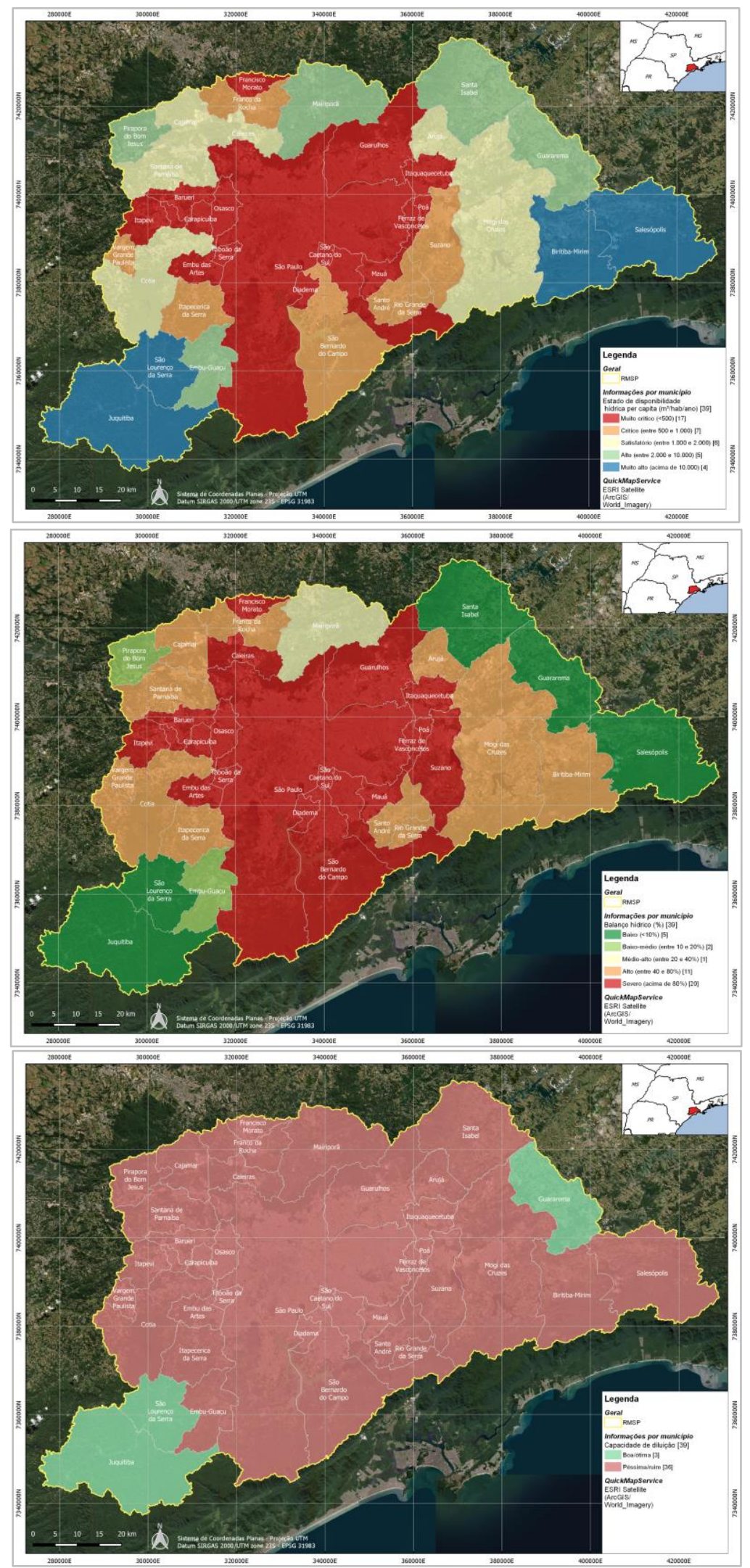

Figura 35: De cima para baixo - disponibilidade hídrica per capita, balanço hídrico (demandas $/ Q_{95 \%}$ ) e capacidade de diluição dos corpos hídricos por município. Fonte: IBGE (2015b), ANA (2018b) e DAEE (2018a, 2018b). Elaborado pelo autor 


\subsubsection{Demandas consuntivas de água}

Estimativas de demandas consuntivas para a BH-AT variam de 86,5 a 92,3 m³/s. Ainda que diferentes publicações apresentem valores totais semelhantes, há significante variabilidade das estimativas por uso, principalmente para a indústria e irrigação, conforme mostra a Tabela 48.

Tabela 48: Estimativas de demandas consuntivas de água na BH-AT

\begin{tabular}{|c|c|c|c|c|c|c|c|}
\hline Estudo & $\begin{array}{l}\text { Urbano } \\
\left(\mathrm{m}^{3} / \mathrm{s}\right)\end{array}$ & $\begin{array}{l}\text { Industrial } \\
\left(\mathrm{m}^{3} / \mathrm{s}\right)\end{array}$ & $\begin{array}{l}\text { Irrigação } \\
\left(\mathrm{m}^{3} / \mathrm{s}\right)\end{array}$ & $\begin{array}{l}\text { Outros } \\
\left(\mathrm{m}^{3} / \mathrm{s}\right)\end{array}$ & $\begin{array}{l}\text { Total } \\
\left(\mathrm{m}^{3} / \mathrm{s}\right)\end{array}$ & $\begin{array}{l}\text { Ano } \\
\text { base }\end{array}$ & Fonte \\
\hline $\begin{array}{l}\text { Plano Diretor de } \\
\text { Aproveitamento de } \\
\text { Recursos Hídricos para } \\
\text { a Macrometrópole } \\
\text { Paulista, no Estado de } \\
\text { São Paulo }\end{array}$ & 76,9 & $10,8^{(\mathrm{a})}$ & 4,5 & - & 92,3 & $\begin{array}{l}2018 \\
\text { (projeção) }\end{array}$ & $\begin{array}{l}\text { DAEE } \\
(2013)\end{array}$ \\
\hline $\begin{array}{l}\text { Plano da Bacia } \\
\text { Hidrográfica da Bacia } \\
\text { do Alto Tietê: Relatório } \\
\text { Parcial de Diagnóstico } \\
\text { (RPD) }\end{array}$ & 75,3 & 6,5 & 3,8 & 2,6 & 88,2 & 2017 & $\begin{array}{l}\text { FABHAT } \\
(2018 a)\end{array}$ \\
\hline $\begin{array}{l}\text { Relatório de Situação } \\
\text { dos Recursos Hídricos: } \\
\text { Bacia Hidrográfica do } \\
\text { Alto Tietê - UGHRI-06 }\end{array}$ & 77,3 & 5,9 & 1,0 & 2,3 & 86,5 & 2016 & $\begin{array}{l}\text { FABHAT } \\
(2017)\end{array}$ \\
\hline $\begin{array}{l}\text { Plano Estadual de } \\
\text { Recursos Hídricos: } \\
\text { PERH 2016-2019 } \\
\end{array}$ & & Não discrir & na por uso & & $86,5^{(b)}$ & 2016 & $\begin{array}{l}\text { SSRH-SP } \\
(2017)\end{array}$ \\
\hline
\end{tabular}

(a) Valor apresentado no relatório é de $38,63 \mathrm{~m}^{3} / \mathrm{s}$. No entanto, consta também no documento que esse valor considera 27,8 $\mathrm{m}^{3} / \mathrm{s}$ outorgados à EMAE para a Usina Termelétrica de Piratininga, os quais foram subtraídos do total.

(b) Valor apresentado no relatório é $55,49 \mathrm{~m}^{3} / \mathrm{s}$, havendo indicação de $31 \mathrm{~m}^{3} / \mathrm{s}$ outorgados na UGRHI-05 (PCJ) para abastecimento do Sistema Cantareira. Dado que a informação buscada é de demanda e não de vazão retirada, os valores foram somados.

A Tabela 49 apresenta estimativas por tipo de uso para os 39 municípios da RMSP, sendo 37 contemplados pelo Plano de Bacia Hidrográfica do Alto Tietê (PBH-AT) e 2 pelo Plano de Bacia Hidrográfica do Paraíba do Sul (PBH-PS). Dado que o PBH-PS não faz diferenciação para entre indústria ligada ou não à rede da concessionária, os valores apresentados foram considerados conjuntamente e agrupados como "Indústria". O PBH-PS também não apresenta as demandas para "outras finalidades", as quais foram obtidas a partir de dados de outorgas estaduais e federais constantes no REGLA e cedidos pela ANA (2016a). 
Tabela 49: Demandas de água por tipo de uso e município da RMSP

\begin{tabular}{|c|c|c|c|c|c|c|c|c|c|}
\hline \multirow[b]{2}{*}{ Município } & \multirow{2}{*}{$\begin{array}{l}\text { Abast. humano } \\
\text { urbano }(\mathrm{I} / \mathrm{s})^{(1)} \\
\text { Doméstico, } \\
\text { serviços e } \\
\text { comércio }(\mathrm{l} / \mathrm{s})\end{array}$} & \multicolumn{2}{|l|}{ Industrial } & \multicolumn{3}{|l|}{ Rural } & \multirow[b]{2}{*}{$\begin{array}{l}\text { Outros } \\
(\mathrm{I} / \mathrm{s})\end{array}$} & \multirow[b]{2}{*}{$\begin{array}{l}\text { Demanda } \\
\text { total }(\mathrm{I} / \mathrm{s})\end{array}$} & \multirow[b]{2}{*}{$\%$} \\
\hline & & $\begin{array}{l}\text { Indústria } \\
\text { ligada à } \\
\text { rede }(\mathrm{I} / \mathrm{s})\end{array}$ & $\begin{array}{l}\text { Indústria } \\
\text { isolada } \\
(\mathrm{l} / \mathrm{s})\end{array}$ & $\begin{array}{l}\text { Irrigação } \\
(\mathrm{I} / \mathrm{s})\end{array}$ & $\begin{array}{l}\text { Abast. } \\
\text { humano } \\
(\mathrm{l} / \mathrm{s})\end{array}$ & $\begin{array}{l}\text { Dessedentação } \\
\text { animal (I/s) }\end{array}$ & & & \\
\hline Arujá & 222,0 & 8,6 & 13,3 & 31,3 & 6,5 & 0,2 & 3,6 & 285,5 & $0,3 \%$ \\
\hline Barueri & $1.022,3$ & 29,7 & 23,0 & 0,0 & 0,0 & 0,0 & 53,1 & $1.128,1$ & $1,3 \%$ \\
\hline Biritiba-Mirim & 39,1 & 0,1 & 1,4 & 844,8 & 2,8 & 6,5 & 3,7 & 898,3 & $1,0 \%$ \\
\hline Caieiras & 312,6 & 7,1 & 394,7 & 12,3 & 1,2 & 0,0 & 7,4 & 735,2 & $0,8 \%$ \\
\hline Cajamar & 248,4 & 4,5 & 125,6 & 1,3 & 3,6 & 0,0 & 51,8 & 435,1 & $0,5 \%$ \\
\hline Carapicuíba & $1.269,7$ & 5,7 & 15,4 & 0,0 & 0,0 & 0,0 & 23,2 & $1.314,0$ & $1,5 \%$ \\
\hline Cotia & 798,8 & 19,3 & 36,3 & 214,9 & 0,0 & 0,0 & 25,2 & $1.094,5$ & $1,2 \%$ \\
\hline Diadema & $1.199,0$ & 25,0 & 28,7 & 0,0 & 0,0 & 0,0 & 86,8 & $1.339,5$ & $1,5 \%$ \\
\hline Embu das Artes & 751,4 & 10,0 & 65,2 & 0,0 & 0,0 & 0,0 & 34,6 & 861,2 & $1,0 \%$ \\
\hline Embu-Guaçu & 139,3 & 3,3 & 1,8 & 4,1 & 1,1 & 0,0 & 11,1 & 160,7 & $0,2 \%$ \\
\hline Ferraz de Vasconcelos & 451,5 & 7,9 & 4,3 & 17,6 & 6,5 & 0,1 & 0,6 & 488,5 & $0,6 \%$ \\
\hline Francisco Morato & 507,8 & 0,6 & 0,0 & 2,3 & 0,2 & 0,0 & 4,2 & 515,1 & $0,6 \%$ \\
\hline Franco da Rocha & 424,7 & 1,8 & 17,9 & 55,6 & 12,5 & 0,0 & 9,7 & 522,2 & $0,6 \%$ \\
\hline Guararema(2) $^{(2)}$ & 37,0 & $69,6^{(3)}$ & & 152,4 & 2,92 & 5,3 & $0^{(4)}$ & 267,2 & $0,3 \%$ \\
\hline Guarulhos & $4.196,3$ & 49,7 & 471,4 & 181,5 & 0,0 & 0,1 & 170,5 & $5.069,4$ & $5,8 \%$ \\
\hline Itapecerica da Serra & 467,8 & 6,9 & 28,8 & 25,6 & 0,8 & 0,0 & 17,2 & 547,1 & $0,6 \%$ \\
\hline Itapevi & 619,5 & 3,3 & 68,3 & 0,0 & 0,0 & 0,0 & 41,3 & 732,4 & $0,8 \%$ \\
\hline Itaquaquecetuba & 956,6 & 12,5 & 33,2 & 76,2 & 0,0 & 0,6 & 21,0 & $1.100,1$ & $1,2 \%$ \\
\hline Jandira & 362,4 & 4,4 & 5,4 & 0,0 & 0,0 & 0,0 & 7,8 & 380,0 & $0,4 \%$ \\
\hline Juquitiba & 59,0 & 0,0 & 0,0 & 3,8 & 5,6 & 0,0 & 0,0 & 68,5 & $0,1 \%$ \\
\hline Mairiporã & 167,8 & 1,6 & 217,1 & 3,6 & 5,2 & 0,0 & 32,8 & 428,0 & $0,5 \%$ \\
\hline Mauá & $1.183,9$ & 14,0 & 183,9 & 7,4 & 0,0 & 0,1 & 16,6 & $1.405,9$ & $1,6 \%$ \\
\hline Mogi das Cruzes & $1.483,0$ & 17,4 & 566,3 & $1.166,3$ & 25,2 & 7,5 & 65,7 & $3.331,3$ & $3,8 \%$ \\
\hline Osasco & $3.160,6$ & 32,2 & 58,9 & 0,0 & 0,0 & 0,0 & 48,5 & $3.300,2$ & $3,7 \%$ \\
\hline Pirapora do Bom Jesus & 59,8 & 0,3 & 5,4 & 4,6 & 0,0 & 0,0 & 0,6 & 70,6 & $0,1 \%$ \\
\hline Poá & 299,4 & 5,8 & 20,9 & 15,3 & 2,5 & 0,0 & 15,5 & 359,3 & $0,4 \%$ \\
\hline Ribeirão Pires & 291,9 & 6,9 & 13,4 & 0,0 & 0,0 & 0,1 & 9,4 & 321,6 & $0,4 \%$ \\
\hline Rio Grande da Serra & 90,6 & 0,8 & 18,5 & 0,0 & 0,0 & 0,0 & 0,0 & 109,9 & $0,1 \%$ \\
\hline Salesópolis & 21,5 & 0,0 & 0,0 & 102,7 & 3,8 & 2,7 & 0,2 & 130,9 & $0,1 \%$ \\
\hline
\end{tabular}




\begin{tabular}{|c|c|c|c|c|c|c|c|c|c|}
\hline \multirow[b]{2}{*}{ Município } & \multirow{2}{*}{$\begin{array}{l}\text { Abast. humano } \\
\text { urbano }(\mathrm{l} / \mathrm{s})^{(1)} \\
\text { Doméstico, } \\
\text { serviços e } \\
\text { comércio }(\mathrm{l} / \mathrm{s})\end{array}$} & \multicolumn{2}{|l|}{ Industrial } & \multicolumn{3}{|l|}{ Rural } & \multirow[b]{2}{*}{$\begin{array}{l}\text { Outros } \\
(\mathrm{I} / \mathrm{s})\end{array}$} & \multirow[b]{2}{*}{$\begin{array}{l}\text { Demanda } \\
\text { total (I/s) }\end{array}$} & \multirow[b]{2}{*}{$\%$} \\
\hline & & $\begin{array}{l}\text { Indústria } \\
\text { ligada à } \\
\text { rede }(\mathrm{I} / \mathrm{s})\end{array}$ & $\begin{array}{l}\text { Indústria } \\
\text { isolada } \\
(\mathrm{l} / \mathrm{s})\end{array}$ & $\begin{array}{l}\text { Irrigação } \\
(\mathrm{l} / \mathrm{s})\end{array}$ & $\begin{array}{l}\text { Abast. } \\
\text { humano } \\
(\mathrm{l} / \mathrm{s})\end{array}$ & $\begin{array}{l}\text { Dessedentação } \\
\text { animal (I/s) }\end{array}$ & & & \\
\hline Santa Isabel(2) & 114,6 & $147,9^{(3)}$ & & 53 & 8,80 & 7,2 & $1,9^{(4)}$ & 333,4 & $0,4 \%$ \\
\hline Santana de Parnaíba & 481,4 & 2,8 & 48,8 & 0,9 & 0,0 & 0,0 & 143,9 & 677,8 & $0,8 \%$ \\
\hline Santo André & $2.440,6$ & 51,3 & 437,1 & 4,2 & 0,0 & 0,0 & 109,9 & $3.043,1$ & $3,5 \%$ \\
\hline São Bernardo do Campo & $3.227,0$ & 111,6 & 256,6 & 25,8 & 36,3 & 0,0 & 114,0 & $3.771,1$ & $4,3 \%$ \\
\hline São Caetano do Sul & 573,6 & 20,4 & 4,8 & 0,5 & 0,0 & 0,0 & 23,0 & 622,3 & $0,7 \%$ \\
\hline São Lourenço da Serra & 27,8 & 0,0 & 0,0 & 0,0 & 1,1 & 0,0 & 0,0 & 28,9 & $0,0 \%$ \\
\hline São Paulo & $44.606,8$ & 561,3 & $1.443,8$ & 173,3 & 105,8 & 0,3 & $1.080,4$ & $47.971,8$ & $54,5 \%$ \\
\hline Suzano & 772,6 & 23,0 & $1.897,8$ & 353,2 & 18,3 & 9,0 & 12,1 & $3.086,0$ & $3,5 \%$ \\
\hline Taboão da Serra & 866,9 & 12,3 & 26,9 & 0,0 & 0,0 & 0,0 & 78,2 & 984,2 & $1,1 \%$ \\
\hline Vargem Grande Paulista & 127,4 & 1,4 & 0,4 & 48,6 & 0,0 & 0,0 & 0,0 & 177,9 & $0,2 \%$ \\
\hline TOTAL & 74.082 & 7.816 & & 3.583 & 251 & 40 & 2.326 & 88.097 & $100 \%$ \\
\hline Participação & $84,1 \%$ & $8,9 \%$ & & $4,1 \%$ & $0,3 \%$ & $0,0 \%$ & $2,6 \%$ & $100 \%$ & - \\
\hline
\end{tabular}

Valores realçados são os mais 5 mais expressivos de cada coluna.

(1) O PBH-AT soma os valores de indústria ligada à rede e das demais demandas urbanas. Na tabela acima, procedeu-se à distinção entre os usos.

2) Municípios constantes no PBH-PS (CEIVAP, 2014). Todos os demais constam no PBH-AT (FABHAT, 2018b, 2018a).

(3) $\mathrm{O} P B H-P S$ não discrimina consumos industriais ligados à rede e isolados.

(4) Obtido pelo somatório das outorgas com finalidade "Outros" no REGLA (ANA, 2016a).

Fonte: adaptado de (1) FABHAT (2018b, 2018a); (2) CEIVAP (2014); (3) ANA (2016a) 
Conforme dados da Tabela 49, as demandas totais de água na RMSP somam 88,1 $\mathrm{m}^{3} / \mathrm{s}$, sendo que usos para abastecimento humano urbano são claramente os predominantes: $74,1 \mathrm{~m}^{3} / \mathrm{s}$, ou $84,1 \%$ do total. As demandas industriais (somadas as ligadas à rede e isoladas) são de $7,8 \mathrm{~m}^{3} / \mathrm{s}$ e equivalem a $8,9 \%$ do total. Apesar de ser uma região altamente urbanizada, a RMSP também detém demandas significativas para irrigação, totalizando $3,5 \mathrm{~m}^{3} / \mathrm{s}$, ou $4,1 \%$ do total. A Figura 37 ilustra a distribuição das demandas por finalidade de uso.

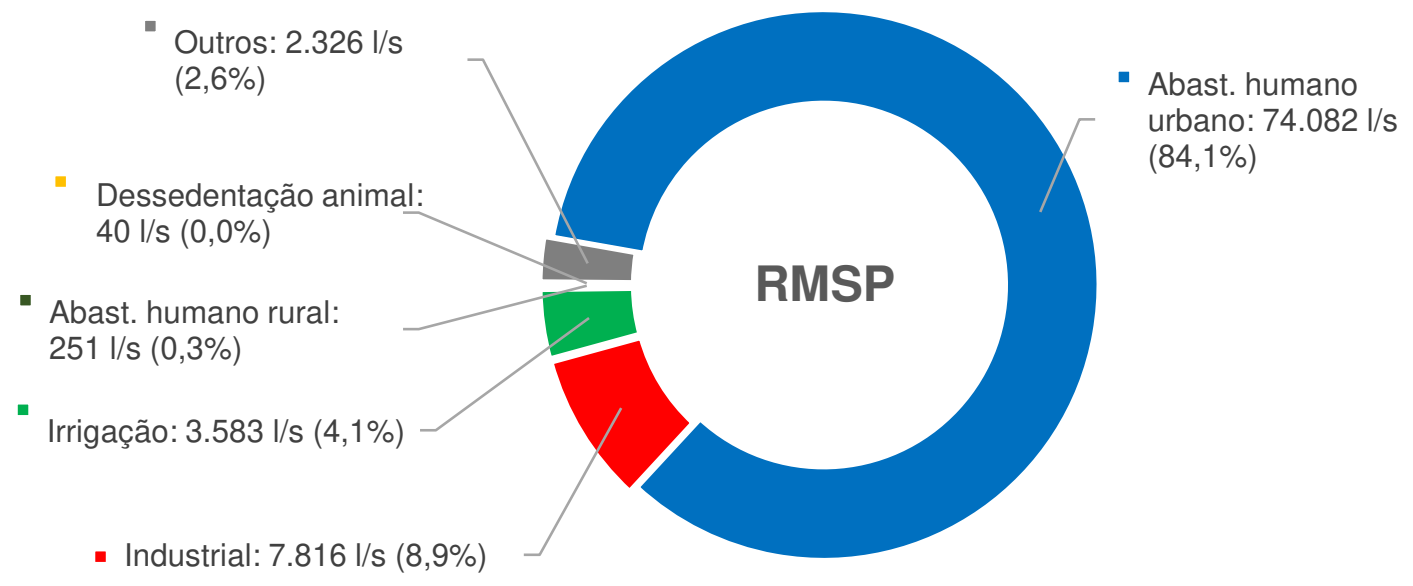

Figura 36: Gráfico da distribuição das demandas de água por tipo de uso na RMSP Fonte: adaptado de CEIVAP (2014), (3) ANA (2016a) e FABHAT (2018b, 2018a). Elaborado pelo autor.

Em geral, os municípios que possuem as maiores demandas de abastecimento urbano também apresentam as maiores vazões para os demais usos. O município de São Paulo concentra $54,5 \%$ de toda a demanda de água, principalmente por conta dos usos para abastecimento humano e indústria. Guarulhos, Mogi das Cruzes, Osasco e São Bernardo do Campo também são grandes consumidores de água. Entretanto, há algumas peculiaridades, como Suzano, onde as demandas industriais superam as demais; Mogi das Cruzes, com alta representatividade de usos de irrigação e industrial; e Biritiba-Mirim, onde quase a totalidade da demanda é referente a usos em irrigação, como se vê na Figura 37. 


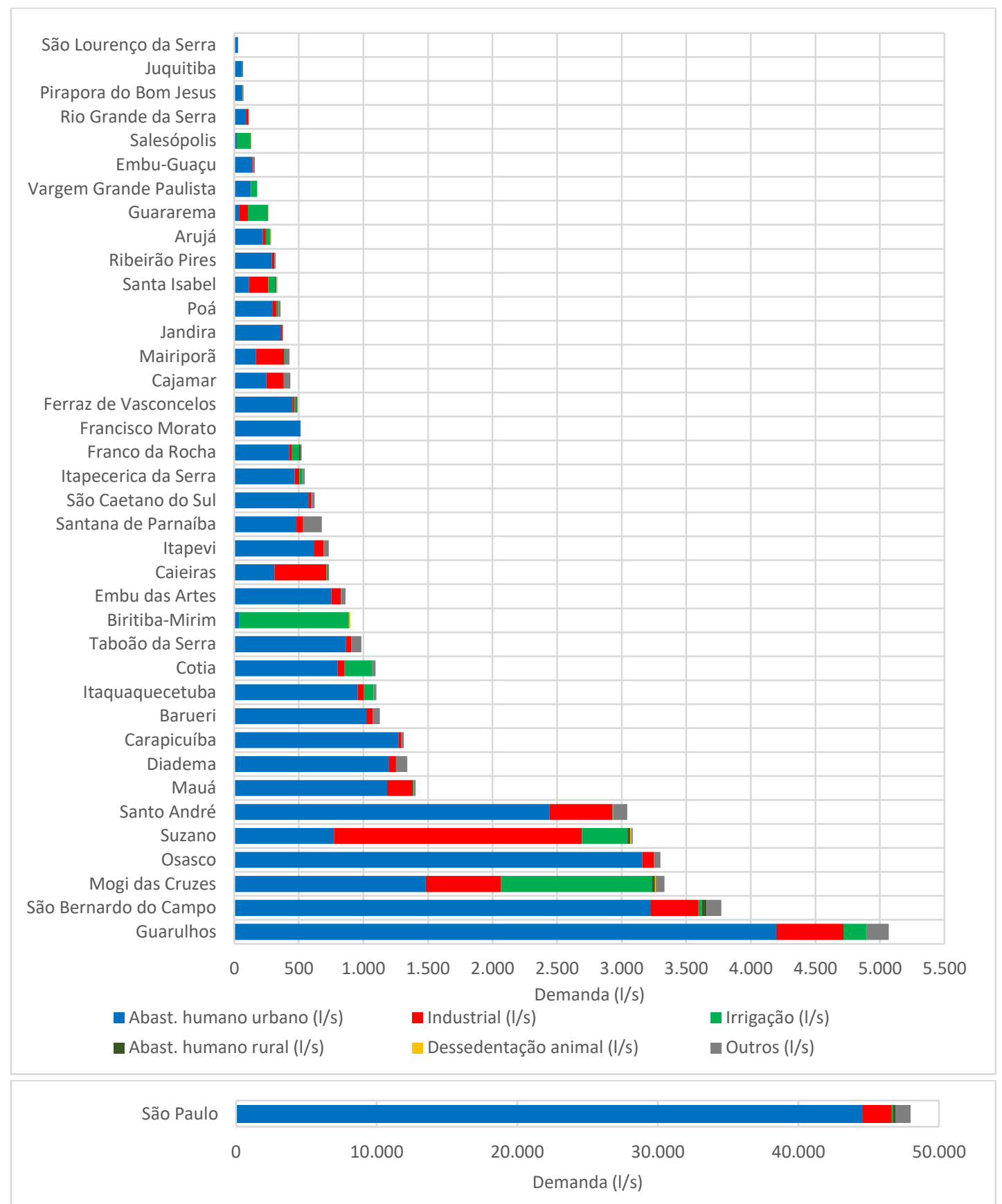

Figura 37: Gráfico da distribuição das demandas de água por tipo de uso e município da RMSP Fonte: adaptado de CEIVAP (2014), (3) ANA (2016a) e FABHAT (2018b, 2018a). Elaborado pelo autor.

5.3.1.2 Demandas de interesse específico para reúso não potável: indústria e irrigação

Conforme visto no item 3.2.2, atualmente as demandas industriais e de irrigação são as que apresentam as maiores possibilidades de atendimento por água de reúso não potável no mundo (FAO, 2016; LAUTZE et al., 2014). Posto isso, serão mais bem 
detalhadas as estimativas de demanda para estas finalidades, buscando-se maior compreensão sobre o tema. Os usos serão detalhados tanto no nível dos municípios como por usuário.

\subsection{Por município}

No caso de demandas industriais, são apresentadas abaixo quatro estimativas distintas. A primeira delas é a constante na Tabela 49, obtida a partir de dados do PBH-AT e do PBH-PS (CEIVAP, 2014; FABHAT, 2018a, 2018b); a segunda é oriunda de dados da publicação "Água na indústria: usos e coeficientes técnicos" da ANA (ANA, 2017c, 2017d); a terceira foi realizada pela agregação das outorgas federais e estaduais de captação superficial e subterrânea pela indústria constantes no REGLA (ANA, 2016a); e a quarta a partir das outorgas estaduais do DAEE disponibilizadas diretamente pela Diretoria de Procedimentos de Outorga e Fiscalização (DPO) e federais disponibilizadas no site da ANA agregadas por município (ANA, 2018b; DAEE, 2018a, 2018b). A Tabela 50 resume os valores por município e por fonte.

Tabela 50: Comparação entre estimativas de demandas industriais na RMSP

\begin{tabular}{|c|c|c|c|c|}
\hline \multirow[b]{2}{*}{ Município } & \multicolumn{4}{|c|}{ Demanda industrial (I/s) } \\
\hline & $\begin{array}{l}\text { Planos de } \\
\text { bacia(1) }^{(1)}\end{array}$ & $\begin{array}{l}\text { Água na } \\
\text { indústria } \\
(A N A)^{(2)}\end{array}$ & $\begin{array}{l}\text { REGLA } \\
(A N A)^{(3)}\end{array}$ & $\begin{array}{l}A N A \text { e } \\
D A E E^{(4)}\end{array}$ \\
\hline Arujá & 21,9 & 47,6 & 32,7 & 24,4 \\
\hline Barueri & 52,8 & 180,4 & 51,1 & 46,3 \\
\hline Biritiba-Mirim & 1,4 & 0,4 & 2,9 & 1,2 \\
\hline Caieiras & 401,8 & $1.081,2$ & 494,7 & 393,4 \\
\hline Cajamar & 130,1 & 82,2 & 157,6 & 122,4 \\
\hline Carapicuíba & 21,0 & 29,3 & 7,3 & 9,2 \\
\hline Cotia & 55,6 & 104,6 & 50,7 & 87,7 \\
\hline Diadema & 53,7 & 275,8 & 63,3 & 61,5 \\
\hline Embu das Artes & 75,2 & $70,5 Z$ & 89,7 & 179,9 \\
\hline Embu-Guaçu & 5,1 & 20,2 & 3,8 & 3,2 \\
\hline Ferraz de Vasconcelos & 12,2 & 77,7 & 7,8 & 3,0 \\
\hline Francisco Morato & 0,6 & 2,1 & 0,0 & 4,5 \\
\hline Franco da Rocha & 19,7 & 16,5 & 66,1 & 39,3 \\
\hline Guararema & 69,6 & 19,0 & 97,4 & 152,9 \\
\hline Guarulhos & 521,0 & 826,6 & 770,0 & 709,6 \\
\hline Itapecerica da Serra & 35,7 & 23,7 & 24,3 & 26,4 \\
\hline Itapevi & 71,6 & 84,8 & $1.761,9$ & 143,2 \\
\hline Itaquaquecetuba & 45,7 & 101,2 & 15,5 & 105,4 \\
\hline Jandira & 9,8 & 49,6 & 8,0 & 28,1 \\
\hline Juquitiba & 0,0 & 2,2 & 2,7 & 2,3 \\
\hline Mairiporã & 218,7 & 20,6 & 12,3 & 228,7 \\
\hline Mauá & 197,8 & 261,6 & 63,0 & 209,7 \\
\hline Mogi das Cruzes & 583,7 & 640,1 & 276,1 & 498,8 \\
\hline Osasco & 91,1 & 149,0 & 90,3 & 145,9 \\
\hline Pirapora do Bom Jesus & 5,7 & 10,8 & 6,9 & 8,6 \\
\hline Poá & 26,7 & 67,8 & 1,1 & 39,9 \\
\hline Ribeirão Pires & 20,2 & 33,8 & 8,7 & 195,5 \\
\hline
\end{tabular}




\begin{tabular}{|c|c|c|c|c|}
\hline \multirow[b]{2}{*}{ Município } & \multicolumn{4}{|c|}{ Demanda industrial (I/s) } \\
\hline & $\begin{array}{l}\text { Planos de } \\
\operatorname{bacia}^{(1)}\end{array}$ & $\begin{array}{l}\text { Água na } \\
\text { indústria } \\
(A N A)^{(2)}\end{array}$ & $\begin{array}{l}R E G L A \\
(A N A)^{(3)}\end{array}$ & $\begin{array}{l}A N A \text { e } \\
D A E E^{(4)}\end{array}$ \\
\hline Rio Grande da Serra & 19,3 & 6,8 & 7,2 & 18,5 \\
\hline Salesópolis & 0,0 & 0,6 & 0,0 & 0,0 \\
\hline Santa Isabel & 147,9 & 53,5 & 248,7 & 128,0 \\
\hline Santana de Parnaíba & 51,6 & 49,6 & 67,5 & 62,0 \\
\hline Santo André & 488,4 & 290,9 & 422,5 & 511,3 \\
\hline São Bernardo do Campo & 368,2 & 539,1 & 254,7 & 277,9 \\
\hline São Caetano do Sul & 25,2 & 169,2 & 1,8 & 14,6 \\
\hline São Lourenço da Serra & 0,0 & 2,3 & 0,0 & 0,3 \\
\hline São Paulo & $2.005,2$ & $5.199,4$ & $2.883,8$ & $2.574,5$ \\
\hline Suzano & $1.920,8$ & 454,8 & 409,6 & $2.199,9$ \\
\hline Taboão da Serra & 39,2 & 70,8 & 51,3 & 14,8 \\
\hline Vargem Grande Paulista & 1,8 & 33,1 & 23,2 & 13,0 \\
\hline Total & 7.816 & 11.149 & 8.536 & 9.286 \\
\hline
\end{tabular}

Nota: valores realçados são os cinco maiores de cada coluna.

Fontes: (1) CEIVAP (2014) e FABHAT (2018a, 2018b); (2) ANA (2017c, 2017d); (3) ANA (2016a); (4) ANA (2018b) e DAEE (2018a, 2018b).

Analisando-se os dados da Tabela 50, verifica-se que as variações são significativas, com valor mínimo de $7.816 \mathrm{l} / \mathrm{s}$ (planos de bacia) a máximo de $11.149 \mathrm{l} / \mathrm{s}$ (publicação "Água na indústria" da ANA). Seria esperado que estimativas realizadas diretamente por outorgas (REGLA e DAEE) fossem coincidentes, mas se veem diferenças muito expressivas para municípios como Suzano e Itapevi. Ainda assim, em geral as estimativas apontam que os municípios de São Paulo, Suzano, Guarulhos, Santo André e Mogi das Cruzes são importantes concentradores de demandas industriais.

Quanto às demandas de irrigação, além das vazões foram levantadas também as áreas irrigadas, uma vez que esse dado é geralmente utilizado para estimativas de demanda. A Tabela 51 apresenta áreas irrigadas (em hectares, ha) e demandas de irrigação por município.

Tabela 51: Comparação entre estimativas de demandas de irrigação na RMSP

\begin{tabular}{l|ll|lll}
\hline \multirow{2}{*}{ Município } & Área irrigada (ha) & \multicolumn{4}{|l}{ Demandas de irrigação (I/s) } \\
\cline { 2 - 6 } & $\begin{array}{l}\text { Planos de } \\
\text { bacia }^{(1)}\end{array}$ & $A N A^{(2)}$ & $\begin{array}{l}\text { Planos de } \\
\text { bacia }^{(1)}\end{array}$ & $\begin{array}{l}\text { REGLA } \\
(A N A)^{(3)}\end{array}$ & $\begin{array}{l}\text { ANA e } \\
\text { DAEE(4) }\end{array}$ \\
\hline Arujá & 66 & 73 & 31 & 0,4 & 0,2 \\
\hline Barueri & 0 & 0 & 0 & 2,8 & 0,0 \\
\hline Biritiba-Mirim & 1.779 & 1.498 & 845 & 702,4 & 642,5 \\
\hline Caieiras & 26 & 33 & 12 & 2,2 & 0,7 \\
\hline Cajamar & 3 & 3 & 1 & 0 & 0,2 \\
\hline Carapicuíba & 0 & 0 & 0 & 0 & 0,0 \\
\hline Cotia & 452 & 571 & 215 & 19,1 & 3,2 \\
\hline Diadema & 0 & 0 & 0 & 0 & 0,0 \\
\hline Embu das Artes & 0 & 0 & 0 & 4,2 & 29,6 \\
\hline Embu-Guaçu & 9 & 11 & 4 & 0 & 0,0 \\
\hline Ferraz de Vasconcelos & 37 & 63 & 18 & 0 & 0,1 \\
\hline
\end{tabular}




\begin{tabular}{|c|c|c|c|c|c|c|}
\hline \multirow[b]{2}{*}{ Município } & \multicolumn{2}{|c|}{ Área irrigada (ha) } & \multicolumn{4}{|c|}{ Demandas de irrigação (I/s) } \\
\hline & $\begin{array}{l}\text { Planos de } \\
\text { bacia }^{(1)}\end{array}$ & $A N A^{(2)}$ & $\begin{array}{l}\text { Planos de } \\
\text { bacia }^{(1)}\end{array}$ & $\begin{array}{l}\text { REGLA } \\
(A N A)^{(3)}\end{array}$ & $\begin{array}{l}A N A e \\
D A E E^{(4)}\end{array}$ & $\begin{array}{l}\text { Por } \\
\text { ottobacia }^{(5)}\end{array}$ \\
\hline Francisco Morato & 5 & 0 & 2 & 0 & 0,0 & \\
\hline Franco da Rocha & 117 & 136 & 56 & 0,7 & 0,1 & \\
\hline Guararema & 458 & 532 & 152 & 13 & 2,6 & \\
\hline Guarulhos & 382 & 440 & 182 & 0 & 0,0 & \\
\hline Itapecerica da Serra & 54 & 66 & 26 & 3,8 & 1,0 & \\
\hline Itapevi & 0 & 0 & 0 & 0 & 0,6 & \\
\hline Itaquaquecetuba & 160 & 189 & 76 & 0 & 0,0 & \\
\hline Jandira & 0 & 0 & 0 & 0 & 0,0 & \\
\hline Juquitiba & 8 & 7 & 4 & 0 & 0,0 & \\
\hline Mairiporã & 8 & 9 & 4 & 1,1 & 0,0 & \\
\hline Mauá & 16 & 0 & 7 & 1,1 & 0,0 & \\
\hline Mogi das Cruzes & 2.455 & 4.098 & 1.166 & 733,9 & 113,7 & \\
\hline Osasco & 0 & 0 & 0 & 0 & 0,0 & \\
\hline Pirapora do Bom Jesus & 10 & 0 & 5 & 0 & 3,4 & \\
\hline Poá & 32 & 33 & 15 & 0 & 0,0 & \\
\hline Ribeirão Pires & 0 & 0 & 0 & 5,6 & 0,6 & \\
\hline Rio Grande da Serra & 0 & 0 & 0 & 0 & 0,0 & \\
\hline Salesópolis & 216 & 239 & 103 & 61,8 & 9,7 & \\
\hline Santa Isabel & 156 & 128 & 53 & 7,4 & 3,4 & \\
\hline Santana de Parnaíba & 2 & 2 & 1 & 2,2 & 0,0 & \\
\hline Santo André & 9 & 9 & 4 & 0 & 0,0 & \\
\hline São Bernardo do Campo & 54 & 62 & 26 & 0 & 8,2 & \\
\hline São Caetano do Sul & 1 & 1 & 0 & 2,2 & 0,0 & \\
\hline São Lourenço da Serra & 0 & 0 & 0 & 0 & 0,1 & \\
\hline São Paulo & 365 & 406 & 173 & 60,7 & 7,8 & \\
\hline Suzano & 744 & 1.190 & 353 & 283,1 & 33,4 & \\
\hline Taboão da Serra & 0 & 0 & 0 & 0 & 0,0 & \\
\hline Vargem Grande Paulista & 102 & 105 & 49 & 1,9 & 3,0 & \\
\hline Total & 7.725 & 9.904 & 3.583 & 1.909 & 864 & 801 \\
\hline
\end{tabular}

Nota: valores realçados são os cinco maiores de cada coluna.

Fontes: (1) CEIVAP (2014) e FABHAT (2018a, 2018b); (2) ANA (2017e); (3) ANA (2016a); (4) ANA (2018b) e DAEE (2018a, 2018b); (5) ANA (2016b)

Assim como observado para os usos de água pela indústria, a diferença entre as estimativas de demanda de irrigação também é significativa, variando de $801 \mathrm{l} / \mathrm{s}$ a $3.583 \mathrm{l} / \mathrm{s}$; ou seja, o valor máximo supera em quase quatro vezes o mínimo. Ainda assim, mesmo que o somatório total para a RMSP tenha notória variação, os valores por município mantêm alguma proporcionalidade. Tanto os planos de bacia (CEIVAP, 2014; FABHAT, 2018a, 2018b) como o Atlas Irrigação (ANA, 2017e) indicam que Mogi das Cruzes, Biritiba-Mirim, Guararema, Cotia e Suzano possuem as maiores demandas de irrigação na RMSP.

\subsection{Por usuário}

Além dos dados agregados por município, é possível caracterizar as demandas para as finalidades industrial e de irrigação por meio dos registros de outorgas de captação 
estaduais (DAEE) e federais (ANA). Essa abordagem é especialmente importante para aplicação do Modelo ETE-usuário, dado que o nível da análise proposto exige identificação individual dos potenciais usuários de água de reúso.

Foram consultadas quatro bases de dados de outorgas: a do DAEE (2018c) disponível na página do órgão; a do DAEE (2018a, 2018b) cedida diretamente pela Diretoria de Procedimentos de Outorga e Fiscalização (DPO); os registros de outorgas federais da ANA (2018b) disponíveis na página da agência; e dados do REGLA cedidos diretamente pela Superintendência de Recursos Hídricos (SPR) (ANA, 2016a).

A partir dos registros analisados e da devida aplicação de filtros, chegou-se a número de 2.794 outorgas ativas de captação para finalidades industriais e de irrigação, as quais somam vazão outorgada de 10.149,9 l/s. As outorgas se dividem conforme a Tabela 52.

Tabela 52: Outorgas de captação ativas para finalidades industrial e de irrigação na RMSP de acordo com tipo de uso

\begin{tabular}{lcccc}
\hline \multirow{2}{*}{ Finalidade } & \multicolumn{2}{c}{ Quantidade } & \multicolumn{2}{c}{$\mathbf{Q}_{\text {out }}(\mathbf{I} / \mathbf{s})$} \\
\cline { 2 - 5 } & Qtde. & $\%$ & $\mathrm{I} / \mathrm{s}$ & $\%$ \\
\hline Industrial & 2.351 & $84,1 \%$ & $9.285,8$ & $91,5 \%$ \\
\hline Irrigação & 443 & $15,9 \%$ & 864,0 & $8,5 \%$ \\
\hline Total & $\mathbf{2 . 7 9 4}$ & $\mathbf{1 0 0} \%$ & $\mathbf{1 0 . 1 4 9 , 9}$ & $\mathbf{1 0 0 \%}$ \\
\hline \multicolumn{2}{c}{ Fonte: adaptado de ANA (2018b) e DAEE (2018a, 2018b) }
\end{tabular}

Os usos industriais são prevalentes, correspondendo a $84 \%$ das outorgas (em quantidade) e $91,5 \%$ da vazão outorgada.

A distribuição espacial das outorgas de acordo com finalidade de uso é mostrada no mapa da Figura 38. 


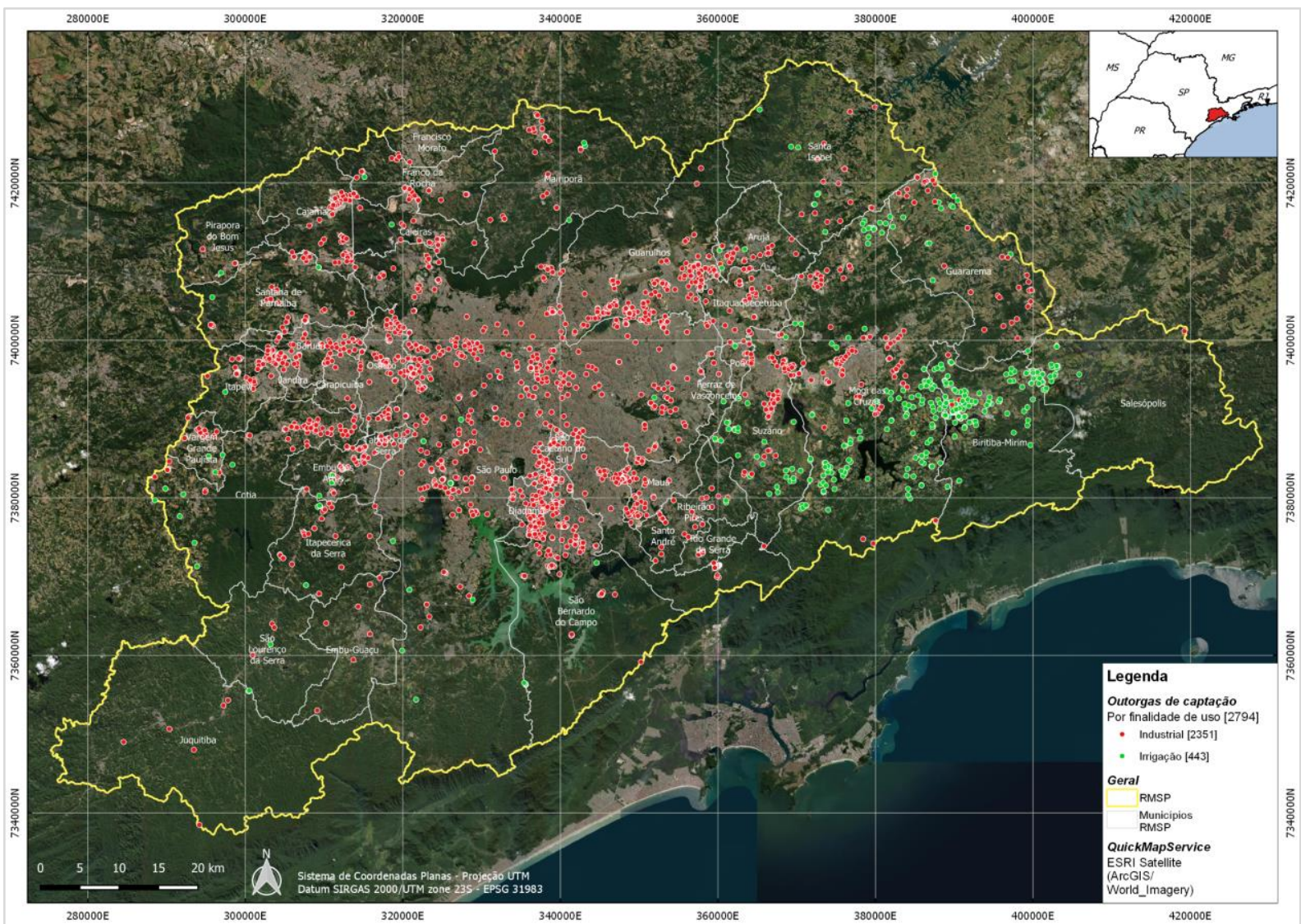

Figura 38: Outorgas de captação ativas para finalidades industriais e de irrigação na RMSP Fonte (dados e shapefiles): IBGE (2015b), ANA (2018b) e DAEE (2018a, 2018b). Elaborado pelo autor.

Vê-se que os usos industriais se concentram principalmente em São Paulo, Guarulhos, Suzano e região do ABCD (Santo André, São Bernardo do Campo, São Caetano do Sul e Diadema). As de irrigação estão majoritariamente localizadas em regiões periféricas no eixo Leste, em municípios como Suzano, Mogi das Cruzes e Biritiba-Mirim.

\subsection{Evapotranspiração local para ajuste das demandas de irrigação}

Conforme explicado no item 5.2.2.2, o Modelo ETE-usuário prevê uso de Evapotranspiração (ETo) para ajuste das vazões outorgadas para irrigação. Utilizando-se o método Blaney-Criddle para estimativa de ETo mensal e as médias mensais e de precipitação para São Paulo (INMET, 2020), foram obtidos os valores apresentados na Tabela 53. 
Tabela 53: Estimativa de demanda de irrigação mensal a partir de P e ETo

\begin{tabular}{|c|c|c|c|c|c|}
\hline Mês & $\begin{array}{l}\text { P média } \\
\text { (mm/mês) }\end{array}$ & $\begin{array}{c}\mathrm{T} \\
\text { média }\left({ }^{\circ} \mathrm{C}\right)\end{array}$ & $\begin{array}{c}\text { ETo } \\
\text { (mm/mês) }\end{array}$ & $\begin{array}{c}\text { Demanda irrigação } \\
\text { (mm/mês) }\end{array}$ & $\begin{array}{l}\text { Irrigação } \\
\text { (S/N) }\end{array}$ \\
\hline jan & 237,4 & 22,1 & 171,1 & 0,0 & $\mathrm{~N}$ \\
\hline fev & 221,5 & 22,4 & 149,7 & 0,0 & $\mathrm{~N}$ \\
\hline mar & 160,5 & 21,8 & 156,0 & 0,0 & $\mathrm{~N}$ \\
\hline$a b r$ & 72,6 & 19,7 & 135,1 & 62,5 & $S$ \\
\hline mai & 71,4 & 17,4 & 125,0 & 53,6 & $\mathrm{~S}$ \\
\hline jun & 50,1 & 16,3 & 114,6 & 64,5 & $\mathrm{~S}$ \\
\hline jul & 43,9 & 15,8 & 117,3 & 73,4 & $S$ \\
\hline ago & 39,6 & 17,1 & 127,2 & 87,6 & $\mathrm{~S}$ \\
\hline set & 70,7 & 17,9 & 132,7 & 62,0 & $\mathrm{~S}$ \\
\hline out & 126,9 & 19,0 & 149,0 & 22,1 & $\mathrm{~S}$ \\
\hline nov & 145,8 & 20,2 & 154,5 & 8,7 & $\mathrm{~S}$ \\
\hline dez & 200,7 & 21,1 & 168,0 & 0,0 & $\mathrm{~N}$ \\
\hline Soma & $\begin{array}{c}1.441,1 \\
\text { (mm/ano) }\end{array}$ & - & $\begin{array}{c}1.700 \\
\text { (mm/ano) }\end{array}$ & $\begin{array}{c}434,4 \\
\text { (mm/ano) }\end{array}$ & - \\
\hline Média & 120,1 & 19,2 & 141,7 & 36,2 & - \\
\hline Máx & 237,4 & 22,4 & 171,1 & 87,6 & - \\
\hline
\end{tabular}

Fonte: dados de precipitação de INMET (2020) e ETo calculado pelo método Blaney-Criddle para latitude $22^{\circ} \mathrm{S}$

Ou seja, conforme apresentado na Tabela 53, a ETo média mensal é de 141,7 $\mathrm{mm} / \mathrm{mês}$ (mensal diária de 4,7 mm/dia), o que está próximo a estimativas entre 3,5 4,5 mm/dia para o estado de São Paulo (CEIVAP, 2014; MARTINS, 2011; TANGUNE, 2017). O valor máximo de demanda de irrigação é $87,6 \mathrm{~mm} / \mathrm{mês}$ (agosto), e a totalização anual é 434,4 mm/ano. Aplicando esses valores à Equação 9 (ver item 5.2.2.2) chega-se ao valor da Equação 17.

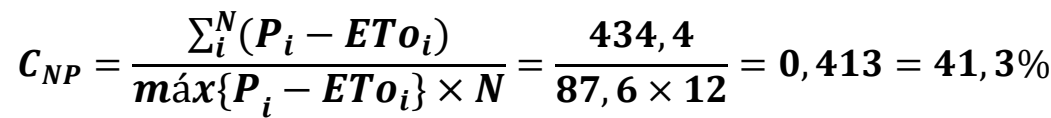

$$
\begin{aligned}
& \text { CNP,irr coef. não potável de irrigação } \\
& \mathrm{Pi} \quad \text { precipitação média no mês "i" } \\
& \text { EToi evapotranspiração média no "i" } \\
& \mathrm{N} \text { meses/ano }
\end{aligned}
$$

Esse valor de $\mathrm{C}_{\mathrm{NP}}$ foi utilizado para ajuste das vazões outorgadas para irrigação na RMSP.

\subsubsection{Coleta e tratamento de esgotos}

Assim como no caso das demandas, foram encontrados distintos valores referentes à abrangência e demais características da infraestrutura de coleta e tratamento de esgotos na RMSP. Para estimativa dos volumes de esgoto gerado e tratado, índices de atendimento e eficiência das ETEs na área de estudo, foram consultadas três fontes: Atlas Esgotos (ANA, 2017b), SNIS 2016 (SNS/MDR, 2018) e Relatório de 
Qualidade das Águas Interiores no Estado de São Paulo 2017 (CETESB, 2018c). Os dados obtidos nas referências indicadas estão apresentados na Tabela 54, na qual também constam os valores de ICTEM por município.

Tabela 54: Geração, coleta e tratamento de esgotos nos municípios da RMSP

\begin{tabular}{|c|c|c|c|c|c|c|c|c|}
\hline \multirow[t]{2}{*}{ Município } & $\begin{array}{c}\text { Esgoto } \\
\text { gerado } \\
(\mathrm{I} / \mathrm{s})\end{array}$ & $\begin{array}{c}\text { Esgoto } \\
\text { tratado } \\
(\mathrm{I} / \mathrm{s})\end{array}$ & $\begin{array}{c}\text { Índice de } \\
\text { tratamento }{ }^{(1)} \\
(\%)\end{array}$ & $\begin{array}{c}\text { Esgoto } \\
\text { gerado } \\
(1 / \mathbf{s})\end{array}$ & $\begin{array}{c}\text { Esgoto } \\
\text { tratado } \\
(1 / \mathbf{s})\end{array}$ & $\begin{array}{c}\text { Índice de } \\
\text { atendimento } \\
(\%)\end{array}$ & $\begin{array}{c}\text { Índice de } \\
\text { atendimento } \\
(\%)\end{array}$ & $\underset{(5)}{\text { ICTEM }}$ \\
\hline & \multicolumn{3}{|c|}{ ANA (2017f) } & \multicolumn{3}{|c|}{ SNS/MDR (2018) } & \multicolumn{2}{|c|}{ Cetesb (2018c, 2018a) } \\
\hline Arujá & 146,7 & 82,5 & $56 \%$ & 137,1 & 62,9 & $46 \%$ & $66 \%$ & 6,2 \\
\hline Barueri & 389,8 & 70,6 & $18 \%$ & 535,8 & 120,1 & $22 \%$ & $29 \%$ & 3,93 \\
\hline Biritiba-Mirim & 107,4 & 34,5 & $32 \%$ & 24,8 & 16,7 & $67 \%$ & $55 \%$ & 4,52 \\
\hline Caieiras & 115,6 & 0,0 & $0 \%$ & 126,6 & 0,0 & $0 \%$ & $0 \%$ & 1,11 \\
\hline Cajamar & 115,2 & 0,0 & $0 \%$ & 118,7 & 0,0 & $0 \%$ & $0 \%$ & 1,08 \\
\hline Carapicuíba & 793,3 & 230,1 & $29 \%$ & 539,1 & 151,2 & $28 \%$ & $37 \%$ & 4,54 \\
\hline Cotia & 395,4 & 73,5 & $19 \%$ & 386,9 & 58,4 & $15 \%$ & $21 \%$ & 1,88 \\
\hline Diadema & 567,6 & 67,1 & $12 \%$ & 615,9 & 135,3 & $22 \%$ & $27 \%$ & 3,57 \\
\hline Embu das Artes & 93,2 & 33,8 & $36 \%$ & 336,9 & 100,7 & $30 \%$ & $36 \%$ & 3,92 \\
\hline Embu-Guaçu & 102,5 & 46,0 & $45 \%$ & 67,3 & 26,7 & $40 \%$ & $38 \%$ & 4,63 \\
\hline Ferraz de Vasconcelos & 310,3 & 136,5 & $44 \%$ & 230,0 & 85,7 & $37 \%$ & $45 \%$ & 4,74 \\
\hline Francisco Morato & 193,6 & 0,0 & $0 \%$ & 184,0 & 0,0 & $0 \%$ & $0 \%$ & 0,6 \\
\hline Franco da Rocha & 191,0 & 0,0 & $0 \%$ & 199,7 & 0,0 & $0 \%$ & $0 \%$ & 0,94 \\
\hline Guararema & 34,2 & 6,6 & $19 \%$ & 36,2 & 20,4 & $56 \%$ & $49 \%$ & 5,8 \\
\hline Guarulhos & $1.750,1$ & 502,3 & $29 \%$ & $2.786,4$ & 58,7 & $2 \%$ & $37 \%$ & 4,77 \\
\hline Itapecerica da Serra & 151,1 & 43,1 & $29 \%$ & 187,5 & 45,9 & $24 \%$ & $27 \%$ & 3,54 \\
\hline Itapevi & 228,1 & 42,7 & $19 \%$ & 260,7 & 64,9 & $25 \%$ & $30 \%$ & 3,95 \\
\hline Itaquaquecetuba & $1.325,9$ & 58,7 & $4 \%$ & 422,1 & 31,0 & $7 \%$ & $9 \%$ & 1,84 \\
\hline Jandira & 138,2 & 8,8 & $6 \%$ & 148,7 & 26,6 & $18 \%$ & $23 \%$ & 3,45 \\
\hline Juquitiba & 21,8 & 7,0 & $32 \%$ & 30,8 & 11,1 & $36 \%$ & $17 \%$ & 3,25 \\
\hline Mairiporã & 153,7 & 42,1 & $27 \%$ & 75,9 & 19,6 & $26 \%$ & $20 \%$ & 3,04 \\
\hline Mauá & 817,7 & 785,0 & $96 \%$ & 520,9 & 338,9 & $67 \%$ & $56 \%$ & 6,05 \\
\hline Mogi das Cruzes & 659,4 & 325,0 & $49 \%$ & 594,2 & 267,9 & $70 \%$ & $57 \%$ & 5,72 \\
\hline Osasco & $1.595,6$ & 395,5 & $25 \%$ & 1147,1 & 286,6 & $25 \%$ & $31 \%$ & 4,12 \\
\hline Pirapora do Bom Jesus & 12,7 & 2,8 & $22 \%$ & 20,1 & 4,5 & $22 \%$ & $23 \%$ & 2,87 \\
\hline Poá & 238,9 & 205,5 & $86 \%$ & 158,4 & 127,8 & $81 \%$ & $89 \%$ & 7,91 \\
\hline Ribeirão Pires & 62,9 & 34,8 & $55 \%$ & 150,3 & 67,1 & $45 \%$ & $50 \%$ & 5,48 \\
\hline Rio Grande da Serra & 16,0 & 8,2 & $51 \%$ & 51,1 & 24,4 & $48 \%$ & $43 \%$ & 4,76 \\
\hline Salesópolis & 59,9 & 41,5 & $69 \%$ & 14,1 & 9,2 & $65 \%$ & $76 \%$ & 6,77 \\
\hline Santa Isabel & 47,3 & 0,0 & $0 \%$ & 51,4 & 0,0 & $0 \%$ & $0 \%$ & 0,93 \\
\hline Santana de Parnaíba & 216,2 & 20,8 & $10 \%$ & 237,7 & 26,8 & $11 \%$ & $13 \%$ & 2,39 \\
\hline Santo André & 895,3 & 361,0 & $40 \%$ & $1.263,9$ & 1,5 & $42 \%$ & $40 \%$ & 4,89 \\
\hline São Bernardo do Campo & $1.483,9$ & 286,7 & $19 \%$ & $1.412,8$ & 386,3 & $27 \%$ & $29 \%$ & 3,85 \\
\hline São Caetano do Sul & 331,7 & 331,7 & $100 \%$ & 396,3 & 0,0 & $85 \%$ & $91 \%$ & 9,87 \\
\hline São Lourenço da Serra & 9,7 & 6,0 & $62 \%$ & 14,1 & 8,3 & $59 \%$ & $31 \%$ & 3,98 \\
\hline São Paulo & $19.783,7$ & $12.976,4$ & $66 \%$ & $20.929,9$ & $12.969,0$ & $62 \%$ & $66 \%$ & 6,58 \\
\hline Suzano & 611,6 & 364,0 & $60 \%$ & 387,1 & 209,1 & $54 \%$ & $64 \%$ & 6,15 \\
\hline Taboão da Serra & 342,2 & 104,5 & $31 \%$ & 404,5 & 123,7 & $31 \%$ & $39 \%$ & 4,84 \\
\hline Vargem Grande Paulista & 69,8 & 0,0 & $0 \%$ & 60,4 & 4,2 & $7 \%$ & $9 \%$ & 1,57 \\
\hline TOTAL & 34.579 & 17.735 & $51,3 \%$ & 35.253 & 15.891 & $45,1 \%$ & $44,5 \%$ & - \\
\hline
\end{tabular}

(1) Calculado a partir da razão esgoto tratado/esgoto gerado. Informação não é explicitamente apresentada pela ANA.

(2) Equivalente a AG010 (água total consumida) - AG19 (água bruta exportada) segundo nomenclaturas do SNIS.

(3) Equivalente ao ES005: sigla do SNIS para informação de esgoto total tratado.

(4) Equivalente ao IN046: sigla do SNIS para índice de tratamento de esgoto referido à água consumida.

(5) ICTEM: Índice de coleta e tratabilidade de esgotos da população urbana de município da Cetesb.

Fonte: adaptado de ANA (2017b), Cetesb (2018c) e SNS/MDR (2018) 
Para ANA (2017b) a vazão total e a abrangência de tratamento são, respectivamente, de $17.735 \mathrm{l} / \mathrm{s}$ e $51,3 \%$; para SNS/MDR (2018) de $15.891 \mathrm{l} / \mathrm{s}$ e $45,1 \%$; e para Cetesb (2018c) a cobertura é de $44,5 \%$ Vale lembrar que a cobertura nacional de é de $43 \%$ (ANA, 2017b; SNS/MDR, 2019), o que posiciona a RMSP somente ligeiramente acima da média do País.

O tratamento de esgotos da RMSP é realizado, em sua maior parte, pelas cinco ETEs que compõem o Projeto Tietê da Sabesp: ETEs ABC, Barueri, Parque Novo Mundo, São Miguel e Suzano, todas com processo de lodos ativados convencional e com capacidade nominal de $20.500 \mathrm{l} / \mathrm{s}$.

A Tabela 55 compila todas as 42 ETEs da RMSP encontradas, apresentando, sempre que foi possível determinar, as coordenadas (projeção plana, SIRGAS2000/UTM 23S) de cada estação. As principais fontes foram a documentação complementar do Atlas Esgotos (ANA, 2017f), o Plano Diretor de Esgotos da Região Metropolitana de São Paulo - PDE 2010 (SABESP, 2010b, 2010a) e dados fornecidos diretamente pela Sabesp via solicitação pelo Serviço de Informação ao Cidadão do Estado de São Paulo (SIC.SP) (SABESP, 2018). Campos cujos dados não foram encontrados constam como "SD" (sem dados).

Tabela 55: Relação das ETEs ativas da RMSP

\begin{tabular}{llllllll}
\hline ETE & Município & Operador & Processo & $\begin{array}{l}\mathbf{Q}_{\text {proj }} \\
(\mathbf{I} / \mathbf{s})\end{array}$ & $\mathbf{Q}_{\text {afl }}(\mathbf{l} / \mathbf{s})$ & $\mathbf{X}(\mathbf{m})^{(1)}$ & $\mathbf{Y}_{(\mathbf{m})^{(1)}}$ \\
\hline Barueri & Barueri & Sabesp (SP) & $\begin{array}{l}\text { Lodos ativados } \\
\text { convencional }\end{array}$ & $12.000,0$ & $10.042,0$ & $311.180,71$ & $7.398 .768,96$ \\
\hline ABC & São Paulo & Sabesp (SP) & $\begin{array}{l}\text { Lodos ativados } \\
\text { convencional }\end{array}$ & $3.000,0$ & $1.598,6$ & $338.141,59$ & $7.387 .541,82$ \\
\hline $\begin{array}{l}\text { Parque Novo } \\
\text { Mundo }\end{array}$ & São Paulo & Sabesp (SP) & $\begin{array}{l}\text { Lodos ativados } \\
\text { convencional }\end{array}$ & $2.500,0$ & $2.613,0$ & $340.860,51$ & $7.398 .658,36$ \\
\hline São Miguel & São Paulo & Sabesp (SP) & $\begin{array}{l}\text { Lodos ativados } \\
\text { convencional }\end{array}$ & $1.500,0$ & 947,1 & $351.899,81$ & $7.402 .148,37$ \\
\hline Suzano & Suzano & Sabesp (SP) & $\begin{array}{l}\text { Lodos ativados } \\
\text { convencional }\end{array}$ & $1.500,0$ & 928,0 & $365.319,59$ & $7.397 .594,48$ \\
\hline Mauá & Mauá & $\begin{array}{l}\text { BRK } \\
\text { Ambiental }\end{array}$ & $\begin{array}{l}\text { Lodos ativados por } \\
\text { batelada }\end{array}$ & $1.125,0$ & 750,0 & $348.548,83$ & $7.383 .058,39$ \\
\hline Bonsucesso & Guarulhos & Sabesp(2) & $\begin{array}{l}\text { RAFA + lodos } \\
\text { ativados }\end{array}$ & 673,0 & 165,3 & $355.903,48$ & $7.409 .036,48$ \\
\hline $\begin{array}{l}\text { Várzea do } \\
\text { Palácio }\end{array}$ & Guarulhos & Sabesp(2) & $\begin{array}{l}\text { RAFA + lodos } \\
\text { ativados }\end{array}$ & 600,0 & 124,0 & $347.606,34$ & $7.404 .013,77$ \\
\hline São João & Guarulhos & Sabesp ${ }^{(2)}$ & $\begin{array}{l}\text { RAFA + lodos } \\
\text { ativados }\end{array}$ & 470,0 & 124,0 & $351.882,94$ & $7.409 .472,77$ \\
\hline Leste & $\begin{array}{l}\text { Mogi das } \\
\text { Cruzes }\end{array}$ & SEMASA & $\begin{array}{l}\text { RAFA + lodos } \\
\text { ativados }\end{array}$ & 250,0 & 125,0 & $380.510,38$ & $7.399 .633,80$ \\
\hline Arujá - Sede & Arujá & Sabesp (SI) & $\begin{array}{l}\text { Lagoa aerada }+ \\
\text { facultativa }\end{array}$ & 150,0 & 45,8 & $361.353,88$ & $7.411 .988,90$ \\
\hline Jardim Japão & Cotia & Sabesp (SI) & RAFA + flotação & 120,0 & 90,9 & $307.592,42$ & $7.391 .037,69$ \\
\hline $\begin{array}{l}\text { Embu-Guaçu - } \\
\text { Sede }\end{array}$ & Embu-Guaçu & Sabesp (SI) & $\begin{array}{l}\text { RAFA + lagoa } \\
\text { facultativa }\end{array}$ & 90,0 & 38,9 & $315.150,66$ & $7.364 .879,12$ \\
\hline Ribeirão Pires & Ribeirão Pires & Sabesp (SI) & RAFA & 70,0 & 34,8 & SD & SD \\
\hline
\end{tabular}


RESULTADOS E DICUSSÕES

APLICAÇÃO À ÁREA DE ESTUDO (RMSP)

\begin{tabular}{|c|c|c|c|c|c|c|c|}
\hline ETE & Município & Operador & Processo & $\begin{array}{l}Q_{\text {proj }} \\
(I / s)\end{array}$ & $Q_{\text {afl }}(\mathrm{I} / \mathrm{s})$ & $X(m)^{(1)}$ & $Y(m)^{(1)}$ \\
\hline Biritiba-Mirim & Biritiba-Mirim & Sabesp (SI) & $\begin{array}{l}\text { Lagoa aerada + } \\
\text { facultativa }\end{array}$ & 55,0 & 28,0 & $393.773,43$ & 7.393.702,99 \\
\hline Cipó & Embu-Guaçu & Sabesp (SI) & $\begin{array}{l}\text { RAFA + lagoa + } \\
\text { infiltração }\end{array}$ & 50,0 & 10,9 & $315.927,33$ & $7.358 .105,81$ \\
\hline Jesus Neto & São Paulo & Sabesp (E) & $\begin{array}{l}\text { Linha 1: RAFA (20l/s). } \\
\text { Linha 2: lodos } \\
\text { ativados (30l/s) }\end{array}$ & 50,0 & 53,0 & $336.720,54$ & $7.390 .820,57$ \\
\hline Jaraguá & São Paulo & Sabesp (E) & RAFA + biodiscos & 38,0 & 19,8 & SD & SD \\
\hline $\begin{array}{l}\text { Mairiporã - } \\
\text { Sede }\end{array}$ & Mairiporã & Sabesp (SI) & $\begin{array}{l}\text { Lagoa anaeróbia + } \\
\text { facultativa }\end{array}$ & 35,0 & 50,9 & $338.640,62$ & $7.420 .818,87$ \\
\hline $\begin{array}{l}\text { Guararema - } \\
\text { Sede }\end{array}$ & Guararema & Sabesp (SI) & $\begin{array}{l}\text { Lodos ativados por } \\
\text { batelada }\end{array}$ & 33,0 & 6,6 & $392.700,44$ & $7.412 .158,92$ \\
\hline $\begin{array}{l}\text { Salesopólis - } \\
\text { Sede }\end{array}$ & Salesópolis & Sabesp (SI) & $\begin{array}{l}\text { Lagoa anaeróbia + } \\
\text { facultativa }+ \\
\text { maturação }\end{array}$ & 33,0 & 19,0 & $411.700,31$ & 7.398.358,97 \\
\hline $\begin{array}{l}\text { Pirapora - } \\
\text { Sede }\end{array}$ & $\begin{array}{l}\text { Pirapora do } \\
\text { Bom Jesus }\end{array}$ & Sabesp (SI) & $\begin{array}{l}\text { Lodo ativado por } \\
\text { batelada }\end{array}$ & 26,0 & 9,1 & $295.660,78$ & $7.411 .808,96$ \\
\hline $\begin{array}{l}\text { Riacho } \\
\text { Grande }\end{array}$ & $\begin{array}{l}\text { São Bernardo } \\
\text { do Campo }\end{array}$ & Sabesp (SI) & Valos de oxidação & 24,0 & 10,9 & $343.793,43$ & 7.369.620,99 \\
\hline $\begin{array}{l}\text { Rio Grande da } \\
\text { Serra }\end{array}$ & $\begin{array}{l}\text { Rio Grande da } \\
\text { Serra }\end{array}$ & Sabesp (SI) & Lagoa facultativa & 24,0 & 9,1 & SD & SD \\
\hline Juquitiba & Juquitiba & Sabesp (SI) & $\begin{array}{l}\text { Lodo ativado por } \\
\text { batelada }\end{array}$ & 18,0 & 7,8 & $289.050,80$ & $7.351 .629,15$ \\
\hline $\begin{array}{l}\text { São Lourenço } \\
\text { da Serra - } \\
\text { Sede }\end{array}$ & $\begin{array}{l}\text { São Lourenço } \\
\text { da Serra }\end{array}$ & Sabesp (SI) & $\begin{array}{l}\text { Lagoa anaeróbia + } \\
\text { facultativa }\end{array}$ & 13,0 & 6,0 & $300.800,69$ & $7.360 .089,08$ \\
\hline Gênesis & $\begin{array}{l}\text { Pirapora do } \\
\text { Bom Jesus }\end{array}$ & Sabesp (SI) & SD & 10,0 & 0,8 & SD & SD \\
\hline Pinheirinho & $\begin{array}{l}\text { São Bernardo } \\
\text { do Campo }\end{array}$ & Sabesp (SI) & RAFA + biodiscos & 7,0 & 5,7 & $336.921,78$ & $7.371 .442,52$ \\
\hline $\begin{array}{l}\text { Parque } \\
\text { Andreense }\end{array}$ & Santo André & Sabesp (SI) & $\begin{array}{l}\text { Lodos ativados por } \\
\text { batelada }\end{array}$ & 5,0 & 1,0 & $350.939,90$ & $7.370 .376,17$ \\
\hline Paiol do Meio & $\begin{array}{l}\text { São Lourenço } \\
\text { da Serra }\end{array}$ & Sabesp (SI) & Tanque filtro & 4,1 & 1,0 & SD & SD \\
\hline Vila Arujá & Arujá & Sabesp (SI) & $\begin{array}{l}\text { Fossa séptica/tanque } \\
\text { Imhoff }\end{array}$ & 3,7 & 2,1 & $368.000,66$ & $7.414 .007,45$ \\
\hline CDP & $\begin{array}{l}\text { Itapecerica da } \\
\text { Serra }\end{array}$ & Sabesp (E) & RAFA + reator aeróbio & 3,5 & 5,2 & SD & SD \\
\hline Bandeirantes & São Paulo & Sabesp (E) & $\begin{array}{l}\text { Tanque séptico + filtro } \\
\text { anaeróbio + } \\
\text { desinfecção }\end{array}$ & 3,0 & 2,6 & $320.329,82$ & $7.406 .558,84$ \\
\hline Remédios & Salesópolis & Sabesp (SI) & $\begin{array}{l}\text { Lagoa facultativa + } \\
\text { infiltração }\end{array}$ & 2,0 & 0,9 & $401.650,38$ & $7.395 .132,66$ \\
\hline $\begin{array}{l}\text { Aldeia da } \\
\text { Serra }\end{array}$ & $\begin{array}{l}\text { Santana de } \\
\text { Parnaíba }\end{array}$ & Sabesp (E) & SD & SD & SD & $300.903,68$ & $7.400 .300,88$ \\
\hline $\begin{array}{l}\text { Vargem } \\
\text { Grande } \\
\text { Paulista }\end{array}$ & $\begin{array}{l}\text { Vargem } \\
\text { Grande } \\
\text { Paulista }\end{array}$ & Sabesp (SI) & SD & SD & SD & $292.717,85$ & 7.387.991,65 \\
\hline $\begin{array}{l}\text { Parque dos } \\
\text { Pinheiros }\end{array}$ & Cajamar & Sabesp (SI) & SD & SD & SD & $312.832,05$ & $7.409 .975,44$ \\
\hline Genesis & $\begin{array}{l}\text { Santana de } \\
\text { Parnaíba }\end{array}$ & Sabesp (SI) & SD & SD & SD & $309.101,66$ & $7.406 .623,44$ \\
\hline Jardim Odete & $\begin{array}{l}\text { Itaquaquecetu } \\
\text { ba }\end{array}$ & Sabesp (SI) & SD & SD & SD & $364.192,38$ & $7.403 .799,06$ \\
\hline Mandi & $\begin{array}{l}\text { Itaquaquecetu } \\
\text { ba }\end{array}$ & Sabesp (SI) & SD & SD & SD & $365.275,87$ & $7.402 .649,01$ \\
\hline Guatambu & $\begin{array}{l}\text { Itaquaquecetu } \\
\text { ba }\end{array}$ & Sabesp (SI) & SD & SD & SD & $365.549,20$ & $7.406 .878,59$ \\
\hline Promissão & $\begin{array}{l}\text { Itaquaquecetu } \\
\text { ba }\end{array}$ & Sabesp (SI) & SD & SD & SD & $365.213,98$ & $7.408 .048,25$ \\
\hline TOTAL & & & & 24.485 & 17.878 & & \\
\hline
\end{tabular}

SP: Sistema Principal da Sabesp; SI: Sistemas Isolados da Sabesp; E: enclave da Sabesp; SD: sem dados; RAFA: reator anaeróbio de fluxo ascendente (UASB)

(1) Datum SIRGAS 2000 / UTM zone 23S

(2) No segundo semestre de 2018, um acordo entre a prefeitura de Guarulhos e o Governo do Estado celebrou a concessão por 40 anos do Serviço Autônomo de Água e Esgotos de Guarulhos (Saee Guarulhos) à Sabesp.

Fonte: adaptado de ANA (2017f) e Sabesp (2010b, 2010a, 2018) 
Somando-se as vazões das ETEs listadas acima, chega-se à capacidade nominal total na RMSP de $24,5 \mathrm{~m}^{3} / \mathrm{s}$. Ainda assim, muitas estações ainda são operadas abaixo de sua capacidade, principalmente por limitações na infraestrutura de coleta, sendo o esgoto total tratado igual a $17.878 \mathrm{l} / \mathrm{s}$, ou $72 \%$ da capacidade nominal.

A Figura 36 apresenta a localização das 36 ETEs cujas coordenadas puderam ser determinadas e o índice de tratamento de esgotos por município segundo o SNIS.

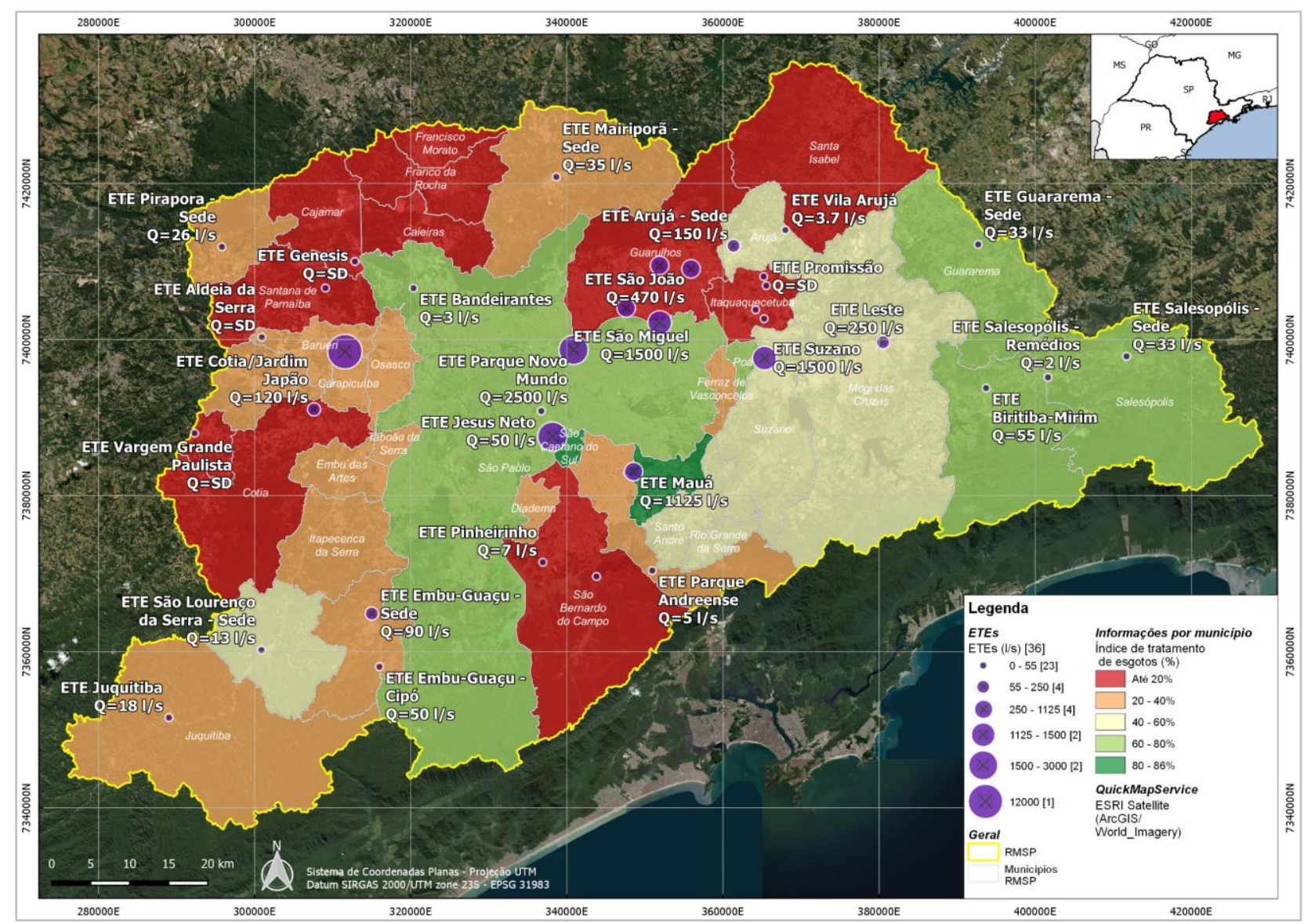

SD: sem dados

Figura 39: ETEs ativas na RMSP por faixa de vazão e índice de tratamento de esgotos por município (IN046 do SNIS)

Fonte: IBGE (2015b), ANA (2017f), Sabesp (2010b, 2010a, 2018) e SNS/MDR (2019). Elaborado pelo autor

\subsubsection{Sobreposição espacial de outorgas e ETEs}

Sobrepondo-se os dados de usuários industriais e de irrigação (outorgas) e ofertas (ETEs), chega-se ao mapa da Figura 40. Tanto as ETEs como as outorgas foram 
classificados em classes de vazão proporcionais ao diâmetro do círculo que as representa.

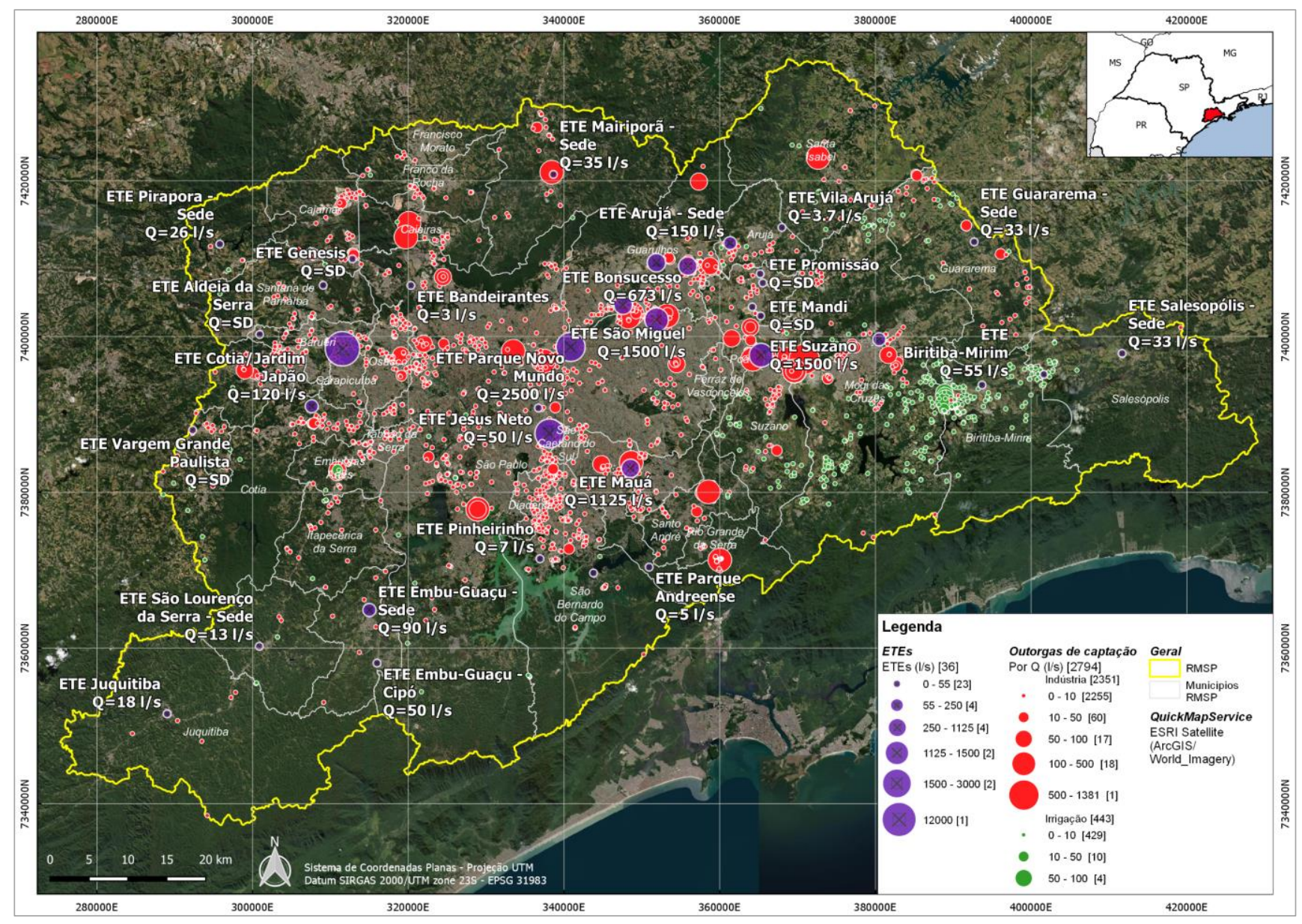

Figura 40: Localização das ETEs e de outorgas de captação para finalidades industriais e de irrigação na RMSP

Fonte: adaptado de IBGE (2015b), ANA (2017f, 2018b), Cetesb (2018c), DAEE (2018a) e Sabesp (2010b, 2010a, 2018). Elaborado pelo autor

A simples observação da Figura 40 mostra a existência de usuários muito expressivos próximos a ETEs como a Suzano, Mauá, Mairiporã, Parque dos Pinheiros, Parque Novo Mundo e São Miguel. Ressalta-se que os valores no mapa da Figura 40 se referem às vazões outorgadas (Qout) e não às não potáveis (QNP), sendo necessário ainda aplicar a correção prevista pelo uso do $\mathrm{CNP}_{\mathrm{NP}}$ de acordo com a atividade econômica para estimativas de potencial de reúso de acordo com o Modelo ETEusuário. 


\subsubsection{Custos de aquisição de água}

A Sabesp é a principal empresa de saneamento na região, sendo responsável pelo tratamento e distribuição de água e coleta e tratamento de esgotos de praticamente todos os 39 municípios da RMSP. A companhia determina tarifas diferenciadas para Grandes Consumidores (GCs) com valores inferiores aos praticados para clientes do rol comum. Segundo o comunicado 06/18 da Sabesp, são GCs aqueles com demanda firme contratada acima de $500 \mathrm{~m}^{3} / \mathrm{mês}$, com faixas de vazão contratada e custos conforme a Tabela 56.

Tabela 56: Tabela de tarifas para grandes consumidores (GC) da Sabesp na RMSP

\begin{tabular}{|c|c|c|c|c|}
\hline \multicolumn{2}{|c|}{$\begin{array}{l}\text { Faixa de demanda } \\
\text { contratada (m³/mês) }\end{array}$} & $\begin{array}{l}\text { Tarifa de água } \\
\left(\mathrm{R} \$ / \mathrm{m}^{3}\right)\end{array}$ & $\begin{array}{l}\text { Tarifa de esgoto } \\
\left(R \$ / m^{3}\right)\end{array}$ & $\begin{array}{l}\text { Tarifa total } \\
\left(\mathrm{R} \$ / \mathrm{m}^{3}\right)\end{array}$ \\
\hline 500 & até 1.000 & 16,29 & 16,29 & 32,58 \\
\hline 1.001 & até 2.999 & 15,34 & 15,34 & 30,68 \\
\hline 3.000 & até 10.000 & 14,40 & 14,40 & 28,80 \\
\hline 1.001 & até 20.000 & 13,49 & 13,49 & 26,98 \\
\hline 20.001 & até 30.000 & 12,61 & 12,61 & 25,22 \\
\hline 30.001 & até 40.000 & 11,72 & 11,72 & 23,44 \\
\hline Acima de & 40.000 & 10,78 & 10,78 & 21,56 \\
\hline
\end{tabular}

Fonte: Comunicado 06/18 da Sabesp. Disponível em:

http://site.sabesp.com.br/site/uploads/file/asabesp doctos/comunicado 06 2018.pdf

Os valores da Tabela 56 foram utilizados como referência para a identificação dos usuários-âncora, conforme explicado na Tabela 47 no item 5.2.5.1.

\subsection{2 Índice de Potencial de Reúso (IPR) por município}

\subsubsection{Bases de dados de entrada e pré-processamento}

Para aplicação do IPR na RMSP, os dados dos parâmetros de cada subcritério foram obtidos conforme fontes relacionadas na Tabela 57.

Tabela 57: Fontes de dados para inserção no modelo do IPR na RMSP

\begin{tabular}{lll}
\hline Sigla & Subcritério & Fonte \\
\hline T1 & Esgoto doméstico gerado & ANA (2017g) \\
\hline T2 & Demandas industriais e agrícolas & Fabhat (2018a); Ceivap (2014) \\
\hline T3 & ICTEM & Cetesb (2018b) \\
\hline \multirow{2}{*}{ T4 } & Capacidade instalada de tratamento de esgotos & Sabesp (2010b, 2010a, 2018); \\
\hline A1 & Balanço hídrico & ANA (2017f) \\
\hline A2 & Condição de capacidade de diluição dos corpos hídricos & Fabhat (2018a); CBH-PS (2016) \\
\hline SE1 & Taxa geométrica de crescimento demográfico & Seade (2018a) \\
\hline SE2 & VA industrial e agrícola & Seade (2017a) \\
\hline
\end{tabular}


Na sequência são apresentados mais detalhes sobre as fontes de dados de cada subcritério.

- T1: Atlas Esgotos da ANA (ANA, 2017b, 2017g), dado que é a única publicação que apresenta diretamente estimativas de esgoto gerado por município. $\mathrm{O}$ SNIS (MCIDADES, 2018), o relatório de qualidade das águas da Cetesb (CETESB, 2018c), os planos de bacia (CEIVAP, 2014; FABHAT, 2018a) e os relatórios de situação das UGHRIs (CBH-PS, 2016; FABHAT, 2017) não possuem os valores de esgotos gerados ou requerem obtenção indireta por meio de outros dados.

- T2: documentações dos planos de bacia ou relatórios situacionais da Bacia Hidrográfica do Alto Tietê (37 municípios) (FABHAT, 2018a, 2018b) e da Bacia Hidrográfica do Paraíba do Sul (Guararema e Santa Isabel) (CBH-PS, 2016; CEIVAP, 2014).

- T3: Apêndice D do Relatório de Qualidade das Águas Interiores no Estado de São Paulo (CETESB, 2018a), onde constam os valores para todos os municípios do estado de São Paulo.

- T4: para as ETEs operadas pela Sabesp, foram utilizados dados presentes no PDE 2010 (SABESP, 2010b, 2010a) e outros cedidos diretamente pela concessionária (SABESP, 2018). Para as ETEs das demais concessionárias, foram utilizados os dados do Atlas Esgotos (ANA, 2017b).

- A1: documentações dos planos de bacia ou relatórios situacionais da Bacia Hidrográfica do Alto Tietê (37 municípios) (FABHAT, 2018a, 2018b) e da Bacia Hidrográfica do Paraíba do Sul (Guararema e Santa Isabel) (CEIVAP, 2014).

- A2: classificação utilizada pelo Atlas Esgotos (ANA, 2017b, 2017g), a qual é dividida em quatro categorias de condição de capacidade de diluição: nula, péssima/ruim, boa/ótima e infinita. Esta última (infinita) refere-se a municípios com possibilidade de lançamento de seus efluentes por emissários submarinos.

- SE1: dados do portal de Informações do Municípios Paulistas da Fundação SEADE (SEADE, 2018a).

- SE2: dados de Valor Adicionado por município, período de 2002 a 2015, disponibilizadas pela Fundação Seade (SEADE, 2017b).

A Tabela B 1 no ANEXO B apresenta os valores absolutos de entrada (não normalizados) de todos os subcritérios para os 39 municípios da RMSP. 
Conforme explicitado na caracterização da RMSP (item 5.3.1), as fontes disponíveis fornecem valores distintos para as mesmas informações, o que dificulta a escolha das bases de dados de entrada no modelo. As maiores dificuldades foram principalmente para os dados referentes aos subcritérios T1 (esgoto doméstico gerado) e T2 (demandas industriais e de irrigação), dado que as estimativas variam consideravelmente (ver Tabela 50, Tabela 51 e Tabela 54) de acordo com a referência. Para cálculo do IPR, foram escolhidas as fontes que, segundo julgamento do autor, apresentavam mais de forma mais clara e coesa as metodologias aplicadas.

Outro ponto é que o município é um limite administrativo, enquanto a bacia hidrográfica é um limite natural. Isso invariavelmente leva a problemas de compatibilização tanto na produção como na consolidação dos dados. A RMSP tem porções de seu território em diferentes bacias hidrográficas (principalmente Alto Tietê e Paraíba do Sul), o que requereu consulta a múltiplas fontes para obtenção e consolidação dos dados por município em base de dados única.

\subsubsection{Parâmetros normalizados por município}

Os valores de entrada foram normalizados conforme os critérios mostrados no item 5.1.4. A Figura 41 ilustra a distribuição dos valores normalizados dos subcritérios para cada um dos municípios. A Tabela B 1 no ANEXO B apresenta os valores normalizados de todos os subcritérios para os 39 municípios da RMSP. 


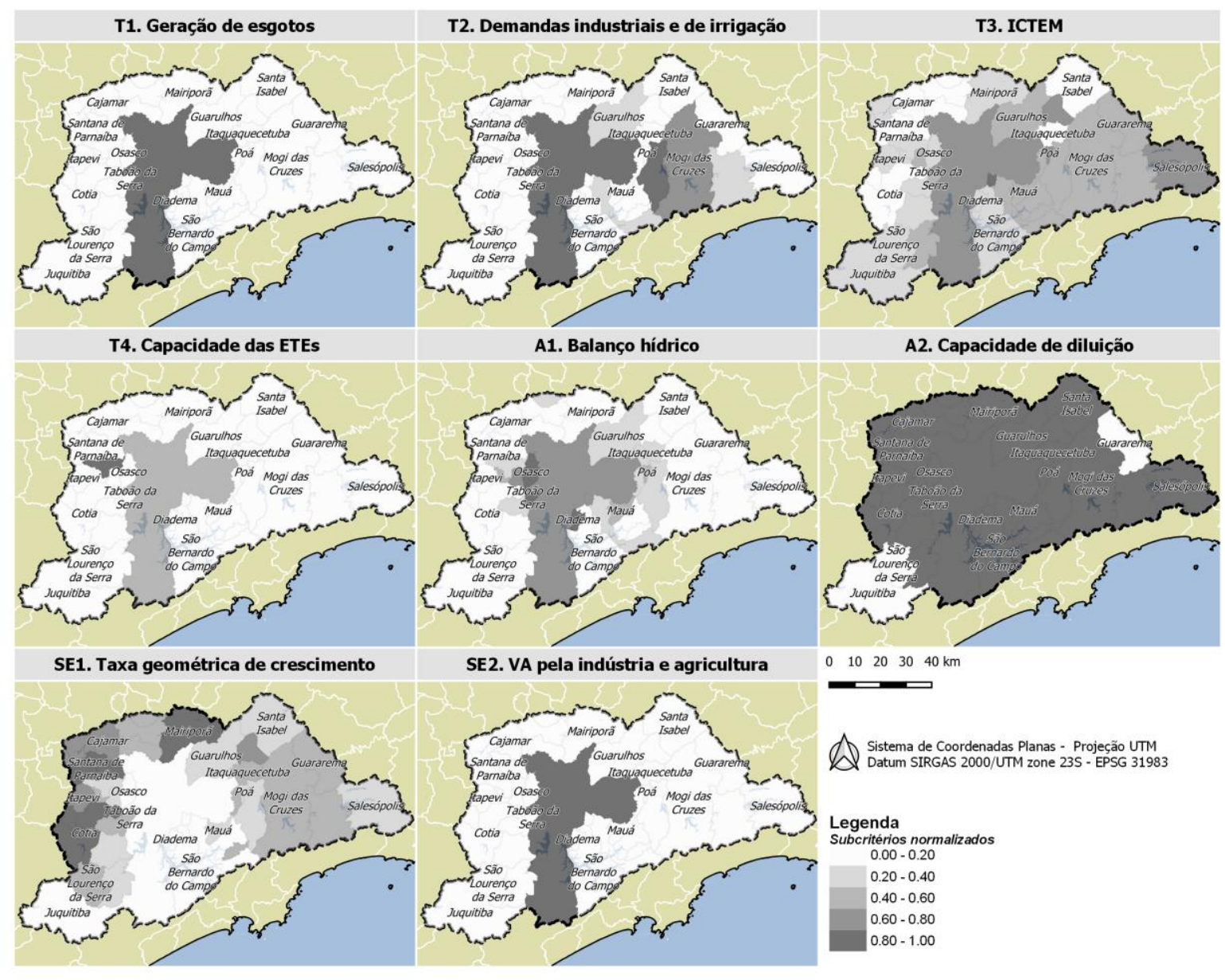

Figura 41: Subcritérios normalizados por município

Fonte: elaborado pelo autor.

\subsubsection{Resultados de IPR por município}

A partir dos valores normalizados e das importâncias globais de cada subcritério foram obtidos os valores de IPR dos municípios. A Tabela 58 e a Figura 42 apresentam os valores de IPR para todos os 39 municípios da RMSP. 
Tabela 58: IPR por município

\begin{tabular}{ll}
\hline Município & IPR \\
\hline Juquitiba & 0,071 \\
\hline São Lourenço da Serra & 0,086 \\
\hline Guararema & 0,117 \\
\hline Santa Isabel & 0,128 \\
\hline Embu-Guaçu & 0,137 \\
\hline Ribeirão Pires & 0,142 \\
\hline Pirapora do Bom Jesus & 0,144 \\
\hline Franco da Rocha & 0,144 \\
\hline Itapecerica da Serra & 0,147 \\
\hline Francisco Morato & 0,149 \\
\hline Salesópolis & 0,15 \\
\hline Rio Grande da Serra & 0,151 \\
\hline Vargem Grande Paulista & 0,157 \\
\hline Cajamar & 0,158 \\
\hline Mairiporã & 0,169 \\
\hline Santana de Parnaíba & 0,171 \\
\hline Arujá & 0,177 \\
\hline Embu das Artes & 0,178 \\
\hline Caieiras & 0,18 \\
\hline Cotia & 0,181 \\
\hline Itapevi & 0,181 \\
\hline Itaquaquecetuba & 0,192 \\
\hline Ferraz de Vasconcelos & 0,196 \\
\hline Jandira & 0,199 \\
\hline São Bernardo do Campo & 0,208 \\
\hline Biritiba-Mirim & 0,209 \\
\hline Poá & 0,215 \\
\hline Santo André & 0,222 \\
\hline Carapicuíba & 0,246 \\
\hline Mauá & 0,248 \\
\hline Diadema & 0,257 \\
\hline São Caetano do Sul & 0,269 \\
\hline Guarulhos & 0,284 \\
\hline Osasco & 0,289 \\
\hline Taboão da Serra & 0,291 \\
\hline Mogi das Cruzes & 0,296 \\
\hline Barueri & 0,309 \\
\hline São Paulo & 0,375 \\
\hline & 0,786 \\
\hline
\end{tabular}

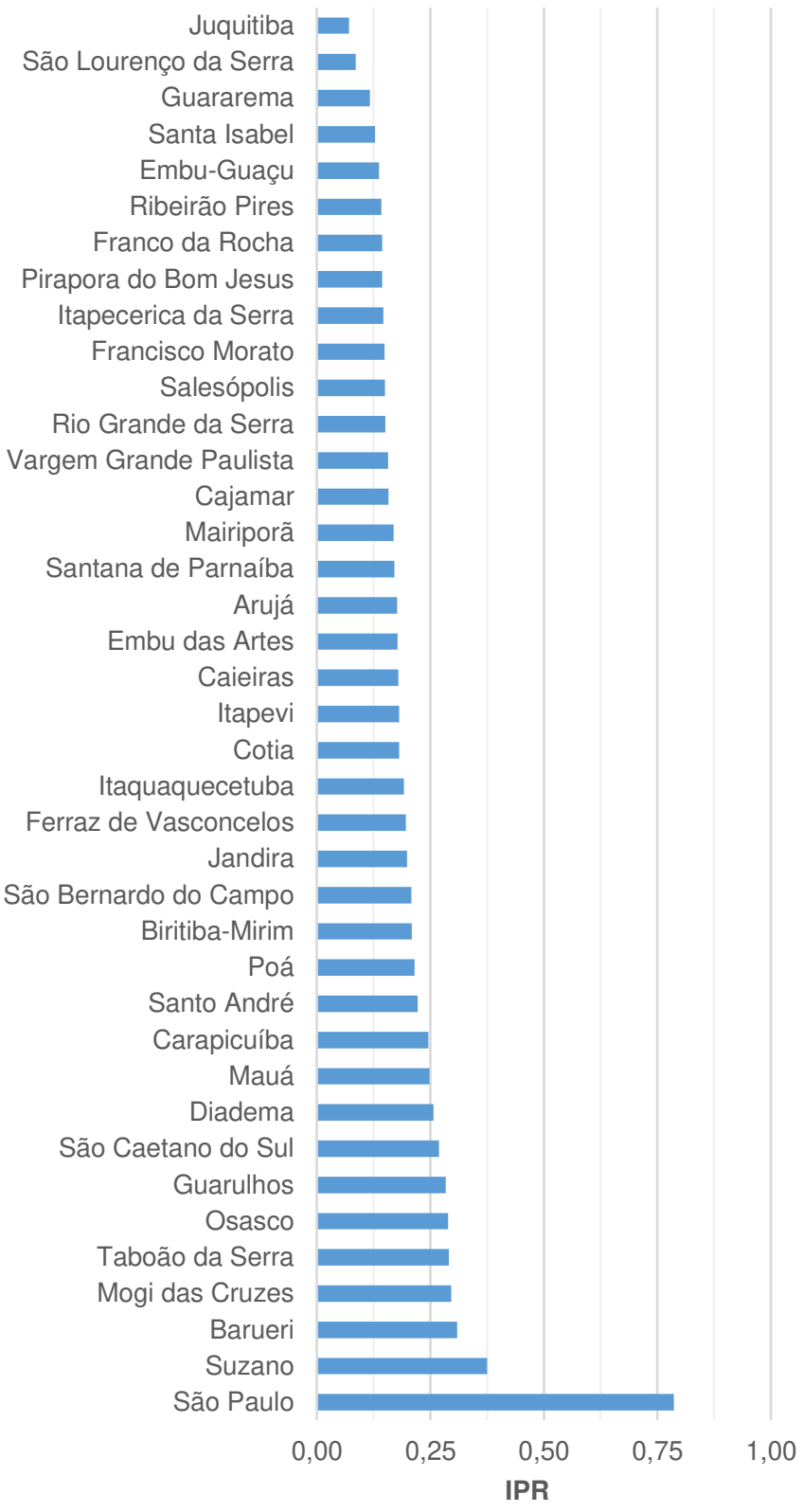

Figura 42: IPR por município

O município de São Paulo possui o maior valor de IPR $(0,786)$, dado que concentra parcelas muito expressivas de parâmetros como geração de esgotos (T1), demandas industriais e de irrigação (T2), capacidade de tratamento instalada (T4) e VA pela indústria e agropecuária (SE2). Outros municípios com valores representativos de IPR foram Suzano $(0,375)$, Barueri $(0,309)$ e Mogi das Cruzes $(0,296)$, Taboão da Serra $(0,291)$, Osasco $(0,289)$ e Guarulhos $(0,284)$. Em diferentes medidas esses municípios apresentam vazões significativas de esgoto gerado (Osasco, Guarulhos e Mogi das Cruzes), altas vazões industriais e de irrigação (Suzano, Guarulhos e Mogi das 
Cruzes), balanços hídricos muito desfavoráveis (Taboão da Serra e Osasco) e altas capacidades instaladas de tratamento de esgotos (Barueri, Guarulhos e Suzano).

A classificação dos resultados pelo método de quebras naturais de Jenks levou aos intervalos constantes na Tabela 59.

Tabela 59: Classificação de resultados de IPR por quebras naturais de Jenks

\begin{tabular}{lll}
\hline Classificação & Faixa de IPR & $\mathbf{N}^{\circ}$ de municípios \\
\hline Muito baixo & Até 0,086 & 2 \\
\hline Baixo & $0,116-0,158$ & 12 \\
\hline Considerável & $0,158-0,222$ & 14 \\
\hline Alto & $0,222-0,375$ & 10 \\
\hline Muito alto & 0,786 & 1 \\
\hline- & - & $\mathbf{3 9}$ \\
\hline
\end{tabular}

A partir disso, os municípios foram classificados conforme apresenta a Tabela 60.

Tabela 60: Resultados classificados de IPR por município

\begin{tabular}{|c|c|c|c|}
\hline Pos. & Município & IPR & Classif. \\
\hline 1 & São Paulo & 0,786 & Muito alto \\
\hline 2 & Suzano & 0,375 & Alto \\
\hline 3 & Barueri & 0,309 & Alto \\
\hline 4 & Mogi das Cruzes & 0,296 & Alto \\
\hline 5 & Taboão da Serra & 0,291 & Alto \\
\hline 6 & Osasco & 0,289 & Alto \\
\hline 7 & Guarulhos & 0,284 & Alto \\
\hline 8 & São Caetano do Sul & 0,269 & Alto \\
\hline 9 & Diadema & 0,257 & Alto \\
\hline 10 & Mauá & 0,248 & Alto \\
\hline 11 & Carapicuíba & 0,246 & Alto \\
\hline 12 & Santo André & 0,222 & Considerável \\
\hline 13 & Poá & 0,215 & Considerável \\
\hline 14 & Biritiba-Mirim & 0,209 & Considerável \\
\hline 15 & São Bernardo do Campo & 0,208 & Considerável \\
\hline 16 & Jandira & 0,199 & Considerável \\
\hline 17 & Ferraz de Vasconcelos & 0,196 & Considerável \\
\hline 18 & Itaquaquecetuba & 0,192 & Considerável \\
\hline 19 & Cotia & 0,181 & Considerável \\
\hline 20 & Itapevi & 0,181 & Considerável \\
\hline
\end{tabular}

\begin{tabular}{llll}
\hline Pos. & Município & IPR & Classif. \\
\hline 21 & Caieiras & 0,180 & Considerável \\
\hline 22 & Embu das Artes & 0,178 & Considerável \\
\hline 23 & Arujá & 0,177 & Considerável \\
\hline 24 & Santana de Parnaíba & 0,171 & Considerável \\
\hline 25 & Mairiporã & 0,169 & Considerável \\
\hline 26 & Cajamar & 0,158 & Baixo \\
\hline 27 & Vargem Grande Paulista & 0,157 & Baixo \\
\hline 28 & Rio Grande da Serra & 0,151 & Baixo \\
\hline 30 & Salesópolis & 0,150 & Baixo \\
\hline 31 & Itancisco Morato & 0,149 & Baixo \\
\hline 32 & Pirapora do Bom Jesus & 0,144 & Baixo \\
\hline 33 & Franco da Rocha & 0,144 & Baixo \\
\hline 34 & Ribeirão Pires & 0,142 & Baixo \\
\hline 35 & Embu-Guaçu & 0,137 & Baixo \\
\hline 36 & Santa Isabel & 0,128 & Baixo \\
\hline 37 & Guararema & 0,117 & Baixo \\
\hline 38 & São Lourenço da Serra & 0,086 & Muito baixo \\
\hline 39 & Juquitiba & 0,071 & Muito baixo \\
\hline
\end{tabular}

Na categoria de IPR considerado "muito baixo" há somente dois municípios, Juquitiba e São Lourenço da Serra, os quais apresentam vazões de esgoto baixas, pouca ou nenhuma presença de demandas industriais e de irrigação, pouca ou nenhuma capacidade de tratamento de esgotos, balanço hídrico favorável, baixo valor adicionado pela indústria e agropecuária e estão entre os três únicos da RMSP que possuem capacidade de diluição "boa/ótima". Estão inseridos, inclusive, em Áreas de Proteção de Mananciais (APMs). 
Entre os 12 municípios com IPR "baixo", figuram algumas cidades com gerações de esgoto e/ou demandas industriais e de irrigação mais expressivas, como Guararema, Salesópolis e Cajamar, bem como outras com balanços hídricos desfavoráveis (Francisco Morato) e também com altas taxas de crescimento demográfico (Vargem Grande Paulista, Cajamar, Pirapora do Bom Jesus e Guararema).

No grupo dos 14 municípios com IPR "considerável" estão cidades como São Bernardo do Campo, Itaquaquecetuba, Biritiba-Mirim, Caieiras e Santo André, que têm gerações de esgotos e/ou demandas industriais e de irrigação bastante importantes. Também figuram municípios que apresentam, por conta de suas altas populações concentradas em áreas reduzidas e balanços hídricos acima de 200\%, como Jandira, Ferraz de Vasconcelos e Poá. Nesse grupo estão também os municípios com as maiores TGCD da RMSP: Santana de Parnaíba, Cotia e Ferraz de Vasconcelos

Entre os 10 municípios com IPR considerado "alto" constam os que tradicionalmente já foram apontados em demais estudos sobre reúso como importantes, como Suzano, Barueri e Mogi das Cruzes. Cidades como Guarulhos, São Caetano do Sul e Mauá também estão nesse grupo, dado que possuem situação "intermediária" de demandas não potáveis, geração de esgotos e estresse hídrico. Há também municípios que se destacam principalmente por conta de suas situações críticas de balanço hídrico, como Taboão da Serra, Osasco, Diadema e Carapicuíba.

Barueri, ainda que não possua gerações de esgoto e demandas industriais e de irrigação relevantes, possui a maior ETE da RMSP (ETE Barueri). Mogi das Cruzes, mesmo com pouca expressão em termos de geração de esgotos, capacidade de tratamento e com balanço hídrico favorável, detém a terceira maior demanda industrial e de irrigação da RMSP. Guarulhos é o segundo maior município da RMSP em termos de população e geração de esgotos, o terceiro em capacidade instalada de tratamento de esgotos e possui demandas industriais significativas.

Somente o município de São Paulo teve IPR considerado "muito alto". Isso ocorre porque o município concentra $57 \%$ de todo o esgoto gerado na RMSP, $19 \%$ das demandas industriais e de irrigação, $29 \%$ da capacidade instalada de tratamento de esgotos e $47 \%$ do VA pela indústria e agropecuária da RMSP. Ou seja, é natural que 
seu valor de IPR seja muito alto frente aos demais, já que ele sozinho representa, para alguns subcritérios, mais da metade de toda a RMSP.

O mapa da Figura 43 mostra a distribuição espacial de IPR. Como será apresentado no item referente aos recursos online adicionais (item 5.4), o mesmo mapa está disponibilizado em versão interativa para navegação ${ }^{12}$.

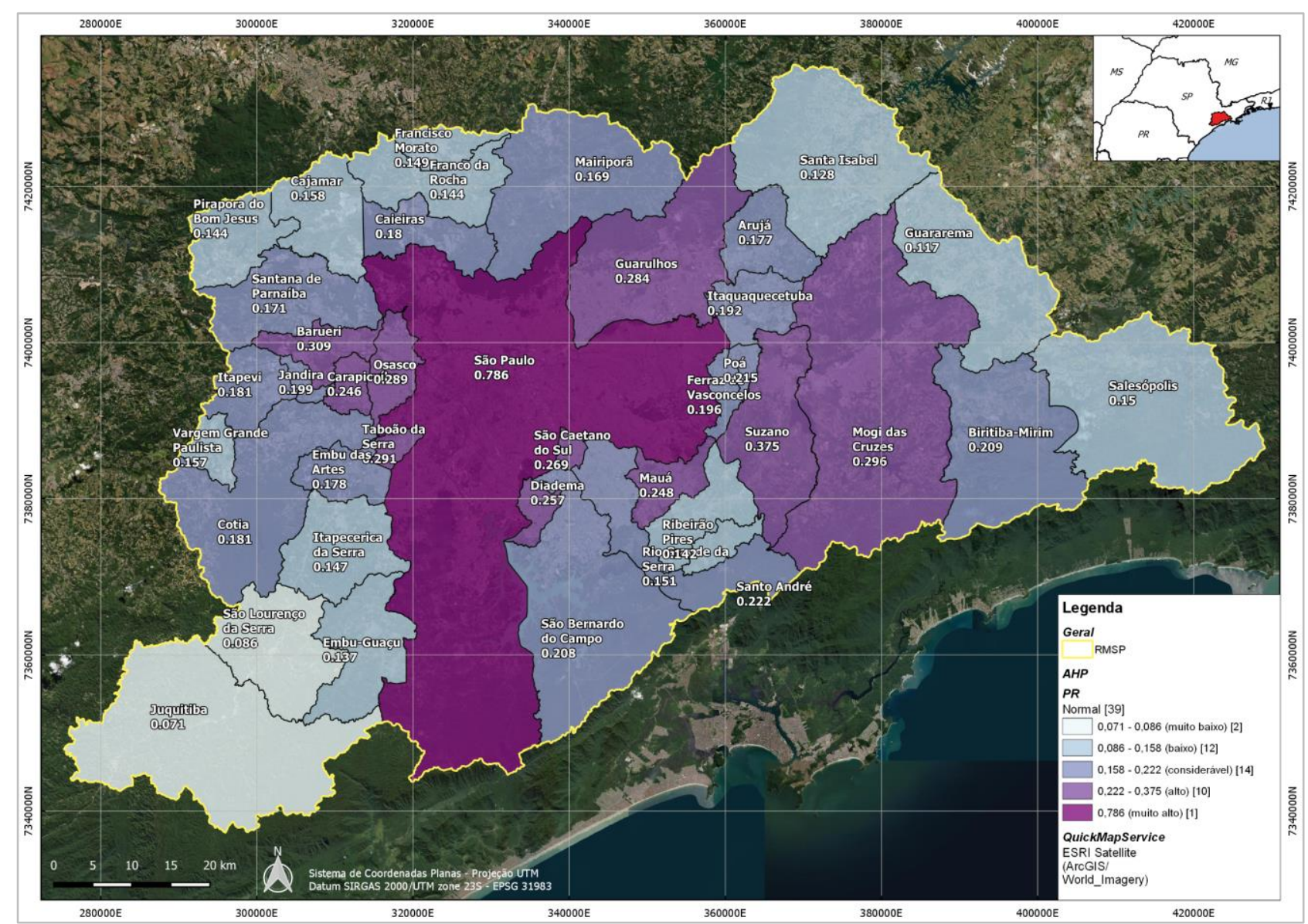

Figura 43: Mapa dos valores de IPR por município

Fonte: Elaborado pelo autor. Nota: o mesmo mapa está disponível para navegação no link: http://reusormsp.orgfree.com/mapa-1/

O valor de IPR tem composições diferentes de acordo com as características do município. A Figura 44 abaixo ilustra a participação dos critérios (técnico, ambiental e socioeconômico) no valor de IPR de cada município.

${ }^{12}$ Acesso: https://brunofukasawa.wixsite.com/reusormsp/mapas 
IPR decomposto por critério

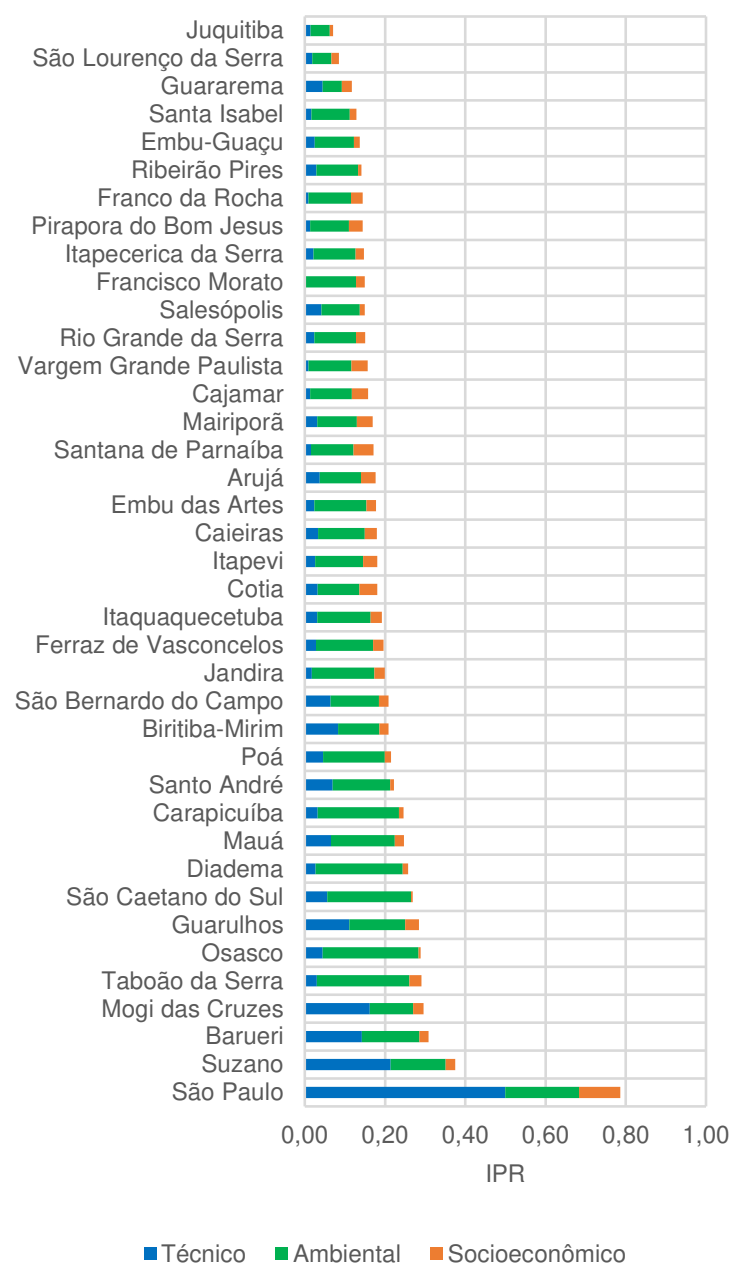

IPR por parcitipação de critério

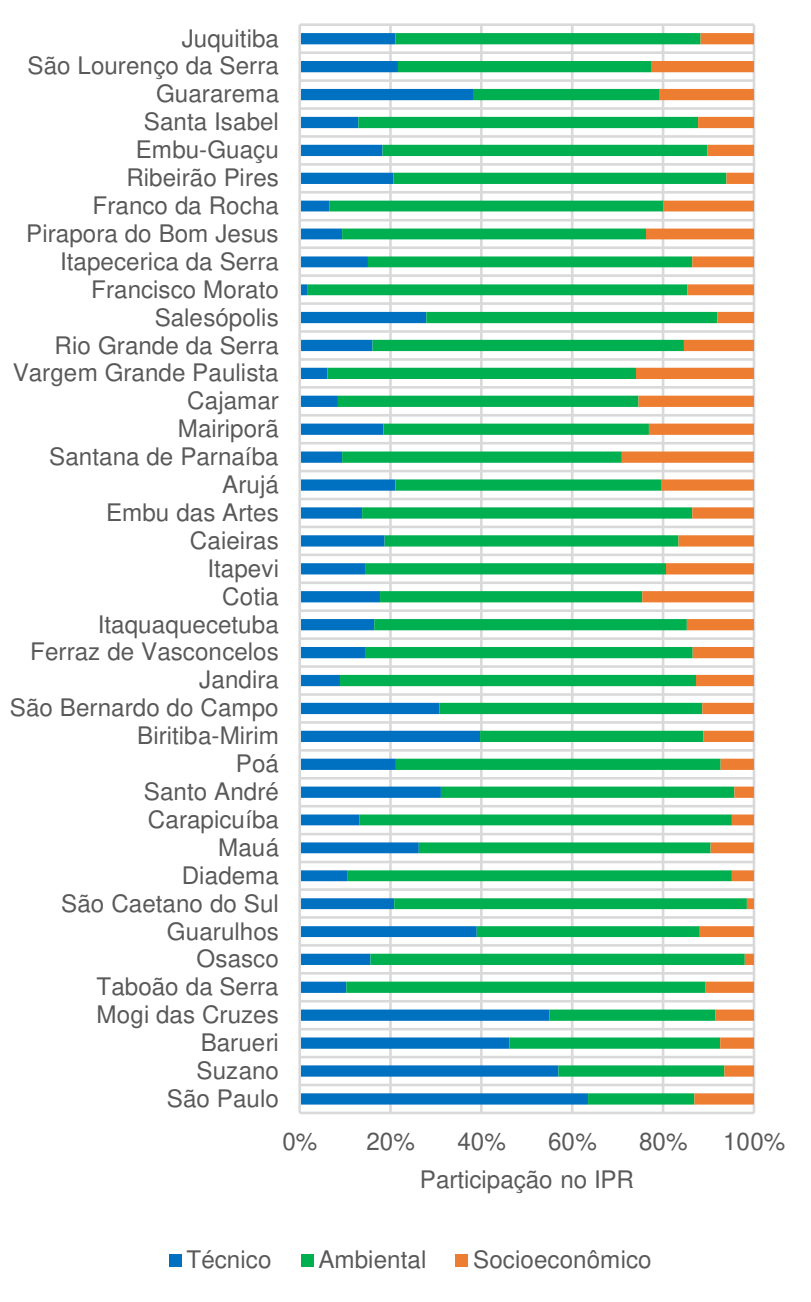

Figura 44: Composição de IPR por critério (à esq.) e participação \% de cada critério (à dir.)

Cidades como São Paulo, Suzano, Barueri, Mogi das Cruzes e Guarulhos devem seu IPR em grande medida aos critérios técnicos, já que possuem altos volumes de esgotos gerados e de demandas industriais. Outros como Osasco, Taboão da Serra, São Caetano do Sul, Mauá e Diadema têm seu IPR composto principalmente por fatores ambientais, com balanços hídricos e capacidades de diluição muito desfavoráveis. Cidades como Vargem Grande Paulista, Santana de Parnaíba e Cotia, por outro lado, possuem maior participação do critério socioeconômico, essencialmente em virtude de suas altas TGCD.

Sabesp (2010) e MCidades (2017), ainda que usando metodologias distintas da deste trabalho, também indicaram São Paulo, Barueri e Suzano como os municípios com maior potencial de reúso na RMSP. Os estudos atribuem isso à concentração de 
capacidade de tratamento de esgotos e de demandas industriais nesses municípios, elementos que também compõem o IPR na forma de subcritérios técnicos. No entanto, como esses estudos não consideram outros tipos de variáveis (como as ambientais e socioeconômicas), ou o fazem de maneira limitada, cidades que devem seu valor de IPR a subcritérios não técnicos são geralmente negligenciadas ou nem ao menos consideradas, como é o caso de Taboão da Serra, Diadema e Osasco.

\subsubsection{Análise de sensibilidade}

Aplicando-se os cenários previstos na análise de sensibilidade (item 5.1.1), chega-se a diferentes valores de IPR para os municípios analisados. Os resultados para os nove cenários mais o cenário "normal" são apresentados na Tabela 61. O nome de cada cenário (colunas) é igual à prioridade atribuída ao critério com maior peso no modelo (técnico), e o cenário "normal" é o resultante da atribuição de prioridades original.

Tabela 61: Valores de IPR por município na análise de sensibilidade

\begin{tabular}{|c|c|c|c|c|c|c|c|c|c|c|}
\hline \multirow[b]{2}{*}{ Município } & \multicolumn{10}{|c|}{ IPR na análise de sensibilidade ( $W_{\text {tec }}$ variando de 0,1 a 0,9 ) } \\
\hline & $\begin{array}{c}\text { Normal } \\
(0,571)\end{array}$ & 0,1 & 0,2 & 0,3 & 0,4 & 0,5 & 0,6 & 0,7 & 0,8 & 0,9 \\
\hline São Paulo & 0,786 & 0,690 & 0,711 & 0,731 & 0,751 & 0,772 & 0,792 & 0,813 & 0,833 & 0,853 \\
\hline Suzano & 0,375 & 0,377 & 0,376 & 0,376 & 0,376 & 0,375 & 0,375 & 0,375 & 0,374 & 0,374 \\
\hline Barueri & 0,309 & 0,374 & 0,360 & 0,346 & 0,333 & 0,319 & 0,305 & 0,291 & 0,277 & 0,263 \\
\hline Mogi das Cruzes & 0,296 & 0,308 & 0,305 & 0,303 & 0,300 & 0,298 & 0,295 & 0,292 & 0,290 & 0,287 \\
\hline Guarulhos & 0,291 & 0,554 & 0,498 & 0,442 & 0,387 & 0,331 & 0,275 & 0,219 & 0,164 & 0,108 \\
\hline Osasco & 0,289 & 0,520 & 0,471 & 0,422 & 0,373 & 0,324 & 0,275 & 0,226 & 0,177 & 0,128 \\
\hline Taboão da Serra & 0,284 & 0,384 & 0,363 & 0,342 & 0,320 & 0,299 & 0,278 & 0,257 & 0,236 & 0,215 \\
\hline São Caetano do Sul & 0,269 & 0,457 & 0,417 & 0,377 & 0,337 & 0,298 & 0,258 & 0,218 & 0,178 & 0,138 \\
\hline Mauá & 0,257 & 0,489 & 0,439 & 0,390 & 0,341 & 0,292 & 0,243 & 0,194 & 0,145 & 0,096 \\
\hline Diadema & 0,248 & 0,395 & 0,364 & 0,332 & 0,301 & 0,270 & 0,239 & 0,207 & 0,176 & 0,145 \\
\hline Santo André & 0,246 & 0,454 & 0,410 & 0,366 & 0,322 & 0,278 & 0,234 & 0,189 & 0,145 & 0,101 \\
\hline Biritiba-Mirim & 0,222 & 0,334 & 0,310 & 0,287 & 0,263 & 0,239 & 0,216 & 0,192 & 0,168 & 0,145 \\
\hline Carapicuíba & 0,215 & 0,364 & 0,332 & 0,301 & 0,269 & 0,238 & 0,206 & 0,174 & 0,143 & 0,111 \\
\hline São Bernardo do Campo & 0,209 & 0,279 & 0,264 & 0,249 & 0,235 & 0,220 & 0,205 & 0,190 & 0,175 & 0,160 \\
\hline Poá & 0,208 & 0,315 & 0,292 & 0,270 & 0,247 & 0,225 & 0,202 & 0,180 & 0,157 & 0,135 \\
\hline Itaquaquecetuba & 0,199 & 0,385 & 0,345 & 0,306 & 0,267 & 0,228 & 0,188 & 0,149 & 0,110 & 0,070 \\
\hline Ferraz de Vasconcelos & 0,196 & 0,358 & 0,324 & 0,290 & 0,255 & 0,221 & 0,187 & 0,152 & 0,118 & 0,084 \\
\hline Jandira & 0,192 & 0,343 & 0,311 & 0,279 & 0,247 & 0,215 & 0,183 & 0,151 & 0,119 & 0,087 \\
\hline Cotia & 0,181 & 0,318 & 0,289 & 0,260 & 0,231 & 0,202 & 0,173 & 0,143 & 0,114 & 0,085 \\
\hline Caieiras & 0,181 & 0,329 & 0,298 & 0,266 & 0,235 & 0,203 & 0,172 & 0,140 & 0,108 & 0,077 \\
\hline Arujá & 0,180 & 0,313 & 0,284 & 0,256 & 0,228 & 0,200 & 0,171 & 0,143 & 0,115 & 0,087 \\
\hline Itapevi & 0,178 & 0,326 & 0,295 & 0,263 & 0,232 & 0,200 & 0,169 & 0,137 & 0,106 & 0,074 \\
\hline Embu das Artes & 0,177 & 0,299 & 0,273 & 0,247 & 0,221 & 0,195 & 0,169 & 0,143 & 0,117 & 0,091 \\
\hline Mairiporã & 0,171 & 0,329 & 0,296 & 0,262 & 0,229 & 0,195 & 0,162 & 0,128 & 0,095 & 0,061 \\
\hline Santana de Parnaíba & 0,169 & 0,295 & 0,268 & 0,241 & 0,215 & 0,188 & 0,161 & 0,135 & 0,108 & 0,081 \\
\hline Salesópolis & 0,158 & 0,305 & 0,274 & 0,243 & 0,211 & 0,180 & 0,149 & 0,117 & 0,086 & 0,055 \\
\hline Cajamar & 0,157 & 0,312 & 0,279 & 0,246 & 0,214 & 0,181 & 0,148 & 0,115 & 0,082 & 0,050 \\
\hline Vargem Grande Paulista & 0,151 & 0,270 & 0,245 & 0,219 & 0,194 & 0,169 & 0,144 & 0,118 & 0,093 & 0,068 \\
\hline Rio Grande da Serra & 0,150 & 0,234 & 0,216 & 0,198 & 0,180 & 0,162 & 0,144 & 0,127 & 0,109 & 0,091 \\
\hline
\end{tabular}




\begin{tabular}{l|c|ccccccccc}
\hline \multirow{2}{*}{ Município } & \multicolumn{1}{c}{ IPR na análise de sensibilidade (W tec Variando de $\mathbf{0 , 1}$ a 0,9) } \\
\cline { 2 - 12 } & $\begin{array}{c}\text { Normal } \\
(0,571)\end{array}$ & $\mathbf{0 , 1}$ & $\mathbf{0 , 2}$ & $\mathbf{0 , 3}$ & $\mathbf{0 , 4}$ & $\mathbf{0 , 5}$ & $\mathbf{0 , 6}$ & $\mathbf{0 , 7}$ & $\mathbf{0 , 8}$ & $\mathbf{0 , 9}$ \\
\hline Itapecerica da Serra & $\mathbf{0 , 1 4 9}$ & 0,309 & 0,275 & 0,241 & 0,207 & 0,173 & 0,140 & 0,106 & 0,072 & 0,038 \\
\hline Ribeirão Pires & $\mathbf{0 , 1 4 7}$ & 0,267 & 0,241 & 0,216 & 0,191 & 0,165 & 0,140 & 0,115 & 0,089 & 0,064 \\
\hline Pirapora do Bom Jesus & $\mathbf{0 , 1 4 4}$ & 0,277 & 0,249 & 0,221 & 0,193 & 0,165 & 0,136 & 0,108 & 0,080 & 0,052 \\
\hline Franco da Rocha & $\mathbf{0 , 1 4 4}$ & 0,284 & 0,255 & 0,225 & 0,195 & 0,165 & 0,135 & 0,106 & 0,076 & 0,046 \\
\hline Francisco Morato & $\mathbf{0 , 1 4 2}$ & 0,241 & 0,220 & 0,199 & 0,178 & 0,157 & 0,136 & 0,115 & 0,093 & 0,072 \\
\hline Embu-Guaçu & $\mathbf{0 , 1 3 7}$ & 0,239 & 0,217 & 0,196 & 0,174 & 0,152 & 0,131 & 0,109 & 0,087 & 0,065 \\
\hline Guararema & $\mathbf{0 , 1 2 8}$ & 0,238 & 0,214 & 0,191 & 0,168 & 0,145 & 0,122 & 0,098 & 0,075 & 0,052 \\
\hline Santa Isabel & $\mathbf{0 , 1 1 7}$ & 0,160 & 0,151 & 0,141 & 0,132 & 0,123 & 0,114 & 0,105 & 0,096 & 0,087 \\
\hline São Lourenço da Serra & $\mathbf{0 , 0 8 6}$ & 0,144 & 0,132 & 0,119 & 0,107 & 0,094 & 0,082 & 0,070 & 0,057 & 0,045 \\
\hline Juquitiba & $\mathbf{0 , 0 7 1}$ & 0,120 & 0,110 & 0,099 & 0,089 & 0,078 & 0,068 & 0,057 & 0,047 & 0,037 \\
\hline
\end{tabular}

Ainda que se observem algumas mudanças significativas, os resultados do modelo apresentam visível estabilidade. Conforme a importância do critério técnico aumenta os municípios com maiores vazões de esgoto gerado (T1) e de demandas industriais e de irrigação (T2) tendem a ocupar as primeiras posições. Dado que São Paulo concentra parcelas muito expressivas de diversos subcritérios técnicos, seu valor de IPR é sempre ascendente. A partir de $\mathrm{w}_{\mathrm{tec}}=0,6$, os cinco primeiros municípios (São Paulo, Suzano, Barueri, Mogi das Cruzes e Guarulhos) se consolidam como aqueles com os maiores valores de IPR, havendo algumas inversões de posição conforme $\mathbf{W}_{\text {tec }}$ se aproxima de 0,9. Ao mesmo tempo, para valores baixos de $\mathrm{w}_{\mathrm{tec}}$, municípios que possuem balanço hídrico muito desfavorável, como Taboão da Serra, Osasco e Diadema, apresentam valor de IPR alto e assumem posições mais altas na classificação.

O supracitado comportamento é ilustrado de maneira mais clara no gráfico da Figura 45, a qual mostra o IPR de todos os municípios na análise de sensibilidade. O eixo "x" representa o peso do critério técnico ( $W_{\text {tec }}$ ) variando de 0,1 a 0,9, e o "y" o valor de IPR para cada um desses cenários. 


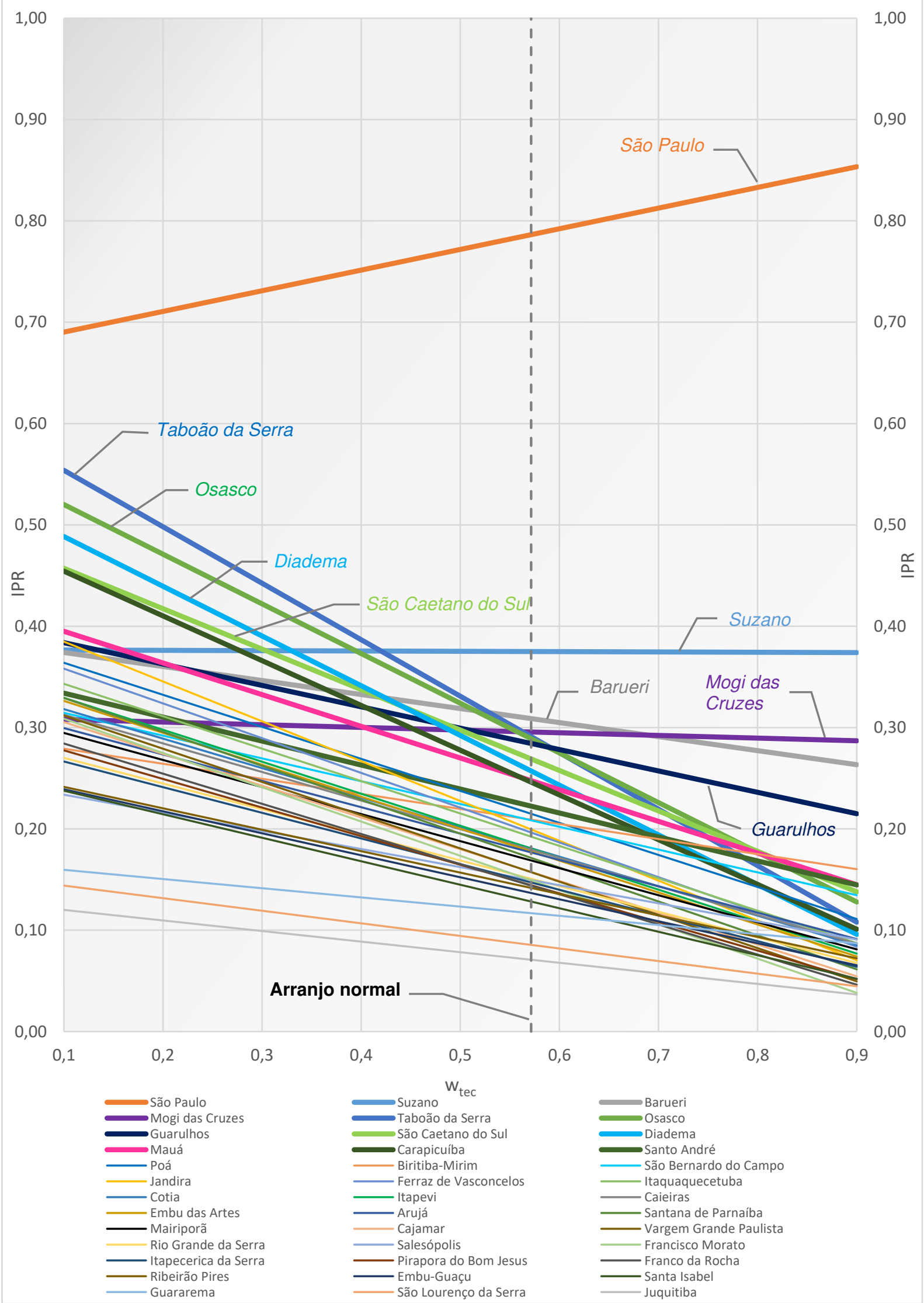

Figura 45: Gráfico de IPR na análise de sensibilidade 
A Figura 46 apresenta a distribuição espacial da variação de IPR na análise de sensibilidade, evidenciando que quanto maior o peso do critério técnico, mais concentrado o IPR se torna em municípios como São Paulo, Suzano, Barueri, Guarulhos e Mogi das Cruzes. A classificação do IPR na análise de sensibilidade também foi realizada por quebras naturais de Jenks.

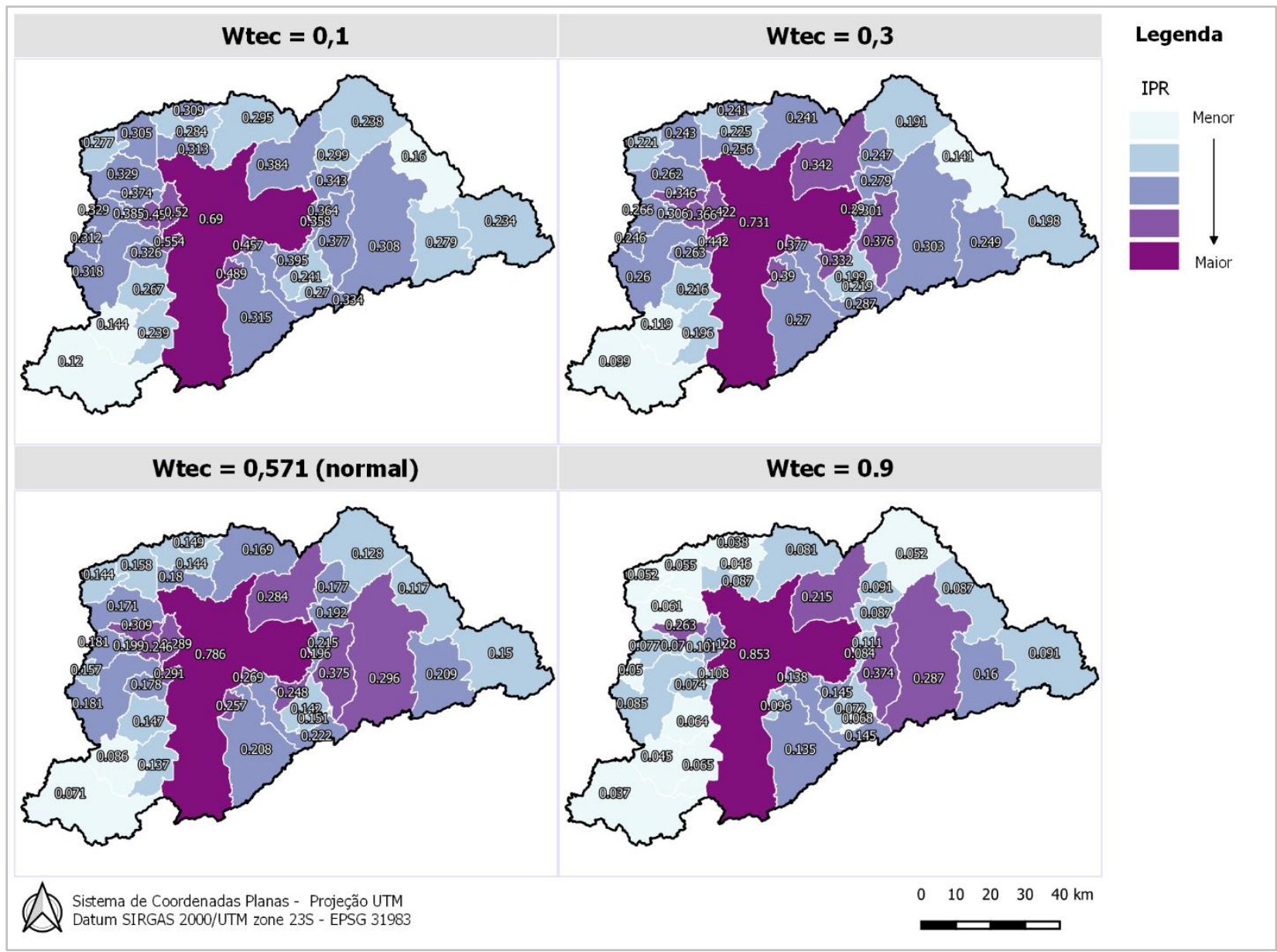

Figura 46: Mapas com resultados da análise de sensibilidade para $\mathbf{w}_{\mathrm{tec}}=0,1 ; 0,3 ; 0,571$ (normal); e 0,9

Fonte: elaborado pelo autor.

Pela análise de sensibilidade, se torna claro como a alteração das atribuições de prioridades leva a diferentes resultados de IPR. Caso os critérios não técnicos (ambiental e socioeconômico) tenham suas importâncias incrementadas no modelo, cidades como Taboão da Serra, Osasco e Diadema atingem classificações melhores que Suzano e Barueri. Ou seja, a análise de sensibilidade fornece insights de como se comporta o IPR caso os julgamentos de prioridades sejam distintos daqueles atribuídos pelo autor, objetivando a redução de conclusões demasiadamente enviesadas pela subjetividade do criadores do modelo 


\subsubsection{Potencial de reúso por ETE-usuário}

Neste item os resultados da aplicação do modelo ETE-usuário são apresentados de forma segmentada pelos seguintes recortes: por ETE; por usuário-âncora; por atividade econômica; e, ao fim, para toda a RMSP. Também foi realizado detalhamento para algumas ETEs específicas com o objetivo de melhor exemplificar os procedimentos e resultados obtidos.

As análises foram realizadas para todas as possibilidades de relação entre ETEs (36 de 42, já que 6 não possuem dados de coordenadas) e usuários industriais e de irrigação (2.794), resultando em mais de 100.000 respostas. Esse procedimento teve como objetivo cobrir todas as possibilidades sem determinação de fatores restritivos a priori, buscando detectar usuários que geralmente não seriam considerados como potenciais consumidores de água de reúso no contexto atual, mas que podem vir a ser abastecidos por novas ETEs e/ou modernização/ampliação das atuais.

\subsubsection{Bases de dados de entrada e pré-processamento}

As bases utilizadas para aplicação do modelo ETE-usuário à RMSP foram conforme apresenta a Tabela 62.

Tabela 62: Fontes de dados de entrada para aplicação do modelo ETE-usuário à RMSP

\begin{tabular}{|c|c|c|c|}
\hline $\begin{array}{l}\text { Grupo de } \\
\text { dados }\end{array}$ & $\begin{array}{l}\text { Tipo de base de } \\
\text { dado }\end{array}$ & Características & Fonte \\
\hline Usuário & $\begin{array}{l}\text { Outorgas de } \\
\text { captação estaduais e } \\
\text { federais ativas }\end{array}$ & $\begin{array}{l}2.794 \text { outorgas } \\
\text { - } 2.531 \text { industriais } \\
-443 \text { de irrigação } \\
\Sigma Q_{\text {out }}=10.149,9 \mathrm{l} / \mathrm{s}\end{array}$ & $\begin{array}{l}\text { ANA }(2018 b) \text { e DAEE }(2018 a \text {, } \\
2018 b)\end{array}$ \\
\hline Oferta & $\begin{array}{l}\text { Bases de dados de } \\
\text { ETEs em operação } \\
\text { das concessionárias } \\
\text { atuantes }\end{array}$ & $\begin{array}{l}42 \text { ETEs } \\
\text { - } 36 \text { com coordenadas } \\
\text { - } 6 \text { sem coordenadas } \\
\text { ¿QETE }=24.485 \mathrm{l} / \mathrm{s}\end{array}$ & $\begin{array}{l}\text { ANA (2017f) e Sabesp (2010b, } \\
2010 a, 2018)\end{array}$ \\
\hline \multirow{5}{*}{ Regionais } & Sistema viário & $\begin{array}{l}\text { Arquivo tipo vetorial do sistema } \\
\text { viário da RMSP }\end{array}$ & CEM (2018) \\
\hline & $\begin{array}{l}\text { Modelo Digital de } \\
\text { Elevação (MDE) }\end{array}$ & $\begin{array}{l}\text { Arquivo tipo raster com elevação } \\
\text { do Estado de São Paulo }\end{array}$ & SMA/CPLA/DIA (2013) \\
\hline & Custos de água & $\begin{array}{l}\text { Relação de tarifas diferenciadas } \\
\text { para GCs na RMSP }\end{array}$ & Comunicado 06/18 da Sabesp \\
\hline & $\begin{array}{l}\text { Custos de energia } \\
\text { elétrica }\end{array}$ & $\begin{array}{l}\text { Tarifa Enel = 0,114 USD/kWh } \\
(\mathrm{R} \$ 0,45 / \mathrm{kWh}, 1 \text { USD = 3,95 BRL) }\end{array}$ & Tarifa Enel para SP em 2019 \\
\hline & Evapotranspiração & $\begin{array}{l}\text { ETo média }=141,7 \mathrm{~mm} / \mathrm{mês} \\
\mathrm{C}_{\mathrm{NP}}=41,3 \% \text { (para irrigação) }\end{array}$ & $\begin{array}{l}\text { Calculado pelo método Blaney- } \\
\text { Criddle com dados de INMET } \\
\text { (2020) (vide item 5.3.1.2.3) }\end{array}$ \\
\hline
\end{tabular}


No caso das outorgas estaduais, utilizou-se base de dados cedida pela Diretoria de Procedimentos de Outorga (DPO) (DAEE, 2018a). Diferentemente dos arquivos disponíveis na página do órgão (DAEE, 2018c), o cedido pela DPO possui colunas de informações de usuário, inclusive com dados sobre a atividade econômica do requerente.

No entanto, as informações de atividade econômica não seguem a estrutura nem os padrões de nenhuma das versões da CNAE. Buscas sobre o histórico de categorização de atividades econômicas no Brasil revelaram que a codificação utilizada pelo DAEE é compatível com o "Código de Atividade da Secretaria da Receita Federal”, o qual foi encontrado somente em legislações, normas e outras publicações principalmente das décadas de 1970 e 1980 (CFQ, 1987; COPAM, 1981; SÃO PAULO (ESTADO), 1979; SILVA, 1987), indicando sua completa obsolescência. Face a isso, procedeu-se à reclassificação das atividades de acordo com a CNAE 2.0 a partir dos demais dados de identificação do usuário. As tipologias da Secretaria da Receita Federal não possuem as mesmas nomenclaturas das da CNAE 2.0, mas serviram como base para a tipificação.

Para as ETEs, os dados foram obtidos a partir de bases de dados da Sabesp (SABESP, 2010a, 2010b, 2018) e, para as ETEs das demais concessionárias, do Atlas Esgotos (ANA, 2017b, 2017f). Os dados de ETEs utilizados são os constantes no tópico de caracterização de demandas por usuário na RMSP (item 5.3.1.2.3).

Em relação aos custos de água, o Comunicado 06/2018 da Sabesp (vide item 5.3.1.5) determina que a última faixa de demanda contratada é para usuários com demanda firme acima de $40.000 \mathrm{~m}^{3} / \mathrm{mês}$, o que equivale a vazão média de aproximadamente $15 \mathrm{l} / \mathrm{s}$; ou seja, é relativamente baixa em relação às consideradas neste estudo. Portanto, assumindo-se que outras faixas de demanda se referem a usuários pouco expressivos, a tarifa de água utilizada como referência foi de $R \$ 10,78 / \mathrm{m}^{3}$, ou 2,73 USD/m³ (1 USD = 3,95 BRL, cotação média de 2019), conforme a Tabela 63. 
Tabela 63: Regra de classificação da tarifa de água de reúso para a RMSP

\begin{tabular}{ccll}
\hline Classe & Atratividade & Valor & $\begin{array}{l}\text { \% da tarifa de GC da } \\
\text { Sabesp }\left(2,37 \text { USD } / \mathbf{m}^{3}\right)\end{array}$ \\
\hline A & Alta & $\leq 2,37$ & $(\leq 100 \%)$ \\
\hline B & Média & $>2,37 \mathrm{e} \leq 4,10$ & $(>100 \%$ e $\leq 150 \%)$ \\
\hline C & Baixa/nenhuma & $>4,10 \%$ & $(>150 \%)$ \\
\hline
\end{tabular}

Vale destacar dois tipos de dados que exigiram esforços de obtenção e préprocessamento além do esperado.

O primeiro deles foi o outorgas estaduais. Como já explicado, a base de dados disponibilizada na página do DAEE não possui informações suficientes para utilização no modelo, ao que se procedeu ao contato direto junto ao órgão. Para sua correta compreensão houve necessidade de nova solicitação de documentações adicionais, uma vez que a codificação utilizada pelo DAEE para denominação dos campos e das variáveis não é intuitiva e não pode ser compreendida sem acesso à relação de legenda.

Em seguida, os procedimentos de saneamento de dados no pré-processamento levaram à exclusão de quase $25 \%$ dos registros brutos, principalmente porque possuíam coordenadas incidentes fora dos limites do estado de São Paulo ou estavam atribuídas a zonas UTM ${ }^{13}$ não compatíveis (o estado de São Paulo está nas zonas UTM $23 S$ e 22S); não possuíam dados sobre o status da outorga (vigente ou não vigente); ou não possuíam dados sobre finalidade de uso. Dos 176.476 registros brutos de outorgas, cerca de 44.000 foram prontamente excluídos por inconsistência antes mesmo da aplicação de filtros (outorgas de captação ativas para finalidades industriais e de irrigação).

No caso dos dados de ETEs, a maior dificuldade residiu no fato de que não há uma fonte de dados única que apresente todas as ETEs da RMSP com o nível desejado de informação (vazões, coordenadas e processo de tratamento). Foi necessária a agregação de múltiplas bases de dados, algumas das quais também requereram solicitações formais ao órgão responsável (Sabesp). Foram também realizadas

${ }^{13}$ UTM: Universal Transversa de Mercator. 
solicitações via SIC.SP (Serviço de Informações ao Cidadão do Estado de São Paulo) para pedido de informações não constantes nos arquivos cedidos diretamente pela Sabesp.

O confrontamento das diferentes bases de dados sobre ETEs indicou diferenças nos nomes das estações, coordenadas e vazões de projeto. Foram priorizados os dados cedidos diretamente pela Sabesp, os quais foram complementados, quando necessário, pelos do Atlas Esgotos da ANA.

\subsubsection{Resultados por ETE}

Das 36 ETEs cuja localização pôde ser levantada, apenas uma parcela possui ao menos um usuários-âncora. Os resultados por ETE são apresentados na Tabela 64, na qual constam as vazões potenciais e quantidade de usuários-âncora para cada uma das estações de tratamento e para todos os seis cenários. Os resultados detalhados para todas as ETEs constam no ANEXO C.

Tabela 64: Vazões potenciais de reúso e quantidade de usuários-âncora por ETE para todos os cenários

\begin{tabular}{|c|c|c|c|c|c|c|c|c|c|c|c|c|c|}
\hline \multirow{3}{*}{ ETE } & \multirow{3}{*}{$\mathbf{Q}_{\mathrm{ETE}}(\mathrm{I} / \mathbf{s})$} & \multicolumn{6}{|c|}{ Cenário 1} & \multicolumn{6}{|c|}{ Cenário 2} \\
\hline & & \multicolumn{2}{|c|}{ C1P } & \multicolumn{2}{|c|}{ C1R } & \multicolumn{2}{|c|}{ C10 } & \multicolumn{2}{|c|}{$\mathrm{C} 2 \mathrm{P}$} & \multicolumn{2}{|c|}{ C2R } & \multicolumn{2}{|c|}{$\mathrm{C2O}$} \\
\hline & & $Q(1 / s)$ & Qtde. & $Q(I / s)$ & Qtde. & $Q(I / s)$ & Qtde. & $Q(1 / s)$ & Qtde. & $Q(1 / s)$ & Qtde. & $Q(I / s)$ & Qtde. \\
\hline Suzano & 1500 & 738,9 & 13 & 754,4 & 16 & 766,6 & 20 & 355,6 & 1 & 355,6 & 1 & 549,1 & 4 \\
\hline Pinheirinho & 7 & 504,1 & 4 & 504,1 & 4 & 514,1 & 6 & 0,0 & 0 & 447,1 & 2 & 447,1 & 2 \\
\hline Mauá & 1125 & 329,4 & 7 & 352,6 & 13 & 361,0 & 17 & 0,0 & 0 & 186,3 & 2 & 254,6 & 3 \\
\hline São Miguel & 1500 & 261,2 & 9 & 269,2 & 11 & 283,8 & 15 & 0,0 & 0 & 129,6 & 1 & 129,6 & 1 \\
\hline Bandeirantes & 3 & 215,9 & 6 & 240,4 & 9 & 246,2 & 10 & 0,0 & 0 & 0,0 & 0 & 62,8 & 1 \\
\hline Biritiba-Mirim & 55 & 176,1 & 10 & 190,0 & 12 & 198,8 & 15 & 176,1 & 10 & 190,0 & 12 & 198,8 & 15 \\
\hline Parque Andreense & 5 & 164,9 & 1 & 164,9 & 1 & 169,9 & 2 & 0,0 & 0 & 164,9 & 1 & 164,9 & 1 \\
\hline $\begin{array}{l}\text { Parque Novo } \\
\text { Mundo }\end{array}$ & 2500 & 133,3 & 3 & 143,5 & 5 & 149,7 & 7 & 0,0 & 0 & 0,0 & 0 & 91,7 & 1 \\
\hline Aldeia da Serra & 0 & 94,9 & 3 & 94,9 & 3 & 94,9 & 3 & 0,0 & 0 & 0,0 & 0 & 0,0 & 0 \\
\hline Bonsucesso & 673 & 88,1 & 3 & 94,0 & 5 & 94,0 & 5 & 0,0 & 0 & 0,0 & 0 & 0,0 & 0 \\
\hline Leste & 250 & 71,3 & 5 & 88,5 & 8 & 92,8 & 9 & 0,0 & 0 & 0,0 & 0 & 0,0 & 0 \\
\hline $\begin{array}{l}\text { Cotia/Jardim } \\
\text { Japão }\end{array}$ & 120 & 81,5 & 6 & 81,5 & 6 & 86,9 & 7 & 11,2 & 1 & 11,2 & 1 & 11,2 & 1 \\
\hline Mairiporã - Sede & 35 & 49,4 & 1 & 49,4 & 1 & 55,3 & 2 & 0,0 & 0 & 0,0 & 0 & 49,4 & 1 \\
\hline $\begin{array}{l}\text { Parque dos } \\
\text { Pinheiros }\end{array}$ & 0 & 37,5 & 3 & 48,4 & 7 & 71,8 & 13 & 0,0 & 0 & 0,0 & 0 & 0,0 & 0 \\
\hline Barueri & 12000 & 20,6 & 1 & 43,8 & 4 & 53,2 & 9 & 0,0 & 0 & 0,0 & 0 & 0,0 & 0 \\
\hline Vila Arujá & 3,7 & 39,2 & 1 & 39,2 & 1 & 39,2 & 1 & 0,0 & 0 & 0,0 & 0 & 0,0 & 0 \\
\hline Várzea do Palácio & 600 & 16,6 & 2 & 28,3 & 5 & 38,0 & 9 & 0,0 & 0 & 0,0 & 0 & 0,0 & 0 \\
\hline Jardim Odete & 0 & 16,9 & 1 & 25,4 & 2 & 25,4 & 2 & 0,0 & 0 & 0,0 & 0 & 0,0 & 0 \\
\hline Guararema - Sede & 33 & 11,8 & 1 & 25,3 & 2 & 25,3 & 2 & 0,0 & 0 & 0,0 & 0 & 0,0 & 0 \\
\hline$A B C$ & 3000 & 21,6 & 1 & 21,6 & 1 & 28,5 & 3 & 0,0 & 0 & 0,0 & 0 & 0,0 & 0 \\
\hline Jesus Neto & 50 & 6,7 & 1 & 11,8 & 2 & 26,5 & 5 & 0,0 & 0 & 0,0 & 0 & 0,0 & 0 \\
\hline São João & 470 & 5,4 & 1 & 5,4 & 1 & 5,4 & 1 & 0,0 & 0 & 0,0 & 0 & 0,0 & 0 \\
\hline Pirapora - Sede & 26 & 0,0 & 0 & 4,9 & 1 & 4,9 & 1 & 0,0 & 0 & 0,0 & 0 & 0,0 & 0 \\
\hline Riacho Grande & 24 & 0,0 & 0 & 0,0 & 0 & 6,3 & 2 & 0,0 & 0 & 0,0 & 0 & 0,0 & 0 \\
\hline Guatambu & 0 & 0,0 & 0 & 0,0 & 0 & 5,3 & 1 & 0,0 & 0 & 0,0 & 0 & 0,0 & 0 \\
\hline
\end{tabular}




\begin{tabular}{|c|c|c|c|c|c|c|c|c|c|c|c|c|c|}
\hline \multirow{3}{*}{ ETE } & \multirow{3}{*}{$\mathbf{Q}_{\text {ete }}(\mathrm{I} / \mathbf{s})$} & \multicolumn{6}{|c|}{ Cenário 1} & \multicolumn{6}{|c|}{ Cenário 2} \\
\hline & & \multicolumn{2}{|c|}{ C1P } & \multicolumn{2}{|c|}{ C1R } & \multicolumn{2}{|c|}{ C10 } & \multicolumn{2}{|c|}{$\mathrm{C} 2 \mathrm{P}$} & \multicolumn{2}{|c|}{ C2R } & \multicolumn{2}{|c|}{$\mathrm{C2O}$} \\
\hline & & $Q(1 / s)$ & Qtde. & $Q(I / s)$ & Qtde. & $Q(1 / s)$ & Qtde. & $Q(\mathrm{l} / \mathrm{s})$ & Qtde. & $Q(1 / s)$ & Qtde. & $Q(1 / s)$ & Qtde. \\
\hline $\begin{array}{l}\text { Vargem Grande } \\
\text { Paulista }\end{array}$ & 0 & 0,0 & 0 & 0,0 & 0 & 5,7 & 2 & 0,0 & 0 & 0,0 & 0 & 0,0 & 0 \\
\hline $\begin{array}{l}\text { Salesopólis - } \\
\text { Remédios }\end{array}$ & 2 & 0,0 & 0 & 0,0 & 0 & 0,0 & 0 & 0,0 & 0 & 0,0 & 0 & 0,0 & 0 \\
\hline Arujá - Sede & 150 & 0,0 & 0 & 0,0 & 0 & 0,0 & 0 & 0,0 & 0 & 0,0 & 0 & 0,0 & 0 \\
\hline $\mathrm{CDP}^{(\mathrm{a})}$ & 3,5 & 0,0 & 0 & 0,0 & 0 & 0,0 & 0 & 0,0 & 0 & 0,0 & 0 & 0,0 & 0 \\
\hline $\begin{array}{l}\text { Embu-Guaçu - } \\
\text { Cipó }\end{array}$ & 50 & 0,0 & 0 & 0,0 & 0 & 0,0 & 0 & 0,0 & 0 & 0,0 & 0 & 0,0 & 0 \\
\hline $\begin{array}{l}\text { Embu-Guaçu - } \\
\text { Sede }\end{array}$ & 90 & 0,0 & 0 & 0,0 & 0 & 0,0 & 0 & 0,0 & 0 & 0,0 & 0 & 0,0 & 0 \\
\hline Gênesis $^{(a)}$ & 0 & 0,0 & 0 & 0,0 & 0 & 0,0 & 0 & 0,0 & 0 & 0,0 & 0 & 0,0 & 0 \\
\hline Jaraguá (a) & 38 & 0,0 & 0 & 0,0 & 0 & 0,0 & 0 & 0,0 & 0 & 0,0 & 0 & 0,0 & 0 \\
\hline Juquitiba & 18 & 0,0 & 0 & 0,0 & 0 & 0,0 & 0 & 0,0 & 0 & 0,0 & 0 & 0,0 & 0 \\
\hline Mandi (a) & 0 & 0,0 & 0 & 0,0 & 0 & 0,0 & 0 & 0,0 & 0 & 0,0 & 0 & 0,0 & 0 \\
\hline Paiol do Meio (a) & 4,1 & 0,0 & 0 & 0,0 & 0 & 0,0 & 0 & 0,0 & 0 & 0,0 & 0 & 0,0 & 0 \\
\hline Pirapora - Gênesis & 10 & 0,0 & 0 & 0,0 & 0 & 0,0 & 0 & 0,0 & 0 & 0,0 & 0 & 0,0 & 0 \\
\hline Promissão & 0 & 0,0 & 0 & 0,0 & 0 & 0,0 & 0 & 0,0 & 0 & 0,0 & 0 & 0,0 & 0 \\
\hline Ribeirão Pires ${ }^{(a)}$ & 70 & 0,0 & 0 & 0,0 & 0 & 0,0 & 0 & 0,0 & 0 & 0,0 & 0 & 0,0 & 0 \\
\hline $\begin{array}{l}\text { Rio Grande da } \\
\text { Serra }\end{array}$ & 24 & 0,0 & 0 & 0,0 & 0 & 0,0 & 0 & 0,0 & 0 & 0,0 & 0 & 0,0 & 0 \\
\hline Salesopólis - Sede & 33 & 0,0 & 0 & 0,0 & 0 & 0,0 & 0 & 0,0 & 0 & 0,0 & 0 & 0,0 & 0 \\
\hline $\begin{array}{l}\text { São Lourenço da } \\
\text { Serra - Sede }\end{array}$ & 13 & 0,0 & 0 & 0,0 & 0 & 0,0 & 0 & 0,0 & 0 & 0,0 & 0 & 0,0 & 0 \\
\hline Total & 24.485 & 3085,4 & 83 & 3281,4 & 120 & 3449,4 & 169 & 542,9 & 12 & 1484,8 & 20 & 1959,3 & 30 \\
\hline
\end{tabular}

SD: sem dados. Q: somatório das vazões não potáveis $\left(\mathrm{Q}_{\mathrm{NP}}\right)$ dos usuários-âncora. Qtde.: quantidade de usuários-âncora.

(a) ETE não analisada por ausência de dados de coordenadas.

Nota: para resultados completos por ETE vide ANEXO C

A ETE Suzano possui as maiores vazões potenciais, em torno de $754 \mathrm{l} / \mathrm{s}$ para os cenários $\mathrm{C1}$. A mesma ETE já é apresentada em outros estudos sobre potencial de reúso na RMSP (CNI, 2017b; MANCUSO, 1992; SABESP, 2010a) como a que possui maior número de usuários industriais relevantes próximos, e, portanto, esse tipo de resultado já era esperado. Para os cenários $\mathrm{C} 2$, as maiores restrições de qualidade levam a reduções relevantes de vazão potencial na ETE.

Um caso particular é o da ETE Pinheirinho, conforme será mais bem discutido à frente (item 5.3.3.5.3). A estação apresenta altas vazões para quase todos os cenários, mas com algumas ressalvas, dado que a totalidade de seu potencial se deve a duas outorgas da Petrobrás localizadas a mais de $15 \mathrm{~km}$, próximas à Usina Elevatória de Pedreira. A excessiva distância, ainda que garanta a viabilidade em termos de tarifa, pode ser restritiva no que se refere a necessidade de intervenções urbanas.

As ETEs Biritiba-Mirim, Mauá, São Miguel, Bandeirantes, Parque Andreense e Parque Novo Mundo aparecem na sequência com as maiores vazões potenciais, sempre superiores a $100 \mathrm{l} / \mathrm{s}$ para C1. Para C2, algumas delas não apresentam vazão potencial. 
Algumas das ETEs com maior vazão potencial de reúso possuem capacidades muito reduzidas $($ Pinheirinho $=7 \mathrm{l} / \mathrm{s}$; Biritiba-Mirim = $50 \mathrm{l} / \mathrm{s}$; Bandeirantes $=3 \mathrm{l} / \mathrm{s}$; Parque Andreense $=5 \mathrm{l} / \mathrm{s}$ ) ou não tiveram suas vazões de projeto encontradas (Aldeia da Serra, Parque dos Pinheiros). Esses casos serão detalhados no item 5.3.3.5.3.

Os mesmos resultados da Tabela 64 são apresentados no gráfico da Figura 47, no qual são mais facilmente visualizadas as diferenças entre os cenários e as faixas de variação dos cenários de custos para cada estação.

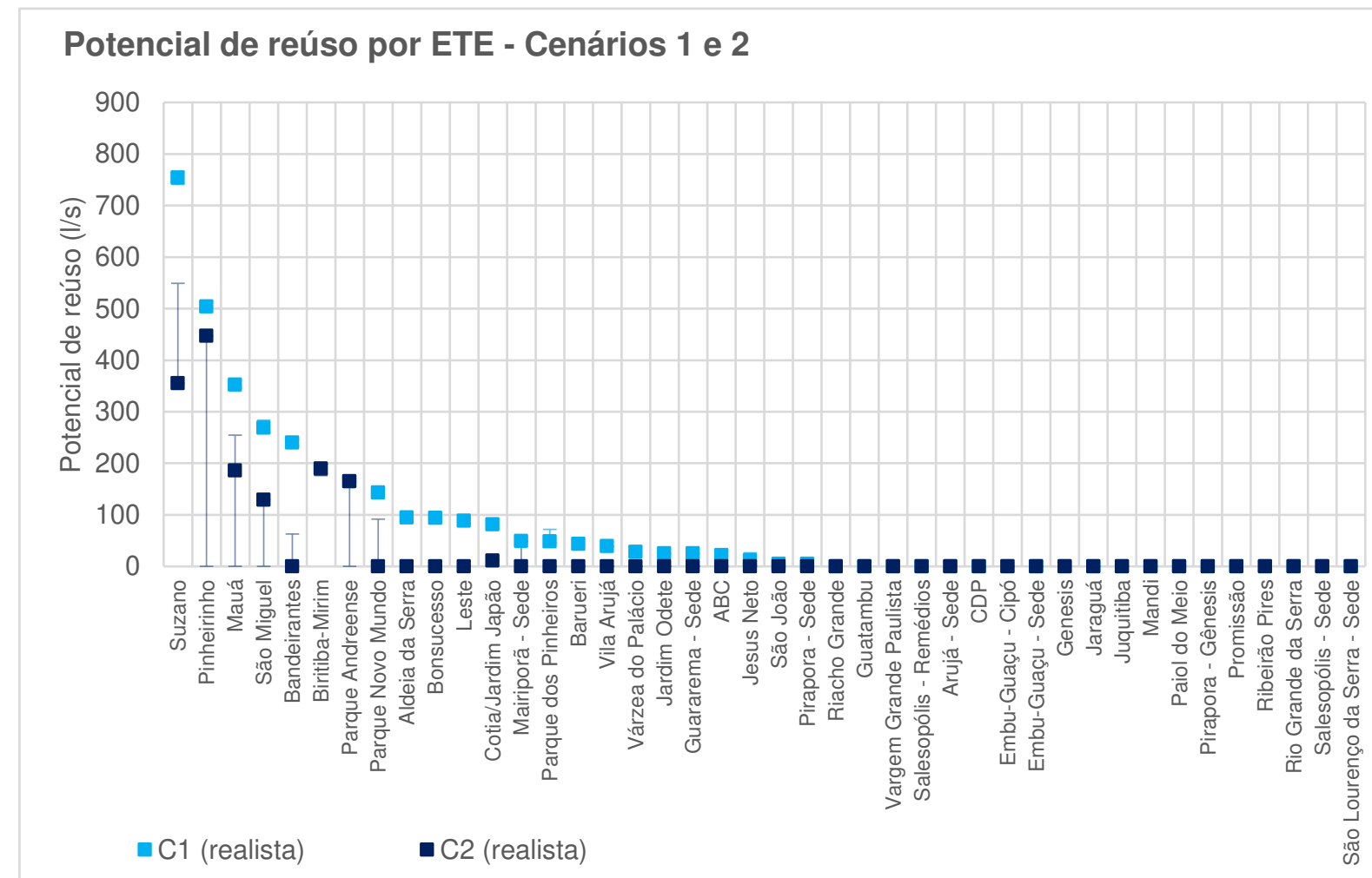

Nota: barras de erros inferior e superior representam cenários "pessimista" e "otimista" respectivamente de C1 e C2.

Figura 47: Vazões potenciais de reúso por ETE para todos os cenários

Para todos os cenários, o reúso para finalidades industriais é preponderante em todas as estações, conforme se vê na Figura 54. As exceções são as ETEs Biritiba-Mirim e Cotia/Jardim Japão, as únicas que apresentam viabilidade de atendimento a usuários irrigantes. 

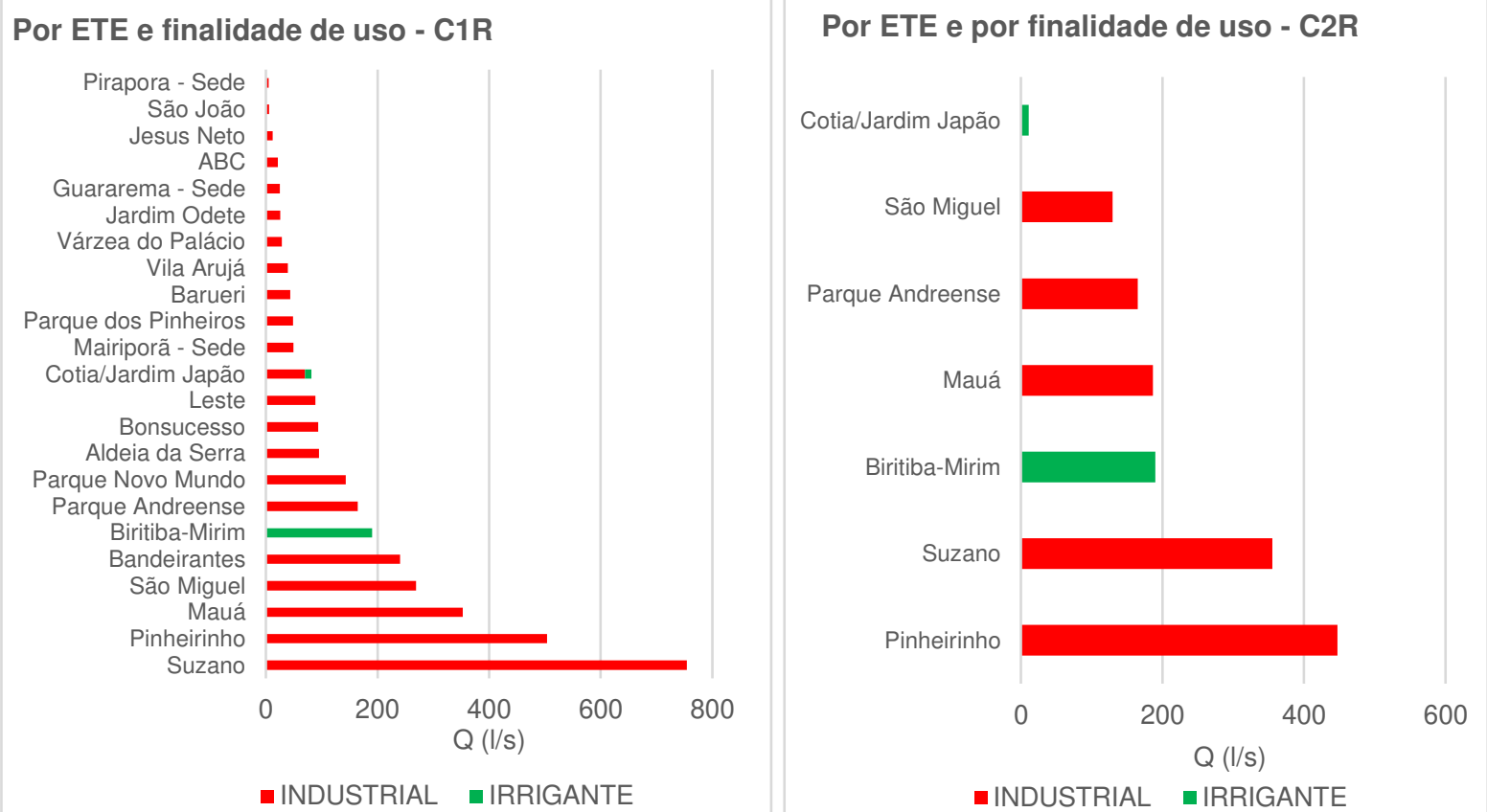

Figura 48: Vazões potenciais de reúso por ETE e finalidade de uso - C1R e C2R

Muitas das ETEs que apresentam vazões potenciais de reúso relevantes possuem duas características importantes: possuem baixa capacidade e estão localizadas em municípios com reduzidos índices de tratamento de esgotos. É o caso de ETEs Jardim Odete (Itaquaquecetuba), Parque dos Pinheiros (Cajamar), Aldeia da Serra (Santana de Parnaíba), Cotia/Jardim Japão (Cotia), Guararema - Sede (Guararema) e Pinheirinho (São Bernardo do Campo).

Ou seja, ainda que algumas das ETEs de baixa capacidade atualmente não tenham vazão suficiente para abastecer seus usuários-âncora, é inegável a necessidade de expansão da cobertura no município onde se encontram. A Tabela 65 cruza os dados de potencial de reúso por ETE com indicadores municipais (tratamento de esgotos e demandas industriais e de irrigação). Constam somente as ETEs com vazão potencial de reúso maior que 0 para C1R.

Tabela 65: Comparação entre as vazões potenciais de reúso por ETEs e déficit de saneamento por município

\begin{tabular}{|c|c|c|c|c|c|c|}
\hline ETE & $\begin{array}{l}Q_{\mathrm{NP}}(\mathrm{I} / \mathrm{s}) \\
(\mathrm{C} 1 \mathrm{R})\end{array}$ & $\begin{array}{l}Q_{\mathrm{ETE}} \\
(\mathrm{I} / \mathrm{s})\end{array}$ & Município & $\begin{array}{l}\% \text { de tratamento } \\
\text { de esgotos do } \\
\text { município (a) }\end{array}$ & $\begin{array}{l}\text { "Déficit de } \\
\text { tratamento" } \\
\text { no município } \\
(\mathrm{I} / \mathrm{s})^{(\mathrm{a}, \mathrm{b})}\end{array}$ & $\begin{array}{l}\text { Demandas } \\
\text { industriais e de } \\
\text { irrigação do } \\
\text { município (l/s) } \\
\text { (c) }\end{array}$ \\
\hline Suzano & 754,4 & 1.500 & Suzano & $59,5 \%$ & 247,6 & 2233,3 \\
\hline Pinheirinho & 504,1 & 7 & $\begin{array}{l}\text { São Bernardo do } \\
\text { Campo }\end{array}$ & $19,3 \%$ & $1.197,2$ & 286,2 \\
\hline Mauá & 352,6 & 1.125 & Mauá & $96,0 \%$ & 32,7 & 209,7 \\
\hline São Miguel & 269,2 & 1.500 & São Paulo & $65,6 \%$ & $6.807,3$ & 2582,3 \\
\hline Bandeirantes & 240,4 & 3 & São Paulo & $65,6 \%$ & $6.807,3$ & 2582,3 \\
\hline
\end{tabular}




\begin{tabular}{|c|c|c|c|c|c|c|}
\hline ETE & $\begin{array}{l}Q_{\mathrm{NP}}(\mathrm{I} / \mathrm{s}) \\
(\mathrm{C} 1 \mathrm{R})\end{array}$ & $\begin{array}{l}Q_{E T E} \\
(1 / s)\end{array}$ & Município & $\begin{array}{l}\% \text { de tratamento } \\
\text { de esgotos do } \\
\text { município (a) }\end{array}$ & $\begin{array}{l}\text { "Déficit de } \\
\text { tratamento" } \\
\text { no município } \\
(\mathrm{I} / \mathrm{s})^{(\mathrm{a}, \mathrm{b})}\end{array}$ & $\begin{array}{l}\text { Demandas } \\
\text { industriais e de } \\
\text { irrigação do } \\
\text { município (l/s) } \\
\text { (c) }\end{array}$ \\
\hline Biritiba-Mirim & 190 & 55 & Biritiba-Mirim & $32,1 \%$ & 72,9 & 643,7 \\
\hline Parque Andreense & 164,9 & 5 & Santo André & $40,3 \%$ & 534,3 & 511,3 \\
\hline Parque Novo Mundo & 143,5 & 2.500 & São Paulo & $65,6 \%$ & $6.807,3$ & 2582,3 \\
\hline Aldeia da Serra & 94,9 & SD & $\begin{array}{l}\text { Santana de } \\
\text { Parnaíba }\end{array}$ & $9,6 \%$ & 195,4 & 62,0 \\
\hline Bonsucesso & 94 & 673 & Guarulhos & $28,7 \%$ & $1.247,8$ & 709,6 \\
\hline Leste & 88,5 & 250 & Mogi das Cruzes & $49,3 \%$ & 334,4 & 612,5 \\
\hline Cotia/Jardim Japão & 81,5 & 120 & Cotia & $18,6 \%$ & 321,9 & 90,9 \\
\hline Mairiporã - Sede & 49,4 & 35 & Mairiporã & $27,4 \%$ & 111,6 & 228,8 \\
\hline $\begin{array}{l}\text { Parque dos } \\
\text { Pinheiros }\end{array}$ & 48,4 & SD & Cajamar & $0,0 \%$ & 115,2 & 122,5 \\
\hline Barueri & 43,8 & 12.000 & Barueri & $18,1 \%$ & 319,2 & 46,3 \\
\hline Vila Arujá & 39,2 & 3,7 & Arujá & $56,2 \%$ & 64,2 & 24,6 \\
\hline Várzea do Palácio & 28,3 & 600 & Guarulhos & $28,7 \%$ & $1.247,8$ & 709,6 \\
\hline Jardim Odete & 25,4 & SD & Itaquaquecetuba & $4,4 \%$ & $1.267,2$ & 105,4 \\
\hline Guararema - Sede & 25,3 & 33 & Guararema & $19,3 \%$ & 27,6 & 155,5 \\
\hline $\mathrm{ABC}$ & 21,6 & 3.000 & São Paulo & $65,6 \%$ & $6.807,3$ & 2582,3 \\
\hline Jesus Neto & 11,8 & 50 & São Paulo & $65,6 \%$ & $6.807,3$ & 2582,3 \\
\hline São João & 5,4 & 470 & Guarulhos & $28,7 \%$ & $1.247,8$ & 709,6 \\
\hline Pirapora - Sede & 4,9 & 26 & $\begin{array}{l}\text { Pirapora do Bom } \\
\text { Jesus }\end{array}$ & $22,0 \%$ & 9,9 & 12,0 \\
\hline
\end{tabular}

SD: sem dados

(a) Com base no Atlas Esgotos (ANA, 2017b, 2017f), o qual tem diferenças consideráveis em relação ao SNIS.

(b) "Déficit de tratamento" é a diferença entre os volumes de esgoto gerado e tratado no município.

(c) Refere-se à vazão total outorgada para fins industriais e de irrigação, sem considerar o $\mathrm{C}_{\mathrm{NP}}$.

As estações Pinheirinho, Parque Andreense, Aldeia da Serra e Parque dos Pinheiros possuem a supracitada concomitância de relevantes vazões potenciais de reúso, baixa capacidade de tratamento e localização em municípios com baixas coberturas de tratamento de esgotos (ou seja, altos "déficits de tratamento"). Isso evidencia a possibilidade de que a futura e necessária expansão da capacidade de tratamento nesses municípios possa também contemplar o fornecimento de água de reúso a usuários próximos, seja pela expansão das estações existentes ou pela construção de novas.

\subsubsection{Resultados por usuário-âncora}

O número de usuários-âncora e a vazão potencial de reúso evidentemente variam de acordo com o cenário estudado. Os resultados apontam de 12 a 169 usuários-âncora, e vazões entre 543 e $3.449 \mathrm{l} / \mathrm{s}$, conforme a Tabela 66. 
Tabela 66: Resumo das vazões potenciais de reúso e quantidade de usuários-âncora para os seis cenários estudados

\begin{tabular}{ccccc}
\hline $\begin{array}{c}\text { Cenário de } \\
\text { abastecimento }\end{array}$ & $\begin{array}{c}\text { Cenário } \\
\text { de custo }\end{array}$ & Cenário & $\boldsymbol{\Sigma Q}(\mathbf{I} / \mathbf{s})$ & $\begin{array}{c}\text { Qtde. de } \\
\text { usuários-âncora }\end{array}$ \\
\hline \multirow{3}{*}{ C1 } & Pessimista & C1P & 3.085 & 83 \\
\cline { 2 - 5 } & Realista & C1R & 3.281 & 120 \\
\cline { 2 - 5 } & Otimista & C1O & 3.449 & 169 \\
\hline \multirow{3}{*}{ C2 } & Pessimista & C2P & 543 & 12 \\
\cline { 2 - 5 } & Realista & C2R & 1.485 & 20 \\
\cline { 2 - 5 } & Otimista & C2O & 1.959 & 30 \\
\hline
\end{tabular}

Entre os cenários realistas (C1R e C2R), a vazão varia de $3.281 \mathrm{l} / \mathrm{s}$ e 120 usuáriosâncora $(C 1 R)$ a $1.485 \mathrm{l} / \mathrm{s}$ e 20 usuários-âncora $(\mathrm{C} 2 \mathrm{R})$, redução devida às maiores restrições de qualidade impostas pelo cenário C2 para usuários industriais. A variação do número de usuários-âncora é muito mais expressiva do que a de vazão potencial, uma vez que os usuários com as maiores demandas são menos suscetíveis às variações de custos previstas nos cenários, justamente pelos ganhos de escala no tratamento.

$\mathrm{Na}$ Tabela 67 constam as tarifas para os vinte principais usuários-âncora e para todos os cenários. A depender do cenário, um usuário é considerado âncora ou não (valores realçados em verde são os abaixo da tarifa de corte, $\left.2,73 \mathrm{USD} / \mathrm{m}^{3}\right)$. A relação de todos os usuários-âncora é apresentada ao final do ANEXO C. O código único sequencial (ID) que consta na tabela foi adotado para integração entre as bases de dados da ANA e DAEE e maior controle sobre os registros.

Tabela 67: Relação dos vinte principais usuários-âncora (menores tarifas para C1R)

\begin{tabular}{|c|c|c|c|c|c|c|c|c|c|c|c|c|c|}
\hline \multirow[b]{2}{*}{ ID } & \multirow{2}{*}{ Usuário } & \multirow{2}{*}{$\mathbf{Q}(\mathbf{l} / \mathbf{s})$} & \multirow{2}{*}{$\begin{array}{l}Q_{N P} \\
(I / s)\end{array}$} & \multirow{2}{*}{$\begin{array}{l}\text { Grupo } \\
\text { CNAE } \\
2.0\end{array}$} & \multirow{2}{*}{ Fin. } & \multirow{2}{*}{$\begin{array}{l}\text { ETE mais } \\
\text { próxima }\end{array}$} & \multirow{2}{*}{ (km) } & \multicolumn{6}{|c|}{ Tarifa $\left(\mathrm{USD} / \mathrm{m}^{3}\right)$} \\
\hline & & & & & & & & C10 & C1R & C1P & $\mathrm{C2O}$ & C2R & $\mathrm{C} 2 \mathrm{P}$ \\
\hline 82327 & $\begin{array}{l}\text { SUZANO PAPEL E } \\
\text { CELULOSE S.A. }\end{array}$ & 1380,8 & 355,6 & 17.20 & Ind. & Suzano & 6,84 & 0,79 & 0,88 & 1,04 & 1,70 & 2,06 & 2,67 \\
\hline 97161 & $\begin{array}{l}\text { PETROLEO } \\
\text { BRASILEIRO S.A. - } \\
\text { PETROBRAS }\end{array}$ & 429,2 & 291,9 & 35.10 & Ind. & Pinheirinho & 15,39 & 0,91 & 1,02 & 1,21 & 1,86 & 2,25 & 2,91 \\
\hline 11903 & $\begin{array}{l}\text { COMPANHIA NITRO } \\
\text { QUIMICA BRASILEIRA }\end{array}$ & 150,7 & 129,6 & 20.90 & Ind. & São Miguel & 1,68 & 0,92 & 1,02 & 1,21 & 2,07 & 2,51 & 3,25 \\
\hline 8012 & $\begin{array}{l}\text { PETROLEO } \\
\text { BRASILEIRO S.A. - } \\
\text { PETROBRAS }\end{array}$ & 137,0 & 93,2 & 35.10 & Ind. & Mauá & 1,96 & 0,99 & 1,10 & 1,31 & 2,23 & 2,70 & 3,51 \\
\hline 8004 & $\begin{array}{l}\text { PETROLEO } \\
\text { BRASILEIRO S.A. - } \\
\text { PETROBRAS }\end{array}$ & 137,0 & 93,2 & 35.10 & Ind. & Mauá & 1,98 & 0,99 & 1,10 & 1,31 & 2,23 & 2,70 & 3,51 \\
\hline 164306 & $\begin{array}{l}\text { UNIPAR INDUPA DO } \\
\text { BRASIL S/A }\end{array}$ & 191,8 & 164,9 & 20.20 & Ind. & $\begin{array}{l}\text { Parque } \\
\text { Andreense }\end{array}$ & 13,22 & 1,01 & 1,13 & 1,35 & 2,10 & 2,54 & 3,29 \\
\hline 9524 & $\begin{array}{l}\text { INDS.MATARAZZO DE } \\
\text { PAPEIS S.A }\end{array}$ & 356,2 & 91,7 & 17.20 & Ind. & $\begin{array}{l}\text { Parque } \\
\text { Novo } \\
\text { Mundo } \\
\end{array}$ & 5,49 & 1,05 & 1,17 & 1,39 & 2,29 & 2,78 & 3,60 \\
\hline
\end{tabular}




\begin{tabular}{|c|c|c|c|c|c|c|c|c|c|c|c|c|c|}
\hline \multirow[b]{2}{*}{ ID } & \multirow[b]{2}{*}{ Usuário } & \multirow[b]{2}{*}{$Q(I / s)$} & \multirow{2}{*}{$\begin{array}{l}Q_{N P} \\
(1 / s)\end{array}$} & \multirow{2}{*}{$\begin{array}{l}\text { Grupo } \\
\text { CNAE } \\
2.0 \\
\end{array}$} & \multirow[b]{2}{*}{ Fin. } & \multirow{2}{*}{$\begin{array}{l}\text { ETE mais } \\
\text { próxima }\end{array}$} & \multirow{2}{*}{$\begin{array}{l}\mathrm{L} \\
(\mathbf{k m})\end{array}$} & \multicolumn{6}{|c|}{ Tarifa $\left(\right.$ USD/m $\left.{ }^{3}\right)$} \\
\hline & & & & & & & & C10 & C1R & C1P & C2O & C2R & $\mathrm{C} 2 \mathrm{P}$ \\
\hline 108631 & $\begin{array}{l}\text { LEAO \& JETEX } \\
\text { INDUSTRIA TEXTIL } \\
\text { LTDA. }\end{array}$ & 205,5 & 73,5 & 13.40 & Ind. & Suzano & 3,02 & 1,06 & 1,18 & 1,41 & 2,36 & 2,87 & 3,73 \\
\hline 97168 & $\begin{array}{l}\text { PETROLEO } \\
\text { BRASILEIRO S.A. - } \\
\text { PETROBRAS }\end{array}$ & 228,3 & 155,3 & 35.10 & Ind. & Pinheirinho & 15,39 & 1,05 & 1,18 & 1,41 & 2,15 & 2,61 & 3,37 \\
\hline 23839 & CLARIANT S.A. & 82,2 & 70,7 & 20.90 & Ind. & Suzano & 5,05 & 1,10 & 1,24 & 1,47 & 2,42 & 2,94 & 3,81 \\
\hline 9530 & $\begin{array}{l}\text { MAIRIPORA IND E COM } \\
\text { DE PAPEL E PAPELAO } \\
\text { LTDA }\end{array}$ & 191,8 & 49,4 & 17.20 & Ind. & $\begin{array}{l}\text { Mairiporã - } \\
\text { Sede }\end{array}$ & 1,22 & 1,12 & 1,25 & 1,49 & 2,55 & 3,09 & 4,02 \\
\hline 82329 & $\begin{array}{l}\text { SUZANO PAPEL E } \\
\text { CELULOSE S.A. }\end{array}$ & 191,8 & 49,4 & 17.20 & Ind. & Suzano & 5,28 & 1,20 & 1,35 & 1,61 & 2,63 & 3,19 & 4,15 \\
\hline 60357 & $\begin{array}{l}\text { PROCOSA PRODUTOS } \\
\text { DE BELEZA LTDA. }\end{array}$ & 73,1 & 62,8 & 20.60 & Ind. & $\begin{array}{l}\text { Bandeirant } \\
\text { es }\end{array}$ & 9,03 & 1,21 & 1,36 & 1,63 & 2,57 & 3,11 & 4,03 \\
\hline 171886 & $\begin{array}{l}\text { DU SOL COMERCIO DE } \\
\text { BEBIDAS LIMITADA - } \\
\text { EPP }\end{array}$ & 112,0 & 68,3 & 11.20 & Ind. & Mauá & 12,58 & 1,24 & 1,40 & 1,68 & 2,57 & 3,11 & 4,03 \\
\hline 130690 & $\begin{array}{l}\text { ALIMENKO } \\
\text { IMPORTADORA } \\
\text { EEXPORTADORA LTDA. }\end{array}$ & 82,2 & 40,7 & 10.90 & Ind. & Suzano & 4,81 & 1,25 & 1,40 & 1,68 & 2,74 & 3,33 & 4,32 \\
\hline 9527 & $\begin{array}{l}\text { INDUSTRIAS } \\
\text { MATARAZZO DE } \\
\text { EMBALAGENS LTDA }\end{array}$ & 137,0 & 35,3 & 17.20 & Ind. & São Miguel & 3,63 & 1,26 & 1,42 & 1,70 & 2,80 & 3,41 & 4,43 \\
\hline 17097 & $\begin{array}{l}\text { VISCOFAN DO BRASIL } \\
\text { SOC COMERCIAL E } \\
\text { INDUSTRIAL LTDA }\end{array}$ & 137,0 & 35,3 & 17.20 & Irr. & São Miguel & 4,21 & 1,28 & 1,44 & 1,72 & 2,82 & 3,42 & 4,45 \\
\hline 62786 & $\begin{array}{l}\text { ASSOCIACAO } \\
\text { AGRICOLA } \\
\text { DESPORTIVA E } \\
\text { CULTURAL DO SOGO }\end{array}$ & 73,7 & 30,2 & 01.10 & Irr. & $\begin{array}{l}\text { Biritiba- } \\
\text { Mirim }\end{array}$ & 8,27 & 1,28 & 1,47 & 1,79 & 1,28 & 1,47 & 1,79 \\
\hline 62775 & $\begin{array}{l}\text { ASSOCIACAO } \\
\text { AGRICOLA } \\
\text { DESPORTIVA E } \\
\text { CULTURAL DO SOGO }\end{array}$ & 60,2 & 24,7 & 01.10 & Irr. & $\begin{array}{l}\text { Biritiba- } \\
\text { Mirim }\end{array}$ & 6,51 & 1,30 & 1,49 & 1,82 & 1,30 & 1,49 & 1,82 \\
\hline 51800 & MD PAPEIS LTDA. & 191,8 & 49,4 & 17.20 & Ind. & $\begin{array}{l}\text { Bandeirant } \\
\text { es }\end{array}$ & 9,84 & 1,31 & 1,47 & 1,77 & 2,74 & 3,32 & 4,30 \\
\hline
\end{tabular}

\begin{tabular}{llll}
\hline Classe A $\left(\leq 2,73 \mathrm{USD} / \mathrm{m}^{3}\right)$ & Classe B $\left(>2,73\right.$ e $\left.\leq 4,10 \mathrm{USD} / \mathrm{m}^{3}\right)$ & Classe C $\left(>4,10 \mathrm{USD} / \mathrm{m}^{3}\right)$
\end{tabular}

Nota: resultados completos por usuário-âncora no ANEXO C.

Alguns deles são considerados âncora independente do cenário (p.e. ID 82327), dado que sua condição é muito favorável ao reúso. Outros, no entanto, têm suas tarifas aumentadas além da tarifa de corte para cenários mais pessimistas. A Figura 49 ilustra graficamente a variação de tarifa para alguns dos casos acima. 


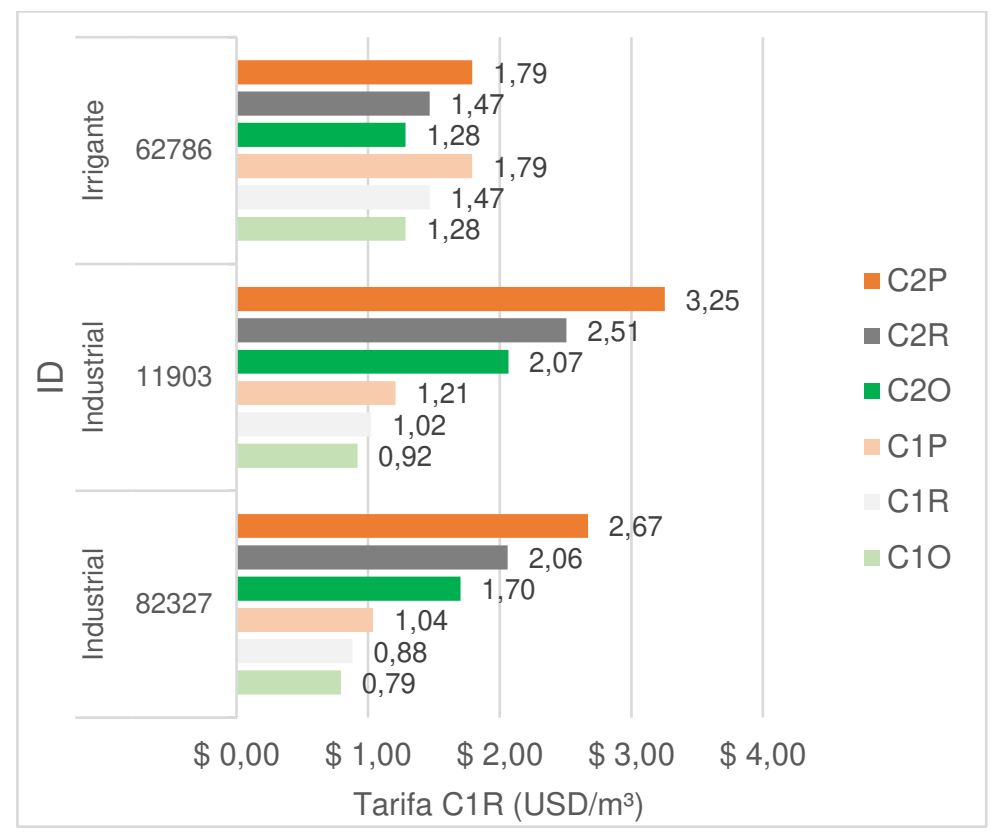

Figura 49: Exemplos de variação de tarifa por usuário para os seis cenários para três usuários (ID 62786, 11903 e 82327)

Mesmo que não sejam considerados âncora, vale menção aos usuários classificados como classe B. Somando-os aos classe A, o incremento de vazão varia de 1.911 a $2.847 \mathrm{l} / \mathrm{s}$, conforme Tabela 68 e Figura 50.

Tabela 68: Vazão e quantidade de usuários classe $A$ e $B$ por cenário

\begin{tabular}{|c|c|c|c|c|c|c|}
\hline \multirow{2}{*}{ Cenário } & \multicolumn{2}{|c|}{ Classe A } & \multicolumn{2}{|c|}{ Classe B } & \multirow{2}{*}{$\begin{array}{l}\text { Incremento } \\
\% \text { em } Q_{\mathrm{NP}}\end{array}$} & \multirow{2}{*}{$\begin{array}{l}\text { Incremento } \\
\% \text { em qtde. }\end{array}$} \\
\hline & $\mathrm{Q}_{\mathrm{NP}}(\mathrm{I} / \mathrm{s})$ & Qtde. & $\mathrm{Q}_{\mathrm{NP}}(\mathrm{I} / \mathrm{s})$ & Qtde. & & \\
\hline C1P & 3.085 & 83 & 2.847 & 186 & $92 \%$ & $224 \%$ \\
\hline C1R & 3.281 & 120 & 2.354 & 298 & $72 \%$ & $248 \%$ \\
\hline C1O & 3.449 & 169 & 2.387 & 391 & $69 \%$ & $231 \%$ \\
\hline $\mathrm{C} 2 \mathrm{P}$ & 543 & 12 & 1.911 & 30 & $352 \%$ & $250 \%$ \\
\hline $\mathrm{C} 2 \mathrm{R}$ & 1.485 & 20 & 2.790 & 73 & $188 \%$ & $365 \%$ \\
\hline $\mathrm{C} 2 \mathrm{O}$ & 1.959 & 30 & 2.488 & 116 & $127 \%$ & $387 \%$ \\
\hline
\end{tabular}



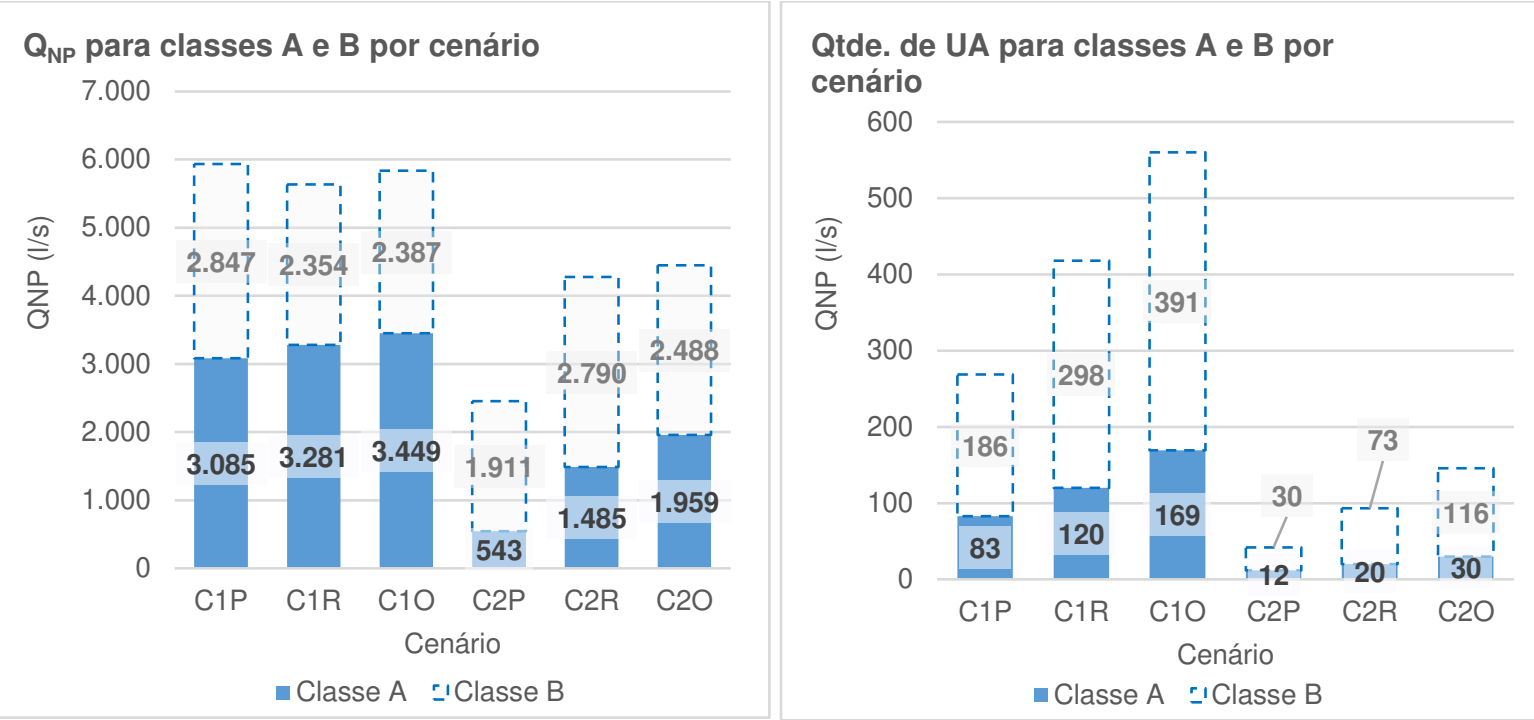

Figura 50: Vazão (à esq.) e quantidade (à dir.) de usuários classe A e B por cenário

Proporcionalmente, a inclusão de usuários classe B promove aumentos mais expressivos em quantidade de usuários do que em vazão, dado que usuários classe B em geral possuem menores demandas em comparação aos classe A.

Comparando-se a variação relativa das tarifas dos cenários otimistas e pessimistas em relação aos realistas, vê-se faixa de $-10 /-20 \%$ (otimista) e $+20 /+30 \%$ (pessimista), como pode ser visto na Figura 51, na qual também se nota que usuários com menores vazões são mais sensíveis às variações de parâmetros.
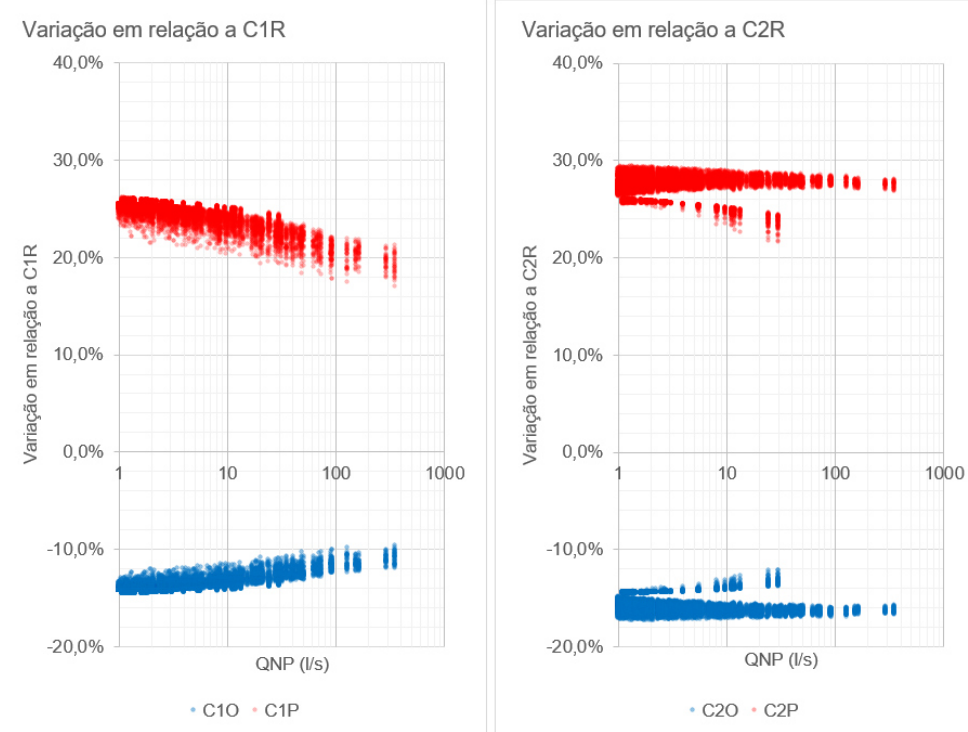

Nota: QNp em log

Figura 51: Distribuição da variação (\%) dos cenários otimista e pessimista em relação ao realista para C1 e C2 em função de $Q_{N P}$

Nota: valores ordenados em ordem crescente de vazão não potável 
5.3.3.3.1 Por custo decomposto

Para ilustrar o comportamento da decomposição de custos, a Figura 52 apresenta os 120 usuários-âncoras para o cenário C1R ordenados em ordem crescente de tarifa. São apresentados os custos totais, unitários e proporcionais divididos em Capextr, Capexee, Capexadutoras, Opextr e Opexad. Cada coluna empilhada representa um usuário-âncora. 


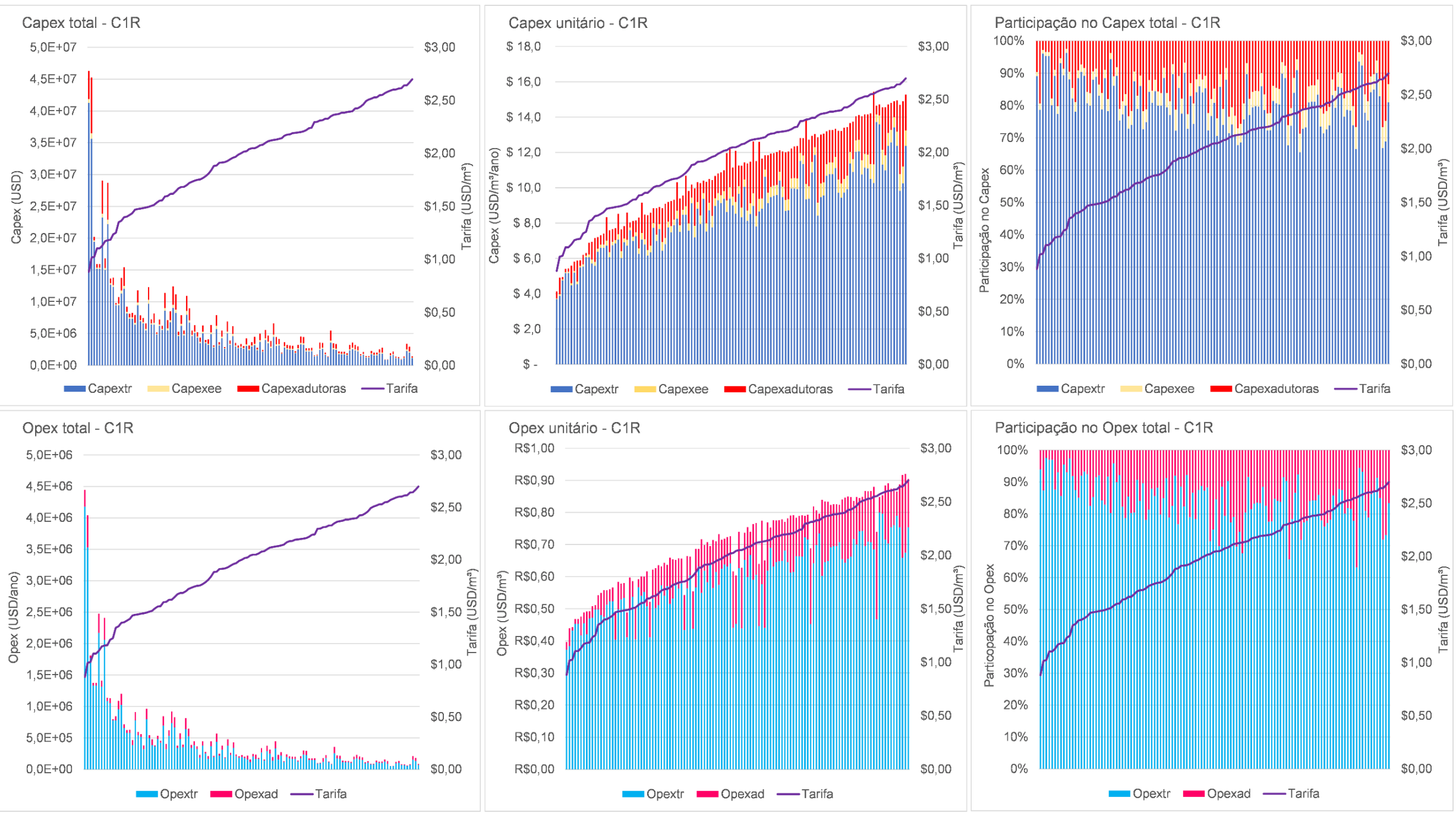

Nota: cada coluna representa um usuário. Usuários ordenados em ordem crescente de tarifa. A linha magenta representa a tarifa calculada.

Figura 52: Tarifa e decomposição de custos para usuários-âncora (classe A) - C1R (120 usuários) 
Como esperado, usuários com custos unitários menores, seja de tratamento ou de adução, possuem as menores tarifas. Esses mesmos usuários são os que apresentam os maiores custos totais de tratamento, dado que, por conta do ganho de escala, quanto maior a vazão de água de reúso produzida menores são os custos unitários.

Pela Figura 52 também se nota a tendência de que o aumento da tarifa é acompanhado pelo incremento da participação dos custos de adução em relação ao total. Em outras palavras, os usuários que possuem as menores tarifas em geral são aqueles que são menos impactados pelos custos de adução. Essa tendência é mais relevante no caso dos custos de operação de adução (Opexad), demonstrando que o maior impacto negativo da necessidade de adução por longas distâncias ocorre de forma mais relevante durante a etapa de operação (Opex), e não na de implantação (Capex).

Em termos porcentuais, os custos de adução permanecem entre 30\% e 40\% do total para usuários-âncora. Conforme as necessidades de adução aumentam, o incremento de tarifa começa a se tornar impeditivo, descaracterizando um usuário como âncora. Essa tendência é clara quando se plotam os valores para todos os usuários classe $A$ e classe B ordenados em ordem crescente de tarifa, conforme apresenta a Figura 53.
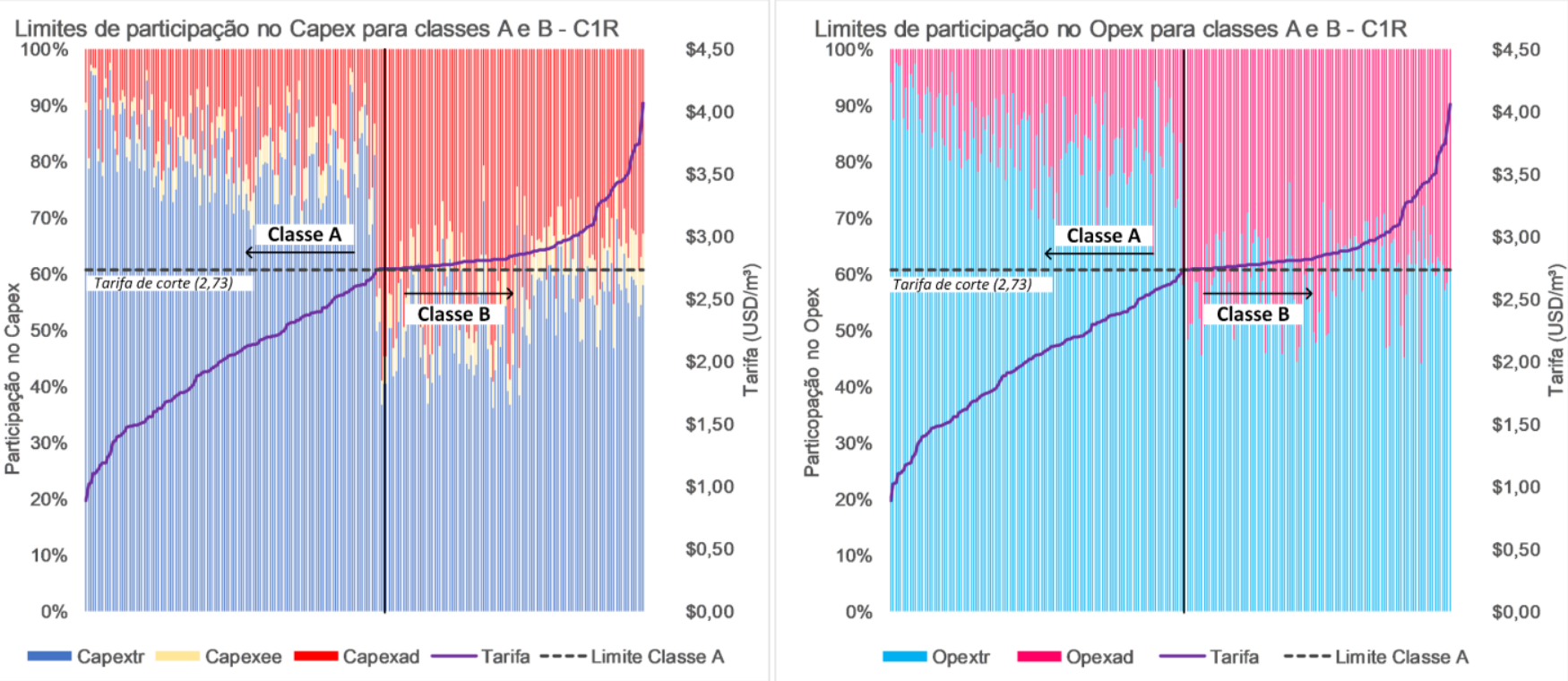

Nota: cada coluna representa um usuário. Usuários ordenados em ordem crescente de tarifa. A linha magenta representa a tarifa calculada.

Figura 53: Comparação de participação no Capex e Opex de custos de adução para usuários classes A e B - C1R 
Pela Figura 53 é graficamente observável que a proporção dos custos de adução nos usuários da classe $B$ é muito mais expressiva quando em comparação aos classe $A$.

De forma genérica, notou-se que em média o comprimento de adutora que se mostrou viável é em torno de 5-6 km com valores máximos entre 6-12 km. Há alguns casos específicos que extrapolam esse limite (como adutoras com mais de $15 \mathrm{~km}$ ) que se mostraram economicamente viáveis somente por conta de altas vazões não potáveis dos usuários (QNP >100 l/s).

\subsubsection{Resultados por atividade econômica}

O maior potencial na RMSP é, para todos os cenários, para finalidades industriais. A Figura 54 ilustra as vazões potenciais de reúso para cada um dos cenários por finalidades (indústria e irrigação).

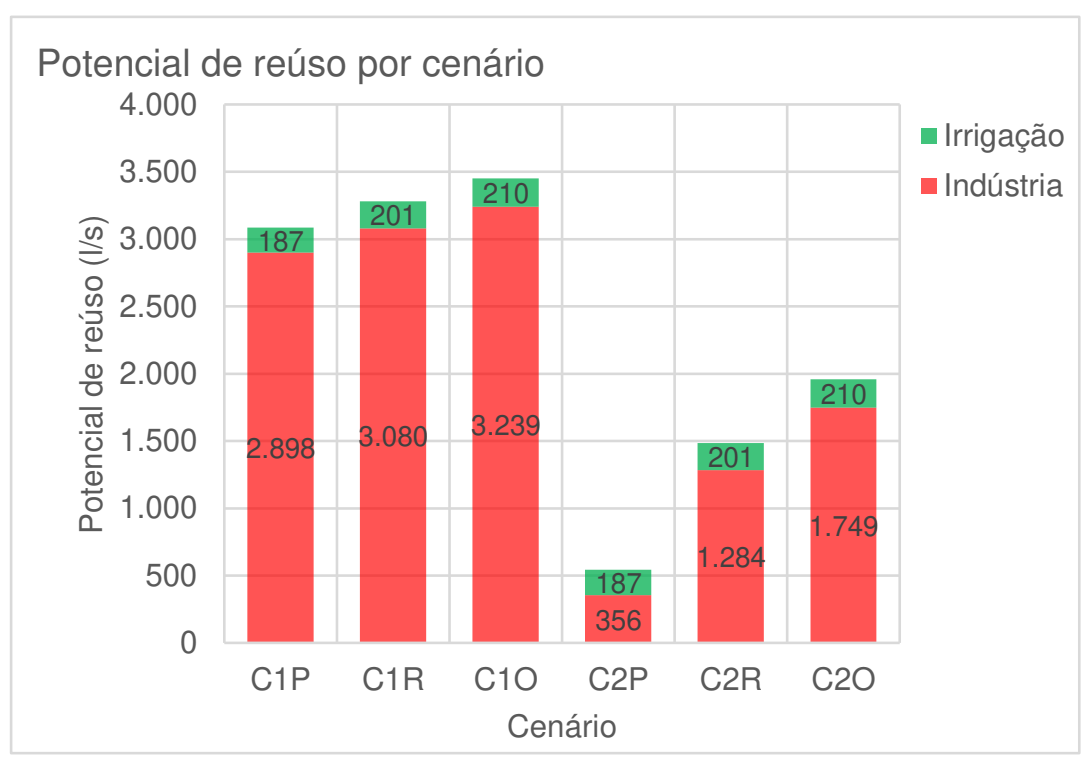

Figura 54: Vazões potenciais de reúso totais por finalidade para todos os cenários

Os cenários C2 apresentam vazões industriais inferiores, já que as restrições de qualidade à indústria nesses cenários levam a maiores custos. As de irrigação, por sua vez, não são alteradas entre C1 e C2, visto que as modificações previstas entre estes cenários não influenciam os padrões de qualidade de usuários irrigantes.

Em relação às atividades econômicas, as de fabricação de celulose, papel e produtos de papel, gás e outras utilidades, produtos químicos, e produtos têxteis são as mais 
relevantes. A Tabela 69 sumariza as vazões não potáveis por divisão da CNAE 2.0 para os cenários C1R e C2R.

Tabela 69: Vazões potenciais de reúso (I/s) segundo divisões e classes da CNAE 2.0 - C1R e C2R

\begin{tabular}{|c|c|c|}
\hline \multirow{2}{*}{ Divisões e classes CNAE 2.0} & \multicolumn{2}{|c|}{$Q_{N P}(I / s)$} \\
\hline & C1R & $\mathrm{C} 2 \mathrm{R}$ \\
\hline FABRICAÇÃO DE CELULOSE, PAPEL E PRODUTOS DE PAPEL & 949,1 & 366,8 \\
\hline Fabricação de embalagens de papel, cartolina, papel-cartão e papelão ondulado & 16,9 & 11,2 \\
\hline Fabricação de papel, cartolina e papel-cartão & 920,2 & 355,6 \\
\hline Fabricação de produtos diversos de papel, cartolina, papel-cartão e papelão ondulado & 12,0 & - \\
\hline ELETRICIDADE, GÁS E OUTRAS UTILIDADES & 687,0 & 633,4 \\
\hline Geração, transmissão e distribuição de energia elétrica & 680,0 & 633,4 \\
\hline Produção e distribuição de combustíveis gasosos por redes urbanas & 7,0 & - \\
\hline FABRICAÇÃO DE PRODUTOS QUÍMICOS & 655,2 & 294,5 \\
\hline Fabricação de fibras artificiais e sintéticas & 11,8 & - \\
\hline Fabricação de produtos e preparados químicos diversos & 249,5 & 129,6 \\
\hline Fabricação de produtos químicos orgânicos & 191,2 & 164,9 \\
\hline $\begin{array}{l}\text { Fabricação de sabões, detergentes, produtos de limpeza, cosméticos, produtos de } \\
\text { perfumaria e de higiene pessoal }\end{array}$ & 179,1 & - \\
\hline Fabricação de tintas, vernizes, esmaltes, lacas e produtos afins & 23,7 & - \\
\hline FABRICAÇÃO DE PRODUTOS TÉXTEIS & 250,7 & - \\
\hline Acabamentos em fios, tecidos e artefatos têxteis & 119,0 & - \\
\hline Fabricação de artefatos têxteis, exceto vestuário & 11,3 & - \\
\hline Preparação e fiação de fibras têxteis & 120,5 & - \\
\hline AGRICULTURA, PECUÁRIA E SERVIÇOS RELACIONADOS & 208,3 & 190,0 \\
\hline Pecuária & 18,3 & - \\
\hline Produção de lavouras temporárias & 190,0 & 190,0 \\
\hline FABRICAÇÃO DE PRODUTOS FARMOQUÍMICOS E FARMACÊUTICOS & 146,0 & - \\
\hline Fabricação de produtos farmacêuticos & 146,0 & - \\
\hline FABRICAÇÃO DE BEBIDAS & 143,1 & - \\
\hline Fabricação de bebidas alcoólicas & 43,5 & - \\
\hline Fabricação de bebidas não-alcoólicas & 99,7 & - \\
\hline METALURGIA & 66,1 & - \\
\hline Metalurgia dos metais não-ferrosos & 6,9 & - \\
\hline Siderurgia & 59,1 & - \\
\hline FABRICAÇÃO DE PRODUTOS ALIMENTÍCIOS & 59,5 & - \\
\hline Fabricação de outros produtos alimentícios & 59,5 & - \\
\hline FABRICAÇÃO DE PRODUTOS DE MINERAIS NÃO-METÁLICOS & 38,7 & - \\
\hline $\begin{array}{l}\text { Fabricação de artefatos de concreto, cimento, fibrocimento, gesso e materiais } \\
\text { semelhantes }\end{array}$ & 13,5 & - \\
\hline Fabricação de cimento & 25,2 & - \\
\hline FABRICAÇÃO DE PRODUTOS DE BORRACHA E DE MATERIAL PLÁSTICO & 29,4 & - \\
\hline Fabricação de produtos de borracha & 29,4 & - \\
\hline FABRICAÇÃO DE VEICCULOS AUTOMOTORES, REBOQUES E CARROCERIAS & 24,2 & - \\
\hline Fabricação de peças e acessórios para veículos automotores & 24,2 & - \\
\hline FABRICAÇÃO DE MÁQUINAS, APARELHOS E MATERIAIS ELÉTRICOS & 20,5 & - \\
\hline Fabricação de eletrodomésticos & 5,1 & - \\
\hline Fabricação de equipamentos para distribuição e controle de energia elétrica & 13,2 & - \\
\hline Fabricação de lâmpadas e outros equipamentos de iluminação & 2,1 & - \\
\hline CONFECÇÃO DE ARTIGOS DO VESTUÁRIO E ACESSÓRIOS & 3,5 & - \\
\hline Confecção de artigos do vestuário e acessórios & 3,5 & - \\
\hline Total Geral & 3.281 & 1.485 \\
\hline
\end{tabular}

${ }^{*}$ Em tese, vazões para irrigação não mudam entre os cenários C1 e C2. No entanto, a base de dados do DAEE aponta uma outorga de finalidade industrial para usuário agrícola, o que gerou a diferença observada para divisão 1 da CNAE 2.0. 
Em termos porcentuais, a participação de cada divisão CNAE 2.0 é como mostra a Tabela 70. As supracitadas atividades de celulose, gás, produtos químicos e têxteis somam $78 \%(\mathrm{C} 1 \mathrm{R})$ e $88 \%(\mathrm{C} 2 \mathrm{R})$ da vazão potencial de reúso.

Tabela 70: Vazões potenciais de reúso (\%) segundo divisões e classes da CNAE 2.0 - C1R e C2R

\begin{tabular}{lll}
\hline \multirow{2}{*}{ Divisão CNAE 2.0 } & QNP (I/s) & \\
\cline { 2 - 3 } & C1R & C2R \\
\hline Fabricação de celulose, papel e produtos de papel & $29 \%$ & $25 \%$ \\
\hline Eletricidade, gás e outras utilidades & $21 \%$ & $43 \%$ \\
\hline Fabricação de produtos químicos & $20 \%$ & $20 \%$ \\
\hline Fabricação de produtos têxteis & $8 \%$ & - \\
\hline Agricultura, pecuária e serviços relacionados & $6 \%$ & $13 \%$ \\
\hline Fabricação de produtos farmoquímicos e farmacêuticos & $4 \%$ & - \\
\hline Fabricação de bebidas & $4 \%$ & - \\
\hline Metalurgia & $2 \%$ & - \\
\hline Fabricação de produtos alimentícios & $2 \%$ & - \\
\hline Fabricação de produtos de minerais não-metálicos & $1 \%$ & - \\
\hline Fabriçãão de produtos de borracha e de material plástico & $1 \%$ & - \\
\hline Fabricação de veículos automotores, reboques e carrocerias & $1 \%$ & - \\
\hline Fabricação de máquinas, aparelhos e materiais elétricos & $1 \%$ & - \\
\hline Confecção de artigos do vestuário e acessórios & $0 \%$ & - \\
\hline
\end{tabular}

Essa preponderância de alguns setores industriais indica a oportunidade para que programas de reúso considerem as especificidades de cada uma dessas atividades. Isso permite que sejam estabelecidos diálogos não somente junto a usuários isolados, mas também a associações setoriais que possam promover adequada articulação entre os atores interessados.

\subsubsection{Casos escolhidos para detalhamento}

Foram escolhidas algumas ETEs para o detalhamento dos resultados, buscando-se melhor exemplificação dos procedimentos adotados e resultados obtidos. Os casos escolhidos foram:

- ETE Suzano: a que apresenta as maiores vazões potenciais de reúso para quase todos os cenários. Seus usuários-âncora são todos industriais. Vazões potenciais variando de 356 a $767 \mathrm{l} / \mathrm{s}$.

- ETE Biritiba-Mirim: relevantes usuários de irrigação nas proximidades. Vazões potenciais variando de 176 a 199 l/s.

- ETEs do sistema isolado da Sabesp: plantas de baixa capacidade com relevante potencial de reúso. Caso escolhido para exemplificação da existência de plantas que em futuras expansões podem considerar o fornecimento de água de reúso. 
Outros casos também considerados importantes (ETEs Mauá, Leste, Várzea do

Palácio, São Miguel Paulista e Parque Novo Mundo) constam no ANEXO C.

As análises apresentadas neste tópico foram realizadas somente para resultados do cenário $\mathrm{C} 1 \mathrm{R}$, havendo considerações pontuais sobre o C2R.

\subsection{ETE Suzano}

A ETE Suzano já foi apontada por outros estudos como a que possui maior potencial de reúso na RMSP (CNI, 2017b; MANCUSO, 1992; SABESP, 2010a), justamente por se localizar próxima a grandes plantas industriais. Entre todas as analisadas, é a que detém o maior número de usuários-âncora para quase todos os cenários. A Tabela 71 identifica individualmente cada um deles, apresentando a vazão outorgada (Qout), a vazão não potável (QNP), a tarifa para C1R, comprimento da adutora (L) e a atividade econômica de cada usuário (grupo CNAE 2.0).

Tabela 71: Usuários-âncora para a ETE Suzano para C1R

\begin{tabular}{|c|c|c|c|c|c|c|c|}
\hline $\begin{array}{l}\text { ID } \\
\text { outorga }\end{array}$ & $\begin{array}{l}Q_{\text {out }} \\
(1 / \mathbf{s})^{(1)}\end{array}$ & $\begin{array}{l}Q_{\mathrm{NP}} \\
(\mathbf{I} / \mathbf{s})\end{array}$ & $\begin{array}{l}\text { Tarifa } \\
\text { C1R } \\
\left(\text { USD/m }{ }^{3}\right)\end{array}$ & $\begin{array}{l}\mathrm{L} \\
(\mathrm{km})\end{array}$ & Usuário & $\begin{array}{l}\text { CNAE } 2.0 \\
\text { (grupo) }\end{array}$ & CNAE 2.0 (grupo) \\
\hline 82327 & 1380,8 & 355,6 & $\$ 0,88$ & 6,84 & $\begin{array}{l}\text { SUZANO PAPEL E } \\
\text { CELULOSE S.A. }\end{array}$ & 17.20 & $\begin{array}{l}\text { Fabricação de papel, cartolina e } \\
\text { papel-cartão }\end{array}$ \\
\hline 108631 & 205,5 & 73,5 & $\$ 1,18$ & 3,02 & $\begin{array}{l}\text { LEAO \& JETEX INDUSTRIA } \\
\text { TEXTIL LTDA. }\end{array}$ & 13.40 & $\begin{array}{l}\text { Acabamentos em fios, tecidos e } \\
\text { artefatos têxteis }\end{array}$ \\
\hline 23839 & 82,2 & 70,7 & $\$ 1,24$ & 5,05 & CLARIANT S.A. & 20.90 & $\begin{array}{l}\text { Fabricação de produtos e preparados } \\
\text { químicos diversos }\end{array}$ \\
\hline 82329 & 191,8 & 49,4 & $\$ 1,35$ & 5,28 & $\begin{array}{l}\text { SUZANO PAPEL E } \\
\text { CELULOSE S.A. }\end{array}$ & 17.20 & $\begin{array}{l}\text { Fabricação de papel, cartolina e } \\
\text { papel-cartão }\end{array}$ \\
\hline 130690 & 82,2 & 40,7 & $\$ 1,40$ & 4,81 & $\begin{array}{l}\text { ALIMENKO IMPORTADORA } \\
\text { EEXPORTADORA LTDA. }\end{array}$ & 10.90 & $\begin{array}{l}\text { Fabricação de outros produtos } \\
\text { alimentícios }\end{array}$ \\
\hline 46337 & 33,3 & 30,6 & $\$ 1,48$ & 4,17 & $\begin{array}{l}\text { SANOFI AVENTIS } \\
\text { FARMACEUTICA LTDA. }\end{array}$ & 21.20 & Fabricação de produtos farmacêuticos \\
\hline 8402 & 109,6 & 28,2 & $\$ 1,55$ & 5,38 & $\begin{array}{l}\text { MELHORAMENTOS PAPEIS } \\
\text { LTDA. }\end{array}$ & 17.20 & $\begin{array}{l}\text { Fabricação de papel, cartolina e } \\
\text { papel-cartão }\end{array}$ \\
\hline 46343 & 20,5 & 18,9 & $\$ 1,67$ & 4,09 & $\begin{array}{l}\text { SANOFI AVENTIS } \\
\text { FARMACEUTICA LTDA. }\end{array}$ & 21.20 & Fabricação de produtos farmacêuticos \\
\hline 82330 & 18,3 & 17,6 & $\$ 1,75$ & 5,28 & $\begin{array}{l}\text { SUZANO PAPEL E } \\
\text { CELULOSE S.A. }\end{array}$ & 17.20 & $\begin{array}{l}\text { Fabricação de papel, cartolina e } \\
\text { papel-cartão }\end{array}$ \\
\hline 171874 & 68,5 & 13,2 & $\$ 1,78$ & 3,17 & $\begin{array}{l}\text { GL ELETRO - ELETRONICOS } \\
\text { LTDA. }\end{array}$ & 27.30 & $\begin{array}{l}\text { Fabricação de equipamentos para } \\
\text { distribuição e controle de energia } \\
\text { elétrica }\end{array}$ \\
\hline 46346 & 21,2 & 10,5 & $\$ 1,97$ & 4,41 & $\begin{array}{l}\text { SANOFI AVENTIS } \\
\text { FARMACEUTICA LTDA. }\end{array}$ & 21.20 & Fabricação de produtos farmacêuticos \\
\hline 169522 & 13,7 & 18,26 & $\$ 2,13$ & 14,94 & KAZUHIRO INO E OUTRO & 01.50 & Pecuária \\
\hline 10330 & 11,4 & 11,78 & $\$ 2,21$ & 10,03 & $\begin{array}{l}\text { RESANA S.A. IND. } \\
\text { QUIMICAS }\end{array}$ & 20.20 & $\begin{array}{l}\text { Fabricação de produtos químicos } \\
\text { orgânicos }\end{array}$ \\
\hline 83559 & 8,9 & 7,63 & $\$ 2,42$ & 8,26 & $\begin{array}{l}\text { DAG QUIMICA IND., COM. E } \\
\text { REPRESENTACOES LTDA. }\end{array}$ & 20.90 & $\begin{array}{l}\text { Fabricação de produtos e preparados } \\
\text { químicos diversos }\end{array}$ \\
\hline 32195 & 4,9 & 3,26 & $\$ 2,51$ & 2,26 & AUNDE BRASIL S.A. & 13.10 & Preparação e fiação de fibras têxteis \\
\hline 46344 & 5,5 & 4,54 & $\$ 2,53$ & 4,60 & $\begin{array}{l}\text { SANOFI AVENTIS } \\
\text { FARMACEUTICA LTDA. }\end{array}$ & 21.20 & Fabricação de produtos farmacêuticos \\
\hline Total & 2.267 & 754,4 & - & - & & & \\
\hline Média & 141,4 & 47,1 & $\$ 1,75$ & 5,72 & & & \\
\hline
\end{tabular}

(1) $Q_{\text {out }}$ Vazão total outorgada. Incluída para comparação com a vazão não potável $\left(Q_{N P}\right)$. 
A ETE Suzano possui capacidade de $1.500 \mathrm{l} / \mathrm{s}$ e, para o cenário $\mathrm{C} 1 \mathrm{R}$, o somatório das vazões não potáveis dos usuários-âncora é igual a 754,4 l/s, ou cerca de $50 \%$ de sua vazão de projeto.

As tarifas variam de 0,88 a 2,53 USD $/ \mathrm{m}^{3}$, com valor médio de $1,75 \mathrm{USD} / \mathrm{m}^{3}$. Usuários como a Suzano Papel e Celulose, Leão \& Jetex, Clariant, Alimenko, Sanofi e Melhoramentos Papeis possuem vazões não potáveis muito expressivas, todos com tarifas inferiores a $1,70 \mathrm{USD} / \mathrm{m}^{3}$. A Suzano e a Sanofi possuem, inclusive, mais de uma outorga da mesma área, as quais, mesmo que analisadas individualmente, apresentam viabilidade econômica.

De maneira a se ilustrar a variabilidade das tarifas calculadas para múltiplos potenciais usuários em relação à ETE Suzano, a Figura 55 mostra gráfico de dispersão 3D de tarifa $\left(U S D / m^{3}\right)$ em função de $Q\left(\mathrm{~m}^{3} / \mathrm{s}\right)$ e $L(\mathrm{~km})$ para os cenários C1R e C2R.
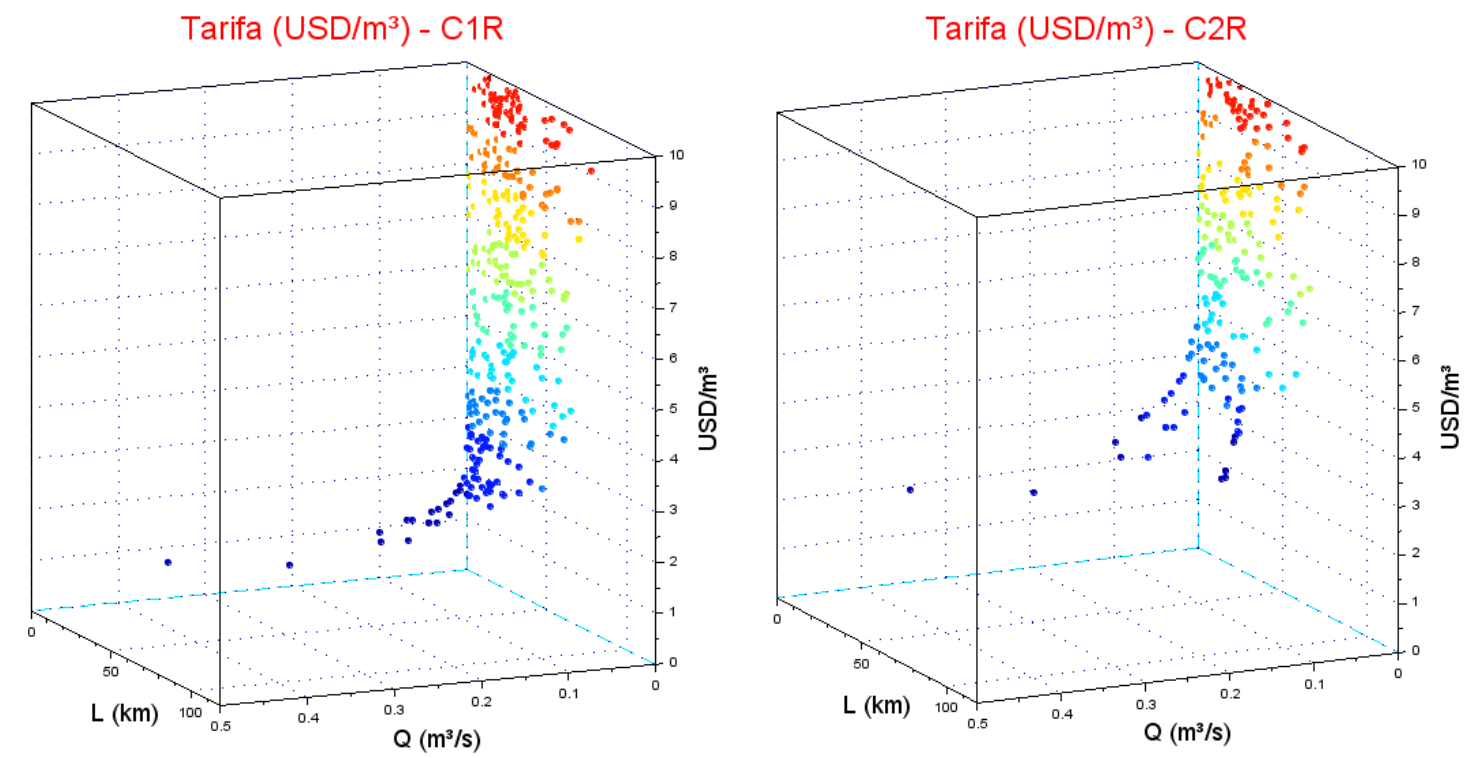

Nota: por conveniência na exibição gráfica foram plotados somente valores para tarifas até $10 \mathrm{USD} / \mathrm{m}^{3}$.

Figura 55: Dispersão 3D de tarifas (USD/m³) em função de $Q\left(\mathrm{~m}^{3} / \mathrm{s}\right)$ e $\mathrm{L}(\mathrm{km})$ para a ETE Suzano - C1R e C2R

Fonte: elaborado pelo autor

A tendência de ganho de escala de vazão é bastante evidente, bem como o de aumento de custos com a distância. Como previsto, as tarifas do C2R são maiores que as do C1R, com exceção daquelas destinadas a usos de irrigação, dado que estas não mudam entre cenários 1 e 2 . 
A maioria dos usuários-âncora se localiza a distâncias que requerem de 5-6 km de comprimento de adutora. O principal usuário-âncora da RMSP, Suzano Papel e Celulose $\left(Q_{N P}=355 \mathrm{l} / \mathrm{s}\right.$ e $\left.\mathrm{L}=6,8 \mathrm{~km}\right)$, possui tarifa de $0,88 \mathrm{USD} / \mathrm{m}^{3}$, o menor valor entre todos os calculados. Alguns usuários estão nas divisas ou já nos municípios de Ferraz de Vasconcelos e Itaquaquecetuba, em virtude da proximidade da ETE a essas cidades. Há também usuários localizados ao Sul da represa de Taiaçupeba que, ainda que afastados em 10-14 km da ETE, apresentaram tarifas viáveis.

A Figura 56 ilustra a distribuição espacial dos usuários-âncora em relação à ETE, bem como os traçados utilizados para determinação dos comprimentos de adutoras. As retas que conectam a ETE e os usuários mostram as tarifas calculadas para cada um.

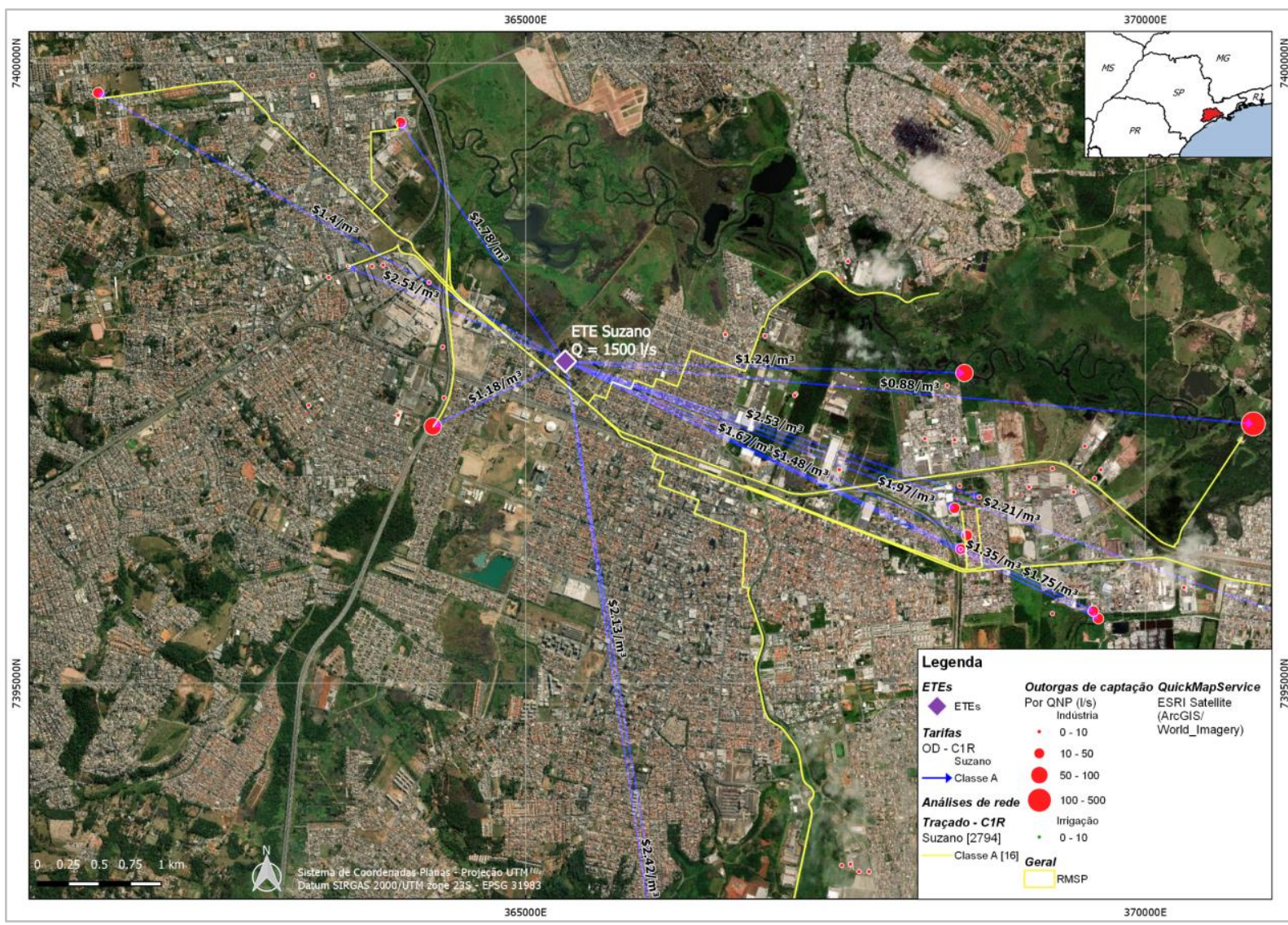

Figura 56: Distribuição dos usuários-âncora em relação à ETE Suzano para C1R: traçados de adutoras (em amarelo) e OD (origem-destino) com tarifas (em azul).

Fonte: elaborado pelo autor

As atividades econômicas preponderantes dos usuários-âncora da ETE Suzano são as de fabricação de papel e celulose (60\%), produtos químicos (10\%), têxtil (10\%) e produtos farmacêuticos (9\%), como se vê na Figura 57. 
ETE Suzano - vazão potencial por atividade (I/s e \%)

Pecuária; 18,$3 ; 2 \%$

Fabricação de outros produtos alimentícios; 40,7; 5\%

Fabricação de produtos farmacêuticos; 64,$6 ; 9 \%$

Acabamentos em fios, tecidos e artefatos têxteis; 73,$5 ; 10 \%$

Fabricação de papel, cartolina e papel-cartão; 450,8; 60\%

Fabricação de produtos e preparados químicos diversos; 78,3; $10 \%$

Figura 57: Participação por atividade econômica (grupo CNAE 2.0) na vazão potencial de reúso da ETE Suzano

\subsection{ETE Biritiba-Mirim}

A ETE Biritiba-Mirim está localizada próxima a importantes usos de irrigação às margens do rio Biritiba-Mirim, já quase em sua confluência com o Tietê. Ainda que sejam outorgas diferentes, todas foram requeridas pelo mesmo usuário e mesmo tipo de atividade (produção de lavouras temporárias). A Tabela 72 sintetiza os 12 usuáriosâncora para a ETE Biritiba-Mirim.

Tabela 72: Usuários-âncora para a ETE Biritiba-Mirim - C1R

\begin{tabular}{|c|c|c|c|c|c|c|c|}
\hline $\begin{array}{l}\text { ID } \\
\text { outorga }\end{array}$ & $\begin{array}{l}Q_{\text {out }} \\
(1 / \mathbf{s})^{(1)}\end{array}$ & $\begin{array}{l}Q_{N P} \\
(I / s)\end{array}$ & $\begin{array}{l}\text { Tarifa } \\
\text { C1R } \\
(\text { USD/m³) }\end{array}$ & $\begin{array}{l}\mathrm{L} \\
(\mathrm{km})\end{array}$ & Usuário & $\begin{array}{l}\text { CNAE } 2.0 \\
\text { (grupo) }\end{array}$ & CNAE 2.0 (grupo) \\
\hline 62786 & 73,7 & 30,2 & $\$ 1,47$ & 8,27 & $\begin{array}{l}\text { ASSOCIACAO AGRICOLA DESPORTIVA } \\
\text { E CULTURAL DO SOGO }\end{array}$ & 01.10 & $\begin{array}{l}\text { Produção de lavouras } \\
\text { temporárias }\end{array}$ \\
\hline 62775 & 60,2 & 24,7 & $\$ 1,49$ & 6,51 & $\begin{array}{l}\text { ASSOCIACAO AGRICOLA DESPORTIVA } \\
\text { E CULTURAL DO SOGO }\end{array}$ & 01.10 & $\begin{array}{l}\text { Produção de lavouras } \\
\text { temporárias }\end{array}$ \\
\hline 62781 & 73,4 & 30,1 & $\$ 1,51$ & 9,67 & $\begin{array}{l}\text { ASSOCIACAO AGRICOLA DESPORTIVA } \\
\text { E CULTURAL DO SOGO }\end{array}$ & 01.10 & $\begin{array}{l}\text { Produção de lavouras } \\
\text { temporárias }\end{array}$ \\
\hline 62785 & 60,2 & 24,7 & $\$ 1,60$ & 9,68 & $\begin{array}{l}\text { ASSOCIACAO AGRICOLA DESPORTIVA } \\
\text { E CULTURAL DO SOGO }\end{array}$ & 01.10 & $\begin{array}{l}\text { Produção de lavouras } \\
\text { temporárias }\end{array}$ \\
\hline 62779 & 32,9 & 13,5 & $\$ 1,75$ & 6,51 & $\begin{array}{l}\text { ASSOCIACAO AGRICOLA DESPORTIVA } \\
\text { E CULTURAL DO SOGO }\end{array}$ & 01.10 & $\begin{array}{l}\text { Produção de lavouras } \\
\text { temporárias }\end{array}$ \\
\hline 62776 & 29,6 & 12,1 & $\$ 1,81$ & 6,51 & $\begin{array}{l}\text { ASSOCIACAO AGRICOLA DESPORTIVA } \\
\text { E CULTURAL DO SOGO }\end{array}$ & 01.10 & $\begin{array}{l}\text { Produção de lavouras } \\
\text { temporárias }\end{array}$ \\
\hline 62784 & 27,4 & 11,2 & $\$ 2,02$ & 9,67 & $\begin{array}{l}\text { ASSOCIACAO AGRICOLA DESPORTIVA } \\
\text { E CULTURAL DO SOGO }\end{array}$ & 01.10 & $\begin{array}{l}\text { Produção de lavouras } \\
\text { temporárias }\end{array}$ \\
\hline 62778 & 19,7 & 8,1 & $\$ 2,04$ & 6,51 & $\begin{array}{l}\text { ASSOCIACAO AGRICOLA DESPORTIVA } \\
\text { E CULTURAL DO SOGO }\end{array}$ & 01.10 & $\begin{array}{l}\text { Produção de lavouras } \\
\text { temporárias }\end{array}$ \\
\hline 62787 & 28,8 & 11,8 & $\$ 2,05$ & 10,77 & $\begin{array}{l}\text { ASSOCIACAO AGRICOLA DESPORTIVA } \\
\text { E CULTURAL DO SOGO }\end{array}$ & 01.10 & $\begin{array}{l}\text { Produção de lavouras } \\
\text { temporárias }\end{array}$ \\
\hline 62782 & 23,6 & 9,7 & $\$ 2,12$ & 9,67 & $\begin{array}{l}\text { ASSOCIACAO AGRICOLA DESPORTIVA } \\
\text { E CULTURAL DO SOGO }\end{array}$ & 01.10 & $\begin{array}{l}\text { Produção de lavouras } \\
\text { temporárias }\end{array}$ \\
\hline 62788 & 20,1 & 8,3 & $\$ 2,31$ & 10,77 & $\begin{array}{l}\text { ASSOCIACAO AGRICOLA DESPORTIVA } \\
\text { E CULTURAL DO SOGO }\end{array}$ & 01.10 & $\begin{array}{l}\text { Produção de lavouras } \\
\text { temporárias }\end{array}$ \\
\hline 62783 & 13,9 & 5,7 & $\$ 2,55$ & 9,67 & $\begin{array}{l}\text { ASSOCIACAO AGRICOLA DESPORTIVA } \\
\text { E CULTURAL DO SOGO }\end{array}$ & 01.10 & $\begin{array}{l}\text { Produção de lavouras } \\
\text { temporárias }\end{array}$ \\
\hline Total & 463,5 & 190,0 & - & - & & & \\
\hline Média & 38,6 & 15,8 & $\$ 1,89$ & 8,69 & & & \\
\hline
\end{tabular}

(1) $Q_{\text {out }}$ : Vazão total outorgada. Incluída para comparação com a vazão não potável $\left(Q_{N P}\right)$. 
A ETE possui capacidade de $55 \mathrm{l} / \mathrm{s}$ e o somatório das vazões não potáveis de seus usuários-âncora é igual a 190 l/s (C1R). Ou seja, as vazões de reúso superam em quase quatro vezes a vazão de projeto da estação.

As tarifas variam de 1,47 a $2,55 \mathrm{USD} / \mathrm{m}^{3}$, com valor médio de $1,89 \mathrm{USD} / \mathrm{m}^{3}$. Dado que os usuários-âncora detectados extraem água do rio Biritiba-Mirim, é muito provável que seus custos atuais sejam muito inferiores às tarifas calculadas, o que deve ser levado em consideração caso se deseje oferecer-Ihes água de reúso. A distribuição espacial dos usuários-âncora e da ETE Biritiba-Mirim, o traçado de adutoras e as tarifas calculadas são mostrados no mapa na Figura 58.

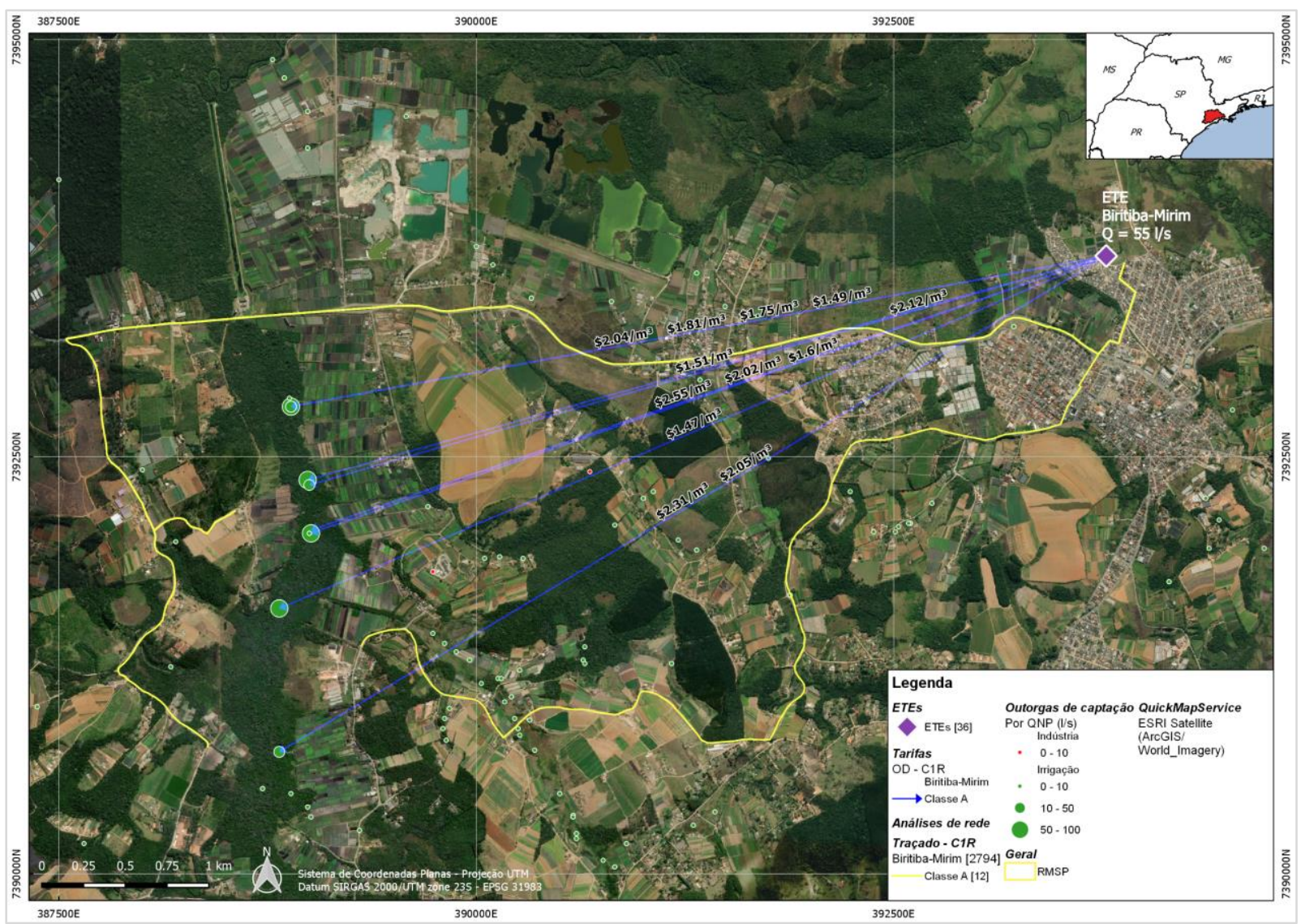

Figura 58: Distribuição dos usuários-âncora em relação à ETE Biritiba-Mirim para C1R: traçados de adutoras (em amarelo) e OD (origem destino) com tarifas (em azul)

Fonte: elaborado pelo autor

Nesse caso é possível verificar alguns desvios causados pelo uso do sistema viário para determinação de traçado de adutoras. Como o algoritmo aplicado não considera a possibilidade de passagem por áreas não carroçáveis nem de travessias sobre rios 
e córregos, o caminhamento tende a ser mais longo para regiões onde a malha viária é menos capilarizada.

A região de Biritiba-Mirim é brevemente citada por Mancuso (1992) como uma das que apresentam potencialidades de reúso para finalidades agrícolas, sem, no entanto, ter seu potencial determinado. A área irrigada do município é, segundo ANA (2017e), a segunda maior da RMSP (1.498 ha), atrás apenas de Mogi das Cruzes (ver Tabela $51)$.

\subsection{ETEs de baixa vazão (sistema isolado Sabesp)}

Diversas ETEs do sistema isolado da Sabesp com baixas vazões se localizam próximas a usuários relevantes. É o caso das ETEs Bandeirantes (São Paulo), Aldeia da Serra (Itapevi), Cotia/Jardim Japão (Cotia), Vargem Grande Paulista (Vargem Grande Paulista), Parque Andreense (Santo André), Mairiporã - Sede (Mairiporã) e Guararema Sede (Guararema).

Esses casos são especialmente importantes quando se considera que essas estações poderão ser ampliadas/modernizadas futuramente, ou que outras plantas serão instaladas em regiões próximas para incremento da capacidade de tratamento de esgotos do município. A consideração de produção e venda de água de reúso pode, se devidamente considerada no planejamento das futuras modificações, inclusive atuar positivamente na viabilização econômica dessas iniciativas.

A Tabela 73 apresenta os usuários-âncora para as sete supracitadas ETEs.

Tabela 73: Usuários-âncora para a ETEs Pinheirinho, Aldeia da Serra, Bandeirantes, Cotia/Jardim Japão, Mairiporã - Sede, Parque Andreense e Parque dos Pinheiros - C1R

\begin{tabular}{|c|c|c|c|c|c|c|c|}
\hline $\begin{array}{l}\text { ETE / } \\
\text { ID outorga }\end{array}$ & $\begin{array}{l}\text { Qout } \\
(1 / s)^{(1)}\end{array}$ & $\begin{array}{l}Q_{\mathrm{NP}} \\
(1 / \mathrm{s})\end{array}$ & $\begin{array}{l}\text { Tarifa } \\
\left(\mathrm{USD} / \mathrm{m}^{3}\right)\end{array}$ & $\mathbf{L}(\mathbf{k m})$ & Usuário & $\begin{array}{l}\text { CNAE 2.0 } \\
\text { (grupo) }\end{array}$ & CNAE 2.0 (grupo) \\
\hline Pinheirinho & 738,1 & 504,1 & $\begin{array}{l}\$ 1,47 \\
\text { (média) }\end{array}$ & $\begin{array}{l}12,97 \\
\text { (média) }\end{array}$ & & & \\
\hline 97161 & 429,2 & 291,9 & $\$ 1,02$ & 15,39 & $\begin{array}{l}\text { PETROLEO BRASILEIRO S.A. - } \\
\text { PETROBRÁS }\end{array}$ & 35.10 & $\begin{array}{l}\text { Geração, transmissão e distribuição de } \\
\text { energia elétrica }\end{array}$ \\
\hline 97168 & 228,3 & 155,3 & $\$ 1,18$ & 15,39 & $\begin{array}{l}\text { PETROLEO BRASILEIRO S.A. - } \\
\text { PETROBRAS }\end{array}$ & 35.10 & $\begin{array}{l}\text { Geração, transmissão e distribuição de } \\
\text { energia elétrica }\end{array}$ \\
\hline 97169 & 68,5 & 46,6 & $\$ 1,62$ & 15,39 & $\begin{array}{l}\text { PETROLEO BRASILEIRO S.A. - } \\
\text { PETROBRAS }\end{array}$ & 35.10 & $\begin{array}{l}\text { Geração, transmissão e distribuição de } \\
\text { energia elétrica }\end{array}$ \\
\hline 28705 & 12,1 & 10,4 & $\$ 2,05$ & 5,70 & BASF S.A. & 20.70 & $\begin{array}{l}\text { Fabricação de tintas, vernizes, esmaltes, } \\
\text { lacas e produtos afins }\end{array}$ \\
\hline Bandeirantes & 586,8 & 240,4 & $\begin{array}{l}\$ 1,91 \\
\text { (média) }\end{array}$ & $\begin{array}{l}9,34 \\
\text { (média) }\end{array}$ & & & \\
\hline 60357 & 73,1 & 62,8 & $\$ 1,36$ & 9,03 & $\begin{array}{l}\text { PROCOSA PRODUTOS DE } \\
\text { BELEZA LTDA. }\end{array}$ & 20.60 & $\begin{array}{l}\text { Fabricação de sabões, detergentes, } \\
\text { produtos de limpeza, cosméticos, produtos } \\
\text { de perfumaria e de higiene pessoal }\end{array}$ \\
\hline 51800 & 191,8 & 49,4 & $\$ 1,47$ & 9,84 & MD PAPEIS LTDA. & 17.20 & $\begin{array}{l}\text { Fabricação de papel, cartolina e papel- } \\
\text { cartão }\end{array}$ \\
\hline
\end{tabular}


RESULTADOS E DICUSSÕES

APLICAÇÃO À ÁREA DE ESTUDO (RMSP)

\begin{tabular}{|c|c|c|c|c|c|c|c|}
\hline $\begin{array}{l}\text { ETE / } \\
\text { ID outorga }\end{array}$ & $\begin{array}{l}\text { Qout } \\
(1 / \mathbf{s})^{(1)}\end{array}$ & $\begin{array}{l}Q_{N P} \\
(1 / s)\end{array}$ & $\begin{array}{l}\text { Tarifa } \\
\text { (USD/m³) }\end{array}$ & L (km) & Usuário & $\begin{array}{l}\text { CNAE 2.0 } \\
\text { (grupo) }\end{array}$ & CNAE 2.0 (grupo) \\
\hline 13210 & 160,3 & 41,3 & $\$ 1,64$ & 13,67 & MELHORAMENTOS CMPC LTDA & 17.20 & $\begin{array}{l}\text { Fabricação de papel, cartolina e papel- } \\
\text { cartão }\end{array}$ \\
\hline 60354 & 32,9 & 28,3 & $\$ 1,68$ & 9,13 & $\begin{array}{l}\text { PROCOSA PRODUTOS DE } \\
\text { BELEZA LTDA. }\end{array}$ & 20.60 & $\begin{array}{l}\text { Fabricação de sabões, detergentes, } \\
\text { produtos de limpeza, cosméticos, produtos } \\
\text { de perfumaria e de higiene pessoal }\end{array}$ \\
\hline 91574 & 59,4 & 21,2 & $\$ 1,77$ & 7,90 & TEXTIL LAPO S.A. & 13.40 & $\begin{array}{l}\text { Acabamentos em fios, tecidos e artefatos } \\
\text { têxteis }\end{array}$ \\
\hline 60353 & 15,1 & 13,0 & $\$ 2,12$ & 9,26 & $\begin{array}{l}\text { PROCOSA PRODUTOS DE } \\
\text { BELEZA LTDA. }\end{array}$ & 20.60 & $\begin{array}{l}\text { Fabricação de sabões, detergentes, } \\
\text { produtos de limpeza, cosméticos, produtos } \\
\text { de perfumaria e de higiene pessoal }\end{array}$ \\
\hline 60355 & 10,0 & 8,6 & $\$ 2,37$ & 9,15 & $\begin{array}{l}\text { PROCOSA PRODUTOS DE } \\
\text { BELEZA LTDA. }\end{array}$ & 20.60 & $\begin{array}{l}\text { Fabricação de sabões, detergentes, } \\
\text { produtos de limpeza, cosméticos, produtos } \\
\text { de perfumaria e de higiene pessoal }\end{array}$ \\
\hline 91573 & 22,8 & 8,2 & $\$ 2,39$ & 8,21 & TEXTIL LAPO S.A. & 13.40 & $\begin{array}{l}\text { Acabamentos em fios, tecidos e artefatos } \\
\text { têxteis }\end{array}$ \\
\hline 91575 & 21,5 & 7,7 & $\$ 2,40$ & 7,88 & TEXTIL LAPO S.A. & 13.40 & $\begin{array}{l}\text { Acabamentos em fios, tecidos e artefatos } \\
\text { têxteis }\end{array}$ \\
\hline $\begin{array}{l}\text { Aldeia da } \\
\text { Serra }\end{array}$ & 114,2 & 94,9 & $\begin{array}{l}\$ 1,78 \\
\text { (média) }\end{array}$ & $\begin{array}{l}\text { 10,66 } \\
\text { (média) }\end{array}$ & & & \\
\hline 161848 & 55,5 & 51,0 & $\$ 1,50$ & 10,02 & ITACEL FARMOQUIMICA LTDA & 21.20 & Fabricação de produtos farmacêuticos \\
\hline 11845 & 38,4 & 25,2 & $\$ 1,89$ & 12,13 & S.A INDUSTRIAS VOTORANTIM & 23.20 & Fabricação de cimento \\
\hline 161841 & 20,3 & 18,7 & $\$ 1,96$ & 9,83 & ITACEL FARMOQUIMICA LTDA & 21.20 & Fabricação de produtos farmacêuticos \\
\hline $\begin{array}{l}\text { Cotia/ } \\
\text { Jardim Japão }\end{array}$ & 225,4 & 81,5 & $\begin{array}{l}\$ 2,05 \\
\text { (média) }\end{array}$ & $\begin{array}{l}8,35 \\
\text { (média) }\end{array}$ & & & \\
\hline 9138 & 82,2 & 21,2 & $\$ 1,68$ & 12,19 & $\begin{array}{l}\text { REPASA S.A. CELULOSE E } \\
\text { PAPEL }\end{array}$ & 17.20 & $\begin{array}{l}\text { Fabricação de papel, cartolina e papel- } \\
\text { cartão }\end{array}$ \\
\hline 98872 & 32,9 & 19,6 & $\$ 1,93$ & 4,77 & GERDAU ACOS LONGOS S.A. & 24.20 & Siderurgia \\
\hline 9495 & 60,3 & 15,5 & $\$ 2,10$ & 11,69 & RIPASA S.A. CELULOSE E PAPEL & 17.20 & $\begin{array}{l}\text { Fabricação de papel, cartolina e papel- } \\
\text { cartão }\end{array}$ \\
\hline 159071 & 27,4 & 11,2 & $\$ 2,13$ & 11,69 & $\begin{array}{l}\text { IBEMA COMPANHIA BRASILEIRA } \\
\text { DE PAPEL }\end{array}$ & 17.30 & $\begin{array}{l}\text { Fabricação de embalagens de papel, } \\
\text { cartolina, papel-cartão e papelão ondulado }\end{array}$ \\
\hline 74560 & 11,0 & 7,1 & $\$ 2,24$ & 4,98 & $\begin{array}{l}\text { HORIZON ARTEFATOS DE } \\
\text { BORRACHA LTDA. }\end{array}$ & 22.10 & Fabricação de produtos de borracha \\
\hline 98870 & 11,7 & 7,0 & $\$ 2,24$ & 4,81 & GERDAU ACOS LONGOS S.A. & 24.20 & Siderurgia \\
\hline $\begin{array}{l}\text { Mairiporã - } \\
\text { Sede }\end{array}$ & 191,8 & 49,4 & $\begin{array}{l}\$ 1,25 \\
\text { (média) }\end{array}$ & $\begin{array}{l}1,22 \\
\text { (média) }\end{array}$ & & & \\
\hline 9530 & 191,8 & 49,4 & $\$ 1,25$ & 1,22 & $\begin{array}{l}\text { MAIRIPORA IND E COM DE } \\
\text { PAPEL E PAPELAO LTDA }\end{array}$ & 17.20 & $\begin{array}{l}\text { Fabricação de papel, cartolina e papel- } \\
\text { cartão }\end{array}$ \\
\hline $\begin{array}{l}\text { Parque } \\
\text { Andreense }\end{array}$ & 191,8 & 164,9 & $\begin{array}{l}\$ 1,13 \\
\text { (média) }\end{array}$ & $\begin{array}{l}13,22 \\
\text { (média) }\end{array}$ & & & \\
\hline 164306 & 191,8 & 164,9 & $\$ 1,13$ & 13,22 & UNIPAR INDUPA DO BRASIL S/A & 20.20 & $\begin{array}{l}\text { Fabricação de produtos químicos } \\
\text { orgânicos }\end{array}$ \\
\hline $\begin{array}{l}\text { Parque dos } \\
\text { Pinheiros }\end{array}$ & 73,4 & 48,4 & $\begin{array}{l}\$ 2,29 \\
\text { (média) }\end{array}$ & $\begin{array}{l}2,70 \\
\text { (média) }\end{array}$ & & & \\
\hline 116230 & 38,0 & 18,8 & $\$ 1,73$ & 5,44 & $\begin{array}{l}\text { NACOM GOYA INDUSTRIA E } \\
\text { COMERCIO DE ALIMENTOS LTDA }\end{array}$ & 10.90 & Fabricação de outros produtos alimentícios \\
\hline 55115 & 11,4 & 9,8 & $\$ 1,88$ & 2,43 & $\begin{array}{l}\text { INDUSTRIA E COMERCIO DE } \\
\text { COSMETICOS NATURA LTDA }\end{array}$ & 20.60 & $\begin{array}{l}\text { Fabricação de sabões, detergentes, } \\
\text { produtos de limpeza, cosméticos, produtos } \\
\text { de perfumaria e de higiene pessoal }\end{array}$ \\
\hline 55116 & 10,3 & 8,8 & $\$ 1,92$ & 2,21 & $\begin{array}{l}\text { INDUSTRIA E COMERCIO DE } \\
\text { COSMETICOS NATURA LTDA }\end{array}$ & 20.60 & $\begin{array}{l}\text { Fabricação de sabões, detergentes, } \\
\text { produtos de limpeza, cosméticos, produtos } \\
\text { de perfumaria e de higiene pessoal }\end{array}$ \\
\hline 22662 & 3,4 & 2,9 & $\$ 2,58$ & 2,64 & $\begin{array}{l}\text { INDUSTRIA E COMERCIO DE } \\
\text { COSMETICOS NATURA LTDA }\end{array}$ & 20.60 & $\begin{array}{l}\text { Fabricação de sabões, detergentes, } \\
\text { produtos de limpeza, cosméticos, produtos } \\
\text { de perfumaria e de higiene pessoal }\end{array}$ \\
\hline 55109 & 3,4 & 2,9 & $\$ 2,60$ & 3,32 & $\begin{array}{l}\text { INDUSTRIA E COMERCIO DE } \\
\text { COSMETICOS NATURA LTDA }\end{array}$ & 20.60 & $\begin{array}{l}\text { Fabricação de sabões, detergentes, } \\
\text { produtos de limpeza, cosméticos, produtos } \\
\text { de perfumaria e de higiene pessoal }\end{array}$ \\
\hline 22663 & 3,4 & 2,9 & $\$ 2,64$ & 2,42 & $\begin{array}{l}\text { INDUSTRIA E COMERCIO DE } \\
\text { COSMETICOS NATURA LTDA }\end{array}$ & 20.60 & $\begin{array}{l}\text { Fabricação de sabões, detergentes, } \\
\text { produtos de limpeza, cosméticos, produtos } \\
\text { de perfumaria e de higiene pessoal }\end{array}$ \\
\hline 22664 & 3,4 & 2,9 & $\$ 2,70$ & 3,05 & $\begin{array}{l}\text { INDUSTRIA E COMERCIO DE } \\
\text { COSMETICOS NATURA LTDA }\end{array}$ & 20.60 & $\begin{array}{l}\text { Fabricação de sabões, detergentes, } \\
\text { produtos de limpeza, cosméticos, produtos } \\
\text { de perfumaria e de higiene pessoal }\end{array}$ \\
\hline Total Geral & 2.121 & 1.184 & $=$ & $=$ & & & \\
\hline
\end{tabular}

(1) Qout: Vazão total outorgada. Incluída para comparação com a vazão não potável $\left(Q_{N P}\right)$. 
Essas sete estações possuem vazão de projeto somada de $170 \mathrm{l} / \mathrm{s}^{14}$, e o somatório das vazões potenciais de reúso é igual a $1.184 \mathrm{l} / \mathrm{s}$ para C1R. Esse valor é muito expressivo frente aos $3.281 \mathrm{l} / \mathrm{s}$ estimados para toda a RMSP para o mesmo cenário, indicando que não é desprezível sua potencialidade de fornecimento de água de reúso. As tarifas variam de $1,05 \mathrm{USD} / \mathrm{m}^{3}$ a $2,70 \mathrm{USD} / \mathrm{m}^{3}$, com valores médios por $\mathrm{ETE}$ variando de 1,13 a $2,29 \mathrm{USD} / \mathrm{m}^{3}$.

Entre os usuários, destacam-se a Melhoramentos Ind e Com de Papel e Papelão LTDA (ETE Mairiporã - Sede) com tarifa de 1,25 USD/m3; Unipar Indupa do Brasil S/A (ETE Parque Andreense), tarifa de 1,13 USD/m³; Petrobrás (ETE Pinheirinho), tarifa de 1,02 USD/m³ Nacom Goya Indústria e Comércio de Alimentos LTDA (ETE Parque dos Pinheiros), tarifa de $1,73 \mathrm{USD} / \mathrm{m}^{3}$.

Mesmo que por conveniência as sete ETEs tenham sido agrupadas neste tópico para análise conjunta, elas estão localizadas em municípios diferentes e têm características de potencial de reúso bastante distintas. A seguir são pontuadas algumas especificidades:

- A ETE Parque dos Pinheiros está muito próxima a múltiplos usuários industriais que, ainda que individualmente possuam relativa baixa vazão (até 18,8 l/s), localizam-se a distâncias curtas o suficiente (média de 2,7 km) para viabilização da tarifa.

- Um caso oposto é a da ETE Pinheirinho, a qual é a mais próxima a altas demandas da Petrobrás próximas à Billings e à Usina Elevatória de Pedreira da EMAE, mas com distâncias superiores a $15 \mathrm{~km}$. Ou seja, ainda que a tarifa seja viável pela existência de altas vazões, as dificuldades de implantação de linhas de adução longas podem ser fator impeditivo ao fornecimento de água de reúso. Casos similares são os das ETEs Bandeirantes, Parque Andreense e Aldeia da Serra, em que um ou poucos usuários relevantes estão localizados a distâncias relativamente altas.

\footnotetext{
${ }^{14}$ Não foram encontrados dados de vazão de projeto ou afluente das ETEs Aldeia da Serra e Parque dos Pinheiros, conforme apresentado na Tabela 55.
} 
- As ETEs Cotia/Jardim Japão e Mairiporã - Sede, por sua vez, têm situação "intermediária", já que possuem usuários-âncora próximos $(<5 \mathrm{~km})$ e outros mais distantes.

A Figura 59 (ETEs Parque dos Pinheiros, Bandeirantes, Aldeia da Serra e Pinheirinho) e Figura 60 (ETEs Parque Andreense, Cotia/Jardim Japão e Mairiporã - Sede) ilustram a distribuição espacial dos usuários-âncora em relação às ETEs e os traçados de adutoras. 


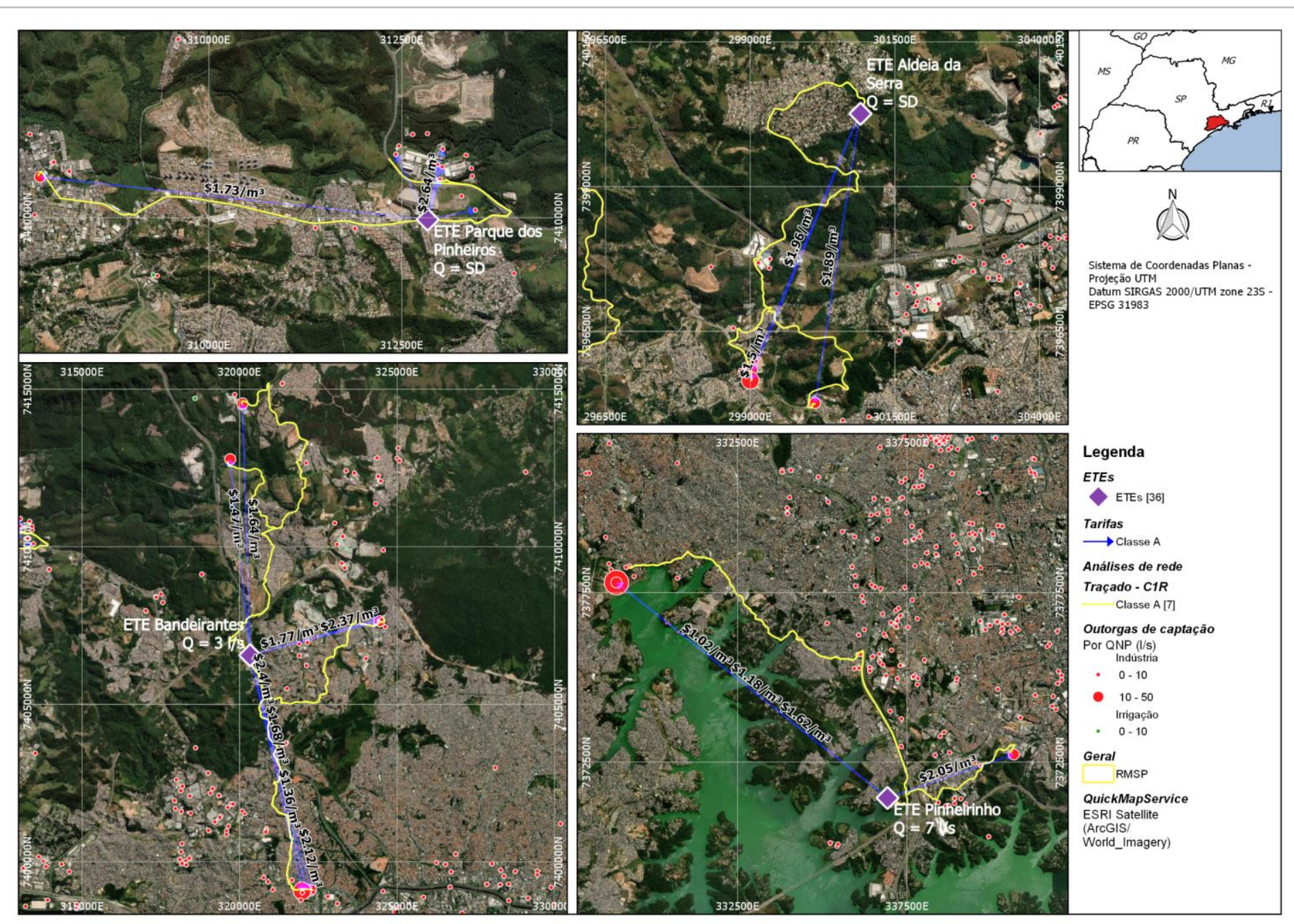

Figura 59: Distribuição dos usuários-âncora em relação à ETEs Parque dos Pinheiros, Aldeia da Serra, Bandeirantes e Pinheirinho para C1R: traçados de adutoras (em amarelo) e OD (origem destino) com tarifas (em azul) Fonte: elaborado pelo autor 

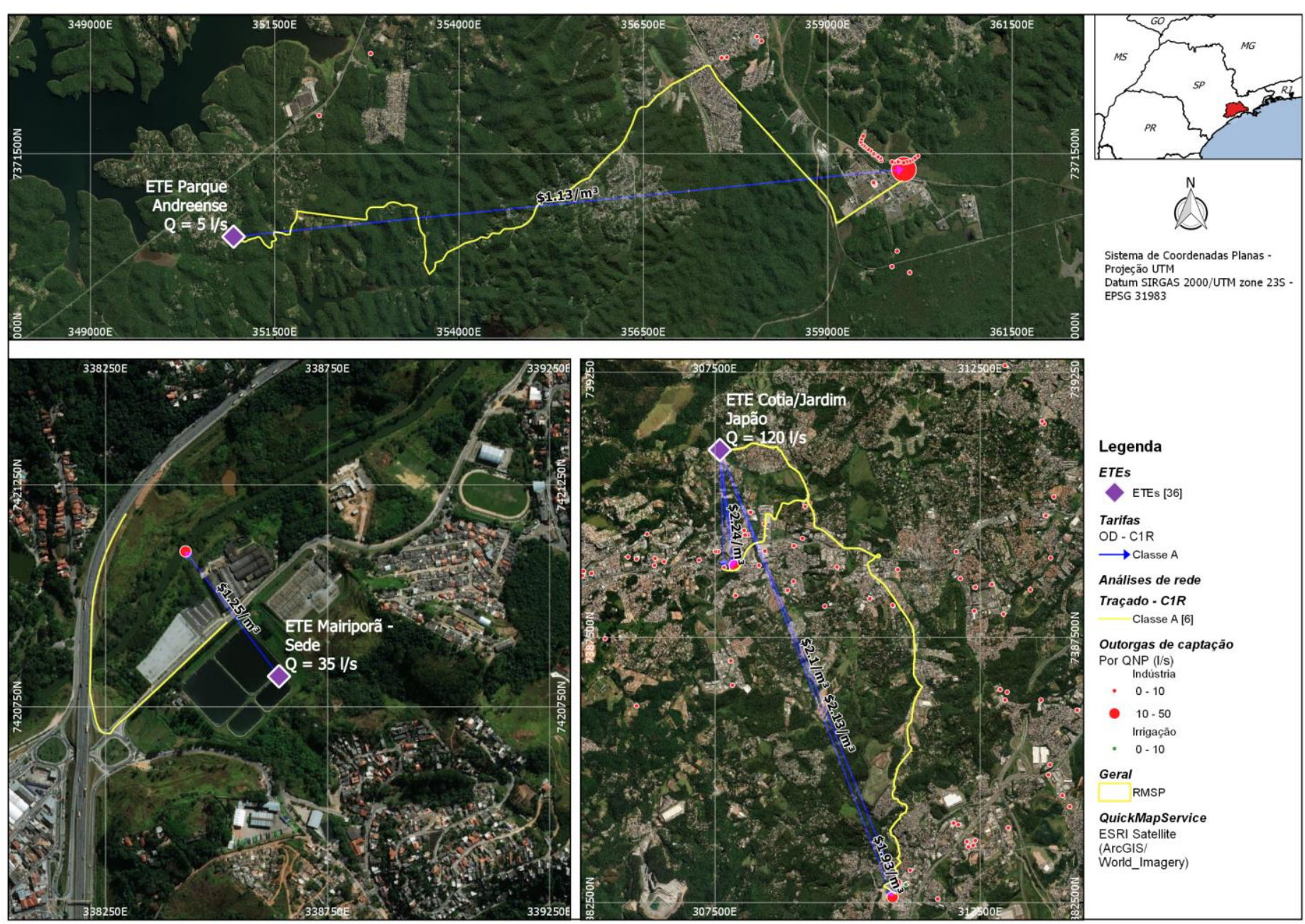

Legenda

$\leftrightarrow$ ETES [36]

Taritas
$O D-C 1 R$

$\longrightarrow$ Classe A

Análises de rede

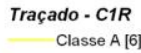

Outorgas de captą̧āo

Por ONP (Ils)
Indistitia
,

0.10
-10.50
-1

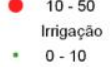

Geral ${ }_{\text {RMSP }}$

auickmapservice

QuickMapservicis
ESRI Satellite

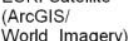

Figura 60: Distribuição dos usuários-âncora em relação à ETEs Parque Andreense, Cotia/Jardim Japão e Mairiporã - Sede para C1R: traçados de adutoras (em amarelo) e OD (origem destino) com tarifas (em azul)

Fonte: elaborado pelo autor 
O destaque às ETEs de baixa vazão mostra que uma parcela importante do potencial de reúso da RMSP se localiza fora da área de atuação das grandes ETEs do Projeto Tietê (Barueri, ABC, Parque Novo Mundo, São Miguel Paulista e Suzano) e de outras de grande porte (Mauá, Bonsucesso, Várzea do Palácio, São João e Leste).

Conforme abordado no item 5.3.3.2 (Tabela 65), muitas dessas estações estão localizadas em municípios com baixos índices de tratamento de esgoto, notadamente as ETEs Pinheirinho (São Bernardo do Campo), Parque Andreense (Santo André) e Aldeia da Serra (Santana de Parnaíba). Ou seja, a inevitável necessidade de expansão da cobertura de tratamento de esgotos conduzirá à produção de maiores volumes de esgotos tratados, o que se apresenta como oportunidade para o fornecimento de água de reúso aos usuários-âncora detectados.

\subsubsection{Resumo e comparação com estudos similares}

As vazões potenciais de reúso estimadas para a RMSP são, ainda que não desprezíveis, relativamente baixas. Para o cenário mais otimista $(3,45 \mathrm{~m} 3 / \mathrm{s}, \mathrm{C1O})$, o valor não chega a $4 \%$ da demanda consuntiva total da RMSP total. A Tabela 74 compila as vazões potenciais de reúso para os seis cenários analisados e os compara às demandas industriais e de irrigação totais e consuntiva total da RMSP.

Tabela 74: Comparação porcentual do potencial de reúso por cenários com demandas totais para indústria e irrigação e consuntiva total da RMSP

\begin{tabular}{|c|c|c|c|}
\hline Cenário & $\begin{array}{l}\text { Potencial de } \\
\text { reúso (I/s) }\end{array}$ & $\begin{array}{c}\text { \% em relação às } \\
\text { demandas industriais e } \\
\text { de irrigação }\left(10,2 \mathrm{~m}^{3} / \mathrm{s}\right)\end{array}$ & $\begin{array}{c}\text { \% em relação à demanda } \\
\text { consuntiva total da RMSP } \\
\left(88,1 \mathrm{~m}^{3} / \mathrm{s}\right)\end{array}$ \\
\hline C1P & 3.085 & $30,4 \%$ & $3,5 \%$ \\
\hline C1R & 3.281 & $32,3 \%$ & $3,7 \%$ \\
\hline C10 & 3.449 & $34,0 \%$ & $3,9 \%$ \\
\hline C2P & 543 & $5,3 \%$ & $0,6 \%$ \\
\hline C2R & 1.485 & $14,6 \%$ & $1,7 \%$ \\
\hline $\mathrm{C} 2 \mathrm{O}$ & 1.959 & $19,3 \%$ & $2,2 \%$ \\
\hline
\end{tabular}

Em relação somente às demandas totais industriais e de irrigação, o cenário mais otimista $(\mathrm{C} 1 \mathrm{R})$ representa $34,0 \%$ do total, enquanto o mais pessimista $(\mathrm{C} 2 \mathrm{P})$ apenas $5,3 \%$. Em relação às demandas consuntivas totais, a representatividade é de $3,9 \%$ e $0,6 \%$, respectivamente. 
Vale lembrar que algumas dessas vazões (notadamente as dos cenários C1) são maiores que as dos sistemas produtores Alto e Baixo Cotia juntos $\left(2,5 \mathrm{~m}^{3} / \mathrm{s}\right)$ e ligeiramente inferiores às do Rio Grande $\left(4,2 \mathrm{~m}^{3} / \mathrm{s}\right)$. Assim, ainda que em termos porcentuais aparentem pouca expressividade, essas vazões são equivalentes a sistemas produtoras de água potável que abastecem cerca de 600 mil (Alto e Baixo Cotia) e 1,2 milhão (Rio Grande) de habitantes.

Os mapas da Figura 61 (C1R) e da Figura $62(\mathrm{C} 2 \mathrm{R})$ ilustram a relação entre todos os usuários-âncora da RMSP e as respectivas ETEs. O mapa com resultados para C1R está disponibilizado em versão online para navegação ${ }^{15}$, versão na qual apresenta as ETEs, usuários, tarifas calculadas e os traçados das adutoras para os 120 usuáriosâncora detectados para o C1R.

${ }^{15}$ Acesso: https://brunofukasawa.wixsite.com/reusormsp/mapas 


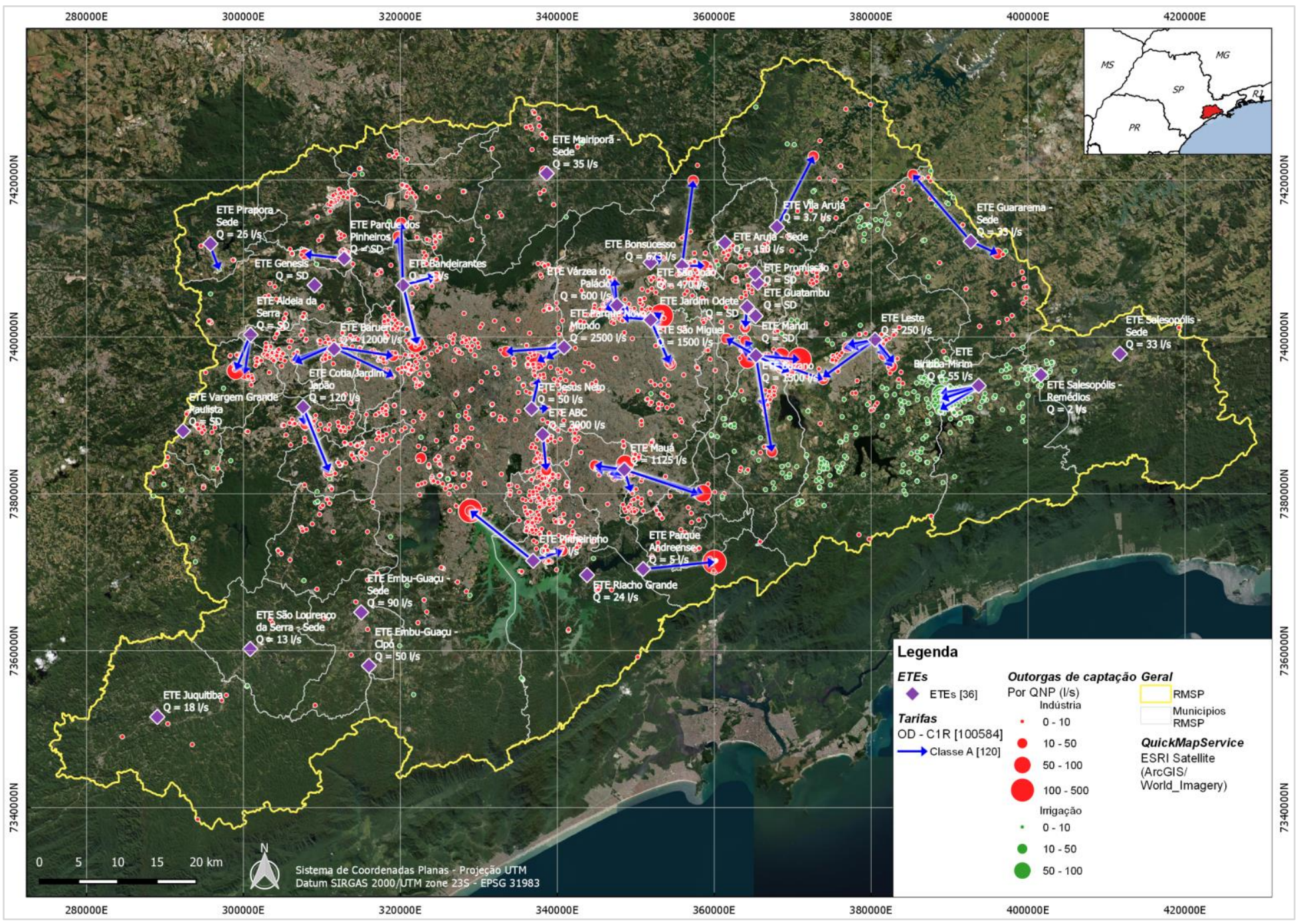

Figura 61: Distribuição dos usuários-âncora em relação às ETEs da RMSP - cenário C1R Fonte: elaborado pelo autor. Nota: o mesmo mapa está disponível par navegação no link: http://reusormsp.orgfree.com/mapa-2/ 


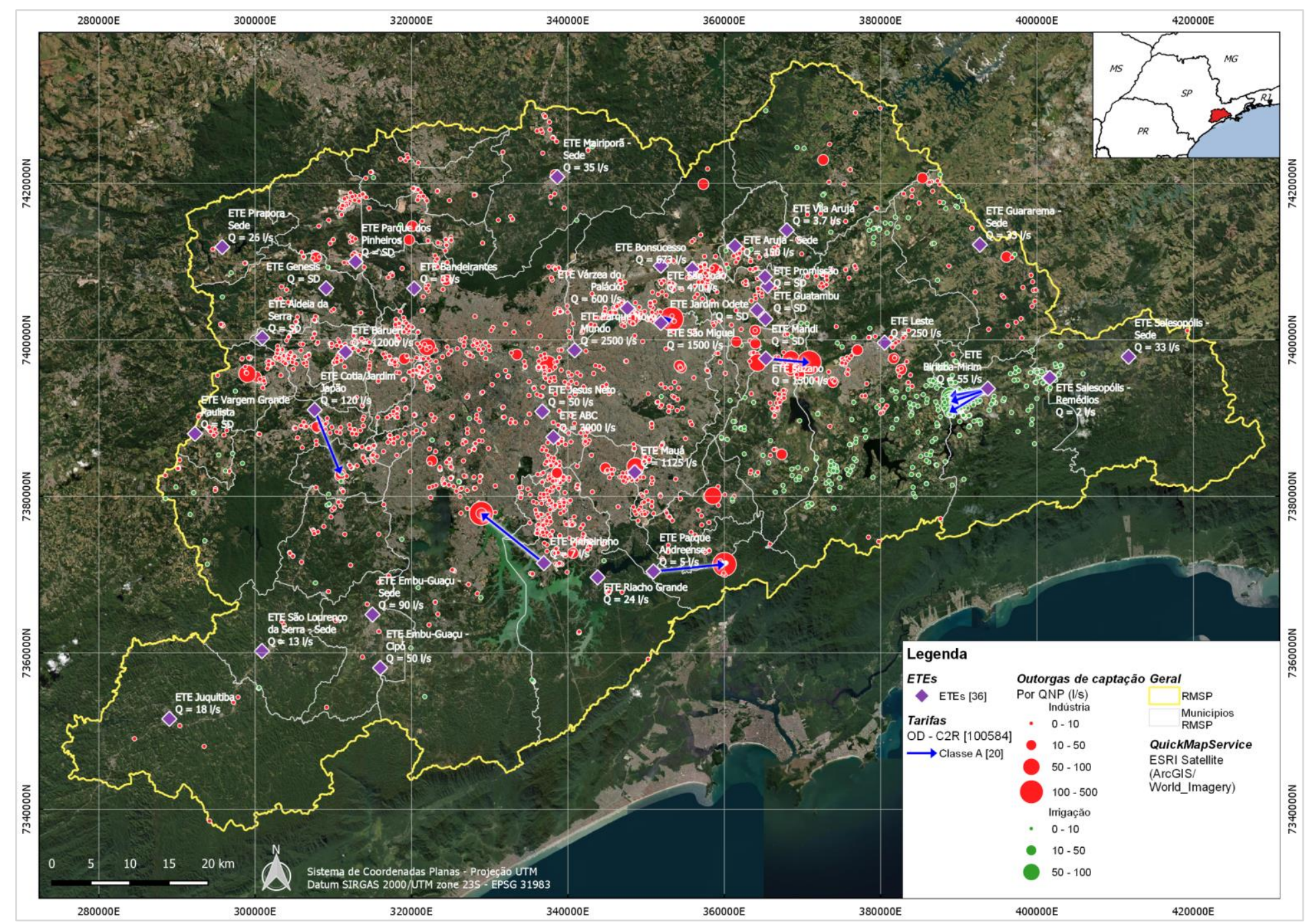

Figura 62: Distribuição dos usuários-âncora em relação às ETEs da RMSP - cenário C2R Fonte: elaborado pelo autor 
Alguns estudos sobre reúso realizados na RMSP levantados no item 3.2.7 também estimaram vazões potenciais de reúso por ETE. A Tabela 75 compara as vazões obtidas pelo Modelo ETE-usuário (cenário C1R) neste trabalho e os apresentados por outros estudos.

Tabela 75: Comparação das vazões potenciais de reúso por ETE para a RMSP deste trabalho e as apresentadas por estudos similares

\begin{tabular}{|c|c|c|c|c|}
\hline ETE & $\begin{array}{c}\text { Modelo ETE- } \\
\text { usuário - C1R (I/s) }\end{array}$ & $\begin{array}{c}\text { Mancuso } \\
(1992)\end{array}$ & $\begin{array}{l}\text { Sabesp } \\
(2010 a)\end{array}$ & CNI (2017b) \\
\hline Suzano & 754,4 & 900 & 1.848 & 2.700 \\
\hline Pinheirinho & 504,1 & - & - & - \\
\hline Mauá & 352,6 & - & - & - \\
\hline São Miguel Paulista & 269,2 & - & 342 & 900 \\
\hline Bandeirantes & 240,4 & - & - & - \\
\hline Biritiba-Mirim & 190 & - & - & - \\
\hline Parque Andreense & 164,9 & - & - & - \\
\hline Parque Novo Mundo & 143,5 & - & 292 & 600 \\
\hline Aldeia da Serra & 94,9 & - & - & - \\
\hline Bonsucesso & 94 & - & - & - \\
\hline Leste & 88,5 & - & - & - \\
\hline Cotia/Jardim Japão & 81,5 & - & - & - \\
\hline Mairiporã - Sede & 49,4 & - & - & - \\
\hline Parque dos Pinheiros & 48,4 & - & - & - \\
\hline Barueri & 43,8 & - & 318 & 400 \\
\hline Vila Arujá & 39,2 & - & - & - \\
\hline Várzea do Palácio & 28,3 & - & - & - \\
\hline Jardim Odete & 25,4 & - & - & - \\
\hline Guararema - Sede & 25,3 & - & - & - \\
\hline$A B C$ & 21,6 & - & 611 & 600 \\
\hline Jesus Neto & 11,8 & - & - & - \\
\hline São João & 5,4 & - & - & - \\
\hline Pirapora - Sede & 4,9 & - & - & - \\
\hline Total & $3.281,4$ & 900 & 3.411 & $4.450^{(a)}$ \\
\hline
\end{tabular}

Nota 1: nesta tabela constam somente ETEs que apresentaram potencial de reúso maior que zero para cenário C1R. Os resultados completos já foram apresentados na Tabela 64.

Nota 2: demais estudos consideram somente demandas industriais.

(a) CNI (2017b) apresenta o somatórios das demandas industriais para cada ETE isoladamente. Para totalização, portanto, é necessário que sejam desconsiderados os usuários "repetidos", o que significa que o total é menor que a soma direta das vazões individuais de cada estação.

Dois pontos são evidentes pela Tabela 75. O primeiro é que, ainda que o valor total obtido pelo modelo ETE-usuário seja relativamente próximo aos de Sabesp (2010a) e CNI (2017b), as vazões por ETE são significativamente menores. O segundo é que no ETE-usuário considerou-se um número muito maior de ETEs, com análises para as 36 ETEs (das 42 identificadas) cujas informações de localização (coordenadas) puderam ser obtidas. 
A principal diferença metodológica que leva às variações observadas é que o modelo ETE-usuário considera os usuários individualmente, realizando correção das vazões (pelo uso do $\mathrm{C}_{\mathrm{NP}}$ ) e classificando um usuário como âncora com base em seu "desempenho" de tarifa, levando em conta custos de tratamento e distribuição. Em comparação, os outros estudos utilizam a vazão outorgada do usuário ${ }^{16}$ diretamente como referência de vazão e não aplicam nenhum critério de restrição de custos, havendo somente, por vezes, indicação das distâncias euclidianas entre ETE e usuário. Ou seja, o modelo ETE-usuário é muito mais restritivo e conservador em seus resultados, o que justifica as menores vazões por ETE.

No entanto, como no ETE-usuário foram utilizados recursos como funções de custos e algoritmos computacionais em ambiente SIG, um número muito maior de possibilidades de relações ( 100.000) foi analisado, levando à produção de resultados para um maior número de ETEs. Além disso, neste trabalho não foram desconsideradas ETEs de baixa vazão, dado que se entende que estas podem ser objeto de expansões futuras que podem prever produção de água de reúso em seus projetos.

De forma mais geral, a Tabela 76 relaciona aspectos metodológicos e resultados da aplicação do modelo ETE-usuário em comparação a outros estudos, alguns dos quais já citados na Tabela 75. Ainda que este trabalho os tenha usado como referência, são destacadas as diferenças metodológicas, as quais invariavelmente conduziram a resultados diferentes.

\footnotetext{
${ }^{16}$ Com exceção de Sabesp (2010a), em que é utilizado fator de correção (equivalente ao $\mathrm{C}_{\mathrm{NP}}$ ) igual a $60 \%$ para todas os usuários indústrias, independentemente de sua atividade.
} 
Tabela 76: Comparação dos resultados da aplicação dos modelo ETE-usuário com outros estudos contemplam a área de estudo (RMSP)

\begin{tabular}{|c|c|c|c|c|c|c|c|c|}
\hline Autor & Abordagem / metodologia & $\begin{array}{l}\text { Quantificação } \\
\text { do potencial } \\
\text { de reúso }\end{array}$ & $\begin{array}{l}\text { Avaliação no } \\
\text { nível do usuário }\end{array}$ & $\begin{array}{c}\text { Estimativa de custos } \\
\text { como critério para } \\
\text { determinação de } \\
\text { viabilidade } \\
\end{array}$ & $\begin{array}{l}\text { Definição de } \\
\text { múltiplos cenários }\end{array}$ & $\begin{array}{l}\text { Detalhamento por } \\
\text { atividade econômica } \\
\text { dos usuários }\end{array}$ & Uso de SIG & $\begin{array}{l}\text { Modalidades e } \\
\text { tipos de reúso } \\
\text { considerados }\end{array}$ \\
\hline Filho (1987) & $\begin{array}{l}\text { Comparação entre demanda industrial } \\
\text { todas e soma da vazão de esgoto } \\
\text { tratado para a RMSP como um todo. } \\
\text { ETEs e usuários não são comparados } \\
\text { individualmente }\end{array}$ & Não & Não & Não & Não & Não & Não & $\begin{array}{l}\text { Não potável direto } \\
\text { e potável indireto }\end{array}$ \\
\hline $\begin{array}{l}\text { Mancuso } \\
\text { (1992) }\end{array}$ & $\begin{array}{l}\text { Similar a Filho (1987), com avaliações } \\
\text { da RMSP como um todo }\end{array}$ & Não & Não & Não & Não & Não & Não & $\begin{array}{l}\text { Não potável direto } \\
\text { e potável indireto }\end{array}$ \\
\hline $\begin{array}{l}\text { Sabesp } \\
\text { (2010a) e } \\
\text { Coroado } \\
\text { Consortium } \\
\text { (2012) }\end{array}$ & $\begin{array}{l}\text { Análise para municípios com } \\
\text { demanda industrial total acima de } 0,1 \\
\mathrm{~m}^{3} / \mathrm{s} \text {. Para cada usuário industrial, } \\
\text { assumiu-se que } 60 \% \text { de suas } \\
\text { demandas (vazão outorgada) podem } \\
\text { ser atendidas por água não potável. }\end{array}$ & $\begin{array}{l}4,27 \mathrm{~m}^{3} / \mathrm{s} \\
\text { (industrial) }\end{array}$ & $\begin{array}{l}\text { Parcial. Considera } \\
\text { amostragem } \\
\text { reduzida de } \\
\text { usuários próximos } \\
\text { a algumas ETEs } \\
\text { específicas }\end{array}$ & $\begin{array}{l}\text { Realiza estimativa geral de } \\
\text { custos, mas não a utiliza } \\
\text { como critério }\end{array}$ & Não & $\begin{array}{l}\text { Faz considerações sobre } \\
\text { o impacto da atividade } \\
\text { econômica para } \\
\text { estimativa de potencial } \\
\text { de reúso, mas utiliza } \\
\text { valor genérico de } 60 \% \\
\text { para todos os casos } \\
\end{array}$ & Não & $\begin{array}{l}\text { Não potável direto } \\
\text { industrial, com } \\
\text { considerações } \\
\text { sobre urbano }\end{array}$ \\
\hline CNI (2017b) & $\begin{array}{l}\text { Consideração de outorgas industriais } \\
\text { de captação localizadas a até } 10 \mathrm{~km} \\
\text { de distância das cinco principais ETEs } \\
\text { da RMSP. Estimativa de custos para } \\
\text { "projeto genérico" }\end{array}$ & $\begin{array}{l}4,45 \mathrm{~m}^{3} / \mathrm{s} \\
\text { (industrial) }\end{array}$ & $\begin{array}{l}\text { Sim, porém } \\
\text { somente para } \\
\text { aqueles } \\
\text { localizados em } \\
\text { raio de } 10 \mathrm{~km} \text { em } \\
\text { torno das cinco } \\
\text { principais ETEs da } \\
\text { RMSP } \\
\end{array}$ & $\begin{array}{l}\text { Realiza estimativa geral de } \\
\text { custos, mas não a utiliza } \\
\text { como critério }\end{array}$ & Não & $\begin{array}{c}\text { Faz considerações sobre } \\
\text { o impacto da atividade } \\
\text { econômica para } \\
\text { estimativa de potencial } \\
\text { de reúso, mas não aplica } \\
\text { nenhum fator de } \\
\text { correção } \\
\end{array}$ & $\begin{array}{l}\text { Parcialmente para } \\
\text { determinação de raios } \\
\text { (buffers) em torno nas } \\
\text { ETEs e exposição de } \\
\text { resultados }\end{array}$ & $\begin{array}{l}\text { Apenas não } \\
\text { potável direto } \\
\text { industrial }\end{array}$ \\
\hline $\begin{array}{l}\text { MCidades } \\
(2017 b \\
2017 c)\end{array}$ & $\begin{array}{l}\text { Modelo considera vazão afluente à } \\
\text { ETEs, necessidade de novas fontes } \\
\text { de abastecimento, manutenção de } \\
\text { vazões mínimas ambientais dos } \\
\text { corpos receptores (lançamento de } \\
\text { esgoto tratado) e existência de fontes } \\
\text { alternativas }\end{array}$ & $\begin{array}{c}2,72 \mathrm{~m}^{3} / \mathrm{s} \\
\text { (total) }\end{array}$ & $\begin{array}{l}\text { Realiza as } \\
\text { análises em nível } \\
\text { municipal a partir } \\
\text { de dados } \\
\text { agregados }\end{array}$ & $\begin{array}{l}\text { Realiza estimativa de } \\
\text { custos somente para cinco } \\
\text { casos específicos no } \\
\text { território nacional }\end{array}$ & $\begin{array}{l}\text { Quatro cenários: A } \\
\text { (otimista e pessimista) } \\
\text { e B (otimista e } \\
\text { pessimista). A e B se } \\
\text { referem à possibilidade } \\
\text { ou não de reúso } \\
\text { potável direto }\end{array}$ & Não & $\begin{array}{l}\text { Parcialmente para } \\
\text { exposição de } \\
\text { resultados }\end{array}$ & $\begin{array}{l}\text { Não potável direto, } \\
\text { potável indireto e } \\
\text { potável direto. } \\
\text { Industrial, } \\
\text { irrigação, urbano, } \\
\text { aquicultura e } \\
\text { abastecimento } \\
\text { humano } \\
\end{array}$ \\
\hline $\begin{array}{l}\text { Este trabalho. } \\
\text { Modelo ETE- } \\
\text { usuário }\end{array}$ & $\begin{array}{l}\text { Avaliação no nível relação ETE } \\
\text { (oferta) e usuário (demanda) } \\
\text { considerando custos de produção e } \\
\text { distribuição de água, atividades } \\
\text { econômicas dos usuários; diferentes } \\
\text { padrões de qualidade e arranjos de } \\
\text { tratamento; cenários de } \\
\text { abastecimento e de custos; e } \\
\text { identificação de usuários-âncora. }\end{array}$ & 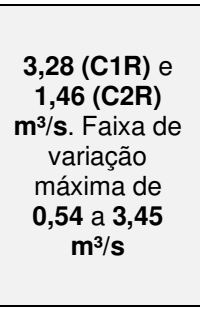 & $\begin{array}{l}\text { Análises para } \\
\text { todos os usuários } \\
\text { (2794) e ETEs (36) } \\
\text { detectados. } \\
\text { Identificação e } \\
\text { caracterização } \\
\text { individual dos } \\
\text { usuários-âncora }\end{array}$ & $\begin{array}{l}\text { Definição de funçães de } \\
\text { custos em função da } \\
\text { vazão para arranjos } \\
\text { distintos de tratamento e } \\
\text { distribuição. Consideração } \\
\text { de custos de distribuição. } \\
\text { Utilização da tarifa } \\
\text { calculada para } \\
\text { determinação de usuários- } \\
\text { âncora }\end{array}$ & $\begin{array}{l}\text { Seis cenários, sendo } 2 \\
\text { de abastecimento e } 3 \\
\text { de custos }\end{array}$ & $\begin{array}{l}\text { Considera as divisões } \\
\text { CNAE } 2.0 \text { atribuídas } \\
\text { individualmente a cada } \\
\text { usuário. Vazões não } \\
\text { potáveis de cada usuário } \\
\text { dependem da atividade } \\
\text { econômica }\end{array}$ & $\begin{array}{l}\text { Extração de dados de } \\
\text { elevação, traçado de } \\
\text { caminhamentos de } \\
\text { adutoras, exposição de } \\
\text { resultados. Elaboração } \\
\text { de webGIS para } \\
\text { compartilhamento de } \\
\text { dados }\end{array}$ & $\begin{array}{l}\text { Não potável direto } \\
\text { para indústria e } \\
\text { irrigação }\end{array}$ \\
\hline
\end{tabular}




\subsection{RECURSOS ONLINE}

Conforme explicado no item 4.4.1.2, foram desenvolvidos dois recursos online adicionais que complementam o conteúdo desta dissertação. São eles:

Repositório com bases de dados. Página web na qual estão indexados os principais arquivos para download, em formato editável. Estão disponíveis as bases de dados de entrada já devidamente organizadas e os resultados da aplicação à RMSP (IPR e ETE-usuário) em forma de planilhas e arquivos espaciais (shp). Acesso: https://brunofukasawa.wixsite.com/reusormsp/downloads.

Mapas interativos. Face à natureza espacial das análises e ao grande número de resultados, principalmente no caso do modelo ETE-usuário, a apresentação em forma de relatório impõe algumas limitações de compreensão. Por isso, foram criados mapas online interativos (webGIS) que permitem navegação de quaisquer que tenham acesso ao link. $\mathrm{O}$ acesso pode ser feito pelo mesmo domínio de acesso ao repositório (https://brunofukasawa.wixsite.com/reusormsp/mapas) ou diretamente pelos links abaixo. Os mapas rodam em versões desktop e mobile (smartphones).

- Mapa 1: IPR por município. Acesso: www.reusormsp.orgfree.com/mapa-1

- Mapa 2: ETE-usuário. Acesso: www.reusormsp.orgfree.com/mapa-2

A Figura 63 ilustra a interface dos mapas. Para obter mais informações sobre as ETEs, outorgas, adutoras, tarifas e demais atributos, basta clicar sobre o elemento para que surja a caixa (pop-up) com informações.
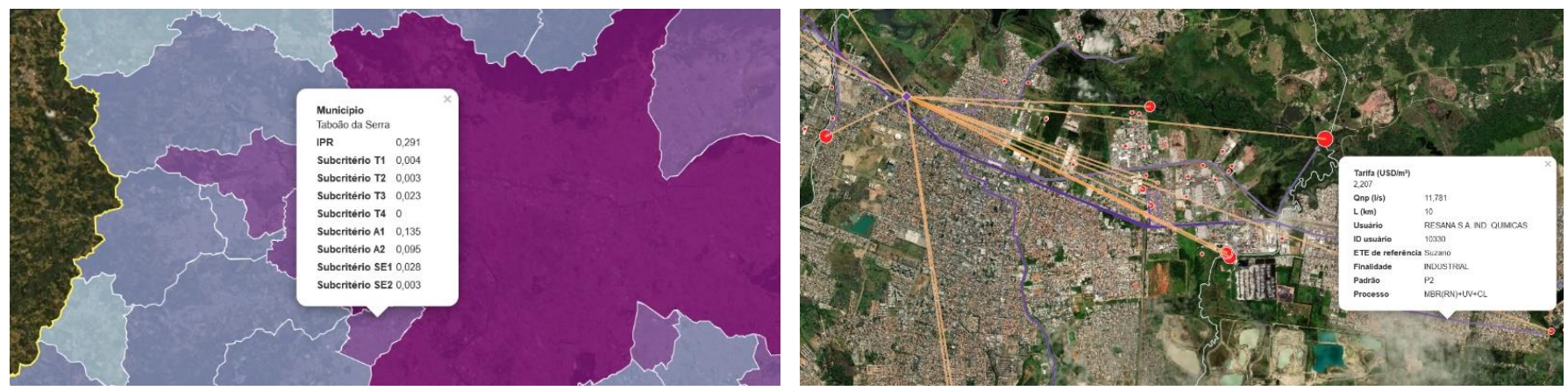

Figura 63: Interface do webGIS: mapas interativos com resultados do IPR (à esq.) e ETEusuário (à dir.) 


\subsection{DISCUSSÃO SOBRE OS MODELOS E POSSIBILIDADES DE APRIMORAMENTO}

\subsubsection{Discussão sobre o IPR}

O IPR, assim como qualquer outro índice, é uma variável resultante da agregação de dados e indicadores. Ao passo que isso é uma vantagem ao facilitar a comunicação junto a públicos menos especializados, também tem como desvantagem a perda de informações das variáveis individuais (GOMES, 2011).

A matriz de prioridades do IPR resultou em favorecimento do critério técnico (e de seus subcritérios, consequentemente), o que é traduzido pelo seu maior peso ( $W_{\text {tec }}=$ 0,571). Na sequência estão o critério ambiental ( $\left.w_{a m b}=0,286\right)$ e socioeconômico ( $w_{\text {se }}$ $=0,143)$, com pesos menores, mas não por isso desprezíveis.

Conforme entendimento deste autor, é evidente que a viabilidade de reúso em determinada área é altamente dependente de atributos como geração de esgotos e demandas não potáveis, os quais participam do modelo na forma dos subcritérios técnicos T1 e T2, respectivamente. Tal importância foi traduzida pelas prioridades a eles atribuídas $\left(\mathrm{w}_{\mathrm{T} 1}=0,244\right.$ e $\left.\mathrm{w}_{\mathrm{T} 2}=0,162\right)$, as maiores entre os subcritérios. No entanto, subcritérios ambientais e socioeconômicos possuem influência notável no modelo, principalmente os ambientais ( $\mathrm{w}_{\mathrm{A} 1}=0,143$ e $\mathrm{w}_{\mathrm{A} 2}=0,143$ ).

Como o IPR é calculado a partir de valores normalizados, seu valor isoladamente não possui significado. Em outras palavras, sua real utilidade reside em classificar entre si as áreas analisadas no que se refere a seu potencial de reúso. Assim, pode-se dizer que o IPR se aproxima mais a uma variável estatística do que uma "medição real" do potencial de reúso, o que está alinhado com o objetivo a que o IPR se propõe a cumprir, que é auxiliar a priorização de áreas que possuem maior potencial de reúso. Disso também resulta o fato de que o IPR é altamente sensível a variações dos dados de entrada, seja por alteração dos parâmetros ou inclusão/exclusão de áreas avaliadas, dado que a normalização leva em consideração toda a série de dados. 
A estrutura do IPR se assemelha às apresentadas por Gdoura et al. (2015), Watson \& Hudson (2015), Teixeira et al. (2018) e Paul et al. (2020), estudos que também utilizam o AHP para lidar com um problema de avaliação/classificação de áreas a partir de análises multicriteriais. Ainda que estes trabalhos possuam áreas de atuação e objetivos diferentes, eles compartilham aspectos metodológicos comuns a problemas multitemáticos de natureza espacial e puderam ser utilizados como referência para o desenvolvimento do IPR.

Dois pontos passíveis de aprimoramento do IPR são destacados pelo autor na sequência.

\section{Redução da subjetividade do criador do modelo.}

A subjetividade é considerada inerente a qualquer processo de atribuição de prioridades, não sendo diferente no caso dos MMAD (MU; PEREYRA-ROJAS, 2017), e, especificamente neste caso, do uso do AHP para desenvolvimento do IPR. É comum que estudos que usam MMAD definam as prioridades dos critérios e subcritérios a partir de consultas a especialistas e partes interessadas (stakeholders). Esse tipo de abordagem reduz a subjetividade do criador do modelo ao absorver opiniões e julgamentos distintos.

O IPR, conforme apresentado no item 5.1.2, teve suas prioridades atribuídas exclusivamente pelo autor, ao que se espera que haja viés indesejado. Portanto, a utilização de métodos para consideração de julgamentos de múltiplos atores é altamente desejada em futuros aprimoramentos do índice, sendo possível uso desde métodos simples como médias geométrica ou aritmética para construção das matrizes de julgamentos ou de metodologias mais sofisticadas como o Delphi.

Vale lembrar que os procedimentos de análise de consistência e a análise de sensibilidade conduzidos tiveram como objetivo lidar com inconsistências internas e excesso de subjetividade por parte do autor.

\section{Flexibilização da aplicação do IPR por meio de uso de SIG.}

Ainda que em sua essência o IPR possa ser aplicado a qualquer tipo de limite geográfico, seu desenvolvimento e aplicação foram realizados tendo-se o município 
como foco. Como já explicado, isso se deve principalmente ao fato de que quase todas as informações são disponibilizadas agregadas por cidade, com raras exceções (como balanço hídrico por ottobacia).

Avaliações mais precisas no nível de microbacias podem levar a resultados mais úteis ao planejamento em reúso. A dificuldade desse procedimento reside na integração entre bases de dados com diferentes recortes geográficos, como, por exemplo, tratamento de esgotos por município e demanda de água por ottobacia. Em ambiente SIG há recursos disponíveis, como "rasterização" de arquivos vetoriais, que reduzem a informação a "porções" menores (pixels) para processamento e geração de resultados, sendo possível agregá-los em seguida conforme necessidade.

Assim, o emprego mais intenso de recursos de SIG poderá conduz a maior flexibilidade na aplicação do IPR, possibilitando novos insights, análises e aprimoramentos do modelo.

\subsubsection{Discussão sobre o modelo ETE-usuário}

O modelo ETE-usuário é uma sistematização objetiva de procedimentos para detecção e caracterização de usuários-âncora de reúso a partir de critério de viabilidade econômica e consequente estimativa de vazões potenciais de reúso. Conforme previsto pelas principais diretrizes de planejamento em reúso (THE EUROPEAN COMMISSION, 2016; U.S. EPA, 2012), a identificação e verificação de viabilidade econômica de usuários prioritários são passos fundamentais.

Uma questão frequentemente levantada em estudos sobre reúso é a de quais são as vazões potenciais de reúso na área analisada. Há diferentes abordagens para tentar responder a essa pergunta, sendo uma bastante recorrente a totalização das demandas não potáveis na área e comparação às vazões de esgoto geradas e/ou tratadas, aplicando-se, em alguns casos, alguns coeficientes de correção. Esse é o caso de estudos como Mancuso (1992), Sabesp (2010a) e CNI (2017b).

Ainda que se entenda que seja esse um bom indicador de potencial de reúso, o modelo ETE-usuário propôs abordagem distinta, utilizando o que foi denominado 
binômio "ETE-usuário" como unidade mínima de análise e estabelecendo critérios de identificação de usuários-âncora por meio de modelagem de custos, composição de tarifa e comparação a custos locais de água.

O modelo avalia de forma mais minuciosa as estimativas de potencial de reúso sem se aprofundar em aspectos específicos de projeto, mantendo-se ainda como uma ferramenta de análise em nível conceitual. Ainda que alguns procedimentos específicos tratem de aspectos razoavelmente detalhados, como traçado de adutoras e estimativa de potência requerida por sistemas elevatórios, o uso de algoritmos computacionais em ambiente SIG e de funções pré-determinadas confere agilidade às análises propostas.

O modelo foi estruturado de maneira a fornecer subsídios à criação de sistemas digitais de suporte à decisão. Exemplos relevantes são o FitWater (CHHIPISHRESTHA et al., 2017b) e o Integrated Urban Reclaimed Water Infraestructure Planning Toolkit - IRIPIT (LEE et al., 2018), ferramentas recentemente desenvolvidas e apresentadas em literatura internacional que, ainda que com objetivos parcialmente diferentes, são fundamentadas em aspectos de engenharia similares aos apresentados neste trabalho e vêm sendo propostas como instrumentos práticos de suporte à decisão em outros países.

O desenvolvimento e aplicação do modelo à RMSP levaram à identificação de diversos aspectos que podem ser aprimorados no modelo, os quais serão discutidos na sequência.

\section{Aprimoramento das estimativas de demanda de água por usuário.}

Este trabalho utilizou outorgas de captação para determinação das demandas de água, ainda que o autor tenha ciência das incertezas provenientes desta escolha. É de conhecimento geral a existência de captações, principalmente subterrâneas, não outorgadas ("clandestinas") ${ }^{17}$, de usuários que exploram mananciais outorgados além

\footnotetext{
${ }^{17}$ Estima-se que o número de captações subterrâneas não outorgadas na RMSP possam chegar a até $70 \%$ do total (BERTOLO et al., 2014; CONICELLI, 2014).
} 
das vazões concedidas (FUKASAWA et al., 2017), e do fato de que poços outorgados não necessariamente estão em exploração (ANA, 2017a).

No entanto, as outorgas são o único tipo de informação que permite a identificação, e mais importante, a espacialização pontual dos usuários de água, o que justifica seu uso no escopo desta pesquisa. Além das vazões em si, o coeficiente de demanda não potável $\left(\mathrm{C}_{\mathrm{NP}}\right)$ utilizado foi baseado em bibliografia internacional, dado que não há estudos nacionais sobre o tema. $\mathrm{O}$ advento de tecnologias como loT (Internet of Things, ou internet das coisas) para telemedição de vazões de usos de água e a consolidação da cobrança de uso de água como instrumento de gestão na bacia hidrográfica podem permitir a construção de bases de dados mais precisas futuramente, aperfeiçoando a qualidade dos dados de entrada.

\section{Consideração de variações de qualidade do esgoto afluente às ETEs e concentração de contaminantes.}

Considerou-se que os esgotos afluentes às ETEs possuem qualidade de esgoto doméstico, mas é sabido que algumas ETEs da RMSP recebem contribuições relevantes de efluentes industriais, o que pode vir a alterar a qualidade do afluente a ponto de demandar processos de tratamento específicos. Além disso o uso de água de reúso por usuários (nesse caso industriais) leva a alterações dos efluentes lançados em rede, ocasionando concentração de componentes recalcitrantes que podem ter implicações negativas nas plantas de tratamento. Futuros detalhamentos podem considerar séries históricas de qualidade dos afluentes às ETEs, levando em conta possíveis peculiaridades que influenciem nos requerimentos de tratamento.

\section{Atualização das funções de custos de tratamento.}

Praticamente não há referências nacionais sobre custos de processos amplamente empregados em produção de água de reúso, como MBR e OR, o que levou à utilização de referências internacionais na modelagem de custos. A escassa bibliografia nacional disponível (DALRI-CECATO et al., 2019) apresenta somente valores unitários, e não funções de custos. O desenvolvimento de futuros estudos no tema no Brasil, o que também depende da própria expansão de plantas que adotem 
tais tecnologias, certamente contribuirá para o aprimoramento das estimativas de custos.

\section{Decomposição de Opextrat para consideração da variabilidade de tarifas de energia elétrica.}

O desenvolvimento das funções de custos de operação de tratamento (Opextrat) baseou-se em referências que apresentavam custos agregados de operação de sistemas, sem discriminação por tipo. Isso levou à impossibilidade de decomposição para consideração individual dos gastos com energia elétrica, o que permitiria que o cálculo desse componente fosse adaptado de acordo com as tarifas de energia elétrica locais. A decomposição de Opextrat em custos de energia elétrica e demais custos (mão-de-obra, químicos, manutenção e reparos, depreciação etc.) é, sem dúvidas, um aprimoramento desejado. Vale lembrar os custos operação de adução (Opexad) consideram essa variabilidade de tarifa de energia elétrica, dado que as funções foram desenvolvidas a partir de estimativas de requerimento de potência de sistemas elevatórios.

\section{Cômputo de demais potenciais usuários.}

A determinação das vazões potenciais foi feita considerando-se somente as vazões dos usuários-âncora, sem cômputo dos demais que poderiam ser abastecidos nas proximidades destes ou das linhas de distribuição. Esse nível de detalhe exige definições mais precisas do traçado de redes, ou seja, avança além do escopo deste trabalho, e pode ser realizado por futuros estudos. Pode-se dizer que, por considerar somente os âncora, a estimativa é relativamente conservadora, já que o valor total tende a ser maior caso sejam incluídos outros usuários.

\section{Agregação de outorgas próximas pertencentes ao mesmo usuário.}

Alguns usuários possuem mais de uma outorga de uso para abastecimento do mesmo ponto do uso ou de unidades muito próximas. A análise deste trabalho considerou as outorgas individualmente, e é uma possibilidade de aprimoramento a agregação de próximas outorgas para um mesmo usuário (p.e. mesmo nome/CNPJ dentro de um raio de até $500 \mathrm{~m}$ ) para contemplar esses casos. 


\section{Consideração da vazão mínima ambiental à jusante das estações de tratamento} de esgotos.

Sabe-se que há casos em que o efluente lançado por ETEs contribui de forma muito relevante para garantia de vazão em períodos de estiagem, mesmo que também resultem na degradação da qualidade do rio. A necessidade de manutenção de vazões ambientais à jusante das ETEs não foi considerada neste trabalho e pode também ser objeto de análise por outros pesquisadores.

\section{Inclusão de outros processos de tratamento.}

Os processos de tratamento contemplados (MBR, MBR(RN), UV, CL e OR) são tecnologicamente viáveis e já consolidados em diversas estações de tratamento ao redor do mundo para produção de água de reúso. No entanto, outros, como MBBR, carvão ativado biologicamente ativado, lodo granular, oxidação química avançada, eletrodiálise e troca iônica, entre outros, também podem ter seus custos estimados, fornecendo aos tomadores de decisão maior flexibilidade na composição de arranjos.

\section{Consideração do processo de tratamento das ETEs.}

Os processos de tratamento atuais das ETEs não foram efetivamente considerados no modelo, assumindo-se a construção de novas estações. No entanto, há casos particulares que podem levar à redução de custos, como o aproveitamento dos decantadores secundários de estações com processo de lodos ativados convencional para instalação de tanques de membranas de UF, realizando-se adaptação de LA para MBR com redução de custos de obras civis.

\section{Otimização dos traçados conceituais de adutoras e de determinação de desníveis geométricos.}

A utilização do sistema viário para traçado de adutoras é uma simplificação que, ainda que mais próxima à realidade que a utilização de distâncias euclidianas, incorre em alguns desvios, como a desconsideração de áreas não carroçáveis e da possibilidade de travessias sobre rios.

De forma similar, o uso do desnível geométrico a partir somente das cotas da ETE e do usuário - isto é, desconsiderando o perfil de elevação do terreno ao longo da 
adutora - também produz desvios, mas a necessidade de capacidade de processamento computacional além da disponível para a realização desse tipo de análise motivou a simplificação adotada. Determinações mais detalhadas do perfil permitem também verificar, a partir do ponto de cota mais alta, os trechos de distribuição que podem ser realizados por escoamento por gravidade.

Dessa forma, a utilização de recursos que possam aprimorar tanto o traçado como a determinação de desnível geométrico e, consequentemente, a estimativa da potência requerida pelos sistemas elevatórios, configuram melhorias importantes.

\section{Consideração da necessidade de gerenciamento de concentrado/rejeito de OR.}

O gerenciamento de rejeito de osmose reversa não foi considerado na determinação de funções de custos. Hoje no Brasil ainda não há limites legais ambientais de SDT para lançamento em copos hídricos ou rede, mas acredita-se que a eventual multiplicação de unidades com OR possa vir a mobilizar a criação de legislações e normas que o façam, principalmente em regiões afastadas da costa onde o lançamento por emissário oceânico não é possível. De maneira a contemplar esse futuro possível cenário, esses custos podem ser incluídos nos arranjos que utilizem OR para separação de íons. 


\section{CONSIDERAÇÕES FINAIS}

Além das discussões sobre os modelos desenvolvidos e os resultados da aplicação à área de estudo (RMSP), emergiram da elaboração deste trabalho outras considerações, de caráter mais amplo, que serão tratadas neste tópico.

i. Reúso não potável como instrumento de diversificação da matriz hídrica, redução de pressão hídrica sobre mananciais, melhoria da qualidade dos corpos hídricos receptores e etapa intermediária para implantação de futuros programas de reúso potável

Ao destinar água de qualidade inferior a usos menos nobres, o reúso não potável permite que água com maior qualidade seja destinada a usos potáveis, reduzindo as vazões retiradas de mananciais. Paralelamente, o crescente comprometimento da qualidade dos corpos hídricos receptores e o esgotamento de sua capacidade de diluição têm levado à necessidade de maiores eficiências de tratamento mesmo para lançamento, havendo atenção inclusive a macronutrientes como nitrogênio e fósforo. Isso aponta para cenário futuro em que as ETEs terão de entregar efluentes com qualidade superior, gerando oportunidade para que, em se havendo articulação entre as devidas áreas, esses efluentes possam ser utilizados para o abastecimento de determinados usuários.

Sistemas biológicos com membranas (MBR) têm sito vastamente utilizados no mundo para tratamento com alta eficiência e/ou produção de água de reúso, possuindo a vantagem de ocuparem menor área em planta quando comparados a lodos ativados (CÔTÉ et al., 2004), um fator decisivo em regiões onde o custo da terra é elevado, como é usual em áreas metropolitanas. A própria multiplicação de estações com processos de membranas pode estimular o mercado interno a nacionalizar a produção de membranas, levando a reduções de custos, maior estabilidade de preços e, consequentemente, maior viabilidade econômica de produção de esgotos tratados com qualidade superior, seja para reúso ou para lançamento.

O Atlas Esgotos (ANA, 2017b) indica que 1.815 municípios brasileiros, os quais correspondem a $46 \%$ da população nacional, necessitam adotar "soluções conjuntas" ou "tratamento secundário avançado" para adequação de qualidade de bacias 
hidrográficas, muitos deles com necessidade também de atenção a macronutrientes ( $\mathrm{N}$ e $\mathrm{P}$ ). Igualmente, 2.454 cidades têm capacidades de diluição de corpos hídricos classificadas como "nula" ou "ruim/péssima". Isso significa que afora medidas articuladas que incluam controle de poluição difusa e preservação de cabeceiras, é necessário que os efluentes lançados sejam tratados com maior eficiência para manutenção mínima de qualidade dos ecossistemas aquáticos e segurança para abastecimento humano. No caso da RMSP, 36 dos 39 municípios têm capacidade de diluição classificada como "péssima/ruim".

Assim, a necessidade de expansão da cobertura de tratamento de esgotos e de produção de efluentes com qualidade superior criará conjunturas mais favoráveis ao reúso, o que deve ser planejado com antecedência para que sejam garantidos atendimentos a critérios técnicos, econômicos e ambientais.

É importante considerar que a experiência mundial indica que o processo de aceitação pública de uso de fontes alternativas pode ser um importante obstáculo à implantação de programas de reúso, mesmo que haja garantias de segurança sanitária e de viabilidade técnico-econômica. Usos não potáveis, nos quais os usuários não têm contato com a água, tendem a ter melhor aceitação pública (GOODWIN et al., 2018; HURLIMANN; DOLNICAR, 2016). Isto indica que a consolidação de programas de reúso não potável para atendimento a demandas específicas pode ser vista como etapa intermediária dentro da diversificação programática de fontes alternativas de abastecimento para áreas urbanas (HURLIMANN, 2008), culminando em maiores probabilidades de êxito de futuras experiências possivelmente mais controversas como o reúso potável direto.

Assim, o planejamento do reúso não se refere somente a aspectos de viabilidade técnico-econômica e ambiental, mas também sociais. Outros fatores que tendem a reduzir a receptividade estão ligados à falta de comunicação entre poder público e a população, pouca informação sobre os reais riscos da prática de reúso (geralmente considerados muito maiores do que os reais) e baixa confiança popular em relação à qualidade dos serviços prestados pelas autoridades e agentes de saneamento (SCHAER-BARBOSA et al., 2014) e pelo serviço público em geral (U.S. EPA, 2012). 
O envolvimento público durante o desenvolvimento de programas de reúso é fundamental para seu sucesso, o que, conforme será discutido mais à frente, recai também no tema de acesso à informação (FIELDING; ROIKO, 2014; GOODWIN et al., 2018).

Os temas de aceitação e envolvimento público, acesso à informação e consideração de critérios que não somente os técnicos no planejamento de reúso, ainda que presentes no levantamento bibliográfico e nas discussões deste trabalho, foram contemplados de maneira limitada pelos modelos propostos. O IPR, apesar de considerar em sua matriz aspectos ambientais e socioeconômicos, prioriza os critérios técnicos como vazões de esgoto bruto e vazões potenciais. O mesmo ocorre, e em maior intensidade, com o Modelo ETE-usuário, em que as análises são baseadas essencialmente em atributos técnico-econômicos.

É evidente que a problemática proposta - de planejamento de reúso - não pode ser encerrada em um único trabalho, havendo necessidade de escolha de um recorte específico de desenvolvimento dentro do tema. O autor compreende as limitações oriundas da especificidade da visão da engenharia ambiental frente à complexidade do assunto das próprias limitações de uma pesquisa de mestrado, não se ausentando, no entanto, de trazer à tona e reforçar a multiplicidade de desafios da área.

\section{ii. Articulação entre áreas considerando o atendimento a demandas não potáveis: potencial de reúso como critério de alocação de ETEs e de potenciais usuários}

Um dos principais fatores que limitam a viabilidade econômica do reúso não potável é a distância excessiva entre o local de produção e os usuários finais, como foi exemplificado no item 5.3.3.3.1. Isso, mais do que mera aleatoriedade, depende de articulação entre áreas que atuam no planejamento territorial e de recursos hídricos e saneamento.

Isso significa que a alocação de novas ETEs pode considerar, entre os demais critérios, a existência de potenciais usuários, existentes ou futuros, de água de reúso nas proximidades, sendo necessária prévia caracterização de suas demandas e exigências de qualidade. A produção e venda de água de reúso a esses usuários 
pode, inclusive, viabilizar economicamente a implantação de novas ETEs. Analogamente, a tomada de decisão sobre ordenamento territorial pode ter em conta as ETEs como potenciais fontes de água de reúso, buscando criar incentivos à instalação de usuários com altas demandas não potáveis em áreas próximas às estações de tratamento.

Conforme visto no item 5.3.3.6, as vazões potenciais não potáveis estimadas para a RMSP são relativamente baixas, mas não desprezíveis. Para o cenário mais otimista, a vazão somada dos usuários-âncora chega a quase $4 \%$ das demandas consuntivas totais. Pode-se compreender esse fato como indicativo de que esse tipo de planejamento articulado não tem sido um critério de desenvolvimento urbano, seja pela falta de ação coordenada entre os atores ou pelo simples desconhecimento das oportunidades existentes.

Ainda que a RMSP venha passando nas últimas décadas por processos de desconcentração industrial (SEADE, 2013), a região ainda detém quase $40 \%$ de todo o PIB industrial do estado de São Paulo (SEADE, 2017a) e prevê-se que receba mais da metade dos investimentos anunciados em indústrias de transformação nos próximos anos, principalmente nos segmentos de produtos alimentícios (Guararema, $\mathrm{R} \$ 500 \mathrm{mi}$ ), produtos farmoquímicos e farmacêuticos (Guarulhos, $R \$ 854 \mathrm{mi}$ ), Metalurgia (Santo André, $\mathrm{R} \$ 500 \mathrm{mi}$ ) e fabricação de produtos automotores (São Caetano do Sul e São Bernardo do Campo, $R \$ 9.312 \mathrm{mi}$ e $R \$ 5,796 \mathrm{mi}$ respectivamente) (SEADE, 2018b). Esses novos investimentos, sejam eles expansões ou novas instalações, irão certamente incrementar a demanda por água, fato que, se avaliado sob a ótica de oportunidades de reúso, pode trazer importantes ganhos à gestão da água na região.

Viu-se que na RMSP determinadas atividades industriais representam a maior parte do potencial de reúso: fabricação de papel e celulose (949 l/s, 29\%), eletricidade e gás $(687 \mathrm{l} / \mathrm{s}, 21 \%)$, produtos químicos (655 l/s, 20\%) e produtos têxteis (251 l/s, 8\%). Compreender quais são as atividades econômicas com maior potencial de reúso abre a possibilidade de articulação não somente junto a usuários individuais, mas também a associações setoriais, federações da indústria e demais stakeholders, buscando 
entender de forma mais ampla quais são as necessidades específicas das empresas associadas, os anseios e inseguranças em relação à utilização de água de reúso e outros pontos que possam vir a contribuir com a concretização de programas de reúso. Sabe-se que diversos usuários potenciais que hoje detêm outorgas próprias de captação temem perdê-las caso migrem para o uso de água de reúso, o que deve também ser considerado nas futuras negociações.

Os modestos índices de cobertura de tratamento de esgotos (43\% no Brasil e entre 45 e 51\% na RMSP) requererão a construção de novas estações ou expansão das já existentes caso se deseje cumprir as metas do ODS6 da ONU. Ou seja, prevê-se aumento tanto da oferta de esgotos como das próprias demandas (nesse caso industriais), e a falta de atenção ao potencial de abastecimento desses usuários por água de reúso pode levar à perda de oportunidades importantes.

Mesmo que não contemplados por este trabalho, vale menção a outros tipos de potenciais usuários, principalmente comerciais de grande porte. Muitos empreendimentos, influenciados por anseios de "sustentabilidade", por obtenção de certificações ambientais como Leed e AQUA ou necessidade de cumprimento de diretrizes de compliance ambiental (CDP-Water, Dow Jones Sustainability Index World etc.) estão adotando soluções próprias de fontes alternativas não potáveis, principalmente reúso. Como brevemente apresentado no item 3.2.3.3, empresas especializadas têm suprido essa demanda por meio de arranjos contratuais do tipo privado-privado com produção in situ de água de reúso. Isso ocorre à margem da atuação de planejadores e gestores públicos, não havendo adequado controle sobre como essas iniciativas, se escaladas, impactam a gestão de água na bacia hidrográfica.

O atendimento a usuários de menor porte pode ser viabilizado a partir da compreensão das potencialidades de centralização versus descentralização na produção e distribuição de água de reúso, conforme será discutido a seguir. 


\section{iii. Centralização versus descentralização para a produção e distribuição de água de reúso}

O reúso em geral tem sido abordado partindo-se do pressuposto de que o maior potencial de reúso reside em grandes empreendimentos, o que, de acordo com este trabalho é também verdadeiro. No entanto, demonstrou-se que importante parcela do potencial de reúso da RMSP está em ETEs de baixa capacidade, muitas delas localizadas em municípios com índices de tratamento de esgotos reduzidos (até 30\%) e onde haverá necessidade de expansões ou implantação de novas estações.

Ao passo que sistemas de tratamento centralizados e de grande porte conduzem a comprovados ganhos de escala no tratamento (GUO et al., 2014; JUNG et al., 2018), estes também requerem maiores investimentos na distribuição da água aos usuários (SGROI et al., 2018) e na própria rede de coleta de esgotos brutos. De outra forma, sistemas descentralizados resultam em economias em obras lineares, mas os custos com os sistemas de tratamento podem aumentar em razão da perda dos ganhos de escala (JUNG et al., 2018). Essa questão é especialmente relevante no caso do reúso não potável direto, uma vez que a prática exige a construção e manutenção de sistemas de distribuição separados da rede potável (WILCOX et al., 2016).

Dessa maneira, não se deve pensar somente no aproveitamento de efluentes oriundos de grandes estações já em operação, e sim em formas de compatibilizar os ganhos de escala e os custos de distribuição a partir de múltiplas avaliações, considerando-se, obviamente, também os custos referentes à coleta de esgotos brutos. A identificação de usuários-âncora a partir de critério econômico pode contribuir com esse tipo de discussão nas etapas de planejamento, indicando arranjos que melhor se adequem às diferentes situações.

A questão dos custos de distribuição vem, inclusive, fortalecendo a visão do reúso potável direto como solução viável, principalmente em razão do aprimoramento e barateamento de tecnologias e equipamentos de tratamento, da possibilidade de utilização da rede potável já existente para distribuição e de restrições em meios urbanos à realização de obras lineares como redes duplas (HESPANHOL, 2015; TCHOBANOGLOUS et al., 2011; WILCOX et al., 2016). E, como recém discutido, o 
reúso não potável pode figurar como elemento de "transição" entre o paradigma atual de dependência completa de mananciais para abastecimento de todas as demandas de água para o de aproveitamento de matrizes diversificadas de oferta de água.

Vale nota que o Aquapolo, a única experiência relevante de reúso não potável do Brasil, opera com uma linha de distribuição de adutora de, aproximadamente, $18 \mathrm{~km}$ para abastecer o Polo Petroquímico de Capuava, o que invariavelmente implica em custos de capital e operação com adução elevados. Ainda que isso não diminua a importância do projeto, é inevitável se questionar se a solução adotada foi a mais adequada quando se considera que os custos operação de adução serão permanentes. É claro que além dos critérios aqui discutidos há outros fatores que influenciam a tomada de decisão. A ETE Mauá, localizada praticamente dentro do polo e candidata mais óbvia a fornecer esgotos tratados, não era operada por nenhuma das empresas do consórcio à época, fato que foge ao escopo de engenharia e pode ter sido mais importante para a escolha da ETE ABC como fonte de esgotos secundários.

\section{iv. Qualidade e acessibilidade das bases de dados sobre recursos hídricos e saneamento}

É inevitável trazer à tona a problematização referente à acessibilidade e à qualidade de bases de dados de recursos hídricos e saneamento, uma vez que foram encontrados significativos obstáculos nas etapas de obtenção, pré-processamento, ajuste e utilização de dados para aplicação dos modelos à área de estudo (vide itens 5.3.2.1 e 5.3.3.1). Esse tema vem sendo considerado uma das prioridades na gestão de água no mundo, estando também na esteira de discussões mais amplas sobre direito à informação em diversas áreas do conhecimento (FGV, 2018; HLPW, 2016, 2017; UNESCO, 2018; WWAP, 2017).

Em escalas mais abrangentes (IPR) ou detalhadas (ETE-usuário), o uso de dados requereu solicitações formais, pedidos via Serviço de Informações ao Cidadão (SIC.SP) e contato direto com órgãos para solicitação de bases de dados que em tese seriam públicas e prontamente disponíveis. Além das dificuldades de obtenção, a falta de clareza, inconsistência e a dificuldade em se lidar com dados diferentes tratando 
do mesmo tema também foram fatores complicadores. Isso ocorreu tanto para informações consideradas "básicas", como demandas e geração de esgotos por município, como também para as mais "detalhadas", como coordenadas de outorgas de captação e das ETEs.

Isso suscita alguns questionamentos. Qual é o nível de acessibilidade e qualidade de dados no Brasil no que se refere a recursos hídricos e saneamento? Quão confiável é planejar e tomar decisão com base nas informações disponíveis? O quanto isso compromete ou retarda a realização de pesquisas e ações práticas no tema?

A criação de recursos online para compartilhamento de dados (ver itens 4.4.1.2 e 5.4) foi motivada justamente pela supracitada dificuldade, esperando-se que esta seja também uma contribuição deste trabalho.

O acesso à informação é, além de um direito do cidadão e essencial para o fomento de pesquisas, um instrumento de gestão compartilhada e de controle social sobre a administração pública. Como já discutido, a construção de confiança entre o público geral e os agentes executores de programas de reúso passa pelo tema do acesso à informação. No entanto, o arcabouço legal sobre o compartilhamento de dados é ainda recente no Brasil (a lei de acesso à informação, n¹2.257/11, é de 2011), o que, de alguma forma, pode explicar a incipiência do tema no País. 


\section{CONCLUSÕES}

A inegável necessidade de diversificação de fontes de água em um cenário de escassez hídrica exige ações coordenadas de planejamento envolvendo não somente as áreas diretamente relacionadas a gestão do uso da água, mas também as de saneamento básico, planejamento urbano, desenvolvimento econômico e meio ambiente.

O reúso se posiciona em uma zona peculiar entre as áreas de tratamento de esgotos e de abastecimento de água, lidando necessariamente e conjuntamente com os conceitos de geração de esgotos, processos de tratamento de efluentes e oferta/demanda de água. Isso Ihe atribui um tipo de complexidade que é ainda amplificada em sistemas complexos como regiões urbanizadas, onde há altas vazões de esgotos produzidos, problemas com manutenção de qualidade dos corpos hídricos, potenciais usuários dispersos pelo território, interferências e sistemas viários complexos.

Frente a isso, este trabalho propôs o desenvolvimento e a aplicação de elementos de planejamento de reúso não potável em áreas urbanas. A ideia central foi o de auxiliar na obtenção de respostas para algumas perguntas como: dada a importância do reúso na gestão de recursos hídricos e de saneamento básico, que elementos podem ser utilizados para seu planejamento em municípios brasileiros?

O desenvolvimento do trabalho foi dividido em duas principais abordagens: o Índice de Potencial de Reúso (IPR) e o Modelo ETE-usuário. Ambos têm naturezas distintas, justamente porque servem a diferentes finalidades e visam fornecer aos tomadores de decisão subsídios para a determinação de alocação de investimentos e realização de estudos mais detalhados sobre reúso não potável, com potencial de escalabilidade e reprodutibilidade para quaisquer regiões do Brasil. Por isso, para ambos se prezou pela utilização de dados que, com poucas exceções, compreendem todo o território nacional.

O IPR é um índice multicritério quantitativo que classifica áreas em relação a seu potencial de reúso. O IPR foi construído a partir do uso de um Método Multicritério de 
Apoio à Decisão (MMAD), o Analytic Hierarchy Process (AHP), para determinação de prioridades entre os 8 subcritérios definidos, sendo 4 técnicos, 2 ambientais e 2 socioeconômicos. De forma a se atenuar os desvios causados por distorções oriundas das atribuições subjetivas de importância, foram adotados procedimentos como a análise de consistência e a análise de sensibilidade. O modelo do IPR também prevê a classificação dos resultados em cinco grupos a partir de métodos estatísticos préestabelecidos, facilitando a compreensão dos resultados por públicos não técnicos.

Por ser multicritério, o IPR contempla variáveis de distintas naturezas, buscando avaliar o potencial de reúso de áreas não somente a partir de variáveis usualmente consideradas, como vazões de esgoto gerado e demandas não potáveis, mas também indicadores ambientais (estresse hídrico e capacidade de diluição de corpos hídricos) e socioeconômicos (valor adicionado pela indústria e irrigação e taxa geométrica de crescimento demográfico).

Entende-se que o IPR pode ser utilizado como instrumento para avaliações abrangentes em nível nacional/regional para direcionamento de alocação de investimentos em estudos mais específicos sobre potencial de reúso. Dos 5.568 municípios brasileiros, alguns certamente apresentam condições mais favoráveis ao reúso que outros, e a utilização de algum critério para a seleção dos prioritários é vista como positiva. A ideia central é que o IPR tenha simples aplicação e compreensão (especialmente por não técnicos), abranja aspectos além de vazões de esgoto e demandas não potáveis (ainda que estas permaneçam sendo os com maiores pesos no modelo) e tenha potencial de replicação. Os aprimoramentos discutidos no item 5.5.1 são desejáveis para que, a partir do modelo inicial, o IPR possa ser melhorado.

De outra forma, o Modelo ETE-usuário se foca na estimativa de vazões potenciais de reúso a partir de análises mais detalhadas. Sua operação é orientada por análises no nível denominado "ETE-usuário", buscando a identificação de usuários-âncora por meio de critério de viabilidade econômica. Usuários-âncora são aqueles que oferecem condições para a produção e distribuição de água de reúso com tarifas que, em comparação aos custos locais de água potável, se mostram viáveis. 
O modelo considera as Estações de Tratamento de Esgotos (ETEs) como potenciais ofertas de água de reúso e as outorgas de uso de captação como referência de localização e demandas dos usuários. Também são contempladas variáveis de terreno e de custos locais de água potável e de energia elétrica. Análises de engenharia preveem caracterização dos usuários, determinação de suas demandas não potáveis, padrões de água de reúso compatíveis com sua atividade econômica, arranjos de tratamento, e características da distribuição, como comprimento da adutora e potência requerida pelo sistema elevatório. A modelagem de custos, realizada pelo uso de funções de custos de capital (Capex) e de operação (Opex) de produção e distribuição de água de reúso, fornece subsídios para a estimativa de tarifa mínima. A tarifa mínima é então comparada aos custos locais de água potável, levando à identificação de usuários-âncora a partir de regra de classificação préestabelecida. Diferentes cenários de abastecimento de custos também compõem o modelo, tendo como objetivo verificar o impacto da alteração de variáveis de projeto e econômico-financeiras nas tarifas e na estimativa de potencial de reúso.

As possibilidades de aprimoramento do modelo ETE-usuário elencadas no item 5.5 .2 são, assim como no caso do IPR, igualmente desejáveis, e espera-se que sejam contempladas por futuros estudos.

Ambos os modelos foram aplicados a uma área de estudo escolhida, a Região Metropolitana de São Paulo (RMSP). A aplicação, além de ter como objetivo exemplificar a utilização dos modelos e verificar seu desempenho, também gerou resultados que podem ser utilizados no planejamento de reúso na área. $A$ classificação dos 39 municípios da RMSP de acordo com o IPR e a identificação e caracterização dos usuários-âncora e estimativas de tarifa e de vazões potenciais de reúso do Modelo ETE-usuário podem, então, ser consideradas também produtos positivos deste trabalho.

O desenvolvimento e a apresentação dos modelos foram orientados pela possibilidade de automação de seus procedimentos, ensejando a criação de sistemas ou plataformas digitais de suporte à decisão no tema de reúso. A indissociável natureza espacial do assunto reforça a importância do uso de Sistema de Informações 
Geográficas (SIG), abordagem extensivamente explorada nesta pesquisa. Por isso, os recursos adicionais criados, principalmente os mapas interativos online ${ }^{18}$, tiveram como motivação não só a facilitação do acesso às bases de dados e resultados deste trabalho, em observância aos princípios FAIR, como também a demonstração da potencialidade de utilização de sistemas digitais em ambiente SIG no planejamento de reúso.

Conclui-se, então, que os objetivos deste trabalho foram cumpridos a partir do que foi apresentado. Como considerações finais, tem-se:

- Foram desenvolvidos e aplicados elementos de suporte à decisão de reúso, sendo um deles com visão mais generalista (IPR) e o outro com abordagem mais detalhada (Modelo ETE-usuário). Como ferramentas de planejamento, ambos fornecem elementos práticos para planejamento de reúso e podem ser integrados a sistemas de suporte à decisão.

- O planejamento de reúso é complexo e deve ser feito a partir de abordagens multissetoriais que envolvam a articulação de múltiplas áreas, posicionando o reúso como um elemento de planejamento urbano.

- Potencial de reúso pode ser considerado como critério para alocação de novas ETEs e novos usuários relevantes, aliando as vantagens de redução de pressão sobre mananciais, melhoria da qualidade de corpos hídricos e redução de custos dos distribuição de água.

- São necessários avanços substanciais na gestão de dados e políticas de acesso à informação nas áreas de recursos hídricos e saneamento, o que estimula melhores ações de planejamento, pesquisa e de aceitação pública de iniciativas de uso de fontes alternativas.

\footnotetext{
${ }^{18}$ Acesso em: https://brunofukasawa.wixsite.com/reusormsp/mapas
} 


\section{REFERÊNCIAS BIBLIOGRÁFICAS E FONTES DE DADOS}

ABNT - ASSOCIAÇÃO BRASILEIRA DE NORMAS TÉCNICAS. NBR 13969: Tanques sépticos - Unidades de tratamento complementar e disposição final dos efluentes líquidos - Projeto, construção e operação. Rio de Janeiro: ABNT, 1997.

ABNT - ASSOCIAÇÃO BRASILEIRA DE NORMAS TÉCNICAS. ABNT NBR 16.783 Uso de fontes alternativas de água não potável em edificações. Rio de Janeiro: ABNT, 2019.

ADHAM, S.; DECAROLIS, J. F. Optimization of Various MBR Systems for Water Reclamation: Phase III. p. 71, 2004.

ALAMI MERROUNI, A. et al. A GIS-AHP combination for the sites assessment of large-scale CSP plants with dry and wet cooling systems. Case study: Eastern Morocco. Solar Energy, v. 166, n. September 2017, p. 2-12, 2018.

ALCALDE-SANZ, L.; GAWLIK, B. Minimum quality requirements for water reuse in agricultural irrigation and aquifer recharge: towards a legal instrument on water reuse. Luxemburgo: Publications Office of the European Union, 2017. Disponível em: <https://ec.europa.eu/jrc/en/publication/eur-scientific-and-technicalresearch-reports/minimum-quality-requirements-water-reuse-agricultural-irrigationand-aquifer-recharges.

ALVES, S. A. F. DA S.; RUFINO, I. A. A.; RÊGO, J. C. Gerenciamento da água superficial no perímetro irrigado de Sumé-PB usando GIS-MCDA. IRRIGA, v. 22, n. 3, p. 606-628, 2017.

ANA - AGÊNCIA NACIONAL DE ÁGUAS. Conjuntura dos recursos hídricos no Brasil 2009. Brasília: Agência Nacional de Águas, 2009.

Conjuntura dos recursos hídricos no Brasil: informe 2012. Brasília: Agência Nacional de Águas, 2012.

. Conjuntura dos recursos hídricos no Brasil: informe 2015. Brasília: Agência Nacional de Águas, 2015.

Usuários cadastrados no REGLA (Sistema Federal de Regulação de Uso) até junho de 2016 [shapefile]. [s.I.] Arquivo shp fornecido pela equipe de metadados da ANA para elaboração da pesquisa, 2016a. 
. Vazão de retirada para irrigação $(\mathrm{m} 3 / \mathrm{s})$ [shapefile]. Disponível em: <http://metadados.ana.gov.br/geonetwork/srv/en/resources.get?id=312\&fname=SNI $\mathrm{RH} \_D e m a n d a l r r i g a c a o . z i p \& a c c e s s=$ private $>$. Acesso em: 26 jun. 2016b.

. Conjuntura dos recursos hídricos no Brasil 2017: relatório pleno. Brasília: ANA, 2017a. Disponível em: <http://conjuntura.ana.gov.br/>.

Atlas esgotos: despoluição de bacias hidrográficas. Brasília: ANA, 2017b. Disponível em: <http://atlasesgotos.ana.gov.br/>.

Água na indústria: usos e coeficientes técnicos. Brasília: ANA, 2017c. Disponível em: <http://www3.ana.gov.br/portal/ANA/noticias/estudo-da-agencianacional-de-aguas-aborda-uso-da-agua-no-setor-industrial/agua-na-industria-uso-ecoeficientes-tecnicos-versao-final.pdf/view>.

. Demanda Hídrica da Indústria de Transformação em 2015 - Resultados por UF, Município e tipologia industrial - Planilha. Disponível em: $<$ http://metadados.ana.gov.br/geonetwork/srv/en/resources.get?id=460\&fname=_AN A_Demandalndustrial2015_Resumo_dos_Resultados.xlsx\&access=private $>$. Acesso em: 15 abr. 2017d.

Atlas Irrigação: uso da água na agricultura irrigada. Brasília: ANA, 2017e.

ATLAS Esgotos - Estações de Tratamento de Esgoto (2013) - Planilha.

Disponível em:

<http://metadados.ana.gov.br/geonetwork/srv/en/resources.get?id=471\&fname=ATL AS_Esgotos_Tabela_ETEs_2013.xlsx\&access=private>. Acesso em: 15 abr. 2018f.

.ATLAS_Esgotos_Tabela_Completa_por_Municipio. Disponível em: $<$ http://metadados.ana.gov.br/geonetwork/srv/en/resources.get?id=471\&fname=ATL AS_Esgotos_Tabela_Completa_por_Municipio.xlsx\&access=private>. Acesso em: 15 abr. 2018g.

. Capacidade de diluição dos esgotos por município (SHP) [shapefile].

Disponível em:

<http://metadados.ana.gov.br/geonetwork/srv/en/resources.get?id=471\&fname=Cap acidade_de_Diluicao_dos_Esgotos_por_Municipio.zip\&access=private>. Acesso em: 25 jul. $2018 \mathrm{~h}$.

Conjuntura dos recursos hídricos no Brasil 2018: informe anual. Brasília: Agência Nacional de Águas, 2018a. Disponível em: $<$ http://arquivos.ana.gov.br/portal/publicacao/Conjuntura2018.pdf>. 
. Planilha de outorgas. Disponível em:

<http://www3.ana.gov.br/portal/ANA/gestao-da-agua/outorga-e-

fiscalizacao/principais-servicos/outorgas-emitidas>. Acesso em: 26 jul. 2018b.

. Conjuntura dos recursos hídricos no Brasil 2019: informe anual. Brasília:

Agência Nacional de Águas, 2019.

ANANE, M. et al. Ranking suitable sites for irrigation with reclaimed water in the Nabeul-Hammamet region (Tunisia) using GIS and AHP-multicriteria decision analysis. Resources, Conservation and Recycling, v. 65, p. 36-46, 2012.

AYDI, A. Evaluation of groundwater vulnerability to pollution using a GIS-based multicriteria decision analysis. Groundwater for Sustainable Development, v. 7, n. May, p. 204-211, 2018.

AZEVEDO NETTO, J. M. DE; FERNANDEZ, M. F. Y. Manual de hidráulica. São Paulo: Edgard Blucher, 1998.

BELO HORIZONTE. Lei n 10.840, de 28 de agosto de 2015. Belo Horizonte: Câmara Municipal de Belo Horizonte, 2015.

BERTOLO, A. R.; HIRATA, R.; CONICELLI, B. Situação das Reservas e Utilização das Águas Subterrâneas na Região Metropolitana de São Paulo. São Paulo: Centro de Pesquisas de Águas Subterrâneas Instituto de Geociências - USP, 2014.

BRASIL. Lei Complementar n¹4, de 8 de junho de 1973. Disponível em: <http://www.planalto.gov.br/ccivil_03/leis/lcp/Lcp14.htm>.

BRASIL. Resolução No 54, 28 de novembro de 2005. Disponível em: <http://www.mma.gov.br/port/conama/processos/838F10BD/Resol5408_ReusoDiretoAgua1.pdf>.

BRITES, A. P. Z. Enquadramento dos corpos de água através de metas progressivas: probabilidade de ocorrência e custos de despoluição hídrica. São Paulo: Tese (Doutorado) - Escola Politécnica da Universidade de São Paulo para obtenção do título de Doutor em Engenharia, 2010.

CAIXETA, C. E. T. Avaliação do atual potencial de reúso de água no estado do Ceará e propostas para um sistema de gestão. Fortaleza: Tese (Doutorado) Universidade Federal do Ceará. Departamento de Engenharia Hidráulica e Ambiental, 2010.

CAMPINAS. Resolução conjunta SVDS/SMS no 09/2014. v. 2014, p. 1-7, 2014. 
CAMPOLINA, A. G. et al. Análise de decisão multicritério para alocação de recursos e avaliação de tecnologias em saúde: tão longe e tão perto? Cadernos de Saúde Pública, v. 33, n. 10, p. 1-15, 2017.

CAÑEQUE, F. C.; SMITH, D.; JOCHAUD, P. D4.1 - Market analysis of key water reuse technologies. [s.I.] DEMOWARE, 2015.

CAO, F.; GE, Y.; WANG, J. Spatial data discretization methods for geocomputation. International Journal of Applied Earth Observation and Geoinformation, v. 26, n. 1, p. 432-440, 2014.

CBH-PS - COMITÊ DAS BACIAS HIDROGRÁFICAS DO RIO PARAÍBA DO SUL. UGRHI-02: Relatório de situação 2016 - Ano base 2015. [s.l: s.n.].

CBIC - CÂMARA BRASILEIRA DA INDÚSTRIA DA CONSTRUÇÃO CIVIL. Guia orientativo das normas de conservação de água, fontes alternativas não potáveis e aproveitamento de água de chuva em edificações. Brasília: Câmara Brasileira da Indústria da Construção Civil, 2019.

CEARÁ. Resolução COEMA n02, de 02 de fevereiro de 2017. p. 56-61, 2017.

CEIVAP - Comitê de Integração da Bacia Hidrográfica do Rio Paraíba do Sul. Plano integrado de recursos hídricos da bacia hidrográfica do Rio Paraíba do Sul e planos de ação de recursos hídricos das bacias afluentes: relatório de diagnóstico RP-06, tomo III. São Paulo: CEIVAP, 2014. Disponível em: <http://ceivap.org.br/conteudo/relatorio-diagnostico-rp6-tomo3.pdf>.

CEM - CENTRO DE ESTUDOS DA METRÓPOLE. Base Cartográfica Digital Georreferenciada de Logradouros da Região Metropolitana de São Paulo - Edição 2018. Disponível em: <http://centrodametropole.fflch.usp.br/pt-br/download-dedados?\%5B0\%5D=facets_temas\%3Asistema viario>. Acesso em: 20 fev. 2019.

CETESB - COMPANHIA AMBIENTAL DO ESTADO DE SÃO PAULO. Qualidade das águas interiores no estado de São Paulo 2017 - Apêndice D - Qualidade das águas interiores no Estado de São Paulo. São Paulo: CETESB, 2018a.

. Qualidade das águas interiores no estado de São Paulo 2017 - Apêndice C - Dados do saneamento básico dos municípios paulistas. São Paulo: Cetesb, 2018b.

Qualidade das águas interiores no estado de São Paulo 2017. São Paulo: CETESB, 2018c. 
CFQ - CONSELHO FEDERAL DE QUÍMICA. Resolução normativa no 105, de 17.09.1987. Disponível em: <http://www.cfq.org.br/rn/RN105.htm>. Acesso em: 26 jul. 2018.

CHHIPI-SHRESTHA, G.; HEWAGE, K.; SADIQ, R. Fit-for-purpose wastewater treatment: Conceptualization to development of decision support tool (I). Science of the Total Environment, v. 607-608, p. 600-612, 2017a.

CHHIPI-SHRESTHA, G.; HEWAGE, K.; SADIQ, R. Fit-for-purpose wastewater treatment: Testing to implementation of decision support tool (II). Science of the Total Environment, v. 607-608, p. 403-412, 2017b.

CNI - CONFEDERAÇÃO NACIONAL DA INDÚSTRIA. O uso racional da água no setor industrial. Brasília: CNI, 2017a.

Reúso de efluentes: metodologia para análise do potencial do uso de efluentes tratados para abastecimento industrial. Brasília: CNI, 2017b.

. Reúso de efluentes para abastecimento industrial: avaliação da oferta e da demanda no estado do Rio de Janeiro. Brasília: CNI, 2019a.

. Reúso de efluentes para abastecimento industrial: avaliação da oferta e da demanda no estado de Pernambuco. Brasília: Confederação Nacional da Indústria, 2019b.

Reúso de efluentes para abastecimento industrial: avaliação da oferta e da demanda no estado do Ceará. Brasília: Confederação Nacional da Indústria, 2019c.

. Reúso de efluentes para abastecimento industrial: avaliação da oferta e da demanda no estado do Espírito Santo. Brasília: CNI, 2019d.

. Reúso de efluentes para abastecimento industrial: avaliação da oferta e da demanda no estado do Rio Grande do Norte. Brasília: Confederação Nacional da Indústria, 2019e.

CONICELLI, B. P. Gestão das Águas Subterrâneas na Bacia Hidrográfica do Alto Tietê (SP). São Paulo: Tese (Doutorado) - Universidade de São Paulo. Programa de Pós-Graduação em Recursos Minerais e Hidrogeologia, 2014.

COPAM - COMISSÃO DE POLÍTICA AMBIENTAL. Deliberação Normativa COPAM no 06, de 29 de setembro de 1981. Disponível em: <http://www.siam.mg.gov.br/sla/download.pdf?idNorma=8635>. Acesso em: 26 jul. 2018. 
COROADO CONSORTIUM. Technologies for water recycling and reuse in Latin American context: assessment, decision tools and implementable strategies under an uncertain future. D.2.1. Report on the context of the areas, workshop structure, and development. São Paulo: Coroado Consortium, 2012.

CÔTÉ, P.; MASINI, M.; MOURATO, D. Comparison of membrane options for water reuse and reclamation. Desalination, v. 167, n. 1-3, p. 1-11, 2004.

DA LUZ, L. D.; NEVES, L. A. D. S. Análise de alternativas para sistema adutor de água em região da Bacia do Rio Itapicuru - Bahia, por meio de programação matemática. Revista Eletrônica de Gestão e Tecnologias Ambientais, v. 2, n. 1, p. 69, 2014.

DAEE - DEPARTAMENTO DE ÁGUAS E ENERGIA ELÉTRICA DO ESTADO DE SÃO PAULO. Plano Diretor de Aproveitamento de Recursos Hídricos para a Macrometrópole Paulista, no Estado de São Paulo: Relatório Final - volume I. São Paulo: DAEE, 2013.

. Banco de dados de outorgas de uso de água. São Paulo: Cedido pela Diretoria de Procedimento de Outorgas no escopo da elaboração deste trabalho., 2018a.

. PastaTabelasFCHE (planilha). Sâo Paulo: Cedido pela Diretoria de

Procedimento de Outorgas no escopo da elaboração deste trabalho., 2018b.

. Relatórios de usos de recursos hídricos, cadastrados ou outorgados no DAEE. Disponível em: <http://www.aplicacoes.daee.sp.gov.br/usosrec/fchweb.html>. Acesso em: 15 jan. $2018 \mathrm{c}$.

DALRI-CECATO, L. et al. Estimativa dos custos de operação de um biorreator a membrana. Revista DAE, v. 67, n. 217, p. 90-102, 2019.

DECAROLIS, J. et al. Cost Trends of MBR Systems for Municipal Wastewater Treatment. Proceedings of the Water Environment Federation, v. 2007, n. 15, p. 3407-3418, 2007.

DELL'OVO, M.; CAPOLONGO, S.; OPPIO, A. Combining spatial analysis with MCDA for the siting of healthcare facilities. Land Use Policy, v. 76, n. March, p. 634-644, 2018.

EBRAHIMIAN GHAJARI, Y. et al. Urban vulnerability under various blast loading scenarios: Analysis using GIS-based multi-criteria decision analysis techniques.

Cities, v. 72, n. August 2017, p. 102-114, 2018. 
EDWARDS, J. et al. GIS and hydraulic model integration: Implementing cost-effective sustainable modeling solutions. Journal / American Water Works Association, v. 101, n. 11, p. 34-42, 2009.

ESMAIL, B. A.; GENELETTI, D. Multi-criteria decision analysis for nature conservation: A review of 20 years of applications. Methods in Ecology and Evolution, v. 9, n. 1, p. 42-53, 2018.

ESTADO DE SÃO PAULO. Resolução conjunta SES/SIMA n 01, de 13 de fevereiro de 2020. São Paulo: 2020, p. 1-10.

EUROPEAN COMMISSION. Guidelines on Integrating Water Reuse into Water Planning and Management in the context of the WFD. n. June, p. 1-95, 2016.

FABHAT - FUNDAÇÃO AGÊNCIA BACIA HIDROGRÁFICA DO ALTO TIETÊ. Relatório De Situação Dos Recursos Hídricos Bacia Hidrográfica Do Alto Tietê Ugrhi-06. São Paulo: FABHAT, 2017. Disponível em:

<http://www.sigrh.sp.gov.br/public/uploads/documents//CBH-

AT/12322/relatorio_situacao_dos_recursos_hidricos_ugrhi_06_2017.pdf>.

. Plano da Bacia Hidrográfica do Alto Tietê - PBHAT: Relatório Parcial de Diagnóstico (RPD). São Paulo: FABHAT, 2018a. Disponível em:

<https://drive.google.com/open?id=1KC7gfRRiUnXejlcGk4atfABkj_-2uHV7>.

Plano da Bacia Hidrográfica do Alto Tietê - PBHAT: Diagnóstico - Anexo

II - Indicadores. São Paulo: FABHAT, 2018b. Disponível em:

<https://drive.google.com/open?id=1KC7gfRRiUnXejlcGk4atfABkj_-2uHV7>.

FAO - FOOD AND AGRICULTURE ORGANIZATION OF THE UNITED NATIONS. User manual for irrigation with treated wastewater. 2003.

FAO - FOOD AND AGRICULTURE ORGANIZATION OF THE UNITED NATIONS. AQUASTAT Main Database. Food and Agriculture Organization of the United Nations. Disponível em: <http://www.fao.org/nr/water/aquastat/main/index.stm>. Acesso em: 15 maio. 2018.

FGV - FUNDAÇÃO GETÚLIO VARGAS. Medindo o saneamento potencialidades e limitados dos bancos de dados brasileiros - 2018. São Paulo: Centro de estudos em regulação de infraestrutura (CERI), 2018.

FIELDING, K. S.; ROIKO, A. H. Providing information promotes greater public support for potable recycled water. Water Research, v. 61, p. 86-96, 2014.

FILHO, J. L. Contribuição para o entendimento do reuso planejado da água e algumas considerações sobre suas possibilidades no Brasil. São Paulo: 
Dissertação (Mestrado) - Escola Politécnica da Universidade de São Paulo. Departamento de Engenharia Hidráulica e Ambiental, 1987.

FUKASAWA, B. N. et al. Estimativa do potencial de utilização de água de reúso não potável para fins industriais na Região Metropolitana de Fortaleza - CE. Artigo técnico apresentado no Congresso ABES Fenasan 2017. São Paulo: Associação Brasileira de Engenharia Sanitária, 2017

GDOURA, K.; ANANE, M.; JELLALI, S. Geospatial and AHP-multicriteria analyses to locate and rank suitable sites for groundwater recharge with reclaimed water.

Resources, Conservation and Recycling, v. 104, p. 19-30, 2015.

GENERINO, R. C. M. Contribuição da abordagem multicritério na seleção de alternativas de reúso de água: aplicação em um caso de irrigação agrícola e paisagística no Distrito Federal. São Paulo: Tese (Doutorado) - Faculdade de Saúde Pública da Universidade de São Paulo. Programa de Pós-Graduação em Saúde Pública, 2006.

GICC - NORTH CAROLINA GEOGRAPHIC INFORMATION COORDINATING COUNCIL. Open Source GIS Software: a guide for understanding current GIS softwares solutions. GIS Technical Advisory Committee (TAC), 2017.

GOLDSTEIN, B. D. John Snow, the Broad Street pump and the precautionary principle. Environmental Development, v. 1, n. 1, p. 3-9, 2012.

GOMES, P. R. Indicadores ambientais na discussão da sustentabilidade: uma proposta de análise estratégica no contexto do etanol de cana-de- açúcar no Estado de São Paulo. Dissertação (Mestrado) - Escola de Engenharia de São Carlos da Universidade de São Paulo. Área de concentração em Ciências da Engenharia Ambiental, 2011.

GOODWIN, D. et al. Informing public attitudes to non-potable water reuse - The impact of message framing. Water Research, v. 145, p. 125-135, 2018.

GOULTER, I. C.; FORREST, D. Use of Geographic Information Systems (GIS) in River Basin Management. Wat. Sci. Tech., v. 19, n. 9, p. 81-86, 1987.

GU, Q. et al. Public perception and acceptability toward reclaimed water in Tianjin. Resources, Conservation and Recycling, v. 104, p. 291-299, 2015.

GUO, T.; ENGLEHARDT, J.; WU, T. Review of cost versus scale: Water and wastewater treatment and reuse processes. Water Science and Technology, v. 69, n. 2, p. 223-234, 2014. 
HERMAN, J. G.; SCRUGGS, C. E.; THOMSON, B. M. The costs of direct and indirect potable water reuse in a medium-sized arid inland community. Journal of Water Process Engineering, v. 19, n. August, p. 239-247, 2017.

HERNÁNDEZ-SANCHO, F. et al. Economic valuation of wastewater: the cost of action and the cost of no action. Nairóbi: United Nations Environment Programme, 2015.

HESPANHOL, I. Potencial de reúso de água no Brasil: agricultura, indústria, municípios, recarga de aqüíferos. Revista Brasileira de Recursos Hídricos, v. 7, n. 4, p. 75-95, 2002.

HESPANHOL, I. Reúso potável direto e o desafio dos poluentes emergentes. Revista USP, v. 0, n. 106, p. 79, 2015.

HLPW - UNITED NATIONS HIGH LEVEL PANEL ON WATER. United Nations High Level Panel on Water action plan. [s.l: s.n.]. Disponível em:

$<$ https://sustainabledevelopment.un.org/content/documents/11280HLPW_Action_Pla n_DEF_11-1.pdf>.

HLPW - UNITED NATIONS HIGH LEVEL PANEL ON WATER. World Water Data Initiative Roadmap. Genebra: HLPW, 2017. Disponível em:

$<$ https://sustainabledevelopment.un.org/content/documents/13327HLPW_WWDI_Ro admap.pdf>.

HUANG, B. Comprehensive Geographic Information Systems. Volume I: GIS methods and techniques. Waltham: Elsevier Inc., 2017.

HUNTER WATER CORPORATION. Operating and maintenance cost estimating guideline. p. 14, 2013.

HURLIMANN, A. Research Report: Community Attitudes to Recycled Water Use: an Urban Australian Case Study - Part 2. Salisbury. Cooperative Research Centre for Water Quality and Treatment, 2008.

HURLIMANN, A.; DOLNICAR, S. When public opposition defeats alternative water projects - The case of Toowoomba Australia. Water Research, v. 44, n. 1, p. 287297, 2010.

HURLIMANN, A.; DOLNICAR, S. Public acceptance and perceptions of alternative water sources: A comparative study in nine locations. International Journal of Water Resources Development, v. 32, n. 4, p. 650-673, 2016. 
IBGE - INSTITUTO BRASILEIRO DE GEOGRAFIA E ESTATÍSTICA. Resolução PR n 01/2015. Disponível em: <http://pubs.acs.org/doi/abs/10.1021/ja00829a034>. Acesso em: 15 jun. 2018a.

. [Shapefile] Bases e referenciais. Bases cartográficas: malhas digitais.

Disponível em: <https://mapas.ibge.gov.br/bases-e-referenciais/basescartograficas/malhas-digitais.html>. Acesso em: 21 jun. $2018 \mathrm{~b}$.

. CNAE20_EstruturaDetalhada - Estrutura detalhada da Classificação Nacional de Atividades Econômicas 2.0 (CNAE 2.0). Disponível em:

<https://concla.ibge.gov.br/images/concla/downloads/revisao2007/PropCNAE20/CN AE20_EstruturaDetalhada.xIs>. Acesso em: 28 maio. 2018.

IEMA - INSTITUTO DE MEIO AMBIENTE E RECURSOS HÍDRICOS. Série Termoeletricidade em foco: uso de água em termoelétricas. São Paulo: Instituto de Energia e Meio Ambiente, 2016.

IGC-SP - INSTITUTO GEOGRÁFICO E CARTOGRÁFICO DO ESTADO DE SÃO PAULO. [Shapefile] Limites das UGRHIs. Disponível em:

$<$ http://datageo.ambiente.sp.gov.br/geoserver/datageo/LimiteUGRHI/wfs?version=1. 0.0\&request=GetFeature\&outputFormat=SHAPE-ZIP\&typeName=LimiteUGRHI>. Acesso em: 21 abr. 2018.

IGLESIAS, R. et al. Water reuse in spain: Data overview and costs estimation of suitable treatment trains. Desalination, v. 263, n. 1-3, p. 1-10, 2010.

INAMDAR, P. M. et al. Evaluation of Stormwater Harvesting Sites Using Multi Criteria Decision Methodology. Journal of Hydrology, v. 562, n. September 2017, p. 181-192, 2018.

INMET - INSTITUTO NACIONAL DE METEOROLOGIA. Precipitação acumulada e temperatura média - Est. Mirante de Santana - 1961-1990. Disponível em: <http://www.inmet.gov.br/portal/index.php?r=estacoes/estacoesautomaticas>. Acesso em: 12 fev. 2020.

ISHIZAKA, A.; LUSTI, M. How to derive priorities in AHP: A comparative study. Central European Journal of Operations Research, v. 14, n. 4, p. 387-400, 2006.

JARAMILLO, M. F.; RESTREPO, I. Wastewater reuse in agriculture: A review about its limitations and benefits. Sustainability (Switzerland), v. 9, n. 10, 2017.

JAYARATHNA, L. et al. A GIS based spatial decision support system for analysing residential water demand: A case study in Australia. Sustainable Cities and Society, v. 32, p. 67-77, 2017. 
JELOKHANI-NIARAKI, M.; SADEGHI-NIARAKI, A.; CHOI, S. M. Semantic interoperability of GIS and MCDA tools for environmental assessment and decision making. Environmental Modelling and Software, v. 100, p. 104-122, 2018.

JUDD, S. J. Membrane technology costs and me. Water Research, v. 122, p. 1-9, 2017.

JUNG, Y. T.; NARAYANAN, N. C.; CHENG, Y. L. Cost comparison of centralized and decentralized wastewater management systems using optimization model. Journal of Environmental Management, v. 213, p. 90-97, 2018.

KIRCHHERR, J. et al. Barriers to the Circular Economy: Evidence From the European Union (EU). Ecological Economics, v. 150, n. April, p. 264-272, 2018.

$\mathrm{KOCH}, \mathrm{T}$.; DENIKE, K. Crediting his critics' concerns: Remaking John Snow's map of Broad Street cholera, 1854. Social Science and Medicine, v. 69, n. 8, p. 12461251, 2009.

LATRE, M. Á. et al. Spatial Data Infrastructures for environmental e-government services: The case of water abstractions authorisations. Environmental Modelling \& Software, v. 48, p. 81-92, 1 out. 2013.

LAUTZE, J. et al. Global experiences in water reuse. Colombo, Sri Lanka: International Water Management Institute, 2014. Disponível em: $<$ http://www.iwmi.cgiar.org/Publications/wle/rrr/resource_recovery_and_reuseseries_4.pdf $>$.

LEE, E. J. et al. Decision support toolkit for integrated analysis and design of reclaimed water infrastructure. Water Research, v. 134, p. 234-252, 2018.

LIMA, J. D. DE et al. Uso de modelos de apoio a decisão para análise de alternativas tecnológicas de tratamento de resíduos sólidos urbanos na Região Sul do Brasil. Engenharia Sanitária e Ambiental, v. 19, n. 1, p. 33-42, 2014.

LIMA, E. P. DE C. Água e indústria: experiências e desafios. Brasília: Infinita Imagem, 2018.

LUTHRA, S. et al. Barriers to renewable/sustainable energy technologies adoption: Indian perspective. Renewable and Sustainable Energy Reviews, v. 41, p. 762776, 2015.

MALCZEWSKI, J.; RINNER, C. Multicriteria Decision Analysis in Geographic Information Science. Nova lorque: Springer Science+Business Media, 2015. 
MALINOWSKI, A. Aplicação de metodologia para estruturação de diretrizes para o planeamento do reúso de água no meio urbano. Curitiba: Dissertação (Mestrado) - Universidade Federal do Paraná. Programa de Pós-Graduação em Engenharia de Recursos Hídricos e Ambiental do Setor de Tecnologia, 2006.

MANCUSO, P. C. S. O reúso de água e sua possibilidade na Região Metropolitana de São Paulo. São Paulo: Tese (Doutorado) - Faculdade de Saúde Pública da Universidade de São Paulo. Departamento de Saúde Ambiental, 1992.

MARTINS, C. A. Estimativa da evapotranspiração no estado de São Paulo com o modelo da biosfera SiB2 Estimativa da evapotranspiração no estado de São Paulo com o modelo da biosfera SiB2. São Paulo: Dissertação (Mestrado) Instituto de Astronomia, Geofísica e Ciências Atmosféricas da Universidade de São Paulo. Área de concentração em Meteorologia, 2011.

MCIDADES - MINISTÉRIO DAS CIDADES. Elaboração de Proposta do Plano de Ações para Instituir uma Política de Reúso de Efluente Sanitário Tratado no Brasil. Produto II - Experiências de reúso (RP01A). Brasília: MCidades, 2016.

Elaboração de Proposta do Plano de Ações para Instituir uma Política de Reúso de Efluente Sanitário Tratado no Brasil. Produto III - Critérios de qualidade de água (RP01B). Brasília: MCidades, 2017a.

. Elaboração de Proposta do Plano de Ações para Instituir uma Política de Reúso de Efluente Sanitário Tratado no Brasil. Produto IV - Avaliação do potencial de reúso (RP01C). Brasília: MCidades, 2017b.

.RP01C_Potencial de Reúso_20set2018 - planilha com resultados por município. Brasília: MCidades, 2017c.

Sistema Nacional de Informações sobre Saneamento: diagnóstico dos serviços de água e esgotos - 2016. Brasília: SNSA/MCIDADES, 2018.

MIERZWA, J. C. O uso racional e o reúso como ferramentas para o gerenciamento de águas e efluentes na indústria: estudo de caso da Kodak brasileira (volumes 1 e 2). São Paulo: Tese (Doutorado) - Escola Politécnica da Universidade de São Paulo. Departamento de Engenharia Hidráulica e Sanitária, 2002.

MIERZWA, J. C.; HESPANHOL, I. Água na indústria: uso racional e reúso. São Paulo: Oficina de Textos, 2005. 
MOLINOS-SENANTE, M. et al. Assessment of wastewater treatment plant design for small communities: Environmental and economic aspects. Science of the Total Environment, v. 427-428, p. 11-18, 2012.

MOSTRÖM, J. Statistiskt meddelande - Industrins vattenanvändning 2015. n. september 2016, 2015.

MU, E.; PEREYRA-ROJAS, M. Practical decision making: an introduction to the Analytic Hierarchy Process (AHP) using super decisions V2. Nova lorque: Springer International Publishing, 2017.

NEJI, H. B. B.; TURKI, S. Y. GIS - based multicriteria decision analysis for the delimitation of an agricultural perimeter irrigated with treated wastewater.

Agricultural Water Management, v. 162, p. 78-86, 2015.

NOGUEIRA, M. R. DE S. Otimização econômica do uso de esgoto tratado: uma análise do transporte da água de reúso em busca da sustentabilidade. Rio de Janeiro: Dissertação (Mestrado) - Universidade Federal do Rio de Janeiro. Programa de Pós-graduação em Engenharia de Produção (COPPE), 2010.

OECD EAP - ORGANISATION FOR ECONOMIC CO-OPERATION AND DEVELOPMENT - ENVIRONMENTAL ACTION PROGRAMME. Rural cost functions for water supply and sanitation: technology overview and cost functions. 2005.

OMS - ORGANIZAÇÃO MUNDIAL DA SAÚDE. WHO Guidelines for the Safe Use of Wastewater, Excreta, and Greywater. Volume IV - excreta and greywater use in agriculture. Genebra: WHO, 2006. Disponível em:

<http://whqlibdoc.who.int/publications/2006/9241546832_eng.pdf>.

ONU - ORGANIZAÇÃO DAS NAÇÕES UNIDAS. Resolution A/RES/70/1.

Transforming our world: the 2030 agenda for sustainable developmentUnited Nations General Assembly. [s.I.] ONU, 2015. Disponível em:

<http://www.un.org/ga/search/view_doc.asp?symbol=A/RES/70/1\&Lang=E>.

ORENGO, H. Open Source GIS and Geospatial Software in Archaeology: Towards their Integration into Everyday Archaeological Practice. Open Source Archaeology: Ethics and Practice, n. November, p. 64-82, 2015.

OSARAGI, T. Classification methods for spatial data representation. Centre for Advanced Spatial Analysis, 2002.

PAOLI, G. DEL. D4.5 Financing solutions for water reuse schemes. [s.I.] DEMOWARE, 2016. 
PAUL, M. et al. Assessment of agricultural land suitability for irrigation with reclaimed water using geospatial multi-criteria decision analysis. Agricultural Water Management, v. 231, n. December 2019, p. 105987, 2020.

PETIT-BOIX, A.; LEIPOLD, S. Circular economy in cities: Reviewing how environmental research aligns with local practices. Journal of Cleaner Production, v. 195, p. 1270-1281, 2018.

PISTOCCHI, A. et al. The potential of water reuse for agricultural irrigation in the EU a hydro-economic analysis. Luxembourg: Publications Office of the European Union, 2017.

SAATY, T. L. What Is the Analytic Hierarchy Process? Mathematical Models for Decision Support, p. 109-121, 1988.

SAATY, T. L. How to make a decision: The analytic hierarchy process. European Journal of Operational Research, v. 48, n. 1, p. 9-26, 1990.

SAATY, T. L. Fundamentals of Decision Making and Priority Theory with the Analytic Hierarchy. Nova lorque: McGraw Hill Publishers, 2000.

SAATY, T. L. Decision making with the analytic hierarchy process. International Journal of Services Sciences, v. 1, n. 1, p. 83, 2008.

SAATY, T. L.; ERGU, D. When is a Decision-Making Method Trustworthy? Criteria for Evaluating Multi-Criteria Decision-Making Methods. International Journal of Information Technology \& Decision Making, v. 14, n. 06, p. 1171-1187, 2015.

SAATY, T. L.; SAGIR, M. Choosing the best city of the future. Journal of Urban Management, v. 4, n. 1, p. 3-23, 2015.

SAATY, T. L.; VARGAS, L. G. Models, Methods, Concepts \& Applications of the Analytic Hierarchy Process. Londres: Springer Science+Business Media, 2012.

SABESP - COMPANHIA DE SANEAMENTO BÁSICO DO ESTADO DE SÃO PAULO. Plano Diretor de Esgotos da Região Metropolitana de São Paulo. Relatório final: Volume III - Sistema Principal de Esgotos. São Paulo: Sabesp, 2010a.

. Plano Diretor de Esgotos da Região Metropolitana de São Paulo. Relatório final: Volume IV - Sistemas Isolados de Esgotos. São Paulo: Sabesp, 2010b.

Reuso para uso urbano não potável. $6^{\circ}$ Seminário sobre Tecnologias Limpas Porto Alegre, 10 de Junho de 2015. Sabesp, 2015. 
. Declaração de dados das ETEs do Sistema Isolado da Sabesp na RMSP realizada via SIC.SP, 2018.

SALGOT, M.; FOLCH, M.; UNIT, S. S. Wastewater treatment and water reuse. Current Opinion in Environmental Science \& Health, v. 2, p. 64-74, 2018.

SÃO PAULO. Lei No 16.174 de 22 de abril de 2015. Estabelece regramento e medidas para fomento ao reúso de água para aplicações não potáveis, oriundas do polimento do efluente final do tratamento de esgoto, de recuperação de água de chuva, da drenagem de recintos subterrâneos e de rebaixamento de lençol freático e revoga a Lei Municipal no 13.309/2002, no âmbito do Município de São Paulo e dá outras providências. São Paulo: 2015.

SÃO PAULO (ESTADO). Decreto no 13.095, de 05 de janeiro de 1979. Disponível em: <http://www.al.sp.gov.br/repositorio/legislacao/decreto/1979/decreto-1309505.01.1979.html>. Acesso em: 26 jul. 2018.

SCHAER-BARBOSA, M.; SANTOS, M. E. P. DOS; MEDEIROS, Y. D. P. Viabilidade do reúso de água como elemento mitigador dos efeitos da seca no semiárido da Bahia. Ambiente \& Sociedade, v. 17, n. 2, p. 17-32, 2014.

SCHIMMOLLER, L.; KEALY, M. J. Fit for Purpose Water: The Cost of Overtreating Reclaimed Water. WateReuse Webcast October, 2013

SDCWA - SAN DIEGO COUNTY WATER AUTHORITY. Technical Information for Cooling Towers Using Recycled Water. San Diego: SDCWA, 2009.

SEADE - FUNDAÇÃO SISTEMA ESTADUAL DE ANÁLISE DE DADOS. Onde a indústria se fortalece no estado de São Paulo. São Paulo: Fundação Sistema Estadual de Análise de Dados, 2013.

PIB dos municípios paulistas: 2012-2014. São Paulo: Fundação Sistema Estadual de Análise de Dados, 2017a. Disponível em: <http://www.seade.gov.br/produtos/midia/2017/07/PIB_2002_2014_FINAL_reduzido. $\mathrm{pdf}>$.

PIB dos municípios paulistas 2002-2015. Disponível em:

<http://www.seade.gov.br/produtos/pib-municipal/>. Acesso em: 6 jun. 2018b.

. Informações dos Municípios Paulistas. Disponível em:

<http://www.imp.seade.gov.br/frontend/\#/tabelas>. Acesso em: 19 jun. 2018a.

. Pesquisa de Investimentos Anunciados no Estado de São Paulo (Piesp). Disponível em: <http://www.piesp.seade.gov.br/>. Acesso em: 11 maio. 2018b. 
SGROI, M.; VAGLIASINDI, F. G. A.; ROCCARO, P. Feasibility, sustainability and circular economy concepts in water reuse. Current Opinion in Environmental Science \& Health, v. 2, p. 20-25, 2018.

SHAMSI, U. M. GIS applications for water, wastewater, and stormwater systems. $1^{\text {st }}$ ed. Boca Raton: CRC Press, 2005.

SHARVELLE, S. et al. A geospatially-enabled web tool for urban water demand forecasting and assessment of alternative urban water management strategies. Environmental Modelling and Software, v. 97, p. 213-228, 2017.

SICHE, R. et al. Índices versos indicadores: precisões conceituais na discussão da sustentabilidade de países. Ambiente \& Sociedade, v. X, n. 2, p. 137-148, 2007.

SILVA, J. C. F. DA. Diferenciação salarial na indústria brasileira. Rio de Janeiro: Tese (Doutorado) - Fundação Getúlio Vargas. Escola de Pós-Graduação em Economia., 1987.

SINDHU, S.; NEHRA, V.; LUTHRA, S. Solar energy deployment for sustainable future of India: Hybrid SWOC-AHP analysis. Renewable and Sustainable Energy Reviews, v. 72, n. September 2015, p. 1138-1151, 2017.

SINDUSCON-SP - SINDICATO DA CONSTRUÇÃO CIVIL DO ESTADO DE SÃO PAULO. Conservação e reúso da água em edificações. São Paulo: SindusConSP, 2005.

SINGH, L. K.; JHA, M. K.; CHOWDARY, V. M. Multi-criteria analysis and GIS modeling for identifying prospective water harvesting and artificial recharge sites for sustainable water supply. Journal of Cleaner Production, v. 142, p. 1436-1456, 2017.

SMA/CPLA/DIA - SECRETARIA DE MEIO AMBIENTE / COORDENADORIA DE PLANEAMENTO AMBIENTAL. Modelo Digital de Elevação do Estado de São Paulo [raster]. Disponível em: <http://datageo.ambiente.sp.gov.br/app/?ctx=DATAGEO>.

SMITH, H. M. et al. Public responses to water reuse - Understanding the evidence. Journal of Environmental Management, v. 207, p. 43-50, 2018.

SNS/MDR - SECRETARIA NACIONAL DE SANEAMENTO / MINISTÉRIO DO DESENVOLVIMENTO REGIONAL. Sistema Nacional de Informações sobre Saneamento: 24o Diagnóstico dos Serviços de Água e Esgotos - 2018. Brasília: SNS/MDR, 2019.

SNSA/MCIDADES - SECRETARIA NACIONAL DE SANEAMENTO AMBIENTAL / MINISTÉRIO DAS CIDADES. Plano Nacional de Saneamento Básico - 
PLANSAB. Brasília: SNSA/MCIDADES, 2013. Disponível em: <http://www.cecol.fsp.usp.br/dcms/uploads/arquivos/1446465969_BrasilPlanoNacionalDeSaneamentoBásico-2013.pdf>.

SSRH-SP - SECRETARIA DE SANEAMENTO E RECURSOS HÍDRICOS DO ESTADO DE SÃO PAULO. Plano Estadual de Recursos Hídricos: PERH 20162019. São Paulo: SSRH, 2017. Disponível em:

<http://www.sigrh.sp.gov.br/public/uploads/ckfinder/files/PERH_2016_2019_MINUTA _FINAL.pdf>.

STATISTICS CANADA. Table 38-10-0056-01 Water intake in manufacturing industries, by purpose of initial use and North American Industry Classification System (x 1,000,000). Disponível em:

$<$ https://www150.statcan.gc.ca/t1/tbl1/en/cv.action?pid=3810005601 >. Acesso em: 14 set. 2018.

TANGUNE, B. F. Evapotranspiração de referência no estado de São Paulo: métodos empíricos, aprendizado de máquica e geoespacial. Botucatu: Tese (Doutorado) Faculdade de Ciências Agronômicas da Unesp, Campus de Botucatu, para obtenção do título de Doutor em Agronomia (Irrigação e Drenagem), 2017.

TCHOBANOGLOUS, G. et al. Direct potable reuse - a path forward. WateReuse Research Foundation, 2011.

TEIXEIRA, Z. et al. Identification of potential aquaculture sites in solar saltscapes via the Analytic Hierarchy Process. Ecological Indicators, v. 93, n. January, p. 231242, 2018.

THE EUROPEAN COMMISSION. Guidelines on Integrating Water Reuse into Water Planning and Management in the context of the WFD. n. June, p. 1-95, 2016.

TORRIERI, F. Spatial Multi-Criteria Decision Support System and Strategic Environmental Assessment: A Case Study. Buildings, v. 7, n. 4, p. 96, 2017.

TRAN, Q. K.; SCHWABE, K. A.; JASSBY, D. Wastewater reuse for agriculture: Development of a regional water reuse decision-support model (RWRM) for costeffective irrigation sources. Environmental Science and Technology, v. 50, n. 17, p. 9390-9399, 2016a.

TRAN, Q. K.; SCHWABE, K. A.; JASSBY, D. Wastewater reuse for agriculture: Development of a regional water reuse decision-support model (RWRM) for costeffective irrigation sources - supporting information. Environmental Science and Technology, v. 50, n. 17, p. 9390-9399, 2016b. 
TSUTIYA, M. T. Abastecimento de água. São Paulo: Departamento de Engenharia Hidráulica e Sanitária da Escola Politécnica da Universidade de São Paulo, 2006.

U.S. EPA - UNITED STATES ENVIRONMENTAL PROTECTION AGENCY. Technologies and Costs Document for the Final Long Term 2 Enhanced Surface Water Treatment Rule and Final Stage 2 Disinfectants and Disinfection Byproducts Rule. Washington D.C.: EPA, 2005.

. Wastewater Management Fact Sheet: Membrane Bioreactors. Washington D.C.: EPA, 2007.

. Guidelines for Water Reuse 2012. Washington D.C.: U.S. EPA, 2012.

UNESCO - ORGANIZAÇÃO DAS NAÇÕES UNIDAS PARA A EDUCAÇÃO, A CIÊNCIA E A CULTURA. The handbook on water information systems: administration, processing and exploitation of water-related data. Paris: UNESCO, 2018.

VAN DER LEEDEN, F.; TROISE, F.; TODD, D. K. The Water Encyclopedia. 2a ed. Michigan: Lewis Publishers, 1990.

VASILEIOU, M.; LOUKOGEORGAKI, E.; VAGIONA, D. G. GIS-based multi-criteria decision analysis for site selection of hybrid offshore wind and wave energy systems in Greece. Renewable and Sustainable Energy Reviews, v. 73, n. February, p. 745-757, 2017.

VELASQUEZ, M.; HESTER, P. T. An Analysis of Multi-Criteria Decision Making Methods. International Journal of Operations Research, v. 10, n. 2, p. 56-66, 2013.

VILLACRESES, G. et al. Wind farms suitability location using geographical information system (GIS), based on multi-criteria decision making (MCDM) methods: The case of continental Ecuador. Renewable Energy, v. 109, p. 275-286, 2017.

VOULVOULIS, N. Water Reuse from a Circular Economy Perspective and Potential Risks from an Unregulated Approach. Current Opinion in Environmental Science \& Health, 2018.

WATSON, J. J. W.; HUDSON, M. D. Regional Scale wind farm and solar farm suitability assessment using GIS-assisted multi-criteria evaluation. Landscape and Urban Planning, v. 138, p. 20-31, 2015.

WEI, R.; TONG, D.; PHILLIPS, J. M. An integrated classification scheme for mapping estimates and errors of estimation from the American Community Survey.

Computers, Environment and Urban Systems, v. 63, p. 95-103, 2017. 
WILCOX, J. et al. Urban water reuse: A triple bottom line assessment framework and review. Sustainable Cities and Society, v. 27, p. 448-456, 2016.

WWAP - WORLD WATER ASSESSMENT PROGRAMME. Wastewater: The Untapped Resource. Paris: Organização das Nações Unidas para a Educação, a Ciência e a Cultura, 2017.

YALCIN, M.; KILIC GUL, F. A GIS-based multi criteria decision analysis approach for exploring geothermal resources: Akarcay basin (Afyonkarahisar). Geothermics, v. 67, p. 18-28, 2017.

ZAYAS, I. et al. D4.3 - Cost-benefit analysis approach suited for water reuse schemes. DEMOWARE, 2016. 


\section{ANEXO A. Informações complementares sobre a estrutura do Modelo ETE-usuário}

Neste item constam maiores detalhes sobre o Modelo ETE-usuário desenvolvido e apresentado nos itens 4.3 e 5.2 .

\section{A1. Relação das divisões CNAE 2.0 utilizadas para tipificação das atividades econômicas dos usuários}

Tabela A 1: Relação completa de seções e divisões segundo a CNAE 2.0 do IBGE utilizadas para classificação de usuários

\begin{tabular}{|c|c|c|}
\hline Seção & Divisão & Descrição da divisão \\
\hline \multirow{3}{*}{$\begin{array}{l}\text { A - AGRICULTURA, PECUÁRIA, } \\
\text { PRODUÇÃO FLORESTAL, } \\
\text { PESCA E AQUICULTURA }\end{array}$} & 1 & Agricultura, pecuária e serviços relacionados \\
\hline & 2 & Producão florestal \\
\hline & 3 & Pesca e aquicultura \\
\hline \multirow{5}{*}{ B - INDÚSTRIAS EXTRATIVAS } & 5 & Extração de carvão mineral \\
\hline & 6 & Extração de petróleo e gás natural \\
\hline & 7 & Extração de minerais metálicos \\
\hline & 8 & Extração de minerais não-metálicos \\
\hline & 9 & Atividades de apoio à extração de minerais \\
\hline \multirow{24}{*}{$\begin{array}{l}\text { C - INDÚSTRIAS DE } \\
\text { TRANSFORMAÇÃO }\end{array}$} & 10 & Fabricação de produtos alimentícios \\
\hline & 11 & Fabricação de bebidas \\
\hline & 12 & Fabricação de produtos do fumo \\
\hline & 13 & Fabricação de produtos têxteis \\
\hline & 14 & Confecção de artigos do vestuário e acessórios \\
\hline & 15 & $\begin{array}{l}\text { Preparação de couros e fabricação de artefatos de couro, artigos para } \\
\text { viagem e calçados }\end{array}$ \\
\hline & 16 & Fabricação de produtos de madeira \\
\hline & 17 & Fabricação de celulose, papel e produtos de papel \\
\hline & 18 & Impressão e reprodução de gravações \\
\hline & 19 & $\begin{array}{l}\text { Fabricação de coque, de produtos derivados do petróleo e de } \\
\text { biocombustíveis }\end{array}$ \\
\hline & 20 & Fabricação de produtos químicos \\
\hline & 21 & Fabricação de produtos farmoquímicos e farmacêuticos \\
\hline & 22 & Fabricação de produtos de borracha e de material plástico \\
\hline & 23 & Fabricação de produtos de minerais não-metálicos \\
\hline & 24 & Metalurgia \\
\hline & 25 & Fabricação de produtos de metal, exceto máquinas e equipamentos \\
\hline & 26 & Fabricação de equipamentos de informática, produtos eletrônicos e ópticos \\
\hline & 27 & Fabricação de máquinas, aparelhos e materiais elétricos \\
\hline & 28 & Fabricação de máquinas e equipamentos \\
\hline & 29 & Fabricação de veículos automotores, reboques e carrocerias \\
\hline & 30 & $\begin{array}{l}\text { Fabricação de outros equipamentos de transporte, exceto veículos } \\
\text { automotores }\end{array}$ \\
\hline & 31 & Fabricação de móveis \\
\hline & 32 & Fabricação de produtos diversos \\
\hline & 33 & Manutenção, reparação e instalação de máquinas e equipamentos \\
\hline D - ELETRICIDADE E GÁS & 35 & Eletricidade, gás e outras utilidades \\
\hline \multirow{4}{*}{$\begin{array}{l}\text { E - ÁGUA, ESGOTO, } \\
\text { ATIVIIDADES DE GESTÃO DE } \\
\text { RESÍDUOS E } \\
\text { DESCONTAMINAÇÃO }\end{array}$} & 36 & Captação, tratamento e distribuição de água \\
\hline & 37 & Esgoto e atividades relacionadas \\
\hline & 38 & Coleta, tratamento e disposição de resíduos; recuperação de materiais \\
\hline & 39 & Descontaminação e outros serviços de gestão de resíduos \\
\hline \multirow{3}{*}{ F - CONSTRUÇÃO } & 41 & Construção de edifícios \\
\hline & 42 & Obras de infraestrutura \\
\hline & 43 & Serviços especializados para construção \\
\hline
\end{tabular}




\section{A2. Resumo das referências utilizadas para determinação das funções de custos}

A Tabela A 2 resume os métodos e fontes utilizados para a definição de cada uma das funções de custos.

Tabela A 2: Métodos de determinação das funções de custo

\begin{tabular}{|c|c|c|}
\hline Tipo & Capex & Opex \\
\hline \multicolumn{3}{|l|}{ Tratamento } \\
\hline MBR & $\begin{array}{l}\text { Composição (média) a partir de } \\
\text { Adham \& DeCarolis (2004), Côte et } \\
\text { al. (2004), DeCarolis (2007), Guo et } \\
\text { al. (2014), Molinos-Senante } \\
\text { et al. (2012), CNI (2019a) }\end{array}$ & $\begin{array}{l}\text { Composição (média) a partir de Adham \& } \\
\text { DeCarolis (2004), Côte et al. (2004), DeCarolis } \\
\text { (2007), Guo et al. (2014), Molinos-Senante } \\
\text { et al. (2012), Tran et al. (2016a, 2016b), CNI } \\
\text { (2019a) }\end{array}$ \\
\hline $\operatorname{MBR}(\mathrm{RN})$ & $\begin{array}{l}\text { Estimativa por dimensionamento a } \\
\text { partir de MBR (incremento de custo } \\
\text { por implantação de tanque anóxico e } \\
\text { sistema de recirculação de efluente } \\
\text { nitrificado) }\end{array}$ & $\begin{array}{l}\text { Estimativa por dimensionamento a partir de } \\
\text { MBR (redução de custos por menores } \\
\text { demandas de ar soprado por conta da demanda } \\
\text { de } \mathrm{O}_{2} \text { "satisfeita" e aumento pelos maiores } \\
\text { requerimentos de energia elétrica para } \\
\text { recirculação de efluente nitrificado) }\end{array}$ \\
\hline OR & $\begin{array}{l}\text { Composição (média) a partir de EPA } \\
\text { (2005), Guo et al. (2014) e Judd } \\
\text { (2017) }\end{array}$ & $\begin{array}{l}\text { Composição (média) a partir de Schimmoler \& } \\
\text { Kealy (2013), Herman et al. (2017) e Guo et al. } \\
(2014)\end{array}$ \\
\hline CL & $\begin{array}{l}\text { Composição a partir de MCidades } \\
\text { (2017a) e Tran et al. (2016a, 2016b) }\end{array}$ & $\begin{array}{l}\text { Adaptado de Iglesias et al. } \\
\text { (2010), MCidades (2017a) e Tran et al. (2016a, } \\
2016 b)\end{array}$ \\
\hline UV & $\begin{array}{l}\text { Adaptado de EPA (2005) e Tran et al. } \\
\text { (2016a, 2016b) }\end{array}$ & $\begin{array}{l}\text { Adaptado de EPA (2005) e Tran et al. (2016a, } \\
\text { 2016b) }\end{array}$ \\
\hline \multicolumn{3}{|l|}{ Adução } \\
\hline EE & Adaptado de Sabesp (2010a) & \multirow{2}{*}{$\begin{array}{l}\text { Estimativa por traçado de adutoras, cálculo de } \\
\text { AMT e determinação de potência requerida. } \\
\text { Inclui custos de manutenção conforme OECD } \\
\text { (2005), Nogueira (2010) e MCidades (2017a) }\end{array}$} \\
\hline Adução & Adaptado de CNI (2017b) & \\
\hline
\end{tabular}

\section{A3. Custos de tratamento}

As funções de custos de tratamento (Capextrat e Opextrat) foram baseados em literatura, principalmente internacional. Para o caso específico de $\operatorname{MBR}(R N)$, as funções de custos foram determinadas com base em adaptações de MBR (inclusão de pré-desnitrificação para remoção de nitrogênio).

As funções de Capex e Opex de tratamento presentes nos itens 3.2.5.1 e 5.2.3.2 são oriundas de diferentes fontes. Em alguns casos, os estudos apresentam as funções em si, caso no qual se procedeu somente à conversão das unidades de entrada e saída e correção monetária. Em outros, são apresentados valores isolados a partir 
dos quais este autor definiu as funções que possuíam maior aderência $\left(R^{2}\right)$. A Tabela A 3 mostra as funções originais utilizadas.

Tabela A 3: Funções originais de Capex e Opex de tratamento utilizadas como referência

\begin{tabular}{|c|c|c|c|}
\hline Referência & Processo & Ano base & Função original \\
\hline \multicolumn{4}{|l|}{ Capex } \\
\hline $\begin{array}{l}\text { Adham \& } \\
\text { DeCarolis (2004) }\end{array}$ & MBR & 2004 & Determinada por este autor com $\mathrm{R}^{2}=0,929$ \\
\hline Côte et al. (2004) & MBR & 2004 & Determinada por este autor com $\mathrm{R}^{2}=0,990$ \\
\hline $\begin{array}{l}\text { Molinos-Senante } \\
\text { et al. (2012) }\end{array}$ & MBR & 2012 & $\begin{array}{l}\boldsymbol{C}=\mathbf{5 . 6 3 5 , 3} \mathbf{p e}^{-0,352} \\
\mathrm{C} \text { em } € / \text { pe } \\
\text { pe: equivalente pop. }\end{array}$ \\
\hline Guo et al. (2014) & MBR & 2014 & $\begin{array}{l}\log (C)=0,569 \times[\log (Q)]^{1,135}+4,605 \\
C \text { em USD } \\
Q \text { em m/dia }\end{array}$ \\
\hline CNI (2019a) & MBR & 2017 & $\begin{array}{l}C=6,3053 Q^{-0,252} \\
C \text { em } R \$ /\left(m^{3} / \text { ano }\right) \\
Q \text { em I/s }\end{array}$ \\
\hline EPA (2005) & UV & 2005 & Determinada por este autor com $\mathrm{R}^{2}=0,873$ \\
\hline MCidades (2017a) & $\mathrm{CL}$ & 2017 & Determinada por este autor com $\mathrm{R}^{2}=0,983$ \\
\hline EPA (2005) & OR & 2005 & Determinada por este autor com $\mathrm{R}^{2}=0,989$ \\
\hline Guo et al. (2014) & OR & 2014 & $\begin{array}{l}\log (C)=\mathbf{0}, 996 \times \log (Q)^{0,929}+3,082 \\
\text { C em USD } \\
\text { Q em m³/dia }\end{array}$ \\
\hline Judd (2017) & OR & 2015 & Determinada por este autor com $\mathrm{R}^{2}=0,676$ \\
\hline Herman et al. (2017) & OR & 2017 & Determinada por este autor com $\mathrm{R}^{2}=0,921$ \\
\hline \multicolumn{4}{|r|}{ - } \\
\hline $\begin{array}{l}\text { Adham \& } \\
\text { DeCarolis (2004) }\end{array}$ & MBR & 2004 & Determinada por este autor com $\mathrm{R}^{2}=0,838$ \\
\hline Côte et al. (2004) & MBR & 2004 & Determinada por este autor com $\mathrm{R}^{2}=0,963$ \\
\hline \multirow{2}{*}{$\begin{array}{l}\text { Molinos-Senante } \\
\text { et al. (2012) }\end{array}$} & \multirow[b]{2}{*}{ MBR } & \multirow[b]{2}{*}{2012} & $C=30,15 p e+13.542$ \\
\hline & & & $\begin{array}{l}\text { C em } € / \text { ano } \\
\text { pe: equivalente pop. }\end{array}$ \\
\hline \multirow[b]{2}{*}{ Guo et al. (2014) } & \multirow[b]{2}{*}{ MBR } & \multirow[b]{2}{*}{2014} & $\log (C)=0,639 \log (Q)^{1,143}+2,633$ \\
\hline & & & $\begin{array}{l}\text { C em USD/ano } \\
\text { Q em m³/dia }\end{array}$ \\
\hline \multirow[b]{2}{*}{ CNI (2019a) } & \multirow[b]{2}{*}{ MBR } & \multirow[b]{2}{*}{2017} & $C=1,7093 Q^{-0,075(b)}$ \\
\hline & & & $\begin{array}{l}\text { C em } R \$ / m^{3} \\
Q \text { em l/s }\end{array}$ \\
\hline MCidades (2017a) & $\mathrm{CL}$ & 2017 & Determinada por este autor com $\mathrm{R}^{2}=0,983$ \\
\hline EPA (2005) & UV & 2005 & Determinada por este autor com $\mathrm{R}^{2}=0,672$ \\
\hline \multirow[b]{2}{*}{ Guo et al. (2014) } & \multirow[b]{2}{*}{ OR } & \multirow[b]{2}{*}{2014} & $\log (C)=0,534 \log (Q)^{1,253}+2,786$ \\
\hline & & & $\begin{array}{l}\text { C em USD/ano } \\
\text { Q em m²/dia }\end{array}$ \\
\hline Herman et al. (2017) & OR & 2017 & Determinada por este autor com $\mathrm{R}^{2}=0,913$ \\
\hline $\begin{array}{l}\text { Schimmoler } \\
\text { \& Kealy (2013) }\end{array}$ & OR & 2013 & Determinada por este autor com $\mathrm{R}^{2}=0,91$ \\
\hline
\end{tabular}

\section{A4. Custos de adução}

As funções de Capexad e Opexad foram determinadas com base em literatura e em dimensionamentos específicos. 
Capexadutoras foi estimado de acordo com os custos unitários de CNI (2019a). O estudo apresenta apenas custos isolados em função de DN, e determinou-se função por regressão com $R^{2}=0,9704$.

O Capexee foi estimado conforme apresentado por Sabesp (2010a), ou seja, em função da potência requerida. De acordo com o discutido no item 3.2.5.2.1, a utilização somente da vazão para determinação de custos de EE ignora as perdas de carga na linha de adução, implicando em maiores possibilidades de inconsistências. Para compatibilização de unidades, a equação de Sabesp (2010a) foi transformada de CV para kW.

O Opexad se deve principalmente à demanda de energia elétrica para recalque e gastos com manutenção geral do sistema. Ou seja, em suma, depende da potência requerida pelo sistema elevatório e de características da linha de distribuição.

- Custos com energia elétrica: dependem da potência requerida pelo sistema, o que, por sua vez, é função principalmente da Altura Manométrica Total (AMT) do sistema. Depende também da tarifa local de energia elétrica.

- Custos de manutenção: relativos à manutenção de componentes do sistema (elevatória e adutora). Foram baseados em literatura (MCIDADES, 2017a; NOGUEIRA, 2010; OECD EAP, 2005). Conforme faixa apresentada em literatura (de 3 a $6 \%$, ver item 3.2.5.2.3), fixou-se que custo de manutenção igual a $4,5 \%$ do Capex total do sistema de bombeamento, incluindo elevatórias e adutoras.

As funções originais utilizadas na composição de Capexaduturas e Capexee são as da Tabela A 4

Tabela A 4: Funções originais de Capex de adução utilizadas como referência

\begin{tabular}{|c|c|c|c|c|}
\hline Custo & Referência & Tipo & $\begin{array}{l}\text { Ano- } \\
\text { base }\end{array}$ & Função original \\
\hline Capexadutoras & CNI (2019a) & Capex de adutoras & 2017 & $\begin{array}{l}\text { Determinada por este autor com } \\
R^{2}=0,9704\end{array}$ \\
\hline \multirow{3}{*}{ Capex $_{e e}$} & \multirow{3}{*}{ Sabesp (2010a) } & $\begin{array}{l}\text { Elevatórias - } \\
\text { eletromecânica }\end{array}$ & 2009 & $\begin{array}{l}\boldsymbol{C}=\mathbf{1 8 . 2 8 6} \boldsymbol{P}^{-\mathbf{0}, 6852} \\
\mathrm{C} \text { em } \mathrm{R} \$ \\
\mathrm{P} \text { em CV }\end{array}$ \\
\hline & & $\begin{array}{l}\text { Elevatórias - obras } \\
\text { civis }\end{array}$ & 2009 & $\begin{array}{l}C=19.317 P^{0,5222} \\
C \text { em } R \$ /\left(m^{3} / \text { ano }\right) \\
P \text { em CV }\end{array}$ \\
\hline & & Elevatórias - total & 2009 & $\begin{array}{l}\boldsymbol{C}=\mathbf{3 4 . 6 7 7} \boldsymbol{P}^{-\mathbf{0 , 6 4 3 2}} \\
\mathrm{C} \text { em } \mathrm{R} \$ /\left(\mathrm{m}^{3} / \text { ano }\right) \\
\mathrm{P} \text { em } \mathrm{CV}\end{array}$ \\
\hline
\end{tabular}


$\mathrm{Na}$ sequência são apresentados os cálculos realizados para o dimensionamento genérico de adutoras, determinação de potência requerida de sistemas elevatórios e Opex de adução.

\section{a) Determinação de diâmetros nominais (DN)}

O DN das adutoras foi determinado com base em duas premissas de simplificação:

- diâmetros determinados a partir de velocidade de adução fixa, com $\mathrm{K}$ $=0,95$ (Bresse), ou seja, $\mathrm{v}=1,41 \mathrm{~m} / \mathrm{s}$, dentro da faixa recomendada por Tsutiya (2006);

- adoção de diâmetros resultantes da relação direta entre vazão e área de escoamento. Em outras palavras, adotou-se o diâmetro exato resultante da razão entre vazão e área de seção, sem utilização de diâmetros nominais (DN) comerciais. Ou seja, $\mathrm{D}=\mathrm{DN}$.

Ou seja, assumiu-se que o diâmetro "DN" utilizado é exatamente o resultante da equação da continuidade, o que, em termos práticos não é realidade. Em geral adotase diâmetro nominal próximo e superior ao obtido pela equação de Bresse. Entretanto, isso implica no fato de que não é possível expressar o diâmetro resultante diretamente por função matemática. Portanto, e por simplificação, adotou-se, que o diâmetro de fato utilizado é idêntico ao obtido pela equação, sendo esse inclusive o valor do diâmetro interno.

A fórmula de Bresse é conforme a Equação 18.

$$
D=K \times \sqrt{Q}
$$

Equação 18

$\begin{array}{ll}D(\mathrm{~mm}) & \text { diâmetro nominal } \\ \mathrm{K}(\mathrm{adim} .) & \text { coeficiente de Bresse } \\ \mathrm{Q}\left(\mathrm{m}^{3} / \mathrm{s}\right) & \text { vazão }\end{array}$

A equação de continuidade é como na Equação 19.

$$
\begin{aligned}
& v=\frac{Q}{A}=\frac{Q}{\frac{\pi D^{2}}{4}} \rightarrow D=\sqrt{\frac{4 Q}{\pi v}} \\
& v(\mathrm{~m} / \mathrm{s}) \quad \text { velocidade de escoamento } \\
& \mathrm{Q}\left(\mathrm{m}^{3 / \mathrm{s}}\right) \quad \text { vazão }
\end{aligned}
$$



$A\left(m^{2}\right)$
área interna de seção da tubulação
$D(m)$
diâmetro interno da tubulação

Em termos práticos, determinou-se valor de $\mathrm{K}=0,95$ (faixa usual entre 0,8 e 1,2). Em outras palavras, a velocidade é fixa e tem valor constante de $v=1,41 \mathrm{~m} / \mathrm{s}$. Ainda que as funções tenham sido mantidas em função de "v", na prática seu valor é fixo e igual a $1,41 \mathrm{~m} / \mathrm{s}$.

\section{b) Perdas de carga distribuída e localizada}

A perda de carga distribuída (J) foi calculada conforme a fórmula empírica de HazenWilliams para condutos forçados mostrada na Equação 20.

$$
J=\frac{10,643 \times Q^{1,85}}{C^{1,85} D^{4,87}}
$$

Substituindo-se "D" da Equação 19 na Equação 20, chega-se a "J" em função de "v".

$$
J=\frac{10,643 \times Q^{1,85}}{C^{1,85} D^{4,87}}=\frac{10,643 \times Q^{1,85}}{C^{1,85}\left(\sqrt{\frac{4 Q}{\pi v}}\right)^{4,87}}=\frac{10,643 \times Q^{1,85}}{C^{1,85}\left(\frac{4 Q}{v \pi}\right)^{\left(\frac{4,87}{2}\right)}}=\frac{5,9461 \times Q^{-0,585}}{C^{1,85} \times v^{-2,435}} \quad \text { Equação }
$$

$\begin{array}{ll}J(\mathrm{~m} / \mathrm{m}) & \text { perda de carga distribuída } \\ \mathrm{Q}\left(\mathrm{m}^{3} / \mathrm{s}\right) & \text { vazão } \\ \mathrm{C}\left(\mathrm{m}^{0,387} / \mathrm{s}\right) & \text { coeficiente de rugosidade } \\ \mathrm{V}(\mathrm{m} / \mathrm{s}) & \text { velocidade de escoamento }\end{array}$

As perdas de carga localizadas são calculadas pelo somatório dos coeficientes de perda de carga singular $(\Sigma \mathrm{Ks})$ e a velocidade de escoamento a partir da fórmula Universal de Darcy-Weisbach, como mostra a Equação 22.

$$
\Delta H_{L}=\frac{v^{2}}{2 g} \sum K_{s}
$$

Equação 22

$\begin{array}{ll}\Delta H_{L}(\mathrm{~m}) & \text { perdas de carga localizadas } \\ \vee(\mathrm{m} / \mathrm{s}) & \text { velocidade de escoamento } \\ \mathrm{g}\left(\mathrm{m} / \mathrm{s}^{2}\right) & \text { aceleração da gravidade } \\ \Sigma \mathrm{Ks} & \text { somatório dos coeficientes de perda de carga singular }\end{array}$

Dado o escopo desta pesquisa, é impraticável especificar os componentes e dispositivos hidráulicos ao longo de todas as adutoras, e por isso foram assumidas algumas singularidades com base em experiência do autor em projetos de obras 
lineares. A Tabela A 5 apresenta as singularidades consideradas, os coeficientes de perda de carga singular (K), a quantidade e o somatório $\Sigma \mathrm{Ks}$.

Tabela A 5: Quantitativo de peças hidráulicas para determinação de $\Sigma$ Ks padrão nas adutoras

\begin{tabular}{lll|l}
\hline Item & $\mathbf{K}$ & $\mathbf{Q t d e}$ & $\mathbf{K}^{\star} \mathbf{Q t d e}$ \\
\hline Curva $90^{\circ}$ & 0,4 & 3 & 1,2 \\
\hline Curva $45^{\circ}$ & 0,2 & 3 & 0,6 \\
\hline Entrada em canalização & 0,5 & 1 & 0,5 \\
\hline Válvula de pé & 1,75 & 2 & 3,5 \\
\hline Saída de canalização & 1 & 1 & 1 \\
\hline Tê de passagem direta & 0,6 & 4 & 2,4 \\
\hline Tê de saída de lado & 1,3 & 4 & 5,2 \\
\hline Válvula gaveta aberta & 0,2 & 5 & 1 \\
\hline Válvula de retenção & 2,5 & 2 & 5 \\
\hline IKs & & & $\mathbf{2 0 , 4}$
\end{tabular}

Fonte: K de acordo com Azevedo Netto \& Fernandez (1998)

Portanto, assumiu-se como valor base $\Sigma K s=20$, valor que pode ser considerado conservador.

A altura manométrica total (AMT) é a soma das perdas de carga distribuídas (J) e localizadas e do desnível geométrico que precisa ser vencido, conforme Equação 23.

$$
A M T=J \times L+\Delta H_{L}+\Delta H_{g}
$$

Equação 23

$\begin{array}{ll}\text { AMT }(m) & \text { altura manométrica total } \\ \mathrm{J}(\mathrm{m} / \mathrm{m}) & \text { perda de carga distribuída } \\ \mathrm{L}(\mathrm{m}) & \text { comprimento da tubulação } \\ \Delta \mathrm{H}_{\mathrm{L}}(\mathrm{m}) & \text { perda de carga localizada } \\ \Delta \mathrm{Hg}(\mathrm{m}) & \text { desnível geométrico }\end{array}$

Substituindo "J" da Equação 21 e " $\Delta \mathrm{HL}_{\mathrm{L}}$ " da Equação 22 na Equação 23, tem-se:

$$
A M T=\frac{5,9461 \times Q^{-0,585}}{C^{1,85} \times v^{-2,435}} \times L+\frac{v^{2}}{2 g} \sum K_{s}+\Delta H_{g}
$$

$\begin{array}{ll}\text { AMT }(\mathrm{m}) & \text { altura manométrica total } \\ \mathrm{Q}\left(\mathrm{m}^{3 / \mathrm{s}}\right) & \text { vazão } \\ \mathrm{C}\left(\mathrm{m}^{0,387} / \mathrm{s}\right) & \text { coeficiente de rugosidade } \\ \mathrm{V}(\mathrm{m} / \mathrm{s}) & \text { velocidade de escoamento } \\ \mathrm{L}(\mathrm{m}) & \text { comprimento da tubulação } \\ \mathrm{Ks} & \text { coeficiente de perda de carga singular } \\ \mathrm{g}\left(\mathrm{m} / \mathrm{s}^{2}\right) & \text { aceleração da gravidade } \\ \Delta \mathrm{Hg}(\mathrm{m}) & \text { desnível geométrico }\end{array}$


Como explicado no item 3.2.5.2, o desnível geométrico $\Delta \mathrm{Hg}$ foi obtido em ambiente SIG a partir da diferença de cotas entre ETE e usuário, sendo estabelecido valor mínimo de $10 \mathrm{~m}$.

\section{c) Potência requerida pelo sistema elevatório}

A potência é basicamente função da vazão da manométrica total. A equação prática de potência é como na Equação 25.

$$
P=\frac{9,85 \times Q \times A M T}{\eta}
$$

Potência $(\mathrm{kW}) \quad$ potência requerida do conjunto motor-bomba

$\mathrm{Q}\left(\mathrm{m}^{3} / \mathrm{s}\right) \quad$ vazão

AMT (m)

$\eta(\%)$

altura manométrica total

eficiência do conjunto motor-bomba

Substituindo AMT da Equação 24 na Equação 25, chega-se à Equação 26.

$$
P=\frac{9,85 \times Q}{\eta} \times\left(\frac{5,9461 \times Q^{-0,585}}{C^{1,85} \times v^{-2,435}} \times L+\frac{v^{2}}{2 g} \sum K_{s}+\Delta H_{g}\right)
$$

Potência (kW) potência requerida do conjunto motor-bomba

$\mathrm{Q}\left(\mathrm{m}^{3} / \mathrm{s}\right) \quad$ vazão

AMT $(\mathrm{m}) \quad$ altura manométrica total

$\eta(\%) \quad$ eficiência do conjunto motor-bomba

$v(\mathrm{~m} / \mathrm{s}) \quad$ velocidade de escoamento

$\mathrm{L}(\mathrm{m}) \quad$ comprimento da tubulação

Ks coeficiente de perda de carga singular

$\mathrm{g}\left(\mathrm{m} / \mathrm{s}^{2}\right) \quad$ aceleração da gravidade

$\Delta \mathrm{Hg}(\mathrm{m}) \quad$ desnível geométrico

\section{d) Custos de energia elétrica para adução}

O custo de operação com adução referente à necessidade de energia elétrica é dependente da potência exigida pelo sistema, do tempo de operação e da tarifa de energia elétrica.

$$
\text { Opex }_{a d}=P \times \text { tempo } \times T E
$$

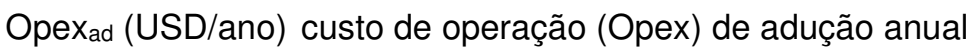
Potência (kW) potência requerida do conjunto motor-bomba tempo (h/ano) tempo de operação anual TE (USD/kWh) tarifa de energia elétrica 


\section{A5. Composição de tarifa mínima}

As tarifas mínimas são aquelas que resultam em Valor Presente Líquido (VPL) igual a zero ao final do período de retorno "N", considerando taxa de juros "i". O cálculo genérico de VPL é como apresenta a Equação 28.

$$
V P L=-\operatorname{Capex}+\sum_{n=1}^{N} \frac{F C}{(1+i)^{n}}
$$

VPL (USD) valor presente líquido

FC (USD/ano) fluxo de caixa anual

i (\% aa) taxa anual de juros

$\mathrm{n}$ (anos) ano analisado

$\mathrm{N}$ (anos) tempo de retorno no investimento

O fluxo de caixa (FC) anual é a subtração da receita da venda de água reúso (Tarifa $\times Q_{\text {anual }}$ ) subtraída pelo Opex anual. Ou seja, pode-se reescrever a Equação 28 como a Equação 29.

$$
V P L=- \text { Capex }+\sum_{n=1}^{N} \frac{F C}{(1+i)^{n}}=- \text { Capex }+\sum_{n=1}^{N} \frac{\text { Tarifa } \times Q_{a n u a l}-\text { Opex }_{\text {anual }}}{(1+i)^{n}}
$$

$$
\begin{array}{ll}
\text { VPL (USD) } & \text { valor presente líquido } \\
\text { Capex (USD) } & \text { custo de implantação } \\
\text { FC (USD/ano) } & \text { fluxo de caixa anual } \\
\text { Qanual ( } \left.\mathrm{m}^{3} / \text { ano }\right) & \text { vazão anual } \\
\text { Opexanual }(U S D / a n o) & \text { custo de operação anual } \\
\text { Tarifa (USD } \left./ \mathrm{m}^{3}\right) & \text { tarifa unitária a ser praticada } \\
\text { i } \% \text { aa) } & \text { taxa anual de juros } \\
\mathrm{n}(\text { anos }) & \text { ano } \\
\mathrm{N}(\text { anos }) & \text { tempo de retorno de investimento }
\end{array}
$$

Para o caso de $\mathrm{n}=\mathrm{N}$ (ou seja, ao final do tempo de retorno analisado), o somatório $\sum_{n=1}^{N} \frac{1}{(1+i)^{n}}$ pode ser expresso como na Equação 30.

$$
\sum_{n=1}^{N} \frac{1}{(1+i)^{n}}=\frac{1-(1+i)^{-n}}{i} \leftrightarrow n=N
$$

$\begin{array}{ll}\mathrm{i}(\% \text { aa) } & \text { taxa anual de juros } \\ \mathrm{N}(\text { anos }) & \text { tempo de retorno de investimento } \\ \mathrm{n} \text { (anos) } & \text { ano }\end{array}$

Substituindo-se a Equação 30 na Equação 29 e isolando-se a variável de tarifa, a tarifa mínima é calculada pela Equação 31. 
Tarifa $=\left(\frac{\text { Capex } \times i}{1-(1+i)^{-N}}+\right.$ Opex $\left._{\text {anual }}\right) \frac{1}{Q_{\text {anual }}}$

Tarifa $\left(\mathrm{USD} / \mathrm{m}^{3}\right) \quad$ tarifa unitária a ser praticada

Capex (USD) custo de implantação

FC (USD/ano) fluxo de caixa anual

Qanual ( $\left.\mathrm{m}^{3} / \mathrm{ano}\right) \quad$ vazão anual

Opexanual (USD/ano) custo de operação anual

i (\% aa) taxa anual de juros

$\mathrm{N}$ (anos) $\quad$ tempo de retorno de investimento

\section{A6. Custos específicos de desnitrificação - MBR(RN)}

No caso da previsão de desnitrificação, $\operatorname{MBR}(\mathrm{RN})$, os valores de Capex e Opex foram baseados nos de MBR. O arranjo proposto de $\operatorname{MBR}(R N)$ é de pré-desnitrificação, ou seja, com uma câmara seletora anóxica à montante do tanque de areação (TA). A estimativa foi realizada a partir de dimensionamentos conceituais considerando:

- alteração do Capex por conta de implantação de câmara seletora anóxica e de sistema de recirculação de efluente nitrificado do TA;

- alteração do Opex por conta da redução da demanda de $\mathrm{O}_{2}$ e dos requerimentos de energia elétrica para recirculação de efluente nitrificado.

a) Aumento do Capex por conta de implantação de tanque anóxico e de sistema de recirculação de efluente nitrificado

A implantação de um tanque anóxico resulta em maiores custos de Capex em relação a um processo MBR sem desnitrificação. Esse cômputo foi realizado considerando:

- custos com construção do tanque;

- implantação de sistema de recirculação de efluente nitrificado.

Usualmente, o volume do tanque anóxico é incluído no cálculo de volume de reator aeróbio, sendo geralmente uma porcentagem deste (entre 15 e 35\% geralmente). Por isso, a previsão de câmara anóxica não necessariamente incide em necessidade de aumento do volume total do sistema, e sim de divisão. Ainda assim, em se tratando de estimativa a favor da segurança, admitiu-se que o Capex de inclusão de etapa anóxica refere-se à construção de um tanque à parte. 
Tomaram-se como base os custos presentes no SINAPI nov/2019 ${ }^{19}$, Estado de São Paulo, para fornecimento e mão-de-obra de concreto usinado, armação e formas, e considerando-se alto valor de contingência (+50\%) por conta do nível simplificado de estimativa. Os parâmetros de determinação de volume de tanque e de quantitativo de materiais, bem como custos unitários (já convertidos em USD, 1 USD = 3,95BRL), seguem na Tabela A 6.

Tabela A 6: Parâmetros de dimensionamento, quantitativo e custos unitários para implantação de tanque anóxico para MBR(RN)

\begin{tabular}{|c|c|c|c|}
\hline Item & Descrição & Unid. & Valor \\
\hline \multicolumn{4}{|l|}{ Parâmetros } \\
\hline $\mathrm{TRH}$ & Tempo de retenção hidráulica do sistema MBR & $\mathrm{h}$ & 30 \\
\hline Anóxico & Fração anóxica & $\%$ TA & $20 \%$ \\
\hline $\mathrm{H}$ & Altura total do tanque & $\mathrm{m}$ & 3,5 \\
\hline $\mathrm{e}$ & Espessura das paredes & $\mathrm{m}$ & 0,25 \\
\hline Aço & Taxa de aço para armação & $\mathrm{kg} / \mathrm{m}^{3}$ concreto & 150 \\
\hline \multicolumn{4}{|c|}{ Custos unitários } \\
\hline Concreto* & Usinado fck $20 \mathrm{Mpa}$ & USD $/ \mathrm{m}^{3}$ & $\$ 96,18$ \\
\hline Armação* & CA-50 & USD/kg & $\$ 1,62$ \\
\hline Formas* & - & USD $/ \mathrm{m}^{2}$ & $\$ 3,73$ \\
\hline Contingência & - & $\%$ & $50 \%$ \\
\hline
\end{tabular}

Calculando-se os custos para vazões entre 0,01 e $2,0 \mathrm{~m}^{3} / \mathrm{s}$, tem-se a os valores da Tabela A 7.

Tabela A 7: Custos em função de vazão para implantação de tanque anóxico para MBR(RN)

\begin{tabular}{l|l|l|l|l|l|l|l|l}
\hline $\begin{array}{l}\mathbf{Q} \\
\left(\mathbf{m}^{\mathbf{3}} \mathbf{s} \mathbf{s}\right)\end{array}$ & $\begin{array}{l}\text { Volume } \\
\text { TA total } \\
\left(\mathbf{m}^{\mathbf{3}}\right)\end{array}$ & $\begin{array}{l}\text { Volume } \\
\text { anóxico } \\
\left(\mathbf{m}^{3}\right)\end{array}$ & $\mathbf{L} \mathbf{( m )}$ & $\begin{array}{l}\text { Volume de } \\
\text { concreto } \\
\left(\mathbf{m}^{3}\right)\end{array}$ & Aço $\mathbf{( k g )}$ & $\begin{array}{l}\text { Formas } \\
\left(\mathbf{m}^{2}\right)\end{array}$ & $\begin{array}{l}\text { Capex } \\
\text { tanque } \\
(\mathbf{U S D})\end{array}$ & $\begin{array}{l}\text { Capex tanque } \\
\left(\mathbf{U S D} / \mathbf{m}^{3} / \mathbf{a n o}\right)\end{array}$ \\
\hline 0,01 & 1.080 & 216 & 7,9 & 58 & 8.753 & 343 & $\$ 31.571$ & $\$ 0,10$ \\
\hline 0,05 & 5.400 & 1.080 & 17,6 & 216 & 32.365 & 1.109 & $\$ 115.837$ & $\$ 0,07$ \\
\hline 0,1 & 10.800 & 2.160 & 24,8 & 396 & 59.328 & 1.930 & $\$ 211.763$ & $\$ 0,07$ \\
\hline 0,25 & 27.000 & 5.400 & 39,3 & 909 & 136.336 & 4.186 & $\$ 485.238$ & $\$ 0,06$ \\
\hline 0,5 & 54.000 & 10.800 & 55,5 & 1.737 & 260.592 & 7.727 & $\$ 925.951$ & $\$ 0,06$ \\
\hline 1 & 108.000 & 21.600 & 78,6 & 3.361 & 504.100 & 14.542 & $\$ 1.788 .937$ & $\$ 0,06$ \\
\hline 2 & 216.000 & 43.200 & 111,1 & 6.560 & 984.041 & 27.796 & $\$ 3.488 .826$ & $\$ 0,06$
\end{tabular}

TA: tanque de areação. L: comprimento das paredes. Tanques com seção em planta quadrada.

Em relação à implantação de sistema de recirculação, considerou-se somente aquisição e implantação de equipamentos eletromecânicos, dado que a sucção ocorrerá direto do tanque de membranas e não haverá custos com obras de poço específico. Os custos de implantação de tubulação foram considerados irrisórios e não

${ }^{19}$ SINAPI_Custo_Ref_Composicoes_Sintetico_SP_201911_NaoDesonerado. Acesso disponível em 
foram contemplados. Os custos foram baseados em Sabesp (2010a) para estimativa de custos com eletromecânica de sistemas elevatórios, e a potência foi determinada conforme Equação 26 (item II - Custos de adução deste Anexo). Os parâmetros de cálculo seguem na Tabela A 8.

Tabela A 8: Parâmetros de dimensionamento para implantação de sistema de recirculação de efluente nitrificado para $\operatorname{MBR}(\mathrm{RN})$

\begin{tabular}{l|l|l|l}
\hline Item & Descrição & Unid. & Valor \\
\hline Taxa_recirc & $\begin{array}{l}\text { Taxa de recirculação do tanque de } \\
\text { membranas ao reator anóxico }\end{array}$ & $\%$ & $70 \%$ \\
\hline Qrec & Vazão de recirculação & $\%$ Qafl & $70 \%$ \\
\hline $\mathrm{L}$ & Comprimento da linha & $\mathrm{m}$ & 50 \\
\hline$\Delta \mathrm{Hg}$ & Desnível geométrico & $\mathrm{m}$ & 5 \\
\hline $\mathrm{V}$ & Velocidade de escoamento. K=0,88 (Bresse) & $\mathrm{m} / \mathrm{s}$ & 1,64 \\
\hline$\Sigma \mathrm{Ks}$ & Somatório dos coeficientes de perda de carga singular & - & 5 \\
\hline $\mathrm{C}$ & Coeficiente de rugosidade da tubulação & $\mathrm{m}$, $385 / \mathrm{s}$ & 120 \\
\hline $\mathrm{n}$ & Rendimento das bombas & $\%$ & $80 \%$ \\
\hline
\end{tabular}

Para vazões de 0,01 a 2,0 m³/s, chega-se aos custos da Tabela A 9 .

Tabela A 9: Custos para implantação de sistema de recirculação de efluente nitrificado para $\operatorname{MBR}(\mathbf{R N})$

\begin{tabular}{l|l|l|l|l|l}
\hline $\mathbf{Q}\left(\mathbf{m}^{\mathbf{3}} \mathbf{s}\right)$ & Qrecirc $\left(\mathbf{m}^{\mathbf{3}} \mathbf{s}\right)$ & $\mathbf{P}(\mathbf{k W})$ & $\mathbf{P}(\mathbf{C V})$ & $\begin{array}{l}\text { Custo total de } \\
\text { sistema de } \\
\text { recirculação (USD) }\end{array}$ & $\begin{array}{l}\text { Custo unitários de } \\
\text { sistema de } \\
\text { recirculação } \\
\text { (USD/m } / \text { ano) }\end{array}$ \\
\hline 0,01 & 0,007 & 1 & 1 & $\$ 29.253$ & $\$ 0,071$ \\
\hline 0,05 & 0,035 & 5 & 6 & $\$ 80.997$ & $\$ 0,033$ \\
\hline 0,1 & 0,07 & 9 & 13 & $\$ 126.042$ & $\$ 0,023$ \\
\hline 0,25 & 0,175 & 23 & 32 & $\$ 226.545$ & $\$ 0,015$ \\
\hline 0,5 & 0,35 & 46 & 63 & $\$ 353.310$ & $\$ 0,011$ \\
\hline 1 & 0,7 & 92 & 126 & $\$ 551.270$ & $\$ 0,008$ \\
\hline 2 & 1,4 & 185 & 251 & $\$ 860.420$ & $\$ 0,006$ \\
\hline
\end{tabular}

Somando-se as duas componentes acima calculadas, o Capex de $\operatorname{MBR}(\mathrm{RN})$ para faixas de vazão entre 0,01 e 2,0 m³/s (Tabela A 8 e Tabela A 9) foram obtidos os valores da Tabela A 10.

Tabela A 10: Valores de Capex de MBR(RN) em função da vazão

\begin{tabular}{|c|c|c|c|c|c|}
\hline$Q\left(m^{3} / s\right)$ & $\begin{array}{l}\text { Capex MBR } \\
\text { (USD/m³/ano) }\end{array}$ & $\begin{array}{l}\text { Capex tanque } \\
\text { anóxico } \\
\text { (USD/m³/ano) }\end{array}$ & $\begin{array}{l}\text { Capex } \\
\text { recirculação } \\
\text { (USD/m³/ano) }\end{array}$ & \begin{tabular}{|l|} 
Capex \\
MBR(RN) \\
(USD/m³/ano) \\
\end{tabular} & Dif. (\%) \\
\hline 0,01 & $\$ 8,76$ & $\$ 0,10$ & $\$ 0,071$ & $\$ 8,93$ & $1,9 \%$ \\
\hline 0,05 & $\$ 5,85$ & $\$ 0,07$ & $\$ 0,033$ & $\$ 5,95$ & $1,8 \%$ \\
\hline 0,1 & $\$ 4,91$ & $\$ 0,07$ & $\$ 0,023$ & $\$ 5,01$ & $1,8 \%$ \\
\hline 0,25 & $\$ 3,90$ & $\$ 0,06$ & $\$ 0,015$ & $\$ 3,98$ & $1,9 \%$ \\
\hline 0,5 & $\$ 3,28$ & $\$ 0,06$ & $\$ 0,011$ & $\$ 3,35$ & $2,1 \%$ \\
\hline 1 & $\$ 2,76$ & $\$ 0,06$ & $\$ 0,008$ & $\$ 2,82$ & $2,3 \%$ \\
\hline 2 & $\$ 2,32$ & $\$ 0,06$ & $\$ 0,006$ & $\$ 2,38$ & $2,6 \%$ \\
\hline
\end{tabular}

A partir dos valores da Tabela A 10, a função de Capex de $M B R(R N)$ é conforme Equação 32. 


$$
\operatorname{Capex} \operatorname{MBR}(R N)=2,8208 Q^{-0,25} \quad R^{2}=1
$$

Capex MBR(RN) (USD/m³/ano) $\mathrm{Q}\left(\mathrm{m}^{3} / \mathrm{s}\right)$ custo de capital de $\operatorname{MBR}(\mathrm{RN})$ vazão

A Figura A 1 apresenta as curvas de Capex $\operatorname{MBR}(R N)$ e, para fins de comparação, também a de Capex MBR.

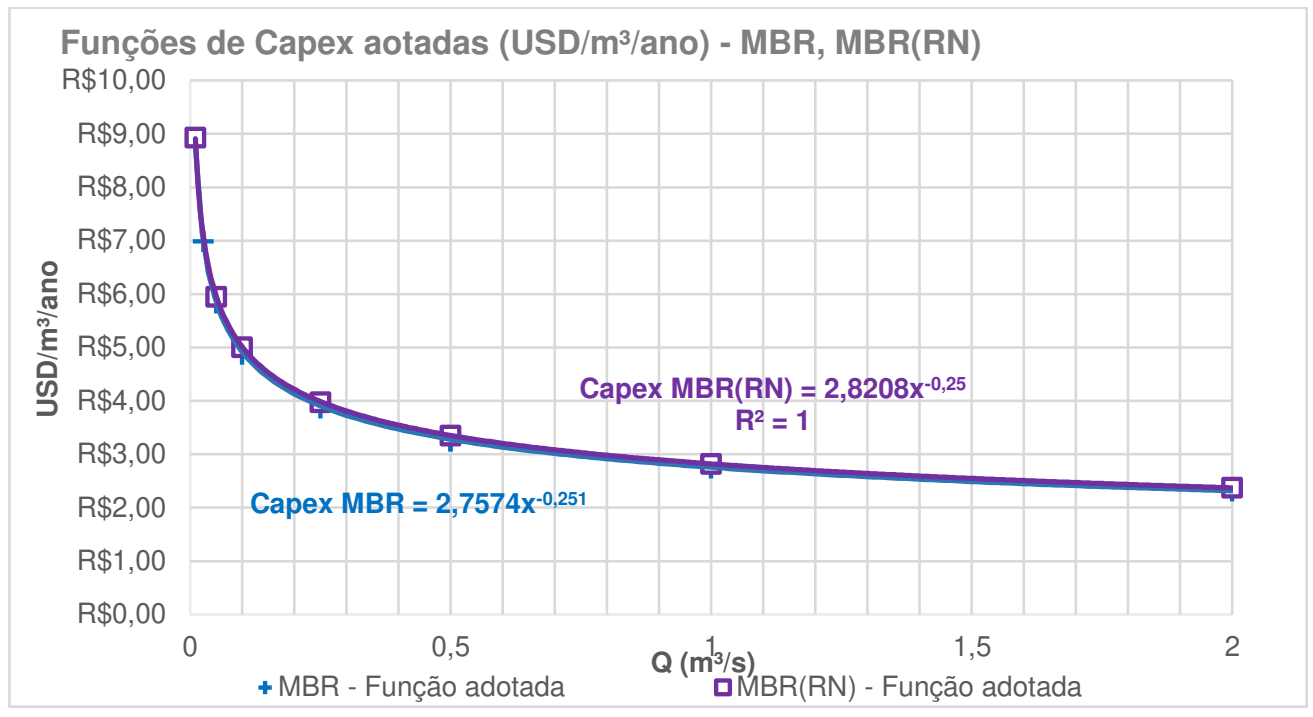

Figura A 1: Curvas de Capex MBR(RN) e Capex MBR

b) Alteração do Opex por conta da demanda satisfeita de $\mathrm{O}_{2}$ e recirculação de efluente nitrificado

Em sistemas MBR, cerca de 35\% de Opex se deve a custos de energia elétrica para aeração (ADHAM; DECAROLIS, 2004; DECAROLIS et al., 2007). Parte do ar soprado se destina à limpeza física (scouring) das membranas de MF/UF, enquanto a outra é responsável pela transferência de $\mathrm{O}_{2}$ ao meio líquido.

Em sistemas com etapa de pré-desnitrificação, parte da demanda de oxigênio é "satisfeita" pela desnitrificação, dado que há liberação de $\mathrm{O}_{2}$ durante o processo de redução do nitrato a nitrogênio elementar $\left(\mathrm{N}_{2}\right)$.

Assumiu-se que $70 \%$ se deve à transferência de oxigênio e os $30 \%$ restantes à limpeza das membranas. Em se tratando de esgoto doméstico, é usual que a relação DBO:NTK seja da ordem de 100:5. Os coeficientes de demanda de ar para oxidação de $\mathrm{DBO}, \mathrm{N}$ e de $\mathrm{O}_{2}$ retornado pela desnitrificação são os usualmente adotados em 
projetos de saneamento. A Tabela A 11 apresenta os parâmetros e valores utilizados na estimativa $\mathrm{O}_{2}$ satisfeito pela desnitrificação.

Tabela A 11: Variáveis para cálculo do \% de demanda de $\mathrm{O}_{2}$ satisfeita pela desnitrificação

\begin{tabular}{|c|c|c|c|}
\hline Item & Descrição & Unid. & Valor \\
\hline DBO NTK & Relação DBO/NTK afluente & $\mathrm{kgDBO} / \mathrm{kgNTK}$ & 5 \\
\hline $\mathrm{MO}$ & Demanda de $\mathrm{O}_{2}$ para oxidação da DBO & $\mathrm{kgO} / \mathrm{kgDBO}$ & 2,3 \\
\hline MO_nitr & Demanda de $\mathrm{O}_{2}$ para nitrificação & $\mathrm{kgO} 2 / \mathrm{kgN}-\mathrm{NH} 3$ & 4,57 \\
\hline MO_desnitr & Taxa de $\mathrm{O}_{2}$ retornado pela desnitrificação & $\mathrm{kgO} 2 / \mathrm{kgN}-\mathrm{NO} 3$ & 2,86 \\
\hline Taxa_recirc & $\begin{array}{l}\text { Taxa de recirculação do tanque de membranas } \\
\text { ao reator anóxico }\end{array}$ & $\%$ & $70 \%$ \\
\hline \%Opex_ar & $\begin{array}{l}\text { Porcentagem do Opex total do sistema referente à } \\
\text { aeração (limpeza + transferência de } \mathrm{O}_{2} \text { ) }\end{array}$ & - & $35 \%$ \\
\hline \%ar_limpeza & $\begin{array}{l}\text { Porcentagem da vazão total de ar destinada à limpeza } \\
\text { das membranas }\end{array}$ & - & $30 \%$ \\
\hline \%ar_transf & $\begin{array}{l}\text { Porcentagem da vazão total de ar destinada à } \\
\text { transferência de } \mathrm{O}_{2} \text { ao meio líquido }\end{array}$ & - & $70 \%$ \\
\hline
\end{tabular}

A partir dos valores acima, foram calculados os valores relativos (\%) de redução de custos com aeração em razão da demanda satisfeita de $\mathrm{O}_{2}$ pela desnitrificação, conforme a Tabela A 12.

Tabela A 12: Variáveis para cálculo da \% de Opex reduzida pela desnitrificação

\begin{tabular}{l|l|l}
\hline Item & Descrição & $\%$ \\
\hline \%ar_transf_nitr & $\begin{array}{l}\text { Porcentagem da demanda de O2 utilizada na nitrificação em relação a } \\
\text { \%ar_transf }\end{array}$ & $28 \%$ \\
\hline \%ar_satisf_desnitr_rel & $\begin{array}{l}\text { Porcentagem de demanda de O2 satisfeita pela desnitrificação em } \\
\text { relação a \%ar_transf_nitr }\end{array}$ & $44 \%$ \\
\hline \%ar_satisf_desnitr & $\begin{array}{l}\text { Porcentagem de demanda de O2 satisfeita pela desnitrificação em } \\
\text { relação a \%ar_transf }\end{array}$ & $12 \%$ \\
\hline \%Opex_ar_desnitr & $\begin{array}{l}\text { Porcentagem de demanda de } \mathbf{O}_{2} \text { satisfeita pela desnitrificação em } \\
\text { relação ao Opex total }\end{array}$ & $\mathbf{3 , 1} \%$ \\
\hline
\end{tabular}

O cálculo de \%Opex_ar_desnitr apresentado acima foi realizado pela Equação 33. $\% O p e x_{-}\left(a r \_d e s n i t r\right)$

$$
\begin{aligned}
& =\% \text { Opex_ar } \times \% \text { ar_transf } \times \% \text { ar_ }(\text { satisf_desnitr }) \\
& =35 \% \times \mathbf{7 0} \% \times \mathbf{1 2} \%=\mathbf{3}, 1 \%
\end{aligned}
$$

Capex $\operatorname{MBR}(\mathrm{RN})\left(\mathrm{USD} / \mathrm{m}^{3} / \mathrm{ano}\right)$ $\mathrm{Q}\left(\mathrm{m}^{3} / \mathrm{s}\right)$

Ou seja, o Opex de $\operatorname{MBR}(\mathrm{RN})$ é $3,1 \%$ menor que o de $M B R$ no que se refere ao consumo de energia elétrica em sopradores de ar. Ao mesmo tempo, há aumento de consumo de energia elétrica por conta da recirculação interna (do TA ao anóxico). Utilizou-se a Equação 27 (item II - Custos de adução deste Anexo) para cálculo dos custos com energia elétrica. A Tabela A 13 apresenta as variáveis utilizadas e seus respectivos valores. 
Tabela A 13: Variáveis para cálculo de aumento de Opex por conta da desnitrificação (custos energéticos com recirculação)

\begin{tabular}{l|l|l|l}
\hline Item & Descrição & Unid. & Valor \\
\hline Taxa_recirc & $\begin{array}{l}\text { Taxa de recirculação do tanque de } \\
\text { membranas ao reator anóxico }\end{array}$ & $\%$ & $70 \%$ \\
\hline $\mathrm{L}$ & Comprimento da linha de recirculação & $\mathrm{m}$ & 50 \\
\hline$\Delta \mathrm{Hg}$ & Desnível geométrico & $\mathrm{m}$ & 5,0 \\
\hline $\mathrm{v}$ & Velocidade de escoamento. K=0,88 (Bresse) & $\mathrm{m} / \mathrm{s}$ & 1,64 \\
\hline$\Sigma \mathrm{Ks}$ & Somatório dos coeficientes de perda de carga singular & - & 5 \\
\hline $\mathrm{C}$ & Coeficiente de rugosidade & - & 120 \\
\hline $\mathrm{n}$ & Rendimento das bombas & $\%$ & $80 \%$ \\
\hline $\mathrm{TE}$ & Tarifa de energia elétrica & $\mathrm{USD} / \mathrm{kWh}$ & $\$ 0,10$ \\
\hline
\end{tabular}

Aplicando-se a supracitada Equação 27 para cálculo de Opex de recirculação e somando-se a redução de Opex resultante da demanda satisfeita de $\mathrm{O}_{2}$, chega-se aos valores apresentados na Tabela A 14 para vazões entre 0,01 e 2,0 m³.s.

Tabela A 14: Valores de Opex MBR(RN) em função de vazão

\begin{tabular}{l|l|l|l|l|l|l}
\hline $\begin{array}{l}\text { Qafl } \\
\left(\mathbf{m}^{3} \mathbf{s} \mathbf{s}\right)\end{array}$ & $\begin{array}{l}\text { Qrec } \\
\left(\mathbf{m}^{\mathbf{3}} \mathbf{s}\right)\end{array}$ & $\begin{array}{l}\text { Opex MBR } \\
\left(\mathbf{U S D} / \mathbf{m}^{3}\right)\end{array}$ & $\begin{array}{l}\text { Redução de Opex pelo } \\
\mathbf{O}_{2} \text { satisfeito }\left(\mathbf{U S D} / \mathbf{m}^{3}\right)\end{array}$ & $\begin{array}{l}\text { Custo adicional com } \\
\text { recirculação } \\
\left(\mathbf{U S D} / \mathbf{m}^{3}\right)\end{array}$ & $\begin{array}{l}\text { Opex } \\
\mathbf{M B R ( R N )} \\
\left(\mathbf{U S D} / \mathbf{m}^{3}\right)\end{array}$ & Dif. (\%) \\
\hline 0,01 & 0,007 & $\$ 0,44$ & $\$ 0,0133$ & $\$ 0,0038$ & $\$ 0,427$ & $-2,2 \%$ \\
\hline 0,05 & 0,035 & $\$ 0,38$ & $\$ 0,0115$ & $\$ 0,0037$ & $\$ 0,370$ & $-2,1 \%$ \\
\hline 0,1 & 0,07 & $\$ 0,35$ & $\$ 0,0108$ & $\$ 0,0037$ & $\$ 0,347$ & $-2,0 \%$ \\
\hline 0,25 & 0,175 & $\$ 0,33$ & $\$ 0,0100$ & $\$ 0,0037$ & $\$ 0,320$ & $-1,9 \%$ \\
\hline 0,5 & 0,35 & $\$ 0,31$ & $\$ 0,0094$ & $\$ 0,0037$ & $\$ 0,301$ & $-1,9 \%$ \\
\hline 1 & 0,7 & $\$ 0,29$ & $\$ 0,0088$ & $\$ 0,0037$ & $\$ 0,283$ & $-1,8 \%$ \\
\hline 2 & 1,4 & $\$ 0,27$ & $\$ 0,0083$ & $\$ 0,0037$ & $\$ 0,266$ & $-1,7 \%$ \\
\hline
\end{tabular}

Com base na Tabela A 14, a função de Opex de $M B R(R N)$ é como na Equação 34.

$\operatorname{opex} \operatorname{MBR}(R N)=0,2831 Q^{-0,089} R^{2}=1$

Equação 34

Opex $\operatorname{MBR}(\mathrm{RN})\left(\mathrm{USD} / \mathrm{m}^{3}\right)$

custo de operação de $\operatorname{MBR}(\mathrm{RN})$

$\mathrm{Q}\left(\mathrm{m}^{3} / \mathrm{s}\right)$

vazão

A Figura A 2 apresenta as curvas de $\operatorname{Opex} \operatorname{MBR}(\mathrm{RN})$ e, para fins de comparação, também a de Opex MBR. 


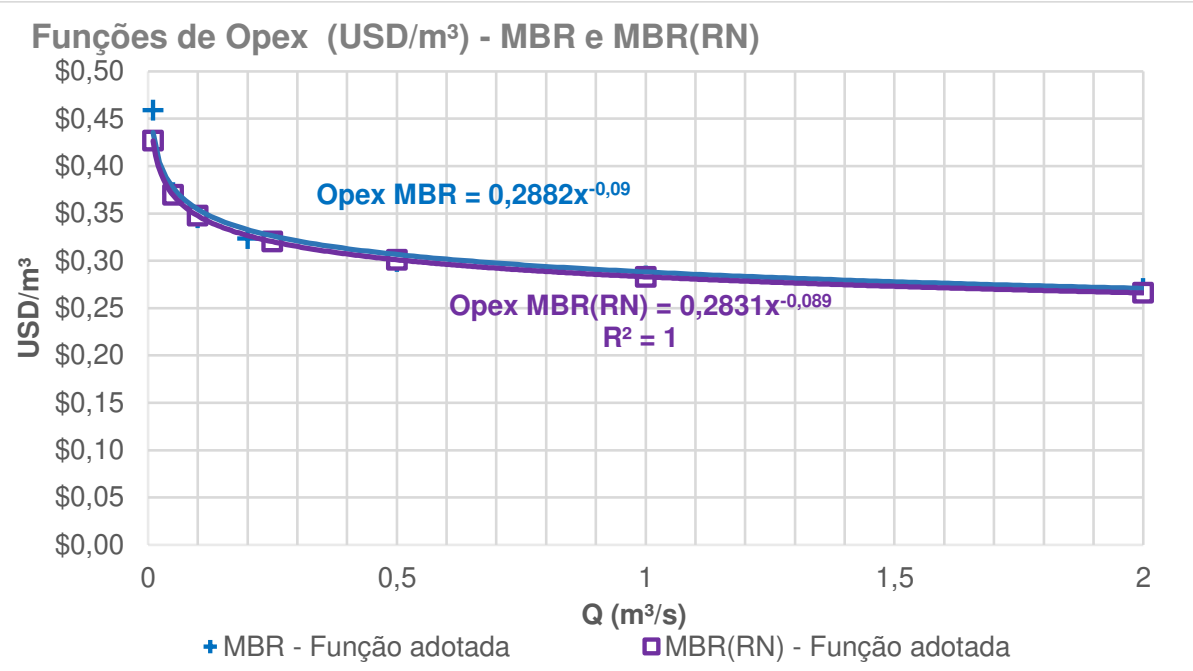

Figura A 2: Curvas de Opex de MBR(RN) e MBR 
ANEXO B. Resultados complementares da aplicação do IPR à RMSP

A Tabela B 1 apresenta os valores absolutos (não normalizados) e normalizados de cada um dos subcritérios do IPR e os resultados para todos os 39 municípios da RMSP. 
Tabela B 1: Parâmetros absolutos e normalizados e resultados completos de IPR para a RMSP por subcritério

\begin{tabular}{|c|c|c|c|c|c|c|c|c|c|c|c|c|c|c|c|c|c|c|c|c|c|c|c|c|c|}
\hline \multirow{5}{*}{ Município } & \multicolumn{12}{|c|}{ Técnicos } & \multicolumn{6}{|c|}{ Ambientais } & \multicolumn{6}{|c|}{ Socioeconômicos } & \multirow{5}{*}{ IPR } \\
\hline & \multicolumn{3}{|l|}{$T 1$} & \multicolumn{3}{|l|}{$T 2$} & & \multirow{2}{*}{\multicolumn{3}{|c|}{$\begin{array}{l}\text { T4 } \\
W=\end{array}$}} & \multicolumn{3}{|c|}{$A 1$} & \multicolumn{3}{|l|}{ A2 } & \multicolumn{3}{|c|}{ SE1 } & \multicolumn{3}{|l|}{ SE2 } & \\
\hline & \multirow{2}{*}{\multicolumn{3}{|c|}{ Unidade: $\mathrm{l} / \mathrm{s}$}} & $w=$ & & 0,162 & $w=$ & & 0,050 & & & & $w=$ & & 0,143 & $w=$ & & 0,143 & & & 0,048 & $w=$ & & 0,095 & \\
\hline & & & & Unidad & le: $1 / \mathrm{s}$ & & 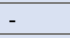 & & & Unidade & $: 1 / s$ & & Unidad & e: $\%$ & & & & & Unidade & : \% a.a & & Unidade: $\mathrm{R} \$$ & $\mathrm{mi} / \mathrm{ano}$ & & \\
\hline & & & w. $x_{\text {norm }}$ & & $x_{\text {norm }}$ & w.Xnorm & A & $x_{\text {norm }}$ & w.Xnorm & $x$ & $x_{\text {norm }}$ & W.Xnorm & & $x_{\text {norm }}$ & W.Xnorm & A & $x_{\text {norm }}$ & w. $x_{\text {norm }}$ & & $x_{\text {norm }}$ & W.Xnorm & & $x_{\text {norm }}$ & & \\
\hline São Paulo & 19.784 & 1,000 & 0,2435 & 2.178 & 0,958 & 0,1548 & 6,58 & 0,645 & 0,0324 & 7.091 & 0,591 & 0,0686 & $490 \%$ & 0,620 & 0,0885 & Péssima/ruim & 0,667 & 0,0952 & $0,55 \%$ & 0,169 & 0,0081 & 63.706 .120 & 1,000 & 0,0952 & 0,786 \\
\hline Suzano & 612 & 0,030 & 0,0074 & 2.274 & 1,000 & 0,1615 & 6,15 & 0,599 & 0,0301 & 1.500 & 0,125 & 0,0145 & $233 \%$ & 0,293 & 0,0419 & Péssima/ruim & 0,667 & 0,0952 & $1,06 \%$ & 0,386 & 0,0184 & 4.052 .945 & 0,063 & 0,0060 & 0,375 \\
\hline Barueri & 390 & 0,019 & 0,0047 & 53 & 0,023 & 0,0037 & 3,93 & 0,359 & 0,0180 & 12.000 & 1,000 & 0,1161 & $267 \%$ & 0,337 & 0,0481 & Péssima/ruim & 0,667 & 0,0952 & $0,97 \%$ & 0,347 & 0,0165 & 4.288 .852 & 0,067 & 0,0064 & 0,309 \\
\hline Mogi das Cruzes & 659 & 0,033 & 0,0080 & 1.750 & 0,770 & 0,1243 & 5,72 & 0,552 & 0,0277 & 250 & 0,021 & 0,0024 & $73 \%$ & 0,090 & 0,0128 & Péssima/ruim & 0,667 & 0,0952 & $1,14 \%$ & 0,419 & 0,0200 & 3.470 .789 & 0,054 & 0,0052 & 0,296 \\
\hline Taboão da Serra & 342 & 0,017 & 0,0041 & 39 & 0,017 & 0,0028 & 4,84 & 0,457 & 0,0230 & 0 & 0,000 & 0,0000 & $746 \%$ & 0,946 & 0,1351 & Péssima/ruim & 0,667 & 0,0952 & $1,55 \%$ & 0,593 & 0,0282 & 1.790 .113 & 0,028 & 0,0026 & $\begin{array}{l}0,291 \\
\end{array}$ \\
\hline Osasco & 1.596 & 0,080 & 0,0195 & 91 & 0,040 & 0,0065 & 4,12 & 0,380 & 0,0191 & 0 & 0,000 & 0,0000 & $789 \%$ & 1,000 & 0,1429 & Péssima/ruim & 0,667 & 0,0952 & $0,21 \%$ & 0,025 & 0,0012 & 3.101 .691 & 0,048 & 0,0046 & 0,289 \\
\hline Guarulhos & 1.750 & 0,088 & 0,0214 & 703 & 0,309 & 0,0499 & 4,77 & 0,450 & 0,0226 & 1.743 & 0,145 & 0,0169 & $247 \%$ & 0,311 & 0,0445 & Péssima/ruim & 0,667 & 0,0952 & $1,04 \%$ & 0,377 & 0,0180 & 10.618 .160 & 0,166 & 0,0158 & 0,284 \\
\hline São Caetano do Sul & 332 & 0,016 & 0,0040 & 26 & 0,011 & 0,0018 & 9,87 & 1,000 & 0,0502 & 0 & 0,000 & 0,0000 & $628 \%$ & 0,796 & 0,1137 & Péssima/ruim & 0,667 & 0,0952 & $0,15 \%$ & 0,000 & 0,0000 & 2.804 .157 & 0,044 & 0,0042 & 0,269 \\
\hline Diadema & 568 & 0,028 & 0,0069 & 54 & 0,024 & 0,0038 & 3,57 & 0,320 & 0,0161 & 0 & 0,000 & 0,0000 & $677 \%$ & 0,858 & 0,1226 & Péssima/ruim & 0,667 & 0,0952 & $0,49 \%$ & 0,144 & 0,0069 & 3.852 .514 & 0,060 & 0,0057 & 0,257 \\
\hline Mauá & 818 & 0,041 & 0,0100 & 205 & 0,090 & 0,0146 & 6,05 & 0,588 & 0,0295 & 1.12 & 0,094 & 0,0109 & $354 \%$ & 0,447 & 0,0639 & Péssima/ruim & 0,667 & 0,0952 & $1,02 \%$ & 0,369 & 0,0176 & 4.067 .033 & 0,063 & 0,0060 & 0,248 \\
\hline Carapicuíba & 793 & 0,040 & 0,0097 & 21 & 0,009 & 0,0015 & 4,54 & 0,425 & 0,0213 & 0 & 0,000 & 0,0000 & $589 \%$ & 0,746 & 0,1065 & Péssima/ruim & 0,667 & 0,0952 & $0,68 \%$ & 0,225 & 0,0107 & 821.452 & 0,013 & 0,0012 & 0,246 \\
\hline Santo André & 895 & 0,045 & 0,0109 & 493 & 0,217 & 0,0350 & 4,89 & 0,463 & 0,0232 & 5 & 0,000 & 0,0000 & $268 \%$ & 0,339 & 0,0484 & Péssima/ruim & 0,667 & 0,0952 & $0,26 \%$ & 0,047 & 0,0022 & 4.996 .810 & 0,078 & 0,0074 & 0,222 \\
\hline Poá & 239 & 0,012 & 0,0028 & 42 & 0,018 & 0,0030 & 7,91 & 0,789 & 0,0396 & 0 & 0,000 & 0,0000 & $324 \%$ & 0,409 & 0,0584 & Péssima/ruim & 0,667 & 0,0952 & $0,89 \%$ & 0,314 & 0,0149 & 39.778 & 0,010 & 0,0009 & 0,215 \\
\hline Biritiba-Mirim & 107 & 0,005 & 0,0012 & 846 & 0,372 & 0,0601 & 4,52 & 0,423 & 0,0212 & 55 & 0,005 & 0,0005 & $44 \%$ & 0,053 & 0,0076 & Péssima/ruim & 0,667 & 0,0952 & $1,27 \%$ & 0,475 & 0,0226 & 392.916 & 0,006 & 0,0005 & 0,209 \\
\hline São Bernardo do $C$ & 1.484 & 0,075 & 0,0182 & 394 & 0,173 & 0,0280 & 3,85 & 0,351 & 0,0176 & 31 & 0,003 & 0,0003 & $143 \%$ & 0,179 & 0,0256 & Péssima/ruim & 0,667 & 0,0952 & $0,62 \%$ & 0,199 & 0,0095 & 9.490 .552 & 0,149 & 0,0142 & 0,208 \\
\hline Jandira & 138 & 0,006 & 0,0016 & 10 & 0,004 & 0,0007 & 3,45 & 0,307 & 0,0154 & 0 & 0,000 & 0,0000 & $338 \%$ & 0,427 & 0,0610 & Péssima/ruim & 0,667 & 0,0952 & $1,36 \%$ & 0,513 & 0,0244 & 756.409 & 0,011 & 0,0011 & 0,199 \\
\hline Ferraz de & 310 & 0,015 & 0,0037 & 30 & 0,013 & 0,0021 & 4,74 & 0,447 & 0,0224 & 0 & 0,000 & 0,0000 & $257 \%$ & 0,325 & 0,0464 & Péssir & 0,667 & 0,0952 & $1,41 \%$ & 0,534 & 0,0254 & 803 & 0,012 & 0,0012 & 0,196 \\
\hline Itaquaquece & 1.326 & 0,067 & 0,0162 & 122 & 0,054 & 0,0087 & 1,84 & 0,134 & 0,0067 & 0 & 0,000 & 0,0000 & $207 \%$ & 0,260 & 0,0371 & Péssima/ruim & 0,667 & 0,0952 & $1,45 \%$ & 0,551 & 0,0262 & 1.4 & 0,023 & 0,0022 & 0,192 \\
\hline Cotia & 395 & 0,020 & 0,0048 & 271 & 0,119 & 0,0192 & 1,88 & 0,138 & 0,0069 & 120 & 0,010 & 0,0012 & $52 \%$ & 0,064 & 0,0091 & Péssima/ruim & 0,667 & 0,0952 & $2,17 \%$ & 0,856 & 0,0408 & 2.54 & 0,040 & 0,0038 & 0,181 \\
\hline Itapevi & 228 & 0,011 & 0,0027 & 72 & 0,031 & 0,0051 & 3,95 & 0,361 & 0,0181 & 0 & 0,000 & 0,0000 & $137 \%$ & 0,172 & 0,0245 & Péssima/ruim & 0,667 & 0,0952 & $1,74 \%$ & 0,674 & 0,0321 & 1.93 & 0,030 & 0,0029 & 0,181 \\
\hline Caieiras & 116 & 0,005 & 0,0013 & 414 & 0,182 & 0,0294 & 1,11 & 0,055 & 0,0028 & 0 & 0,000 & 0,0000 & $118 \%$ & 0,147 & 0,0210 & Péssima/ruim & 0,667 & 0,0952 & $1,56 \%$ & 0,597 & 0,0285 & 955.203 & 0,015 & 0,0014 & 0,180 \\
\hline Embu das Artes & 93 & 0,004 & 0,0010 & 75 & 3 & 0,0053 & 3,92 & 0,358 & 0,0180 & 0 & 0,000 & 0,0000 & $190 \%$ & 0,238 & 0,0341 & a/ruim & 0,667 & 0,0952 & $1,24 \%$ & 0,462 & 0,0220 & 1.4 & 0,022 & 0,0021 & 0,178 \\
\hline Arujá & 147 & 0,007 & 0,0017 & 53 & 0,023 & 0,0038 & 6,20 & 0,604 & 0,0303 & 154 & 0,013 & 0,0015 & $47 \%$ & 0,057 & 0,0081 & Péssima/ruim & 0,667 & 0,0952 & $1,88 \%$ & 0,733 & 0,0349 & 844.072 & 0,013 & 0,0012 & 0,177 \\
\hline Santar & 216 & 0,010 & 0,0025 & 52 & 23 & 0,0037 & 2,39 & 0,193 & 0,0097 & 0 & 0 & 0,0000 & $59 \%$ & 0,072 & 0,0103 & Péssima/ruim & 0,667 & 0,0952 & $2,51 \%$ & 1,000 & 0,0476 & 1.56 & 0,024 & 0,0023 & 0,171 \\
\hline Mairiporã & 154 & 0,007 & 0,0018 & 222 & 0,098 & 0,0158 & 3,04 & 0,263 & 0,0132 & 35 & 0,003 & 0,0003 & $21 \%$ & 0,024 & 0,0034 & Péssima/ruim & 0,667 & 0,0952 & $2,07 \%$ & 0,814 & 0,0387 & 267.262 & 0,004 & 0,0004 & 0,169 \\
\hline Cajamar & 115 & 0,005 & 0,0013 & 131 & 58 & 0,0093 & 1,08 & 0,052 & 0,0026 & 0 & 0,000 & 0,0000 & $52 \%$ & 0,063 & 0,0091 & Péssima/ruim & 0,667 & 0,0952 & $1,99 \%$ & 0,780 & 0,0371 & 1.9 & 0,030 & 0,0029 & 0,158 \\
\hline Vargem Grande Paulista & 70 & 0,003 & 0,0007 & 50 & 0,022 & 0,0036 & 1,57 & 0,105 & 0,0053 & 0 & 0,000 & 0,0000 & $66 \%$ & 0,081 & 0,0116 & Péssima/ruim & 0,667 & 0,0952 & $2,13 \%$ & 0,839 & 0,0400 & 670.654 & 0,010 & 0,0010 & 0,157 \\
\hline Rio Grande da Serra & 16 & 0,000 & 0,0001 & 19 & 0,008 & 0,0014 & 4,76 & 0,449 & 0,0225 & 24 & 0,002 & 0,0002 & $47 \%$ & 0,057 & 0,0082 & Péssima/ruim & 0,667 & 0,0952 & $1,29 \%$ & 0,483 & 0,0230 & 152.599 & 0,002 & 0,0002 & 0,151 \\
\hline Salesópolis & 60 & 0003 & 0006 & 103 & م & 0073 & 677 & 0,666 & 0,0334 & 35 & 0003 & 0,0003 & $5 \%$ & 0,003 & 00005 & Péssima/ruim & 0,667 & 0,0952 & $0,75 \%$ & 0,254 & 0,0121 & 32768 & 0,000 & 0,0000 & 0,150 \\
\hline Francisco Morato & 194 & 0,009 & 0,0023 & 3 & 0,001 & 0,0002 & 0,60 & 0,000 & 0,0000 & 0 & 0,000 & 0,0000 & $165 \%$ & 0,207 & 0,0296 & Péssima/ruim & 0,667 & 0,0952 & $1,23 \%$ & 0,458 & 0,0218 & 129.796 & 0,002 & 0,0002 & 0,149 \\
\hline Itapecerica & 151 & 0007 & 00017 & 61 & 0,027 & 0,0044 & 3,54 & 0,317 & 0,0159 & 4 & 0,000 & 00000 & $57 \%$ & 0,069 & 0,0099 & Péssima/ruim & 0,667 & 0,0952 & $1,09 \%$ & 0,398 & 0,0190 & 669.639 & 0,010 & 0,0010 & 0,147 \\
\hline Pirapora do Bom Jesus & 13 & 0,000 & 0,0000 & 10 & 0,005 & 0,0007 & 2,87 & 0,245 & 0,0123 & 36 & 0,003 & 0,0003 & $10 \%$ & 0,010 & 0,0014 & Péssima/ruim & 0,667 & 0,0952 & $1,85 \%$ & 0,720 & 0,0343 & 53.526 & 0,000 & 0,0000 & 0,144 \\
\hline Franco da Rocha & 191 & nona & 0,0022 & 75 & 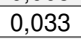 & 0053 & 091 & 0037 & 0,0018 & 0 & 0000 & 00000 & $61 \%$ & 0,075 & & & 0,667 & 0,0952 & $1,51 \%$ & 0,576 & 0,0274 & 010 & 0,013 & 0,0012 & 0,144 \\
\hline Ribeirão Pires & 63 & 0,003 & 0,0007 & 20 & 0,009 & 0,0014 & 5,48 & 0,526 & 0,0264 & 70 & 0,006 & 0,0007 & $50 \%$ & 0,061 & 0,0087 & Péssima/ruim & 0,667 & 0,0952 & $0,53 \%$ & 0,161 & 0,0077 & 641.965 & 0,010 & 0,0009 & 0,142 \\
\hline Embu-Guaçu & 103 & 0,005 & 0,0011 & 9 & (1) & 0,0007 & 4,63 & 0,435 & 0,0218 & 140 & 0,012 & 0,0014 & $16 \%$ & 0,018 & 0,0025 & Péssin & 0,667 & 0,0952 & $0,83 \%$ & 0,288 & 0,0137 & & 0,003 & 0,0003 & 0,137 \\
\hline Santa Isabel & 47 & 0,002 & 0,0005 & 201 & 0,088 & 0,0143 & 0,93 & 0,036 & 0,0018 & 0 & 0,000 & 0,0000 & $6 \%$ & 0,005 & 0,0007 & Péssima/ruim & 0,667 & 0,0952 & $0,91 \%$ & 0,322 & 0,0153 & 340.836 & 0,005 & 0,0005 & 0,128 \\
\hline Guararema & 34 & 0,001 & 0,0003 & 222 & 0,098 & 0158 & 5,80 & 0,561 & 0,0282 & 33 & 0,003 & 0,0003 & $5 \%$ & 0,003 & 0,0005 & Boa & 0,333 & 0,0476 & $1,33 \%$ & 0,500 & 0,0238 & 295.548 & 0,004 & 0,0004 & 0,117 \\
\hline São Lourenço da Serra & 10 & 0,000 & 0,0000 & 0 & 0,000 & 0,0000 & 3,98 & 0,365 & 0,0183 & 17 & 0,001 & 0,0002 & $2 \%$ & 0,001 & 0,0001 & Boa/ótima & 0,333 & 0,0476 & $1,11 \%$ & 0,407 & 0,0194 & 25.210 & 0,000 & 0,0000 & 0,086 \\
\hline Juquitiba & 22 & 0,001 & 0,0001 & 4 & 0,002 & 0,0003 & 3,25 & 0,286 & 0,0144 & 18 & 0,002 & 0,0002 & $2 \%$ & 0,000 & 0,0000 & Boa/ótima & 0,333 & 0,0476 & $0,56 \%$ & 0,174 & 0,0083 & 52.376 & 0,000 & 0,0000 & 0,071 \\
\hline
\end{tabular}

$\mathbf{x}$ : valor absoluto; $\mathbf{x}_{\text {norm: }}$ valor normalizado; w: prioridade global de cada subcritério; $\mathbf{x}_{\text {norm }} \mathbf{w}$ : produto do valor normalizado e da prioridade global de cada subcritério. 
ANEXO C. Resultados complementares da aplicação do modelo ETEusuário à RMSP

Neste anexo constam detalhes adicionais sobre cinco ETEs da RMSP e resultados completos por ETE e por usuário-âncora pela aplicação do Modelo ETE-usuário.

\section{C1. ETE Mauá}

A ETE Mauá se localiza no município de mesmo nome, próxima à divisa com Santo André e está inserida praticamente dentro do Polo Petroquímico de Capuava, o mesmo que é abastecido pelo Aquapolo a partir da ETE ABC. Ainda que se saiba o Aquapolo esteja fornecendo água abaixo de sua capacidade (aprox. 65\%) e que o efluente tratado poderia abastecer outros usuários além da Braskem, a determinação de usuários-âncora para a ETE Mauá foi realizada. A Tabela C 1 relaciona os 13 usuários-âncora para a ETE para cenário C1R.

Tabela C 1: Usuários-âncora para a ETE Mauá - C1R

\begin{tabular}{|c|c|c|c|c|c|c|c|}
\hline $\begin{array}{l}\text { ID } \\
\text { outorga }\end{array}$ & $\begin{array}{l}Q \\
(1 / \mathbf{s})^{(1)}\end{array}$ & $\begin{array}{l}Q_{N P} \\
(I / s)\end{array}$ & $\begin{array}{l}\text { Tarifa } \\
\text { C1R } \\
\left.\text { (USD/m }{ }^{3}\right) \\
\end{array}$ & $\begin{array}{l}\mathrm{L} \\
(\mathrm{km})\end{array}$ & Usuário & $\begin{array}{l}\text { CNAE } \\
2.0 \\
\text { (grupo) }\end{array}$ & CNAE 2.0 (grupo) \\
\hline 8012 & 137,0 & 93,2 & $\$ 1,10$ & 1,96 & $\begin{array}{l}\text { PETROLEO BRASILEIRO S.A. } \\
\text { - PETROBRAS }\end{array}$ & 35.10 & $\begin{array}{l}\text { Geração, transmissão e } \\
\text { distribuição de energia elétrica }\end{array}$ \\
\hline 8004 & 137,0 & 93,2 & $\$ 1,10$ & 1,98 & $\begin{array}{l}\text { PETROLEO BRASILEIRO S.A. } \\
\text { - PETROBRAS }\end{array}$ & 35.10 & $\begin{array}{l}\text { Geração, transmissão e } \\
\text { distribuição de energia elétrica }\end{array}$ \\
\hline 171886 & 112,0 & 68,3 & $\$ 1,40$ & 12,58 & $\begin{array}{l}\text { DU SOL COMERCIO DE } \\
\text { BEBIDAS LIMITADA - EPP }\end{array}$ & 11.20 & $\begin{array}{l}\text { Fabricação de bebidas não- } \\
\text { alcoólicas }\end{array}$ \\
\hline 10156 & 51,4 & 29,4 & $\$ 1,51$ & 4,34 & RHODIA S.A. & 13.10 & $\begin{array}{l}\text { Preparação e fiação de fibras } \\
\text { têxteis }\end{array}$ \\
\hline 171885 & 82,2 & 31,4 & $\$ 1,72$ & 12,32 & $\begin{array}{l}\text { DU SOL COMERCIO DE } \\
\text { BEBIDAS LIMITADA - EPP }\end{array}$ & 11.20 & $\begin{array}{l}\text { Fabricação de bebidas não- } \\
\text { alcoólicas }\end{array}$ \\
\hline 61543 & 9,6 & 8,2 & $\$ 2,18$ & 5,52 & $\begin{array}{l}\text { RHODIA POLIAMIDA E } \\
\text { ESPECIALIDADES LTDA }\end{array}$ & 20.20 & $\begin{array}{l}\text { Fabricação de produtos } \\
\text { químicos orgânicos }\end{array}$ \\
\hline 164530 & 9,0 & 5,8 & $\$ 2,19$ & 2,88 & $\begin{array}{l}\text { TP INDUSTRIAL DE PNEUS } \\
\text { BRASIL LTDA }\end{array}$ & 22.10 & $\begin{array}{l}\text { Fabricação de produtos de } \\
\text { borracha }\end{array}$ \\
\hline 164527 & 7,6 & 4,2 & $\$ 2,30$ & 1,88 & $\begin{array}{l}\text { TP INDUSTRIAL DE PNEUS } \\
\text { BRASIL LTDA }\end{array}$ & 22.10 & $\begin{array}{l}\text { Fabricação de produtos de } \\
\text { borracha }\end{array}$ \\
\hline 164534 & 5,2 & 4,9 & $\$ 2,33$ & 3,17 & $\begin{array}{l}\text { TP INDUSTRIAL DE PNEUS } \\
\text { BRASIL LTDA }\end{array}$ & 22.10 & $\begin{array}{l}\text { Fabricação de produtos de } \\
\text { borracha }\end{array}$ \\
\hline 164529 & 6,5 & 4,1 & $\$ 2,44$ & 3,10 & $\begin{array}{l}\text { TP INDUSTRIAL DE PNEUS } \\
\text { BRASIL LTDA }\end{array}$ & 22.10 & $\begin{array}{l}\text { Fabricação de produtos de } \\
\text { borracha }\end{array}$ \\
\hline 164531 & 6,4 & 3,3 & $\$ 2,49$ & 2,20 & $\begin{array}{l}\text { TP INDUSTRIAL DE PNEUS } \\
\text { BRASIL LTDA }\end{array}$ & 22.10 & $\begin{array}{l}\text { Fabricação de produtos de } \\
\text { borracha }\end{array}$ \\
\hline 10135 & 5,1 & 4,5 & $\$ 2,53$ & 4,49 & TINTAS CORAL S.A. & 20.70 & $\begin{array}{l}\text { Fabricação de tintas, vernizes, } \\
\text { esmaltes, lacas e produtos afins }\end{array}$ \\
\hline 11038 & 3,4 & 2,1 & $\$ 2,62$ & 1,08 & PHILIPS DO BRASIL LTDA & 27.40 & $\begin{array}{l}\text { Fabricação de lâmpadas e } \\
\text { outros equipamentos de } \\
\text { iluminação }\end{array}$ \\
\hline Total & 572,4 & 353,6 & - & - & & & \\
\hline Média & 44,0 & 27,1 & $\$ 1,99$ & 4,42 & & & \\
\hline
\end{tabular}


Além dos usuários no próprio polo petroquímico, há outros já em Ribeirão Pires, localizados após o Rodoanel Mario Covas. Provavelmente a ETE Ribeirão Pires $(Q=$ $70 \mathrm{l} / \mathrm{s}$ ) seja melhor opção de abastecimento para esses casos, mas as coordenadas desta estação não foram encontradas para a realização de análises espaciais e determinação de tarifas. A Figura C 1 apresenta mapa com a distribuição dos usuários-âncora.

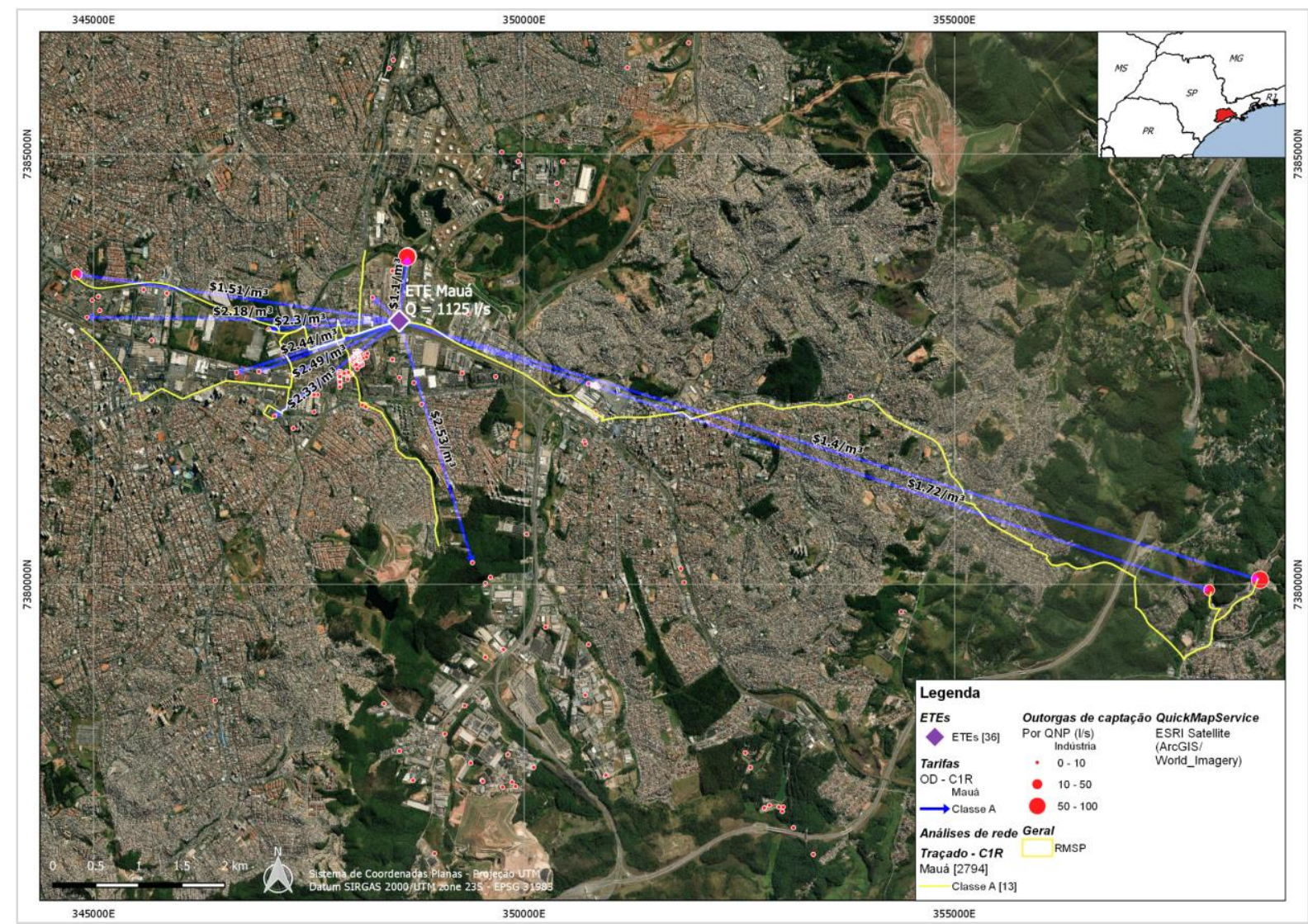

Figura C 1: Distribuição dos usuários-âncora em relação à ETE Mauá para C1R: traçados de adutoras (em amarelo) e OD (origem destino) com tarifas (em azul)

Fonte: elaborado pelo autor

\section{C2. ETE Leste}

A ETE Leste se localiza no município de Mogi das Cruzes e possui capacidade de 250 I/s. É a maior ETE da RMSP não operada pela Sabesp ou BRK. Está localizada a aproximadamente $15 \mathrm{~km}$ da ETE Suzano. A Tabela C 2 apresenta os 8 usuáriosâncora da ETE Leste (C1R). 
Tabela C 2: Usuários-âncora para a ETE Leste - C1R

\begin{tabular}{|c|c|c|c|c|c|c|c|}
\hline $\begin{array}{l}\text { ID } \\
\text { outorga }\end{array}$ & $\begin{array}{l}Q \\
(1 / s)^{(1)}\end{array}$ & $\begin{array}{l}Q_{\mathrm{NP}} \\
(\mathrm{I} / \mathrm{s})\end{array}$ & $\begin{array}{l}\text { Tarifa } \\
\text { C1R } \\
\left(\mathrm{USD} / \mathrm{m}^{3}\right)\end{array}$ & $\begin{array}{l}\mathrm{L} \\
(\mathrm{km})\end{array}$ & Usuário & $\begin{array}{l}\text { CNAE } \\
2.0 \\
\text { (grupo) }\end{array}$ & CNAE 2.0 (grupo) \\
\hline 123281 & 54,8 & 32,60 & $\$ 1,48$ & 4,71 & GERDAU S.A. & 24.20 & Siderurgia \\
\hline 77962 & 43,8 & 11,29 & $\$ 1,91$ & 4,08 & $\begin{array}{l}\text { MULTIVERDE PAPEIS } \\
\text { ESPECIAIS LTDA }\end{array}$ & 17.20 & $\begin{array}{l}\text { Fabricação de papel, } \\
\text { cartolina e papel-cartão }\end{array}$ \\
\hline 10772 & 35,6 & 9,17 & $\$ 1,99$ & 3,57 & INDS DE PAPEL SIMAO S A & 17.20 & $\begin{array}{l}\text { Fabricação de papel, } \\
\text { cartolina e papel-cartão }\end{array}$ \\
\hline 65652 & 43,8 & 11,29 & $\$ 2,14$ & 8,18 & $\begin{array}{l}\text { KIMBERLY-CLARK BRASIL } \\
\text { IND COM PROD DE HIGIENE } \\
\text { LTDA }\end{array}$ & 17.20 & $\begin{array}{l}\text { Fabricação de papel, } \\
\text { cartolina e papel-cartão }\end{array}$ \\
\hline 8332 & 10,3 & 6,99 & $\$ 2,22$ & 4,58 & AIR PRODUCTS BRASIL LTDA & 35.20 & $\begin{array}{l}\text { Produção e distribuição de } \\
\text { combustíveis gasosos por } \\
\text { redes urbanas }\end{array}$ \\
\hline 9599 & 20,5 & 5,29 & $\$ 2,37$ & 4,16 & $\begin{array}{l}\text { IND DE CELULOSE E PAPEL } \\
\text { BANDEIRANTES SA }\end{array}$ & 17.20 & $\begin{array}{l}\text { Fabricação de papel, } \\
\text { cartolina e papel-cartão }\end{array}$ \\
\hline 13187 & 21,9 & 5,64 & $\$ 2,55$ & 6,70 & $\begin{array}{l}\text { KLABIN FABRICADORA DE } \\
\text { PAPEL E CELULOSE S/A. }\end{array}$ & 17.30 & $\begin{array}{l}\text { Fabricação de embalagens } \\
\text { de papel, cartolina, papel- } \\
\text { cartão e papelão ondulado }\end{array}$ \\
\hline 10333 & 7,2 & 6,22 & $\$ 2,67$ & 9,20 & RESANA S.A. IND. QUIMICAS & 20.20 & $\begin{array}{l}\text { Fabricação de produtos } \\
\text { químicos orgânicos }\end{array}$ \\
\hline Total & 238,1 & 88,5 & - & - & & & \\
\hline Média & 29,8 & 11,1 & $\$ 2,17$ & 5,56 & & & \\
\hline
\end{tabular}

Assim como no caso da ETE Suzano, há grande participação de atividades de papel e celulose, mas o principal usuário-âncora é do setor siderúrgico (Gerdau). A Figura C 2 apresenta mapa com a distribuição dos usuários-âncora.

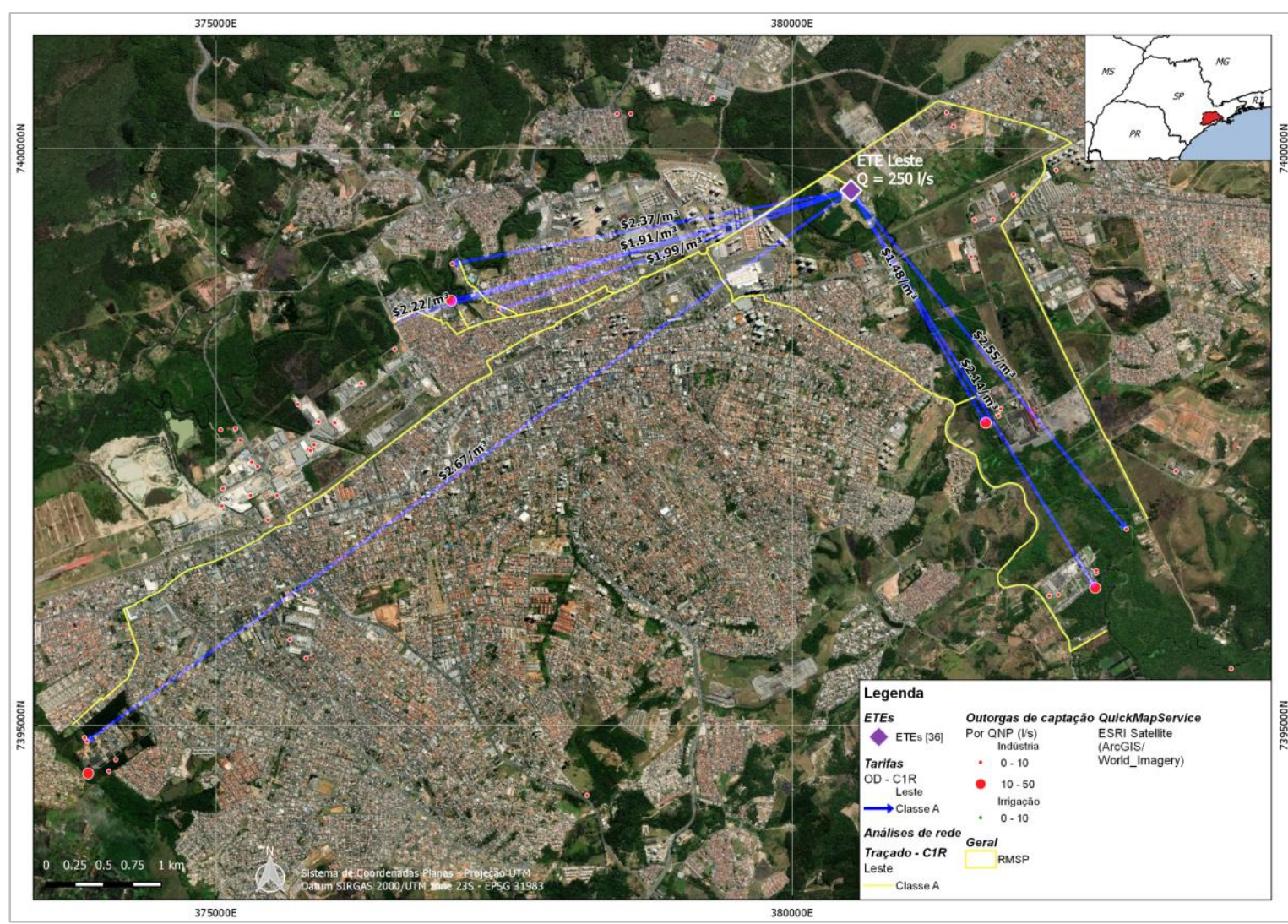

Figura C 2: Distribuição dos usuários-âncora em relação à ETE Leste para C1R: traçados de adutoras (em amarelo) e OD (origem destino) com tarifas (em azul)

Fonte: elaborado pelo autor 


\section{C3. ETEs Várzea do Palácio e São Miguel Paulista}

As ETEs São Miguel Paulista (São Paulo) e Várzea do Palácio (Guarulhos) estão localizadas próximas uma à outra (aprox. $5 \mathrm{~km}$ ), e por isso possuem usuários-âncora também próximos entre si. Desde 2018, a operação das ETEs do SAEE Guarulhos foi concedida à Sabesp, entre elas a Várzea do Palácio. A Tabela C 3 apresenta os usuários-âncora para as duas ETEs. Foram identificados 11 para a ETE São Miguel e 5 para a Várzea do Palácio.

Tabela C 3: Usuários-âncora para as ETEs São Miguel e Várzea do Palácio - C1R

\begin{tabular}{|c|c|c|c|c|c|c|c|}
\hline $\begin{array}{l}\text { ETE/ } \\
\text { ID outorga }\end{array}$ & $\begin{array}{l}Q \\
(\mathbf{l} / \mathbf{s})^{(1)}\end{array}$ & $\begin{array}{l}Q_{\mathrm{NP}} \\
(\mathrm{I} / \mathrm{s})\end{array}$ & $\begin{array}{l}\text { Tarifa } \\
\text { C1R } \\
\left(\text { USD } / \mathrm{m}^{3}\right)\end{array}$ & L (km) & Usuário & $\begin{array}{l}\text { CNAE } \\
2.0 \\
\text { (grupo) }\end{array}$ & CNAE 2.0 (grupo) \\
\hline São Miguel & 622,4 & 269,2 & $\begin{array}{l}\$ 1,94 \\
\text { (média) }\end{array}$ & $\begin{array}{l}5,10 \\
\text { (média) }\end{array}$ & & & \\
\hline 11903 & 150,7 & 129,6 & $\$ 0,97$ & 1,68 & $\begin{array}{l}\text { COMPANHIA NITRO } \\
\text { QUIMICA BRASILEIRA }\end{array}$ & 20.90 & $\begin{array}{l}\text { Fabricação de produtos e } \\
\text { preparados químicos diversos }\end{array}$ \\
\hline 9527 & 137,0 & 35,3 & $\$ 1,36$ & 3,63 & $\begin{array}{l}\text { INDUSTRIAS } \\
\text { MATARAZZO DE } \\
\text { EMBALAGENS LTDA }\end{array}$ & 17.20 & $\begin{array}{l}\text { Fabricação de papel, cartolina } \\
\text { e papel-cartão }\end{array}$ \\
\hline 17097 & 137,0 & 35,3 & $\$ 1,38$ & 4,21 & $\begin{array}{l}\text { VISCOFAN DO } \\
\text { BRASIL SOC } \\
\text { COMERCIAL E } \\
\text { INDUSTRIAL LTDA } \\
\end{array}$ & 17.20 & $\begin{array}{l}\text { Fabricação de papel, cartolina } \\
\text { e papel-cartão }\end{array}$ \\
\hline 11902 & 10,3 & 8,8 & $\$ 2,01$ & 9,82 & $\begin{array}{l}\text { COMPANHIA NITRO } \\
\text { QUIMICA BRASILEIRA }\end{array}$ & 20.90 & $\begin{array}{l}\text { Fabricação de produtos e } \\
\text { preparados químicos diversos }\end{array}$ \\
\hline 11900 & 9,1 & 7,9 & $\$ 2,14$ & 10,16 & $\begin{array}{l}\text { COMPANHIA NITRO } \\
\text { QUIMICA BRASILEIRA }\end{array}$ & 20.90 & $\begin{array}{l}\text { Fabricação de produtos e } \\
\text { preparados químicos diversos }\end{array}$ \\
\hline 11207 & 54,8 & 14,1 & $\$ 2,10$ & 7,07 & $\begin{array}{l}\text { CIA GUAIANAZES DE } \\
\text { PAPEL }\end{array}$ & 17.20 & $\begin{array}{l}\text { Fabricação de papel, cartolina } \\
\text { e papel-cartão }\end{array}$ \\
\hline 9967 & 27,4 & 9,8 & $\$ 1,95$ & 3,69 & $\begin{array}{l}\text { D. K. TINTURARIA } \\
\text { INDUSTRIAL LTDA }\end{array}$ & 13.10 & $\begin{array}{l}\text { Preparação e fiação de fibras } \\
\text { têxteis }\end{array}$ \\
\hline 11407 & 23,7 & 8,5 & $\$ 2,13$ & 6,07 & $\begin{array}{l}\text { INDUSTRIAS TEXTEIS } \\
\text { SUECO LTDA. }\end{array}$ & 13.10 & $\begin{array}{l}\text { Preparação e fiação de fibras } \\
\text { têxteis }\end{array}$ \\
\hline 11571 & 46,6 & 12,0 & $\$ 1,99$ & 3,37 & $\begin{array}{l}\text { MANIKRAFT } \\
\text { GUAIANAZES IND.DE } \\
\text { CELULOSE E PAPEL } \\
\text { LTDA. }\end{array}$ & 17.40 & $\begin{array}{l}\text { Fabricação de produtos } \\
\text { diversos de papel, cartolina, } \\
\text { papel-cartão e papelão } \\
\text { ondulado }\end{array}$ \\
\hline 10044 & 20,5 & 3,5 & $\$ 2,32$ & 3,21 & $\begin{array}{l}\text { KOOK'S TINTURARIA } \\
\text { E ESTAMPARIA LTDA. }\end{array}$ & 14.10 & $\begin{array}{l}\text { Confecção de artigos do } \\
\text { vestuário e acessórios }\end{array}$ \\
\hline 11898 & 5,3 & 4,5 & $\$ 2,67$ & 6,07 & $\begin{array}{l}\text { COMPANHIA NITRO } \\
\text { QUIMICA BRASILEIRA }\end{array}$ & 20.90 & $\begin{array}{l}\text { Fabricação de produtos e } \\
\text { preparados químicos diversos }\end{array}$ \\
\hline $\begin{array}{l}\text { Várzea do } \\
\text { Palácio }\end{array}$ & 68,0 & 28,3 & $\begin{array}{l}\$ 2,44 \\
\text { (média) }\end{array}$ & $\begin{array}{l}4,74 \\
\text { (média) }\end{array}$ & & & \\
\hline 20420 & 23,7 & 8,5 & $\$ 2,18$ & 5,75 & ROSSET \& CIA LTDA. & 13.40 & $\begin{array}{l}\text { Acabamentos em fios, tecidos } \\
\text { e artefatos têxteis }\end{array}$ \\
\hline 113393 & 31,5 & 8,1 & $\$ 2,19$ & 5,52 & $\begin{array}{l}\text { DAMAPEL IND. COM. } \\
\text { E DISTRIBUICAO DE } \\
\text { PAPEIS LTDA }\end{array}$ & 17.20 & $\begin{array}{l}\text { Fabricação de papel, cartolina } \\
\text { e papel-cartão }\end{array}$ \\
\hline 170817 & 4,6 & 4,2 & $\$ 2,59$ & 5,66 & $\begin{array}{l}\text { FARMARIN } \\
\text { INDUSTRIA E } \\
\text { COMERCIO LTDA }\end{array}$ & 21.20 & $\begin{array}{l}\text { Fabricação de produtos } \\
\text { farmacêuticos }\end{array}$ \\
\hline 55263 & 5,1 & 4,7 & $\$ 2,60$ & 4,61 & $\begin{array}{l}\text { INOVAT INDUSTRIA } \\
\text { FARMACEUTICA }\end{array}$ & 21.20 & $\begin{array}{l}\text { Fabricação de produtos } \\
\text { farmacêuticos }\end{array}$ \\
\hline 54066 & 3,0 & 2,8 & $\$ 2,61$ & 2,17 & $\begin{array}{l}\text { PHIBRO SAUDE } \\
\text { ANIMAL } \\
\text { INTERNACIONAL } \\
\text { LTDA }\end{array}$ & 21.20 & $\begin{array}{l}\text { Fabricação de produtos } \\
\text { farmacêuticos }\end{array}$ \\
\hline
\end{tabular}

(1) Vazão total outorgada. Incluída para comparação com a vazão não potável $\left(Q_{N P}\right)$ 
Nessa região, atividades de produção de produtos químicos, papel e celulose, produtos têxteis e produtos farmacêuticos são as mais representativas. Usuários como a Companhia Nitroquímica, Matarazzo Embalagens, Viscofan, Guianazes Papel e Rosset \& Cia. se destacam. A Figura C 3 ilustra os usuários-âncora em relação a ambas as ETEs.

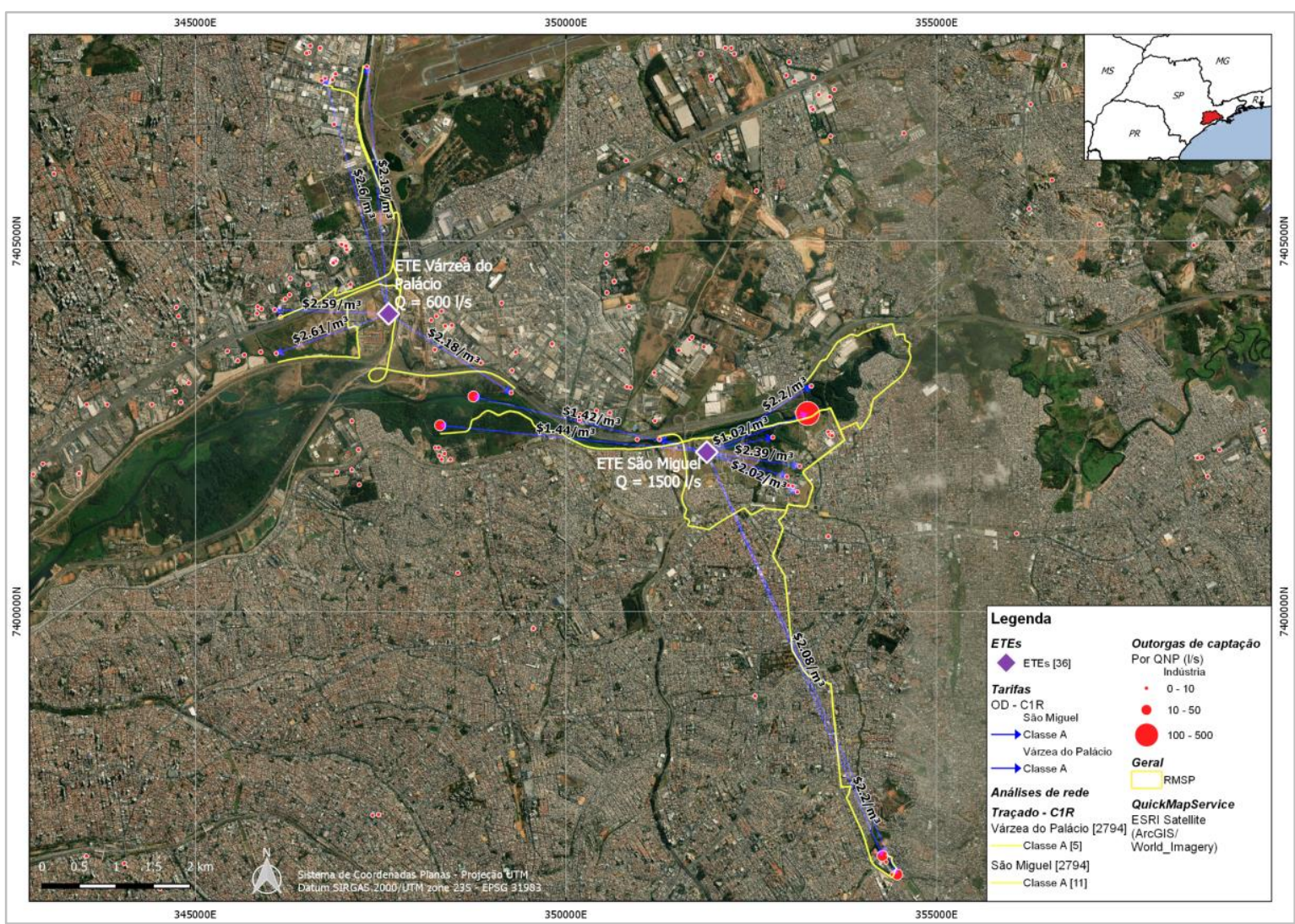

Figura C 3: Distribuição dos usuários-âncora em relação às ETEs Várzea do Palácio e São Miguel para C1R: traçados de adutoras (em amarelo) e OD (origem destino) com tarifas (em azul)

Fonte: elaborado pelo autor

\section{C4. ETE Parque Novo Mundo}

A ETE Parque Novo Mundo (PNM) detém a terceira maior capacidade da RMSP (2,5 $\mathrm{m}^{3} / \mathrm{s}$ ). A Tabela C 4 relaciona os cinco usuários-âncora para a ETE Parque Novo Mundo.

Tabela C 4: Usuários-âncora para as ETE Parque Novo Mundo - C1R

\begin{tabular}{llllllll}
\hline $\begin{array}{l}\text { ETE/ } \\
\text { ID outorga }\end{array}$ & $\begin{array}{l}\mathbf{Q} \\
(\mathbf{I} / \mathbf{s})^{(\mathbf{1})}\end{array}$ & $\begin{array}{l}\mathbf{Q}_{\mathbf{N P}} \\
\mathbf{( I / s )}\end{array}$ & $\begin{array}{l}\text { Tarifa } \\
\mathbf{C 1 R} \\
\left(\mathbf{U S D} / \mathbf{m}^{3}\right)\end{array}$ & $\begin{array}{l}\mathbf{L} \\
\mathbf{( k m )}\end{array}$ & Usuário & $\begin{array}{l}\text { CNAE } \\
\mathbf{2 . 0} \\
(\mathbf{g r u p o})\end{array}$ & CNAE 2.0 (grupo) \\
\hline 9524 & 356,2 & 91,7 & $\$ 1,17$ & 5,49 & $\begin{array}{l}\text { INDS.MATARAZZO DE } \\
\text { PAPEIS S.A }\end{array}$ & 17.20 & $\begin{array}{l}\text { Fabricação de papel, cartolina } \\
\text { e papel-cartão }\end{array}$ \\
\hline 14778 & 123,3 & 31,7 & $\$ 1,62$ & 9,02 & KLABIN FABRICADORA & 17.20 & Fabricação de papel, cartolina \\
\hline
\end{tabular}




\begin{tabular}{|c|c|c|c|c|c|c|c|}
\hline $\begin{array}{l}\text { ETE/ } \\
\text { ID outorga }\end{array}$ & $\begin{array}{l}Q \\
(1 / \mathbf{s})^{(1)}\end{array}$ & $\begin{array}{l}Q_{\mathrm{NP}} \\
(\mathrm{I} / \mathrm{s})\end{array}$ & $\begin{array}{l}\text { Tarifa } \\
\text { C1R } \\
\left(\text { USD/m }{ }^{3}\right)\end{array}$ & $\begin{array}{l}\mathrm{L} \\
(\mathrm{km})\end{array}$ & Usuário & $\begin{array}{l}\text { CNAE } \\
2.0 \\
\text { (grupo) }\end{array}$ & CNAE 2.0 (grupo) \\
\hline & & & & & $\begin{array}{l}\text { DE PAPEL E CELULOSE } \\
\text { S.A. }\end{array}$ & & e papel-cartão \\
\hline 12545 & 27,4 & 9,8 & $\$ 2,00$ & 4,33 & VICUNHA S.A. & 13.10 & $\begin{array}{l}\text { Preparação e fiação de fibras } \\
\text { têxteis }\end{array}$ \\
\hline 22913 & 5,9 & 5,1 & $\$ 2,38$ & 4,00 & $\begin{array}{l}\text { SCARLAT INDUSTRIAL } \\
\text { LTDA }\end{array}$ & 20.60 & $\begin{array}{l}\text { Fabricação de sabões, } \\
\text { detergentes, produtos de } \\
\text { limpeza, cosméticos, produtos } \\
\text { de perfumaria e de higiene } \\
\text { pessoal }\end{array}$ \\
\hline 22912 & 5,9 & 5,1 & $\$ 2,38$ & 4,01 & $\begin{array}{l}\text { SCARLAT INDUSTRIAL } \\
\text { LTDA }\end{array}$ & 20.60 & $\begin{array}{l}\text { Fabricação de sabões, } \\
\text { detergentes, produtos de } \\
\text { limpeza, cosméticos, produtos } \\
\text { de perfumaria e de higiene } \\
\text { pessoal }\end{array}$ \\
\hline Total Geral & 518,7 & 143,5 & - & - & & & \\
\hline Média & 103,7 & 28,7 & $\$ 1,91$ & 5,37 & & & \\
\hline
\end{tabular}

(1) Vazão total outorgada. Incluída para comparação com a vazão não potável $\left(Q_{N P}\right)$

Assim como no caso das ETEs Suzano, Leste e São Miguel, as atividades de fabricação de papel e celulose se destacam. A Matarazzo Papel e Klabin são os principais usuários-âncora, com presença de usuários de outras atividades também: a Vicunha (têxtil) e Scarlat Industrial (cosmético). O mapa da Figura C 4 apresenta os usuários-âncora em relação à ETE.

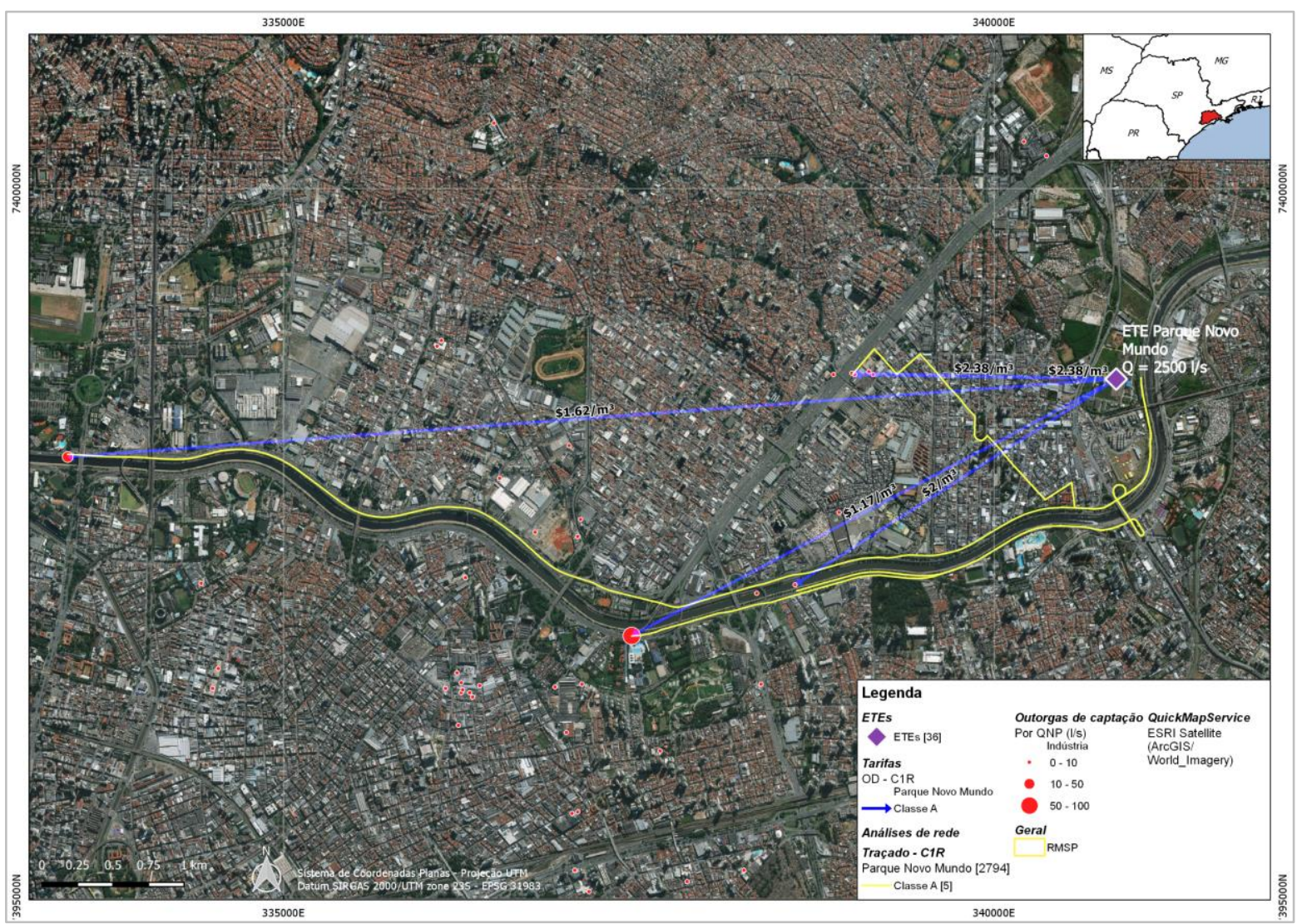

Figura C 4: Distribuição dos usuários-âncora em relação à ETE Parque Novo Mundo para C1R: traçados de adutoras (em amarelo) e OD (origem destino) com tarifas (em azul) 
Fonte: elaborado pelo autor 


\section{C5. Resultados completos para todas as ETEs}

A Tabela C 5 apresenta os resultados para todas as ETEs que tiveram ao menos um usuário-âncora para os cenários C1R e C2R, com dados sobre as vazões de água de reúso, tarifas, comprimento da adutora e informações sobre os usuários. 
Tabela C 5: Resultados detalhados da aplicação do Modelo ETE-usuário à RMSP por ETE - cenários C1R e C2R

\begin{tabular}{|c|c|c|c|c|c|c|c|c|c|}
\hline \multirow[b]{2}{*}{$\begin{array}{l}\text { ETE / } \\
\text { ID outorga }\end{array}$} & \multicolumn{2}{|c|}{ C1R } & \multicolumn{2}{|c|}{$\mathrm{C} 2 \mathrm{R}$} & \multirow{3}{*}{$L(\mathrm{~km})$} & \multirow[b]{2}{*}{ Usuário } & \multirow{2}{*}{$\begin{array}{l}\text { CNAE } 2.0 \\
\text { (grupo) }\end{array}$} & \multirow[b]{2}{*}{ CNAE 2.0 (grupo) } & \multirow[b]{2}{*}{ Finalidade } \\
\hline & $\begin{array}{c}\text { Tarifa } \\
\left(\mathrm{USD} / \mathrm{m}^{3}\right)\end{array}$ & $Q_{N P}(1 / \mathbf{s})$ & $\begin{array}{c}\text { Tarifa } \\
\left(\mathrm{USD} / \mathrm{m}^{3}\right)\end{array}$ & $Q_{\mathrm{NP}}(\mathrm{l} / \mathbf{s})$ & & & & & \\
\hline Suzano & - & 754,4 & & 355,6 & & & & & \\
\hline 82327 & $\$ 0,88$ & 355,6 & $\$ 2,06$ & 355,6 & 6,84 & SUZANO PAPEL E CELULOSE S.A. & 17.20 & Fabricação de papel, cartolina e papel-cartão & INDUSTRIAL \\
\hline 108631 & $\$ 1,18$ & 73,5 & - & - & 3,02 & LEAO \& JETEX INDUSTRIA TEXTIL LTDA. & 13.40 & Acabamentos em fios, tecidos e artefatos têxteis & INDUSTRIAL \\
\hline 23839 & $\$ 1,24$ & 70,7 & - & - & 5,05 & CLARIANT S.A. & 20.90 & $\begin{array}{l}\text { Fabricação de produtos e preparados químicos } \\
\text { diversos }\end{array}$ & INDUSTRIAL \\
\hline 82329 & $\$ 1,35$ & 49,4 & - & - & 5,28 & SUZANO PAPEL E CELULOSE S.A. & 17.20 & $\begin{array}{l}\text { alversos } \\
\text { Fabricação de papel, cartolina e papel-cartão }\end{array}$ & INDUSTRIAL \\
\hline 130690 & $\$ 1,40$ & 40,7 & - & - & 4,81 & $\begin{array}{l}\text { ALIMENKO IMPORTADORA EEXPORTADORA } \\
\text { LTDA. }\end{array}$ & 10.90 & Fabricação de outros produtos alimentícios & INDUSTRIAL \\
\hline $\begin{array}{l}46337 \\
8402 \\
46343 \\
82330\end{array}$ & $\begin{array}{l}\$ 1,48 \\
\$ 1,55 \\
\$ 1,67 \\
\$ 1,75\end{array}$ & $\begin{array}{l}30,6 \\
28,2 \\
18,9 \\
17,6\end{array}$ & $\begin{array}{l}- \\
- \\
-\end{array}$ & $\begin{array}{l}- \\
- \\
-\end{array}$ & $\begin{array}{l}4,17 \\
5,38 \\
4,09 \\
5,28\end{array}$ & $\begin{array}{l}\text { SANOFI AVENTIS FARMACEUTICA LTDA. } \\
\text { MELHORAMENTOS PAPEIS LTDA. } \\
\text { SANOFI AVENTIS FARMACEUTICA LTDA. } \\
\text { SUZANO PAPEL E CELULOSE S.A. }\end{array}$ & $\begin{array}{l}21.20 \\
17.20 \\
21.20 \\
17.20\end{array}$ & $\begin{array}{l}\text { Fabricação de produtos farmacêuticos } \\
\text { Fabricação de papel, cartolina e papel-cartão } \\
\text { Fabricação de produtos farmacêuticos } \\
\text { Fabricação de papel, cartolina e papel-cartão }\end{array}$ & $\begin{array}{l}\text { INDUSTRIAL } \\
\text { INDUSTRIAL } \\
\text { INDUSTRIAL } \\
\text { INDUSTRIAL }\end{array}$ \\
\hline 171874 & $\$ 1,78$ & 13,2 & - & - & 3,17 & GL ELETRO - ELETRONICOS LTDA. & 27.30 & $\begin{array}{l}\text { Fabricação de equipamentos para distribuição e } \\
\text { controle de energia elétrica }\end{array}$ & INDUSTRIAL \\
\hline $\begin{array}{l}46346 \\
169522 \\
10330\end{array}$ & $\begin{array}{l}\$ 1,97 \\
\$ 2,13 \\
\$ 2,21\end{array}$ & $\begin{array}{l}10,5 \\
18,3 \\
11,8\end{array}$ & $\begin{array}{l}- \\
- \\
-\end{array}$ & - & $\begin{array}{l}4,41 \\
14,94 \\
10,03\end{array}$ & $\begin{array}{l}\text { SANOFI AVENTIS FARMACEUTICA LTDA. } \\
\text { KAZUHIRO INO E OUTRO } \\
\text { RESANA S.A. IND. QUIMICAS }\end{array}$ & $\begin{array}{l}21.20 \\
01.50 \\
20.20\end{array}$ & $\begin{array}{l}\text { Fabricação de produtos farmacêuticos } \\
\text { Pecuária } \\
\text { Fabricação de produtos químicos orgânicos }\end{array}$ & $\begin{array}{l}\text { INDUSTRIAL } \\
\text { INDUSTRIAL } \\
\text { INDUSTRIAL }\end{array}$ \\
\hline 83559 & $\$ 2,42$ & 7,6 & - & - & 8,26 & $\begin{array}{l}\text { DAG QUIMICA IND., COM. E REPRESENTACOES } \\
\text { LTDA. }\end{array}$ & 20.90 & $\begin{array}{l}\text { Fabricação de produtos e preparados químicos } \\
\text { diversos }\end{array}$ & INDUSTRIAL \\
\hline $\begin{array}{l}32195 \\
46344\end{array}$ & $\$ 2,51$ & $\begin{array}{l}3,3 \\
4,5\end{array}$ & - & - & $\begin{array}{l}2,26 \\
4,60\end{array}$ & $\begin{array}{l}\text { AUNDE BRASIL S.A. } \\
\text { SANOFI AVENTIS FARMACEUTICA LTDA. }\end{array}$ & $\begin{array}{l}13.10 \\
21.20\end{array}$ & $\begin{array}{l}\text { Preparação e fiação de fibras têxteis } \\
\text { Fabricação de produtos farmacêuticos }\end{array}$ & $\begin{array}{l}\text { INDUSTRIAL } \\
\text { INDUSTRIAL }\end{array}$ \\
\hline Pinheirinho & - & 504,1 & - & 447,1 & & & & & \\
\hline 97161 & $\$ 1,02$ & 291,9 & $\$ 2,25$ & 291,9 & 15,39 & PETROLEO BRASILEIRO S.A. - PETROBRAS & 35.10 & $\begin{array}{l}\text { Geração, transmissão e distribuição de energia } \\
\text { elétrica }\end{array}$ & INDUSTRIAL \\
\hline 97168 & $\$ 1,18$ & 155,3 & $\$ 2,62$ & 155,3 & 15,39 & PETROLEO BRASILEIRO S.A. - PETROBRAS & 35.10 & $\begin{array}{l}\text { Geração, transmissão e distribuição de energia } \\
\text { elétrica }\end{array}$ & INDUSTRIAL \\
\hline 97169 & $\$ 1,62$ & 46,6 & - & - & 15,39 & PETROLEO BRASILEIRO S.A. - PETROBRAS & 35.10 & $\begin{array}{l}\text { Geração, transmissão e distribuição de energia } \\
\text { elétrica }\end{array}$ & INDUSTRIAL \\
\hline 28705 & $\$ 2,05$ & 10,4 & - & - & 5,70 & BASF S.A. & 20.70 & $\begin{array}{l}\text { Fabricação de tintas, vernizes, esmaltes, lacas e } \\
\text { produtos afins }\end{array}$ & INDUSTRIAL \\
\hline Mauá & - & 352,6 & - & 186,3 & & & & & \\
\hline 8012 & $\$ 1,10$ & 93,2 & $\$ 2,72$ & 93,2 & 1,96 & PETROLEO BRASILEIRO S.A. - PETROBRAS & 35.10 & $\begin{array}{l}\text { Geração, transmissão e distribuição de energia } \\
\text { elétrica }\end{array}$ & INDUSTRIAL \\
\hline 8004 & $\$ 1,10$ & 93,2 & $\$ 2,72$ & 93,2 & 1,98 & PETROLEO BRASILEIRO S.A. - PETROBRAS & 35.10 & $\begin{array}{l}\text { Geração, transmissão e distribuição de energia } \\
\text { elétrica }\end{array}$ & INDUSTRIAL \\
\hline 171886 & $\$ 1,40$ & 68,3 & - & - & 12,58 & $\begin{array}{l}\text { DU SOL COMERCIO DE BEBIDAS LIMITADA - } \\
\text { EPP }\end{array}$ & 11.20 & Fabricação de bebidas não-alcoólicas & INDUSTRIAL \\
\hline 10156 & $\$ 1,51$ & 29,4 & - & - & 4,34 & RHODIA S.A. & 13.10 & Preparação e fiação de fibras têxteis & INDUSTRIAL \\
\hline 171885 & $\$ 1,72$ & 31,4 & - & - & 12,32 & $\begin{array}{l}\text { DU SOL COMERCIO DE BEBIDAS LIMITADA - } \\
\text { EPP }\end{array}$ & 11.20 & Fabricação de bebidas não-alcoólicas & INDUSTRIAL \\
\hline $\begin{array}{l}61543 \\
164530 \\
164527 \\
164534\end{array}$ & $\begin{array}{l}\$ 2,18 \\
\$ 2,19 \\
\$ 2,30 \\
\$ 2,33\end{array}$ & $\begin{array}{l}8,2 \\
5,8 \\
4,2 \\
4,9\end{array}$ & $\begin{array}{l}- \\
- \\
-\end{array}$ & $\begin{array}{l}- \\
- \\
-\end{array}$ & $\begin{array}{l}5,52 \\
2,88 \\
1,88 \\
3,17\end{array}$ & $\begin{array}{l}\text { RHODIA POLIAMIDA E ESPECIALIDADES LTDA } \\
\text { TP INDUSTRIAL DE PNEUS BRASIL LTDA } \\
\text { TP INDUSTRIAL DE PNEUS BRASIL LTDA } \\
\text { TP INDUSTRIAL DE PNEUS BRASIL LTDA }\end{array}$ & $\begin{array}{l}20.20 \\
22.10 \\
22.10 \\
22.10\end{array}$ & $\begin{array}{l}\text { Fabricação de produtos químicos orgânicos } \\
\text { Fabricação de produtos de borracha } \\
\text { Fabricação de produtos de borracha } \\
\text { Fabricação de produtos de borracha }\end{array}$ & $\begin{array}{l}\text { INDUSTRIAL } \\
\text { INDUSTRIAL } \\
\text { INDUSTRIAL } \\
\text { INDUSTRIAL }\end{array}$ \\
\hline
\end{tabular}




\begin{tabular}{|c|c|c|c|c|c|c|c|c|c|}
\hline \multirow{2}{*}{$\begin{array}{l}\text { ETE / } \\
\text { ID outorga }\end{array}$} & \multicolumn{2}{|c|}{ C1R } & \multicolumn{2}{|c|}{$\mathrm{C} 2 \mathrm{R}$} & \multirow[b]{2}{*}{$\mathrm{L}(\mathrm{km})$} & \multirow[b]{2}{*}{ Usuário } & \multirow[b]{2}{*}{$\begin{array}{l}\text { CNAE } 2.0 \\
\text { (grupo) }\end{array}$} & \multirow[b]{2}{*}{ CNAE 2.0 (grupo) } & \multirow[b]{2}{*}{ Finalidade } \\
\hline & $\begin{array}{c}\text { Tarifa } \\
\left(\mathrm{USD} / \mathrm{m}^{3}\right)\end{array}$ & $Q_{\mathrm{NP}}(1 / \mathbf{s})$ & $\begin{array}{c}\text { Tarifa } \\
\left(\mathrm{USD} / \mathrm{m}^{3}\right)\end{array}$ & $Q_{\mathrm{NP}}(\mathrm{I} / \mathbf{s})$ & & & & & \\
\hline $\begin{array}{l}164529 \\
164531\end{array}$ & $\begin{array}{l}\$ 2,44 \\
\$ 2,49\end{array}$ & $\begin{array}{l}4,1 \\
3,3\end{array}$ & - & $\dot{-}$ & $\begin{array}{l}3,10 \\
2,20\end{array}$ & $\begin{array}{l}\text { TP INDUSTRIAL DE PNEUS BRASIL LTDA } \\
\text { TP INDUSTRIAL DE PNEUS BRASIL LTDA }\end{array}$ & $\begin{array}{l}22.10 \\
22.10\end{array}$ & \multirow{4}{*}{$\begin{array}{l}\text { Fabricação de produtos de borracha } \\
\text { Fabricação de produtos de borracha } \\
\text { Fabricação de tintas, vernizes, esmaltes, lacas e } \\
\text { produtos afins } \\
\text { Fabricação de lâmpadas e outros equipamentos } \\
\text { de iluminação }\end{array}$} & $\begin{array}{l}\text { INDUSTRIAL } \\
\text { INDUSTRIAL }\end{array}$ \\
\hline 10135 & $\$ 2,53$ & 4,5 & - & - & 4,49 & TINTAS CORAL S.A. & 20.70 & & INDUSTRIAL \\
\hline 11038 & $\$ 2,62$ & 2,1 & - & - & 1,08 & PHILIPS DO BRASIL LTDA & 27.40 & & INDUSTRIAL \\
\hline São Miguel & - & 269,2 & - & 129,6 & & & & & \\
\hline 11903 & $\$ 1,02$ & 129,6 & $\$ 2,52$ & 129,6 & 1,68 & COMPANHIA NITRO QUIMICA BRASILEIRA & 20.90 & $\begin{array}{l}\text { Fabricação de produtos e preparados químicos } \\
\text { diversos }\end{array}$ & INDUSTRIAL \\
\hline 9527 & $\$ 1,42$ & 35,3 & - & - & 3,63 & $\begin{array}{l}\text { INDUSTRIAS MATARAZZO DE EMBALAGENS } \\
\text { LTDA }\end{array}$ & 17.20 & Fabricação de papel, cartolina e papel-cartão & INDUSTRIAL \\
\hline 17097 & $\$ 1,44$ & 35,3 & - & - & 4,21 & $\begin{array}{l}\text { VISCOFAN DO BRASIL SOC COMERCIAL E } \\
\text { INDUSTRIAL LTDA }\end{array}$ & 17.20 & Fabricação de papel, cartolina e papel-cartão & INDUSTRIAL \\
\hline 11902 & $\$ 2,02$ & 8,8 & - & - & 3,69 & COMPANHIA NITRO QUIMICA BRASILEIRA & 20.90 & \multirow{9}{*}{$\begin{array}{l}\text { Fabricação de produtos e preparados químicos } \\
\text { diversos } \\
\text { Fabricação de produtos e preparados químicos } \\
\text { diversos } \\
\text { Fabricação de papel, cartolina e papel-cartão } \\
\text { Preparação e fiação de fibras têxteis } \\
\text { Preparação e fiação de fibras têxteis } \\
\text { Fabricação de produtos diversos de papel, } \\
\text { cartolina, papel-cartão e papelão ondulado } \\
\text { Confecção de artigos do vestuário e acessórios } \\
\text { Fabricação de produtos e preparados químicos } \\
\text { diversos }\end{array}$} & INDUSTRIAL \\
\hline 11900 & $\$ 2,06$ & 7,9 & - & - & 3,37 & COMPANHIA NITRO QUIMICA BRASILEIRA & 20.90 & & INDUSTRIAL \\
\hline 11207 & $\$ 2,08$ & 14,1 & - & - & 9,82 & CIA GUAIANAZES DE PAPEL & 17.20 & & INDUSTRIAL \\
\hline 9967 & $\$ 2,17$ & 9,8 & - & - & 7,07 & D. K. TINTURARIA INDUSTRIAL LTDA & 13.10 & & INDUSTRIAL \\
\hline 11407 & $\$ 2,20$ & 8,5 & - & - & 6,07 & INDUSTRIAS TEXTEIS SUECO LTDA. & 13.10 & & INDUSTRIAL \\
\hline 11571 & $\$ 2,20$ & 12,0 & - & - & 10,16 & \multirow{2}{*}{$\begin{array}{l}\text { MANIKRAFT GUAIANAZES IND.DE CELULOSE E } \\
\text { PAPEL LTDA. } \\
\text { KOOK'S TINTURARIA E ESTAMPARIA LTDA. }\end{array}$} & 17.40 & & INDUSTRIAL \\
\hline 10044 & $\$ 2,33$ & 3,5 & - & - & 1,25 & & 14.10 & & INDUSTRIAL \\
\hline 11898 & $\$ 2,39$ & 4,5 & - & - & 3,21 & COMPANHIA NITRO QUIMICA BRASILEIRA & 20.90 & & INDUSTRIAL \\
\hline Bandeirantes & - & 240,4 & - & - & & & & & \\
\hline 60357 & $\$ 1,36$ & 62,8 & - & - & 9,03 & PROCOSA PRODUTOS DE BELEZA LTDA. & 20.60 & $\begin{array}{l}\text { Fabricação de sabões, detergentes, produtos de } \\
\text { limpeza, cosméticos, produtos de perfumaria e } \\
\text { de higiene pessoal }\end{array}$ & INDUSTRIAL \\
\hline 51800 & $\$ 1,47$ & 49,4 & - & - & 9,84 & MD PAPEIS LTDA. & 17.20 & Fabricação de papel, cartolina e papel-cartão & INDUSTRIAL \\
\hline 13210 & $\$ 1,64$ & 41,3 & - & - & 13,67 & MELHORAMENTOS CMPC LTDA & 17.20 & $\begin{array}{l}\text { Fabricação de papel, cartolina e papel-cartão } \\
\text { Fabricação de sabões, detergentes, produtos de }\end{array}$ & INDUSTRIAL \\
\hline 60354 & $\$ 1,68$ & 28,3 & - & - & 9,13 & PROCOSA PRODUTOS DE BELEZA LTDA. & 20.60 & $\begin{array}{l}\text { limpeza, cosméticos, produtos de perfumaria e } \\
\text { de higiene pessoal }\end{array}$ & INDUSTRIAL \\
\hline 91574 & $\$ 1,77$ & 21,2 & - & - & 7,90 & TEXTIL LAPO S.A. & 13.40 & $\begin{array}{l}\text { Acabamentos em fios, tecidos e artefatos têxteis } \\
\text { Fabricacão de sabões, detergentes, produtos de }\end{array}$ & INDUSTRIAL \\
\hline 60353 & $\$ 2,12$ & 13,0 & - & - & 9,26 & PROCOSA PRODUTOS DE BELEZA LTDA. & 20.60 & $\begin{array}{l}\text { limpeza, cosméticos, produtos de perfumaria e } \\
\text { de higiene pessoal }\end{array}$ & INDUSTRIAL \\
\hline 91573 & $\$ 2,37$ & 8,2 & - & - & 8,21 & TEXTIL LAPO S.A. & 13.40 & Acabamentos em fios, tecidos e artefatos têxteis & INDUSTRIAL \\
\hline 91575 & $\$ 2,39$ & 7,7 & - & - & 7,88 & TEXTIL LAPO S.A. & 13.40 & $\begin{array}{l}\text { Acabamentos em fios, tecidos e artefatos têxteis } \\
\text { Fabricação de sabões, detergentes, produtos de }\end{array}$ & INDUSTRIAL \\
\hline 60355 & $\$ 2,40$ & 8,6 & - & - & 9,15 & PROCOSA PRODUTOS DE BELEZA LTDA. & 20.60 & $\begin{array}{l}\text { limpeza, cosméticos, produtos de perfumaria e } \\
\text { de higiene pessoal }\end{array}$ & INDUSTRIAL \\
\hline Biritiba-Mirim & - & 190,0 & - & 190,0 & & & & & \\
\hline 62786 & $\$ 1,47$ & 30,2 & $\$ 1,39$ & 30,2 & 8,27 & $\begin{array}{l}\text { ASSOCIACAO AGRICOLA DESPORTIVA E } \\
\text { CULTURAL DO SOGO }\end{array}$ & 01.10 & Produção de lavouras temporárias & IRRIGANTE \\
\hline 62775 & $\$ 1,49$ & 24,7 & $\$ 1,41$ & 24,7 & 6,51 & $\begin{array}{l}\text { ASSOCIACAO AGRICOLA DESPORTIVA E } \\
\text { CULTURAL DO SOGO }\end{array}$ & 01.10 & Produção de lavouras temporárias & IRRIGANTE \\
\hline
\end{tabular}




\begin{tabular}{|c|c|c|c|c|c|c|c|c|c|}
\hline \multirow[b]{2}{*}{$\begin{array}{l}\text { ETE / } \\
\text { ID outorga }\end{array}$} & \multicolumn{2}{|c|}{ C1R } & \multicolumn{2}{|c|}{ C2R } & \multirow[b]{2}{*}{ L (km) } & \multirow[b]{2}{*}{ Usuário } & \multirow[b]{2}{*}{$\begin{array}{l}\text { CNAE } 2.0 \\
\text { (grupo) }\end{array}$} & \multirow[b]{2}{*}{ CNAE 2.0 (grupo) } & \multirow[b]{2}{*}{ Finalidade } \\
\hline & $\begin{array}{c}\text { Tarifa } \\
\left.\text { (USD/m } / \mathrm{m}^{3}\right)\end{array}$ & $\mathbf{Q}_{\mathrm{NP}}(1 / \mathrm{s})$ & $\begin{array}{c}\text { Tarifa } \\
\left(\mathrm{USD} / \mathrm{m}^{3}\right)\end{array}$ & $\mathbf{Q}_{\mathrm{NP}}(\mathbf{I} / \mathbf{s})$ & & & & & \\
\hline 62781 & $\$ 1,51$ & 30,1 & $\$ 1,43$ & 30,1 & 9,67 & $\begin{array}{l}\text { ASSOCIACAO AGRICOLA DESPORTIVA E } \\
\text { CULTURAL DO SOGO }\end{array}$ & 01.10 & Produção de lavouras temporárias & IRRIGANTE \\
\hline 62785 & $\$ 1,60$ & 24,7 & $\$ 1,52$ & 24,7 & 9,68 & $\begin{array}{l}\text { ASSOCIACAO AGRICOLA DESPORTIVA E } \\
\text { CULTURAL DO SOGO }\end{array}$ & 01.10 & Produção de lavouras temporárias & IRRIGANTE \\
\hline 62779 & $\$ 1,75$ & 13,5 & $\$ 1,67$ & 13,5 & 6,51 & $\begin{array}{l}\text { ASSOCIACAO AGRICOLA DESPORTIVA E } \\
\text { CULTURAL DO SOGO }\end{array}$ & 01.10 & Produção de lavouras temporárias & IRRIGANTE \\
\hline 62776 & $\$ 1,81$ & 12,1 & $\$ 1,72$ & 12,1 & 6,51 & $\begin{array}{l}\text { ASSOCIACAO AGRICOLA DESPORTIVA E } \\
\text { CULTURAL DO SOGO }\end{array}$ & 01.10 & Produção de lavouras temporárias & IRRIGANTE \\
\hline 62784 & $\$ 2,02$ & 11,2 & $\$ 1,93$ & 11,2 & 9,67 & $\begin{array}{l}\text { ASSOCIACAO AGRICOLA DESPORTIVA E } \\
\text { CULTURAL DO SOGO }\end{array}$ & 01.10 & Produção de lavouras temporárias & IRRIGANTE \\
\hline 62778 & $\$ 2,04$ & 8,1 & $\$ 1,95$ & 8,1 & 6,51 & $\begin{array}{l}\text { ASSOCIACAO AGRICOLA DESPORTIVA E } \\
\text { CULTURAL DO SOGO }\end{array}$ & 01.10 & Produção de lavouras temporárias & IRRIGANTE \\
\hline 62787 & $\$ 2,05$ & 11,8 & $\$ 1,96$ & 11,8 & 10,77 & $\begin{array}{l}\text { ASSOCIACAO AGRICOLA DESPORTIVA E } \\
\text { CULTURAL DO SOGO }\end{array}$ & 01.10 & Produção de lavouras temporárias & IRRIGANTE \\
\hline 62782 & $\$ 2,12$ & 9,7 & $\$ 2,03$ & 9,7 & 9,67 & $\begin{array}{l}\text { ASSOCIACAO AGRICOLA DESPORTIVA E } \\
\text { CULTURAL DO SOGO }\end{array}$ & 01.10 & Produção de lavouras temporárias & IRRIGANTE \\
\hline 62788 & $\$ 2,31$ & 8,3 & $\$ 2,22$ & 8,3 & 10,77 & $\begin{array}{l}\text { ASSOCIACAO AGRICOLA DESPORTIVA E } \\
\text { CULTURAL DO SOGO }\end{array}$ & 01.10 & Produção de lavouras temporárias & IRRIGANTE \\
\hline 62783 & $\$ 2,55$ & 5,7 & $\$ 2,46$ & 5,7 & 9,67 & $\begin{array}{l}\text { ASSOCIACAO AGRICOLA DESPORTIVA E } \\
\text { CULTURAL DO SOGO }\end{array}$ & 01.10 & Produção de lavouras temporárias & IRRIGANTE \\
\hline Parque Andreense & - & 164,9 & - & 164,9 & & & & & \\
\hline 164306 & $\$ 1,13$ & 164,9 & $\$ 2,55$ & 164,9 & 13,22 & UNIPAR INDUPA DO BRASIL S/A & 20.20 & Fabricação de produtos químicos orgânicos & INDUSTRIAL \\
\hline $\begin{array}{l}\text { Parque Novo } \\
\text { Mundo }\end{array}$ & - & 143,5 & - & - & & & & & \\
\hline 9524 & $\$ 1,17$ & 91,7 & - & - & 5,49 & INDS.MATARAZZO DE PAPEIS S.A & 17.20 & Fabricação de papel, cartolina e papel-cartão & INDUSTRIAL \\
\hline 14778 & $\$ 1,62$ & 31,7 & - & - & 9,02 & $\begin{array}{l}\text { KLABIN FABRICADORA DE PAPEL E CELULOSE } \\
\text { SA. }\end{array}$ & 17.20 & Fabricação de papel, cartolina e papel-cartão & INDUSTRIAL \\
\hline 12545 & $\$ 2,00$ & 9,8 & - & - & 4,33 & VICUNHA S.A. & 13.10 & $\begin{array}{l}\text { Preparação e fiação de fibras têxteis } \\
\text { Fabricação de sabões, detergentes, produtos de }\end{array}$ & INDUSTRIAL \\
\hline 22912 & $\$ 2,38$ & 5,1 & - & - & 4,00 & SCARLAT INDUSTRIAL LTDA & 20.60 & $\begin{array}{l}\text { limpeza, cosméticos, produtos de perfumaria e } \\
\text { de higiene pessoal } \\
\text { Fabricação de sabões, detergentes, produtos de }\end{array}$ & INDUSTRIAL \\
\hline 22913 & $\$ 2,38$ & 5,1 & - & - & 4,01 & SCARLAT INDUSTRIAL LTDA & 20.60 & $\begin{array}{l}\text { limpeza, cosméticos, produtos de perfumaria e } \\
\text { de higiene pessoal }\end{array}$ & INDUSTRIAL \\
\hline Aldeia da Serra & - & 94,9 & - & - & & & & & \\
\hline 161848 & $\$ 1,50$ & 51,0 & - & - & 10,02 & ITACEL FARMOQUIMICA LTDA & 21.20 & Fabricação de produtos farmacêuticos & INDUSTRIAL \\
\hline 11845 & $\$ 1,89$ & 25,2 & - & - & 12,13 & S.A INDUSTRIAS VOTORANTIM & 23.20 & Fabricação de cimento & INDUSTRIAL \\
\hline 161841 & $\$ 1,96$ & 18,7 & - & - & 9,83 & ITACEL FARMOQUIMICA LTDA & 21.20 & Fabricação de produtos farmacêuticos & INDUSTRIAL \\
\hline Bonsucesso & - & 94,0 & - & - & & & & & \\
\hline 79014 & $\$ 1,54$ & 20,4 & - & - & 1,53 & $\begin{array}{l}\text { OSWALDO CRUZ QUIMICA INDUSTRIA E } \\
\text { COMERCIO LTDA. }\end{array}$ & 20.90 & $\begin{array}{l}\text { Fabricação de produtos e preparados químicos } \\
\text { diversos }\end{array}$ & INDUSTRIAL \\
\hline 91266 & $\$ 1,56$ & 24,2 & - & - & 3,73 & $\begin{array}{l}\text { MODINE DO BRASIL SISTEMAS TERMICOS } \\
\text { LTDA. }\end{array}$ & 29.40 & $\begin{array}{l}\text { Fabricação de peças e acessórios para veículos } \\
\text { automotores }\end{array}$ & INDUSTRIAL \\
\hline 133274 & $\$ 1,59$ & 43,5 & - & - & 13,20 & AMBEV S.A. & 11.10 & Fabricação de bebidas alcoólicas & INDUSTRIAL \\
\hline $\begin{array}{l}11123 \\
1112 ?\end{array}$ & $\$ 2,29$ & 3,9 & - & - & 1,54 & $\begin{array}{l}\text { INDUSTRIA DE MEIAS SCALINA LTDA } \\
\text { INDUSTRIA DE MEIAS SCALINA LTDA }\end{array}$ & $\begin{array}{l}13.50 \\
13.50\end{array}$ & Fabricação de artefatos têxteis, exceto vestuário & $\begin{array}{l}\text { INDUSTRIAL } \\
\text { INDUSTRIAI }\end{array}$ \\
\hline $\begin{array}{l}11122 \\
\text { Leste }\end{array}$ & $\$ 2,57$ & $\begin{array}{c}2,0 \\
88,5\end{array}$ & $\begin{array}{l}- \\
-\end{array}$ & - & 0,57 & INDUSTRIA DE MEIAS SCALINA LTDA & 13.50 & Fabricação de artefatos têxteis, exceto vestuário & INDUSTRIAL \\
\hline 123281 & $\$ 1,48$ & 32,6 & - & - & 4,71 & GERDAU S.A. & 24.20 & Siderurgia & INDUSTRIAL \\
\hline 77962 & $\$ 1,91$ & 11,3 & - & - & 4,08 & MULTIVERDE PAPEIS ESPECIAIS LTDA & 17.20 & Fabricação de papel, cartolina e papel-cartão & INDUSTRIAL \\
\hline
\end{tabular}




\begin{tabular}{|c|c|c|c|c|c|c|c|c|c|}
\hline \multirow{2}{*}{$\begin{array}{l}\text { ETE } / \\
\text { ID outorga }\end{array}$} & \multicolumn{2}{|c|}{$\mathrm{C1R}$} & \multicolumn{2}{|c|}{ C2R } & \multirow[b]{2}{*}{ L (km) } & \multirow[b]{2}{*}{ Usuário } & \multirow{2}{*}{$\begin{array}{l}\text { CNAE } 2.0 \\
\text { (grupo) }\end{array}$} & \multirow[b]{2}{*}{ CNAE 2.0 (grupo) } & \multirow[b]{2}{*}{ Finalidade } \\
\hline & $\begin{array}{c}\text { Tarifa } \\
\left(\mathrm{USD} / \mathrm{m}^{3}\right)\end{array}$ & $\mathbf{Q}_{\mathrm{NP}}(1 / \mathrm{s})$ & $\begin{array}{c}\text { Tarifa } \\
\left(\mathrm{USD} / \mathrm{m}^{3}\right)\end{array}$ & $\mathbf{Q}_{\mathrm{NP}}(\mathrm{I} / \mathbf{s})$ & & & & & \\
\hline 10772 & $\$ 1,99$ & 9,2 & - & - & 3,57 & INDS DE PAPEL SIMAO S A & 17.20 & Fabricação de papel, cartolina e papel-cartão & INDUSTRIAL \\
\hline 65652 & $\$ 2,14$ & 11,3 & - & - & 8,18 & $\begin{array}{l}\text { KIMBERLY-CLARK BRASIL IND COM PROD DE } \\
\text { HIGIENE LTDA }\end{array}$ & 17.20 & Fabricação de papel, cartolina e papel-cartão & INDUSTRIAL \\
\hline 8332 & $\$ 2,22$ & 7,0 & - & - & 4,58 & AIR PRODUCTS BRASIL LTDA & 35.20 & $\begin{array}{l}\text { Produção e distribuição de combustíveis gasosos } \\
\text { por redes urbanas }\end{array}$ & INDUSTRIAL \\
\hline 9599 & $\$ 2,37$ & 5,3 & - & - & 4,16 & $\begin{array}{l}\text { IND DE CELULOSE E PAPEL BANDEIRANTES } \\
\text { SA }\end{array}$ & 17.20 & Fabricação de papel, cartolina e papel-cartão & INDUSTRIAL \\
\hline 13187 & $\$ 2,55$ & 5,6 & - & - & 6,70 & $\begin{array}{l}\text { KLABIN FABRICADORA DE PAPEL E CELULOSE } \\
\text { S/A. }\end{array}$ & 17.30 & $\begin{array}{l}\text { Fabricação de embalagens de papel, cartolina, } \\
\text { papel-cartão e papelão ondulado }\end{array}$ & INDUSTRIAL \\
\hline 10333 & $\$ 2,67$ & 6,2 & - & - & 9,20 & RESANA S.A. IND. QUIMICAS & 20.20 & Fabricação de produtos químicos orgânicos & INDUSTRIAL \\
\hline $\begin{array}{l}\text { Cotia/Jardim } \\
\text { Japão }\end{array}$ & 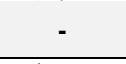 & 81,5 & - & 11,2 & & & & & \\
\hline $\begin{array}{l}98872 \\
9138 \\
9495\end{array}$ & $\begin{array}{l}\$ 1,68 \\
\$ 1,93 \\
\$ 2,10\end{array}$ & $\begin{array}{l}19,6 \\
21,2 \\
15,5\end{array}$ & $\begin{array}{l}- \\
- \\
-\end{array}$ & $\begin{array}{l}- \\
- \\
-\end{array}$ & $\begin{array}{l}4,77 \\
12,19 \\
11,69\end{array}$ & $\begin{array}{l}\text { GERDAU ACOS LONGOS S.A. } \\
\text { REPASA S.A. CELULOSE E PAPEL } \\
\text { RIPASA S.A. CELULOSE E PAPEL }\end{array}$ & $\begin{array}{l}24.20 \\
17.20 \\
17.20\end{array}$ & $\begin{array}{l}\text { Siderurgia } \\
\text { Fabricação de papel, cartolina e papel-cartão } \\
\text { Fabricação de papel, cartolina e papel-cartão }\end{array}$ & $\begin{array}{l}\text { INDUSTRIAL } \\
\text { INDUSTRIAL } \\
\text { INDUSTRIAL }\end{array}$ \\
\hline 159071 & $\$ 2,13$ & 11,2 & $\$ 2,04$ & 11,2 & 11,69 & IBEMA COMPANHIA BRASILEIRA DE PAPEL & 17.30 & $\begin{array}{l}\text { Fabricação de embalagens de papel, cartolina, } \\
\text { papel-cartão e papelão ondulado }\end{array}$ & IRRIGANTE \\
\hline $\begin{array}{l}98870 \\
74560\end{array}$ & $\begin{array}{l}\$ 2,24 \\
\$ 2,24\end{array}$ & $\begin{array}{l}7,0 \\
7,1\end{array}$ & - & - & $\begin{array}{l}4,81 \\
4,98\end{array}$ & $\begin{array}{l}\text { GERDAU ACOS LONGOS S.A. } \\
\text { HORIZON ARTEFATOS DE BORRACHA LTDA. }\end{array}$ & $\begin{array}{l}24.20 \\
22.10\end{array}$ & $\begin{array}{l}\text { Siderurgia } \\
\text { Fabricação de produtos de borracha }\end{array}$ & $\begin{array}{l}\text { INDUSTRIAL } \\
\text { INDUSTRIAL }\end{array}$ \\
\hline Mairiporã - Sede & - & 49,4 & - & - & & & & & \\
\hline 9530 & $\$ 1,25$ & 49,4 & - & - & 1,22 & $\begin{array}{l}\text { MAIRIPORA IND E COM DE PAPEL E PAPELAO } \\
\text { LTDA }\end{array}$ & 17.20 & Fabricação de papel, cartolina e papel-cartão & INDUSTRIAL \\
\hline $\begin{array}{l}\text { Parque dos } \\
\text { Pinheiros }\end{array}$ & - & 48,4 & - & - & & & & & \\
\hline 116230 & $\$ 1,73$ & 18,8 & - & - & 5,44 & $\begin{array}{l}\text { NACOM GOYA INDUSTRIA E COMERCIO DE } \\
\text { ALIMENTOS LTDA }\end{array}$ & 10.90 & Fabricação de outros produtos alimentícios & INDUSTRIAL \\
\hline 55115 & $\$ 1,88$ & 9,8 & - & - & 2,43 & $\begin{array}{l}\text { INDUSTRIA E COMERCIO DE COSMETICOS } \\
\text { NATURA LTDA }\end{array}$ & 20.60 & $\begin{array}{l}\text { Fabricação de sabões, detergentes, produtos de } \\
\text { limpeza, cosméticos, produtos de perfumaria e } \\
\text { de higiene pessoal }\end{array}$ & INDUSTRIAL \\
\hline 55116 & $\$ 1,92$ & 8,8 & - & - & 2,21 & $\begin{array}{l}\text { INDUSTRIA E COMERCIO DE COSMETICOS } \\
\text { NATURA LTDA }\end{array}$ & 20.60 & $\begin{array}{l}\text { Fabricação de sabões, detergentes, produtos de } \\
\text { limpeza, cosméticos, produtos de perfumaria e } \\
\text { de higiene pessoal }\end{array}$ & INDUSTRIAL \\
\hline 16518 & $\$ 2,58$ & 2,0 & - & - & 0,71 & IBRAME IND. BRAS. DE METAIS LTDA & 24.40 & Metalurgia dos metais não-ferrosos & INDUSTRIAL \\
\hline 22663 & $\$ 2,60$ & 2,9 & - & - & 2,42 & $\begin{array}{l}\text { INDUSTRIA E COMERCIO DE COSMETICOS } \\
\text { NATURA LTDA }\end{array}$ & 20.60 & $\begin{array}{l}\text { Fabricação de sabões, detergentes, produtos de } \\
\text { limpeza, cosméticos, produtos de perfumaria e } \\
\text { de higiene pessoal }\end{array}$ & INDUSTRIAL \\
\hline 22662 & $\$ 2,64$ & 2,9 & - & - & 2,64 & $\begin{array}{l}\text { INDUSTRIA E COMERCIO DE COSMETICOS } \\
\text { NATURA LTDA }\end{array}$ & 20.60 & $\begin{array}{l}\text { Fabricação de sabões, detergentes, produtos de } \\
\text { limpeza, cosméticos, produtos de perfumaria e } \\
\text { de higiene pessoal }\end{array}$ & INDUSTRIAL \\
\hline 22664 & $\$ 2,70$ & 2,9 & - & - & 3,05 & $\begin{array}{l}\text { INDUSTRIA E COMERCIO DE COSMETICOS } \\
\text { NATURA LTDA }\end{array}$ & 20.60 & $\begin{array}{l}\text { Fabricação de sabões, detergentes, produtos de } \\
\text { limpeza, cosméticos, produtos de perfumaria e } \\
\text { de higiene pessoal }\end{array}$ & INDUSTRIAL \\
\hline Barueri & - & 43,8 & - & - & & & & & \\
\hline 10957 & $\$ 1,84$ & 20,6 & - & - & 9,41 & FABR DE TECIDOS TATUAPE S/A & 13.10 & Preparação e fiação de fibras têxteis & INDUSTRIAL \\
\hline 169517 & $\$ 2,31$ & 8,8 & - & - & 8,23 & $\begin{array}{l}\text { EUROAMERICAN DO BRASIL IMPORTACAO IND. } \\
\text { E COM. LTDA }\end{array}$ & 20.70 & $\begin{array}{l}\text { Fabricação de tintas, vernizes, esmaltes, lacas e } \\
\text { produtos afins }\end{array}$ & INDUSTRIAL \\
\hline 95469 & $\$ 2,43$ & 7,1 & - & - & 7,45 & $\begin{array}{l}\text { AKUA IND COM IMPORT E EXPORT DE } \\
\text { COSMETICOS LTDA. }\end{array}$ & 20.60 & $\begin{array}{l}\text { Fabricação de sabões, detergentes, produtos de } \\
\text { limpeza, cosméticos, produtos de perfumaria e } \\
\text { de higiene pessoal }\end{array}$ & INDUSTRIAL \\
\hline
\end{tabular}




\begin{tabular}{|c|c|c|c|c|c|c|c|c|c|}
\hline \multirow{2}{*}{$\begin{array}{l}\text { ETE / } \\
\text { ID outorga }\end{array}$} & \multicolumn{2}{|c|}{$\mathrm{C} 1 \mathrm{R}$} & \multicolumn{2}{|c|}{$\mathrm{C} 2 \mathrm{R}$} & \multirow[b]{2}{*}{$\mathrm{L}(\mathrm{km})$} & \multirow[b]{2}{*}{ Usuário } & \multirow[b]{2}{*}{$\begin{array}{l}\text { CNAE 2.0 } \\
\text { (grupo) } \\
\end{array}$} & \multirow[b]{2}{*}{ CNAE 2.0 (grupo) } & \multirow[b]{2}{*}{ Finalidade } \\
\hline & $\begin{array}{c}\text { Tarifa } \\
\left.\text { (USD/m } m^{3}\right)\end{array}$ & $\mathbf{Q}_{\mathrm{NP}}(\mathbf{I} / \mathbf{s})$ & $\begin{array}{c}\text { Tarifa } \\
\left(\mathrm{USD} / \mathrm{m}^{3}\right)\end{array}$ & $Q_{\mathrm{NP}}(1 / \mathbf{s})$ & & & & & \\
\hline $\begin{array}{l}10906 \\
\text { Vila Arujá }\end{array}$ & $\$ 2,64$ & $\begin{array}{c}7,3 \\
39,2 \\
\end{array}$ & - & - & 10,89 & ADAMAS S.A. PAPEIS E PAPELOES ESPECIAIS & 17.20 & Fabricação de papel, cartolina e papel-cartão & INDUSTRIAL \\
\hline 11294 & $\$ 1,70$ & 39,2 & - & - & 13,79 & $\begin{array}{l}\text { PARAMOUNT TEXTEIS INDUSTRIA E } \\
\text { COMERCIO S.A. }\end{array}$ & 13.10 & Preparação e fiação de fibras têxteis & INDUSTRIAL \\
\hline Várzea do Palácio & - & 28,3 & - & - & & & & & \\
\hline 20420 & $\$ 2,18$ & 8,5 & - & - & 5,75 & \multirow{5}{*}{$\begin{array}{l}\text { ROSSET \& CIA LTDA. } \\
\text { DAMAPEL IND. COM. E DISTRIBUICAO DE } \\
\text { PAPEIS LTDA } \\
\text { INOVAT INDUSTRIA FARMACEUTICA } \\
\text { FARMARIN INDUSTRIA E COMERCIO LTDA } \\
\text { PHIBRO SAUDE ANIMAL INTERNACIONAL LTDA }\end{array}$} & 13.40 & Acabamentos em fios, tecidos e artefatos têxteis & INDUSTRIAL \\
\hline 113393 & $\$ 2,19$ & 8,1 & - & - & 5,52 & & 17.20 & Fabricação de papel, cartolina e papel-cartão & INDUSTRIAL \\
\hline $\begin{array}{l}170817 \\
55263\end{array}$ & $\$ 2,59$ & $\begin{array}{l}4,2 \\
4,7\end{array}$ & - & - & $\begin{array}{l}4,61 \\
5,66\end{array}$ & & $\begin{array}{l}21.20 \\
21.20\end{array}$ & $\begin{array}{l}\text { Fabricação de produtos farmacêuticos } \\
\text { Fabricação de produtos farmacêuticos }\end{array}$ & $\begin{array}{l}\text { INDUSTRIAL } \\
\text { INDUSTRIAL }\end{array}$ \\
\hline $\begin{array}{l}54066 \\
\text { Jardim Odete }\end{array}$ & $\$ 2,61$ & 2,8 & - & - & 2,17 & & 21.20 & Fabricação de produtos farmacêuticos & INDUSTRIAL \\
\hline $\begin{array}{l}\text { Jardim Odete } \\
69440\end{array}$ & $\begin{array}{l}- \\
\$ 1,91\end{array}$ & $\begin{array}{l}25,4 \\
16,9\end{array}$ & - & $\overline{-}$ & 8,43 & & 1720 & cartว̃ก & 10 \\
\hline 69442 & $\$ 2,36$ & $\begin{array}{l}16,9 \\
8,5\end{array}$ & - & - & 8,43 & 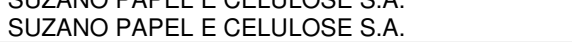 & 17.20 & $\begin{array}{l}\text { Fabricação de papel, cartolina e papel-cartão } \\
\text { Fabricação de papel, cartolina e papel-cartão }\end{array}$ & $\begin{array}{l}\text { INDUSTRIAL } \\
\text { INDUSTRIAL }\end{array}$ \\
\hline Guararema - Sede & - & 25,3 & - & - & & & & & \\
\hline 11398 & $\$ 1,94$ & 11,8 & - & - & 5,10 & \multirow{3}{*}{$\begin{array}{l}\text { OCFIBRAS LTDA } \\
\text { GALLEON ESTRUTURA PRE-MOLDADAS DE } \\
\text { CONC. LTDA. EPP }\end{array}$} & 20.40 & \multirow{3}{*}{$\begin{array}{l}\text { Fabricação de fibras artificiais e sintéticas } \\
\text { Fabricação de artefatos de concreto, cimento, } \\
\text { fibrocimento, gesso e materiais semelhantes }\end{array}$} & INDUSTRIAL \\
\hline 170170 & $\$ 2,35$ & 13,5 & - & - & 14,88 & & 23.30 & & INDUSTRIAL \\
\hline$A B C$ & - & 21,6 & - & - & & & & & \\
\hline 156443 & $\$ 1,74$ & 21,6 & - & - & 7,50 & COLGATEPALMOLIVE INDUSTRIAL LTDA. & 20.60 & $\begin{array}{l}\text { Fabricação de sabões, detergentes, produtos de } \\
\text { limpeza, cosméticos, produtos de perfumaria e } \\
\text { de higiene pessoal }\end{array}$ & INDUSTRIAL \\
\hline Jesus Neto & - & 11,8 & - & - & & & & & \\
\hline 11182 & $\$ 2,08$ & 6,7 & - & - & 2,51 & $\begin{array}{l}\text { COMPANHIA INDUSTRIAL PAULISTA DE PAPEIS } \\
\text { E PAPELAO }\end{array}$ & 17.20 & Fabricação de papel, cartolina e papel-cartão & INDUSTRIAL \\
\hline 12255 & $\$ 2,52$ & 5,1 & - & - & 5,48 & $\begin{array}{l}\text { WALLIG NORDESTE S/A INDUSTRIA E } \\
\text { COMERCIO }\end{array}$ & 27.50 & Fabricação de eletrodomésticos & INDUSTRIAL \\
\hline São João & - & 5,4 & - & - & & & & & \\
\hline 11127 & $\$ 2,14$ & 5,4 & - & - & 1,84 & INDUSTRIA DE MEIAS SCALINA LTDA & 13.50 & Fabricação de artefatos têxteis, exceto vestuário & INDUSTRIAL \\
\hline $\begin{array}{l}\text { Plrapora-Seae } \\
71016\end{array}$ & $\$ 2,46$ & $\begin{array}{l}4,9 \\
4,9\end{array}$ & - & - & 4,50 & MINERACAO TABOCA S.A. & 24.40 & Metalurgia dos metais não-ferrosos & INDUSTRIAL \\
\hline Total Geral & & 3281,4 & & 34,8 & & & & & \\
\hline
\end{tabular}




\section{C6. Resultados completos por usuário-âncora}

A Tabela C 6 relaciona e traz informações sobre todos os usuários-âncora identificados para todos os seis cenários. As cores utilizadas identificam a condição do usuário em relação à sua atratividade $(A, B$ ou $C)$ de acordo com os cenários. 
Tabela C 6: Resultados completos da aplicação do Modelo ETE-usuário à RMSP para todos os usuários-âncora e cenários

\begin{tabular}{|c|c|c|c|c|c|c|c|c|c|c|c|c|c|c|c|c|c|}
\hline \multirow[b]{2}{*}{ ID } & \multirow[b]{2}{*}{ Usuário } & \multirow[b]{2}{*}{$Q(1 / \mathbf{s})$} & \multirow[b]{2}{*}{$\begin{array}{l}Q_{N P} \\
(/ / \mathbf{s})\end{array}$} & \multirow[b]{2}{*}{$\begin{array}{l}\text { Divisão } \\
\text { CNAE } \\
2.0 \\
\end{array}$} & \multirow[b]{2}{*}{$\begin{array}{l}\text { Grupo } \\
\text { CNAE } \\
2.0 \\
\end{array}$} & \multirow[b]{2}{*}{ Grupo CNAE 2.0} & \multirow[b]{2}{*}{ Finalidade } & \multirow[b]{2}{*}{$\begin{array}{l}\text { ETE de } \\
\text { referência }\end{array}$} & \multirow[b]{2}{*}{$X(m)$} & \multicolumn{2}{|c|}{ Legenda de cores } & \multicolumn{2}{|c|}{ Classe A } & \multicolumn{2}{|c|}{ Classe B } & \multicolumn{2}{|c|}{ Classe C } \\
\hline & & & & & & & & & & $Y(m)$ & $\mathrm{L}(\mathrm{km})$ & C10 & C1R & C1P & $\mathbf{C 2 O}$ & C2R & $\mathrm{C} 2 \mathrm{P}$ \\
\hline 82327 & $\begin{array}{l}\text { SUZANO PAPEL E CELULOSE } \\
\text { S.A. }\end{array}$ & 1380,8 & 355,6 & 17 & 17.20 & $\begin{array}{l}\text { Fabricação de papel, } \\
\text { cartolina e papel-cartão }\end{array}$ & Industrial & Suzano & $370.870,0$ & $7.397 .089,8$ & 6,84 & 0,79 & 0,88 & 1,04 & 1,70 & 2,06 & 2,67 \\
\hline 97161 & $\begin{array}{l}\text { PETROLEO BRASILEIRO S.A. - } \\
\text { PETROBRAS }\end{array}$ & 429,2 & 291,9 & 35 & 35.10 & $\begin{array}{l}\text { Geração, transmissão e } \\
\text { distribuição de energia } \\
\text { elétrica }\end{array}$ & Industrial & Pinheirinho & $328.920,0$ & $7.377 .799,8$ & 15,39 & 0,91 & 1,02 & 1,21 & 1,86 & 2,25 & 2,91 \\
\hline 11903 & $\begin{array}{l}\text { COMPANHIA NITRO QUIMICA } \\
\text { BRASILEIRA }\end{array}$ & 150,7 & 129,6 & 20 & 20.90 & $\begin{array}{l}\text { Fabricação de produtos e } \\
\text { preparados químicos } \\
\text { diversos }\end{array}$ & Industrial & São Miguel & $353.260,0$ & $7.402 .669,9$ & 1,68 & 0,92 & 1,02 & 1,21 & 2,07 & 2,51 & 3,25 \\
\hline 8012 & $\begin{array}{l}\text { PETROLEO BRASILEIRO S.A. - } \\
\text { PETROBRAS }\end{array}$ & 137,0 & 93,2 & 35 & 35.10 & $\begin{array}{l}\text { Geração, transmissão e } \\
\text { distribuição de energia } \\
\text { elétrica }\end{array}$ & Industrial & Mauá & $348.640,0$ & $7.383 .799,8$ & 1,96 & 0,99 & 1,10 & 1,31 & 2,23 & 2,70 & 3,51 \\
\hline 8004 & $\begin{array}{l}\text { PETROLEO BRASILEIRO S.A. - } \\
\text { PETROBRAS }\end{array}$ & 137,0 & 93,2 & 35 & 35.10 & $\begin{array}{l}\text { Geração, transmissão e } \\
\text { distribuição de energia } \\
\text { elétrica }\end{array}$ & Industrial & Mauá & $348.650,0$ & $7.383 .810,1$ & 1,98 & 0,99 & 1,10 & 1,31 & 2,23 & 2,70 & 3,51 \\
\hline 164306 & UNIPAR INDUPA DO BRASIL S/A & 191,8 & 164,9 & 20 & 20.20 & $\begin{array}{l}\text { Fabricação de produtos } \\
\text { químicos orgânicos }\end{array}$ & Industrial & $\begin{array}{l}\text { Parque } \\
\text { Andreense }\end{array}$ & $360.030,0$ & $7.371 .290,0$ & 13,22 & 1,01 & 1,13 & 1,35 & 2,10 & 2,54 & 3,29 \\
\hline 9524 & INDS.MATARAZZO DE PAPEIS S.A & 356,2 & 91,7 & 17 & 17.20 & $\begin{array}{l}\text { Fabricação de papel, } \\
\text { cartolina e papel-cartão }\end{array}$ & Industrial & $\begin{array}{l}\text { Parque Novo } \\
\text { Mundo }\end{array}$ & $337.450,0$ & $7.396 .850,1$ & 5,49 & 1,05 & 1,17 & 1,39 & 2,29 & 2,78 & 3,60 \\
\hline 97168 & $\begin{array}{l}\text { PETROLEO BRASILEIRO S.A. - } \\
\text { PETROBRAS }\end{array}$ & 228,3 & 155,3 & 35 & 35.10 & $\begin{array}{l}\text { Geração, transmissão e } \\
\text { distribuição de energia } \\
\text { elétrica }\end{array}$ & Industrial & Pinheirinho & $328.920,0$ & $7.377 .799,8$ & 15,39 & 1,05 & 1,18 & 1,41 & 2,15 & 2,61 & 3,37 \\
\hline 108631 & $\begin{array}{l}\text { LEAO \& JETEX INDUSTRIA } \\
\text { TEXTIL LTDA. }\end{array}$ & 205,5 & 73,5 & 13 & 13.40 & $\begin{array}{l}\text { Acabamentos em fios, } \\
\text { tecidos e artefatos têxteis }\end{array}$ & Industrial & Suzano & $364.250,0$ & $7.397 .069,8$ & 3,02 & 1,06 & 1,18 & 1,41 & 2,36 & 2,87 & 3,73 \\
\hline 23839 & CLARIANT S.A. & 82,2 & 70,7 & 20 & 20.90 & $\begin{array}{l}\text { Fabricação de produtos e } \\
\text { preparados químicos } \\
\text { diversos }\end{array}$ & Industrial & Suzano & $368.540,0$ & $7.397 .500,0$ & 5,05 & 1,10 & 1,24 & 1,47 & 2,42 & 2,94 & 3,81 \\
\hline 9530 & $\begin{array}{l}\text { MAIRIPORA IND E COM DE } \\
\text { PAPEL E PAPELAO LTDA }\end{array}$ & 91,8 & 49,4 & 17 & 17.20 & $\begin{array}{l}\text { Fabricação de papel, } \\
\text { cartolina e papel-cartão }\end{array}$ & Industrial & $\begin{array}{l}\text { Mairiporã - } \\
\text { Sede }\end{array}$ & $338.430,0$ & $7.421 .100,1$ & 1,22 & 1,12 & 1,25 & 1,49 & 2,55 & 3,09 & 4,02 \\
\hline 82329 & $\begin{array}{l}\text { SUZANO PAPEL E CELULOSE } \\
\text { S.A. }\end{array}$ & 191,8 & 49,4 & 17 & 17.20 & $\begin{array}{l}\text { Fabricação de papel, } \\
\text { cartolina e papel-cartão }\end{array}$ & Industrial & Suzano & $369.580,0$ & $7.395 .580,1$ & 5,28 & 1,20 & 1,35 & 1,61 & 2,63 & 3,19 & 4,15 \\
\hline 60357 & $\begin{array}{l}\text { PROCOSA PRODUTOS DE } \\
\text { BELEZA LTDA. }\end{array}$ & 73,1 & 62,8 & 20 & 20.60 & $\begin{array}{l}\text { Fabricação de sabões, } \\
\text { detergentes, produtos de } \\
\text { limpeza, cosméticos, } \\
\text { produtos de perfumaria e } \\
\text { de higiene pessoal }\end{array}$ & Industrial & Bandeirantes & $321.980,0$ & $7.399 .080,1$ & 9,03 & 1,21 & 1,36 & 1,63 & 2,57 & 3,11 & 4,03 \\
\hline 171886 & $\begin{array}{l}\text { DU SOL COMERCIO DE BEBIDAS } \\
\text { LIMITADA - EPP }\end{array}$ & 12,0 & 68,3 & 11 & 11.20 & $\begin{array}{l}\text { Fabricação de bebidas } \\
\text { não-alcoólicas }\end{array}$ & Industrial & Mauá & $358.550,0$ & $7.380 .049,8$ & 12,58 & 1,24 & 1,40 & 1,68 & 2,57 & 3,11 & 4,03 \\
\hline 130690 & $\begin{array}{l}\text { ALIMENKO IMPORTADORA } \\
\text { EEXPORTADORA LTDA. }\end{array}$ & 82,2 & 40,7 & 10 & 10.90 & $\begin{array}{l}\text { Fabricação de outros } \\
\text { produtos alimentícios }\end{array}$ & Industrial & Suzano & $361.550,0$ & $7.399 .759,8$ & 4,81 & 1,25 & 1,40 & 1,68 & 2,74 & 3,33 & 4,32 \\
\hline 9527 & $\begin{array}{l}\text { INDUSTRIAS MATARAZZO DE } \\
\text { EMBALAGENS LTDA }\end{array}$ & 137,0 & 35,3 & 17 & 17.20 & $\begin{array}{l}\text { Fabricação de papel, } \\
\text { cartolina e papel-cartão }\end{array}$ & Industrial & São Miguel & $348.750,0$ & $7.402 .899,9$ & 3,63 & 1,26 & 1,42 & 1,70 & 2,80 & 3,41 & 4,43 \\
\hline 17097 & $\begin{array}{l}\text { VISCOFAN DO BRASIL SOC } \\
\text { COMERCIAL E INDUSTRIAL LTDA }\end{array}$ & 137,0 & 35,3 & 17 & 17.20 & $\begin{array}{l}\text { Fabricação de papel, } \\
\text { cartolina e papel-cartão }\end{array}$ & Industrial & São Miguel & $348.300,0$ & $7.402 .509,8$ & 4,21 & 1,28 & 1,44 & 1,72 & 2,82 & 3,42 & 4,45 \\
\hline
\end{tabular}


\begin{tabular}{|llll}
\hline Legenda de cores & Classe A & Classe B & Classe C \\
\hline
\end{tabular}

\begin{tabular}{|c|c|c|c|c|c|c|c|c|c|c|c|c|c|c|c|c|c|}
\hline & \multicolumn{2}{|c|}{ Legenda de cores } & \multicolumn{2}{|c|}{ Classe A } & \multicolumn{2}{|c|}{ Classe B } & \multicolumn{2}{|c|}{ Classe C } \\
\hline ID & Usuário & $\mathbf{Q}(1 / \mathbf{s})$ & $\begin{array}{l}Q_{N p} \\
(I / s)\end{array}$ & $\begin{array}{l}\text { Divisão } \\
\text { CNAE } \\
2.0 \\
\end{array}$ & $\begin{array}{l}\text { Grupo } \\
\text { CNAE } \\
2.0 \\
\end{array}$ & Grupo CNAE 2.0 & Finalidade & $\begin{array}{l}\text { ETE de } \\
\text { referência }\end{array}$ & $X(m)$ & $Y(m)$ & $\mathrm{L}(\mathbf{k m})$ & C10 & C1R & C1P & $\mathrm{C2O}$ & C2R & C2P \\
\hline 62786 & $\begin{array}{l}\text { ASSOCIACAO AGRICOLA } \\
\text { DESPORTIVA E CULTURAL DO } \\
\text { SOGO }\end{array}$ & 73,7 & 30,2 & 1 & 01.10 & $\begin{array}{l}\text { Produção de lavouras } \\
\text { temporárias }\end{array}$ & Irrigante & Biritiba-Mirim & $388.820,0$ & $7.391 .589,8$ & 8,27 & 1,28 & 1,47 & 1,79 & 1,28 & 1,47 & 1,79 \\
\hline 51800 & MD PAPEIS LTDA. & 191,8 & 49,4 & 17 & 17.20 & $\begin{array}{l}\text { Fabricação de papel, } \\
\text { cartolina e papel-cartão }\end{array}$ & Industrial & Bandeirantes & $319.700,0$ & $7.412 .779,8$ & 9,84 & 1,31 & 1,47 & 1,77 & 2,74 & 3,32 & 4,30 \\
\hline 123281 & GERDAU S.A. & 54,8 & 32,6 & 24 & 24.20 & Siderurgia & Industrial & Leste & $381.680,0$ & $7.397 .620,1$ & 4,71 & 1,31 & 1,48 & 1,77 & 2,88 & 3,50 & 4,55 \\
\hline 46337 & $\begin{array}{l}\text { SANOFI AVENTIS } \\
\text { FARMACEUTICA LTDA. }\end{array}$ & 33,3 & 30,6 & 21 & 21.20 & $\begin{array}{l}\text { Fabricação de produtos } \\
\text { farmacêuticos }\end{array}$ & Industrial & Suzano & $368.560,0$ & $7.396 .189,9$ & 4,17 & 1,32 & 1,48 & 1,78 & 2,91 & 3,53 & 4,60 \\
\hline 62775 & $\begin{array}{l}\text { ASSOCIACAO AGRICOLA } \\
\text { DESPORTIVA E CULTURAL DO } \\
\text { SOGO }\end{array}$ & 60,2 & 24,7 & 1 & 01.10 & $\begin{array}{l}\text { Produção de lavouras } \\
\text { temporárias }\end{array}$ & Irrigante & Biritiba-Mirim & $388.890,0$ & $7.392 .799,8$ & 6,51 & 1,30 & 1,49 & 1,82 & 1,30 & 1,49 & 1,82 \\
\hline 161848 & ITACEL FARMOQUIMICA LTDA & 55,5 & 51,0 & 21 & 21.20 & $\begin{array}{l}\text { Fabricação de produtos } \\
\text { farmacêuticos }\end{array}$ & Industrial & $\begin{array}{l}\text { Aldeia da } \\
\text { Serra }\end{array}$ & $299.000,0$ & $7.395 .649,9$ & 10,02 & 1,33 & 1,50 & 1,79 & 2,75 & 3,32 & 4,30 \\
\hline 10156 & RHODIA S.A. & 82,2 & 29,4 & 13 & 13.10 & $\begin{array}{l}\text { Preparação e fiação de } \\
\text { fibras têxteis }\end{array}$ & Industrial & Mauá & $344.800,0$ & $7.383 .600,1$ & 4,34 & 1,34 & 1,51 & 1,81 & 2,94 & 3,57 & 4,65 \\
\hline 62781 & $\begin{array}{l}\text { ASSOCIACAO AGRICOLA } \\
\text { DESPORTIVA E CULTURAL DO } \\
\text { SOGO }\end{array}$ & 73,4 & 30,1 & 1 & 01.10 & $\begin{array}{l}\text { Produção de lavouras } \\
\text { temporárias }\end{array}$ & Irrigante & Biritiba-Mirim & $388.990,0$ & $7.392 .359,9$ & 9,67 & 1,32 & 1,51 & 1,85 & 1,32 & 1,51 & 1,85 \\
\hline 79014 & $\begin{array}{l}\text { OSWALDO CRUZ QUIMICA } \\
\text { INDUSTRIA E COMERCIO LTDA. }\end{array}$ & 23,7 & 20,4 & 20 & 20.90 & $\begin{array}{l}\text { Fabricação de produtos e } \\
\text { preparados químicos } \\
\text { diversos }\end{array}$ & Industrial & Bonsucesso & $356.660,0$ & $7.409 .040,0$ & 1,53 & 1,36 & 1,54 & 1,84 & 3,11 & 3,78 & 4,92 \\
\hline 8402 & MELHORAMENTOS PAPEIS LTDA. & 109,6 & 28,2 & 17 & 17.20 & $\begin{array}{l}\text { Fabricação de papel, } \\
\text { cartolina e papel-cartão }\end{array}$ & Industrial & Suzano & $369.620,0$ & $7.395 .520,0$ & 5,38 & 1,38 & 1,55 & 1,87 & 3,00 & 3,64 & 4,73 \\
\hline 91266 & $\begin{array}{l}\text { MODINE DO BRASIL SISTEMAS } \\
\text { TERMICOS LTDA. }\end{array}$ & 54,8 & 24,2 & 29 & 29.40 & $\begin{array}{l}\text { Fabricação de peças e } \\
\text { acessórios para veículos } \\
\text { automotores }\end{array}$ & Industrial & Bonsucesso & $358.770,0$ & $7.409 .049,8$ & 3,73 & 1,38 & 1,56 & 1,87 & 3,06 & 3,72 & 4,83 \\
\hline 133274 & AMBEV S.A. & 71,2 & 43,5 & 11 & 11.10 & $\begin{array}{l}\text { Fabricação de bebidas } \\
\text { alcoólicas }\end{array}$ & Industrial & Bonsucesso & $357.330,0$ & $7.419 .899,9$ & 13,20 & 1,41 & 1,59 & 1,92 & 2,88 & 3,49 & 4,53 \\
\hline 62785 & $\begin{array}{l}\text { ASSOCIACAO AGRICOLA } \\
\text { DESPORTIVA E CULTURAL DO } \\
\text { SOGO }\end{array}$ & 60,2 & 24,7 & 1 & 01.10 & $\begin{array}{l}\text { Produção de lavouras } \\
\text { temporárias }\end{array}$ & Irrigante & Biritiba-Mirim & $389.010,0$ & $7.392 .040,0$ & 9,68 & 1,39 & 1,60 & 1,96 & 1,39 & 1,60 & 1,96 \\
\hline 14778 & $\begin{array}{l}\text { KLABIN FABRICADORA DE PAPEL } \\
\text { E CELULOSE S.A. }\end{array}$ & 123,3 & 31,7 & 17 & 17.20 & $\begin{array}{l}\text { Fabricação de papel, } \\
\text { cartolina e papel-cartão }\end{array}$ & Industrial & $\begin{array}{l}\text { Parque Novo } \\
\text { Mundo }\end{array}$ & $33.480,0$ & $7.398 .109,9$ & 9,02 & 1,43 & 1,62 & 1,95 & 3,01 & 3,65 & 4,74 \\
\hline 97169 & $\begin{array}{l}\text { PETROLEO BRASILEIRO S.A. - } \\
\text { PETROBRAS }\end{array}$ & 68,5 & 46,6 & 35 & 35.10 & $\begin{array}{l}\text { Geração, transmissão e } \\
\text { distribuição de energia } \\
\text { elétrica }\end{array}$ & Industrial & Pinheirinho & $328.920,0$ & $7.377 .799,8$ & 15,39 & 1,43 & 1,62 & 1,95 & 2,88 & 3,49 & 4,52 \\
\hline 13210 & MELHORAMENTOS CMPC LTDA & 160,3 & 41,3 & 17 & 17.20 & $\begin{array}{l}\text { Fabricação de papel, } \\
\text { cartolina e papel-cartão }\end{array}$ & Industrial & Bandeirantes & $320.090,0$ & $7.414 .549,8$ & 13,67 & 1,45 & 1,64 & 1,98 & 2,94 & 3,56 & 4,62 \\
\hline 46343 & $\begin{array}{l}\text { SANOFI AVENTIS } \\
\text { FARMACEUTICA LTDA. }\end{array}$ & 20,5 & 18,9 & 21 & 21.20 & $\begin{array}{l}\text { Fabricação de produtos } \\
\text { farmacêuticos }\end{array}$ & Industrial & Suzano & $368.510,0$ & $7.396 .080,1$ & 4,09 & 1,48 & 1,67 & 2,01 & 3,25 & 3,95 & 5,14 \\
\hline 60354 & $\begin{array}{l}\text { PROCOSA PRODUTOS DE } \\
\text { BELEZA LTDA. }\end{array}$ & 32,9 & 28,3 & 20 & 20.60 & $\begin{array}{l}\text { Fabricação de sabões, } \\
\text { detergentes, produtos de } \\
\text { limpeza, cosméticos, } \\
\text { produtos de perfumaria e } \\
\text { de higiene pessoal }\end{array}$ & Industrial & Bandeirantes & $322.120,0$ & $7.399 .120,1$ & 9,13 & 1,49 & 1,68 & 2,03 & 3,11 & 3,77 & 4,89 \\
\hline 98872 & GERDAU ACOS LONGOS S.A. & 32,9 & 19,6 & 24 & 24.20 & Siderurgia & Industrial & $\begin{array}{l}\text { Cotia/Jardim } \\
\text { Japão }\end{array}$ & $307.870,0$ & $7.388 .859,9$ & 4,77 & 1,49 & 1,68 & 2,03 & 3,25 & 3,95 & 5,14 \\
\hline
\end{tabular}




\begin{tabular}{|c|c|c|c|c|c|c|c|c|c|c|c|c|c|c|c|c|c|}
\hline & & & & & & & & & & \multirow{2}{*}{\multicolumn{2}{|c|}{ Legenda de cores }} & \multirow{2}{*}{\multicolumn{2}{|c|}{ Classe $\mathrm{A}$}} & \multirow{2}{*}{\multicolumn{2}{|c|}{ Classe B }} & \multirow{2}{*}{\multicolumn{2}{|c|}{ Classe C }} \\
\hline & & & & & & & & & & & & & & & & & \\
\hline ID & Usuário & $\mathbf{Q}(1 / \mathbf{s})$ & $\begin{array}{l}\mathrm{Q}_{\mathrm{NP}} \\
(1 / \mathbf{s})\end{array}$ & $\begin{array}{l}\text { Divisão } \\
\text { CNAE } \\
2.0\end{array}$ & $\begin{array}{l}\text { Grupo } \\
\text { CNAE } \\
2.0\end{array}$ & Grupo CNAE 2.0 & Finalidade & $\begin{array}{l}\text { ETE de } \\
\text { referência }\end{array}$ & $X(m)$ & $Y(m)$ & L (km) & C10 & C1R & C1P & C2O & $\mathbf{C} 2 \mathrm{R}$ & C2P \\
\hline 11294 & $\begin{array}{l}\text { PARAMOUNT TEXTEIS } \\
\text { INDUSTRIA E COMERCIO S.A. }\end{array}$ & 109,6 & 39,2 & 13 & 13.10 & $\begin{array}{l}\text { Preparação e fiação de } \\
\text { fibras têxteis }\end{array}$ & Industrial & Vila Arujá & $372.650,0$ & $7.423 .000,0$ & 13,79 & 1,50 & 1,70 & 2,04 & 3,01 & 3,64 & 4,71 \\
\hline 171885 & $\begin{array}{l}\text { DU SOL COMERCIO DE BEBIDAS } \\
\text { LIMITADA - EPP }\end{array}$ & 51,4 & 31,4 & 11 & 11.20 & $\begin{array}{l}\text { Fabricação de bebidas } \\
\text { não-alcoólicas }\end{array}$ & Industrial & Mauá & $357.960,0$ & $7.379 .930,2$ & 12,32 & 1,52 & 1,72 & 2,08 & 3,10 & 3,76 & 4,88 \\
\hline 116230 & $\begin{array}{l}\text { NACOM GOYA INDUSTRIA E } \\
\text { COMERCIO DE ALIMENTOS LTDA }\end{array}$ & 38,0 & 18,8 & 10 & 10.90 & $\begin{array}{l}\text { Fabricação de outros } \\
\text { produtos alimentícios }\end{array}$ & Industrial & $\begin{array}{l}\text { Parque dos } \\
\text { Pinheiros }\end{array}$ & $307.810,0$ & $7.410 .529,8$ & 5,44 & 1,53 & 1,73 & 2,09 & 3,31 & 4,02 & 5,22 \\
\hline 156443 & $\begin{array}{l}\text { COLGATEPALMOLIVE } \\
\text { INDUSTRIAL LTDA. }\end{array}$ & 25,1 & 21,6 & 20 & 20.60 & $\begin{array}{l}\text { Fabricação de sabões, } \\
\text { detergentes, produtos de } \\
\text { limpeza, cosméticos, } \\
\text { produtos de perfumaria e } \\
\text { de higiene pessoal }\end{array}$ & Industrial & $A B C$ & $338.600,0$ & $7.382 .980,0$ & 7,50 & 1,54 & 1,74 & 2,10 & 3,26 & 3,96 & 5,15 \\
\hline 82330 & $\begin{array}{l}\text { SUZANO PAPEL E CELULOSE } \\
\text { S.A. }\end{array}$ & 68,5 & 17,6 & 17 & 17.20 & $\begin{array}{l}\text { Fabricação de papel, } \\
\text { cartolina e papel-cartão }\end{array}$ & Industrial & Suzano & $369.580,0$ & $7.395 .580,1$ & 5,28 & 1,55 & 1,75 & 2,11 & 3,35 & 4,07 & 5,29 \\
\hline 62779 & $\begin{array}{l}\text { ASSOCIACAO AGRICOLA } \\
\text { DESPORTIVA E CULTURAL DO } \\
\text { SOGO }\end{array}$ & 32,9 & 13,5 & 1 & 01.10 & $\begin{array}{l}\text { Produção de lavouras } \\
\text { temporárias }\end{array}$ & Irrigante & Biritiba-Mirim & $388.890,0$ & $7.392 .799,8$ & 6,51 & 1,53 & 1,75 & 2,16 & 1,53 & 1,75 & 2,16 \\
\hline 91574 & TEXTIL LAPO S.A. & 59,4 & 21,2 & 13 & 13.40 & $\begin{array}{l}\text { Acabamentos em fios, } \\
\text { tecidos e artefatos têxteis }\end{array}$ & Industrial & Bandeirantes & $324.440,0$ & $7.407 .640,1$ & 7,90 & 1,56 & 1,77 & 2,13 & 3,29 & 3,99 & 5,19 \\
\hline 171874 & $\begin{array}{l}\text { GL ELETRO - ELETRONICOS } \\
\text { LTDA. }\end{array}$ & 21,2 & 13,2 & 27 & 27.30 & $\begin{array}{l}\text { Fabricação de } \\
\text { equipamentos para } \\
\text { distribuição e controle de } \\
\text { energia elétrica }\end{array}$ & Industrial & Suzano & $363.990,0$ & $7.399 .520,0$ & 3,17 & 1,58 & 1,78 & 2,15 & 3,50 & 4,26 & 5,54 \\
\hline 62776 & $\begin{array}{l}\text { ASSOCIACAO AGRICOLA } \\
\text { DESPORTIVA E CULTURAL DO } \\
\text { SOGO }\end{array}$ & 29,6 & 12,1 & 1 & 01.10 & $\begin{array}{l}\text { Produção de lavouras } \\
\text { temporárias }\end{array}$ & Irrigante & Biritiba-Mirim & $388.890,0$ & $7.392 .799,8$ & 6,51 & 1,57 & 1,81 & 2,23 & 1,57 & 1,81 & 2,23 \\
\hline 10957 & FABR DE TECIDOS TATUAPE S/A & 57,5 & 20,6 & 13 & 13.10 & $\begin{array}{l}\text { Preparação e fiação de } \\
\text { fibras têxteis }\end{array}$ & Industrial & Barueri & $319.070,0$ & $7.397 .560,1$ & 9,41 & 1,62 & 1,84 & 2,23 & 3,36 & 4,08 & 5,30 \\
\hline 55115 & $\begin{array}{l}\text { INDUSTRIA E COMERCIO DE } \\
\text { COSMETICOS NATURA LTDA }\end{array}$ & 11,4 & 9,8 & 20 & 20.60 & $\begin{array}{l}\text { Fabricação de sabões, } \\
\text { detergentes, produtos de } \\
\text { limpeza, cosméticos, } \\
\text { produtos de perfumaria e } \\
\text { de higiene pessoal }\end{array}$ & Industrial & $\begin{array}{l}\text { Parque dos } \\
\text { Pinheiros }\end{array}$ & $312.960,0$ & $7.410 .689,9$ & 2,43 & 1,66 & 1,88 & 2,27 & 3,72 & 4,52 & 5,89 \\
\hline 11845 & S.A INDUSTRIAS VOTORANTIM & 38,4 & 25,2 & 23 & 23.20 & Fabricação de cimento & Industrial & $\begin{array}{l}\text { Aldeia da } \\
\text { Serra } \\
\end{array}$ & $300.120,0$ & $7.395 .259,8$ & 12,13 & 1,67 & 1,89 & 2,27 & 3,33 & 4,03 & 5,21 \\
\hline 77962 & $\begin{array}{l}\text { MULTIVERDE PAPEIS ESPECIAIS } \\
\text { LTDA }\end{array}$ & 43,8 & 11,3 & 17 & 17.20 & $\begin{array}{l}\text { Fabricação de papel, } \\
\text { cartolina e papel-cartão }\end{array}$ & Industrial & Leste & $377.040,0$ & $7.398 .680,2$ & 4,08 & 1,69 & 1,91 & 2,31 & 3,68 & 4,47 & 5,82 \\
\hline 69440 & $\begin{array}{l}\text { SUZANO PAPEL E CELULOSE } \\
\text { S.A. }\end{array}$ & 65,8 & 16,9 & 17 & 17.20 & $\begin{array}{l}\text { Fabricação de papel, } \\
\text { cartolina e papel-cartão }\end{array}$ & Industrial & Jardim Odete & $363.950,0$ & $7.401 .200,2$ & 8,43 & 1,69 & 1,91 & 2,32 & 3,51 & 4,25 & 5,52 \\
\hline 55116 & $\begin{array}{l}\text { INDUSTRIA E COMERCIO DE } \\
\text { COSMETICOS NATURA LTDA }\end{array}$ & 10,3 & 8,8 & 20 & 20.60 & $\begin{array}{l}\text { Fabricação de sabões, } \\
\text { detergentes, produtos de } \\
\text { limpeza, cosméticos, } \\
\text { produtos de perfumaria e } \\
\text { de higiene pessoal }\end{array}$ & Industrial & $\begin{array}{l}\text { Parque dos } \\
\text { Pinheiros }\end{array}$ & $312.990,0$ & $7.410 .500,0$ & 2,21 & 1,69 & 1,92 & 2,32 & 3,80 & 4,62 & 6,02 \\
\hline 9138 & REPASA S.A. CELULOSE E PAPEL & 82,2 & 21,2 & 17 & 17.20 & $\begin{array}{l}\text { Fabricação de papel, } \\
\text { cartolina e papel-cartão }\end{array}$ & Industrial & $\begin{array}{l}\text { Cotia/Jardim } \\
\text { Japão }\end{array}$ & $310.850,0$ & $7.382 .600,1$ & 12,19 & 1,70 & 1,93 & 2,34 & 3,43 & 4,15 & 5,39 \\
\hline 11398 & OCFIBRAS LTDA & 13,7 & 11,8 & 20 & 20.40 & $\begin{array}{l}\text { Fabricação de fibras } \\
\text { artificiais e sintéticas }\end{array}$ & Industrial & $\begin{array}{l}\text { Guararema - } \\
\text { Sede }\end{array}$ & $396.100,0$ & $7.410 .600,1$ & 5,10 & 1,71 & 1,94 & 2,35 & 3,69 & 4,48 & 5,83 \\
\hline
\end{tabular}




\begin{tabular}{|c|c|c|c|c|c|c|c|c|c|c|c|c|c|c|c|c|c|}
\hline & & & & & & & & & & Legenda d & cores & & & Clas: & se B & Clas & \\
\hline ID & Usuário & $Q(1 / \mathbf{s})$ & $\begin{array}{l}Q_{\mathrm{NP}} \\
(1 / \mathbf{s})\end{array}$ & $\begin{array}{l}\text { Divisão } \\
\text { CNAE } \\
2.0 \\
\end{array}$ & $\begin{array}{l}\text { Grupo } \\
\text { CNAE } \\
2.0\end{array}$ & Grupo CNAE 2.0 & Finalidade & $\begin{array}{l}\text { ETE de } \\
\text { referência }\end{array}$ & $X(m)$ & $Y(m)$ & L (km) & C10 & C1R & C1P & $\mathrm{C} 2 \mathrm{O}$ & C2R & C2P \\
\hline 161841 & ITACEL FARMOQUIMICA LTDA & 20,3 & 18,7 & 21 & 21.20 & $\begin{array}{l}\text { Fabricação de produtos } \\
\text { farmacêuticos }\end{array}$ & Industrial & $\begin{array}{l}\text { Aldeia da } \\
\text { Serra }\end{array}$ & $299.030,0$ & $7.395 .830,1$ & 9,83 & 1,73 & 1,96 & 2,36 & 3,51 & 4,25 & 5,50 \\
\hline 46346 & $\begin{array}{l}\text { SANOFI AVENTIS } \\
\text { FARMACEUTICA LTDA. }\end{array}$ & 11,4 & 10,5 & 21 & 21.20 & $\begin{array}{l}\text { Fabricação de produtos } \\
\text { farmacêuticos }\end{array}$ & Industrial & Suzano & $368.460,0$ & $7.396 .410,2$ & 4,41 & 1,73 & 1,97 & 2,38 & 3,76 & 4,57 & 5,95 \\
\hline 10772 & INDS DE PAPEL SIMAO S A & 35,6 & 9,2 & 17 & 17.20 & $\begin{array}{l}\text { Fabricação de papel, } \\
\text { cartolina e papel-cartão }\end{array}$ & Industrial & Leste & $377.450,0$ & $7.398 .600,1$ & 3,57 & 1,75 & 1,99 & 2,41 & 3,84 & 4,67 & 6,08 \\
\hline 12545 & VICUNHA S.A. & 27,4 & 9,8 & 13 & 13.10 & $\begin{array}{l}\text { Preparação e fiação de } \\
\text { fibras têxteis }\end{array}$ & Industrial & $\begin{array}{l}\text { Parque Novo } \\
\text { Mundo }\end{array}$ & $338.600,0$ & $7.397 .210,0$ & 4,33 & 1,76 & 2,00 & 2,42 & 3,82 & 4,64 & 6,04 \\
\hline 11902 & $\begin{array}{l}\text { COMPANHIA NITRO QUIMICA } \\
\text { BRASILEIRA }\end{array}$ & 10,3 & 8,8 & 20 & 20.90 & $\begin{array}{l}\text { Fabricação de produtos e } \\
\text { preparados químicos } \\
\text { diversos }\end{array}$ & Industrial & São Miguel & $353.120,0$ & $7.401 .609,9$ & 3,69 & 1,78 & 2,02 & 2,44 & 3,88 & 4,72 & 6,14 \\
\hline 62784 & $\begin{array}{l}\text { ASSOCIACAO AGRICOLA } \\
\text { DESPORTIVA E CULTURAL DO } \\
\text { SOGO }\end{array}$ & 27,4 & 11,2 & 1 & 01.10 & $\begin{array}{l}\text { Produção de lavouras } \\
\text { temporárias }\end{array}$ & Irrigante & Biritiba-Mirim & $389.010,0$ & $7.392 .060,1$ & 9,67 & 1,75 & 2,02 & 2,50 & 1,75 & 2,02 & 2,50 \\
\hline 62778 & $\begin{array}{l}\text { ASSOCIACAO AGRICOLA } \\
\text { DESPORTIVA E CULTURAL DO } \\
\text { SOGO }\end{array}$ & 19,7 & 8,1 & 1 & 01.10 & $\begin{array}{l}\text { Produção de lavouras } \\
\text { temporárias }\end{array}$ & Irrigante & Biritiba-Mirim & $388.890,0$ & $7.392 .799,8$ & 6,51 & 1,77 & 2,04 & 2,53 & 1,77 & 2,04 & 2,53 \\
\hline 28705 & BASF S.A. & 12,1 & 10,4 & 20 & 20.70 & $\begin{array}{l}\text { Fabricação de tintas, } \\
\text { vernizes, esmaltes, lacas } \\
\text { e produtos afins }\end{array}$ & Industrial & Pinheirinho & $340.650,0$ & $7.372 .730,0$ & 5,70 & 1,80 & 2,05 & 2,48 & 3,83 & 4,65 & 6,06 \\
\hline 62787 & $\begin{array}{l}\text { ASSOCIACAO AGRICOLA } \\
\text { DESPORTIVA E CULTURAL DO } \\
\text { SOGO }\end{array}$ & 28,8 & 11,8 & 1 & 01.10 & $\begin{array}{l}\text { Produção de lavouras } \\
\text { temporárias }\end{array}$ & Irrigante & Biritiba-Mirim & $388.820,0$ & $7.390 .730,0$ & 10,77 & 1,78 & 2,05 & 2,53 & 1,78 & 2,05 & 2,53 \\
\hline 11900 & $\begin{array}{l}\text { COMPANHIA NITRO QUIMICA } \\
\text { BRASILEIRA }\end{array}$ & 9,1 & 7,9 & 20 & 20.90 & $\begin{array}{l}\text { Fabricação de produtos e } \\
\text { preparados químicos } \\
\text { diversos }\end{array}$ & Industrial & São Miguel & $352.980,0$ & $7.401 .819,8$ & 3,37 & 1,81 & 2,06 & 2,50 & 3,98 & 4,83 & 6,29 \\
\hline 11207 & CIA GUAIANAZES DE PAPEL & 54,8 & 14,1 & 17 & 17.20 & $\begin{array}{l}\text { Fabricação de papel, } \\
\text { cartolina e papel-cartão }\end{array}$ & Industrial & São Miguel & $354.470,0$ & $7.396 .450,2$ & 9,82 & 1,82 & 2,08 & 2,52 & 3,72 & 4,51 & 5,86 \\
\hline 11182 & $\begin{array}{l}\text { COMPANHIA INDUSTRIAL } \\
\text { PAULISTA DE PAPEIS E PAPELAO }\end{array}$ & 26,0 & 6,7 & 17 & 17.20 & $\begin{array}{l}\text { Fabricação de papel, } \\
\text { cartolina e papel-cartão }\end{array}$ & Industrial & Jesus Neto & $338.890,0$ & $7.390 .890,1$ & 2,51 & 1,83 & 2,08 & 2,52 & 4,07 & 4,95 & 6,46 \\
\hline 9495 & RIPASA S.A. CELULOSE E PAPEL & 60,3 & 15,5 & 17 & 17.20 & $\begin{array}{l}\text { Fabricação de papel, } \\
\text { cartolina e papel-cartão }\end{array}$ & Industrial & $\begin{array}{l}\text { Cotia/Jardim } \\
\text { Japão }\end{array}$ & $310.910,0$ & $7.382 .859,9$ & 11,69 & 1,84 & 2,10 & 2,55 & 3,70 & 4,49 & 5,82 \\
\hline 60353 & $\begin{array}{l}\text { PROCOSA PRODUTOS DE } \\
\text { BELEZA LTDA. }\end{array}$ & 15,1 & 13,0 & 20 & 20.60 & $\begin{array}{l}\text { Fabricação de sabões, } \\
\text { detergentes, produtos de } \\
\text { limpeza, cosméticos, } \\
\text { produtos de perfumaria e } \\
\text { de higiene pessoal }\end{array}$ & Industrial & Bandeirantes & $322.260,0$ & $7.399 .109,9$ & 9,26 & 1,86 & 2,12 & 2,57 & 3,79 & 4,60 & 5,97 \\
\hline 62782 & $\begin{array}{l}\text { ASSOCIACAO AGRICOLA } \\
\text { DESPORTIVA E CULTURAL DO } \\
\text { SOGO }\end{array}$ & 23,6 & 9,7 & 1 & 01.10 & $\begin{array}{l}\text { Produção de lavouras } \\
\text { temporárias }\end{array}$ & Irrigante & Biritiba-Mirim & $389.000,0$ & $7.392 .330,1$ & 9,67 & 1,84 & 2,12 & 2,63 & 1,84 & 2,12 & 2,63 \\
\hline 169522 & KAZUHIRO INO E OUTRO & 18,3 & 18,3 & 1 & 01.50 & Pecuária & Industrial & Suzano & $367.350,0$ & $7.385 .350,1$ & 14,94 & 1,87 & 2,13 & 2,59 & 3,66 & 4,43 & 5,74 \\
\hline 159071 & $\begin{array}{l}\text { IBEMA COMPANHIA BRASILEIRA } \\
\text { DE PAPEL }\end{array}$ & 27,4 & 11,2 & 17 & 17.30 & $\begin{array}{l}\text { Fabricação de } \\
\text { embalagens de papel, } \\
\text { cartolina, papel-cartão e } \\
\text { papelão ondulado }\end{array}$ & Irrigante & $\begin{array}{l}\text { Cotia/Jardim } \\
\text { Japão }\end{array}$ & $310.910,0$ & $7.382 .859,9$ & 11,69 & 1,85 & 2,13 & 2,64 & 1,85 & 2,13 & 2,64 \\
\hline 65652 & $\begin{array}{l}\text { KIMBERLY-CLARK BRASIL IND } \\
\text { COM PROD DE HIGIENE LTDA }\end{array}$ & 43,8 & 11,3 & 17 & 17.20 & $\begin{array}{l}\text { Fabricação de papel, } \\
\text { cartolina e papel-cartão }\end{array}$ & Industrial & Leste & $382.630,0$ & $7.396 .189,9$ & 8,18 & 1,88 & 2,14 & 2,60 & 3,87 & 4,70 & 6,11 \\
\hline
\end{tabular}




\begin{tabular}{|c|c|c|c|c|c|c|c|c|c|c|c|c|c|c|c|c|c|}
\hline & & & & & & & & & & \multirow{2}{*}{\multicolumn{2}{|c|}{ Legenda de cores }} & \multirow{2}{*}{\multicolumn{2}{|c|}{ Classe A }} & \multirow{2}{*}{\multicolumn{2}{|c|}{ Classe B }} & \multirow{2}{*}{\multicolumn{2}{|c|}{ Classe C }} \\
\hline & & & & & & & & & & & & & & & & & \\
\hline ID & Usuário & $\mathbf{Q}(1 / \mathbf{s})$ & $\begin{array}{l}Q_{N P} \\
(I / s)\end{array}$ & $\begin{array}{l}\text { Divisão } \\
\text { CNAE } \\
2.0 \\
\end{array}$ & $\begin{array}{l}\text { Grupo } \\
\text { CNAE } \\
2.0\end{array}$ & Grupo CNAE 2.0 & Finalidade & $\begin{array}{l}\text { ETE de } \\
\text { referência }\end{array}$ & $X(m)$ & $Y(m)$ & $L(\mathbf{k m})$ & C10 & C1R & C1P & $\mathrm{C} 2 \mathrm{O}$ & C2R & C2P \\
\hline 11127 & $\begin{array}{l}\text { INDUSTRIA DE MEIAS SCALINA } \\
\text { LTDA }\end{array}$ & 15,1 & 5,4 & 13 & 13.50 & $\begin{array}{l}\text { Fabricação de artefatos } \\
\text { têxteis, exceto vestuário }\end{array}$ & Industrial & São João & $353.480,0$ & $7.410 .109,9$ & 1,84 & 1,89 & 2,14 & 2,60 & 4,24 & 5,16 & 6,72 \\
\hline 9967 & $\begin{array}{l}\text { D. K. TINTURARIA INDUSTRIAL } \\
\text { LTDA }\end{array}$ & 27,4 & 9,8 & 13 & 13.10 & $\begin{array}{l}\text { Preparação e fiação de } \\
\text { fibras têxteis }\end{array}$ & Industrial & São Miguel & $351.260,0$ & $7.402 .319,8$ & 7,07 & 1,90 & 2,17 & 2,64 & 3,96 & 4,81 & 6,25 \\
\hline 20420 & ROSSET \& CIA LTDA. & 23,7 & 8,5 & 13 & 13.40 & $\begin{array}{l}\text { Acabamentos em fios, } \\
\text { tecidos e artefatos têxteis }\end{array}$ & Industrial & $\begin{array}{l}\text { Várzea do } \\
\text { Palácio }\end{array}$ & $349.260,0$ & $7.402 .950,2$ & 5,75 & 1,91 & 2,18 & 2,65 & 4,04 & 4,90 & 6,38 \\
\hline 61543 & $\begin{array}{l}\text { RHODIA POLIAMIDA E } \\
\text { ESPECIALIDADES LTDA }\end{array}$ & 9,6 & 8,2 & 20 & 20.20 & $\begin{array}{l}\text { Fabricação de produtos } \\
\text { químicos orgânicos }\end{array}$ & Industrial & Mauá & $344.920,0$ & $7.383 .100,1$ & 5,52 & 1,91 & 2,18 & 2,65 & 4,05 & 4,92 & 6,41 \\
\hline 113393 & $\begin{array}{l}\text { DAMAPEL IND. COM. E } \\
\text { DISTRIBUICAO DE PAPEIS LTDA }\end{array}$ & 31,5 & 8,1 & 17 & 17.20 & $\begin{array}{l}\text { Fabricação de papel, } \\
\text { cartolina e papel-cartão }\end{array}$ & Industrial & $\begin{array}{l}\text { Várzea do } \\
\text { Palácio }\end{array}$ & $347.310,0$ & $7.407 .350,1$ & 5,52 & 1,92 & 2,19 & 2,66 & 4,07 & 4,94 & 6,43 \\
\hline 164530 & $\begin{array}{l}\text { TP INDUSTRIAL DE PNEUS } \\
\text { BRASIL LTDA }\end{array}$ & 9,0 & 5,8 & 22 & 22.10 & $\begin{array}{l}\text { Fabricação de produtos } \\
\text { de borracha }\end{array}$ & Industrial & Mauá & $346.920,0$ & $7.382 .470,2$ & 2,88 & 1,93 & 2,19 & 2,66 & 4,24 & 5,16 & 6,72 \\
\hline 11407 & $\begin{array}{l}\text { INDUSTRIAS TEXTEIS SUECO } \\
\text { LTDA. }\end{array}$ & 23,7 & 8,5 & 13 & 13.10 & $\begin{array}{l}\text { Preparação e fiação de } \\
\text { fibras têxteis }\end{array}$ & Industrial & São Miguel & $353.310,0$ & $7.403 .040,0$ & 6,07 & 1,93 & 2,20 & 2,67 & 4,05 & 4,92 & 6,41 \\
\hline 11571 & $\begin{array}{l}\text { MANIKRAFT GUAIANAZES IND.DE } \\
\text { CELULOSE E PAPEL LTDA. }\end{array}$ & 46,6 & 12,0 & 17 & 17.40 & $\begin{array}{l}\text { Fabricação de produtos } \\
\text { diversos de papel, } \\
\text { cartolina, papel-cartão e } \\
\text { papelão ondulado }\end{array}$ & Industrial & São Miguel & $354.270,0$ & $7.396 .700,2$ & 10,16 & 1,93 & 2,20 & 2,68 & 3,90 & 4,73 & 6,14 \\
\hline 10330 & RESANA S.A. IND. QUIMICAS & 13,7 & 11,8 & 20 & 20.20 & $\begin{array}{l}\text { Fabricação de produtos } \\
\text { químicos orgânicos }\end{array}$ & Industrial & Suzano & $373.890,0$ & $7.394 .580,1$ & 10,03 & 1,94 & 2,21 & 2,69 & 3,91 & 4,74 & 6,16 \\
\hline 8332 & AIR PRODUCTS BRASIL LTDA & 10,3 & 7,0 & 35 & 35.20 & $\begin{array}{l}\text { Produção e distribuição } \\
\text { de combustíveis gasosos } \\
\text { por redes urbanas }\end{array}$ & Industrial & Leste & $376.550,0$ & $7.398 .509,8$ & 4,58 & 1,95 & 2,22 & 2,70 & 4,17 & 5,07 & 6,59 \\
\hline 98870 & GERDAU ACOS LONGOS S.A. & 11,7 & 7,0 & 24 & 24.20 & Siderurgia & Industrial & $\begin{array}{l}\text { Cotia/Jardim } \\
\text { Japão }\end{array}$ & $307.820,0$ & $7.388 .790,0$ & 4,81 & 1,96 & 2,24 & 2,72 & 4,18 & 5,08 & 6,62 \\
\hline 74560 & $\begin{array}{l}\text { HORIZON ARTEFATOS DE } \\
\text { BORRACHA LTDA. }\end{array}$ & 11,0 & 7,1 & 22 & 22.10 & $\begin{array}{l}\text { Fabricação de produtos } \\
\text { de borracha }\end{array}$ & Industrial & $\begin{array}{l}\text { Cotia/Jardim } \\
\text { Japão }\end{array}$ & $307.670,0$ & $7.388 .819,8$ & 4,98 & 1,97 & 2,24 & 2,73 & 4,18 & 5,08 & 6,61 \\
\hline 11123 & $\begin{array}{l}\text { INDUSTRIA DE MEIAS SCALINA } \\
\text { LTDA }\end{array}$ & 11,0 & 3,9 & 13 & 13.50 & $\begin{array}{l}\text { Fabricação de artefatos } \\
\text { têxteis, exceto vestuário }\end{array}$ & Industrial & Bonsucesso & $355.970,0$ & $7.409 .779,8$ & 1,54 & 2,02 & 2,29 & 2,79 & 4,54 & 5,53 & 7,21 \\
\hline 164527 & $\begin{array}{l}\text { TP INDUSTRIAL DE PNEUS } \\
\text { BRASIL LTDA }\end{array}$ & 6,5 & 4,2 & 22 & 22.10 & $\begin{array}{l}\text { Fabricação de produtos } \\
\text { de borracha }\end{array}$ & Industrial & Mauá & $347.030,0$ & $7.382 .960,0$ & 1,88 & 2,02 & 2,30 & 2,79 & 4,51 & 5,49 & 7,15 \\
\hline 62788 & $\begin{array}{l}\text { ASSOCIACAO AGRICOLA } \\
\text { DESPORTIVA E CULTURAL DO } \\
\text { SOGO }\end{array}$ & 20,1 & 8,3 & 1 & 01.10 & $\begin{array}{l}\text { Produção de lavouras } \\
\text { temporárias }\end{array}$ & Irrigante & Biritiba-Mirim & $388.820,0$ & $7.390 .730,0$ & 10,77 & 2,00 & 2,31 & 2,87 & 2,00 & 2,31 & 2,87 \\
\hline 169517 & $\begin{array}{l}\text { EUROAMERICAN DO BRASIL } \\
\text { IMPORTACAO IND. E COM. LTDA }\end{array}$ & 10,2 & 8,8 & 20 & 20.70 & $\begin{array}{l}\text { Fabricação de tintas, } \\
\text { vernizes, esmaltes, lacas } \\
\text { e produtos afins }\end{array}$ & Industrial & Barueri & $306.200,0$ & $7.397 .009,8$ & 8,23 & 2,03 & 2,31 & 2,82 & 4,14 & 5,02 & 6,52 \\
\hline 164534 & $\begin{array}{l}\text { TP INDUSTRIAL DE PNEUS } \\
\text { BRASIL LTDA }\end{array}$ & 7,6 & 4,9 & 22 & 22.10 & $\begin{array}{l}\text { Fabricação de produtos } \\
\text { de borracha }\end{array}$ & Industrial & Mauá & $347.100,0$ & $7.381 .950,2$ & 3,17 & 2,04 & 2,33 & 2,83 & 4,44 & 5,40 & 7,04 \\
\hline 10044 & $\begin{array}{l}\text { KOOK'S TINTURARIA E } \\
\text { ESTAMPARIA LTDA. }\end{array}$ & 20,5 & 3,5 & 14 & 14.10 & $\begin{array}{l}\text { Confecção de artigos do } \\
\text { vestuário e acessórios }\end{array}$ & Industrial & São Miguel & $352.790,0$ & $7.402 .350,1$ & 1,25 & 2,05 & 2,33 & 2,83 & 4,63 & 5,64 & 7,36 \\
\hline 170170 & $\begin{array}{l}\text { GALLEON ESTRUTURA PRE- } \\
\text { MOLDADAS DE CONC. LTDA. EPP }\end{array}$ & 20,5 & 13,5 & 23 & 23.30 & $\begin{array}{l}\text { Fabricação de artefatos } \\
\text { de concreto, cimento, } \\
\text { fibrocimento, gesso e } \\
\text { materiais semelhantes }\end{array}$ & Industrial & $\begin{array}{l}\text { Guararema - } \\
\text { Sede }\end{array}$ & $385.350,0$ & $7.420 .669,9$ & 14,88 & 2,06 & 2,35 & 2,87 & 3,97 & 4,81 & 6,24 \\
\hline 69442 & $\begin{array}{l}\text { SUZANO PAPEL E CELULOSE } \\
\text { S.A. }\end{array}$ & 32,9 & 8,5 & 17 & 17.20 & $\begin{array}{l}\text { Fabricação de papel, } \\
\text { cartolina e papel-cartão }\end{array}$ & Industrial & Jardim Odete & $363.950,0$ & $7.401 .200,2$ & 8,43 & 2,07 & 2,36 & 2,88 & 4,20 & 5,09 & 6,62 \\
\hline
\end{tabular}




\begin{tabular}{|c|c|c|c|c|c|c|c|c|c|c|c|c|c|c|c|c|c|}
\hline & & & \multirow[b]{3}{*}{$\begin{array}{l}Q_{N P} \\
(I / s)\end{array}$} & \multirow[b]{3}{*}{$\begin{array}{l}\text { Divisão } \\
\text { CNAE } \\
2.0 \\
\end{array}$} & \multirow[b]{3}{*}{$\begin{array}{l}\text { Grupo } \\
\text { CNAE } \\
2.0\end{array}$} & \multirow[b]{3}{*}{ Grupo CNAE 2.0} & \multirow[b]{3}{*}{ Finalidade } & \multirow[b]{3}{*}{$\begin{array}{l}\text { ETE de } \\
\text { referência }\end{array}$} & \multirow[b]{3}{*}{$X(m)$} & \multirow{2}{*}{\multicolumn{2}{|c|}{ Legenda de cores }} & \multirow{2}{*}{\multicolumn{2}{|c|}{ Classe A }} & \multirow{2}{*}{\multicolumn{2}{|c|}{ Classe B }} & \multirow{2}{*}{\multicolumn{2}{|c|}{ Classe C }} \\
\hline & & & & & & & & & & & & & & & & & \\
\hline ID & Usuário & $\mathbf{Q}(\mathbf{l} / \mathbf{s})$ & & & & & & & & $Y(m)$ & L (km) & C10 & C1R & C1P & $\mathbf{C 2 O}$ & C2R & C2P \\
\hline 91573 & TEXTIL LAPO S.A. & 22,8 & 8,2 & 13 & 13.40 & $\begin{array}{l}\text { Acabamentos em fios, } \\
\text { tecidos e artefatos têxteis }\end{array}$ & Industrial & Bandeirantes & $324.500,0$ & $7.407 .720,2$ & 8,21 & 2,07 & 2,37 & 2,89 & 4,22 & 5,12 & 6,65 \\
\hline 9599 & $\begin{array}{l}\text { IND DE CELULOSE E PAPEL } \\
\text { BANDEIRANTES SA }\end{array}$ & 20,5 & 5,3 & 17 & 17.20 & $\begin{array}{l}\text { Fabricação de papel, } \\
\text { cartolina e papel-cartão }\end{array}$ & Industrial & Leste & $377.050,0$ & $7.399 .000,0$ & 4,16 & 2,08 & 2,37 & 2,89 & 4,44 & 5,40 & 7,03 \\
\hline 22912 & SCARLAT INDUSTRIAL LTDA & 5,9 & 5,1 & 20 & 20.60 & $\begin{array}{l}\text { Fabricação de sabões, } \\
\text { detergentes, produtos de } \\
\text { limpeza, cosméticos, } \\
\text { produtos de perfumaria e } \\
\text { de higiene pessoal }\end{array}$ & Industrial & $\begin{array}{l}\text { Parque Novo } \\
\text { Mundo }\end{array}$ & $339.020,0$ & $7.398 .689,9$ & 4,00 & 2,09 & 2,38 & 2,90 & 4,47 & 5,43 & 7,08 \\
\hline 22913 & SCARLAT INDUSTRIAL LTDA & 5,9 & 5,1 & 20 & 20.60 & $\begin{array}{l}\text { Fabricação de sabões, } \\
\text { detergentes, produtos de } \\
\text { limpeza, cosméticos, } \\
\text { produtos de perfumaria e } \\
\text { de higiene pessoal }\end{array}$ & Industrial & $\begin{array}{l}\text { Parque Novo } \\
\text { Mundo }\end{array}$ & $339.000,0$ & $7.398 .700,2$ & 4,01 & 2,09 & 2,38 & 2,90 & 4,47 & 5,43 & 7,08 \\
\hline 11898 & $\begin{array}{l}\text { COMPANHIA NITRO QUIMICA } \\
\text { BRASILEIRA }\end{array}$ & 5,3 & 4,5 & 20 & 20.90 & $\begin{array}{l}\text { Fabricação de produtos e } \\
\text { preparados químicos } \\
\text { diversos }\end{array}$ & Industrial & São Miguel & $353.150,0$ & $7.401 .960,0$ & 3,21 & 2,10 & 2,39 & 2,91 & 4,54 & 5,52 & 7,20 \\
\hline 91575 & TEXTIL LAPO S.A. & 21,5 & 7,7 & 13 & 13.40 & $\begin{array}{l}\text { Acabamentos em fios, } \\
\text { tecidos e artefatos têxteis }\end{array}$ & Industrial & Bandeirantes & $324.430,0$ & $7.407 .649,9$ & 7,88 & 2,10 & 2,39 & 2,92 & 4,27 & 5,18 & 6,74 \\
\hline 60355 & $\begin{array}{l}\text { PROCOSA PRODUTOS DE } \\
\text { BELEZA LTDA. }\end{array}$ & 10,0 & 8,6 & 20 & 20.60 & $\begin{array}{l}\text { Fabricação de sabões, } \\
\text { detergentes, produtos de } \\
\text { limpeza, cosméticos, } \\
\text { produtos de perfumaria e } \\
\text { de higiene pessoal }\end{array}$ & Industrial & Bandeirantes & $322.110,0$ & $7.399 .089,8$ & 9,15 & 2,10 & 2,40 & 2,92 & 4,22 & 5,11 & 6,64 \\
\hline 83559 & $\begin{array}{l}\text { DAG QUIMICA IND., COM. E } \\
\text { REPRESENTACOES LTDA. }\end{array}$ & 8,9 & 7,6 & 20 & 20.90 & $\begin{array}{l}\text { Fabricação de produtos e } \\
\text { preparados químicos } \\
\text { diversos }\end{array}$ & Industrial & Suzano & $366.300,0$ & $7.391 .149,9$ & 8,26 & 2,12 & 2,42 & 2,96 & 4,30 & 5,21 & 6,78 \\
\hline 95469 & $\begin{array}{l}\text { AKUA IND COM IMPORT E } \\
\text { EXPORT DE COSMETICOS LTDA. }\end{array}$ & 8,2 & 7,1 & 20 & 20.60 & $\begin{array}{l}\text { Fabricação de sabões, } \\
\text { detergentes, produtos de } \\
\text { limpeza, cosméticos, } \\
\text { produtos de perfumaria e } \\
\text { de higiene pessoal }\end{array}$ & Industrial & Barueri & $306.560,0$ & $7.396 .720,2$ & 7,45 & 2,12 & 2,43 & 2,96 & 4,34 & 5,26 & 6,85 \\
\hline 164529 & $\begin{array}{l}\text { TP INDUSTRIAL DE PNEUS } \\
\text { BRASIL LTDA }\end{array}$ & 6,4 & 4,1 & 22 & 22.10 & $\begin{array}{l}\text { Fabricação de produtos } \\
\text { de borracha }\end{array}$ & Industrial & Mauá & $346.660,0$ & $7.382 .460,0$ & 3,10 & 2,14 & 2,44 & 2,98 & 4,64 & 5,64 & 7,35 \\
\hline 71016 & MINERACAO TABOCA S.A. & 8,2 & 4,9 & 24 & 24.40 & $\begin{array}{l}\text { Metalurgia dos metais } \\
\text { não-ferrosos }\end{array}$ & Industrial & $\begin{array}{l}\text { Pirapora - } \\
\text { Sede }\end{array}$ & $298.780,0$ & $7.409 .799,8$ & 4,50 & 2,16 & 2,46 & 3,00 & 4,56 & 5,54 & 7,22 \\
\hline 164531 & $\begin{array}{l}\text { TP INDUSTRIAL DE PNEUS } \\
\text { BRASIL LTDA }\end{array}$ & 5,1 & 3,3 & 22 & 22.10 & $\begin{array}{l}\text { Fabricação de produtos } \\
\text { de borracha }\end{array}$ & Industrial & Mauá & $347.300,0$ & $7.382 .430,2$ & 2,20 & 2,19 & 2,49 & 3,04 & 4,81 & 5,85 & 7,63 \\
\hline 32195 & AUNDE BRASIL S.A. & 9,1 & 3,3 & 13 & 13.10 & $\begin{array}{l}\text { Preparação e fiação de } \\
\text { fibras têxteis }\end{array}$ & Industrial & Suzano & $363.570,0$ & $7.398 .359,9$ & 2,26 & 2,20 & 2,51 & 3,06 & 4,83 & 5,87 & 7,66 \\
\hline 12255 & $\begin{array}{l}\text { WALLIG NORDESTE S/A } \\
\text { INDUSTRIA E COMERCIO }\end{array}$ & 8,2 & 5,1 & 27 & 27.50 & $\begin{array}{l}\text { Fabricação de } \\
\text { eletrodomésticos }\end{array}$ & Industrial & Jesus Neto & $337.650,0$ & $7.394 .669,9$ & 5,48 & 2,20 & 2,52 & 3,07 & 4,58 & 5,56 & 7,24 \\
\hline 10135 & TINTAS CORAL S.A. & 5,2 & 4,5 & 20 & 20.70 & $\begin{array}{l}\text { Fabricação de tintas, } \\
\text { vernizes, esmaltes, lacas } \\
\text { e produtos afins }\end{array}$ & Industrial & Mauá & $349.400,0$ & $7.380 .250,0$ & 4,49 & 2,21 & 2,53 & 3,09 & 4,66 & 5,67 & 7,38 \\
\hline 46344 & $\begin{array}{l}\text { SANOFI AVENTIS } \\
\text { FARMACEUTICA LTDA. }\end{array}$ & 4,9 & 4,5 & 21 & 21.20 & $\begin{array}{l}\text { Fabricação de produtos } \\
\text { farmacêuticos }\end{array}$ & Industrial & Suzano & $368.660,0$ & $7.396 .500,0$ & 4,60 & 2,21 & 2,53 & 3,09 & 4,66 & 5,66 & 7,37 \\
\hline
\end{tabular}


\begin{tabular}{llll}
\hline Legenda de cores & Classe $\mathbf{A}$ & Classe B & Classe C
\end{tabular}

\begin{tabular}{|c|c|c|c|c|c|c|c|c|c|c|c|c|c|c|c|c|c|}
\hline & & & & & & & & & & Legenda d & cores & & & & sse B & & \\
\hline ID & Usuário & $\mathbf{Q}(\mathbf{I} / \mathbf{s})$ & $\begin{array}{l}Q_{N P} \\
(I / s)\end{array}$ & $\begin{array}{l}\text { Divisão } \\
\text { CNAE } \\
2.0 \\
\end{array}$ & $\begin{array}{l}\text { Grupo } \\
\text { CNAE } \\
2.0\end{array}$ & Grupo CNAE 2.0 & Finalidade & $\begin{array}{l}\text { ETE de } \\
\text { referência }\end{array}$ & $X(m)$ & $Y(m)$ & L (km) & C10 & C1R & C1P & $\mathrm{C2O}$ & C2R & C2P \\
\hline 13187 & $\begin{array}{l}\text { KLABIN FABRICADORA DE PAPEL } \\
\text { E CELULOSE S/A. }\end{array}$ & 21,9 & 5,6 & 17 & 17.30 & $\begin{array}{l}\text { Fabricação de } \\
\text { embalagens de papel, } \\
\text { cartolina, papel-cartão e } \\
\text { papelão ondulado }\end{array}$ & Industrial & Leste & $382.900,0$ & $7.396 .700,2$ & 6,70 & 2,23 & 2,55 & 3,12 & 4,56 & 5,53 & 7,20 \\
\hline 62783 & $\begin{array}{l}\text { ASSOCIACAO AGRICOLA } \\
\text { DESPORTIVA E CULTURAL DO } \\
\text { SOGO }\end{array}$ & 13,9 & 5,7 & 1 & 01.10 & $\begin{array}{l}\text { Produção de lavouras } \\
\text { temporárias }\end{array}$ & Irrigante & Biritiba-Mirim & $389.010,0$ & $7.392 .060,1$ & 9,67 & 2,20 & 2,55 & 3,18 & 2,20 & 2,55 & 3,18 \\
\hline 11122 & $\begin{array}{l}\text { INDUSTRIA DE MEIAS SCALINA } \\
\text { LTDA }\end{array}$ & 5,5 & 2,0 & 13 & 13.50 & $\begin{array}{l}\text { Fabricação de artefatos } \\
\text { têxteis, exceto vestuário }\end{array}$ & Industrial & Bonsucesso & $355.490,0$ & $7.409 .100,1$ & 0,57 & 2,25 & 2,57 & 3,13 & 5,20 & 6,33 & 8,27 \\
\hline 16518 & $\begin{array}{l}\text { IBRAME IND. BRAS. DE METAIS } \\
\text { LTDA }\end{array}$ & 3,4 & 2,0 & 24 & 24.40 & $\begin{array}{l}\text { Metalurgia dos metais } \\
\text { não-ferrosos }\end{array}$ & Industrial & $\begin{array}{l}\text { Parque dos } \\
\text { Pinheiros }\end{array}$ & $313.450,0$ & $7.410 .100,1$ & 0,71 & 2,27 & 2,58 & 3,14 & 5,18 & 6,31 & 8,24 \\
\hline 170817 & $\begin{array}{l}\text { INOVAT INDUSTRIA } \\
\text { FARMACEUTICA }\end{array}$ & 4,6 & 4,2 & 21 & 21.20 & $\begin{array}{l}\text { Fabricação de produtos } \\
\text { farmacêuticos }\end{array}$ & Industrial & $\begin{array}{l}\text { Várzea do } \\
\text { Palácio }\end{array}$ & $346.070,0$ & $7.404 .069,8$ & 4,61 & 2,27 & 2,59 & 3,17 & 4,75 & 5,78 & 7,52 \\
\hline 55263 & $\begin{array}{l}\text { FARMARIN INDUSTRIA E } \\
\text { COMERCIO LTDA }\end{array}$ & 5,1 & 4,7 & 21 & 21.20 & $\begin{array}{l}\text { Fabricação de produtos } \\
\text { farmacêuticos }\end{array}$ & Industrial & $\begin{array}{l}\text { Várzea do } \\
\text { Palácio }\end{array}$ & $346.750,0$ & $7.407 .189,9$ & 5,66 & 2,28 & 2,60 & 3,18 & 4,70 & 5,70 & 7,43 \\
\hline 22663 & $\begin{array}{l}\text { INDUSTRIA E COMERCIO DE } \\
\text { COSMETICOS NATURA LTDA }\end{array}$ & 3,4 & 2,9 & 20 & 20.60 & $\begin{array}{l}\text { Fabricação de sabões, } \\
\text { detergentes, produtos de } \\
\text { limpeza, cosméticos, } \\
\text { produtos de perfumaria e } \\
\text { de higiene pessoal }\end{array}$ & Industrial & $\begin{array}{l}\text { Parque dos } \\
\text { Pinheiros }\end{array}$ & $313.020,0$ & $7.410 .660,2$ & 2,42 & 2,28 & 2,60 & 3,18 & 4,97 & 6,04 & 7,88 \\
\hline 54066 & $\begin{array}{l}\text { PHIBRO SAUDE ANIMAL } \\
\text { INTERNACIONAL LTDA }\end{array}$ & 3,0 & 2,8 & 21 & 21.20 & $\begin{array}{l}\text { Fabricação de produtos } \\
\text { farmacêuticos }\end{array}$ & Industrial & $\begin{array}{l}\text { Várzea do } \\
\text { Palácio }\end{array}$ & $346.090,0$ & $7.403 .480,0$ & 2,17 & 2,29 & 2,61 & 3,19 & 5,01 & 6,10 & 7,96 \\
\hline 11038 & PHILIPS DO BRASIL LTDA & 3,4 & 2,1 & 27 & 27.40 & $\begin{array}{l}\text { Fabricação de lâmpadas } \\
\text { e outros equipamentos } \\
\text { de iluminação }\end{array}$ & Industrial & Mauá & $348.240,0$ & $7.383 .330,1$ & 1,08 & 2,29 & 2,62 & 3,19 & 5,18 & 6,31 & 8,23 \\
\hline 22662 & $\begin{array}{l}\text { INDUSTRIA E COMERCIO DE } \\
\text { COSMETICOS NATURA LTDA }\end{array}$ & 3,4 & 2,9 & 20 & 20.60 & $\begin{array}{l}\text { Fabricação de sabões, } \\
\text { detergentes, produtos de } \\
\text { limpeza, cosméticos, } \\
\text { produtos de perfumaria e } \\
\text { de higiene pessoal }\end{array}$ & Industrial & $\begin{array}{l}\text { Parque dos } \\
\text { Pinheiros }\end{array}$ & $313.030,0$ & $7.410 .890,1$ & 2,64 & 2,31 & 2,64 & 3,23 & 5,00 & 6,08 & 7,93 \\
\hline 10906 & $\begin{array}{l}\text { ADAMAS S.A. PAPEIS E } \\
\text { PAPELOES ESPECIAIS }\end{array}$ & 28,5 & 7,3 & 17 & 17.20 & $\begin{array}{l}\text { Fabricação de papel, } \\
\text { cartolina e papel-cartão }\end{array}$ & Industrial & Barueri & $319.130,0$ & $7.394 .970,2$ & 10,89 & 2,31 & 2,64 & 3,24 & 4,50 & 5,46 & 7,09 \\
\hline 10333 & RESANA S.A. IND. QUIMICAS & 7,2 & 6,2 & 20 & 20.20 & $\begin{array}{l}\text { Fabricação de produtos } \\
\text { químicos orgânicos }\end{array}$ & Industrial & Leste & $373.880,0$ & $7.394 .859,9$ & 9,20 & 2,33 & 2,67 & 3,27 & 4,61 & 5,59 & 7,27 \\
\hline 22664 & $\begin{array}{l}\text { INDUSTRIA E COMERCIO DE } \\
\text { COSMETICOS NATURA LTDA }\end{array}$ & 3,4 & 2,9 & 20 & 20.60 & $\begin{array}{l}\text { Fabricação de sabões, } \\
\text { detergentes, produtos de } \\
\text { limpeza, cosméticos, } \\
\text { produtos de perfumaria e } \\
\text { de higiene pessoal }\end{array}$ & Industrial & $\begin{array}{l}\text { Parque dos } \\
\text { Pinheiros }\end{array}$ & $312.420,0$ & $7.410 .819,8$ & 3,05 & 2,36 & 2,70 & 3,30 & 5,05 & 6,14 & 8,00 \\
\hline 55109 & $\begin{array}{l}\text { INDUSTRIA E COMERCIO DE } \\
\text { COSMETICOS NATURA LTDA }\end{array}$ & 3,4 & 2,9 & 20 & 20.60 & $\begin{array}{l}\text { Fabricação de sabões, } \\
\text { detergentes, produtos de } \\
\text { limpeza, cosméticos, } \\
\text { produtos de perfumaria e } \\
\text { de higiene pessoal }\end{array}$ & Industrial & $\begin{array}{l}\text { Parque dos } \\
\text { Pinheiros }\end{array}$ & $312.460,0$ & $7.410 .930,2$ & 3,32 & 2,39 & 2,74 & 3,35 & 5,08 & 6,18 & 8,05 \\
\hline 10027 & TEXTIL TECNICOR LTDA & 11,9 & 4,2 & 13 & 13.50 & $\begin{array}{l}\text { Fabricação de artefatos } \\
\text { têxteis, exceto vestuário }\end{array}$ & Industrial & São Miguel & $353.310,0$ & $7.403 .040,0$ & 6,07 & 2,39 & 2,74 & 3,35 & 4,87 & 5,91 & 7,70 \\
\hline
\end{tabular}




\begin{tabular}{|c|c|c|c|c|c|c|c|c|c|c|c|c|c|c|c|c|c|}
\hline \multirow[b]{2}{*}{ ID } & \multirow[b]{2}{*}{ Usuário } & \multirow[b]{2}{*}{$\mathbf{Q}(\mathbf{I} / \mathbf{s})$} & & \multirow[b]{2}{*}{$\begin{array}{l}\text { Divisão } \\
\text { CNAE } \\
2.0\end{array}$} & & \multirow[b]{2}{*}{ Grupo CNAE 2.0} & \multirow[b]{2}{*}{ Finalidade } & \multirow[b]{2}{*}{$\begin{array}{l}\text { ETE de } \\
\text { referência }\end{array}$} & \multirow[b]{2}{*}{$X(m)$} & \multicolumn{2}{|c|}{ Legenda de cores } & \multicolumn{2}{|c|}{ Classe $\mathrm{A}$} & \multicolumn{2}{|c|}{ Classe B } & \multicolumn{2}{|c|}{ Classe C } \\
\hline & & & $\begin{array}{l}Q_{N P} \\
(I / s) \\
\end{array}$ & & $\begin{array}{l}\text { Grupo } \\
\text { CNAE } \\
2.0\end{array}$ & & & & & $Y(m)$ & $\mathrm{L}(\mathrm{km})$ & C10 & C1R & C1P & $\mathrm{C2O}$ & C2R & C2P \\
\hline 20426 & $\begin{array}{l}\text { CAMELON MAMUT TINTURARIA E } \\
\text { MALHARIA LTDA. }\end{array}$ & 11,9 & 4,2 & 13 & 13.40 & $\begin{array}{l}\text { Acabamentos em fios, } \\
\text { tecidos e artefatos têxteis }\end{array}$ & Industrial & São Miguel & $353.310,0$ & $7.403 .040,0$ & 6,07 & 2,39 & 2,74 & 3,35 & 4,87 & 5,91 & 7,70 \\
\hline 89837 & $\begin{array}{l}\text { ORGUS INDUSTRIA E COMERCIO } \\
\text { LTDA. }\end{array}$ & 5,6 & 3,6 & 22 & 22.20 & $\begin{array}{l}\text { Fabricação de produtos } \\
\text { de material plástico }\end{array}$ & Industrial & $\begin{array}{l}\text { Vargem } \\
\text { Grande } \\
\text { Paulista }\end{array}$ & $296.000,0$ & $7.387 .830,1$ & 4,76 & 2,39 & 2,74 & 3,36 & 4,97 & 6,03 & 7,86 \\
\hline 76252 & $\begin{array}{l}\text { ROTOCROM INDUSTRIA E } \\
\text { COMERCIO LTDA. }\end{array}$ & 22,8 & 5,9 & 17 & 17.40 & $\begin{array}{l}\text { Fabricação de produtos } \\
\text { diversos de papel, } \\
\text { cartolina, papel-cartão e } \\
\text { papelão ondulado }\end{array}$ & Industrial & $\begin{array}{l}\text { Mairiporã - } \\
\text { Sede }\end{array}$ & $336.550,0$ & $7.426 .859,9$ & 9,51 & 2,40 & 2,75 & 3,37 & 4,71 & 5,70 & 7,41 \\
\hline 104587 & $\begin{array}{l}\text { NADIR FIGUEIREDO INDUSTRIA E } \\
\text { COMERCIO S.A. }\end{array}$ & 5,5 & 3,6 & 23 & 23.10 & $\begin{array}{l}\text { Fabricação de vidro e de } \\
\text { produtos do vidro }\end{array}$ & Industrial & Suzano & $369.250,0$ & $7.395 .560,1$ & 4,84 & 2,40 & 2,75 & 3,37 & 4,98 & 6,05 & 7,87 \\
\hline 11339 & $\begin{array}{l}\text { INDUSTRIA E COMERCIO } \\
\text { JOLITEX LTDA }\end{array}$ & 16,4 & 5,9 & 13 & 13.50 & $\begin{array}{l}\text { Fabricação de artefatos } \\
\text { têxteis, exceto vestuário }\end{array}$ & Industrial & Pinheirinho & $338.380,0$ & $7.378 .600,1$ & 9,71 & 2,41 & 2,76 & 3,39 & 4,72 & 5,72 & 7,44 \\
\hline 60832 & LABORATORIO BIO-VET LTDA & 2,3 & 2,1 & 21 & 21.20 & $\begin{array}{l}\text { Fabricação de produtos } \\
\text { farmacêuticos }\end{array}$ & Industrial & $\begin{array}{l}\text { Vargem } \\
\text { Grande } \\
\text { Paulista }\end{array}$ & $293.930,0$ & $7.388 .680,2$ & 1,80 & 2,42 & 2,76 & 3,38 & 5,32 & 6,47 & 8,44 \\
\hline 9291 & BOMBRIL S.A. & 4,7 & 4,0 & 20 & 20.60 & $\begin{array}{l}\text { Fabricação de sabões, } \\
\text { detergentes, produtos de } \\
\text { limpeza, cosméticos, } \\
\text { produtos de perfumaria e } \\
\text { de higiene pessoal }\end{array}$ & Industrial & $A B C$ & $338.880,0$ & $7.383 .310,1$ & 5,96 & 2,42 & 2,77 & 3,40 & 4,93 & 5,98 & 7,79 \\
\hline 11765 & $\begin{array}{l}\text { FEVAP-PAINEIS E ETIQUETAS } \\
\text { METALICAS S/A. }\end{array}$ & 17,1 & 10,2 & 24 & 24.40 & $\begin{array}{l}\text { Metalurgia dos metais } \\
\text { não-ferrosos }\end{array}$ & Industrial & Jesus Neto & $322.610,0$ & $7.384 .540,0$ & 18,24 & 2,42 & 2,78 & 3,41 & 4,46 & 5,40 & 7,00 \\
\hline 86085 & HYPERMARCAS S.A. & 1,9 & 1,8 & 21 & 21.20 & $\begin{array}{l}\text { Fabricação de produtos } \\
\text { farmacêuticos }\end{array}$ & Industrial & Barueri & $312.330,0$ & $7.398 .870,1$ & 1,25 & 2,44 & 2,79 & 3,41 & 5,45 & 6,64 & 8,67 \\
\hline 86088 & HYPERMARCAS S.A. & 2,0 & 1,8 & 21 & 21.20 & $\begin{array}{l}\text { Fabricação de produtos } \\
\text { farmacêuticos }\end{array}$ & Industrial & Barueri & $312.500,0$ & $7.398 .890,1$ & 1,44 & 2,44 & 2,79 & 3,42 & 5,43 & 6,61 & 8,62 \\
\hline 104589 & $\begin{array}{l}\text { NADIR FIGUEIREDO INDUSTRIA E } \\
\text { COMERCIO S.A. }\end{array}$ & 5,3 & 3,5 & 23 & 23.10 & $\begin{array}{l}\text { Fabricação de vidro e de } \\
\text { produtos do vidro }\end{array}$ & Industrial & Suzano & $369.060,0$ & $7.396 .580,1$ & 5,08 & 2,46 & 2,81 & 3,45 & 5,05 & 6,13 & 7,98 \\
\hline 22661 & $\begin{array}{l}\text { INDUSTRIA E COMERCIO DE } \\
\text { COSMETICOS NATURA LTDA }\end{array}$ & 3,4 & 2,9 & 20 & 20.60 & $\begin{array}{l}\text { Fabricação de sabões, } \\
\text { detergentes, produtos de } \\
\text { limpeza, cosméticos, } \\
\text { produtos de perfumaria e } \\
\text { de higiene pessoal }\end{array}$ & Industrial & $\begin{array}{l}\text { Parque dos } \\
\text { Pinheiros }\end{array}$ & $312.830,0$ & $7.411 .089,8$ & 3,91 & 2,46 & 2,81 & 3,45 & 5,15 & 6,25 & 8,15 \\
\hline 113641 & ESTAMPARIA SALETE LTDA. & 16,4 & 5,9 & 13 & 13.10 & $\begin{array}{l}\text { Preparação e fiação de } \\
\text { fibras têxteis }\end{array}$ & Industrial & $\begin{array}{l}\text { Parque dos } \\
\text { Pinheiros }\end{array}$ & $311.400,0$ & $7.417 .109,9$ & 10,71 & 2,49 & 2,85 & 3,50 & 4,79 & 5,81 & 7,54 \\
\hline 163076 & ESTAMPARIA SALETE LTDA & 16,4 & 5,9 & 13 & 13.10 & $\begin{array}{l}\text { Preparação e fiação de } \\
\text { fibras têxteis }\end{array}$ & Industrial & $\begin{array}{l}\text { Parque dos } \\
\text { Pinheiros }\end{array}$ & $311.400,0$ & $7.417 .109,9$ & 10,71 & 2,49 & 2,85 & 3,50 & 4,79 & 5,81 & 7,54 \\
\hline 33497 & $\begin{array}{l}\text { OSWALDO CRUZ QUIMICA } \\
\text { INDUSTRIA E COMERCIO LTDA }\end{array}$ & 6,2 & 5,3 & 20 & 20.90 & $\begin{array}{l}\text { Fabricação de produtos e } \\
\text { preparados químicos } \\
\text { diversos }\end{array}$ & Industrial & Guatambu & $372.860,0$ & $7.406 .960,0$ & 9,45 & 2,50 & 2,87 & 3,51 & 4,86 & 5,89 & 7,65 \\
\hline 155777 & $\begin{array}{l}\text { PRODUQUIMICA INDUSTRIA E } \\
\text { COMERCIO S.A. }\end{array}$ & 2,1 & 1,8 & 20 & 20.10 & $\begin{array}{l}\text { Fabricação de produtos } \\
\text { químicos inorgânicos }\end{array}$ & Industrial & Mauá & $348.470,0$ & $7.383 .640,1$ & 1,61 & 2,51 & 2,87 & 3,51 & 5,52 & 6,72 & 8,77 \\
\hline 102510 & PEPSICO DO BRASIL LTDA. & 5,5 & 2,7 & 10 & 10.90 & $\begin{array}{l}\text { Fabricação de outros } \\
\text { produtos alimentícios }\end{array}$ & Industrial & $\begin{array}{l}\text { Várzea do } \\
\text { Palácio } \\
\end{array}$ & $347.090,0$ & $7.404 .410,2$ & 3,85 & 2,51 & 2,88 & 3,53 & 5,25 & 6,39 & 8,32 \\
\hline 86086 & HYPERMARCAS S.A. & 1,5 & 1,3 & 21 & 21.20 & $\begin{array}{l}\text { Fabricação de produtos } \\
\text { farmacêuticos }\end{array}$ & Industrial & Barueri & $311.900,0$ & $7.398 .870,1$ & 0,82 & 2,53 & 2,90 & 3,54 & 5,73 & 6,98 & 9,12 \\
\hline
\end{tabular}


\begin{tabular}{llll}
\hline Legenda de cores & Classe $\mathbf{A}$ & Classe B & Classe C
\end{tabular}

\begin{tabular}{|c|c|c|c|c|c|c|c|c|c|c|c|c|c|c|c|c|c|}
\hline & & & & & & & & & & Legenda d & cores & $\mathrm{Cla}$ & & & se B & & \\
\hline ID & Usuário & $Q(1 / \mathbf{s})$ & $\begin{array}{l}Q_{N P} \\
(I / s)\end{array}$ & $\begin{array}{l}\text { Divisão } \\
\text { CNAE } \\
2.0 \\
\end{array}$ & $\begin{array}{l}\text { Grupo } \\
\text { CNAE } \\
2.0\end{array}$ & Grupo CNAE 2.0 & Finalidade & $\begin{array}{l}\text { ETE de } \\
\text { referência }\end{array}$ & $X(m)$ & $Y(m)$ & L (km) & C10 & C1R & C1P & $\mathrm{C} 2 \mathrm{O}$ & C2R & $\mathrm{C} 2 \mathrm{P}$ \\
\hline 69253 & BRASKEM S.A. & 2,7 & 2,4 & 20 & 20.90 & $\begin{array}{l}\text { Fabricação de produtos e } \\
\text { preparados químicos } \\
\text { diversos }\end{array}$ & Industrial & Jesus Neto & $338.750,0$ & $7.389 .080,1$ & 3,12 & 2,53 & 2,90 & 3,55 & 5,36 & 6,51 & 8,49 \\
\hline 10701 & $\begin{array}{l}\text { ANDERSON CLAYTON S A IND E } \\
\text { COM }\end{array}$ & 11,8 & 5,8 & 10 & 10.40 & $\begin{array}{l}\text { Fabricação de óleos e } \\
\text { gorduras vegetais e } \\
\text { animais }\end{array}$ & Industrial & Bandeirantes & $324.550,0$ & $7.399 .069,8$ & 11,25 & 2,54 & 2,91 & 3,57 & 4,85 & 5,87 & 7,63 \\
\hline 34087 & $\begin{array}{l}\text { INDUSTRIA E COMERCIO DE } \\
\text { ALIMENTOS SANTA MARTA LTDA }\end{array}$ & 6,9 & 3,4 & 10 & 10.90 & $\begin{array}{l}\text { Fabricação de outros } \\
\text { produtos alimentícios }\end{array}$ & Industrial & $\begin{array}{l}\text { Parque dos } \\
\text { Pinheiros }\end{array}$ & $307.470,0$ & $7.410 .419,9$ & 5,78 & 2,54 & 2,91 & 3,57 & 5,14 & 6,24 & 8,12 \\
\hline 32194 & AUNDE BRASIL S.A. & 5,7 & 2,0 & 13 & 13.10 & $\begin{array}{l}\text { Preparação e fiação de } \\
\text { fibras têxteis }\end{array}$ & Industrial & Suzano & $363.410,0$ & $7.398 .270,0$ & 2,46 & 2,54 & 2,91 & 3,57 & 5,46 & 6,64 & 8,67 \\
\hline 86087 & HYPERMARCAS S.A. & 1,5 & 1,3 & 21 & 21.20 & $\begin{array}{l}\text { Fabricação de produtos } \\
\text { farmacêuticos }\end{array}$ & Industrial & Barueri & $312.040,0$ & $7.398 .830,1$ & 0,92 & 2,56 & 2,92 & 3,58 & 5,75 & 7,01 & 9,16 \\
\hline 15251 & REINAG QUIMICA LTDA & 4,7 & 4,1 & 20 & 20.10 & $\begin{array}{l}\text { Fabricação de produtos } \\
\text { químicos inorgânicos }\end{array}$ & Industrial & Pinheirinho & $337.250,0$ & $7.377 .040,0$ & 7,52 & 2,55 & 2,93 & 3,60 & 5,06 & 6,13 & 7,98 \\
\hline 11210 & $\begin{array}{l}\text { COTONIFICIO GUILHERME } \\
\text { GIORGI S/A }\end{array}$ & 8,2 & 2,9 & 13 & 13.10 & $\begin{array}{l}\text { Preparação e fiação de } \\
\text { fibras têxteis }\end{array}$ & Industrial & $\begin{array}{l}\text { Parque Novo } \\
\text { Mundo }\end{array}$ & $343.300,0$ & $7.395 .700,2$ & 4,81 & 2,56 & 2,94 & 3,61 & 5,25 & 6,38 & 8,31 \\
\hline 109775 & $\begin{array}{l}\text { QUIRIOS PRODUTOS QUIMICOS } \\
\text { S.A. }\end{array}$ & 3,7 & 3,1 & 20 & 20.90 & $\begin{array}{l}\text { Fabricação de produtos e } \\
\text { preparados químicos } \\
\text { diversos }\end{array}$ & Industrial & Barueri & $307.590,0$ & $7.400 .879,9$ & 5,51 & 2,59 & 2,97 & 3,64 & 5,24 & 6,36 & 8,28 \\
\hline 55261 & $\begin{array}{l}\text { FARMARIN INDUSTRIA E } \\
\text { COMERCIO LTDA }\end{array}$ & 3,4 & 3,2 & 21 & 21.20 & $\begin{array}{l}\text { Fabricação de produtos } \\
\text { farmacêuticos }\end{array}$ & Industrial & $\begin{array}{l}\text { Várzea do } \\
\text { Palácio }\end{array}$ & $346.700,0$ & $7.407 .160,2$ & 5,66 & 2,60 & 2,98 & 3,66 & 5,25 & 6,37 & 8,30 \\
\hline 53118 & SCARLAT INDUSTRIAL LTDA & 3,6 & 3,1 & 20 & 20.60 & $\begin{array}{l}\text { Fabricação de sabões, } \\
\text { detergentes, produtos de } \\
\text { limpeza, cosméticos, } \\
\text { produtos de perfumaria e } \\
\text { de higiene pessoal }\end{array}$ & Industrial & Suzano & $367.770,0$ & $7.393 .480,0$ & 5,62 & 2,61 & 2,99 & 3,67 & 5,26 & 6,39 & 8,32 \\
\hline 55113 & $\begin{array}{l}\text { INDUSTRIA E COMERCIO DE } \\
\text { COSMETICOS NATURA LTDA }\end{array}$ & 2,7 & 2,4 & 20 & 20.60 & $\begin{array}{l}\text { Fabricação de sabões, } \\
\text { detergentes, produtos de } \\
\text { limpeza, cosméticos, } \\
\text { produtos de perfumaria e } \\
\text { de higiene pessoal }\end{array}$ & Industrial & $\begin{array}{l}\text { Parque dos } \\
\text { Pinheiros }\end{array}$ & $312.640,0$ & $7.411 .080,1$ & 3,69 & 2,61 & 2,99 & 3,67 & 5,44 & 6,61 & 8,61 \\
\hline 27563 & $\begin{array}{l}\text { MAGGION INDUSTRIA DE PNEUS } \\
\text { E MAQUINAS LTDA }\end{array}$ & 3,3 & 2,1 & 22 & 22.10 & $\begin{array}{l}\text { Fabricação de produtos } \\
\text { de borracha }\end{array}$ & Industrial & $\begin{array}{l}\text { Várzea do } \\
\text { Palácio }\end{array}$ & $345.660,0$ & $7.403 .460,0$ & 3,17 & 2,62 & 3,01 & 3,69 & 5,51 & 6,71 & 8,74 \\
\hline 62791 & $\begin{array}{l}\text { ASSOCIACAO AGRICOLA } \\
\text { DESPORTIVA E CULTURAL DO } \\
\text { SOGO }\end{array}$ & 9,9 & 4,0 & 1 & 01.10 & $\begin{array}{l}\text { Produção de lavouras } \\
\text { temporárias }\end{array}$ & Irrigante & Biritiba-Mirim & $388.720,0$ & $7.390 .509,8$ & 10,85 & 2,60 & 3,03 & 3,79 & 2,60 & 3,03 & 3,79 \\
\hline 10332 & RESANA S.A. IND. QUIMICAS & 5,1 & 4,4 & 20 & 20.20 & $\begin{array}{l}\text { Fabricação de produtos } \\
\text { químicos orgânicos }\end{array}$ & Industrial & Leste & $373.860,0$ & $7.394 .890,1$ & 9,16 & 2,64 & 3,03 & 3,73 & 5,11 & 6,19 & 8,05 \\
\hline 48646 & $\begin{array}{l}\text { MAGNETI MARELLI COFAP CIA } \\
\text { FABRICADORA DE PECAS }\end{array}$ & 3,9 & 1,7 & 29 & 29.40 & $\begin{array}{l}\text { Fabricação de peças e } \\
\text { acessórios para veículos } \\
\text { automotores }\end{array}$ & Industrial & Mauá & $348.470,0$ & $7.382 .609,9$ & 2,27 & 2,65 & 3,04 & 3,73 & 5,68 & 6,91 & 9,02 \\
\hline 62777 & $\begin{array}{l}\text { ASSOCIACAO AGRICOLA } \\
\text { DESPORTIVA E CULTURAL DO } \\
\text { SOGO }\end{array}$ & 6,2 & 2,5 & 1 & 01.10 & $\begin{array}{l}\text { Produção de lavouras } \\
\text { temporárias }\end{array}$ & Irrigante & Biritiba-Mirim & $388.890,0$ & $7.392 .799,8$ & 6,51 & 2,62 & 3,06 & 3,83 & 2,62 & 3,06 & 3,83 \\
\hline 107475 & TITAN PNEUS DO BRASIL LTDA. & 5,1 & 3,3 & 22 & 22.10 & $\begin{array}{l}\text { Fabricação de produtos } \\
\text { de borracha }\end{array}$ & Industrial & $\begin{array}{l}\text { Parque Novo } \\
\text { Mundo }\end{array}$ & $336.910,0$ & $7.396 .490,2$ & 6,68 & 2,66 & 3,06 & 3,76 & 5,28 & 6,41 & 8,34 \\
\hline
\end{tabular}




\begin{tabular}{|c|c|c|c|c|c|c|c|c|c|c|c|c|c|c|c|c|c|}
\hline & & \multirow[b]{3}{*}{$\mathbf{Q}(\mathbf{I} / \mathbf{s})$} & \multirow[b]{3}{*}{$\begin{array}{l}Q_{\mathrm{NP}} \\
(1 / \mathbf{s})\end{array}$} & \multirow[b]{3}{*}{$\begin{array}{l}\text { Divisão } \\
\text { CNAE } \\
2.0 \\
\end{array}$} & \multirow[b]{3}{*}{$\begin{array}{l}\text { Grupo } \\
\text { CNAE } \\
2.0 \\
\end{array}$} & \multirow[b]{3}{*}{ Grupo CNAE 2.0} & \multirow[b]{3}{*}{ Finalidade } & \multirow[b]{3}{*}{$\begin{array}{l}\text { ETE de } \\
\text { referência }\end{array}$} & \multirow[b]{3}{*}{$X(m)$} & \multirow{2}{*}{\multicolumn{2}{|c|}{ Legenda de cores }} & \multirow{2}{*}{\multicolumn{2}{|c|}{ Classe $\mathrm{A}$}} & \multirow{2}{*}{\multicolumn{2}{|c|}{ Classe B }} & \multirow{2}{*}{\multicolumn{2}{|c|}{ Classe $\mathrm{C}$}} \\
\hline & & & & & & & & & & & & & & & & & \\
\hline ID & Usuário & & & & & & & & & $Y(m)$ & $L(\mathbf{k m})$ & C10 & C1R & C1P & $\mathrm{C} 2 \mathrm{O}$ & C2R & C2P \\
\hline 10512 & IND AMERICANA DE PAPEL S A & 13,7 & 3,5 & 17 & 17.20 & $\begin{array}{l}\text { Fabricação de papel, } \\
\text { cartolina e papel-cartão }\end{array}$ & Industrial & São Miguel & $350.960,0$ & $7.402 .319,8$ & 7,34 & 2,67 & 3,07 & 3,77 & 5,26 & 6,38 & 8,30 \\
\hline 21960 & $\begin{array}{l}\text { CABOT BRASIL INDUSTRIA E } \\
\text { COMERCIO LTDA }\end{array}$ & 2,9 & 2,5 & 20 & 20.90 & $\begin{array}{l}\text { Fabricação de produtos e } \\
\text { preparados químicos } \\
\text { diversos }\end{array}$ & Industrial & Mauá & $349.950,0$ & $7.384 .990,2$ & 4,53 & 2,68 & 3,08 & 3,78 & 5,48 & 6,65 & 8,67 \\
\hline 12653 & $\begin{array}{l}\text { CIA. ANTARTICA PTA. IND. BRAS. } \\
\text { BEBIDAS E CONEXOS }\end{array}$ & 3,4 & 2,1 & 11 & 11.10 & $\begin{array}{l}\text { Fabricação de bebidas } \\
\text { alcoólicas }\end{array}$ & Industrial & Jesus Neto & $335.690,0$ & $7.393 .799,8$ & 3,49 & 2,68 & 3,08 & 3,78 & 5,59 & 6,79 & 8,85 \\
\hline 27750 & $\begin{array}{l}\text { VOLKSWAGEN DO BRASIL IND } \\
\text { DE VEIC AUTOMOTORES LTDA }\end{array}$ & 7,2 & 3,2 & 29 & 29.10 & $\begin{array}{l}\text { Fabricação de } \\
\text { automóveis, camionetas } \\
\text { e utilitários }\end{array}$ & Industrial & $\begin{array}{l}\text { Riacho } \\
\text { Grande }\end{array}$ & $342.060,0$ & $7.374 .930,2$ & 6,55 & 2,69 & 3,09 & 3,79 & 5,33 & 6,47 & 8,42 \\
\hline 91056 & AKZO NOBEL LTDA. & 9,7 & 2,5 & 32 & 32.90 & $\begin{array}{l}\text { Fabricação de produtos } \\
\text { diversos }\end{array}$ & Industrial & Mauá & $349.610,0$ & $7.380 .080,1$ & 4,73 & 2,69 & 3,09 & 3,80 & 5,48 & 6,65 & 8,67 \\
\hline 54065 & $\begin{array}{l}\text { PHIBRO SAUDE ANIMAL } \\
\text { INTERNACIONAL LTDA }\end{array}$ & 1,8 & 1,7 & 21 & 21.20 & $\begin{array}{l}\text { Fabricação de produtos } \\
\text { farmacêuticos }\end{array}$ & Industrial & $\begin{array}{l}\text { Várzea do } \\
\text { Palácio }\end{array}$ & $345.880,0$ & $7.403 .500,0$ & 2,44 & 2,70 & 3,09 & 3,80 & 5,74 & 6,98 & 9,11 \\
\hline 11126 & $\begin{array}{l}\text { INDUSTRIA DE MEIAS SCALINA } \\
\text { LTDA }\end{array}$ & 7,1 & 2,5 & 13 & 13.50 & $\begin{array}{l}\text { Fabricação de artefatos } \\
\text { têxteis, exceto vestuário }\end{array}$ & Industrial & São Miguel & $353.540,0$ & $7.401 .009,8$ & 4,84 & 2,70 & 3,10 & 3,81 & 5,48 & 6,66 & 8,67 \\
\hline 27758 & $\begin{array}{l}\text { VOLKSWAGEN DO BRASIL IND } \\
\text { DE VEIC AUTOMOTORES LTDA }\end{array}$ & 7,1 & 3,2 & 29 & 29.10 & $\begin{array}{l}\text { Fabricação de } \\
\text { automóveis, camionetas } \\
\text { e utilitários }\end{array}$ & Industrial & $\begin{array}{l}\text { Riacho } \\
\text { Grande }\end{array}$ & $342.060,0$ & $7.375 .060,1$ & 6,60 & 2,70 & 3,10 & 3,81 & 5,35 & 6,49 & 8,44 \\
\hline 10150 & DIANDA E CIA LTDA & 19,2 & 4,9 & 17 & 17.20 & $\begin{array}{l}\text { Fabricação de papel, } \\
\text { cartolina e papel-cartão }\end{array}$ & Industrial & $\begin{array}{l}\text { Parque } \\
\text { Andreense }\end{array}$ & $357.070,0$ & $7.377 .500,0$ & 11,54 & 2,71 & 3,11 & 3,83 & 5,11 & 6,19 & 8,03 \\
\hline 19824 & $\begin{array}{l}\text { RECKITT BENCKISER (BRASIL) } \\
\text { LTDA. }\end{array}$ & 6,2 & 5,3 & 20 & 20.60 & $\begin{array}{l}\text { Fabricação de sabões, } \\
\text { detergentes, produtos de } \\
\text { limpeza, cosméticos, } \\
\text { produtos de perfumaria e } \\
\text { de higiene pessoal }\end{array}$ & Industrial & $\begin{array}{l}\text { Cotia/Jardim } \\
\text { Japão }\end{array}$ & $317.820,0$ & $7.390 .379,9$ & 12,66 & 2,71 & 3,12 & 3,84 & 5,07 & 6,14 & 7,97 \\
\hline 9296 & BOMBRIL S.A. & 3,3 & 2,8 & 20 & 20.60 & $\begin{array}{l}\text { Fabricação de sabões, } \\
\text { detergentes, produtos de } \\
\text { limpeza, cosméticos, } \\
\text { produtos de perfumaria e } \\
\text { de higiene pessoal }\end{array}$ & Industrial & $\mathrm{ABC}$ & $338.480,0$ & $7.383 .399,9$ & 5,91 & 2,73 & 3,13 & 3,85 & 5,44 & 6,61 & 8,60 \\
\hline 85086 & FLAVIO YAZAWA & 5,5 & 2,2 & 1 & 01.10 & $\begin{array}{l}\text { Produção de lavouras } \\
\text { temporárias }\end{array}$ & Irrigante & Biritiba-Mirim & $390.320,0$ & $7.390 .919,9$ & 6,32 & 2,72 & 3,17 & 3,97 & 2,72 & 3,17 & 3,97 \\
\hline
\end{tabular}

